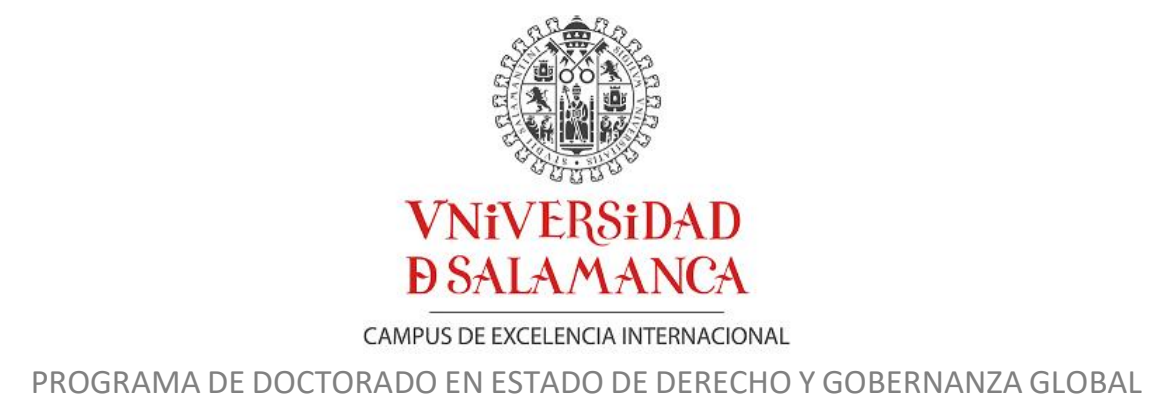

TESIS DOCTORAL

\title{
EL ROL DE LOS \\ TRIBUNALES DE JUSTICIA \\ EN LOS PROCESOS DE INTEGRACIÓN REGIONAL EN AMÉRICA LATINA
}

\author{
Miguel Ángel Moraga Mejías \\ Autor
}

Dr. Juan Santos Vara

Director 
Universidad De Salamanca

Campus de excelencia internacional

Escuela de doctorado

Plan de estudio: Estado de derecho y gobernanza global

Tesis doctoral

EL ROL DE LOS TRIBUNALES DE JUSTICIA EN LOS PROCESOS

DE INTEGRACIÓN REGIONAL EN AMÉRICA LATINA

Autor: Miguel Ángel Moraga Mejías

miguel.moraga@usal.es

Director: Dr. Juan Santos Vara

Año 2020

Salamanca, España 
INDICE

ACRÓNIMOS. .11

INTRODUCCIÓN.. .15

Agradecimientos. .33

\title{
CAPÍtulo I
}

\begin{abstract}
ANÁLISIS HISTÓRICO DEL FENÓMENO INTEGRACIONISTA EN AMÉRICA LATINA COMO ANTECEDENTE Y CONTEXTO DE LOS SINGULARES TRIBUNALES DE CADA ESQUEMA REGIONAL
\end{abstract}

1. ANTECEDENTES de UNA AMÉRICA LATINA EN El CAMINO DE SU PROPIA INTEGRACIÓN Y NO DE IMPORTACIONES GEOMÉTRICAS ECLIPSANTES E INEFICIENTES. .37

2. LA INTEGRACIÓN LATINOAMERICANA NO PUEDE ENCAPSULARSE PORQUE FLUYE DEL ACERVO HISTÓRICO DE UNA INTEGRACIÓN QUE MUTA EN SÍ MISMA. 39

3. EL NUEVO REGIONALISMO PROPICIA EL ESCENARIO PERFECTO PARA IMPULSAR LOS NACIMIENTOS MODERNOS DE LOS TRES PROYECTOS LATINOAMERICANOS Y DE SUS SINGULARES TRIBUNALES. .54

4. El cambio de milenio trajo nuevas metas y nuevos problemas para los esquemas de INTEGRACIÓN A AMBOS LADOS DEL ATLÁNTICO. 62

5. EL IMPERIO MAYA SE RE-INTEGRA: UN ESFUERZO DE UNIDAD EN EL ISTMO A TRAVÉS DEL SISTEMA DE LA INTEGRACIÓN CENTROAMERICANA - EL SICA.

6. El LEGAdO de LA CORTE de CARTAGO ES RECEPCIONADO POR LA JUSTICIA DE INTEGRACIÓN MODERNA Centroamericana: LA CoRTE Centroamericana de JustiCIA - CCJ. .71

7. UNA HISTORIA DE CONFLICTOS Y CONCRECIONES: LA COMUNIDAD ANDINA DE NACIONES - CAN.......74

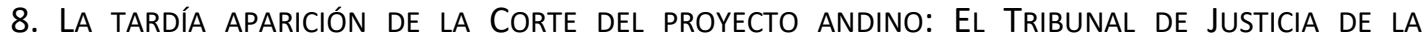
COMUNIDAD ANDINA - TJCA. .75

9. UNA HISTORIA DE INTEGRACIÓN AL SUR DEL MUNDO CON VISTA AL ATLÁNTICO deSDE El AMAZONAS A LA PATAGONIA: EL MERCADO COMÚN DEL SUR - MERCOSUR. 
9.1. Las Etapas de desarrollo del Sistema de Solución de Controversias del Mercosur SE DESPLIEGAN CONFORME MADURABA EL PROYECTO COMPLETO - SSCM .81

9.2. UNA CORTE SUPERIOR JERÁRQUICA Y DE DERECHO ESTRICTO QUE CONTINÚA SIENDO DE SUSTRATO ARBITRAL: EL TRIBUNAL PERMANENTE DE REVISIÓN - TPRM. .83

10. LAS DIFERENTES NATURALEZAS JURÍDICAS ENTRE EL SICA, LA CAN Y EL MERCOSUR VERSUS LA DE LA UNIÓN EUROPEA: MÁS QUE ENORMES CONTRASTES MARCAN SENDEROS DIFERENTES, AUNQUE NO EXCLUYENTE.

\section{CAPÍtulo II}

LAS VÍAS DE ACCESO A LA JURISDICCIÓN DE LOS TRIBUNALES DE LOS PROCESOS DE INTEGRACIÓN EN AMÉRICA LATINA: UN ANÁLIS COMPARADO CON LA UNIÓN EUROPEA

1. INTRODUCCIÓN. .97

2. LOS PRINCIPALES CONCEPTOS DE LA JURISDICCIÓN INTEGRACIONISTA Y SU DIMENSIÓN ORGÁNICA: EN LA BÚSQUEDA DE UNA POSICIÓN JURÍDICA MÁS EXACTA DE LAS CORTES DE INTEGRACIÓN. 100

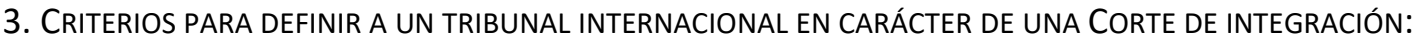
Los PATRONES CENTRALES. 110

3.1. LA APLICACIÓN DEL PRINCIPIO GENERAL DE DERECHO ACCESORIUM SEQUITUR PRINCIPALE.

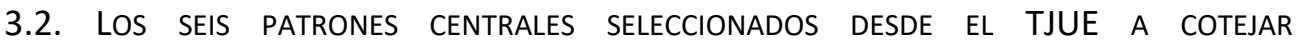
ESTATUTARIAMENTE CON LAS CORTES LATINOAMERICANAS.

3.2.1. LA FUNCIÓN INTERPRETATIVA DE LAS CARTAS CONSTITUTIVAS: SU JUSTIFICACIÓN Y SU PRESENCIA ESTATUTARIA.

3.2.2. LA FUNCIÓN CONSULTIVA EN LAS CORTES LATINOAMERICANAS: SU JUSTIFICACIÓN Y SU PRESENCIA ESTATUTARIA.

3.2.3. El CONTROL DE LEGALIDAD DE LOS ACTOS EN LAS CORTES LATINOAMERICANAS: SU JUSTIFICACIÓN Y SU PRESENCIA ESTATUTARIA.

3.2.3.1. LA PRESENCIA LEGISLATIVA DE LAS ACCIONES DE NULIDAD Y DE INCUMPLIMIENTO DEL SICA V/S LA ACCIÓN DE INCUMPLIMIENTO Y EL RECURSO POR OMISIÓN O DE INACTIVIDAD DE LA CAN 
3.2.3.2. LA PRESENCIA LEGISLATIVA DE LA ACCIÓN DE NULIDAD EN EL SICA Y EN LA CAN

3.2.3.3. EL CAUCE INDIRECTO DE LAS CONSULTAS PREJUDICIALES EN LOS TRES MODELOS LATINOAMERICANOS.. .130

3.2.3.4. EL CONTROL DE LEGALIDAD INDIRECTO QUE DEBE EMPLEARSE EN EL MeRCOSUR.

3.2.4. El CARÁCTER dE CUASI TRIBUNAL CONSTITUCIONAL QUE PUDIERAN OSTENTAR LAS CORTES LATINOAMERICANAS: SU JUSTIFICACIÓN Y EL DESARROLLO ESTATUTARIO QUE LO RESPALDA.

133

3.2.4.1. ANÁLISIS DEL POSIBLE CARÁCTER DE CUASI TRIBUNAL CONSTITUCIONAL DE LA CCJ A PARTIR DE SU MARCO ESTATUTARIO

3.2.4.2. ANÁlISIS DEL POSIBLE CARÁCTER DE CUASI TRIBUNAL CONSTITUCIONAL DEL TJCA A PARTIR DE SU MARCO ESTATUTARIO. 144

3.2.4.3. ANÁLISIS DEL POSIBLE CARÁCTER DE CUASI TRIBUNAL CONSTITUCIONAL DEL TPRM A PARTIR DE SU MARCO ESTATUTARIO...........146

3.2.5. LAS ESTRUCTURAS LEGISLATIVAS Y CONDICIONES QUE FAVORECEN EL RESPETO A LA RES IUDICATA PARA LAS SENTENCIAS DE LAS CORTES LATINOAMERICANAS. 149

3.2.6. LOS SISTEMAS DE SELECTIVIDAD DE JUECES FAVORECEN LA CONSTRUCCIÓN DEL AUCTORITAS: LA SOLUCIÓN DE LA UE Y LA DE LAS CORTES LATINOAMERICANAS..........157

3.3. LOS SIMPLES RASGOS COMUNES DE LAS CORTES LATINOAMERICANAS A LA LUZ DE LA CORTE DE LUXEMBURGO. .165

3.3.1. LA PRESENCIA DE LAS COMPETENCIAS NEGATIVAS EN LOS MODELOS DE LAS CORTES LATINOAMERICANAS

.165

3.3.2. LA PRESENCIA DE POLÍTICAS DE IMPUGNACIÓN JERÁRQUICAS EN LOS MODELOS DE LAS CORTES LATINOAMERICANAS. 169

3.3.3. LA EXCLUSIÓN DE LOS VOTOS DISIDENTES EN LOS MODELOS DE LAS CORTES LATINOAMERICANAS CONFRONTADO AL PRINCIPIO DE PUBLICIDAD Y TRANSPARENCIA 174

3.3.4. LA MAYOR AMPLITUD DEL LOCUS STANDI EN LOS ESQUEMAS DE LAS CORTES LATINOAMERICANAS EN COMPARACIÓN A LOS MODELOS DE JURISDICCIÓN INTERNACIONAL CLÁSICOS 178 


\section{CAPítulo III}

\section{EL ROL DE LOS TRIBUNALES DE INTEGRACIÓN LATINOAMERICANOS EN EL MARCO DE LOS PROCESOS REGIONALES A LOS QUE PERTENECEN: UN ANÁLISIS DE SUS JURISPRUDENCIAS INTEGRACIONISTAS}

1. INTRODUCCIÓN. 189

2. LA JURISPRUDENCIA DEL TRIBUNAL DE JUSTICIA DE LA UNIÓN EUROPEA COMO MODELO DE REFERENCIA EN AMÉRICA LATINA.

3. LOS NUEVE BLOQUES TEMÁtICOS QUE ABORDAN LAS JURISPRUDENCIAS DE LAS CORTES LATINOAMERICANAS QUE FUERON CREADOS POR EL TJUE 197

4. LA JURISPRUDENCIA INTEGRACIONISTA DE LAS CORTES CREADAS EN LOS PROCESOS DE INTEGRACIÓN REGIONAL EN AMÉRICA LATINA. 199

4.1. LA PRODUCCIÓN DE JURISPRUDENCIA INTEGRACIONISTA DE LA CORTE CENTROAMERICANA DE JUSTICIA....... 200

4.1.1. LA JURISPRUDENCIA DE LA CCJ RELACIONADA A LA JERARQUÍA Y VIGENCIA DEL DERECHO INTERNO, INTERNACIONAL Y COMUNITARIO. 201

4.1.2. LA JURISPRUDENCIA DE LA CCJ REFERIDA AL DESAPODERAMIENTO COMPETENCIAL, AL PRINCIPIO DE ATRIBUCIÓN DE COMPETENCIAS, AL CONCEPTO DE COMUNIDAD Y A LA RESPONSABILIDAD QUE TODO AQUELLO IMPLICA. 206

4.1.3. LA JURISPRUDENCIA DE LA CCJ REFERIDA AL CONCEPTO DE DESARROLLO PROGRESIVO DEL PROCESO DE INTEGRACIÓN CENTROAMERICANO.

4.2. LA PRODUCCIÓN DE JURISPRUDENCIA INTEGRACIONISTA POR EL TRIBUNAL DE JUSTICIA DE LA COMUNIDAD ANDINA .218

4.2.1. LA CONSOLIDACIÓN FORMAL DE LA PRIMACÍA DEL DERECHO DE LA CAN GRACIAS AL EJERCICIO DE LA CORTE ANDINA.

219

4.2.2. UN CAMBIO DE CRITERIO COMPLETAMENTE EVOLUTIVO DE LA CORTE ANDINA SOBRE LA INTERPRETACIÓN DE LA LEY COMUNITARIA DEROGADA Y LA SUPREMACÍA DEL DERECHO DE LA CAN. .225

4.2.2.1. LA INTERPRETACIÓN DE NORMAS DEROGADAS DE LA CAN POR EL TJCA: UN CAMBIO DE CRITERIO..

4.2.2.2. EL CRITERIO DE LA CORTE ANDINA RESPECTO DE UNA CIERTA DOSIS JERÁRQUICA DE LAS CORTES DE INTEGRACIÓN SOBRE LOS TRIBUNALES NACIONALES. .231 
4.2.2.3. El ROBUSteCimiento del DeRECHO de la CAN gRACIAS al EJERCICIO DE LA CORTE ANDINA. 235

4.2.2.3.1. LA INAPLICABILIDAD DE LA NORMA NACIONAL CONTRARIA AL DERECHO DE LA CAN. 236

4.2.2.3.2. LA CORTE ANDINA EVITA EL CAOS JURISPRUDENCIAL...240

4.3. LA JURISPRUDENCIA EXPANSIVA DE LOS TRIBUNALES ARBITRALES AD HOC Y DEL TRIBUNAL PeRMANente de ReVIsión Mercosur. .246

4.3.1. UNA INTEGRACIÓN SINGULAR Y PROPIA PARA EL MERCOSUR EN LA QUE COLABORAN LOS TAAM. 248

4.3.2. EL PRINCIPIO IN DUBIO PRO COMMUNITATE Y LA TENDENCIA PRO INTEGRATIONE INCORPORADOS POR UN TAAM AL ACERVO DEL MERCOSUR. .252

4.3.3. EL TEST DE COMPATIBILIDAD DEL DERECHO NACIONAL CON EL MERCOSUREÑO ANTE LA INEXISTENCIA DEL RECURSO DE INCUMPLIMIENTO, Y EL FACTOR DE PROGRESIVIDAD APLICADOS POR EL TPRM. .255

\section{CAPÍtULO IV}

\section{EL DIÁLOGO JUDICIAL ENTRE LOS TRIBUNALES DE INTEGRACIÓN}

1. INTRODUCCIÓN.

3. EL DIÁLOGO JUDICIAL AL SERVICIO DE LOS DESARROLLOS Y APORTES DE LAS CORTES LATINOAMERICANAS EN CADA UNO DE LOS PROCESOS DE INTEGRACIÓN REGIONAL

4. EL USO CONCRETO DE CONEXIONES EXTRA-ORGÁNICAS COMO CRITERIO DE SELECCIÓN DE LA JURISPRUDENCIA LATINOAMERICANA PARA EL ANÁLISIS DEL DIÁLOGO JUDICIAL EMPLEADO POR LA CCJ, EL TJCA Y EL TPRM Y TAAM .282

5. LA CCJ RECURRE AL DIÁLOGO JUDICIAL PARA CONTRIBUIR AL FORTALECIMIENTO DEL SICA .284

5.1. LA PRIMERA ETAPA: EL DIÁLOGO JUDICIAL, UN CASO DE TRIPLE CONEXIÓN EFECTUADA POR LA CCJ Y UN INCIPIENTE DIÁLOGO INTERAMERICANO.

5.2. LA SEGUNDA ETAPA: EL PROCESO DE REITERACIÓN MEDIANTE UN DIÁLOGO MENOS INTENSO DE LA CCJ 
5.3. LA TERCERA ETAPA: EL RECURSO AL DIÁLOGO JUDICIAL SE HACE MENOS PERCEPTIBLE.......296

6. El DIÁlOgO JUdiCIAL EMPLEAdO POR EL TJCA PARA CONTRIBUIR AL FORTALECIMIENTO DE LA CAN.

6.1. LA PRIMERA ETAPA: El DIÁLOGO JUdICIAL A FINES DEL SIGLO XX EN EL TRIBUNAL DE JUSTICIA DEL ACUERDO DE CARTAGENA 299

6.2. La Segunda etapa: El Renovado Tribunal de Justicia de la Comunidad AndinA y el DIÁLOGO JUDICIAL. .308

6.3. La tercera etapa: El diálogo judicial Se hace menos perceptible al agotar DETERMINADAS MATERIAS.

6.3.1. El PRIMER PRECEDENTE CITAdO COMO PROPIO SIN REVELAR LA FUENTE EUROPEA. 313

6.3.2. El SEgundo PRECEDENTE CitAdo COMO PROPIO Sin REVELAR LA fUeNTE EUROPEA

317

7. EL DIÁLOGO JUDICIAL EMPLEAdO POR LOS TAAM Y POR EL TPRM PARA FORTALECER EL MERCOSUR. 322

7.1. La Primera Etapa: La singular conexión de algunos taAM CON JURISDICCIONES AJENAS AL MERCOSUR PARA DISOCIARSE DEL MODELO EUROPEO. .324

7.1.1. LA PRIMERA CONEXIÓN DE LA PRIMERA ETAPA: UN TAAM SE CONECTA CON EL TJUE PARA DISTANCIARSE DE LA UE. .324

7.1.2. LA SEGUNDA CONEXIÓN DE LA PRIMERA ETAPA: UN LAUDO DICOTÓMICO QUE SE APROXIMA A LOS DDHH Y SE DISTANCIA DE LA UE. .329

7.1.3. LA ÚlTIMA CONEXIÓN DE LA PRIMERA ETAPA: UNA ESCUETA REFERENCIA A LA CORTE INTERNACIONAL DE JUSTICIA.

7.2. La Segunda Etapa: la génesis del ReCURSO al diálogo Judicial de las Cortes MERCosureÑAs CON LA CORTE de LUXEMBURGo... .335

7.3. La Tercera etapa: el tPRM y el mayor empleo del diálogo judicial con el TJUE. .339

7.3.1. EL PRIMER IMPULSO CONTUNDENTE DENTRO DE LA TERCERA ETAPA: NACE EL TPRM E IRRUMPE CONECTÁNDOSE A TRAVÉS DEL DIÁLOGO JUDICIAL DE MODO CONCRETO CON LA CORTE DE LUXEMBURGO Y CON LA CORTE ANDINA. .339 
7.3.2. LA SEGUNDA CONEXIÓN DENTRO DE LA TERCERA ETAPA: EL TPRM ACLARA SU LAUDO ANTERIOR MEDIANTE UN TÍMIDO DIALOGO JUDICIAL CON EL TJUE.

7.3.3. LA ÚLTIMA CONEXIÓN DENTRO DE LA TERCERA ETAPA: EL TPRM MEDIANTE EL DIALOGO JUDICIAL MÁS CONTUNDENTE QUE HAYA EFECTUADO DESPOJA AL MERCOSUR

DE LOS OBSTÁCULOS HISTÓRICOS. .343

7.3.4. LA ANTESALA DE UN DIÁLOGO MÁS INTENSO DENTRO DE LA TERCERA ETAPA: LA PREEMINENCIA DEL DERECHO MERCOSUR, EL DESPLAZAMIENTO DE LA LEY NACIONAL Y EL ORDEN PÚBLICO INTERNO NO ES UNA EXCEPCIÓN. .351

\section{CAPítulo V}

\section{EL FUTURO DE LOS} TRIBUNALES DE INTEGRACIÓN EN LOS PROCESOS REGIONALES DE AMÉRICA LATINA

1. INTRODUCCIÓN. 361

2. LOS DESAFÍOS DE LOS MODELOS DE INTEGRACIÓN REGIONALES DE LATINOAMÉRICA QUE AFECTAN A SUS TRIBUNALES DE INTEGRACIÓN. .365

3. LOS DESAFíOS DE FUTURO DE LAS CORTES LATINOAMERICANAS DE LOS PROCESOS DE INTEGRACIÓN REGIONALES. 370

3.1. LOS DESAFÍOS DE FUTURO DE LA CORTE CENTROAMERICANA DE JUSTICIA 373

3.2. LOS DESAFÍ́OS DE FUTURO DEL TRIBUNAL DE JUSTICIA DE LA COMUNIDAD ANDINA .379

3.3. LOS DESAFíOS DE FUTURO DEL SISTEMA DE SOLUCIÓN DE CONTROVERSIAS DEL MERCOSUR.

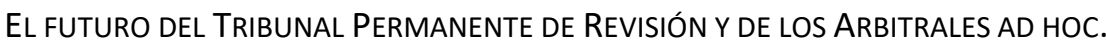
390

3.4. El Proyecto de la nueva Corte De Justicia Para Mercosur - CJM. 395

\section{CONCLUSIONES}

CONCLUSIONES GENERALES Y DISOLUCIÓN DE LA HIPÓTESIS. .405

\section{Bibliografía}

TODAS LAS FUENTES CONSULTADAS

1. MONOGRAFÍAS, PARTICIPACIÓN EN OBRAS COLECTIVAS Y ARTÍCULOS CIENTÍFICOS .417

2. TRATADOS INTERNACIONALES, CARTAS CONSTITUTIVAS Y DOCUMENTOS PÚBLICOS 440 


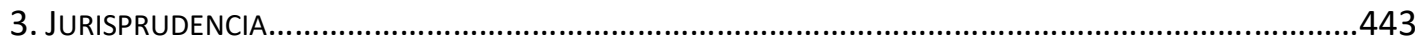

3.1. JURISPRUDENCIA DEL TRIBUNAL DE JUSTICIA DE LA UNIÓN EUROPEA..............................443

3.2. JURISPRUDENCIA DEL TRIBUNAL GENERAL DE LA UNIÓN EUROPEA.................................447

3.3. JURISPRUDENCIA DE LA CORTE CENTROAMERICANA DE JUSTICIA...................................448

3.4. JURISPRUDENCIA DEL TRIBUNAL DE JUSTICIA DE LA COMUNIDAD ANDINA.........................448

3.5. JURISPRUdencia del TRIBUnal PERMANENTE de REVISIÓN MERCOSUR........................450

3.6. JURISPRUdENCIA DE LOS TRIBUNALES ARBITRALES AD HOC MERCOSUR............................451

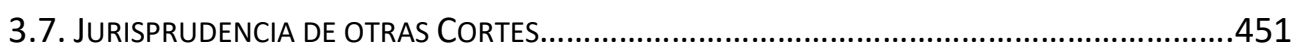

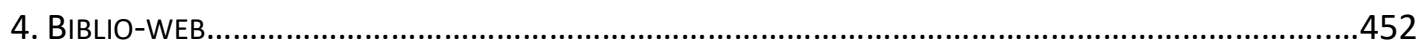




\section{ACRÓNIMOS}

Siglas y abreviaturas más frecuentes empleadas en esta tesis

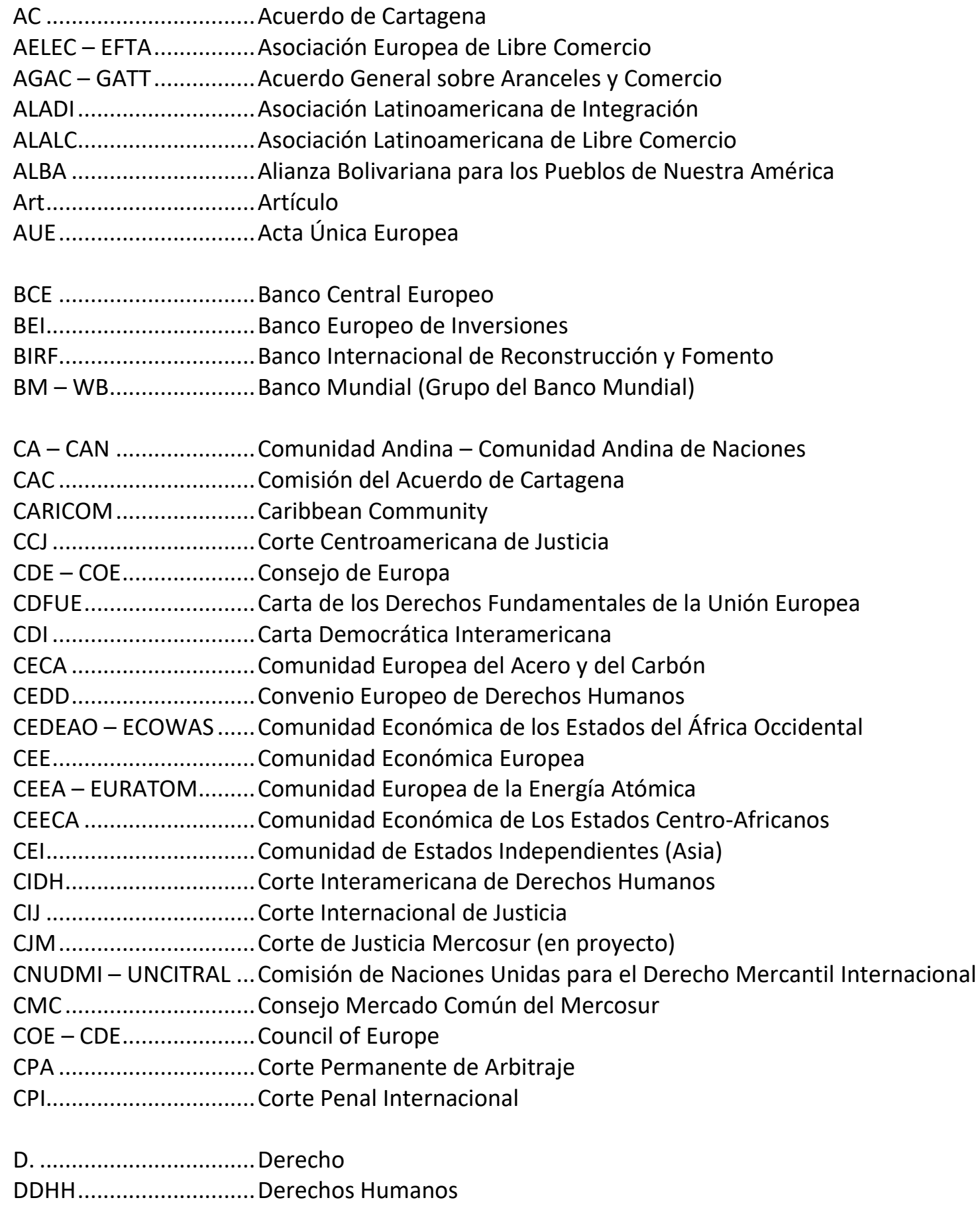


DI ............................. Derecho Internacional

ECOWAS - CEDEAO ....... Economic Community of West African States

EEE ............................Espacio Económico Europeo

EEUU.......................... Estados Unidos de Norteamérica

EFTA - AELEC ................ European Free Trade Association

ELSJ ............................. Espacio de Libertad, Seguridad y Justicia (de la UE)

EURATOM .................... Comunidad Europea de la Energía Atómica

GATT - AGAC ............... General Agreement on Tariffs and Trade

GOAC ....................... Gaceta Oficial del Acuerdo de Cartagena

I GM.......................... Primera Guerra Mundial

II GM ..........................Segunda Guerra Mundial

MERCOSUR ................... Mercado Común del Sur (América)

NU - ONU - UN ........... Naciones Unidas

ODECA ........................ Organización de Estados de Centro América

OEA .......................... Organización de Estados Americanos

Ol .............................. Organización Internacional

OMC - WTO .................. Organización Mundial del Comercio

ONU - UN - NU ............ Organización de Naciones Unidas.

OSD ............................ Órgano de Solución de Diferencias de la OMC

PARLACEN.................... Parlamento Centroamericano

PE..............................Parlamento Europeo

PESC.......................... Política Exterior y de Seguridad Común de la UE

POPSCM...................... Protocolo de Olivos para la Solución de Controversias en el Mercosur

PT..............................Protocolo de Tegucigalpa - SICA

Rep. .......................... República

S. ............................. Siglo

SS.............................. Siguientes

SAI.......................... Sistema Andino de Integración

SICA ........................... Sistema de la Integración Centroamericana

SSCM ........................ Sistema de Solución de Controversias Mercosur

T...............................Tribunal

TA ..............................Tratado de Asunción

TAAM......................... Tribunal ad hoc Mercosur

TC............................. Tribunal Constitucional

TCUE ..........................Tribunal de Cuentas de la Unión Europea

TEDH ......................... Tribunal Europeo de Derechos Humanos

TFUE ......................... Tratado de Funcionamiento de la Unión Europea 
TFPUE Tribunal de la Función Pública de la Unión Europea (cesado)

TGUE. Tribunal General de la Unión Europea

$\mathrm{TI}$ .Tribunal internacional

TJ ................................Tribunal de Justicia (Unión Europea)

TJAC ............................Tribunal de Justicia del Acuerdo de Cartagena (antecesor del TJCA)

TJCA ............................. Tribunal de Justicia de la Comunidad Andina

TJCE ........................... Tribunal de Justicia de las Comunidades Europeas (antecesor del TJUE)

TJUE ........................... Tribunal de Justicia de la Unión Europea

TPUE ............................Tribunal de Primera Instancia de la Unión Europea (antecesor del TGUE)

TPRM .........................Tribunal Permanente de Revisión de Mercosur

TUE .............................Tratado de la Unión Europea

UE ...............................Unión Europea

UN - NU - ONU ............. United Nations

UNASUR .......................Unión de Naciones Suramericanas

URSS ............................Unión de Repúblicas Socialistas Soviéticas

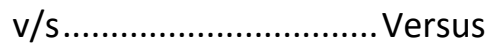

v.gr.............................. Verbi gratia

Vid. .............................. Véase

WB - BM.....................World Bank (World Bank Group)

WTO - OMC................. World Trade Organization 
INTRODUCCIÓN 


\section{INTRODUCCIÓN}

os tribunales de integración son un tipo de Cortes internacionales muy singulares y relativamente recientes en el panorama internacional. La primera de estas Cortes inició su proceso de gestación durante la reconstrucción organizativa política de la Europa post Segunda Guerra Mundial tras un proceso cooperativo intenso que dio paso a las tres Comunidades Europeas y desde allí, en un extenso itinerario arribó a la actual Unión Europea (UE). Este modelo de organización pasó a conocerse bajo la noción de organización de integración, la cual está dotada de diversos órganos propios, entre los cuales se ubica el órgano jurisdiccional. En la matriz institucional de la UE el Tribunal de Justicia (TJUE) ostenta la condición de institución. Lo importante a destacar aquí, es que esta clase de órgano jurisdiccional transnacional pasaría a identificarse con una nueva dimensión de la jurisdicción internacional, a saber, la de Corte de integración.

El modelo de integración de la UE ha sido objeto de múltiples intentos de copias parciales tanto en América Latina como en África y en Asia. Puntualmente en América Latina la idea de replicar en parte el esquema europeo se justificaba en lo beneficioso que resultaría ser la implementación de aquel tipo de esquema integracionista para enfrentar el nuevo escenario mundial. Sin duda América Latina resultaría ser a la postre la principal región receptora del modelo europeo, desarrollándose en definitiva tres experiencias sub-regionales, el Sistema 
de Integración Centroamericano (SICA - 1992, vigor 1993), la Comunidad Andina de Naciones (CAN o CA - 1969) y el Mercado Común del Sur (MERCOSUR - 1991).

De los tres esquemas latinoamericanos recién señalados -SICA, CAN y MERCOSURúnicamente el SICA incorporó a su arquitectura orgánica desde su inicio, a un tribunal, la actual Corte Centroamericana de Justicia (CCJ, Estatutos 1992, vigor 1994) o Corte centroamericana, aunque este tribunal posee raíces muy remotas que incluso llegan a conectarse con el primer tribunal internacional de naturaleza jurisdiccional y permanente de la historia, la Corte de Cartago de 1907, tal como lo veremos.

En cambio, en el Cono Sur de América la CAN y el MERCOSUR nacieron sin órganos jurisdiccionales, debiendo incorporarlos retrasadamente a sus institucionalidades, generando desfases orgánicos muy relevantes según analizaremos en detalle en esta tesis. Así, por una parte, en la CAN se crea el Tribunal de Justicia del Acuerdo de Cartagena (TJAC - 1983) el que luego pasó a denominarse Tribunal de Justicia de la Comunidad Andina (TJCA - 1996, vigente 1999) o genéricamente Corte andina. En el MERCOSUR se incorporan primero a su Sistema de Solución de Controversias Mercosur (SSCM) los Tribunales Arbitrales ad hoc Mercosur (TAAM - 1991) y más tarde se añadió el Tribunal Permanente de Revisión Mercosur (TPRM - 2002, vigor 2004) en carácter de superior jerárquico.

Toda la ingeniería latinoamericana sigue a la experiencia de la UE, ya sea por construcciones orgánicas fruto del derecho comparado y/o mediante el fenómeno del diálogo de fuentes y del dialogo judicial. Aunque cada una de estas construcciones - como se pondrá de manifiesto - apareja sus propias particularidades. Esta tesis se enfoca en el estudio de la CCJ, el TJCA y el TPRM intentando desvelar la forma en que dichos órganos jurisdiccionales transnacionales sui generis, contribuyen de modo sustancial con cada uno de los proyectos políticos a los que pertenecen. Además analizaremos el hecho de que en el ejercicio jurisdiccional de los referidos tribunales, éstos mantienen como referente absoluto al TJUE, tanto desde lo orgánico — pues se han importado estatutariamente varias soluciones institucionales y competenciales europeas - como desde los razonamientos jurisprudenciales - los cuales extraen a través de un muy particular diálogo judicial que analizaremos rigurosamente.

Para la labor anunciada en el párrafo anterior, cotejaremos a las referidas Cortes de América Latina con el modelo de la UE y con la jurisprudencia del TJUE desde tres ángulos de análisis, en primer lugar, desde un punto de vista estatutario, aquí el paralelo lo conduciremos por un conjunto de características que hemos denominado patrones centrales, los cuales se refieren a singularidades y competencias propias del TJUE y de las Cortes latinoamericanas en carácter de canales de conexión, o líneas de similitud, que intentan 18 
darle un carácter un poco más global al derecho de la integración comprendido en un sentido amplio. El criterio de selección de dichas características lo explicaremos al abordar cada uno de los «seis patrones centrales» por los que nos conduciremos; en segundo lugar, efectuaremos un análisis de la jurisprudencia integracionista que producen las Cortes latinoamericanas. Para esta segunda labor recurriremos a un criterio de selección de sentencias de la CCJ, del TJCA y del TPRM en materias que posean un correlato en la base jurisprudencial del TJUE, lo cual hemos ordenado en «nueve bloques temáticos» que explicaremos al momento de comenzar con dicho análisis; y por último, en tercer lugar, constataremos un posible tipo de diálogo judicial de las Cortes latinoamericanas con el TJUE u otros tribunales. Para tal análisis usaremos un criterio de selección de jurisprudencia orientado a «verificar la presencia concreta de esta herramienta de comunicación entre tribunales, sin atender a la materia en que se produzca».

Para los efectos de una exacta comprensión de los aspectos centrales que componen esta tesis doctoral, así como de determinados conceptos o nociones que emplearemos durante su desarrollo, procederemos a continuación, a través de los siguientes siete puntos, a precisar el sentido amplio del derecho de la integración, el contexto de nuestros objetos de estudio, la hipótesis de esta tesis y algunos criterios más, del modo que sigue.

1. Respecto del contexto de los tribunales de integración debemos considerar que, tanto esta clase de tribunales como otros institutos del derecho contemporáneo son producto del acuerdo de diversos Estados, mediante las herramientas propias del Derecho Internacional (DI) y del Derecho Procesal. Insertándose dicho tipo de tribunales en el desafío de la coexistencia en paz y progreso para la humanidad. En tal esfuerzo es que se constata el beneficio de la cooperación para alcanzar metas mayores en diversos ámbitos. Además, tal actividad cooperativa es más fructífera cuando sobrepasa lo local estructurando redes transnacionales.

Este último fenómeno cooperativo transnacional ha alcanzado un enorme desarrollo a través de su institucionalización, principalmente mediante las denominadas Organizaciones Internacionales (OI), las que comportan construcciones jurídicas de muy difícil, sino imposible, conceptualización ${ }^{1}$, razón por la cual la doctrina es proclive a exigirles

\footnotetext{
${ }^{1}$ No existe un acuerdo en la doctrina respecto de un concepto unívoco para definir a una OI, pues resulta ser muy complejo construir una noción que cubra a todos estos constructos. En tal sentido WHITE expresa «A precise definition of an international organisation is not posible. (...) an international organisation can be viewed very differently by different States, actors and writers. Even from the narrow perspective of international law, the sheer variety of institutional forms of co-operation between States belies the possibility of providing a precise legal definition». WHITE, N. D. (2005). The law of international organisations. Manchester: Manchester University press., p. 1. Por su parte SEYERSTED destaca la enorme variedad de las OI, lo cual dificulta su conceptualización, subrayando que existen «international organizations of States - so-
} 
determinadas características para reconocerlas como tales ${ }^{2}$. Ahora bien, para nuestro interés en esta tesis, subrayemos que dentro de las estructuras de algunas de estas OI se contemplan en carácter de órganos o Instituciones permanentes, a diversas Cortes internacionales. Tales órganos jurisdiccionales poseen múltiples competencias y son de las más variadas naturalezas jurídicas, dependiendo de los objetivos y del tipo de organización a que dicha Corte pertenezca.

En el contexto que estamos delimitando y para el interés que tenemos en esta tesis, recordemos que el fenómeno organizativo supranacional se vio muy tensionado tras el término de la Segunda Guerra Mundial lo que significó para el DI un hito transicional de alta relevancia, dando lugar a un nuevo modelo histórico que ha venido en denominarse por

called intergovernmental organizations - as opposed to non-governmental organizations, which are compose of private individuals and/or of national associations of individuals or companies. (...). There are many different types of intergovernmental organizations - inter alia according to: a) Size (membership)... b) Purposes... c) Functions and powers... d) Duration (...)». SEYERSTED, F. (2008). Common law of international organizations. Leiden, Boston: Martinus Nijhoff, p. 3 y 9-10. Tal vasto contexto es el que destaca SANTOS para explicar que, no ha de extrañar que el DI no haya adoptado una definición de OI. Precisando este autor, que, más bien, todas ellas tienden a develarse tras el reconocimiento de su elemento más identificatorio por la Sociedad Internacional, cual es, la noción de función. SANTOS VARA, J. (2002). La participación de la unión europea en las organizaciones internacionales. Madrid: Colex. Intr., pp. 33-34 (apartado II, número 1 Una aproximación a los elementos que identifican a las organizaciones internacionales). Para SOBRINO las OI son asociaciones voluntarias de Estados, creadas por acuerdos internacionales y dotadas de órganos propios, permanentes e independientes, encargados de gestionar intereses colectivos y capaces de expresar una voluntad jurídicamente distinta a la de los Estados miembros. SOBRINO HEREDIA, J. M. (2010b, reimpr. 2014). Las organizaciones internacionales: generalidades. En M. Díez de Velasco Vallejo y J. M. Sobrino Heredia, Las organizaciones internacionales (16 ${ }^{\mathrm{a}}$ ed.). Madrid: Tecnos., p. 43.

${ }^{2}$ Al constatarse la dificultad en la construcción de un concepto de OI, la doctrina pasa a poner el acento en determinadas características que deberían verificarse en estos entes. Por ejemplo ÁLVAREZ comienza por reconocer la problemática, señalando «Elaborate definitions of international organizations raise more problems than they are worth». Y desde ese punto de inflexión pasa a destacar criterios que genéricamente destaca la doctrina, recordando "An IO must have genuinely international aims intended to cover at least three states; its membership must include full voting rights and be open to states appropriately qualified in the organization's area of operations; voting must be such that no one national group exerts control; its constitution must provide for formal structure giving members the right periodically to elect governing bodies and officers; there should be the possibility of the continuous operation of operation of a permanent headquarters; IO officers should not engage in profit-making activities and there should be a substantial contribution to the budget from at least three states; each IO must show that it can exist independently and elect its own officials; evidence of current activities must be available; size, politics, ideology, fields of activity, geographical location of headquarters, nomenclature are, however, irrelevant». ÁLVAREZ, J. E. (2006). International organizations as law-makers (1es. ed.). Oxford; Madrid etc.: Oxford University Press., p. 4. 
algunos como DI contemporáneo ${ }^{3}$, y por otros como DI post-clásico ${ }^{4}$, lo que es una cuestión de contexto relevante para esta investigación, ya que los tribunales que estudiaremos nacen, se sitúan y se desarrollan en dicho campo.

El hito de transición recién señalado produjo múltiples consecuencias, entre las cuales hay tres bien diferenciadas que dibujan el precedente cercano de nuestros objetos de estudio, primero, una global, el nacimiento de Naciones Unidas (NU - ONU, 1945) en carácter de una OI planetaria ${ }^{5}$; segundo, una continental de carácter dual, así por una parte en América se consolida la Organización de Estados Americanos (OEA, 1948 y en 1978 nacería su Tribunal Interamericano de Derechos Humanos) y por otro extremo en Europa surge el Consejo de Europa (1949, y en 1950 se crearía a su Tribunal Europeo de Derechos Humanos); y tercero, una consecuencia de margen sub-continental, compuesta por el nacimiento de la Comunidad Europea del Carbón y el Acero (CECA, junto a su Tribunal CECA, 1951), más en 1957 el surgimiento de la Comunidad Económica Europea (CEE) y

\footnotetext{
${ }^{3}$ La noción de derecho internacional contemporáneo se acuña en la realidad de post guerras europeas. Así por ejemplo DIEZ DE VELASCO explica que, el fin de la II GM significó para el DI un hito transicional de alta relevancia, lo cual ocasionó que el DI clásico entrara definitivamente en crisis a causa de diversos factores, dando lugar a un nuevo modelo histórico que ha venido en denominarse Derecho Internacional contemporáneo. DIEZ DE VELASCO VALLEJO, M. y ESCOBAR HERNÁNDEZ, C. (act.). El concepto de derecho internacional público (i). En Diez de Velasco Vallejo, M. (2013, reimpr. 2015). Instituciones de derecho internacional público (18 ${ }^{\mathrm{a}}$ ed.). Madrid: Tecnos., p. 65.

${ }^{4}$ El derecho internacional post-clásico, para GAMARRA y FERNANDEZ viene a aparecer en un proceso que comienza como consecuencia del fracaso de la Sociedad de Naciones para haber prevenido la guerra y de otras relevantes piezas de la historia del Derecho Internacional, todo lo cual conformarían los inicios del Derecho Internacional de hoy, de lo que se puede denominar: Derecho internacional post-clásico. GAMARRA CHOPO, Y. \& FERNANDEZ LIESA, C. R. (2015). Nota preliminar. El comienzo de una nueva era para el derecho internacional. En Grasa, R., Forcadell, C., Peiró, I., Huguet, M., Magallón, C. \& Blasco, S., Fernández, C., ... Ripol, S. Los orígenes del derecho internacional contemporáneo (1 ${ }^{\mathrm{a}}$ ed.). Zaragoza: Institución Fernando el Católico., p. 17.

${ }^{5}$ El hito histórico que introduce la aparición de NU con la Corte Internacional de Justicia (CIJ) en el concierto global post guerra, que entre otros daría paso al recién referido DI post-clásico -vid. notas 3 y 4- es un hecho objetivo de mutación del esquema organizativo mundial. Et al.: CEDE y SUCHARIPA-BEHRMANN presentando un recorrido desde el período previo a la Liga de las Naciones, y hasta la fundación de ONU, abordando la importancia de la Carta de NU destacan las circunstancias, expresando «The great authority the UN Charter enjoys today and its universal validity are further strong arguments in favor of the world organization. As nearly all States have become members of the UN, the UN Charter occupies a position that gives it an enhanced status among all other international treaties, (...). Within its objectives and principles the Charter contains a number of rules which are of central importance to the peaceful cooperation among States». CEDE, F. \& SUCHARIPA-BEHRMANN, L. (2001). The united nations : Law and practice. The Hague: Kluwer Law International., pp. 3-9.
} 
de la Comunidad Europea de la Energía Atómica (CEEA o EURATOM) conformándose así las tres Comunidades Europeas ${ }^{6}$.

Las consecuencias recién descritas en el párrafo anterior marcarían el entorno histórico cercano en que más tarde aparecerían las Cortes de integración tal como hoy las conocemos. Ahora bien, es precisamente la tercera arista - del hito de transición señalado - la que concretamente dio paso a un nuevo tipo de organización internacional, de mayor intensidad, a la cual la doctrina bautizaría como organizaciones de integración ${ }^{7}$, y dentro de su institucionalidad encontramos a nuestro objeto de estudio, los tribunales de integración.

Estas Cortes de integración existen en calidad de órganos jurisdiccionales supranacionales y permanentes, unidos a su organización de la cual dependen, encuadrados en la clásica razón órgano/organización. De allí entonces y por simple coherencia orgánica, quedan al servicio de los objetivos de tales organizaciones sui generis. Siendo la primera experiencia de este tipo la hoy denominada Unión Europea ${ }^{8}$, y la única realmente supranacional.

\footnotetext{
${ }^{6}$ Más tarde el Tratado de Maastricht (1992) modificaría a la CEE por la Comunidad Europea (CE) y a la vez nacería la Unión Europea (UE), la cual tras el Tratado de Lisboa (2007) absorbería definitivamente a la CE, asentándose en plenitud la actual UE en carácter de organización de integración regional sub-continental, con su singular Poder Judicial. Actualmente el art. 19.1 del Tratado de la UE (TUE) es la norma que describe la estructura del Poder Judicial de la UE en los siguientes términos: «El Tribunal de Justicia de la Unión Europea comprenderá el Tribunal de Justicia, el Tribunal General y los tribunales especializados [...]».

${ }^{7}$ La doctrina identifica de diferentes formas a esta nueva construcción jurídica, dependiendo de la distancia que le reconocen respecto de una OI típica. Para lo cual usan conceptos tales como «organizaciones de integración o de unificación», "organizaciones internacionales de integración», u «organizaciones sui generis». Para algunos autores estos constructos jurídicos serían una simple forma de clasificar a las OI, mientras que para otros son estructuras completamente diferentes y con principios propios. Para VIRALLY las organizaciones de integración se separan completamente de las OI típicas, este autor prefiere visualizar una clara frontera jurídica entre ellas. VIRALLY, M. (1998). El devenir del derecho internacional: Ensayos escritos al correr de los años (1 ${ }^{a}$ ed.). México, D.F.: Fondo de Cultura Económica., p. 262. En cambio PASTOR las aborda a partir de un método de cooperación, como un nivel clasificatorio, concluyendo que serían «el supuesto de cooperación más intenso». PASTOR RIDRUEJO, J. A. (2010). Curso de derecho internacional público y organizaciones internacionales (14 ed.). Madrid: Tecnos., pp. 664-667. Para DIEZ DE VELASCO estas construcciones quedan comprendidas dentro de la clasificación que él denomina «organizaciones de integración o de unificación» las cuales — según explica-se sitúan entre las OI clásicas y las estructuras federales, precisando que: se ha extendido en la doctrina el uso de la categoría de «organizaciones internacionales de integración» para explicar a la CE y ahora a la UE. DIEZ DE VELASCO VALLEJO, M. \& SOBRINO HEREDIA, J. M. (2010 -reimpr. 2014). Las organizaciones internacionales (16 $6^{\mathrm{a}}$ ed.). Madrid: Tecnos., pp. 47-53 y 593.

${ }^{8}$ El proceso histórico que desemboca en la actual Unión Europea es riquísimo, y precisamente como uno de sus resultados encontraremos el Instituto aquí en estudio, los «Tribunales de Integración». La idea unitaria de Europa es antiquísima de hecho jugaron un papel trascendental tanto el Imperio como el Papado, más tarde la academia identificó el deber urgente de las naciones de Europa de crear una unión económica y política para 22
} 
Ingeniería seguida más tarde de modo parcial y en evidente menor medida en otras regiones del mundo, sin llegar a ser ninguna de las nuevas experiencias de carácter supranacional.

2. Resulta menester, a efectos de evitar confusiones o desconexiones conceptuales, dejar bien establecido desde ya algunos aspectos, criterios, selecciones y conceptos generales que afectan a toda nuestra investigación y que mantendremos constante durante el desarrollo de la tesis. Éstos los hemos ordenado mediante seis cauces principales, cada uno de los cuales presenta las siguientes cuestiones:

En primer lugar consideraremos que el derecho que regula este fenómeno jurídico fue conocido inicialmente en Europa como Derecho Comunitario, luego como Derecho de la Integración y actualmente como Derecho de la UE, aunque en muchas ocasiones se le identifica únicamente como Derecho de la Unión ${ }^{9}$. Por su parte, en América Latina también se le conoció en su primera época como Derecho Comunitario y luego como Derecho de la Integración. A lo que se suma la circunstancia de que regionalmente se hable de Derecho del SICA o derecho centroamericano, Derecho de la CAN o derecho andino, y Derecho del MERCOSUR o derecho mercosureño, según corresponda en cada caso.

Al hilo de lo anterior, resulta imprescindible para comprender con toda nitidez el fenómeno jurídico que enfrentaremos, tener claridad absoluta sobre una realidad jurídica concreta que se produce en América Latina, consistente en la aceptación de una noción amplia del derecho de la integración. Así, en el SICA, en la CAN y en el MERCOSUR se hace referencia al derecho de la integración en carácter de genérico, con el fin de intentar destacar las similitudes entre todos los proyectos extra-UE.

garantizar la seguridad y el progreso social, incluso durante el desarrollo de la II GM, baste con recordar el sentido discurso de W. Churchill en Septiembre de 1946 en la Universidad de Zúrich llamando a la unión de Europa; los esfuerzos decantarían en el mítico Congreso de la Haya de mayo del año 1949, donde se manifestaron dos visiones divergentes de la integración, por uno los moderados que deseaban sólo una cooperación intergubernamental sin afectar la soberanía, versus los extremistas partidarios de una integración de carácter federal, los primeros serían premiados ese mismo año de 1949 con la creación del Consejo de Europa, pero más tarde lo serían los segundos, al dar paso en 1965 a la Comunidad Europea, antecesora de la actual Unión Europea que emerge en 1993. Vid. TRUYOL Y SERRA, A. (1999). La integración europea: Análisis histórico-institucional con textos y documentos. - Tomo I génesis y desarrollo de la unión europea (1951-1979). Madrid: Tecnos.

${ }^{9}$ En la UE existe múltiple normativa redactada de esta simple manera, como Derecho de la Unión, v.gr. en el TUE el art. 6.3 «... formarán parte del Derecho de la Unión como principios generales», el art. 17.1 «.. del Derecho de la Unión bajo el...», siguen los arts. 19.1, 19.3.b, 64,1, etc., luego en el TFUE el art. 16.2 «...del Derecho de la Unión, y...», el art. 58, «...de la violación del Derecho de la Unión por parte...», el art. 62 «...o de la coherencia del Derecho de la Unión», le siguen los arts. 62 ter, 197.1, etc. 
En realidad los esquemas latinoamericanos siguen las soluciones del referente europeo, considerando los valores, principios, libertades y criterios de la UE ampliamente y como todo un modelo a seguir. Por lo tanto, la CCJ, el TJCA y el TPRM intentan homogenizar las soluciones jurisdiccionales —en la medida de lo posible - con los precedentes jurisprudenciales del TJUE y además incluso con las normas y criterios de la UE.

Se colige entonces que, para los latinoamericanos implicados en los aspectos que vamos a analizar, el derecho de la integración se entiende básicamente como una rama del derecho, que lógicamente presentaría algunas diferencias en cada una de las sub-regiones del mundo en que se desarrolla, pero cuya fuente sería clara, el sistema de la UE. Cuestión que fluye muy fácil tras analizar la jurisprudencia emanada de la CCJ, el TJCA y del TPRM, más del estudio comparativo de los Estatutos y normas que regulan orgánica y funcionalmente a dichas Cortes latinoamericanas.

Lo que nosotros entendemos, e intentaremos manifestar por los diversos conductos de esta tesis, es que si bien no existe una unidad del derecho de la integración en sentido geométrico a ambos lados del Atlántico, si pueden advertirse algunos elementos comunes que permitirían comprender al derecho de la integración, en la actualidad, como un nivel o rama del derecho, debido a que los esquemas latinoamericanos se construyeron estatutariamente copiando las orgánicas del modelo europeo, dotaron a sus Cortes de algunas competencias similares a las del TJUE, y además, dichas Cortes latinoamericanas importan soluciones desde el TJUE, en un ejercicio que supone compatibilidad de criterios, es decir, se exportan soluciones desde el TJUE por los Tribunales latinoamericanos, porque éstos lo consideran como un modelo a seguir pues el TJUE administra la fuente del derecho de la integración. Analizando este fenómeno jurídico es que intentaremos identificar principios rectores - o patrones centrales_- pero jamás de una igualdad absoluta entre los ordenamientos jurídicos extra-UE versus el sistema de la UE. Todo lo anterior origina en definitiva que para los sistemas latinoamericanos enfocados -SICA, CAN y MERCOSUR - sienten y están convencidos de que el derecho de la integración - como un abstracto - coincidiría casi perfecto con el Derecho de la UE, modelo jurídico que pasó a convertirse para los esquemas latinoamericanos en un patrón ideal con el cual se miden constantemente, en tanto cercanía o lejanía.

Emplearemos la noción de «derecho de la integración con un carácter amplio» cada vez que hagamos referencia a la globalidad del fenómeno. Las otras acepciones las usaremos cuando necesitemos precisar un modelo regional en particular. También tengamos presente que algunos autores — que en cada caso indicaremos- emplean los conceptos amplios de Derecho del grupo, o simplemente Derecho de la Unión para referirse de modo general a todos estos esquemas en el mundo. 
En segundo lugar, cada vez que hagamos referencia a las Cortes americanas o latinoamericanas o a los Tribunales de América, estaremos refiriéndonos a nuestros objetos de estudio, la CCJ, el TJCA y el TPRM. En este último caso - de no precisarloestaremos incluyendo a los TAAM, pues le damos un tratamiento unitario, al igual que lo haremos respecto de nuestro referente, el TJUE (o simplemente TJ, o Corte de Luxemburgo), es decir, entendiendo comprendido al Tribunal General de la Unión Europea (TGUE).

En tercer lugar, subrayamos desde ya que nuestro objeto de estudio son sólo las Cortes latinoamericanas recién precisadas, y en ningún caso el modelo de la UE ni el TJUE. Estos últimos únicamente asumen en la presente tesis una posición de referentes, a efectos de permitir llevar adelante los pertinentes cotejos jurídicos, así como para destacar el nacimiento de determinadas instituciones, conceptos, criterios o soluciones jurisprudenciales.

En cuarto lugar, los esquemas de integración latinoamericanos - SICA, CAN y MERCOSUR - asumen la posición de receptores incompletos del modelo europeo. En dicho contexto nosotros nos acotaremos sólo al campo de sus respectivas Cortes, y aún más, gravitando exclusivamente en sus características centrales, esto es, en los patrones centrales — tal como ya lo explicamos en esta misma sección, párrafos atrás.

En quinto lugar, hablamos de esquemas de integración «sub-regionales» atendiendo a la idea de que no abarcan un continente por completo, sino sólo a una zona menor, cual es justamente el caso del SICA, la CAN y el MERCOSUR. De hecho las Cortes que analizaremos se refieren expresamente a los procesos en que se insertan empleando la noción de sub-región del continente americano, v.gr. et al. la CCJ en Nicaragua/Honduras ${ }^{10}$ recoge la postura del demandado así «...j) que "el término integración, tal como se utiliza en el Sistema subregional centroamericano...»" ${ }^{11}$, el TJCA en Junta/Venezuela ${ }^{12}$ ha expresado «...el Acuerdo Subregional Andino no contiene norma sustantiva relativa a las medidas de efecto equivalente contenidas en el art. 30 del Tratado de la Comunidad Económica Europea» ${ }^{13}$, en el MERCOSUR en Argentina/Uruguay ${ }^{14}$ el TAAM indica «...crean distorsiones en la asignación de recursos en el ámbito

\footnotetext{
${ }^{10}$ Sentencia de la CCJ de 27 de noviembre de 2001, Nicaragua c. Honduras, expediente 25-05-29-11-1999, as. $69 / 01$.

${ }^{11}$ Literal j) de la Resulta XLIX) en sentencia ibídem.

${ }^{12}$ Sentencia del TJCA de 20 de octubre de 1999, Sumario por incumplimiento de la sentencia del Proceso 1AI-97 Junta/Venezuela. GOAC 500, 25-10-99.

${ }^{13}$ Párrafo trece del apartado 8 en sentencia ibídem.

${ }^{14}$ Laudo del TAAM (número 9) de 4 de abril de 2003, República de Argentina c. República Oriental del Uruguay.
} 
subregional» ${ }^{15}$. Se suman luego los instrumentos legislativos v.gr. el Acuerdo de Integración 'Subregional' Andino que como vemos desde su nombre en adelante se encuentra colmado de referencias hacia la noción sub-regional, entre otras señala «RESUELTOS a fortalecer la unión de sus pueblos y sentar las bases para avanzar hacia la formación de una comunidad subregional andina» ${ }^{16}$. Por último, también buena parte de la doctrina ${ }^{17}$ apunta al carácter subregional de los esquemas de integración latinoamericanos.

En Europa, también la UE solo cubre una parcialidad, aunque más bien aquí no se habla de región ni sub-región, sino sólo de proceso de integración. Ahora, a modo de sinónimo muchos autores se refieren indistintamente a esquemas regionales o bien sub-regionales. La idea de modelos sub-regional o regional de integración, es menor a la noción que empleamos para sistema de integración, pues con en éste último intentamos englobar el fenómeno completo en el mundo, el cual nace en Europa manteniéndose la UE en su calidad de modelo pionero y vanguardista, y al que le intentan seguir otros tantos modelos en Latino América, África y también en Asia en carácter de receptores incompletos.

En sexto lugar, precisamos que, si bien los conceptos de supremacía y de primacía del derecho de la integración en ocasiones se han empleado como sinónimos, es cierto que han pasado a diferenciarse. Esta tesis no se encarga de dibujar la frontera que los separa, tan sólo tengamos presente que supremacía gira aludiendo al carácter supranacional de la UE, pero primacía, es más bien un concepto posterior que surge para dejar a salvo la terminología referida a la supremacía constitucional, entendiendo que el derecho de la integración prima sobre el nacional en las materias abordadas por él. Lo aclaramos porque los autores, y determinadas sentencias, no hacen siempre la diferencia.

Por último, en séptimo lugar, otro aspecto de contexto relevante de considerar, es que mediante el principio de atribución de competencias a los tribunales de integración se les asigna una amplia cantidad de materias en el complejo entramado del derecho de la integración. Pero lo más particular, en el caso concreto del TJUE, es que dicha función competencial no se agota en la simple disolución del contencioso, sino que se pone al

\footnotetext{
${ }^{15}$ Párrafo 3 del Considerando 42 en laudo ibídem.

${ }^{16}$ Párrafo RESUELTOS, en las Motivaciones del Acuerdo de Integración 'Subregional' Andino - Acuerdo de Cartagena.

${ }^{17}$ MEJÍA HERRERA «Es un hecho notorio [...] la 'influencia' de la doctrina jurisprudencial del antiguo TJCE, ahora llamado TJUE, en las sentencias [...] de los tribunales [...] de las principales organizaciones internacionales de integración subregional existentes en América Latina y el Caribe». MEJÍA HERRERA, O. (2011). El diálogo entre tribunales: la jurisprudencia del tribunal de justicia de la unión europea como fuente de inspiración para los tribunales de los sistemas de integración latinoamericanos. Boletín electrónico sobre integración regional del CIPEI,(1), 14-34. Disponible en el Portal oficial CIPEI $<$ http://www.boletincipei.unanleon.edu.ni/articulos.html> [última consulta, diciembre 13, 2018]. 
servicio efectivo de todo el proceso integracionista en la UE, tal como iremos destacando oportunamente en esta tesis.

3. Entonces, teniendo presente los siete cauces de contexto recién precisados, procederemos a subsumir nuestros objetos de estudio en un acabado análisis estatutario, jurisprudencial y doctrinal, recurriendo a nuestro modelo europeo de referencia, buscando la solución para el siguiente planteamiento doble, primero, respecto de la problemática que se nos presenta al intentar determinar qué tan integracionistas podemos considerar que sean la CCJ, el TJCA y el TPRM, por ser éstas Cortes latinoamericanas bien diferentes entre sí, e insertarse en experiencias sub-regionales donde el carácter de integracionista tiende a diluirse, por no representar la organización a la que pertenecen —el SICA, la CAN y el MERCOSURorganizaciones de integración plenas, ni menos supranacionales, según lo analizaremos rigurosamente en cada caso, y segundo, en tales coordenadas nos plantearemos ¿cuál es el verdadero rol que juegan este tipo especial de tribunales en los procesos de integración latinoamericanos? Y además, si dichos tribunales son efectivamente órganos centrales en cada proyecto de integración al que pertenecen.

Para abordar el anterior planteamiento dual comenzaremos considerando que, en todo ordenamiento jurídico es preferentemente el tribunal el órgano resolutor de conflictos. Pero esta cuestión en el nivel internacional se complica lo suficiente, pues no necesariamente es un tribunal el órgano preferente para la resolución de conflictos, sino más bien se intenta recurrir a las vías diplomáticas tradicionales mucho menos intensas que un tribunal internacional. A esto se suma el hecho de que en la dimensión internacional - como sabemos - incluso se efectúa una triple diferenciación, distinguiéndose entre algunas situaciones internacionales, controversias y conflictos internacionales ${ }^{18}$.

18 En este campo se reúnen tres conceptos: «situaciones internacionales susceptibles de conducir al quebrantamiento de la paz», «controversias» y «conflictos». El primero es el menos intenso y está contenido en los artículos (arts.) 1.1 y 34 de la Carta de NU, refiriéndose a un potencial detonador de la problemática. En cambio, controversia y conflicto son diferenciadores de la intensidad de la problemática. La controversia indica un umbral de criterios divergentes. Por su parte, conflicto supone el estallido de hostilidades graves e incluso ataques armados. La expresión controversia está empleada por la Carta de NU en los arts. 2.4, 34 y otros. A su vez la doctrina ha distinguido entre dos clases de controversias: las políticas y las jurídicas. En dicho sentido AMIGO ROMAN explica que las políticas son aquellas que friccionan por la modificación del derecho en vigor, posición incómoda para un tribunal, pues este aplica la ley o la interpreta, pero no la modifica. Las jurídicas son las que pueden resolverse mediante la aplicación del derecho vigente, posición propia para la Judicatura; aunque no hay una frontera clara entre ambas y habitualmente las controversias son de carácter mixto. AMIGO ROMÁN, C. (1995). La solución de controversias internacionales y sus mecanismos. BFD: Boletín de la facultad de derecho de la UNED, (8), 511-534. En este punto RODRÍGUEZ MACKAY, habla de la noción de diferencias, las que podrán ser jurídicas, políticas o mixtas; y también clasificables entre diferencias jurisdiccionales y no jurisdiccionales. RODRÍGUEZ MACKAY, M. Á. (2013). El principio de solución pacífica de controversias como norma de ius cogens en el derecho internacional. Lex: Revista de la facultad de derecho y ciencia política de la universidad alas peruanas, 11(12), 105-140 (123- 
Para enfrentar la triple diferenciación recién señalada, existen desde simples y hasta sofisticadas herramientas al servicio del principio de la resolución pacífica de toda controversia $^{19}$. Dicho paradigma fue proclamado en la Carta de NU (1945) y luego desarrollado en la Declaración de Principios de DI Referente a las Relaciones de Amistad y Cooperación entre los Estados de NU (1970) ${ }^{20}$. Ahora bien, los anteriores documentos presuponen la existencia de diversos medios de resolución de controversias y conflictos, partiendo por las negociaciones, las vías diplomáticas, el arbitraje y hasta los tribunales internacionales, pues de lo contrario se desplomaría todo el sentido buscado por la referida Carta y la señalada Declaración.

Si nos centramos en los tribunales internacionales se advierte además que, éstos en sí mismos son bastante complejos, pues abarcan diferentes materias, están dispersos en varias regiones y son de múltiples naturalezas jurídicas. Por tal motivo para llevar adelante esta tesis hemos de considerar que la CCJ y el TJCA se corresponden con órganos de naturaleza jurisdiccional, en cambio el TPRM incluidos los TAAM son de naturaleza arbitral. Aunque todos son a la vez potencialmente clasificables como tribunales de integración $-\mathrm{O}$ a lo menos de aspiraciones integracionistas.

124). Por su parte, la jurisprudencia ha ido objetivando la noción de «controversia». De hecho, el antiguo Tribunal Permanente de Justicia Internacional de la Sociedad de Las Naciones en el asunto de las Concesiones Mavrommatis en Palestina, causa Grecia contra Reino Unido, lo definió como «un desacuerdo sobre una cuestión de derecho o de hecho, una contradicción, una oposición de tesis jurídicas o de intereses entre dos personas» jurisprudencia que ha continuado delimitándose por la CIJ.

${ }^{19}$ El principio de la resolución pacífica de toda controversia, si bien se encuentra contenido desde el año 1945 en el artículo (art.) 2.3 de la Carta de NU, no fue sino hasta 1970 que se desarrollaría al ser abordado en la «Declaración Sobre Los Principios de DI Referentes a las Relaciones de Amistad y a la Cooperación entre los Estados de Conformidad con la Carta de las NU» A/RES/2625(XXV). Según expone RODRÍGUEZ MACKAY la Guerra Fría habría sido la que impidió el desarrollo de todos los principios contenidos en el art. 2 de la Carta de NU, superándose en 1970 con la Resolución 2625 supra. Explica que el principio referido, es parte de un marco general de referencia conformado por todos los indicados en el art. 2 supra, los que jurídicamente pretenden enmarcar el comportamiento de los órganos de NU y de las relaciones entre los Estados miembros, ya que - plantea RODRÍGUEZ MACKAY — la Sociedad Internacional se caracteriza por tener una naturaleza cambiante, compleja, heterogénea y poco integrada, por lo que la forma de someter una realidad social como esta, a un cierto orden jurídico que otorgue la necesaria coherencia y estabilidad a la producción y cambio de las normas que regulan las relaciones en su seno, es justamente a través de estas estructuras, como NU y el marco general que entregan sus principios. RODRÍGUEZ MACKAY, 2013, pp. 111-112.

${ }^{20} \mathrm{La} \ll$ Declaración Sobre Los Principios de Derecho Internacional Referentes a las Relaciones de Amistad y a la Cooperación entre los Estados de Conformidad con la Carta de las Naciones Unidas» A/RES/2625(XXV), puede consultarse en: Portal oficial de Naciones Unidas <http://www.un.org>. También puede revisarse con inclusión de un comentario previo en ANDRÉS SÁENZ DE SANTA MARÍA, P. (2013). Derecho internacional público: Textos y materiales ( $2^{\mathrm{a}}$ ed.). Madrid: Civitas Thomson Reuters., pp 25-28. 
La labor es dificultosa pues no existe un grupo de Cortes de integración de características homogéneas, sino que cada una es muy singular. Puntualicemos que sólo el TJUE es una verdadera Corte de integración y la UE la única organización de integración plena y verdaderamente supranacional. En cambio los modelos latinoamericanos no son plenos. Si no incompletos y más bien de aspiraciones integracionistas. De hecho este es uno de los puntos de contraste general en que ahondaremos en nuestra tesis.

Tras lo que venimos diciendo, para centrarnos en aquellos tribunales que son nuestro objeto de estudio, abandonaremos el umbral de la mera disolución del contencioso e ingresaremos a los aspectos centrales del derecho de la integración - considerado en sentido amplio tal como ya lo aclaramos en el número 2, líneas atrás-, de tal suerte que si el mentado derecho de la integración es ejecutado o aplicado desajustado al bloque de legalidad del grupo, quedan expuestas dichas situaciones a las acciones de los legitimados y bajo las competencias de estos tribunales.

Justamente en la etapa de subsistencia y de desarrollo de cada proyecto regional latinoamericano es donde todos los órganos articularán dentro de la geometría orgánica asignada estatutariamente, campo donde se inserta el órgano jurisdiccional de la organización, así por ejemplo el TJUE ha sido clave en la evolución del Derecho de la UE. Sin embargo, nosotros veremos cuál ha sido la participación y la contribución de las Cortes latinoamericanas en cada una de sus sub-regiones en América. Pues en términos amplios estos tribunales muchas veces afrontan los puntos claves del desarrollo del proyecto de integración. Así en su caso deberán resolver cómo interpretar alguna sección de una norma originaria, o bien cómo recomprender los objetivos de la organización a la que pertenecen ante un mundo dinámico y cambiante. O bien, deberán determinar si es correcto o no, asumir compromisos internacionales, en el sentido de que éstos no vayan en desmedro de la integración lograda.

En el fondo analizaremos si los tribunales latinoamericanos resuelven en línea con los conceptos europeos, si consideran o no las consecuencias, advertiremos si la misma solución vale para cualquier época y cualquier región, también será parte de esta tesis el cuestionarnos si la jurisprudencia es o no lo suficientemente convincente como para reconducir un fenómeno socio-político y otras tantas complejas circunstancias que extraeremos de sus principales sentencias.

En definitiva, buscaremos razonar sobre si es o no el tribunal de integración latinoamericano un órgano o Institución clave para el mantenimiento y desarrollo de todo el proyecto socio-político, obrando al mismo tiempo como tensores internos que intenten evitar por una parte que los Estados miembros abandonen el proyecto, y por otra, que se 
produzca un desencanto en los destinatarios, para esto será fundamental que sus sentencias sean convincentes.

4. En cuanto a la hipótesis de nuestra investigación la presentamos del siguiente modo: «las Cortes latinoamericanas CCJ, TJCA y TPRM a pesar de pertenecer a singulares procesos sub-regionales y siendo éstas bien diferentes, se logran identificar entre estos sui generis tribunales algunas características comunes o patrones centrales con el TJUE como modelo de referencia. Básicamente porque los esquemas latinoamericanos SICA, CAN y MERCOSUR copian y se influencian del modelo de la UE, aunque al ejecutarlos en Latino América lo hacen con menor intensidad, dejando a la vista claros modelos incompletos. Pero a pesar de aquello las Cortes bajo estudio han llevado adelante un ejercicio jurisdiccional articulando sus densas competencias, las cuales les fuerzan a desplazarse en un equilibrio dual, por una parte disolviendo el contencioso y por otra, ingresando a los principales aspectos de la integración. Y además se relacionan de modo dicotómico con el derecho de la integración comprendido éste en sentido amplio, pues se nutren de él y a la vez lo robustecen inyectándole nuevos conceptos. Asumiendo así un rol central en cada uno de sus proyectos sub-regionales en Latino América».

5. La justificación para llevar adelante esta investigación se basa en la singularidad que se extrae al observar que, si bien el SICA, la CAN y el MERCOSUR no son organizaciones de integración plenas, como lo es la UE, tampoco son simples organizaciones internacionales. Sino que poseen la potencialidad de desplazarse en sus objetivos y conquistas, y en dicho progreso, podremos constatar que nuestros objetos de estudio han desempeñado un rol extraordinario considerando sus realidades locales. Es cierto que el SICA, la CAN y el MERCOSUR son construcciones que intentan replicar el modelo de la UE en sub-regiones de Latino América compuestas por países en vías de desarrollo y por ende sólo lo pueden hacer en la medida de lo posible, dando cuenta de sendas carencias si se les compara con la mega construcción europea, pero a pesar de aquello y dentro de su contexto se han concretado significativos avances.

En el sentido recién indicado es que estos proyectos latinoamericanos asumen el carácter de organizaciones de aspiraciones integracionistas —en ningún caso supranacionales-, es decir, se ubican en una posición intermedia lejos de una OI clásica y sin llegar a ser tampoco una organización de integración robusta o plena como la UE, por tal motivo comportan sistemas híbridos de integración como ha ido destacando la doctrina ${ }^{21}$. Esta

\footnotetext{
${ }^{21}$ BIACCHI, CARTAWINTER y BUTTENDORFF comparando entre determinados aspectos de la UE $v / s$ el SICA y la CAN, les parece más acertado afirmar que los modelos latinoamericanos son sistemas híbridos de integración que no alcanzan al modelo de plena integración, expresando en lo pertinente «Lo que se tiene son 'sistemas híbridos de integración' esto es, sistemas que jurídicamente adoptan el Derecho Comunitario, pero en la práctica no es efectivo, tanto por la falta de voluntad política de sus aliados, como por la falta de 30
} 
posición intermedia se explica básicamente en razón de que los tres esquemas se aproximan a la noción amplia del derecho de la integración, lo que fluye nítido a través de dos conductos, uno, se proponen estatutariamente fines propios del derecho de la integración, y dos, los ejercicios jurisprudenciales de la CCJ, del TJCA y del TPRM vienen impregnados de abrumadores criterios de cercanía a la noción amplia del derecho de la integración. Concluimos entonces que es justamente esta posición intermedia la que les imprime a las organizaciones latinoamericanas - SICA, CAN y MERCOSUR — un carácter especial que atrae la atención investigativa, ya que poseen la potencialidad de desplazarse hacia contenidos más maduros de la integración.

Entonces, como las Cortes que estudiaremos son órganos de las recién referidas y singulares organizaciones, se vuelve del todo interesante jurídicamente analizar de forma horizontal la cercanía o la lejanía que hay entre los mismos tribunales latinoamericanos enfocados y luego de éstos con el referente, el TJUE. Ya que los efectos que se siguen de los ejercicios de las Cortes enfocadas, afectan directamente a las personas que habitan cada zona, reconociéndoles más —o en ocasiones - menos derechos, dependiendo de la región de Latino América en que se encuentren. Al tiempo de impactar en todas las relaciones transnacionales que incluyan a los Estados miembros, a las personas jurídicas y físicas que pertenezcan a cada una de las tres experiencias latinoamericanas.

Por cierto resulta ser inabordable el cúmulo de extremos que fluyen de los fenómenos latinoamericanos, por tal razón es que debemos tener presente que en esta tesis sólo nos centramos en un único aspecto dentro del entramado general del fenómeno integracionista, la posición de un tipo de órgano dentro de la organización, el tribunal de integración. Intentando demostrar que la CCJ, el TJCA y el TPRM poseen perfiles en algún nivel similar al TJUE, y que ejercen un rol central en los esquemas de integración latinoamericanos a los que pertenecen.

6. Para la labor anunciada precedentemente, recurriremos a una estrategia metodológica múltiple dado el amplio espectro de los procesos integracionistas. Así usaremos el método dogmático al estudiar la doctrina y la jurisprudencia seleccionada, a efectos de construir descripciones sólidas del derecho aplicable a cada tema, más allá de lo puramente normativo. El método comparado lo emplearemos al analizar los Estatutos, la jurisprudencia y la doctrina del modelo de la UE enfrentada con el latinoamericano. Además como esta investigación implica advertir un proceso en despliegue y en diferentes

efectivas instituciones supranacionales». BIACCHI GOMES, E., CARTAWINTER, L. A. \& BUTTENDORFF R. BECKERS, A. C. (2018). Supranationalem and fundamental rights: the effectivity of the secondary legislation in the andenean community system and community and in the central american integration. Estudios constitucionales, 16(1), 99-128. Disponible en <http://dx.doi.org/10.4067/S071852002018000100099> [última consulta, septiembre 7, 2019]. 
niveles —dependiendo de la región en estudio - es oportuno el uso del método histórico, pues éste reconoce todo aquello de que se valió el proceso para posicionar el objeto de estudio en su actual situación. Y en razón de que nos deberemos enfrentar la interpretación normativa y jurisprudencial para comprender el ancho potencial de algunas construcciones jurídicas, nos valdremos también de las versatilidades del método hermenéutico.

7. En cuanto a la estructura general de la tesis esta se despliega del siguiente modo: en el capítulo I veremos el contexto histórico en que surgen el SICA, la CAN y el MERCOSUR y sus cortes, la CCJ, el TJCA y el SSCM con los TAAM y el TPRM. El capítulo II tendrá como objeto efectuar un análisis estatutario de las Cortes de integración, cotejando sus principales normativas entre el TJUE como referente, versus las Cortes latinoamericanas en calidad de receptores. Este ejercicio jurídico nos permitirá identificar a nuestros objetos de estudio con mayor rigurosidad técnica. Dicho análisis se acota a una selección de las principales características de las Cortes enfocadas, aquellas que denominamos patrones centrales. Así veremos que — sólo desde lo estatutario- las Cortes latinoamericanas presentan bastantes similitudes con el modelo europeo, aunque al ejecutar estas competencias se aprecian muy distantes del TJUE.

En el capítulo III nos centraremos en el rol de los tribunales de integración en sus procesos regionales y en la producción de jurisprudencia integracionista, entendida esta última como un tipo particular de jurisprudencia expansiva. Destacando que es esta la forma idónea en que una Corte de integración contribuye al éxito de todo el proyecto político. Mediante el capítulo IV constataremos que entre las Cortes latinoamericanas se desarrolla un tráfico de información recurriendo a la figura del diálogo judicial, aunque se presenta meramente extractivo desde el TJUE, y en cuanto a su entorno cercano, se aprecia un débil diálogo judicial inter-americano.

En el capítulo V presentaremos una visión de futuro para los tribunales de integración, lo que es bastante relevante, pues en Latino América se producen en muchas ocasiones dificultades en los proyectos SICA, CAN y MERCOSUR. También presentaremos determinados gráficos y estadísticas que confeccionamos mediante la tabulación de toda la producción de las Cortes latinoamericanas analizadas. Luego desarrollaremos las conclusiones generales de la tesis con la pertinente disolución de la hipótesis. Por último presentaremos la bibliografía detallando todas las fuentes consultadas y empleadas durante los años de investigación. 


\section{AgRADECIMIENTOS}

Antes de iniciar las líneas que nos esperan, es mi sincero deseo agradecer de manera especial la constante guía y preocupación de mi director el Dr. Juan Santos Vara, quien ha efectuado siempre rigurosas observaciones para el mejor logro de esta tesis, y yo por cierto abusando de su tiempo. También quedo en deuda con todo el equipo profesional de la Biblioteca Francisco de Vitoria pues constantemente han estado dispuestos a facilitar mi trabajo, así como con el equipo profesional del Centro de Documentación Europea quienes destacan por su amabilidad y profesionalismo. A los muchos profesores de la Universidad de Salamanca, que por temor a dejar alguno afuera prefiero no nombrarlos, quienes en tantas ocasiones me han hecho algún comentario o precisión, a todos ellos les agradezco infinitamente. En lo profesional agradezco a mis colegas profesores de derecho en Chile, a mis ayudantes e incluso alumnos, pues todos ellos han facilitado mis extensas estancias en España, así como a mis colegas abogados que en tantas oportunidades han debido reemplazarme en algún alegato o juicio, siempre con la mejor disposición y camaradería. A mis admirables compañeros de doctorado y amigos de Salamanca, con quienes hemos sostenido largas discusiones, análisis y vivencias, todos han estado presente de forma constante y desinteresada para apoyarme. No puedo dejar de mencionar aquí a mi madre, a mi familia, sobrinos, amigas y amigos de Chile, pues muy a pesar mío, se han debido postergar en demasiadas ocasiones, y sin su valioso apoyo durante estos años, no hubiese podido concentrarme en esta extensa labor investigativa. 
Capítulo I

\section{ANÁLISIS HISTÓRICO DEL FENÓMENO INTEGRACIONISTA EN AMÉRICA LATINA COMO ANTECEDENTE Y CONTEXTO DE LOS SINGULARES TRIBUNALES DE CADA ESQUEMA REGIONAL}




\section{Capítulo I}

\section{ANÁLISIS HISTÓRICO DEL FENÓMENO INTEGRACIONISTA EN AMÉRICA LATINA COMO ANTECEDENTE Y CONTEXTO DE LOS SINGULARES TRIBUNALES DE CADA ESQUEMA REGIONAL}

\section{ANTECEDENTES dE UNA AMÉRICA LATINA EN EL CAMINO} DE SU PROPIA INTEGRACIÓN Y NO DE IMPORTACIONES

1 meditar sobre una América Latina responsable de su propio porvenir, intentando sortear los desafíos de un mundo cada vez más sofisticado, se hace imposible desatender a su tan reciente origen histórico. La herencia del Imperio Español con la consiguiente amalgama cultural, más los posteriores progresos locales en los territorios americanos por donde este imperio se extendió, a la postre culminaría por configurar la mega región que hoy conocemos como América Latina, diversa, multifacética y en ocasiones incluso exótica, pero con un innegable tensor cultural basado en el idioma, la religión y sus costumbres, lo que influye ciertamente en los sistemas jurídicos de cada nación. Estos sistemas normativos de orden público guiados por la moral y las buenas costumbres se construyen sobre las estructuras del derecho indiano dejado por España, por lo que una de sus consecuencias es la relativa homogeneidad entre los mismos.

Los conceptos anteriores deberían facilitar cualquier proceso de integración, lo lamentable es que el subdesarrollo imperante en las naciones socias de los modelos que lo han intentado y que aún continúan en este esfuerzo, termina muchas veces por opacar las luces 
que traen los sueños y las alabanzas iniciales de mentadas empresas ${ }^{1}$. Aunque tal semblante gris aflora únicamente al contrastar los avances latinoamericanos con la monumental Unión Europea (UE), lo que en justicia no es correcto, porque eclipsa los éxitos alcanzados y escamotea la realidad, ya que ninguno de los tres proyectos de integración modernos en Latinoamérica, el Sistema de Integración Centroamericano (SICA), la Comunidad Andina de Naciones (CAN) y el Mercado Común del Sur (MERCOSUR), le han ocasionado daños a sus respectivos socios, sino que claramente han logrado generar mejores condiciones de vida y de desarrollo en cada una de sus regiones. El análisis histórico que se pueda hacer de las tres regiones, comparando las condiciones previas a la implementación de los esquemas de integración versus las actuales, sería elocuente.

Sin embargo todo oscurece cuando ingresamos en las absurdas dinámicas de una importación geométrica del modelo de integración europeo para América Latina, primero porque no se requiere, y segundo, porque sinceramente el sentir latinoamericano no desea tamaña cercanía entre los Estados. Seguramente este sentimiento atemperado se deba a que América Latina no fue traumada por la Segunda Guerra Mundial (II GM) ${ }^{2}$, por ende todas estas naciones, de igual idioma, religión e increíbles cercanías culturales y jurídicas, no se miren con tan enorme desconfianza, como para verse obligadas a someterse a un mega gobierno - cuasi imperio contemporáneo - con la misión de poner orden, mantener la paz y guiarlos hacia el desarrollo exponencial. Los latinoamericanos simplemente tienen otra realidad y otra temperatura.

\footnotetext{
${ }^{1}$ Los tres esquemas latinoamericanos que estudiaremos en esta tesis, el SICA, la CAN y el MERCOSUR se caracterizan por componerse de países en vías de desarrollo, sin perjuicio de que participen naciones de mayor capacidad económica, como el gigante Brasil o Argentina en el Mercosur. Para ACOSTA esta dificultad es mayúscula, cuestión que acentúa al referirse a la CAN, expresando «En un mundo globalizado, en el cual todo sucede a una escala mayor, la CAN constituía una opción para construir economías de escala de distinto tipo: políticas, productivas, sociales y de conocimiento. Pero el subdesarrollo a veces acaba con los sueños». ACOSTA PUERTAS, J. (2006). La desintegración andina. Nueva sociedad, 204, pp. 4-13.

${ }^{2}$ Razonando sobre el trauma europeo y la feliz respuesta que la UE ha brindado GIL ROBLES expresa «Quiero decir que los europeos tenemos ya una sensibilidad muy especial a todo lo que suponga conseguir la ausencia de enfrentamiento. Mi generación es la primera generación de europeos que probablemente no ha ido a una guerra, y las siguientes más todavía. Todas las anteriores habían estado en una guerra, mundial, europea, o entre sus correspondientes países». GIL ROBLES, J. M. (2002). Los retos de la globalización y el liderazgo de la unión europea. Revista de derecho de la unión europea, 2, pp. 225-232. (p. 228).
} 


\section{LA INTEGRACIÓN LATINOAMERICANA NO PUEDE ENCAPSULARSE PORQUE FLUYE DEL ACERVO HISTÓRICO DE UNA INTEGRACIÓN QUE MUTA EN SÍ MISMA}

Es cierto que en Europa fue la región del mundo donde se anidó, surgió y se desarrolló el fenómeno de la integración, el cual en la actualidad se encauza y estructura a través de la Unión Europea, sin embargo América Latina tiene sus propios esquemas, iniciados como copias incompletas del mega proyecto europeo, pero de esfuerzos realmente valorables.

Se dice que las raíces unitarias de Europa son extremadamente remotas, tanto así que los historiadores europeos ${ }^{3}$ dan cuenta de un sentimiento de unidad del viejo continente, desde el mundo antiguo con las Ligas de las ciudades griegas, transitando luego a formas de integración forzada en el Imperio Romano, fluyendo hacia la noción unitaria en torno a la religión en la edad media y hasta que los humanistas del Renacimiento le imprimieron a Europa el concepto de entidad cultural y política en una dinámica de tránsito desde una res pública christiana a una pluralidad de Estados soberanos. Mientras en Europa se desarrollaba ese lejano sentimiento unitario, América aguardaba ser descubierta, y aún más, las regiones conquistadas por el Imperio Español debieron esperar el paso de Napoleón por España para recién iniciar los procesos independentistas.

Es dramáticamente diferente el paralelo histórico para observar las nociones lejanas de unidad en Europa versus las de América. En el mundo antiguo europeo las Ligas de las ciudades griegas pasaron a denominarse Anfictionías, las cuales eran agrupaciones de ciudades inicialmente de carácter religioso que derivaron en importantes asociaciones religioso-políticas ${ }^{4}$, entre éstas la Liga de Corinto evolucionó mutando hacia una especie de

\footnotetext{
${ }^{3}$ Diversos investigadores - sino la mayoría - dan cuenta de estas extensas raíces del sentimiento unitario europeo, vid. et al. AHIJADO QUINTILLÁN, M. (2000). Historia de la unidad europea: Desde los precedentes remotos a la ampliación al este ( $1^{\mathrm{a}}$ ed.) Ediciones Pirámide. BERDAH, J. F. (2007). Los orígenes de la construcción europea. De la idea europea a la europa unida. Cuadernos europeos de deusto, (37), 49-71. BENGTSON \& SCHRADER, 2008; TRUYOL \& SERRA, 1999, nos referiremos a estos oportunamente en cada caso pertinente.

${ }^{4}$ La noción de Anfictionía es la de «asociación religioso-política alrededor de una divinidad tutelar». Corresponden a formas asociativas surgidas en la profundidad de la historia griega antigua en la época del primer milenio a. C. La más remota es la Anfictionía jónica o Liga de los jonios que aparece en la época de transición (800 a. C. aproximadamente). En la época de la gran colonización griega surge la Anfictionía o Liga de Antela, y luego alrededor del 600 a.C. aflora la Anfictionía délfica o Liga de Delfos. En especial la Anfictionía de Delfos, fue, y es, la más conocida y estudiada. Ella agrupaba a doce Estados. BENGTSON, H., SCHRADER, C. \& CALONGE RUIZ, J. (trans.) (2008). Historia de grecia. Madrid: Gredos (Original en alemán, título original: Griechische Geschichte von den Anfängen bis in die römische Kaiserzeit), p. 63, p. 91, p. 172 y p. 566. Otro, MANGAS MANJARRÁS, J. (1986). Textos para la historia antigua de grecia (4a ed.). Madrid: Cátedra, pp. 60-61.
} 
organización internacional, dotándose incluso de un órgano, el Synédrion o Sinedrio, en el cual Filipo II no tenía asiento, lo que configura un primer indicio de lo que en la actualidad explicamos como el carácter supraestatal ${ }^{5}$.

En aquella época la tríada de principios griegos en el ámbito internacional se conformaba por el equilibrio político, la intervención y el arbitraje, incluso se permitía aplicar medidas coercitivas contra un país o ciudad infractora. Pero la unificación concreta la lograría el Imperio Romano mediante la fuerza y las alianzas estratégicas. Lo anterior es una cuestión que en la actualidad la doctrina recoge para estudiar y dividir los tipos de integración y unificación, reconociéndose como una clase de integración la implementada por la fuerza ${ }^{6}$,

${ }^{5}$ A esta enorme estructura jurídica Filipo II la llamaba simplemente «los griegos». Tras diversos estudios históricos, hoy es claro que la Liga de Corinto o Liga Helénica (aproximadamente del año 338 a. C.) comportó una especie de forma federativa, con órganos propios y de decisiones vinculantes. Todo el mundo griego concurrió a la Liga de Corinto - excepto los espartanos - tras el auspicio del Rey Filipo II, quien prefirió no azotar Grecia, y optar por esta singular forma organizativa internacional, a la cual los historiadores tildan de «una especie de organización federativa». Toda su estructura jurídica y fines, los comienza ideando Filipo, proceso que — según los historiadores - apoya como hombre de talento excepcional, determinado, militar victorioso y político sobresaliente, padre de Alejandro Magno su sucesor. POMEROY, B., BURSTEIN, S., DONLAN, W. \& TOLBERT, J. (2001). La antigua grecia: Historia política, social y cultural. (trans. T. de Lozoya). Barcelona: Crítica (Original: Ancient Greece: a political, social, and cultural history), pp. 416-419. PASCUAL GONZÁLEZ, J. (1997). Grecia en el siglo IV a. C.: Del imperialismo espartano a la muerte de filipo de macedonia. Madrid: Síntesis, pp. 189-190. BENGTSON, SCHRADER \& CALONGE RUIZ, 2008, pp. 307-309.

${ }^{6}$ Los conceptos de unificación e integración actualmente son diferentes. La unificación refleja un nivel final, más propio de un sistema federal, en cambio la integración se encamina a procesos de cooperación internacional que pueden ser de mayor o menor intensidad, y en su máxima expresión llega a ser de carácter supranacional, como es el caso de la actual UE. La complejidad de los procesos de integración y unitarios han sido motivo de diversos estudios históricos, pero en lo que nos interesa aquí tengamos presente un par de consideraciones que reconoce la doctrina: A) desde un ángulo histórico y fenomenológico se reconocen: i) La integración autoritaria, dándose como ejemplos el proceso que dio origen al Reino de Italia, o el de China, del Japón. La integración autoritaria también permite la absorción de unidades políticas menores en un solo reino, como lo fueron los casos de España, Francia o Noruega, i.2) La otra tipología dentro de esta categoría, es la integración por coordinación, que requiere de una actividad volitiva de los Estados soberanos. En otro ángulo se encuentran: desde la finalidad del proceso de integración, observándose al menos cuatro tipos, a saber: ii.1) La integración militar. Es un tipo de coordinación entre Estados de objetivos específicos, sin sobrepasar el ámbito de la defensa, como es el caso de OTAN, ii.2) La integración política. Esta a su vez puede tener dos objetivos divergentes: la simple coordinación entre Estados sin sobrepasar ese umbral - como el caso de la OEA—, o bien, partiendo de dicha coordinación política, prever la posibilidad de una mayor estructuración jurídica, dando paso a una federación o confederación de Estados; ii.3) La integración económica. Esta es muy cercana a la anterior, ya que la norma económica de coordinación es también norma política. Un ejemplo lo constituye el Mercosur, y ii.4) La integración cultural. Esta se refiere a la búsqueda de un aspecto intrínsecamente común en el grupo para integrarse, por ejemplo, podemos destacar aquí el caso de la Unión del Magreb Árabe. DOBOVSEK, J. \& SABAT, J. M. (1999). Aspectos institucionales del mercosur. [...]. En J. Irigoin Barrenne (coord.), E. Rey Caro (present.), J. M. Insulza Salinas (disc.), R. Barros Charlín, C. F. Molina del Pozo, L. Narbone, ... G. Holzmann, Chile y el mercosur en américa latina: VI encuentro 40 
entendemos que la unificación es un nivel superior a la integración, pues la primera supone un sistema federal, la segunda se ubica en coordenadas intermedias entre la cooperación y la unificación, justamente esta posición ecléctica es en la que se posiciona la $\mathrm{UE}^{7}$, ya que dicho proyecto no aspira a una meta federativa ${ }^{8}$.

Al finalizar el periodo medieval e inaugurándose la Edad Moderna con el descubrimiento de América (1492) se vendrían a restudiar aquellas antiguas estructuras, pues tal hito incorporó nuevos elementos a las nociones del Derecho Internacional (DI), replanteándose las bases organizativas del mundo conocido. Entorno en que Francisco De Vitoria (1538 aproximadamente) explota intelectualmente los nuevos elementos del problema internacional con un enfoque de un universalismo político y jurídico, dejando traslucir la idea del orbe, del totus orbis, aquella comunidad de todos los pueblos de la tierra fundada en el derecho natural. Siendo la fuente de ese universalismo, la unidad del género humano, la cual se sigue de la igualdad esencial de los hombres y los pueblos, en la forma proclamada por la antropología estoica y cristiana haciendo foco en el fin del ser humano ${ }^{9}$, circunstancias y realidades a las que Vitoria se refiere expresamente.

En esas coordenadas comenzaba a tomar forma la noción de la «comunidad internacional universal». La cual —explica Vitoria — es fruto de la sociabilidad natural del hombre, que se extiende más allá de los límites de su ciudad, hasta comprender la universalidad del género humano. Esta cuestión es la que Vitoria asumió plenamente en virtud de su lógica inmanente, que define como el bonum commune totius orbis — principio del bien común

internacional de derecho de américa del sur (1999). Tomo I. Santiago, Chile: Universidad de Chile. Facultad de Derecho (Eds.), Editorial Jurídica de Chile., pp. 241-243.

${ }^{7}$ RODRÍGUEZ IGLESIAS Y LÓPEZ ESCUDERO expresan que la Unión Europea es una organización jurídico-política sui generis situada a caballo entre las organizaciones internacionales clásicas y los Estados federados. RODRÍGUEZ IGLESIAS \& LÓPEZ ESCUDERO, 2010a, p. 593.

${ }^{8}$ MANGAS aclara que la UE no es un Estado federal, es más, enfatiza que ni siquiera es un Estado, sino una organización internacional intergubernamental muy distinta de las clásicas, concluyendo que la UE sería un «ente jurídico-internacional atípico». MANGAS MARTÍN, 2014c, pp. 46-47.

${ }^{9}$ Las nuevas construcciones jurídicas a que el mundo comenzaría a enfrentarse al crecer el mundo conocido, no pueden ser desatendiendo al ser humano. Ahora bien en dicha línea las construcciones modernas como las OI, tribunales, centros de decisión, etc. también deben orientarse en esta especie de ley superior. FRANCISCO DE VITORIA, tomando ese norte, en su época, aclara que el fin central no es la paz, sino que ella es sólo un elemento del verdadero objetivo, cual es la felicidad del Ser Humano. Lo expone en Relectio de Indis donde desarrollando esta idea cita a JOHANNES BURIDANUS y a ARISTÓTELES así «Item Buridanus (5 Polit. cap 3) quaerit utrum pax sit finis civitatis; et respondet quod non, quia felicitas est finis politiae, et pax médium ad felicitaem, quae est finis politiae. Item Aristoteles (3 Politicorum, cap. 6) disputat et determinat quod finis civitatis est bene et beate vivere». DE VITORIA, F., PEREÑA, L., PEREZPRENDES Y MUÑOZ DE ARRACO, J. M. \& BELTRÁN DE HEREDIA, V. (1967). Relectio de indis o libertad de los indios [Español-Latín]. Madrid: Consejo Superior de Investigaciones Científicas., p. 106. 
del orbe- como norma suprema de un orden pacífico mundial ${ }^{10}$. En definitiva serían los humanistas del Renacimiento quienes le imprimen a Europa el concepto de entidad cultural y política, en una dinámica de tránsito desde una res pública christiana a una pluralidad de Estados soberanos.

Ya en el siglo XVIII, la influencia de la evolución del pensamiento kantiano nos presenta por una parte la coincidencia con Vitoria pero con distinto fundamento ${ }^{11}$, y por otra, algunas soluciones para afrontar la organizativa internacional. Immanuel Kant al abordar en varias ocasiones - la temática de la unión de las naciones, va variando la intensidad de sus soluciones, comenzando en 1784 en su obra Ideas para una Historia Universal en Clave Cosmopolita, aquí expone la noción de una Liga de Estados con facultad legislativa y con poder unificado. Pero una década después, en 1795, al aproximarse a la colaboración, en su ensayo Proyecto para la Paz Perpetua, planteó la existencia de una Federación de Repúblicas interdependientes. Finalmente, en 1796, mediante su publicación Metafísica de las Costumbres, entrega una tercera solución de menor intensidad, planteando sólo un Congreso permanente de Estados en carácter de unión voluntaria revocable, instituto mucho más cercano a las organizaciones internacionales actuales ${ }^{12}$.

Iniciándose el siglo XIX tras el Congreso de Viena (1815) existió un intento de organizar a la comunidad internacional a través de la llamada Santa Alianza, la cual implicaba que las

${ }^{10}$ La complejidad del concepto y de los contenidos de la Comunidad Internacional Universal vitoriana surgida en el contexto histórico de la problemática de los derechos de los hombres del nuevo mundo y el ideario de Bien Común Universal, es expuesta por ANTONIO TRUYOL en DE VITORIA, PEREÑA, PEREZ-PRENDES Y MUÑOZ DE ARRACO \& BELTRÁN DE HEREDIA, 1967, pp. CXLVI-CXLIX (vid. Estudios de Introducción, apartado IV. Vitoria en la perspectiva de nuestro tiempo).

${ }^{11}$ En similar línea KANT coincide con DE VITORIA, aunque con diverso fundamento. KANT concluye que la «felicidad es el fin último del ser humano», según lo expone en su obra Fundamentación de la Metafísica de las Costumbres (1785). El razonamiento desplegado fluye así «4) En lo tocante al deber meritorio para con los demás, 'el fin natural que tienen todos los hombres es su propia felicidad'. A decir verdad, la humanidad podría subsistir si nadie contribuyese a la felicidad ajena con el propósito parejo de no sustraerle nada; pero esto supone únicamente una coincidencia negativa y no positiva con la humanidad 'como fin en sí mismo', si cada cual no se esforzase también tanto como pueda por promover los fines ajenos. Pues los fines del sujeto que 'es fin en sí mismo' tienen que ser también mis fines en la medida de lo posible, si aquella representación debe surtir en mí todo su afecto. Este principio de la humanidad y de cualquier ser racional en general como fin en sí mismo (que supone la máxima condición \ restrictiva de la libertad | de las acciones de cada hombre)...» KANT, I. (2002, $3^{\mathrm{a}}$ reimpr. 2008). Fundamentación para una metafísica de las costumbres $\left(1^{\mathrm{a}}\right.$ ed.). (Trad. A. Rodríguez). Madrid: Alianza (Original: Grundlegung zur Metaphysik der Sitten, 1785), p. 118.

${ }^{12}$ El desarrollo de los conceptos de IMMANUEL KANT son altamente complejos y sus variantes dan cuenta de replanteamientos, toda vez que se colisionan los idearios con la realidad. Es notorio el hecho de que va siguiendo un patrón de disminución respecto de la complejidad de la integración. Es decir, finalmente opta por la simplicidad y menor involucración para resolver un tema que no abandona. GUARIGLIA, O. (2010). En camino de una justicia global. Madrid: Marcial Pons, pp. 43-50. 
relaciones internacionales se subsumían en los principios del cristianismo. Operación jurídica de naturaleza defensiva cultural, pues obstaculizaba el ingreso del Imperio Otomano, a pesar de declararse abierta a la potencia que deseara incorporarse. Pero no tuvo mayores logros.

Por esos años en América comenzaban los primeros movimientos independentistas con el paso de Napoleón por España, por tal razón Latino América vino a entender de sueños unitarios a través de los ideales de Simón Bolívar, quien — por todo lo dicho hasta aquíutilizó nociones relativamente modernas de unidad, recurriendo incluso al otrora archienemigo español, la Corona Inglesa, con la esperanza de lograr un verdadero hispanoamericanismo $^{13}$, el cual en un principio debía tener el apoyo de Inglaterra, expresando Bolívar «a su sombra nos presentaremos entre las naciones civilizadas y fuertes [...] pues en la infancia necesitamos apoyo, que en la virilidad ya sabremos defendernos». Inglaterra y Holanda asistieron especialmente al Congreso de Panamá (1826) ${ }^{14}$ en calidad de observadores, naciendo de esa manera en el DI tal calidad de partícipe. En dicha ocasión se firmaron varios instrumentos, entre los cuales estaba el Tratado de Unión, Liga y Confederación Perpetua, cuya sustancia fue claramente utilizada casi cien años más tarde por los redactores del Pacto de la Sociedad de las Naciones (1919) contenido en la Parte Primera del Tratado de Versalles.

El período de los cien años de paz, iniciado tras el fin de las Guerras Napoleónicas y hasta antes de la Primera Guerra Mundial (1814 - 1914) generó las condiciones para que el mundo del pensamiento decantara los evidentes beneficios que podrían lograr las fuerza de un grupo bien organizado de naciones, a diferencia de cualquier país aisladamente considerado, razón por la cual los fenómenos organizativos no tardarían en presentarse, circunstancia que para nuestro interés, nos deja ad portas de los procesos modernos con todo el desarrollo de las Organizaciones Internacionales (OI), las que dentro de sus órganos permanentes contemplaran tribunales del grupo.

\footnotetext{
${ }^{13}$ Puede revisarse un completo desarrollo histórico que comienza desde el descubrimiento de América, pasando por la afirmación doctrinal del particularismo americano de Francisco de Vitoria, las ideas de gobiernos especiales de la Corona española para América —en particular del rey Carlos V- para luego desplegar rigurosamente el extenso derrotero de gestación y nacimiento de la Organización de Estados Americanos (OEA), en FERNÁNDEZ-SHAW, F. (1959). La organización de los estados americanos : (O. E. A.) : Una nueva visión de américa. Madrid: Ediciones Cultura Hispánica, pp. 17-226.

${ }^{14}$ El histórico Congreso de Panamá fue convocado por Simón Bolívar en el año 1824 y se celebró en 1826 con la participación de todas las naciones, menos de Chile, Argentina y Brasil. Por su parte Estados Unidos de Norteamérica no pudo participar porque sus emisarios llegaron atrasados. Inglaterra y Holanda participaron como observadores. FERNÁNDEZ-SHAW, 1959, pp. 37-38.
} 
A esa altura, en Centro América nacía en 1823 la Federación Provincias Unidas Centroamericanas la cual se extendió hasta 1838, y tras su disolución dio paso a las actuales naciones de esa zona. Pero la referida federación no fue más que catalizadora de un enraizado sentido unitario ${ }^{15}$ del istmo centroamericano. Esa sub-región primero estuvo organizada por el Imperio Maya, luego fue reestructurada por el Imperio Español bajo la Capitanía General de Guatemala, le sigue la referida federación y desemboca en varias naciones, aunque Panamá era parte de Colombia, sin embargo en 1903 se separan. A partir de ese momento, comienzan los intentos por reagrupar la zona del istmo.

En el camino de reagrupación de Centro América fue que en 1907 se suscriben diversos convenios en Washington, naciendo la Confederación Centroamericana junto a su «Tribunal de Justicia Centroamericano» más conocido como «Corte de Cartago» pues su sede estaba en dicha ciudad de Costa Rica, pasando a constituir esta Corte el primer tribunal internacional de naturaleza jurisdiccional y de carácter permanente en la historia. De esta forma en Centro América se estaba produciendo un fenómeno trascendente en la transición de los sistemas resolutores de conflicto de tipo arbitral, cuya máxima expresión se asentaba hasta entonces en Europa en la Corte Permanente de Arbitraje ${ }^{16}$, actualmente vigente.

${ }^{15}$ En general los historiadores destacan este sentido unitario en base a los orígenes compactos de dicha región, como una cualidad muy anterior al Imperio Español, y luego de éste, a partir de 1821, siguen fenómenos Federales. Y aunque más tarde se produjeran disociaciones bélicas, llegado el momento de tomar la decisión moderna de integración, fue ese pasado unitario el que jugó un rol central. AGUILERA lo destaca señalando ese pasado común hizo que persistiera un espíritu de regionalización entre los cinco países que habían formado la Unión. AGUILERA PERALTA, G. (2016). El regionalismo centroamericano: entre la unión y la integración. Oasis, 24, 89-105 (pp. 91-92). DOI: http://dx.doi.org/10.18601/16577558.n24.06 (Vid. en particular apartado: La experiencia unitaria centroamericana).

${ }^{16}$ La Corte de Cartago es el antecedente más remoto de la CCJ. Suelen disputarse el hito histórico entre la Corte de Cartago (1907) y la Corte Permanente de Arbitraje (CPA - 1899), pero entre ellas hay diferencias drásticas: Si bien en Europa la CPA posee antecedentes previos (1899), la respuesta en América (1907) presenta a un tribunal de naturaleza jurisdiccional, de carácter permanente, pero de jurisdicción sub-regional. Mientras que la CPA, es un tribunal internacional de naturaleza arbitral, sólo de convocatoria permanente, pero de jurisdicción global. Respecto de cada una, vid. 1) RIPLEY, C. (2018). The central american court of justice (1907-1918): rethinking the word's first court. Diálogos: Revista electronica de historia, 19(1), 47-68. Otro: Portal oficial de la CCJ bajo el apartado "Historia", disponible en: http://portal.ccj.org.ni/ccj/historia-2/ [última consulta, febrero 21, 2019]. 2) La CPA por su parte remonta sus orígenes al momento en que a instancias del Zar Nicolás II de Rusia, se convocó a la Primera Conferencia de Paz de La Haya, con el fin de encontrar medios más efectivos para asegurar a los pueblos los beneficios de una paz real y duradera. VAN DEN HOUT, T. T. (2008). Resolution of international disputes: The role of the permanent court of arbitration - reflections on the centenary of the 1907 convention for the pacific settlement of international disputes. Leiden journal of international law, 21(3), 643-661. Otro, BADENES CASINO, M. (2005). La corte permanente de arbitraje: una institución decimonónica en el siglo XXI. En V. Bou Franch (coord.), M. Badenes Casino, M. Torres Pérez, C. Quesada Alcalá, L. E. Nores Torres, E. López Terrada, ... S. M. Picart García, Nuevas controversias internacionales y nuevos mecanismos de solución ( $1^{\mathrm{a}} \mathrm{ed}$.). Tirant lo Blanch. 
Tal concreción es notable, pues da paso a lo que hoy ha llegado a estructurarse bajo la teoría de la jurisdicción internacional, por la cual - y entre sus diversos aspectos - se explica el abandono del paradigma del monopolio estatal de la función jurisdiccional ${ }^{17}$. Es decir, la Corte de Cartago irrumpe como un nivel muy superior a los sistemas arbitrales internacionales, desplazando de cierto modo las fronteras de la soberanía que hasta aquella época era celosamente ultra-protegida por los Estados ${ }^{18}$. Varios historiadores dejan claro que el establecimiento de la Corte de Cartago sobrepasó su entorno sub-regional latinoamericano, debiendo ser considerado como un hito de la historia universal ${ }^{19}$.

En los siguientes cuarenta años aquella estructura centroamericana se debilitaría. Por una parte caducó la jurisdicción de la Corte de Cartago, pues singularmente se había pactado una duración por diez años, bajo la idea de que sería renovada, pero eso no ocurrió. Y por otra parte, el proyecto político completo perdió fuerza. Más adelante el proceso

${ }^{17}$ La función estatal de administrar justicia, en carácter de único poseedor de aquel poder-deber de hacer respetar las normas y de que ellas se cumplan tras una sentencia de un órgano jurisdiccional que goza de autoridad de res iudicata, ha sido superada por la Teoría de la Jurisdicción Internacional. Por ejemplo MONTERO AROCA tocando este tema al referirse a la UE, expresa que, para el modelo europeo se ha recurrido a una ficción que difícilmente podrá sostenerse y que aunque se apoye desde lo constitucional local, carecería de futuro para seguir explicando el cómo se ha roto el monopolio del Estado en calidad de titular único de la jurisdicción, abriéndose la puerta a algo que no sabe a dónde ha de conducir. MONTERO AROCA, J. (2013). Prólogo. En V. Pardo Iranzo, J. L. Iglesias Buhigues, M. Desantes Real, M. Jimeno Bulnes, C. Arangüena Fanego, F. J. Jimenez Fortea ... M. Cervera Vallterra, El sistema jurisdiccional de la unión europea ( $1^{\mathrm{a}}$ ed.). Navarra: Aranzadi, 2013, pp. 15-17.

${ }^{18}$ Para RIPLEY esta Corte es reflejo del progresismo de las repúblicas centroamericanas, destacando que desde la Paz de Westfalia — donde se sitúa el nacimiento del Estado moderno- las naciones guardaban celosamente su soberanía, siendo reacias a permitir que un organismo internacional juzgase sus acciones, oportunidad en que nació la CPA pero ahora, la Corte de Cartago alcanzaría un estatus superior, pues ella es concretamente un tribunal. Expresando «Unlike other international agreements preceding the CACJ [Central American Court of Justice - 1907], the treaties binding the Central American republics together were more progressive for several reasons. First, the CACJ was the first international court of justice. This step is significant because since the Peace of Westphalia (1648), the beginning of the modern state system, countries have jealously guarded their sovereignty and been reluctant to allow an international body to judge their actions. The Permanent Court of Arbitration, which borne out of the 1899 Hague Peace Conference, [...] The Central American Court, however, achieved the status of being the world's first court to which member states would submit all complaints. [...] In addition to being the first international court, the unprecedented scope of the Court's jurisdiction represented a strong sense of solidarity between the signatory republics». RIPLEY, 2018, vid. apartado The Court Begins.

${ }^{19}$ Para el historiador ARAYA, el establecimiento de esta Corte, constituyó un hecho de dimensiones notables en el marco, tanto de la historia de la región, como de las relaciones internacionales a nivel global. ARAYA I., M. E. (1992). La experiencia histórica en la resolución de conflictos internacionales en centroamérica: Esquipulas II y la corte centroamericana de justicia. Reflexiones, 3(1), vid. en particular el apartado II. En igual línea RIPLEY, 2018, vid. apartado The Court Begins. 
Centroamericano continuaría con la Organización de Estados Centro Americanos (ODECA) y la Corte de Justicia Centroamericana, según veremos.

Paralelamente en Europa al iniciarse el siglo XX y tras el fin de la Primera Guerra Mundial se creaba la Sociedad de las Naciones o Liga de las Naciones (1919) a través del Tratado de Versalles que, como ya anotamos en su Primera Parte se contiene la sustancia del Tratado de Unión, Liga y Confederación Perpetua firmado en el Congreso de Panamá de 1826 en Latino América. En este nivel de progreso jurídico, la Sociedad de las Naciones ya comportaba un modelo mucho más sólido y cercano a las organizaciones internacionales, las cuales — tal como señalamos en la introducción de esta tesis - son de muy difícil sino imposible definición ${ }^{20}$.

Pero las OI consideradas como una respuesta jurídica moderna a las necesidades de cooperación, recién alcanzarían su máxima fuerza de despegue en la era post II GM, ciclo en que como anunciábamos, se puso a prueba al DI, enfrentado a un nuevo mundo que dejaba de ser euro-céntrico ${ }^{21}$ pasando por primera vez, y de manera definitiva, a tomar un carácter de bloque occidental más universal, produciéndose una evolución de toda esa área del derecho, irrogando un nuevo estadio de progreso, el cual vino en denominarse por la doctrina como DI contemporáneo o post-clásico ${ }^{22}$.

${ }^{20}$ WHITE, 2005, p. 1. SEYERSTED, 2008, p. 3 y pp. 9-10. SANTOS, 2002, pp. 33-34. SOBRINO, 2010b, p. 43. Vid. las anteriores en nota 1 de la Introducción de esta tesis. Adicionalmente HuICI explica que la noción de OI se complica por la diversidad de ellas, lo que dificulta la identificación de principios y elementos comunes sobre los que fundamentar una definición. Adscribe a la idea de que incluso existirían tres clases de definiciones: i) las tradicionales o clásicas, ii) las que proyectan retrospectivamente la concepción actual del fenómeno, y iii) las que subrayan los elementos que los autores consideran esenciales de ellas. HUICI SANCHO, L. (2007). El hecho internacionalmente ilícito de las organizaciones internacionales : El proyecto de la Comisión de derecho internacional sobre responsabilidad de las organizaciones internacionales. Barcelona: Bosch., pp. 29-30 (apartado 2 Debates en torno al concepto de organización internacional).

${ }^{21}$ La concepción euro-céntrica de remotos orígenes y construida a partir del desarrollo alcanzado en esa zona del mundo, si bien pierde peso objetivo tras la II GM, continuaba presente al momento de la configuración de la ONU. Pero las políticas de los vencedores y la forma global de enfrentar la nueva organizativa mundial erosionan dicha concepción. SAKSENA destaca este momento histórico al recordar: «The beginning: A eurocentric world: When Nations United conceived in the mid-1940s the world was still Euro-centric. [...]». SAKSENA, K. P. (1993). Reforming the united nations : The challenge of relevance. New Delhi; London: Sage., p. 21.

${ }^{22}$ El derecho internacional post-clásico para GAMARRA y FERNANDEZ viene a aparecer en un proceso que comienza como consecuencia ante el fracaso de la Sociedad de Naciones para haber prevenido la II GM y de otras relevantes piezas de la historia del DI, todo lo cual conformarían los inicios del DI actual, el cual se puede denominar derecho internacional post-clásico. GAMARRA CHOPO, Y. \& FERNANDEZ LIESA, C. R. Nota preliminar. El comienzo de una nueva era para el derecho internacional. En Grasa, R., Forcadell, C., Peiró, I., Huguet, M., Magallón, C. y Blasco, S., Fernández, C., ... Ripol, S. (2015). Los orígenes del derecho internacional contemporáneo ( $1^{\mathrm{a}}$ ed.). Zaragoza: Institución Fernando el Católico., p. 17. Por su parte la noción de derecho internacional contemporáneo la emplea por ejemplo DIEZ DE VELASCO indicando que se 46 
Pues bien, en el período de post guerras en que recién nos hemos posicionado, se produce el nacimiento de organizaciones internacionales de carácter intergubernamental mucho más robustas que las anteriores experiencias ya descritas - desaparece la Sociedad de las Naciones, surgen las Naciones Unidas y prontamente el Consejo de Europa- y a la vez se comenzaría a impulsar el nacimiento del fenómeno integracionista, con las tres Comunidades europeas.

Lo anterior devela dos campos bien diferenciados en que se orientarían las OI —el intergubernamental $v / s$ la noción integracionista supranacional- en ambos casos mostrando un progreso mucho más robusto que el empleado en las épocas anteriores, toda vez que se pasan a emplear herramientas jurídicas de mayor talaje, como por ejemplo el carácter permanente de las instituciones u órganos de estas nuevas organizaciones de mediados del siglo XX. Precisamente entre aquellos órganos encontraremos, en general, a los tribunales internacionales y, en particular, a las Cortes de integración. Pasando estas OI a actuar en calidad de sujetos internacionales ${ }^{23}$.

Retomando la cronología en la que veníamos, en septiembre de 1946 Winston Churchill pronunció su histórico discurso en la Universidad de Zúrich llamando a la unión de Europa. Para él la solución cruzaba por la creación de unos «Estados Unidos de Europa». En tal medida intentaba importar el modelo norteamericano — federal—, y a la vez, imaginaba que el Reino Unido actuaría como promotor de aquel complejo proyecto - lo mismo imaginó Simón Bolívar de Inglaterra pero para Latino América, según vimos líneas atrás. El discurso de Churchill caló hondo en el sentir social y académico, el cual en parte de su texto se lee «si Europa se uniera algún día para compartir su herencia común, no habría

acuñó en la realidad de post guerras europeas, circunstancia que significó para el DI un hito transicional de alta relevancia, lo cual ocasionó que el DI clásico entrara definitivamente en crisis a causa de diversos factores, dando lugar a un nuevo modelo histórico que ha venido en denominarse Derecho Internacional contemporáneo. DIEZ DE VELASCO \& ESCOBAR, 2013, p. 65.

23 Para LAUTERPACH la calidad de sujeto internacional es amplia, abarcando a las organizaciones internacionales «As in any other legal system, so also in the international sphere the subjects of law are the persons, national and juridical, upon whom the law confers rights and imposes duties. In international law these persons are normally States; but they are not so exclusively. Organizations of States, having a different juridical personality from the States composing them, may and have become subjects of international law. This is hardly starling seeing that it is difficult to deny to States acting in association the unchallenged legal personality which they possess when acting in isolation. Individual possess in a limited sphere international legal personality, not always accompanied by corresponding procedural capacity, accorded to them expressly or by implication». LAUTERPACHT, H. \& LAUTERPACHT, E. (1970). International law: Being the collected papers of hersch lauterpacht. Cambridge: University Press, pp. 136-150. (Vid. apartado 47. The definition of subjects of international law). 
límites a la felicidad, la prosperidad y la gloria que gozarían sus [...] millones de habitantes» ${ }^{24}$.

Al ritmo de los acontecimientos mundiales que venimos destacando, en Latino América las nuevas ideas maduraban, así el día 30 de abril de 1948 se firmaba la Carta de Bogotá sustituyéndose a la Unión de Repúblicas Americanas por la Organización de los Estados Americanos (OEA) que mantiene el concepto de «unión moral de las repúblicas del continente americano», la cual en 1978 gestaría a su Tribunal Interamericano de Derechos Humanos. En Europa casi al unísono — sólo al mes siguiente- en mayo de 1948 en el Congreso Europeo de la Haya se enfrentaban dos posiciones, una moderada que apostaba por una integración en base a la cooperación intergubernamental y la otra mucho más osada, pues proponían un sistema federativo. Latino América observaba la discusión de fondo, pues la trascendencia ameritaba la concentración de la academia.

La postura que primó en Europa fue la intergubernamental, y así en Londres en 1949 se decidió la creación de Consejo de Europa, en carácter de una OI intergubernamental con el propósito de «consolidar la paz», basada en la justicia y en la cooperación ${ }^{25}$. Como se

\footnotetext{
${ }^{24}$ Para PACKWOOD el discurso de Zurich fue controvertido pues supone un reacomodo del Reino Unido en aquella dinámica de estar con Europa pero no en Europa. En cuanto a la idea de los Estados Unidos de Europa, Churchill habría tomado este título de un escrito de 1904 que le habían enviado avisándole que un artículo de dicho nombre se publicaría en Alemania. Lo que es indiscutible, es que, Churchill es un admirador del modelo norteamericano y de su desarrollo, además de un convencido de la unificación europea. Pero cuando realmente se involucró en la unificación de Europa fue entre los años 1946 y 1948, aunque, como recalca PACKWOOD, lo hizo a su propia conveniencia «By 1930 he was prepared to go further, and, consciously or unconsciously, took the title of the 1904 paper for his own piece; an article for the Saturday Evening Post called "The United States of Europe". There were clear parallels with his speeches from the early 1920's. [...] was first published in the Saturday Evening Post on 15 February 1930. [...] It seems that both before and after the war, Churchill was prepared to say nice things about Kalergi and his movement but was not prepared to get actively involved. When he does take a clear interest in a United Europe movement between 1946 and 1948, it is on his own terms and to serve his own agenda. [...] Though both the Fulton and the Zurich speeches were controversial, breaking with a wartime ally and urging reconciliation with an enemy, they can also be seen as a continuation of his pre-war thinking, which was itself built on a very traditional British foreign policy of building alliances to maintain the peace in Europe. So far then a consistent line can be traced in Churchill's thinking from the 1920's, if not before, to the 1940's. Yet in the aftermath of the Zurich speech, I think there is a shift in emphasis». PACKWOOD, A. (2016). Churchill and the united states of europe, 1904-1948. Comillas Journal of International Relations (7), 1-9.

${ }^{25}$ El Consejo de Europa pasa a ser una OI de claro carácter intergubernamental, la cual asume la valorativa espiritual y moral de la Europa de aquella época, propugna la fuente de la libertad individual, la libertad política y el imperio del derecho. Aunque de modo central se orientaría a satisfacer el principio en virtud del cual toda persona que se halle bajo su jurisdicción habrá de gozar de los Derechos Humanos y de las Libertades Fundamentales. Estos idearios se encuentran contenidos en los artículos 1 y 3 de su Estatuto Constitutivo, cuyo texto puede revisarse en el Portal oficial del Consejo de Europa. Disponible en: http://www.coe.int/en/web/conventions/full-list/-/conventions/rms/0900001680306052 [última consulta, 48
} 
observa su primer propósito es muy distante al objeto pensado al otro lado del Atlántico, pues en el nuevo mundo se enarbolaba la «unión moral de las repúblicas del continente» en América nada había que pacificar, de hecho la participación de América en la II GM sólo fue de parte de los Estados Unidos de Norte América - y para triunfar - sin costes intra fronteras americanas. En tal clima Latino América se sentía confiada, pues todas sus disputas internas en nada se asemejaban siquiera a la catástrofe europea.

Pero en Europa se insistiría en las ideas más intensas de cooperación, por eso se observa que en 1950 comienzan a gestarse las bases de lo que más tarde pasaría a ser un complejo sistema supraestatal. Tal proceso estaría mucho más cercano a la postura federativa que había sido desechada en el Congreso Europeo de la Haya en 1948. Es así como mediante el Tratado de París de 1951 se creó la CECA (vigor 1952) la cual contó con su Tribunal de Justicia de la CECA (TJCECA) ${ }^{26}$. Cinco años más tarde las negociaciones llevadas adelante en el castillo de Val Duchese en Bruselas, daban como fruto la firma del Tratado de Roma de 1957 creándose otras dos organizaciones la CEE y la CEEA o EURATOM, quedando conformadas las tres Comunidades europeas, nacía la Europa de los seis ${ }^{27}$.

Pero el Reino Unido era un férreo opositor al proyecto europeo, incluso propuso a los miembros de la Organización Europea para la Cooperación Económica que no se sumaran a las Comunidades Europeas y que construyeran otra OI. Cuestión que así hicieron, y en

Enero 21 de 2019]. Su gran logro es la consecución del Convenio para la Protección de los DDHH y de las Libertades Fundamentales del 4 noviembre del año 1950, suscrito en la ciudad de Roma. Este es un documento dicotómico, pues por una parte genera el catálogo de derechos fundamentales europeos, y por otra crea al TEDH. La doctrina subraya que, si bien, dicho tribunal no es fruto del ordenamiento originario, ha sido el mayor aporte del Consejo de Europa no sólo para esta región, sino que sus sentencias sirven de guía al resto del mundo. RIPOL CARULLA subraya que este tribunal fue en realidad fruto de un itinerario complejo e integral de protección de los derechos esenciales del ser humano. RIPOL CARULLA, S. \& TRIBUNAL EUROPEO DE DERECHOS HUMANOS. (2007). El sistema europeo de protección de los derechos humanos y el derecho español: La incidencia de las sentencias del tribunal europeo de derechos humanos en el ordenamiento jurídico español. Barcelona: Atelier.

${ }^{26}$ El Tribunal de Justicia de la CECA fue creado en el año 1952 mediante el Tratado Constitutivo de la CECA, el cual le daba el carácter de órgano de aquella OI, bajo la siguiente fórmula: Articolo 7: Gli Organi della Comunità sono: [...] una CORTE DI GIUSTIZIA, denominata «la Corte». Luego en su Capítulo IV titulado Della Corte, establece y desarrolla sus principales competencias y características funcionales y orgánicas entre los artículos 31 a 44. El art. 45 remite al Protocolo del Estatuto de la Corte, anexo al mismo Tratado. Una versión en italiano del Trattato istitutivo della Comunità Europea del Carbone e dell'Acciaio. Disponible en Portal oficial de Euro-Lex <https://eur-lex.europa.eu/legalcontent/IT/TXT/PDF/?uri=CELEX:11951K/TXT\&from=ES> [última consulta, febrero 18, 2019].

${ }^{27}$ ABELLÁN HONRUBIA presenta de modo compacto el proceso histórico que dio origen a la CECA y a las CEE y CEEA o EURATOM. ABELLÁN HONRUBIA, 2005, pp. 22-26. Otra refiriéndose a los seis Estados miembros originarios de las Comunidades Europeas en RODRÍGUEZ IGLESIAS \& LÓPEZ ESCUDERO, 2010a, p. 583. 
enero del año 1960 crearon la European Free Trade Association. Sin embargo al ver que el desarrollo alcanzado por el proceso europeo los estaba dejando atrás, el Reino Unido recapacitó y en 1961 pidió ingresar a las Comunidades Europeas, siendo aceptado en 1969, ingresando junto a Noruega, Dinamarca e Irlanda.

Al mismo tiempo en América Latina comenzaban a robustecerse los proyectos subregionales, puntualmente en 1951 Costa Rica, El Salvador, Guatemala, Honduras y Nicaragua firmaban la Carta Constitutiva de la Organización de Estados Centro Americanos (ODECA) ${ }^{28}$ la cual en 1962 sería reestructurada y se les uniría Panamá. Los fines explicitaban aspiraciones de una «integración centroamericana» pretendía asegurar el progreso, eliminar las divisiones, mejorar las condiciones de vida de los pueblos, el desarrollo industrial, la estabilidad, la solidaridad centroamericana y otros. Se instituyeron varios órganos, entre los cuales estaba la Corte de Justicia Centroamericana, conformada por los presidentes de los Poderes Judiciales de cada Estado miembro.

Si bien Latino América comenzaba a dar los primeros pasos de una singular integración, el fenómeno en Europa alcanzaba desplazamientos impensados, tanto que hasta se advertían superposiciones de instituciones, observándose movimientos orgánicos de relevancia, así en 1957 ante la repetición de instituciones para cada OI (CECA, CEE y CEEA) se inició un complejo proceso de fusión de instituciones, el cual comenzó con los tribunales, las asambleas y el Comité Económico Social de la CEE con el de la EURATOM, mediante el Convenio relativo a ciertas instituciones comunes. Materialmente nunca existieron tres Cortes, gracias al proceso de fusión señalado. El Convenio contempló a sólo una Corte, que se denominó Tribunal de Justicia de las Comunidades Europeas (TJCE), fluyendo entonces directamente del TJCECA al TJCE. Tal itinerario continúa tras el Tratado de Fusión de 1965 (vigor 1967) en un tan singular ejercicio, que la doctrina lo ha visualizado como un proceso paradigmático $^{29}$. De hecho la CEE recién vía el Tratado de Maastricht (1992, vigor

\footnotetext{
${ }^{28}$ Las cinco naciones del istmo centroamericano Costa Rica, El Salvador, Guatemala, Honduras y Nicaragua eran las mismas cinco naciones que en 1823 habían constituido la Federación Provincias Unidas Centroamericanas y que luego transitaron a la Confederación Centroamericana de 1907. Ahora firmaban la Carta ODECA, a la cual más tarde en 1962 al reestructurarse dicha Carta, se les uniría Panamá.

${ }^{29}$ Para TORRECUADRADA observando los fenómenos de la sucesión entre las OI, advierte diversas posibilidades, como la fusión, absorción, escisión y otras. Dentro de los primeros es donde localizamos la fusión de instituciones, como la que hemos descrito. Otro aspecto es que con posterioridad a la fusión de las instituciones, debamos enfrentar la referida a las OI mismas, en cuya circunstancia, para TORRECUADRADA el paso de la CECA a la CE sería un ejemplo de sucesión por absorción. Para esta autora el caso de la UE es paradigmático pues esta organización ha sufrido profundas modificaciones desde sus primeros inicios, en cuanto a órganos, número de miembros, formas de financiación, en su propio nombre, etc., sin embargo es la misma organización que en sus orígenes. Es decir, se observa una evolución manteniendo su personalidad jurídica. Enfatiza la autora en que no hay una nueva organización, precisamente porque no hay rupturas, no hay transferencias. En definitiva, la continuidad en la personalidad jurídica impide 50
} 
1993) adoptó su popular denominación de «Comunidad Europea», mismo Tratado que crea a la «Unión Europea», organización que más tarde sustituye totalmente a la primera mediante el Tratado de Lisboa (2007, vigor 2009) ${ }^{30}$.

En el Cono Sur de América a inicios de los años sesenta observando el viento a favor que gozaba el avance europeo, determinados Estados suramericanos se animan en llevar adelante un esquema de cooperación que más tarde culminaría en la actual Comunidad Andina de Naciones. Sucedía en aquellos años que Argentina, Chile, México, Paraguay, Perú y Uruguay aunaban voluntades a través del Tratado de Montevideo del año 1960, creando la Asociación Latinoamericana de Libre Comercio (ALALC) en un esquema de integración netamente económico. La ALALC adecuó sus normas al General Agreement on Tariffs and Trade (GATT) ${ }^{31}$, con objetivos de liberalización comercial, de coordinación de políticas de integración económica y de ser un foro regional para proyectarse frente al resto del mundo, entre otros más. La importancia de la ALALC radicó en que fue el primer esfuerzo real destinado a materializar un intercambio comercial.

En el marco de la ALALC el presidente de Colombia, Carlos Lleras Restrepo, propuso la creación de la Comunidad Andina, idea secundada por el presidente de Chile, Eduardo Frei Montalva, arribándose a la Declaración de Bogotá (1966) la cual aparejó un acuerdo de integración subregional, el Acuerdo de Cartagena (1969), celebrado por Bolivia, Colombia,

la sucesión entre OI porque sólo tenemos una OI [...]. Entonces: hay solo una que evoluciona. TORRECUADRADA GARCÍA-LOZANO, S. (2005). La sucesión entre organizaciones internacionales y la unión. Anuario español de derecho internacional, (21), 227-272 (p. 245 y 254-263).

${ }^{30}$ La complejidad del proceso moderno de la integración de Europa y de la institucionalidad de la actual UE desbordan por completo los objetivos de esta tesis. Sin embargo el contexto histórico, marcando los principales hitos por los que circuló la Corte de Luxemburgo no podemos ignorarlos. Resúmenes con los principales hitos pueden verse en ABELLÁN HONRUBIA, 2005, pp. 22-27. MANGAS MARTÍN, 2014a, p. 34. MANGAS MARTÍN, 2014b, pp. 165-166. LIÑÁN NOGUERAS, 2014b, p. 271.

${ }^{31}$ Un antecedente histórico de relevancia para que en América, más tarde, surgiesen proyectos de integración fue el General Agreement on Tariffs and Trade - GATT (Acuerdo General sobre Aranceles Aduaneros y Comercio) cuyos orígenes se remontan al año 1947 bajo el auspicio de la ONU. Su primer antecedente formal fue la reunión de la comisión preparatoria de la conferencia internacional de comercio, celebrada en Londres (1946), una segunda reunión se efectuaría en Ginebra (1947). En esta última se confeccionó un proyecto de documento: la Carta de Comercio Internacional, complementada en noviembre de 1947 en la Conferencia de la Habana, conociéndosele como «GATT 1947». El acuerdo fue firmado por 23 Estados. Durante los años de 1960 el GATT colaboró exitosamente para el crecimiento mundial gracias a las constantes reducciones de aranceles. Un principio central es que todo Estado miembro puede exigir de otro Estado miembro, las mismas ventajas comerciales que las concedidas por este último a cualquier otro país miembro. Sin embargo de 1970 a 1980 se detonó la crisis debido a la reducción mundial de los aranceles a niveles muy bajos. Así las cosas, el 1 de enero de 1995 la Organización Mundial del Comercio (OMC) reemplazó al GATT, quedando en carácter de una OI que supervisa el sistema multilateral de comercio. Portal oficial OMC, disponible en <https://www.wto.org/english/thewto_e/gattmem_e.htm> [última consulta, febrero 5, 2019]. 
Chile, Ecuador y Perú. Proyecto bautizado como Grupo Andino, y finalmente conocido como Pacto Andino o Comunidad Andina de Naciones (CAN o CA), su finalidad se orientó a promover el desarrollo equilibrado de los países miembros mediante la integración y cooperación económica y social, además de facilitar el proceso de integración y favorecer la solidaridad, entre otros.

Es muy relevante para nosotros, destacar que la CAN no consideró en sus inicios a un órgano jurisdiccional. Cuestión que la historia le reprocha constantemente, cada vez que se analiza este convulso proyecto de América del Sur. Incluso tal carencia orgánica, es considerada como una de las causas de la debilidad del proyecto y de su casi desaparición en su primera época. En un inicio la CAN sólo disponía de un débil mecanismo de solución de controversias basado en negociaciones, buenos oficios, mediación y conciliación, es decir, prácticamente apoyado en herramientas diplomáticas típicas ${ }^{32}$.

En el año 1973 se incorpora Venezuela a la CAN, pero en 1976 Chile —durante su dictadura - abandona el proyecto andino por incompatibilidades con la nueva estructura económica del país ${ }^{33}$. Debemos tener presente que el recorrido de la CAN se encuentra plagado de conflictos y crisis permanentes, por lo que en tal ritmo la salida de Chile se consideró un síntoma grave de la crisis de ese momento, lo que se sumaba a otros tantos problemas que podrían haberse solucionado si se hubiese contado con un tribunal apropiado para tal labor.

Bajo los acontecimientos descritos, para América Latina sería un hito altamente significativo que en 1977 Portugal y España solicitaran ingresar al proyecto de integración europeo y que en definitiva se incorporaran en 1985 (vigor 1986), toda vez que existe una

\footnotetext{
${ }^{32}$ La doctrina plantea que la CAN venía con lo que han denominado un pecado original. Por ejemplo VIGIL TOLEDO destaca que el acuerdo nació cojo, al no haberse establecido, desde el mismo momento en que renacía ese embrión de la integración subregional, un garante de legalidad. VIGIL TOLEDO, R. (2011). La estructura jurídica y el futuro de la comunidad andina ( $1^{\mathrm{a}}$ ed.). Madrid: Civitas Thomson Reuters, p. 39. Es constante en la doctrina el vincular la existencia de un tribunal, ya sea internacional o de integración, con una sólida permanencia de una organización internacional y/o de integración. También ZELADA CASTEDO al estudiar los orígenes de la orgánica de este proyecto, advierte la debilidad institucional al no contener a una Corte Internacional entre sus órganos, señalando al respecto: el proceso de integración económica entre los países del Grupo Andino, por consiguiente, nació con una visible deficiencia en su ordenamiento jurídico y en su sistema institucional. ZELADA CASTEDO, A. (1985). Las posibles enmiendas al acuerdo de Cartagena. En Integración latinoamericana. 10(106), INTAL, Buenos Aires, p. 126.

${ }^{33}$ La dictadura se inicia en Chile el 11 de septiembre del año 1973. El gobierno de facto del general Augusto Pinochet consideró lejano a sus nuevas directrices económicas liberales, las fórmulas de la Comunidad Andina, y sin considerar los trascendentes impulsos chilenos en la génesis de la CAN, simplemente en 1976 se retiró de dicha OI.
} 
evidente conexión cultural entre las naciones hispanas, hecho que impulsaría las concreciones integracionistas en Latinoamérica, según veremos un poco más adelante.

Casi simultaneo a la entrada en vigor de las incorporaciones de Portugal y España, se aprobó el Acta Única Europea (AUE, 1986, vigor 1987) la cual afectó los Tratados Fundacionales, redefiniendo el espacio sin fronteras interiores, apuntando a la libre circulación de personas y mercaderías y estableció la posibilidad de crear un tribunal de primera instancia que apoyara al TJCE, entre otros ${ }^{34}$. En 1988 nacería el Tribunal de Primera Instancia de las Comunidades (TPCE, constituido en 1989) ${ }^{35}$, el cual tras el Tratado de Lisboa (2007, vigor 2009) incorporó mejoras y fue rebautizado como Tribunal General de la UE (TGUE) quedando comprendido $^{36}$ orgánicamente dentro de la institucionalidad del TJUE. Además desde el año 2016 absorbió las competencias del desaparecido Tribunal de la Función Pública de la UE (TFPUE) ${ }^{37}$.

${ }^{34}$ El contenido del AUE es múltiple y de gran relevancia en el proceso europeo, una excelente referencia se encuentra en ALDECOA LUZÁRRAGA, F. (2002). La integración europea: Análisis histórico-institucional con textos y documentos - Tomo II génesis y desarrollo de la unión europea (1979-2002). Madrid: Tecnos. [Truyol y Serra, A. (1999). La integración europea: Análisis histórico-institucional con textos y documentos.Tomo I génesis y desarrollo de la unión europea (1951-1979). Madrid: Tecnos], pp. 104-107 (Tomo II).

${ }^{35}$ De tal manera es que se robustece el Poder Judicial del proyecto europeo pues se introduce un doble grado de órganos, lo que aligeró la carga del TJCE, mejorando la protección de los justiciables. ZAPATER DUQUE, 2005b, pp. 107-109.

${ }^{36}$ El diseño del art. 19.1 del TUE es muy singular «TJUE comprenderá el Tribunal de Justicia, el Tribunal General y los tribunales especializados» podría inducir a una confusión dado que la cultura jurídica europea utiliza el acrónimo TJUE para referirse al Tribunal de Justicia directamente. En realidad, lo que sucede es que «no se utilizó la expresión Poder Judicial de la UE» sino Tribunal de Justicia de la Unión Europea. En línea con esta salvedad el Portal oficial del TJUE se identifica y se presenta como «CVRIA». Disponible en <http://curia.europa.eu> [última consulta, febrero 1 de 2019].

${ }^{37}$ El TGUE no fue contemplado en los tratados originarios, sino que la idea de añadir un nuevo órgano al sistema judicial nace en los años setenta, con el fin de establecer un tribunal administrativo, dado el creciente número de funcionarios de la CE. Sin embargo ello no provocó su surgimiento, sino la gran actividad del TJCE. Para LIÑÁN NOGUERAS las principales competencias del TGUE serían (i) conocer de algunos recursos de anulación y por omisión dependiendo de la naturaleza del demandado — básicamente cuando sea la Comisión o el BCE, (ii) sobre las cuestiones prejudiciales se da la paradoja que si bien el TFUE le otorgó competencias en éstas, en los casos que el propio Estatuto del TGUE determinara, éste no identificó ningún tipo de cuestión prejudicial específica de la cual conocer, por lo cual quedó monopolizada la competencia prejudicial en el TJUE, (iii) de los recursos contra las resoluciones de los tribunales especializados que existan - y a su vez estas sentencias pueden ser reexaminadas por el TJUE, (iv) de los recursos de anulación interpuestos por personas físicas o jurídicas en contra de los actos de las Instituciones u organismos de la UE de los que sean destinatarias o les afecten y, de los recursos formulados por los Estados miembros contra el Consejo en relación con los actos adoptados por éste en el ámbito de las ayudas de Estado, las medidas de defensa comercial y los actos por los que ejerce competencias de ejecución, (v) de los recursos dirigidos a obtener indemnización por daños causados por las Instituciones u órganos o agentes de la UE, y (vi) de algunos recursos en el ámbito de la propiedad intelectual, entre otras. LIÑÁN NOGUERAS, 2014b, pp. 282- 


\section{EL NUEVO REGIONALISMO PROPICIA EL ESCENARIO PERFECTO PARA IMPULSAR LOS NACIMIENTOS MODERNOS DE LOS \\ TRES PROYECTOS LATINOAMERICANOS Y DE SUS SINGULARES TRIBUNALES}

Hasta antes de los años noventa los intentos integracionistas modernos ${ }^{38}$ en América Latina aún no se desarrollaban con fuerza, pero el cambio geopolítico a partir del fin de la Guerra Fría con la icónica caída del Muro de Berlín trazaban una visión de futuro auspiciosa y los ánimos latinoamericanos se aceleraban. Básicamente esta nueva velocidad en América Latina se explicaba en la valoración positiva que hacían los latinoamericanos respecto de la segunda etapa del proyecto europeo, aquella en que se le aprecian sus éxitos, concluyendo que era un buen esquema para enfrentar los efectos de la globalización ${ }^{39}$.

Sería en este nuevo concierto en el que algunos Estados en Latino América deciden acercarse con más ímpetu que antaño para enfrentar unidos múltiples problemas locales, como la superación de la pobreza, la pacificación, el desarrollo, etcétera, pero adicionándose ahora la nueva realidad global, la cual se suma, porque conlleva sofisticados requerimientos de los pueblos, los que cada vez se vuelven más exigentes de sus democracias y de las posibilidades de mejorar sus condiciones de vida en un entorno moderno y global ${ }^{40}$.

287. RODRÍGUEZ IGLESIAS \& LÓPEZ ESCUDERO, 2010b, pp. 642-643. Sus principales normativas se encuentran en el TUE en el art. 19.1, y en el TFUE en los arts. 254 y ss.

${ }^{38}$ Nos estamos refiriendo a los impulsos más definitivos de la segunda mitad del siglo XX. Distanciándonos de los procesos unitarios post Imperio Español bajo las ideas libertarias de los próceres americanos, ni de las unitarias bolivarianas, pues aquellas no responden a las visiones organizativas contemporáneas, sin perjuicio de que, como veremos, el devenir de esos primeros impulsos en algo explican algunas singularidades de los tres modelos actuales. Por tal razón hablamos de los esquemas de integración modernos en América.

${ }^{39}$ Esta diferencia en el impulso de los esquemas americanos modernos respecto del europeo, es bastante considerado por la doctrina al intentar explicar las características propias de las soluciones americanas. Por ejemplo ACCIOLY PINTO DE ALMEIDA lo subraya así «felizmente nuestra unión no se hizo por la guerra como en Europa. Nuestra unión se dio por los designios del comercio internacional, para que juntos los países puedan sumar fuerzas para enfrentar la globalización [...]. La Europa Comunitaria es nuestra inspiradora, pero nuestra ruta no es la misma y tendremos que hacer nosotros nuestro propio camino. Al final, nuestras realidades son distintas». ACCIOLY PINTO DE ALMEIDA, E. (1998). Integración europea e integración latinoamericana: dos realidades distintas. En E. Accioly, M. A. Ciuro, C. da Silva, W. Faria, G. Losfeld, F. Mariño, ... G. Zanin, El MERCOSUR en el siglo XXI. Buenos Aires: Ediciones Ciudad Argentina, p. 309.

${ }^{40}$ JARA RONCATI, E. (2012). La unión europea, los países de américa latina y el caribe: Una relación con pasado, presente y futuro. Zaragoza: Fundación Manuel Giménez Abad de Estudios Parlamentarios y del Estado Autonómico, pp. 358-365. 
Hay varios componentes en las experiencias integracionistas de Latino América que permiten comprender sus orígenes, pero es indiscutido que se terminan impulsando para intentar afrontar los diversos efectos de la globalización, tal como lo subraya la doctrina ${ }^{41}$, emergiendo en definitiva el SICA (1992, vigor 1993) con su CCJ (Estatutos 1992, vigor 1994), la CAN (1969) con su TJAC (1983, y TJCA desde 1996, vigente 1999), y el MERCOSUR (1991) con sus TAAM (1991) y con el TPRM (2002, vigor 2004). Como se advierte, son todas experiencias históricamente muy jóvenes, en particular sus tribunales, a diferencia de Europa donde los orígenes del TJUE son del año 1951. Toda la construcción latinoamericana queda entonces contextualizada por una nueva era, inmersa en el denominado nuevo regionalismo ${ }^{42}$ el cual apareja organizaciones internacionales, más actores y nuevos desafíos tecnológicos.

Desde que nos incorporamos a dicha era global, la integración en sí misma, pasó —entre otros aspectos - a ser un esquema útil para enfrentar los efectos de la globalización. De este modo se añadió la integración como tal, a los modelos de interacción trasnacional preglobalización que imperaban hasta aquella época en América Latina. De tal suerte se confirma una vez más que conforme avanza la historia, la noción de evolución se comprende en colaboración ${ }^{43}$. Es más, superados los modelos más básicos e incluso

\footnotetext{
${ }^{41}$ Por ejemplo RUIZ-DÍAZ, subrayando la utilidad de los procesos de integración americanos -refiriéndose en particular al MERCOSUR- explica que su ampliación y desarrollo lo convierte en un bloque de integración Latinoamericano 'para enfrentar la globalización'. RUIZ-DÍAZ LABRANO, R. (1999). Supranacionalidad y mercosur. En Irigoin Barrenne, J. (coord.), Rey Caro, E. (present.), Insulza Salinas, J. M. (disc.), Barros Charlín, R., Molina del Pozo, C. F., Narbone, L., ... Holzmann G., Chile y el mercosur en américa latina: VI encuentro internacional de derecho de américa del sur (1999). Tomo I. Santiago, Chile: Universidad de Chile. Facultad de Derecho, Editorial Jurídica de Chile, pp. 161-172.

42 Esta circunstancia la subraya AgUILERA expresando que en América Latina se han dado diversas experiencias de regionalismo, las que corresponden al nuevo regionalismo. Esta conclusión la basa en HETTNE, toda vez que éste último autor realza la división entre viejo y nuevo regionalismo del siguiente modo «El nuevo regionalismo es el correspondiente a la era de la globalización. El viejo regionalismo se corresponde al mundo de la Guerra Fría, mientras que el nuevo a un orden multipolar. El viejo regionalismo fue proteccionista en términos económicos y el nuevo es abierto a la economía mundial. El viejo regionalismo se ubicaba en la dinámica de los Estados-nación, en cambio el nuevo, forma parte de la nueva estructura mundial en la que actúan también actores no estatales». AGUILERA PERALTA, G. (2016). El regionalismo centroamericano: entre la unión y la integración. Oasis, 24, 89-105 (pp. 90-91). DOI: http://dx.doi.org/10.18601/16577558.n24.06.

${ }^{43}$ La agrupación social del ser humano es uno de los hechos más antiguos de la historia y es la respuesta natural para afrontar las limitadas fuerzas del individualismo. El sistema de organización o agrupación evolucionó desde lo más simple a lo más complejo. En los tiempos prehistóricos las primeras agrupaciones eran sociedades basadas en relaciones de parentescos, cuyo líder solía ser el individuo de mayor edad, quien se encargaba de imponer las leyes y de mantener la concordia. Durante el Neolítico (5000 a. C. aproximadamente) se comenzarían a constituir las primeras ciudades en los valles fértiles — $v$.gr. la ciudad de Uruk - y con ello las primeras leyes escritas. Durante la edad de los metales y principios de la edad antigua encontraríamos las llamadas primeras civilizaciones. Prontamente se producirían procesos de asimilación
} 
arribada la teoría del Estado moderno, se vuelven a presentar determinadas cuestiones que tampoco pueden ser satisfechas por los Estados aisladamente ${ }^{44}$, y dentro del espectro de soluciones posibles, los esquemas de integración representan una buena respuesta. Justamente es este prisma utilitario el que valoran de forma positiva los latinoamericanos de las tres regiones enfocadas para hacer frente al nuevo contexto mundial.

La implementación de los proyectos SICA, CAN y MERCOSUR no se caracterizó porque se diseñaran un traje a la medida, sino que intentaron ajustar el europeo a su talla. En ese sentido los esfuerzos implicaron réplicas parciales de la UE. Por tal razón este plan se efectuaría sólo en la medida de lo posible, dado las singularidades de dichas zonas. Hoy ya está demostrado que en Latino América no pueden haber importaciones forzadas, ni mucho menos una idéntica a la europea, sino que debe amoldarse a su propia realidad, pues lógicamente un elenco de naciones desarrolladas y de gran acervo cultural e histórico, obtendrán con mucha más facilidad un sólido proyecto, a diferencia de una agrupación de países en vías de desarrollo ${ }^{45}$ que de tanto en tanto, presentan diversos conflictos sociales, económicos y políticos.

Si bien el SICA, la CAN y el MERCOSUR tienen similitudes generales, tales como las que hemos ido esbozando hasta aquí, cada uno de los tres proyectos enarbola sus propias singularidades de origen y de posterior desarrollo, siendo precisamente en esas realidades y al servicio de tales proyectos políticos en donde emergen en definitiva las Cortes de cada uno de estos modelos.

entre los diversos pueblos fronterizos mediante la diplomática o directamente por la vía de la guerra y de la conquista. De ese modo nacerían los primeros sistemas de relaciones entre las jóvenes ciudades. Vid. et al.: SERVICE, E. R. \& RUIZ DE ELVIRA HIDALGO, M. (trans.) (1984). Los orígenes del estado y de la civilización : El proceso de la evolución cultural (1ª ed.) Alianza, pp. 21-23, 65-72 y 119-121.

${ }^{44}$ Para PEROTTI la realidad mundial presenta la aparición de nuevos escenarios y espacios de relaciones que ya no pueden ser solucionados por las funciones clásicas del Estado-nación. PEROTTI, J. (2010). La Acción Internacional de las Provincias y Municipios Argentinos. Memorias: $V$ Congreso de Relaciones Internacionales, 24, 25, 26 de noviembre de 2010, Universidad Nacional de La Plata, La Plata, Argentina.

${ }^{45}$ La primera particularidad de los tres proyectos que estudiaremos, es que éstos los componen países en vías de desarrollo, circunstancia que ha de tenerse en cuenta al momento de proyectar cada modelo, y al valorarlo. ACOSTA observa esta dificultad como una de las aristas de importancia, de hecho refiriéndose a la CAN (como lo veremos en el capítulo V) señala «En un mundo globalizado, en el cual todo sucede a una escala mayor, la CAN constituía una opción para construir economías de escala de distinto tipo: políticas, productivas, sociales y de conocimiento. Pero el subdesarrollo a veces acaba con los sueños». ACOSTA PUERTAS, J. (2006). La desintegración andina. Nueva sociedad, (204), 4-13. 
La primera Corte moderna ${ }^{46}$ perteneciente a un plan de integración latinoamericano fue el Tribunal de Justicia del Acuerdo de Cartagena nacido en el año 1983, con la particularidad de haber emergido bastante desfasado del origen de su organización de pertenencia, la CAN (1969). El surgimiento de este órgano jurisdiccional transnacional fue producto de una de las tantas crisis internas de la Comunidad Andina, la cual se ha desplazado en una permanente situación de inestabilidad, circunstancia que lamentablemente se ha instalado como la tónica de dicha asociación ${ }^{47}$. En el año 1984 se dictaría el Reglamento del TJAC y más tarde el Protocolo de Cochabamba del año 1996 (vigente 1999) le cambiaría su nombre por el actual, Tribunal de Justicia de la Comunidad Andina (TJCA).

En la Europa de los años noventa se producían eventos de alta relevancia, por un lado en 1989 como indicamos, caía el muro de Berlín iniciándose una nueva geopolítica mundial, y por otro lado, nacía en el Parlamento Europeo (PE) la ambiciosa idea de una Constitución para Europa, generando esto último una agitada actividad de la academia no sólo en el viejo continente, sino también en las observaciones hechas desde América, pues la idea europea sobresalía ante todas las estructuras jurídicas conocidas hasta entonces ${ }^{48}$.

En América Latina el nuevo regionalismo seguía impulsando ánimos integracionistas —en menor escala que el europeo-, así a inicios de los años noventa sería el turno de la concreción del proyecto entre Brasil, Argentina, Uruguay y Paraguay, quienes apostaron por un plan netamente comercial, es decir, tomando distancia de su vecina la CAN. Únicamente los dos gigantes Brasil y Argentina, se centran en un acuerdo respecto de la conformación de un mercado común, plan secundado casi de inmediato por Uruguay y Paraguay. Lo más interesante es que si bien el MERCOSUR fue aposentado en pilares netamente mercantiles, su madurez a través de profundas mutaciones y nuevas finalidades que incluso han llegado a cubrir aspectos en materias de derechos humanos, lo convierten en un claro ejemplo de voluntad política, pero a las velocidades y ritmos latinoamericanos, todas estas circunstancias las iremos analizando en su pertinente orden dentro de esta tesis.

Ahora bien en lo histórico — que es a lo que nos convoca este capítulo- precisemos que fue a partir del año 1985 que surgen los acercamientos bilaterales entre Brasil y Argentina,

\footnotetext{
${ }^{46}$ Estamos dejando atrás a la Corte de Cartago de 1907 pues en realidad no hay una continuidad perfecta desde su concepción hasta la actual Corte Centroamericana de Justicia, aunque sí representa el antecedente más remoto del órgano jurisdiccional de Centro América según veremos más adelante en este capítulo.

${ }^{47}$ QUINDIMIL constata la crisis constante de la Comunidad Andina de Naciones, incluso como causa del nacimiento del Tribunal de Justicia del Acuerdo de Cartagena. QUINDIMIL LÓPEZ, 2006. En similar línea ZELADA CASTEDo indicando que el proceso de integración [...] nació con una visible deficiencia en su ordenamiento jurídico. ZELADA CASTEDO, 1985, p. 126. Se suma VIGIL TOLEDO, 2011, p. 39.

${ }^{48}$ Aunque ya sabemos que no prosperó bajo el nombre de Constitución, sino que el Tratado de Lisboa 2007 (vigor 2009) sería el receptáculo de salvataje de sus contenidos.
} 
dando como resultado que los presidentes de ambos países, Fernando Collor de Melo y Carlos Menem, firmasen el Acta de Buenos Aires de $1990^{49}$, a través de la cual adelantaban para fines del año 1994 el plazo para la formación de una unión aduanera, era entonces un claro acelerador de los procesos, pues anteriormente el Tratado de Integración, Cooperación y Desarrollo de 1988 le había dado a este objetivo un plazo de diez años, produciéndose de esta forma una evidente anticipación, por cierto impulsada gracias a los nuevos acontecimientos que estaban conformando el ya mencionado nuevo regionalismo. Lo más trascendente del MERCOSUR era que se estaban enarbolando objetivos de cooperación bilateral e integracionistas, es decir hay una clara importación de lenguaje desde el modelo europeo, signos evidentes de influencias parciales en todos los modelos latinoamericanos.

En definitiva a Argentina y Brasil se les unirían Paraguay y Uruguay produciéndose la preparación de un acuerdo cuatripartito ${ }^{50}$, de esta forma se arriba al Tratado de Asunción del año 1991, denominado Tratado para la Constitución del Mercado Común del Sur, suscrito por los referidos cuatro países. Mediante el cual, asumen la construcción de un mercado común que debería estar establecido para 1994, más un Sistema de Solución de Controversias Mercosur (SSCM) cuyo análisis e historia particular veremos más adelante en este mismo capítulo. El proyecto en sí, sería robustecido mediante el Protocolo de Ouro Prieto de $1994^{51}$ más otros extremos que analizaremos líneas más abajo, a efectos de no

\footnotetext{
${ }^{49}$ El Acta de Buenos Aires fue suscrita el 6 de julio de 1990. Este documento es producto del fortalecimiento de los lazos diplomáticos de dichas naciones y viene a cerrar un ciclo de diversos acercamientos bilaterales previos. Mediante esta Acta se anticipaba para fines del año 1994 el plazo para la formación de una unión aduanera, el cual previamente mediante el Tratado de Integración, Cooperación y Desarrollo de 1988 se había fijado en 10 años. Pueden revisarse estos y otros antecedentes históricos en GUERRA, S. (2013). MERCOSUL: Do ideal bolivariano para a realidade atual (e quem sabe futura?). Revista da secretaria do tribunal permanente de revisão, 1(1), 275-293. Una copia del texto histórico del TRATADO DE INTEGRACIÓN, COOPERACIÓN Y DESARROLLO de 1988 está alojado en el Portal oficial de la Embajada de Argentina en Brasil. Disponible en <http://www.argentina-brasil.com/wpcontent/themes/embajada/documentos/acta_1988.pdf> [última consulta, febrero 6, 2019].

${ }^{50} \mathrm{La}$ expansión del interés del vecindario por participar del proyecto, lo recuerda DREYZIN DE KLOR quien relata la incorporación de las dos naciones menores al proyecto mercosureño. DREYZIN DE KLOR, A. (1999). La dinámica institucional del mercosur. En J. Irigoin Barrenne (coord.), E. Rey Caro (present.), J. M. Insulza Salinas (disc.), R. Barros Charlín, C. F. Molina del Pozo, L. Narbone, ... G. Holzmann, Chile y el mercosur en américa latina: VI encuentro internacional de derecho de américa del sur (1999). Tomo I. Santiago, Chile: Universidad de Chile. Facultad de Derecho (Eds.), Editorial Jurídica de Chile, pp. 203-236.

${ }^{51}$ Los instrumentos fundantes de Mercosur, el Tratado para la Constitución del Mercado Común del Sur, sus Protocolos adicionales de Ouro Preto, de Ushuaia, de Olivos sobre la Solución de Controversias, el Constitutivo del Parlamento Mercosur, y otros, se encuentran en el Portal oficial de MERCOSUR. Disponibles en <https://www.mercosur.int/documentos-y-normativa/textos-fundacionales/> [última consulta, febrero 22, 2019].
} 
desatender la cronología del fenómeno global latinoamericano que va a la sombra del europeo.

Dentro de la era del nuevo regionalismo, llegaba entonces el turno de Centroamérica para cerrar la triada de las génesis de los sistemas latinoamericanos modernos ${ }^{52}$ de integración. Fue así entonces que arribado el año 1991, ahora los cinco países que en 1951 habían firmado la Carta ODECA y luego aumentados a seis al firmar la reestructuración de la Carta en 1962 oportunidad en se incluyó a la Corte de Justicia Centroamericana, Costa Rica, El Salvador, Guatemala, Honduras, Nicaragua y Panamá, imbuidos en el contexto de este nuevo regionalismo, firmaban ahora el Protocolo de Tegucigalpa a la Carta de $\operatorname{ODECA}^{53}$ (1991, vigor 1992).

El Protocolo de Tegucigalpa a la Carta de ODECA representa el surgimiento del SICA y de su actual tribunal, la Corte Centroamericana de Justicia. El SICA se definió como una «Comunidad económico-política que aspira a la integración de Centroamérica», con el fin de consolidar la paz de la región, superar la pobreza extrema, lograr mejores condiciones de vida y otros más, pero todo aquello, inmerso en las dinámicas del nuevo regionalismo, es decir, inmersos en la era de la globalización y de sus efectos ${ }^{54}$. En definitiva dicho Protocolo pasó a constituir el denominado Sistema de la Integración Centroamericana, en funciones desde $1993^{55}$, creando al mismo tiempo la Corte Centroamericana de Justicia,

\footnotetext{
52 Recordemos que hablamos de un esquema moderno en Centro América pues la unidad del istmo se remontaba al Imperio Maya, luego al imperio Español y ya desde 1823 mediante la Federación Provincias Unidas Centroamericanas, que luego transitó hacia la Confederación Centroamericana de 1907.

${ }^{53}$ El texto del Protocolo de Tegucigalpa a La Carta de la ODECA está disponible en el Portal oficial del SICA <http://www.sica.int/consulta/documento.aspx?Idn=82677\&IdCat=8\&IdEnt=401\&Idm=1\&IdmStyle=1> [última consulta, febrero 21, 2019].

${ }^{54}$ No es que el objeto único de los proyectos integracionistas latinoamericanos sea enfrentar los efectos de la globalización, sino que ese es su contexto histórico, el cual influyó notablemente en la decisión moderna de instaurar los tres proyectos enfocados. Respecto del SICA destaca esta cuestión central QUINTERO BERGANZA subrayando «En primer lugar, la región centroamericana, considerando el tamaño y el estado actual de sus economías, inevitablemente necesita de la integración regional para hacer frente a la globalización, y a los retos que supone la misma. La integración regional es una herramienta eficaz para afrontar de mejor forma los grandes desafíos que tiene en las vertientes económica y social, pues provee beneficios que no podrían obtenerse si los Estados continuaran actuando de forma individual». QUINTERO BERGANZA, J. G. (2010). Una aplicación a centroamérica de las claves de la unión europea. En P. Caldentey del Pozo (coord.), J. J. Romero Rodríguez (coord.), N. Mariscal Berastegui, A. Rodero Franganillo, M. López Martín, F. Santos Carrillo, ... L. G. Solís Rivera, El SICA y la UE: La integración regional en una perspectiva comparada. Colección de estudios centroamericanos (1). ( $1^{\text {a }}$ Ed.). Córdoba, España. Fundación ETEA para el desarrollo y la cooperación., p. 431.

${ }^{55}$ PÉREZ GONZÁLEZ, 2010, pp. 781-788.
} 
cuyo Estatuto es del año 1992, iniciando sus funciones jurisdiccionales en $1994^{56}$. La creación del SICA fue respaldada por las $\mathrm{NU}^{57}$.

En este orden de ideas y en el contexto global señalado, quedaban enmarcados los antecedentes modernos de la CAN, del MERCOSUR y del SICA, todos inmersos dentro de las dinámicas del nuevo regionalismo ya apuntado y claramente a la estela del modelo europeo de integración, el cual era copiado de manera incompleta por los tres receptores latinoamericanos. En aquella época inicial, el que se apreciaba como más cercano al modelo europeo era la CAN, cuestión que atrajo diversos elogios en su momento, y más aún cuando surge el TJCA el cual se dejaba ver como un tribunal de gran perspectiva y similar incluso al TJUE ${ }^{58}$.

El SICA estaba muy cercano al modelo andino, pero en Centroamérica había una osadía natural, pues se apostaba por introducir más soluciones propias y además arrastrar fórmulas de todo su acervo anterior. En lo principal que nos interesa aquí, oportunamente observaremos que determinadas competencias de la CCJ fluyen desde la Corte de Cartago, e incluso sus fallos son actualmente citados por la CCJ según detalladamente analizaremos. En cambio el MERCOSUR apostaba únicamente por aspectos comerciales.

Así quedaban dibujados los contextos de partida de los tres proyectos Latinoamericanos. Ahondaremos en todos estos aspectos durante el desarrollo de la tesis, pero aquí en este capítulo nuestro objeto es sólo plasmar el entorno histórico que los rodea, toda vez que aquello explicará diversos extremos que se irán detonando en los siguientes años de progresos y también de indeseadas dificultades.

Simultáneamente en Europa, tras el fracaso de la Constitución, se hacía imperioso lograr mayor cohesión política, por lo que a fines de 1991 el Consejo Europeo llegó al acuerdo sobre el texto del Tratado de Maastricht por el que se creó el Tratado de la Unión Europea (TUE, autenticado en febrero de 1992, vigor 1993). Ambos, el Tratado de Maastricht y el TUE imprimieron notables avances, v.gr. la más famosa de las tres comunidades, la CEE pierde su apelativo de económica, pasando a denominarse simplemente Comunidad

\footnotetext{
${ }^{56}$ ARAYA, 1992. AGUILERA, 2016. RIPLEY, 2018. Y en Portal oficial de la CCJ <http://portal.ccj.org.ni> [última consulta, febrero 21, 2019].

${ }^{57}$ Mediante Resolución A/48 L del 10 de diciembre del año 1993, lo que le permite relacionarse con las Naciones Unidas, organización internacional a la que pertenece en calidad de miembro observador. El SICA también se vincula cooperativamente con la OEA y con el resto de las organizaciones internacionales.

${ }^{58}$ QundimIL, «[...] el Tribunal de Justicia de las Comunidades Europeas en Europa y el Tribunal de Justicia de la CAN en el Continente americano. Salvando las distancias existentes entre ambos tribunales, 'puede afirmarse que constituyen, sin duda, los modelos más avanzados de justicia comunitaria'.». QUINDIMIL, 2006, p. 38.
}

60 
Europea (CE), al mismo tiempo se creó la Unión Europea. Estos cambios ocasionaron diversas reformas constitucionales en varios Estados miembros.

En definitiva tan densa construcción jurídica es la que hizo nacer formalmente a la Unión Europea $^{59}$, dio forma a la PESC e impulsó la cooperación en justicia, entre otros múltiples aspectos. En el año 1996 el Tratado de Ámsterdam (vigor 1999) simplificó el proceso de codecisión en el PE, se anclaron en el seno de la UE los principios democráticos del Estado de Derecho, se reconocieron ${ }^{60}$ expresamente las competencias del TJUE en materias de derechos humanos y por primera vez se reguló la institución de la cooperación reforzada ${ }^{61}$.

\footnotetext{
${ }^{59}$ MANGAS MARTÍN, 2014a, pp. 37-39.

60 Subrayemos que por el Tratado de Ámsterdam (en vigor desde 1999), como destaca MANGAS, sólo «se 'reconoció' expresamente la competencia del Tribunal de Justicia en materia de violación de derechos fundamentales». MANGAS MARTÍN, 2014a, p. 40., pues el TJCE, en su tiempo, ya había solucionado esta temática con su conocido triple fundamento, el que luego sería superado con más detalles en un camino de necesaria positivización — tal como lo recalca LIÑÁN- con la posterior formalización jurídica de la protección de los DDHH y de las Libertades Fundamentales en la UE, básicamente gracias al Tratado de Lisboa (en vigor desde el 2009). LIÑÁN NOGUERAS, 2014a, pp. 121-124.

${ }^{61}$ El instituto jurídico de la cooperación reforzada se gesta legislativamente en la UE por medio del Tratado de Ámsterdam, el cual fue potenciado a través del Tratado de Lisboa. Este concepto dicta la posibilidad de que un Estado miembro actúe más allá de lo regulado, asumiendo un compromiso más intenso que el resto, en un sentido positivo y fortalecedor del proceso integracionista. Es decir, cumple más, y de mejor manera, el estándar mínimo acordado, sin obligar al resto de los partícipes a dicho esfuerzo extra, por lo que sobrepasa al principio de la cooperación leal. Ahora bien, trae como consecuencia, la construcción de un acervo común difuso de la unión. Para un análisis comparativo puede revisarse un texto anterior a la positivización de Lisboa, esto es a la luz del Tratado de Ámsterdam en URREA CORRES, M. (2002). La cooperación reforzada en la unión europea: Concepto, naturaleza y régimen jurídico. Madrid: Colex. Y las modificaciones a este principio después de Lisboa pueden consultarse en RODRÍGUEZ IGLESIAS \& LÓPEZ ESCUDERO, 2010a, pp. 609-611.
} 


\section{EL CAMBIO DE MILENIO TRAJO NUEVAS METAS Y NUEVOS PROBLEMAS PARA LOS ESQUEMAS DE INTEGRACIÓN A AMBOS LADOS DEL ATLÁNTICO}

En América Latina el siglo XXI se iniciaba con sus tres proyectos ya inaugurados, el SICA, la CAN y el MERCOSUR. En Centroamérica llegado el año 2000, Belice se incorporaba al SICA y en el 2013 se sumaría la República Dominicana, estabilizándose desde entonces la cantidad de socios del proyecto centroamericano en ocho Estados miembros, a los que se suman una serie de países observadores regionales y extra-regionales ${ }^{62}$.

Ese mismo año 2000, en Europa se arriba al Tratado de Niza (firmas 2001, vigor 2003) el cual dio un fuerte impulso en derechos humanos, acordando firmar la Carta de Derechos Fundamentales de la Unión Europea ${ }^{63}$ aunque sin incorporarla a Niza, sino que dejándolo constreñido al ámbito de un acuerdo político y efectuó la mayor intervención en el sistema judicial europeo ${ }^{64}$, ante la saturación del $\mathrm{TPCE}^{65}$ se posibilitó crear las salas jurisdiccionales ${ }^{66}$ para conocer en primera instancia de materias específicas aunque el Tratado de Lisboa le cambiaría el nombre por tribunales especializados, sin embargo el único tribunal especializado que ha existido fue el TFPUE nacido en $2004^{67}$ y desaparecido

\footnotetext{
${ }^{62}$ Los ocho Estados miembros en orden alfabético son Belice, Costa Rica, El Salvador, Guatemala, Honduras, Nicaragua, Panamá y República Dominicana. En tanto cuenta con 26 observadores, entre ellos la UE. El listado oficial está disponible en <http://www.sica.int/miembros/miembros.aspx > [última consulta, febrero 21 , 2019].

${ }^{63}$ CARTA DE DERECHOS FUNDAMENTALES DE LA UNIÓN EUROPEA (2000/C 364/01). Disponible en el Portal oficial del Parlamento Europeo <http://www.europarl.europa.eu/charter/pdf/text_es.pdf> [última consulta, febrero 20, 2019].

${ }^{64}$ El Tratado de Niza se efectuó entre el 7 y 11 de diciembre del año 2000, sus negociaciones fueron muy difíciles, aunque en particular el tema jurisdiccional ya estaba consensuado por los entonces 15 Estados miembros y, efectivamente esta fue la oportunidad en que se produjo el mayor movimiento reformador del Poder Judicial de la UE, destinado a enfrentar la sobrecarga de trabajo constatada, sumada a la que significaría la inminente incorporación de nuevas naciones. ALDECOA LUZÁRRAGA, F. (2002). La integración europea: Análisis histórico-institucional con textos y documentos - Tomo II génesis y desarrollo de la unión europea (1979-2002). Madrid: Tecnos. [Truyol y Serra, A. (1999). La integración europea: Análisis histórico-institucional con textos y documentos.- Tomo I génesis y desarrollo de la unión europea (1951-1979). Madrid: Tecnos], p. 302.

${ }^{65}$ El Tribunal de Primera Instancia, entre varias competencias también se hacía cargo de los procesos contenciosos especiales por aplicación de normativa sectorial muy específica, como la función pública o el contencioso producto de los títulos europeos de protección de determinados derechos de propiedad industrial y comercial, los que exigen la intervención de jueces especialistas.

${ }^{66}$ ZAPATER DUQUE, 2005b, pp. 111-112.

${ }^{67}$ La competencia ratione materiae del Tribunal de la Función Pública, recaía en la resolución de litigios del contencioso de la función pública de la UE. Sus formaciones reconocían actuaciones en pleno y en salas de 62
} 
en 2016 al asumir el TGUE todas sus competencias. Para el año 2003 se presentaba el proyecto de Tratado para una Constitución Europea, disponible para las firmas en 2004, mismo año en que entró en vigor la Gran Adhesión incorporándose otras diez naciones. Pero en el año 2005 Francia y Holanda, por votación popular, rechazaban la mentada Constitución. Para entonces ya se llegaba a veintisiete Estados miembros.

Al otro lado del Atlántico a mediados del 2005, el MERCOSUR ya daba frutos impensados, pues salía de sus fronteras económicas e ingresaba sin pábulo en un campo bastante más denso que el dibujado en sus orígenes. El cambio de milenio había sido sin lugar a dudas un buen estimulo para el merco-sistema, el cual se aproxima a los derechos humanos desde los más diversos ángulos, entre los cuales destaca la adscripción en ese año 2005 del Protocolo de Asunción sobre Compromiso con la Promoción y Protección de los Derechos Humanos $^{68}$, y en la actualidad el MERCOSUR cuenta con un conjunto amplio de medidas e instrumentos en materias de derechos humanos, sumándose al Protocolo supra, entre otros varios, el Instituto de Políticas Públicas en Derechos Humanos del Mercosur, diversas publicaciones especializadas, declaraciones y los más variados canales de difusión ${ }^{69}$, todas concreciones que evidencian una historia dinámica y amplia de integración en el MERCOSUR dentro de sus posibilidades y a su velocidad, es decir, en código latinoamericano.

Entre tanto, en la zona andina arribado el año 2006 la CAN sería impactada con otro revés ya que Venezuela durante el gobierno de su presidente Hugo Chávez, desahució su participación en el proyecto andino, en una decisión netamente reactiva motivada por la firma de un Tratado de Libre Comercio por Colombia y Perú con los EEUU. Aunque casi al unísono la CAN recibía un bálsamo, que efectivamente en algo lograba compensarla, pues Chile ese mismo año bajo el primer gobierno de Michelle Bachelet volvía a la CAN, aunque sólo como país asociado. Sin embargo el hecho de que el más ordenado y estable país de Latinoamérica apostase nuevamente por la CAN, constituía un voto de confianza desde su entorno cercano a todo el proyecto andino. En la actualidad la CAN está integrada por Colombia, Ecuador, Perú y Bolivia, más otras naciones asociadas.

cinco jueces y salas de juez único. La normativa principal que rigió al Tribunal de la Función Pública, se encontraba en el TUE en su art. 19.1 y en TFUE en su art. 257. Puede revisarse también LIÑÁN NOGUERAS, 2014b, pp. 287-289.

${ }^{68}$ El 20 de junio del año 2005 los cuatro países mercosureños suscribieron el Protocolo de Asunción sobre Compromiso con la Promoción y Protección de los Derechos Humanos, quedando abierto además al resto de los países asociados del Mercosur. Disponible en el Portal oficial del Mercosur en <https://www.mercosur.int/documento/protocolo-de-asuncion-sobre-compromiso-con-la-promocion-yproteccion-de-los-derechos-humanos-en-el-mercosur/> [última consulta, septiembre 1, 2019].

${ }^{69}$ El grupo de acciones e instrumentos en que el MERCOSUR manifiesta su actual grado de compromiso para con los derechos humanos puede revisarse el enlace oficial Derechos Humanos en Mercosur, disponible en <https://www.mercosur.int/temas/derechos-humanos/> [última consulta, septiembre 1, 2019]. 
Pero en 2007 los acontecimientos en Europa llaman poderosamente la atención de Latino América dado que los europeos, en una operación jurídica digna de análisis, intentaban sortear el fracaso de la Constitución utilizando el Tratado de Lisboa (2007, vigor 2009) el cual como hemos dicho, recogió el contenido sustantivo de la Constitución. Maniobra de salvataje que pudo efectuarse pues para muchos el fracaso se había debido a una mera cuestión gramatical, toda vez que la palabra «constitución» es demasiado sensible ${ }^{70}$. Además Lisboa le reconoció personalidad jurídica de la UE, dio paso a dos textos únicos, el reformado TUE y el Tratado de Funcionamiento de la UE (TFUE), y supuso un impulso en derechos humanos desplegando tres operaciones, primero, incorporó al TUE por referencia la Carta de Derechos Fundamentales de la Unión Europea - firmada en Niza 2000, con valor desde 2007-, segundo, le impuso a la UE el objetivo de adherirse al Convenio Europeo de Derechos Humanos ${ }^{71}$, y tercero, mantuvo el criterio del TJUE según el cual los

\footnotetext{
${ }^{70}$ Sobre el hecho de salvar el sustrato central de la Constitución para Europa, y para ello emplear al Tratado de Lisboa como contenedor sustantivo de gran parte del mentado Tratado para la Constitución Europea, puede revisarse en: MÉNDEZ DE VIGO, I. \& OREJA AGUIRRE, M. (2007). ¿Qué fue de la constitución europea? : El tratado de lisboa: Un camino hacia el futuro ( $1^{\mathrm{a}}$ ed.). Madrid: Fundación Rafael del Pino. Otro: MILLÁN MORO, L. (2010). El ordenamiento jurídico comunitario: Del tratado constitucional al tratado de lisboa. Revista de derecho comunitario europeo, 14(36), 401-438. Otro, ALDEOCA LUZURRAGA, F. (2008). El tratado de Lisboa como salida al laberinto constitucional. En J. Martín y Pérez de Nanclares (coord.), F. Aldeoca Luzurraga, N. Mariscal Berástegui, M. A. Alcoceba Gallego, M. Guinea Llorente, A. Fernández Tomás, ... M. Urrea Corres, El tratado de lisboa: La salida de la crisis constitucional : Jornadas de la Asociación Española de Profesores de Derecho Internacional y Relaciones Internacionales celebradas en madrid el 17 y 18 de diciembre 2007 ( $1^{\mathrm{a}}$ ed.). Madrid: Iustel, pp. 35-85.

${ }^{71}$ Cuestión que hasta hoy en día ha sido imposible, ya que tras el mandato de Lisboa se planteó un proyecto de acuerdo, el cual fue sometido en el año 2013 a la valoración vinculante del TJUE, pero en 2014 al pronunciarse la Corte mediante el Dictamen 2/13 (Dictamen del TJ de 18 de diciembre de 2014. Avis rendu en vertu de l'article 218, paragraphe 11, TFUE. Dictamen 2/13, ECLI:EU:C:2014:2454) manifestó diversos riesgos para la autonomía de la UE, pasando a establecer condicionantes para su firma, que prácticamente lo convirtió en imposible de cumplir. Generando una enorme discusión académica y política. MARTÍN Y PÉREZ DE NANCLARES, J. (2015). El TJUE pierde el rumbo en el dictamen 2/13: ¿merece todavía la pena la adhesión de la UE al CEDH?. Revista de derecho comunitario europeo, 19(52), 825-869. ALONSO GARCÍA, R. (2015). Sobre la adhesión de la UE al CEDH (o sobre cómo del dicho al hecho, hay un gran trecho). Civitas. Revista española de derecho europeo, 53, 11-16. MARÍN AÍS, J. R. (2013). La adhesión de la unión europea al convenio de roma. El cumplimiento de las obligaciones derivadas del convenio europeo de derechos humanos en el ordenamiento jurídico de la UE. Revista de derecho comunitario europeo, 17(44), 233-276. MATIA PORTILLA, F. J., (2015). La adhesión de la UE al CEDH hoy: Una valoración de los trabajos realizados hasta el momento. En L. I. Gordillo Pérez (coord.), A. Oehling De Los Reyes, L. Álvarez Álvarez, L. I. Gordillo Pérez, C. Milione Fugali, M. Hernández Ramos, ... A. Tapia Trueba, Constitutionalism of european supranational courts: Recent developments and challenges, Aranzadi., pp. 217-241.
} 
derechos fundamentales forman parte del Derecho de la UE en calidad de principios generales del derecho ${ }^{72}$. Por último le cambió el nombre al TJCE por TJUE.

A diferencia de la intensidad en los ajustes aplicados a las Cortes de Latino América, en Europa la historia modeló con mucho más potencia al Poder Judicial de la UE, permitiéndonos en la actualidad observarlo como del todo supranacional y atípico, entre otros aspectos ha debido soportar varios reacondicionamientos, quedó regulado en el TUE el cual concibe al TJUE como una Institución única, aunque podría ser comprendida hasta por tres tipos de sedes judiciales, pues la fórmula lo permite al indicar «El Tribunal de Justicia de la Unión Europea comprenderá el Tribunal de Justicia, el Tribunal General y los tribunales especializados» ${ }^{73}$, pero en la actualidad no hay tribunales especializados. Esta Institución se subsume en un sistema de cooperación no jerárquico con los tribunales nacionales, siendo éstos los primeros llamados a hacer cumplir el Derecho de la UE en calidad de sus guardianes ${ }^{74}$, pudiendo dirigir consultas prejudicialmente al TJUE, o bien, las partes pueden instar por la consulta. Todo esto distancia al TJUE de un poder judicial nacional tradicional y de un tribunal internacional típico, pues por el primero presenta elementos mixtos y por el segundo, se advierte que la mayor parte de los litigios que conoce no son de carácter internacional, o si lo son, se tornan obligatorias sus sentencias.

\footnotetext{
${ }^{72}$ La construcción jurisprudencial que permitió a la Corte de Luxemburgo efectuar su desarrollo en materia de derechos humanos se basó en una triada conceptual, recurriendo a los principios generales del derecho comunitario, más los principios o tradiciones de cada Estado miembro, y sumando determinados instrumentos internacionales. Desarrollo que se efectúa en su totalidad mediante una secuencia de sentencias, siendo las más significativas la Sentencia del TJ de 12 de noviembre de 1969, Stauder c/ Stadt Ulm - Sozialamt, as. C29/69, ECLI:EU:C:1969:57; la Sentencia del TJ de 17 de diciembre de 1970, Internationale Handelsgesellschaft mbH c/ Einfuhr - und Vorratsstelle für Getreide und Futtermittel, as. C-11/70, ECLI:EU:C:1970:114; y la Sentencia del TJ de 14 de mayo de 1974, Nold, Kohlen - und Baustoffgroßhandlung c/ Comisión de las CE, as. C-4/73, ECLI:EU:C:1974:51. La descripción de la técnica jurisdiccional puede consultarse en MORENO MOLINA, J. A. (2007). Los principios generales del derecho. En L. Ortega Álvarez (dir.), J. A. Moreno Molina (coord.), I. Gallego Córcoles, L. F. Maeso Seco, J. M. A. Magán Perales, J. Morcillo Moreno, ... F. Sánchez Rodríguez, Derecho comunitario europeo ( ${ }^{a}$ ed.). Valladolid: Lex Nova., pp. 32-34.

${ }^{73}$ La estructura gramatical que emplea el transcrito art. 19.1 del TUE es muy singular y no debe conducir a errores, pues al indicar dicha norma que el «TJUE comprenderá el Tribunal de Justicia [TJ], el Tribunal General y los tribunales especializados» podría inducir a una confusión, dado que en la cultura jurídica europea se utiliza la sigla TJUE para referirse al Tribunal de Justicia directamente. En realidad, lo que sucede es que «no se utilizó la expresión Poder Judicial de la UE» sino Tribunal de Justicia de la Unión Europea. En línea con esta salvedad el Portal oficial del TJUE se identifica y se presenta como «CVRIA europea» <http://curia.europa.eu> [última consulta, febrero 19, 2019].

74 SARMIENTO \& RUIZ-JARABO COLOMER. (2004). Poder judicial e integración europea: La construcción de un modelo jurisdiccional para la unión (1 $1^{\mathrm{a}} \mathrm{ed}$.). Madrid: Civitas, pp. 39-50.
} 
Desde nuestra cauta aproximación histórica, resulta evidente que las Cortes de Latino América se distancian de la Corte de Luxemburgo la cual se comprende de modo mucho más denso que un simple tribunal internacional, pues además de la compleja orgánica en que se ubica, funcionalmente ostenta un enorme elenco de competencias $^{75}$ y un rico desarrollo jurisprudencial, según analizaremos en los capítulos posteriores. Pero simplemente al observar de modo global a esta robusta construcción judicial, se hace patente que constituye un Poder Judicial atípico, por tal motivo parte de la doctrina lo ha pasado a identificar como un Poder Judicial híbrido ${ }^{76}$.

El año 2017 para la UE traería la complejidad del Brexit. En noviembre del 2018 se cerró el acuerdo sobre la salida de Reino Unido y se efectuó la Declaración Política que Establece el Marco Para La Relación Futura entre la UE y El Reino Unido ${ }^{77}$, pero en enero del 2019

75 Las competencias del TJUE habitualmente se agrupa en tres categorías: contenciosa, consultiva, y prejudicial, aunque debemos destacar — por su clarificadora importancia — un cuarto tipo que reconocen los Tratados, nos referimos a las competencias negativas. Todas estas potestades cubren los siguientes extremos: Las competencias contenciosas son las más numerosas. Aquí encontramos los litigios contra los Estados miembros por incumplimiento del derecho de la UE y los recursos - acciones - dirigidos a controlar la legalidad de los actos de las instituciones, como los recursos de anulación, de excepción de legalidad y de inactividad. La competencia consultiva se vincula a la posibilidad de celebrar Tratados Internacionales por la UE, ingresándose al TJUE el proyecto de Tratado para su análisis de compatibilidad con el Derecho de la UE. Las competencias en cuestiones prejudiciales pueden ser planteadas por los jueces nacionales de oficio o tras acceder a una sugerencia de las partes. Son de dos tipos: las de interpretación de los tratados constitutivos y del derecho derivativo, y las de apreciación de validez de los actos de las instituciones de la UE. Las competencias negativas son prohibiciones expresas de injerencia del TJUE en determinadas materias. En este campo quedó cualquier posibilidad de controlar las disposiciones en materia de PESC, salvo escuetas excepciones. Tampoco puede controlar judicialmente operativos policiales ni conocer respecto de las posibles responsabilidades de los Estados miembros en el mantenimiento del orden público o seguridad interior. Analizaremos en más detalle todos estos aspectos en los capítulos siguientes.

${ }^{76}$ La doctrina ha ido identificando a esta Institución de la UE con diferentes conceptos, por ejemplo SARMIENTO, bajo el apartado que este autor tituló «El Poder Judicial de la Unión» precisa que como en todo sistema político basado en el reparto de competencias, el Poder Judicial de la Unión se estructura en dos niveles, por un lado los Tribunales de la Unión, y por otro los Tribunales de los Estados miembros. Concluyendo que sería un «Poder Judicial Híbrido». SARMIENTO RAMÍREZ-ESCUDERO, D. (2016). El derecho de la unión europea. Madrid, Barcelona, Buenos Aires, Sao Paulo: Marcial Pons, p. 89, pp. 357-358 y p. 437. Por su parte LENAERTS y GUTIÉRREZ-FONS cotejan que a diferencia de otros sistemas federales la UE tiene un «Poder Judicial Integrado», pues el TJUE lo comparte con los órganos jurisdiccionales nacionales, aunque el TJUE ha introducido elementos jerárquicos en una relación que gira en torno al entendimiento. LENAERTS, K \& GUTIÉRREZ-FONS, J. El papel del tribunal de justicia de la unión europea en el proceso de integración europea. En Beneyto, J. M., Maillo González-Orús, J., Becerril Atienza, B. \& Lenaerts, K. (2012). Tratado de derecho y políticas de la unión europea, Tomo V Sistema jurisdiccional de la ue ( $1^{\mathrm{a}}$ ed.). Cizur Menor: Thomson Reuters Aranzadi., pp. 86-88. Volveremos sobre este tema en el capítulo siguiente.

${ }^{77}$ Declaración XT 21095/18 - BXT 111. Disponible en <http://data.consilium.europa.eu/doc/document/XT21095-2018-INIT/es/pdf> [última consulta, enero 28, 2019].

66 
Londres lo rechazó. Actualmente el gobierno del Reino Unido está en plenas maniobras locales, al tiempo de prepararse para una salida dura. En lo central, compartimos la idea de que el Reino Unido siempre había sentido preferencia por mantener la nación isleña al margen de los asuntos continentales ${ }^{78}$. Actualmente (2019) la UE llega a veintiocho socios, más cinco países candidatos, dos potenciales ${ }^{79}$ y ad portas de restar uno.

Latinoamérica observa y estudia este gran fenómeno europeo importando permanentemente las soluciones de la UE, pues como veremos el Derecho de la UE es materia viva para el diálogo de fuentes con los esquemas latinoamericanos, y los precedentes jurisdiccionales del TJUE también son fuentes para un singular diálogo judicial. Pero en Latino América las soluciones son ajustadas a las realidades locales, tal como lo analizaremos. Por cierto el proyecto europeo no es nuestro objeto estudio y desbordaría, no sólo a esta tesis, sino a cualquier obra que no sea monumental ${ }^{80}$. Sólo hemos resaltado los hitos más significativos, los cuales enseñan a América Latina que la UE no se construyó en un día, sino que es una enorme organización supranacional sui generis, que asume todo el acervo de integración desde el año 1951, más incluso sus antecedentes remotos, y que no detiene su madurez, sino que continúa en pleno progreso.

\footnotetext{
${ }^{78}$ La postura general del Reino Unido con el proyecto europeo para muchos nunca fue decidida. GOSALBO recuerda esta oposición, y cree que se debe a que no se vio tan afectada por la guerra a diferencia de los europeos, pero que tras verificar sus éxitos económicos se sintió atraída. Pero en definitiva — sostiene este autor- el Reino Unido siempre ha sentido preferencia por mantener la nación isleña al margen de los asuntos continentales. GOSALBO BONO, R. (2016). ¿Brexit o bremain?. Revista general de derecho europeo 39, pp. 1-23 (pp. 6-7).

${ }^{79}$ Los actuales cinco países candidatos a la incorporación a la UE son Albania, Antigua República Yugoslava de Macedonia, Montenegro, Serbia y Turquía; más dos candidatos potenciales, Bosnia y Herzegovina, y Kosovo. Disponibles en Portal oficial de la UE <http://europa.eu/about-eu/countries/index_es.htm\#goto_2> [última consulta, enero 28, 2019] (vid. apartados Países candidatos, y Candidatos potenciales).

${ }^{80}$ Una acabada relación de todo el proceso histórico para arribar a la UE, desde la cristiandad europea hasta el año 2002, más una cronología hasta el año 2015, y añadiendo un anexo de los principales instrumentos de la UE, puede encontrarse en TRUYOL \& SERRA, A. (1999). La integración europea: Análisis históricoinstitucional con textos y documentos - Tomo I génesis y desarrollo de la unión europea (1951-1979). Madrid: Tecnos, más ALDECOA LUZÁRRAGA, F. (2002). La integración europea: Análisis histórico-institucional con textos y documentos - Tomo II génesis y desarrollo de la unión europea (1979-2002). Madrid: Tecnos. Otro texto de eminente perfil histórico AHIJADO QUINTILLÁN, M. (2000). Historia de la unidad europea: Desde los precedentes remotos a la ampliación al este ( $1^{\mathrm{a}}$ ed.) Ediciones Pirámide, en esta obra en su primera parte se exponen ejemplos unificadores de carácter federalista y de origen alemán, mientras que su segunda parte se orienta a la génesis y desarrollo del proceso comunitario. Otra, BERDAH, J. F. (2007). Los orígenes de la construcción europea. De la idea europea a la europa unida. Cuadernos europeos de deusto, (37), 49-71.
} 


\section{EL IMPERIO MAYA SE RE-INTEGRA: UN ESFUERZO DE UNIDAD EN EL ISTMO A TRAVÉS DEL SISTEMA DE LA INTEGRACIÓN CENTROAMERICANA EL SICA}

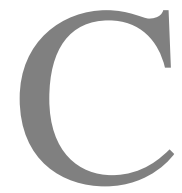

omo decían los mayas en el Popol Vuh, que todos se levanten y que nadie se quede atrás ${ }^{81}$, ese grito unitario y solidario de los mayas es el que el Secretario General del SICA recordó en su discurso de diciembre del 2018 en la $52^{\circ}$ Reunión de Jefes de Estado y de Gobierno del SICA. Dicha frase es una abreviación del concepto más amplio que expresamente utiliza, como párrafo inaugural, de la Declaración de Antigua.

\section{«DECLARACIÓN DE ANTIGUA}

"Que todos se levanten, que se llame a todos, que no haya un grupo, ni dos grupos de entre nosotros que se quede atrás de los demás".

POPOL VUH» ${ }^{82}$.

Tal espíritu unitario de profundas raíces culturales es el que el SICA constantemente intenta concretar por los cauces de la modernidad centroamericana, derrotero en el cual le toca sortear con ingenio, alegría y colores los lastres del subdesarrollo, así es Centro América. Hasta este punto del presente capítulo ya hemos marcado todos los sucesos históricos iniciales que complotaron para conformar al SICA, aunque los vimos entrelazados con los demás acontecimientos de Latino América y de Europa. Si los aislamos en una rápida secuencia, éstos dan cuenta de que la zona estuvo organizada primero por el Imperio Maya $^{83}$, reestructurada luego por el Imperio Español bajo la Capitanía General de Guatemala. Al independizarse se conformó la Federación Provincias Unidas Centroamericanas (1823) la cual en 1838 se disolvió dando paso a las actuales naciones de

${ }^{81}$ El discurso de Vinicio Cerezo estuvo marcado por una profunda visión de futuro. CEREZO, V. (2018). Discurso del Secretario General del SICA (14.12.2018). 52 ${ }^{\circ}$ REUNIÓN DE JEFES DE ESTADO Y DE GOBIERNO DEL SICA. Belize. Disponible en <https://www.sica.int/noticias/presidentes-del-sica-pidenavanzar-en-la-construccion-de-un-modelo-de-desarrollo-sostenible-para-la-region_1_116361.html> [última consulta, septiembre 19, 2019].

${ }^{82}$ Párrafo inicial de la Declaración de Antigua, efectuada tras la reunión de los días 15, 16 y 17 de junio de 1990 de los seis presidentes de las Repúblicas de Costa Rica, El Salvador, Guatemala, Honduras, Nicaragua y Panamá.

${ }^{83}$ Únicamente en Centroamérica encontramos raíces históricas profundas respecto de un sentimiento unitario que precediera a alguno de los tres esquemas de integración actuales latinoamericanos. Vid. AGUILERA, 2016, pp. 91-92. 
la zona. En 1903, Panamá se independiza de Colombia y comienzan los intentos por reagruparse. En 1907, se suscriben diversos convenios en Washington naciendo la Confederación Centroamericana y su Tribunal de Justicia Centroamericano o Corte de Cartago en carácter de primer tribunal internacional de naturaleza jurisdiccional y permanente en la historia. En los siguientes cuarenta años esa estructura se debilitó y caducó la jurisdicción de la Corte. En 1951, los mismos países firman la Carta Constitutiva de ODECA, reestructurada en 1962 ahora también con Panamá, y todo con explícitas aspiraciones de una integración centroamericana.

En la Carta reestructurada se instituían varios órganos, entre los cuales estaba la Corte de Justicia Centroamericana conformada por los presidentes de los Poderes Judiciales de cada Estado miembro. Pero los conflictos continuaban en Centroamérica y se hacía imperioso lograr la paz y democratizar la región, el momento favorable vino al finalizar la Guerra Fría, ocasión en que los Estados de ODECA más Panamá ordenaron un estudio para revitalizar el proyecto, cuestión que tardó diez años y recién en 1990 se firmaría la Declaración de Antigua abogando por una reestructuración.

En dicho contexto los seis países firmaron el Protocolo de Tegucigalpa a la Carta de ODECA $^{84}$ (1991, vigor 1992) declarándose como una Comunidad económico-política que aspira a la integración de Centroamérica, todo — según recalca la mayoría de la doctrinainmerso en las dinámicas del fin de la Guerra Fría ${ }^{85}$ y de los efectos de la globalización ${ }^{86}$

84 Se unía también Panamá. El texto está disponible en el Portal oficial del SICA <http://www.sica.int/consulta/documento.aspx?Idn=82677\&IdCat=8\&IdEnt=401\&Idm=1\&IdmStyle=1> [última consulta, febrero 21, 2019].

${ }^{85}$ AGUILERA lo destaca así «Entre finales de los años ochenta y principios de los noventa del siglo pasado concluyó la Guerra Fría con la desintegración de la Unión Soviética y la caída del muro de Berlín. Ello creo un escenario favorable al progreso de iniciativas que buscaban impulsar la pacificación y la democratización de Centroamérica». AGUILERA, 2016, pp. 95-96.

${ }^{86}$ Tal como ya señalamos, no es que el objeto único de los proyectos integracionistas americanos sea enfrentar la globalización, sino que ese es su contexto histórico, el cual, influyó notablemente en la decisión moderna de instaurar los tres proyectos americanos. Puntualmente para el SICA también se destaca esta arista, por ejemplo QUINTERO BERGANZA subraya la influencia de la globalización para este proyecto del siguiente modo «En primer lugar, la región centroamericana, considerando el tamaño y el estado actual de sus economías, inevitablemente necesita de la integración regional para hacer frente a la globalización, y a los retos que supone la misma. La integración regional es una herramienta eficaz para afrontar de mejor forma los grandes desafíos que tiene en las vertientes económica y social, pues provee beneficios que no podrían obtenerse si los Estados continuaran actuando de forma individual». QUINTERO BERGANZA, J. G. (2010). Una aplicación a centroamérica de las claves de la unión europea. En P. Caldentey del Pozo (coord.), J. J. Romero Rodríguez (coord.), N. Mariscal Berastegui, A. Rodero Franganillo, M. López Martín, F. Santos Carrillo, ... L. G. Solís Rivera, El SICA y la UE: La integración regional en una perspectiva comparada. Colección de estudios centroamericanos (1). ( $1^{\mathrm{a}}$ Ed.). Córdoba, España. Fundación ETEA para el desarrollo y la cooperación., p. 431. 
naciendo así el Sistema de la Integración Centroamericana - SICA, en funciones desde $1993^{87}$ junto la Corte Centroamericana de Justicia - CCJ.

Debemos tener presente que, si bien el SICA posee una estructura orgánica ${ }^{88}$ propia de una organización internacional, se empleó la denominación de «sistema» porque en realidad, el proceso organizativo del istmo centroamericano ya venía avanzado por otros diversos Tratados — los cuales hemos ido precisando - la idea era que todos se sintonizaran en un único gran sistema ${ }^{89}$. Pero ante la evidente dificultad de la sintonización pretendida, ha pasado a observarse como muy poco novedosa la fórmula por una parte de la doctrina ${ }^{90}$ basándose en que únicamente se trataría de añadir nuevos órganos, entre éstos la CCJ.

${ }^{87}$ PÉREZ GONZÁLEZ, 2010, pp. 781-788.

${ }^{88}$ La estructura orgánica del SICA está conformada por una Secretaría General con la función de apoyar a los órganos e instituciones de integración y por el Parlamento Centroamericano (PARLACEN), compuesto por representantes de cada nación y elegidos por sufragio directo, asumiendo la condición de diputados centroamericanos, los que de acuerdo al art. 1 del Tratado Constitutivo del PARLACEM, tienen la función de servir de foro deliberativo sobre cuestiones políticas, económicas y sociales, más otras particularidades. El Comité Consultivo es un órgano de la sociedad civil formado por organizaciones regionales. El Comité Ejecutivo se compone de un representante designado por cada gobierno de los Estados partes y sus funciones - entre otras - son asegurar la ejecución de las decisiones de las reuniones de presidentes, y finalmente la reunión de vicepresidentes. La CCJ es el órgano jurisdiccional del esquema SICA, y sobre el cual estudiaremos múltiples aspectos en esta tesis. El SICA tiene su sede en El Salvador. Los detalles de cada órgano y otros extremos se pueden consultar en el Portal oficial del SICA. Disponible en <http://www.sica.int> [última consulta, febrero 21, 2019].

${ }^{89}$ En este sentido AGUILERA destaca «La denominación de 'sistema' que se dio a la organización, refleja la concepción teórica sistémica que inspiró la nueva arquitectura. En la misma, la organización se estructuraba sobre cinco subsistemas, cada uno de ellos con un tratado u otra norma propia. Los subsistemas fueron originalmente: Político, Económico, Social, Ambiental y Cultural y Educativo. Se entiende que el Protocolo de Tegucigalpa, al crear el SICA, estableció el subsistema Político». AGUILERA, 2016, p. 97.

${ }^{90}$ En dicha línea CALDENTEY DEL POZO expresa «Los acuerdos de los 90 no fueron excesivamente innovadores en materia institucional y la renovación del proceso consistió en añadir institucionalidad a la ya existente. Por ejemplo, sumando secretarías para que el nuevo esquema respondiera bien a su multidimensionalidad. O cubriendo ausencias muy importantes del período de la ODECA y el MCCA con la creación de la Corte Centroamericana de Justicia y el Comité Consultivo de la Sociedad civil». CALDENTEY DEL POZO, P. (2010). Panorama de la integración centroamericana: dinámica, intereses y actores. En P. Caldentey del Pozo (coord.), J. J. Romero Rodríguez (coord.), N. Mariscal Berastegui, A. Rodero Franganillo, M. López Martín, F. Santos Carrillo, ... L. G. Solís Rivera, El SICA y la UE: La integración regional en una perspectiva comparada. Colección de estudios centroamericanos (1). (1 ${ }^{\mathrm{a}} \mathrm{Ed}$.). Córdoba, España. Fundación ETEA para el desarrollo y la cooperación., p. 232. 


\section{El legado de la CoRTe de CARTAgo es ReCEPCIONAdo POR la JUSTICIA DE INTEGRACIÓn MODERnA CENTROAMERICANA: La Corte Centroamericana de Justicia - CCJ}

Resulta particularmente llamativo que la actual Corte Centroamericana de Justicia proceda a citar directamente a las sentencias de la Corte de Cartago, en un concreto sentido de continuidad del antiguo tribunal, confesando de paso raíces de tamaña profundidad histórica. Así puede verse por ejemplo el siguiente considerando de la CCJ:

«Que en atención al derecho a aplicarse en este caso, se destaca en lo fundamental lo consignado en el literal f) del artículo 22 del Convenio de Estatuto de este Tribunal que dice: "La Competencia de La Corte será: f) Conocer y resolver a solicitud del agraviado de conflictos que puedan surgir entre los Poderes u Órganos Fundamentales de los Estados, y cuando de hecho no se respeten los fallos judiciales". 'Esta atribución que forma parte del acervo jurídico centroamericano originada en similar que tuvo la Corte de Justicia Centroamericana (Corte de Cartago), que funcionó de 1908 a 1918, cuyo objeto fue el mantenimiento de la paz en Centroamérica evitando el rompimiento del orden jurídico y logrando el funcionamiento democrático de los Gobiernos', atribución que también está contenida en la Exposición de Motivos del Convenio de Estatuto de este Tribunal» ${ }^{91}$.

Dicha opción del ejercicio jurisdiccional de la CCJ da cuenta del amable sentir histórico que este actual tribunal de integración sui generis pretende impregnarle a la cultura jurídica de la zona cubierta por el SICA, o si se prefiere, es un aporte del todo intencional y concreto de este tribunal moderno, al proceso de integración mediante las herramientas propias de la jurisdicción.

En la dimensión jurisdiccional del proyecto del SICA la posición que emplea la CCJ es privilegiada y central, tanto así que directamente desde sus Estatutos —en la Exposición de Motivos y en su articulado - se expresa que la CCJ satisface el concepto de poder judicial de los países miembros y además que representa la conciencia nacional de Centroamérica, reconociéndosele como la depositaria y custodia de los valores que constituyen esa nacionalidad Centroamericana, la motivación lo anuncia del siguiente modo:

«cabe resaltar el contenido del artículo 6 del Estatuto, que lo toma de lo establecido para La Corte de Justicia Centroamericana, o 'Corte de Cartago de 1907', y lo enriquece, al declarar a La Corte Centroamericana de Justicia, como representante

${ }^{91}$ Considerando (II) en Sentencia de la CCJ de 29 de marzo de 2005, Poder Ejecutivo de Nicaragua c. Asamblea Nacional de Nicaragua, expediente 69-01-03-01-2005. 
de la conciencia nacional de Centroamérica y depositaria de los valores que integran la nacionalidad centroamericana, incorporando así a las nuevas reglas de convivencia de Centroamérica el aporte axiológico que deberá informar a las futuras generaciones de la nuestra Patria Centroamericana ${ }^{92}$.

Mientras que la primera parte del artículo 6 del Estatuto de la CCJ concreta el impulso de las Motivaciones de la siguiente forma «La Corte representa la conciencia nacional de Centroamérica y se considera, además, depositaria y custodia de los valores que constituyen la nacionalidad centroamericana».

El mencionado Estatuto de la CCJ es del año 1992, por el cual se ordenó a las Cortes Supremas de Justicia de cada uno de los Estados miembros que seleccionaran dos representantes cada una de éstas, para integrar el nuevo tribunal del grupo. La CCJ inició sus funciones en el año 1994 y se asentó con sede permanente en la ciudad de Managua ${ }^{93}$.

Desde entonces la CCJ se ha ido adecuando a la realidad Centroamericana y a sus necesidades de una justicia más moderna. Así fue que después de sus primeros 20 años de existencia, llegado el mes de diciembre del año 2014 se entrega la nueva Ordenanza de Procedimientos ante la CCJ, en línea con la profundización de los efectos del avance tecnológico digital, requerimientos de velocidad en las tramitaciones y destacando sobre todo el rol central de la persona humana quien goza de un amplio ius standi ante esta Corte $^{94}$ — temática que abordaremos en el capítulo II.

En general, sus múltiples competencias giran por garantizar el respeto del derecho en la interpretación y ejecución de la norma originaria y de los instrumentos complementarios, más los actos derivados propios de este proceso integrador ${ }^{95}$. En la historia del SICA, la

92 Párrafo final del apartado Conclusiones de la Exposición de Motivos del Estatuto de la Corte Centroamericana de Justicia.

${ }^{93}$ ARAYA, 1992. AGUILERA, 2016. RIPLEY, 2018. Y en Portal oficial de la CCJ <http://portal.ccj.org.ni> [última consulta, febrero 21, 2019].

${ }^{94}$ La Presentación del presidente de la CCJ de estas nuevas Ordenanzas señalan con toda claridad estos objetivos, indicando «En el mundo globalizado en que vivimos, en donde las relaciones comerciales regionales e intrarregionales se insertan en grandes bloques económicos y proliferan los Tratados Bilaterales y Multilaterales suscritos por los Estados Miembros del SICA, los Acuerdos de Asociación entre región y región y, la persona natural y jurídica es sujeto primordial del desarrollo humano, político, económico y social, gozando del derecho del IUS STANDI ante la CCJ, es indispensable modernizar y actualizar la normativa procesal comunitaria a los avances y nuevas realidades de la Justicia». ORDENANZA DE PROCEDIMIENTOS ANTE LA CCJ (2014). Presentación, párrafo $4^{\circ}$. Disponible en Portal oficial de la CCJ $<$ http://portal.ccj.org.ni/ccj/wp-content/uploads/Ordenanza-de-Procedimientos-Corte-Centroamericana-deJusticia-2.pdf> [última consulta, abril 21, 2019].

${ }^{95} \mathrm{La}$ CCJ presenta una particular extensión en sus competencias, atributo que ha sido puesto de relieve de manera preponderante por la doctrina. Nosotros colegimos que esta Corte goza de una competencia casi en carácter de multi-materia, tal como lo veremos en el capítulo II referido el análisis estatutario de las Cortes 72 
Corte Centroamericana de Justicia ha jugado un rol importantísimo ${ }^{96}$, ha ordenado los Estatutos de la región para el mejor logro de los objetivos de la zona y ha contribuido de forma rigurosa al avance del proyecto centroamericano en su globalidad. Todas las anteriores materias las trataremos oportunamente en los próximos capítulos referidos al análisis jurisprudencial y al diálogo judicial.

americanas. ULATE habla de una competencia genérica, exclusiva y excluyente, explicando, además, que esta alta densidad de potestades ha sido la causa de una clasificación doctrinal. En este punto, cita a CHAMORRO, quien diferencia entre competencia internacional, competencia de integración, competencia consultiva, competencia constitucional y competencia arbitral. Aunque ULATE establece tres criterios de clasificación: a) una competencia material, donde ubica a las de integración, internacional, administrativa y constitucional, b) una competencia funcional jurisdiccional, para las contenciosas, de interpretación, consultiva y arbitral y c) otras competencias. ULATE CHACÓN, E. (2008). El protocolo de tegucigalpa y la jurisdicción de la corte centroamericana de justicia. REIB: Revista electrónica iberoamericana, 2(2), 23-42.

${ }^{96}$ El rol central de esta Corte al interior de SICA es subrayado por la doctrina, por ejemplo CANO destacando su posición orgánica y sus laxas competencias, concluye que la CCJ se concibe, al igual que la Declaración de Panamá de 1992, como un paso fundamental en la realización del anhelo centroamericano de justicia, seguridad jurídica y bien común, que reafirma el proceso de integración, además de establecerse como órgano permanente con amplias competencias, y viene en definitiva a dotar al SICA de la imprescindible seguridad jurídica que todo proceso de este tipo requiere. CANO LINARES, M. A. (2009). La corte centroamericana de justicia: un órgano único con diversidad de competencias. En M. Diez de Velasco Vallejo (prol.), C. R. Fernández Liesa, S. Astete Muñoz, F. González Morales, M. A. Cano Linares, B. Olmos Giupponi ... P. Zapatero Miquel. Tribunales internacionales y espacio iberoamericano ( $1^{\mathrm{a}}$ ed.). Cizur Menor: Thomson Reuters, pp. 111-134 (112, 131 y 134). 


\section{UNA HISTORIA DE CONFLICTOS Y CONCRECIONES:} LA COMUNIDAD ANDINA DE NACIONES

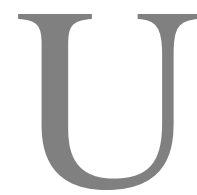

na experiencia de antecedentes bastantes más modernos que los recién vistos para Centroamérica, es la que se desarrolló en el Cono Sur de América, tanto para llegar a estructurar la CAN como el MERCOSUR. En Sudamérica los esfuerzos por desarrollar esquemas modernos de colaboración comienzan sólo a mediados del siglo $\mathrm{XX}^{97}$, en contraste por ejemplo con lo explicado por los historiadores para el istmo centroamericano donde el sentimiento unitario puede rastrearse hasta el Imperio Maya, ni que decir del sentimiento unitario europeo, que como ya anotamos los historiadores lo encontraban desde el mundo griego antiguo en adelante.

Los principales sucesos que forjaron a la CAN ya los fuimos presentando entrelazados en el contexto global de la integración visto líneas atrás, por lo que no repetiremos tales aspectos, sólo retengamos en términos cronológicos que su historia comienza a gestarse en $1960 \mathrm{y}$ culmina en 1969 cuando nace formalmente la Comunidad Andina de Naciones — CAN o CA. De todo lo pertinentemente expuesto en este capítulo respecto de la CAN, es importante asimilar que dicho proyecto se encuentra inmerso dentro del Sistema Andino de Integración (SAI), el cual comprende las estructuras orgánicas de la CAN más otros tantos órganos e instituciones, aflorando un complejo esquema orgánico ${ }^{98}$ que anclan a la CAN a las decisiones de los Estados miembros, toda vez que la encuadra dentro de un perfil intergubernamental. Dicha solución orgánica, que mantiene conectada a la CAN con el SAI, ha sido bastante criticada y se ha abogado por la desconexión total, para así poder

\footnotetext{
${ }^{97}$ Los proyectos del Cono Sur de América son recientes en comparación al referente europeo. Dicha época histórica es remarcada por GAMBOA SERAZZI quien destaca lo nuevo del fenómeno americano, subrayando que fue sólo a mediados del siglo XX que las naciones latinoamericanas emprendieron esquemas de integración de sus economías, sin que llegasen al umbral comunitario, sin embargo al poco andar, se obtuvieron únicamente frutos mínimos de este primer esfuerzo. Para GAMBOA, Bolivia, Colombia, Chile, Ecuador, Perú y Venezuela serían parte de un patrón de integración especial. GAMBOA SERAZZI, F. (2002). Tratado de derecho internacional público. Santiago, Chile: Lexis Nexis, p. 662.

${ }^{98}$ El SAI articula los órganos de la CAN más otros creados en el marco de la integración subregional andina, con lo que permite una coordinación efectiva entre todos estos, profundizando la integración andina y promoviendo su proyección externa, a la vez de robustecer las acciones relacionadas con el proceso integracionista. Véase una presentación del SAI en el Portal oficial de la CAN. Disponible en <http://www.comunidadandina.org/Seccion.aspx?id=4\&tipo=SA\&title=sistema-andino-de-integracion-sai> [última consulta, febrero 22, 2019]. Para un análisis exhaustivo del proceso de creación y de la institucionalidad de la CAN vid. QUINDIMIL, 2006, pp. 49-322.
} 


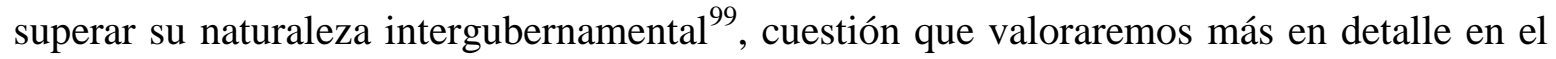
último capítulo de esta tesis.

Dentro de la realidad cotidiana debemos tener presente que el derrotero global de la CAN se encuentra plagado de conflictos y crisis permanentes, cuestión que se asume como un problema de tipo endémico, circunstancia que en la actualidad muestra a la CAN como una organización muy debilitada. Estas situaciones de profundo análisis y sus posibles proyecciones de futuro las abordaremos con propiedad en el capítulo $\mathrm{V}$ de esta tesis, ya que por la presente sección únicamente estamos presentando los antecedentes y contexto histórico de los esquemas de integración latinoamericanos, toda vez que éstos son el solar donde se desarrollan nuestros objetos de estudio, sus Cortes.

\section{LA TARDÍA APARICIÓN DE LA CORTE DEL PROYECTO ANDINO: El TRIBUNAL DE JUSTICIA DE LA COMUNIDAd ANDINA}

Al forjarse la CAN en 1969, se pensó en incorporarle de inmediato un tribunal, máxime en circunstancias que ya estaba a la vista la experiencia europea con el TJUE desde el año 1951, modelo que claramente estaba siendo importado parcialmente a Latino América, sin embargo no se creyó necesario bajo la clásica línea latinoamericana de desarrollos incompletos, aunque sí quedó proyectada la posibilidad, inclusive más tarde se estudió la necesidad de incorporar una Corte sin que prosperase la idea.

En los albores de la CAN sólo se disponía de un muy débil mecanismo de solución de controversias basado en negociaciones, buenos oficios, mediación y conciliación, es decir, prácticamente apoyado en herramientas diplomáticas típicas, lo que evidentemente era una carencia institucional de proporciones ${ }^{100}$, toda vez que a esa altura del desarrollo ya había

\footnotetext{
${ }^{99}$ La desconexión del SAI sería un avance en la CAN. Para BLANCO la crisis de la CAN es política y la presencia del SAI es clave, expresando «sumándose a todo, la concentración de poder en los órganos intergubernamentales del SAI $v / s$ la reducción de funciones y autonomía de los órganos comunitarios como el Parlamento Andino y el TJCA». BLANCO ALVARADO, C. (2014). La crisis de la comunidad andina. Revista de derecho universidad del norte. Barranquilla, Colombia, 42, pp. 1-32. Disponible en <http://www.scielo.org.co/pdf/dere/n42/n42a02.pdf > [última consulta, noviembre 23, 2019].

${ }^{100} \mathrm{La}$ doctrina plantea que la CAN venía con lo que han denominado un pecado original. ZELADA al estudiar los orígenes de la orgánica de este proyecto, advierte la debilidad institucional al no contener a una Corte Internacional entre sus órganos, señalando al respecto: el proceso de integración económica entre los países del Grupo Andino, por consiguiente, nació con una visible deficiencia en su ordenamiento jurídico y en su sistema institucional. ZELADA CASTEDO, A. (1985). Las posibles enmiendas al acuerdo de Cartagena. En Integración latinoamericana. 10(106), INTAL, Buenos Aires, p. 126. Por su parte VIGIL
} 
claridad respecto de la trascendencia de que las OI contasen con órganos jurisdiccionales $^{101}$.

Lo que sucedía era que no se presentaba una gran cantidad de conflictos en la génesis misma de la CAN, sino que estos comenzaron paulatinamente a aumentar y sin darse cuenta llegaron a conformar una masa crítica de conflictividad que amenazaba con la desaparición de la organización. Recién en el año 1978 — casi una década después del nacimiento de la CAN - fue que en Colombia, los Estados miembros de la CAN reconocieron la carencia y declararon la imperiosa necesidad de contar con un tribunal del grupo. Pero otra crisis azotó a la CAN en 1980 la cual produjo la sustitución de la ALALC por la Asociación Latinoamericana de Integración (ALADI) con el fin de establecer — a largo plazo - un mercado común latinoamericano que aprovechara al máximo los factores de producción, asegurara condiciones equitativas de competencia y otros más.

Tal modificación no afectó en lo sustancial ni a la CAN, ni a su necesidad por contar con un órgano jurisdiccional. Como vemos fue el contexto de las problemáticas permanentes del proyecto andino de integración, el que obliga que la Corte nazca, como resultado de una crisis $^{102}$ interna de la CAN. Llegado 1983 - catorce años después del nacimiento de la CAN_- entró en vigor el Tratado de Creación del Tribunal de Justicia del Acuerdo de

destaca que el acuerdo nació cojo, al no haberse establecido, desde el mismo momento en que renacía ese embrión de la integración subregional, un garante de legalidad. VIGIL TOLEDO, R. (2011). La estructura jurídica y el futuro de la comunidad andina ( $1^{\mathrm{a}} \mathrm{ed}$.). Madrid: Civitas Thomson Reuters, p. 39.

${ }^{101}$ Es una constante en la doctrina el vincular la existencia de un tribunal, ya sea internacional o de integración en su caso con una sólida permanencia de una organización internacional y/o de integración. En cuanto al campo integracionista vid. et al. ZELADA 1985 y VIGIL 2011, ibídem. En términos amplios sobre las OI en general REUTER al referirse a los límites funcionales o desviación de poder de las OI, explica que la competencia de ellas está determinada por la función o fines que persigan, cuestión esencial de todo acto, especialmente en las organizaciones y en las cartas que lo declaran expresamente, sin embargo - acota para nuestro interés aquí-, «si una tal concepción no ha sido admitida por todos, y ha sido discutida, ella supone en todo caso para ser eficaz un control judicial muy fuerte». Es decir, da por descontada la existencia del tribunal internacional — que es justo nuestro punto aquí- donde presiona es en que su control sea de alta magnitud. REUTER, P. \& PUENTE EGIDO, J. (1978). Derecho internacional público. Barcelona: Bosch. p. 206.

${ }^{102}$ Abordando esta temática QUINDIMIL recuerda que la Junta del Acuerdo de Cartagena (JUNAC) en su Informe del año 1972 sobre el Establecimiento de un Órgano Jurisdiccional del Acuerdo de Cartagena, sostenía que aún no había una masa considerable de conflictos. Pero más tarde, recuerda el autor, se aumentarían peligrosamente, materializándose una crisis de conflictos de tal magnitud, que aceleró el nacimiento de la Corte. De tal modo — subraya QUINDIMIL - el proceso de existencia de un tribunal comunitario cruzaba el umbral de ser un estado de necesidad, conmutando, por un estado de urgencia. Destaca además el autor, que el conjunto de problemáticas, situaciones de incumplimientos, y ya, en especial, el retiro de Chile en 1976 daban cuenta de una crisis que seguramente sirvió de acicate para el proceso de creación del Tribunal. QUINDIMIL LÓPEZ, J. A. (2006). Instituciones y derecho de la comunidad andina. Valencia: Tirant lo Blanch, pp. 328-330, 334 y 338. 
Cartagena, naciendo el Tribunal de Justicia del Acuerdo de Cartagena (TJAC). En el año 1984 se dictaría su Reglamento. Más tarde el Protocolo de Cochabamba del año 1996 (vigente 1999) le cambió su nombre por el actual, Tribunal de Justicia de la Comunidad Andina - TJCA - , conocido simplemente como Tribunal Andino o Corte andina. Su sede se encuentra en la ciudad de Quito ${ }^{103}$.

Así fue entonces que la Corte andina nació des-sincronizada del desarrollo institucional de su organización de pertenencia. Aunque fácticamente, vino a bajarle la gravedad a la seria problemática que en ese momento amenazaba a todo el proyecto. En cuanto a sus competencias, si bien las analizaremos en el capítulo II, es relevante adelantar desde ya que se presentan seis situaciones, la acción de nulidad, la acción de incumplimiento, la acción de interpretación prejudicial, el recurso por omisión o inactividad, el ejercicio de la función arbitral y la acción laboral ${ }^{104}$.

${ }^{103}$ La integración del TJCA se resuelve en razón de un juez por cada Estado miembro, lo que obliga a una singular solución, pues como en este caso son cuatro, se produce una complejidad al dirimir, por lo que se ha optado por invitar a un juez de un país miembro asociado a integrar el Tribunal Andino. Esta solución operativa de integración se basa en que el Tratado no distingue — para el caso de investir a un magistradoentre países miembros o países asociados. Los jueces deben gozar de una alta consideración moral y reunir en sus países las condiciones para asumir las más altas funciones judiciales o ser jurisconsultos destacados. Exigencia que es casi una copia textual de la norma del TFUE, con la diferencia en que aquí —en el TJCA— no es conjunta la exigencia de ser un jurisconsulto de notoria competencia con las otras (gozar de una alta consideración moral y reunir en sus países las condiciones para asumir las más altas funciones judiciales). El presidente del TJCA es un primus inter pares. La Corte cuenta con un secretario, y abogados generales. Vid. TRATADO DE CREACIÓN DEL TRIBUNAL DE JUSTICIA DE LA COMUNIDAD ANDINA refundido con su PROTOCOLO MODIFICATORIO DE COCHABAMBA de 28 de mayo de 1996. Disponibles en el Portal oficial del Tribunal de Justicia de la Comunidad Andina - TJCA <http://www.tribunalandino.org.ec> [última consulta, febrero 8, 2019].

${ }^{104}$ En los próximos capítulos veremos con propiedad estas competencias, pero en términos introductorios ellas básicamente se refieren a: i) La acción de nulidad: basada en el principio de la tutela y el control de legalidad, mediante ella se ejerce el control de los actos comunitarios, sancionando con ineficacia las decisiones, resoluciones y convenios contrarios al ordenamiento comunitario. ii) La acción de incumplimiento: se vincula con la amplitud de legitimación activa de los demandantes, comprendiendo a las personas físicas o naturales y a las jurídicas. iii) La acción de interpretación prejudicial: copiada de la estructura de la UE, permite desplegar el principio de cooperación entre los jueces comunitarios y los nacionales. iv) El recurso por omisión o inactividad: está previsto para compeler al Consejo Andino de Cancilleres, a la Comisión, o a la Secretaría General, cuando incumplan una actividad a la que están obligados. v) La función arbitral: se emplea para dirimir causas por relaciones contractuales o convenios en determinados casos especiales, y vi) La acción laboral: Es la que en la UE, desarrollaba el TFPUE como tribunal especial, y que actualmente asume el TGUE. VIGIL TOLEDO, 2011, pp. 63-151. QUINDIMIL LÓPEZ, 2006, pp. 323-424. 


\section{UNA HISTORIA DE INTEGRACIÓN AL SUR DEL MUNDO CON VISTA al AtLÁntico deSde el Amazonas a la Patagonia: EL MERCADO COMÚN DEL SUR MERCOSUR}

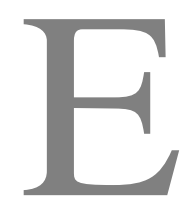

1 MERCOSUR es el más reciente de los tres esquemas latinoamericanos, aposentado en el Cono Sur de América abarca extensos territorios. Se gesta al alero de la ya mencionada ALADI. En tal entorno fue que a partir del año 1985 surgirían varios acercamientos bilaterales entre las dos más extensas naciones de Sudamérica, Brasil y Argentina con el propósito de acelerar el proceso de integración entre estos dos países, desembocando en la firma del Acta de Buenos Aires (1990) ${ }^{105}$ enarbolando objetivos integracionistas y de cooperación bilateral, decidiéndose establecer un mercado común.

Para lo anterior se conformó un grupo de trabajo binacional, el cual procedió a organizar y celebrar reuniones del Grupo Mercado Común Binacional. La primera de tales reuniones se celebró, lógicamente, con representantes de Argentina y Brasil. Pero en la segunda y en tercera reunión se les unieron Paraguay y Uruguay en carácter de observadores, quienes mostraron un gran interés en participar del proceso de integración que se estaba gestando. Este interés produjo la preparación de un acuerdo cuatripartito ${ }^{106}$.

${ }^{105}$ El Acta de Buenos Aires fue suscrita el 6 de julio de 1990 por los presidentes Carlos Menem, de Argentina, y Fernando Collor de Melo de Brasil. Este documento es producto del fortalecimiento de los lazos diplomáticos de dichas naciones $\mathrm{y}$, viene a cerrar un ciclo de diversos acercamientos bilaterales previos. Mediante esta Acta se anticipaba para fines del año 1994 el plazo para la formación de una unión aduanera, el cual previamente mediante el Tratado de Integración, Cooperación y Desarrollo de 1988 se había fijado en 10 años. Pueden revisarse estos y otros antecedentes históricos en GUERRA, S. (2013). MERCOSUL: Do ideal bolivariano para a realidade atual (e quem sabe futura?). Revista da secretaria do tribunal permanente de revisão, 1(1), 275-293. Una copia del texto histórico del TRATADO DE INTEGRACIÓN, COOPERACIÓN Y DESARROLLO de 1988 está alojado en el Portal oficial de la Embajada de Argentina en Brasil. Disponible en <http://www.argentina-brasil.com/wp-content/themes/embajada/documentos/acta_1988.pdf> [última consulta, febrero 6, 2019].

${ }^{106}$ La expansión del interés del vecindario por participar del proyecto, lo recuerda DREYZIN DE KLOR quien relata la incorporación de las dos naciones menores al proyecto mercosureño. DREYZIN DE KLOR, A. (1999). La dinámica institucional del mercosur. En J. Irigoin Barrenne (coord.), E. Rey Caro (present.), J. M. Insulza Salinas (disc.), R. Barros Charlín, C. F. Molina del Pozo, L. Narbone, ... G. Holzmann, Chile y el mercosur en américa latina: VI encuentro internacional de derecho de américa del sur (1999). Tomo I. Santiago, Chile: Universidad de Chile. Facultad de Derecho (Eds.), Editorial Jurídica de Chile, pp. 203-236. 
Por tal motivo, como ya indicamos se arribó en 1991 al Tratado para la Constitución del MERCOSUR, mercado común que debería estar establecido para 1994, más un Sistema de Solución de Controversias Mercosur (SSCM). Sus objetivos se referían a ampliar los mercados nacionales, acelerar el desarrollo económico, la búsqueda de una justicia social con el aprovechamiento de todos los recursos y la conservación del medioambiente, entre otros. Puntualmente, cumplido el plazo, suscribieron el Protocolo de Ouro Prieto (1994) ${ }^{107}$, dándole personalidad jurídica internacional al MERCOSUR y dotándolo de una estructura institucional.

Fue muy trascendente el Protocolo de Ouro Prieto toda vez que definió la naturaleza intergubernamental de los órganos del MERCOSUR, cuestión relevante porque implicaba en aquel momento que, desde lo técnico-jurídico, no estábamos de modo estricto ante un Derecho Comunitario o modernamente denominado Derecho de la Integración ${ }^{108}$, lo que se debe a que sus normas son producto de Tratados Internacionales. De lo que resulta que el MERCOSUR habría sido gestado solo como una OI intergubernamental, pero con personalidad jurídica internacional diferente a la de los Estados partes, cuyas decisiones no se impondrían de forma inmediata o directa ${ }^{109}$.

Pero luego del carácter asumido en su génesis, la historia recorrida por el proyecto mercosureño daría cuenta de un singular itinerario de progreso. Destacándose diversos

\footnotetext{
${ }^{107}$ Los instrumentos fundantes de Mercosur, el Tratado para la Constitución del Mercado Común del Sur, sus Protocolos adicionales de Ouro Preto, de Ushuaia, de Olivos sobre la Solución de Controversias, el Constitutivo del Parlamento Mercosur, y otros, se encuentran en el Portal oficial de MERCOSUR. Disponibles en <https://www.mercosur.int/documentos-y-normativa/textos-fundacionales/> [última consulta, febrero 22, 2019].

${ }^{108}$ Recordemos que - tal como ya precisamos y justificamos en nuestro marco teórico- estamos empleando un concepto amplio para «Derecho de la Integración», y acotado para Derecho de la UE, Derecho del SICA o derecho centroamericano, Derecho de la CAN o derecho andino, y Derecho del MERCOSUR o derecho mercosureño, en cada caso.

${ }^{109}$ Toda la doctrina identifica del mismo modo a la naturaleza jurídica con la cual nace el MERCOSUR, de claro sustrato intergubernamental, circunstancia que incluso se emplea para explicar sus lentos avances en algunas épocas. ARBUET-VIGNALI, H. (1999). El protocolo de ouro preto sus problemas y evolución. En Irigoin Barrenne, J. (coord.), Rey Caro, E. (present.), Insulza Salinas, J. M. (disc.), Barros Charlín, R., Molina del Pozo, C. F., Narbone, L., ... Holzmann G., Chile y el mercosur en américa latina: VI encuentro internacional de derecho de américa del sur (1999). Tomo I. Santiago, Chile: Universidad de Chile. Facultad de Derecho (Eds.), Editorial Jurídica de Chile, pp. 131-160. Misma conclusión en GROS ESPIELL, H., DELPIAZZO, C., ROTONDO F., VÁZQUEZ, C. Y BRITO, M. (1999). El derecho de la integración del mercosur ( $1^{\mathrm{a}}$ ed.). Montevideo: Universidad de Montevideo, Facultad de Derecho, pp. 161-163. También se destaca su naturaleza intergubernamental y de allí la imposibilidad de hablar de Derecho Comunitario, en AMIN FERRAZ, D. \& PICART GARCÍA, S. M. (2005). El arbitraje como forma alternativa de solución de controversias en el mercosur. En V. Bou Franch (coord.), M. Badenes Casino, M. Torres Pérez, C. Quesada Alcalá, L. E. Nores Torres, E. López Terrada, ... S. M. Picart García, Nuevas controversias internacionales y nuevos mecanismos de solución (1 ${ }^{\mathrm{a}}$ ed.) Tirant lo Blanch, pp. 546-549.
} 
hitos, por ejemplo, en el año 2003 se adoptó el Reglamento del Protocolo de Olivos. En el año 2005 continúa su robustecimiento y se crea el Parlamento de Mercosur (PARLASUR). En el año 2006 se produce la primera ampliación adhiriéndose Venezuela, y en el año 2015 la segunda, ingresando Bolivia. A la zaga pasan a participar en calidad de países asociados Chile, Colombia, Perú, Ecuador, Guayana y Surinam. Celebrándose diversos tratados y convenios en las más diversas áreas de interés, incluso en materias de derechos humanos, desbordando los primigenios objetivos del MERCOSUR. Precisamente esta circunstancia de progreso es reconocida y subrayada, con gran acierto, por el TPRM, quien admitió el cambio de nivel del proyecto MERCOSUR en su totalidad, por tal razón ha pasado a desestimar excepciones de incompetencia en materias de derechos fundamentales ${ }^{110}$.

En la actualidad el MERCOSUR se compone del Consejo del Mercado Común (CMC, que es el órgano superior de naturaleza política), el Grupo Mercado Común (GMC, que es el órgano ejecutivo), la Comisión de Comercio, el PARLASUR que es el órgano de representación de los pueblos, independiente y autónomo, el Foro Consultivo Económico y Social, la Secretaría Administrativa y el Tribunal Permanente de Revisión (TPRM). Este tribunal está inserto en el complejo SSCM.

${ }^{110}$ Laudo del TPRM de 21 de julio de 2012, República Oriental del Uruguay, as. 1/2012. En este caso el TPRM generó un avance importante en la comprensión del progreso del MERCOSUR en su totalidad, y las consecuencias que ello generaban. Para lo cual empleó dos aristas relevantes, en primer lugar, razonó sobre su competencia ratione materiae de la siguiente forma «esta jurisdicción se conforma sobre controversias entre los Estados Partes referidas a la interpretación o incumplimiento de la normativa MERCOSUR. No hay, de forma implícita o explícita en el texto del Protocolo de Ouro Preto, exclusión de jurisdicción con base a la materia objeto de la controversia», y en segundo lugar, el laudo articuló conclusivamente lo siguiente «Desde esta óptica, no se puede hablar de "falta de vocación" del sistema para solucionar controversias más allá de la esfera comercial. La legitimidad del sistema se fundamenta en la contribución a la estabilidad, en la medida en que avanza el proceso de integración, en sus diversas esferas. Esta legitimidad debe ser apreciada conforme al texto acordado en el Protocolo de Ouro Preto por los Estados Parte, el cual no excluye a priori el análisis de cualquier tipo de controversia en el marco normativo del Mercosur». Para MOREIRA haciendo un análisis particular de este Laudo, esta sentencia refleja un reconocimiento expreso de la Corte, explicándolo que la decisión bajo análisis reconoce las diversas esferas que ha desarrollado el Mercosur. MOREIRA, A. C. (2014). Mercosur ambiental. el aporte del laudo 1/2012 del tribunal permanente de revisión. Revista da secretaria do tribunal permanente de revisão, 2(3), 59-75. 


\subsection{LAS ETAPAS DE DESARROLlo del Sistema de SOluCióN de Controversias del Mercosur Se despliegan CONFORME MADURABA EL PROYECTO COMPLETO}

La historia mediante la cual llegó a conformarse el actual esquema del denominado Sistema de Solución de Controversias del Mercosur (SSCM), es bastante compleja y se desarrolla básicamente por el cauce de las siguientes cuatro etapas.

La primera etapa se inicia en marzo del año 1991, a través del Tratado de Asunción que establecía en su Anexo III, únicamente un procedimiento no jurisdiccional. Sin órganos específicos, basado en la negociación para solucionar las controversias entre los Estados partes, y acotado a la interpretación del Tratado de Asunción más los instrumentos que lo completasen.

La segunda etapa aparece en diciembre del mismo año 1991, y ésta vino a cargo del Protocolo de Brasilia para la Solución de Controversias, el cual estableció procedimientos mediante un tímido sistema para la solución de los reclamos de los particulares afectados por medidas de sus Estados que violasen el centro normativo de MERCOSUR. Se definieron como instrumentos la negociación, la mediación y el arbitraje. Esto último hacía nacer los Tribunales Arbitrales ad hoc Mercosur (TAAM), Cortes de carácter no permanentes. El avance fue entonces hasta el nivel arbitral.

La tercera etapa viene marcada por el Protocolo de Ouro Preto del año 1994 (vigente desde diciembre de 1995). Este nuevo cuerpo normativo se limitó a identificar y tipificar con mayor precisión más materias susceptibles de ser sometidas al modelo arbitral. Por ejemplo estableció, algunas reclamaciones para ante la Comisión de Comercio, cuya tramitación se detalló en el único anexo del Protocolo y ratificó el procedimiento por el cual, si no era alcanzada la solución por medio de la negociación, se pasaba a la fase de mediación ante el GMC, de la que podría surgir una recomendación al Estado miembro, la que de no ser acatada, se podía recurrir a un TAAM ${ }^{111}$.

La cuarta etapa se inicia con el Protocolo de Olivos para la Solución de Controversias del año 2002 (vigor 2004). Este ha sido el último avance contundente del esquema mercosureño, en lo referido a potenciar el SSCM. Este Protocolo en lo medular trajo dos

\footnotetext{
${ }^{111}$ Pueden verse estas primeras tres etapas en ARBUET-VIGNALI, 1999, pp. 153-156. Compleméntese con
} AMIN FERRAZ \& PICART GARCÍA, 2005, pp. 562-565. 
novedades de trascendencia, por una parte, vino a establecer dos niveles arbitrales, sumándole a los ya creados TAAM, un tribunal superior jerárquico, el TPRM, y por otra parte, incorporó una muy criticada posibilidad, la denominada opción de foro ${ }^{112}$, mediante la cual se puede llevar el conflicto al sistema foráneo del Órgano de Solución de Diferencias (OSD) de la OMC u otro. A la vez, dejó de ser obligatorio el procedimiento ante el GMC para los Estados miembros ${ }^{113}$.

La crítica a la opción de foro es objetivamente fundada, pues esto pudiese implicar que el tribunal necesite interpretar normativa central del MERCOSUR para disolver el conflicto, sin embargo, en tal caso se estaría ingresando a la sensible función interpretativa de las Cartas constitutivas de la organización, cuestión que por ejemplo está prohibido expresamente en la UE según lo dispuesto en el artículo 344 del TFUE. Pero en el MERCOSUR el Protocolo de Olivos, respecto de la aplicación de la función interpretativa, omitió otorgarle a los TAAM y al TPRM competencias para tal función, por lo que estas Cortes lo han debido resolver de modo tangencial — según analizaremos.

Por último y con el único interés de dejar bien acotado los acontecimientos, precisemos que en diciembre del año 2003 mediante Resolución 54/03 del GMC se creaba el Tribunal Administrativo Laboral del Mercosur, lo que si bien es una expansión netamente administrativa, refleja un robustecimiento del entramado del merco-sistema.

\footnotetext{
${ }^{112}$ El denominado derecho de opción de foro se basa tanto en el principio de la autonomía de la voluntad, como en el principio de la especialización. Por los cuales se busca acceder a la sede más especializada posible, para de ese modo lograr el mejor desenlace de la controversia. Quedó regulado en el artículo 1.2 del Protocolo de Olivos, por el cual, el actor — cuando sea un Estado miembro- podría llevar el litigio ante el OSD de la OMC, o bien, ante otros esquemas preferenciales de comercio, del que sean parte ambos Estados en conflicto. La opción de foro, ha recibido las más duras críticas, que acusan lo inapropiado de salirse de un sistema que tanto esfuerzo ha costado crear. Para SILGUERO la opción de foro es completamente ajeno a los sistemas de integración, sino más bien pertenece a esquemas arancelarios o de libre comercio claramente de menor nivel que los clasificados como procesos de integración, por tal razón la existencia de la opción de foro afecta negativamente al Mercosur. SILGUERO, R. F. (2013). Los objetivos del mercosur y la opción de foro. Revista da secretaria do tribunal permanente de revisão, 1(1), 229-257.

113 Esta cuarta etapa y el inicial carácter transitorio del Protocolo de Olivos, puede verse en FABBRICATORE, A. (2011). Los tribunales arbitrales ad-hoc en el mercosur. En C. F. Molina del Pozo y C. Pizzolo, La administración de justicia en la unión europea y el mercosur : un análisis para su fortalecimiento $\left(1^{\text {a }}\right.$ ed.). Buenos Aires: Eudeba, pp. 19-22. Un análisis del sistema de solución de controversias de Mercosur hasta el año 2009 puede revisarse en OLMOS GIUPPONI, B. (2009). El sistema de solución de controversias de mercosur. Análisis de la situación actual y propuestas para el futuro. En M. Diez de Velasco Vallejo (prol.), C. R. Fernández Liesa, S. Astete Muñoz, F. González Morales, M. A. Cano Linares, B. Olmos Giupponi ... P. Zapatero Miquel, Tribunales internacionales y espacio iberoamericano (1 ${ }^{\mathrm{a}}$ ed.). Cizur Menor: Thomson Reuters, pp. 135-152.
} 


\subsection{UNA CORTE SUPERIOR JERÁRQUICA Y DE DERECHO ESTRICTO \\ QUE CONTINÚA SIENDO DE SUSTRATO ARBITRAL:}

EL TRIBUNAL PERMANENTE DE REVISIÓN

TPRM

Como recién acotamos, fue en la cuarta etapa de desarrollo que el Protocolo de Olivos incorporó al TPRM, pero manteniendo la naturaleza arbitral del sistema. Es extraño que le haya añadido el apelativo de permanente, en circunstancias que aquello no es así, pues sólo se reúne si se le convoca para un caso concreto, por tal razón es que en términos procesales estrictos esta es una Corte de convocatoria permanente.

Este modelo de tribunal inauguró su primera sede en el año 2004 en la ciudad de Asunción. Convirtiéndose en el órgano jurisdiccional supremo en materia de interpretación y aplicación del Derecho del Mercosur. Siendo su objeto el garantizar la correcta interpretación, aplicación y cumplimiento de los instrumentos fundamentales de este proceso de integración.

Históricamente el desarrollo del mentado sistema jerárquico de los tribunales en el MERCOSUR es trascendente, pues si bien está aposentado en un umbral arbitral, esto no se articula desde los patrones típicos de dicha solución orgánico-procesal. Así entonces por diversas particularidades que se le imprimieron, lo hacen superar con creces los conceptos típicos de los modelos de arbitraje internacional ${ }^{114}$ existentes hasta ese momento.

Tales singularidades, si bien las abordaremos en los capítulos siguientes, históricamente aquí las precisamos en términos iniciales, subrayando que estas sólo se explican en plenitud al entender claramente tres áreas, en primer lugar, los aspectos orgánicos del TPRM —y del SSCM en general-, en segundo lugar, el tipo de competencias del TPRM, y en tercer lugar, la compleja red de opciones que poseen los legitimados para ingresar al SSCM.

\footnotetext{
${ }^{114} \mathrm{Si}$ bien el sistema de tribunales en el Mercosur es de naturaleza arbitral, pueden descubrirse propiedades y desarrollos jurídicos muy particulares que lo desplazan a un campo ecléctico. Tal como lo ha destacado la doctrina al señalar que el mecanismo creado entre los TAAM y el TPRM, es un sistema arbitral sui generis. Desde ese ángulo lo ponen de relieve por ejemplo CHEDIAK y BENÍTEZ, recordando la opinión de PUCEIRO RIPOLL, al caracterizar el singular mecanismo de solución de controversias de esta experiencia subregional. CHEDIAK GONZÁLEZ, J. \& BENÍTEZ RODRÍGUEZ, P. (2014). Acerca de la competencia consultiva del tribunal permanente de revisión mercosur y de la experiencia del poder judicial del uruguay en la tramitación de opiniones consultivas, Revista de la secretaría del tribunal permanente de revisión. 2(4), 8391.
} 
Por el primer aspecto, el TPRM es integrado por cinco jueces, uno por cada Estado miembro y el quinto es nombrado de común acuerdo por los países partes, pero ante falta de acuerdo se sigue a un sorteo de su nombre desde el listado oficial de árbitros. Podemos apreciar en este modelo que aquí, la paridad de magistrados se resuelve de modo diferente a la CAN ya que para el caso del TJCA se soluciona invitando a un juez de un país miembro asociado.

En el modelo MERCOSUR los Estados miembros poseen derecho al denominado acceso per saltum, mediante el cual pueden accionar directamente ante el TPRM sin la necesidad de tener que pasar por la primera sede —el TAAM. Para este acceso per saltum debe mediar consenso de las partes, o bien, tratarse de una acción de urgencia. El laudo del TPRM es de carácter obligatorio, tiene fuerza de res iudicata, es inapelable e irrevisable, aunque aclarable ${ }^{115}$. Volveremos con toda precisión sobre el respeto a la cosa juzgada y el imperium en los modelos bajo análisis, en el capítulo II.

Por el segundo aspecto, ahora referido a sus competencias, éstas guardan relación con la interpretación, aplicación o incumplimiento del ordenamiento jurídico del MERCOSUR. Pudiendo el TPRM, actuar en única instancia, o bien en sede revisora mediante el recurso de revisión. En éste último caso, la impugnación debe fundamentarse exclusivamente en causales de derecho, por tal razón no proceden recursos de revisión contra laudos de los TAAM dictados ex aequo et bono ${ }^{116}$ según analizaremos más en detalle en el capítulo II.

Además posee competencia para decretar providencias precautorias en casos excepcionales y urgentes. Y si bien puede entender en solicitudes de opiniones consultivas ${ }^{117}$, este es tal vez el campo más débil de todo lo construido, pues ninguna de las respuestas de esta Corte

\footnotetext{
${ }^{115}$ El artículo 28 del Protocolo de Olivos para la Solución de Controversias en el Mercosur, establece la vía procesal que denominó recurso de aclaratoria. Veremos estos aspectos en el capítulo II referido al análisis estatutario de las Cortes en análisis.

${ }^{116}$ Aunque tal imposibilidad es evidente desde lo procesal estricto, el número 3 del art. 17 del Protocolo de Olivos para la Solución de Controversias en el Mercosur lo precisa expresamente del siguiente modo «Los laudos de los TAAM dictados en base a los principios ex aequo et bono no serán susceptibles del recurso de revisión». Volveremos sobre este aspecto en el capítulo II.

${ }^{117}$ Las opiniones consultivas — que analizaremos en el capítulo II- se las pueden dirigir los Estados miembros, los órganos decisorios de Mercosur, los Tribunales Superiores de Justicia de los Estados partes o el PARLASUR. Para llevar adelante esta competencia consultiva, la Corte actuará en pleno, dándose la excepción de que, en el ejercicio de esta competencia se aceptan votos fundados disidentes y concurrentes. Y con la gran debilidad de que el pronunciamiento del TPRM — en esta materia - no es vinculante. MENSA GONZÁLEZ, A. (2011). La competencia consultiva del tribunal permanente de revisión. En C. F. Molina del Pozo \& C. Pizzolo, La administración de justicia en la unión europea y el mercosur : un análisis para su fortalecimiento ( $1^{\mathrm{a}}$ ed.). Buenos Aires: Eudeba, pp. 35-54. Respecto de la procedencia y efectos de las competencias consultivas del TPRM en CHEDIAK GONZÁLEZ \& BENÍTEZ RODRÍGUEZ, 2014.
} 
son vinculantes. Se suma el hecho de que el TPRM carece de algunas trascendentes competencias propias de todo proceso que pretenda ser integracionista, v.gr. no posee las potestades necesarias para conocer de una acción de nulidad o de inaplicabilidad de una norma nacional, lo que debió ser superado jurisprudencialmente por el TPRM mediante la declaración de la incompatibilidad de la norma interna con el Derecho del Mercosur, cuestión que pasó a conocerse como la apreciación de compatibilidad ${ }^{118}$. Tampoco posee competencia para efectuar un control previo de los acuerdos internacionales que el MERCOSUR vaya a suscribir ${ }^{119}$.

Por último, para acceder a la solución de un conflicto, debemos tener presente que existe una entramada red de opciones y, en ocasiones, aceptar el camino único que se presenta. Jugando en este punto, un rol central, la legitimación activa de que pueda gozar el actor para efectuar la elección correcta, en tal sentido si el actor es un Estado miembro debemos considerar que lo primero es recurrir a la vía diplomática, utilizando el mecanismo de la negociación. Si aquello no prospera, podría ejercer el denominado derecho de opción de foro para llevar el asunto a la OMC o a otro organismo. Ahora bien, si el Estado miembro no utiliza el anterior derecho, y se da inicio al procedimiento de solución de controversias al interior del MERCOSUR, ninguna parte podrá ya recurrir a otra sede. Al interior del sistema mercosureño quedan dos opciones, uno, agotada la negociación, podrá llevar el asunto al GMC, o a la Comisión de Comercio Mercosur (CCM) según corresponda, y dos, si no hay éxito, se abre la posibilidad de la vía arbitral con sus dos niveles, el TAAM y luego el TPRM ${ }^{120}$.

En cambio si el actor fuese un particular, ya sea una persona física o bien jurídica dirigiéndose contra un Estado miembro, debemos tener presente que los particulares solo podrán presentar reclamaciones ante la Sección Nacional del Estado del que sea nacional o del Estado donde tenga su residencia habitual o donde tenga la sede de su negocio.

\footnotetext{
${ }^{118}$ Este tema lo abordaremos con propiedad en el capítulo III.

${ }^{119}$ El desarrollo procesal, competencial y orgánico del TPRM es abordado con profundidad en PEROTTI, A. D. (2008). Tribunal permanente de revisión y estado de derecho en el mercosur. Madrid: Marcial Pons. Otro, DELUCA, S. (2012). Metodología para la selección de árbitros del sistema de controversias del mercosur (ad hoc y TPR). En M. Hernández Ramos (dir.), A. Sáiz Arnáis (dir.), A. Torres Pérez (dir.), M. Zelaia Garagarza (dir.), S. Deluca, O. Saldías, ... R. Bustos, Tribunales en organizaciones de integración: Mercosur, comunidad andina y unión europea ( $1^{\mathrm{a}}$ ed.). Cizur Menor: Thomson Reuters Aranzadi, pp. 33-46.

${ }^{120}$ La acción se presenta ante el TAAM, cada Estado parte en la Secretaría Administrativa del Mercosur propone los árbitros, presentan a sus representantes, e informan de todas las diligencias previas agotadas. El proceso puede tener como sede cualquier ciudad de los Estados miembros. El TAAM adoptará sus laudos por mayoría, sin poder redactar o comunicar disidencias. El laudo se dictará en un plazo de 60 días renovables por 30 más. Contra dicho laudo se podrá solicitar recurso de aclaración al mismo TAAM, y recurso de revisión ante el TPRM en un plazo de 15 días. FABBRICATORE, 2011, pp. 22-33. AMIN FERRAZ \& PICART GARCÍA, 2005, pp. 551-565.
} 
Materialmente el reclamo debe ser formalizado ante la Sección Nacional del GMC, es decir, en la Cancillería respectiva, y en la circunstancia que el demandado sea su propio Estado, al particular únicamente le queda recurrir a sus propios tribunales nacionales ${ }^{121}$.

Pues bien, los aspectos históricos del fenómeno de la integración vistos en este capítulo, en el cual hemos abordado sólo los principales hitos de cada sistema americano y de nuestro referente europeo, son suficientes para comprender el entorno general en que se desarrollan las Cortes latinoamericanas que analizaremos en los siguientes capítulos y que en algunos aspectos cotejaremos con el modelo del TJUE.

${ }^{121}$ El locus standi de los particulares en el merco-sistema es muy restringido, generándose como podemos ver, diversas restricciones y discriminaciones procesales. Sobre estos aspectos volveremos con mayor profundidad en el capítulo II al efectuar los cotejos entre los Estatutos de las Cortes bajo análisis. 


\section{LAS DIFERENTES NATURALEZAS JURÍDICAS ENTRE EL SICA, LA CAN Y EL MERCOSUR VERSUS LA DE LA UNIÓN EUROPEA: MÁS QUE ENORMES CONTRASTES MARCAN SENDEROS DIFERENTES}

AUNQUE NO EXCLUYENTES

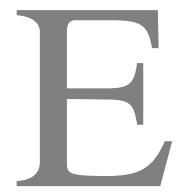

n cada oportunidad en que se estudian las naturalezas jurídicas de las construcciones del derecho, y sobre todo cuando tal labor se complejiza, es habitual que los impulsos iniciales corran por definir lo que no se está enfrentado, ya que dicho análisis negativo tiene la versatilidad de acotar el objeto enfocado, y justamente aquí tenemos uno de aquellos casos. Ninguno de los esquemas que venimos mencionando, ni el SICA, ni la CAN, ni el MERCUSUR, ni menos aún la UE son simples organizaciones internacionales, circunstancias que despejan una sección importante del problema.

La búsqueda de las naturalezas jurídicas de las organizaciones señaladas reporta interés para esta tesis porque la respuesta repercute en la naturaleza del órgano, en este caso el tribunal, el cual es nuestro objeto de estudio. Dicha repercusión se explica en el vínculo de congruencia o correspondencia que hay en la relación organización/órgano, esto es, en la dinámica del órgano al servicio de la organización ${ }^{122}$.

Los modelos extra-UE, concretamente los latinoamericanos, no alcanzan el umbral de supranacionalidad, comprendido como una dimensión desconectada de los poderes nacionales locales, es decir, no se comportan como centros de decisión independientes con la capacidad de imponer su voluntad a las naciones concurrentes, como en la actualidad acontece con la UE, por cierto en un equilibrio único en la historia del derecho.

La singularidad transversal del SICA, de la CAN y del MERCOSUR es que todos estos proyectos, si bien no son organizaciones supranacionales, tampoco pueden ser calificados de organizaciones internacionales clásicas. Con lo anterior tenemos entonces dos conclusiones negativas utilitarias al despeje del campo para intentar identificar una posición

${ }^{122} \mathrm{Si}$ bien volveremos sobre esta correlación en los capítulos siguientes, anunciemos aquí que ésta básicamente se explica en el principio de coherencia orgánica, es decir, que la acción de los órganos tiene como fin el favorecer que la OI alcance sus metas. En menor medida en el nivel nacional es una visión orgánica y administrativa, como por ejemplo el principio de coordinación y el principio de diligencia. En el nivel internacional y aplicado al marco institucional de una OI el principio de coherencia o congruencia orgánica se encuentra positivizado en varios estatutos, vid. notas 5, 6 y 7 del capítulo II. Todo inmerso en la naturaleza de servicio que ya posee la organización internacional. HUICI destaca que la propia creación y existencia de las OI dependen de su naturaleza de servicio. HUICI SANCHO, 2007, p. 37. 
de sus sustratos jurídicos. En tales coordenadas eclécticas advertimos que las tres experiencias latinoamericanas poseen diversas intensidades en la concreción de un modelo de integración propio, siendo esta la cuestión central, pues si no son ni lo uno ni lo otro, entonces cada proyecto latinoamericano dará cuenta de una posición singular de mayor o de menor cercanía con el derecho de la integración comprendido en sentido amplio, circunstancia concreta que afectará a nuestros objetos de estudio — sus tribunales.

Para nosotros fluye de manera idónea al identificar dichos proyectos la noción de organizaciones de integración no plenas, según destaca parte de la doctrina ${ }^{123}$ y también determinadas jurisprudencias, como por ejemplo ha expresado una Corte mercosureña así: «no se entiende que pueda resultar extensiva a normativa derivada de la intervención de órganos de un sistema de integración regional con poderes para la elaboración de reglas comunes, lo cierto es que el ordenamiento jurídico del MERCOSUR (que no hay duda que puede y debe calificarse de tal, por mucho que pueda discutirse su 'plenitud', habida cuenta de que estamos, como se ha descrito, ante un ordenamiento "organizado y estructurado, que posee sus propias fuentes, dotado de órganos y procedimientos aptos para emitirlas, interpretarlas, así como para constatar y sancionar los casos de incumplimiento y las violaciones")»> ${ }^{124}$.

Con tal concepto de organizaciones de integración no plenas, abarcamos un perfil integracionista que indiscutiblemente las tres poseen de un modo singular, pero a la vez denota la particularidad de no agrupar a la totalidad de los contenidos del derecho de la integración comprendido en el sentido amplio que ya hemos explicado, esto es, como una rama del derecho que - para los latinoamericanos - se encuadraría casi perfecto con los desarrollos integracionistas europeos, como modelo ideal con el cual se comparan constantemente y se esfuerzan por lograr. De dicho esfuerzo es que también las comprendemos como «organizaciones internacionales de aspiraciones integracionistas». Por cierto esta es una noción latinoamericana, que a los europeos en nada afecta —ni menos lo meditan - pues el proyecto de la UE no sigue a nadie, sino que construye senderos propios.

Tal ubicación intermedia de los proyectos latinoamericanos es producto de varias causas, entre las cuales hemos podido identificar tres tipos principales, una ya la esbozamos, la de

\footnotetext{
${ }^{123}$ La idea de que no alcanzan un modelo de plena integración sino que más bien son sistemas híbridos de integración en BIACCHI, CARTAWINTER \& BUTTENDORFF (2018). Supranationalem and fundamental rights: the effectivity of the secondary legislation in the andenean community system and community and in the central american integration. Estudios constitucionales, 16(1), 99-128. Vid. nota 20 de la sección Introducción de esta tesis.

${ }^{124}$ Considerando 63 en Laudo del TAAM (número 9) de 4 de abril de 2003, República de Argentina c. República Oriental del Uruguay.

88
} 
índole cultural, en cuanto América Latina no desea en el fondo tanta compenetración entre los Estados partícipes, porque las génesis del SICA, de la CAN y del MERCOSUR no se fundan a partir de un trauma enorme como la II GM, sino que Latinoamérica posee muchos extremos de similitud cultural, religioso, idiomático y jurídico, por lo que en definitiva no se lo ha planteado como indispensable para vivir en paz y progreso, en cierta medida y prima facie les basta con una robusta cooperación. Otra causa es objetiva, esta corre por la imposibilidad concreta de plantearse ideales integracionistas intensos y tener la capacidad de llevarlos a buen puerto, atendida la condición de subdesarrollo de las naciones concurrentes, algunas con más progresos que otras pero en definitiva todas por debajo de un umbral de un país bien desarrollado. Por último, sucede que una vez ya concebidos y avanzados el SICA, la CAN y el MERCOSUR, si bien han llegado a ambicionar salir de la posición intermedia y avanzar, sus historias concretas no se los han permitido.

La naturaleza jurídica actual del SICA recoge un pasado imperial y federal ${ }^{125}$, esto es importante de mantener presente - ya lo acotamos líneas arriba en este capítulo- es decir, que el SICA no asume una función central de agrupación, sino de re-agrupación. El SICA es la respuesta moderna para la unidad del istmo centroamericano y se auto reconoce como un sistema de integración y supranacional, por ejemplo le intenta impregnar este carácter de supranacionalidad a su Corte, al indicarlo así en los Estatutos de la misma:

«Las facultades que se le atribuyan con carácter excluyente, son jurisdiccionales. Se crea así un Órgano 'Supranacional' que permitirá resolver los problemas propios del "Sistema de la Integración Centroamericana" en forma pacífica y civilizada»"

Se suma a lo anterior el hecho de que el Protocolo de Tegucigalpa al enfocarse en la naturaleza del proyecto del SICA, precisamente en el capítulo inaugural titulado «Naturaleza, propósitos, principios y fines» expresa nítido:

«El Sistema de la Integración Centroamericana tiene por objetivo fundamental la realización de la integración de Centroamérica, para constituirla como Región de Paz, Libertad, Democracia y Desarrollo» ${ }^{127}$.

A lo anterior se añade, tal como veremos más adelante, que la jurisprudencia de la CCJ va recalcando esta naturaleza, aunque todo gira en carácter de circunstancia legislativa, más que en una realidad empírica. Es decir, es un hecho que en la práctica el SICA no alcanza a poseer un sustrato verdaderamente supranacional. Sin embargo lo trascendente de todo, es

\footnotetext{
${ }^{125}$ Después del Imperio Maya y de la Capitanía General de Guatemala del Imperio Español, pasó a conformar el proyecto federal llamado Federación Provincias Unidas Centroamericanas de 1823.

${ }^{126}$ Párrafo tercero de las Conclusiones de la Motivaciones del Estatuto de la CCJ.

127 Art. 3 del Protocolo de Tegucigalpa a la Carta de la ODECA - 1992.
} 
que sí tiene las aspiraciones de lograrlo, por tales motivos decimos que es de aspiraciones integracionistas.

La CAN por su parte no puede zafar del SIA, el cual la ancla a un esquema intergubernamental, tal como ya lo $\operatorname{acotamos}^{128}$, sus constantes crisis tampoco le han permitido llevar adelante las reestructuraciones que serían necesarias para una mayor cercanía hacia la supranacionalidad, cuestión que observamos muy complejo según analizaremos apropiadamente en el capítulo $\mathrm{V}$ al proyectar el futuro de la CAN.

La naturaleza jurídica del MERCOSUR ha ido variando conforme ha madurado el proyecto completo, pues iniciado como un esquema de meros perfiles comerciales en la actualidad el espectro de cobertura es enorme respecto de su génesis. Históricamente fue el Protocolo de Ouro Prieto de 1994 el que le dio personalidad jurídica internacional al MERCOSUR, lo dotó de una estructura institucional y definió la naturaleza intergubernamental de sus órganos. Sin embargo aquello es pasado, pues hoy ya 26 años después, se constata cada vez más el recorrido de avance hacia una zona de mayor integración, y por ende, si continúa así, podría robustecerse mucho más aún, de hecho hay jurisprudencia de sus tribunales que reconocen este notable avance poniendo de relieve la ampliación del MERCOSUR en sus diversas esferas, así por ejemplo el TPRM ha expresado:

«Desde esta óptica, no se puede hablar de "falta de vocación" del sistema para solucionar controversias más allá de la esfera comercial. La legitimidad del sistema se fundamenta en la contribución a la estabilidad, en la medida en que avanza el proceso de integración, en sus diversas esferas. Esta legitimidad debe ser apreciada conforme al texto acordado en el Protocolo de Ouro Preto por los Estados Parte, el cual no excluye a priori el análisis de cualquier tipo de controversia en el marco normativo del Mercosur» ${ }^{129}$.

Lo cierto es que el MERCOSUR está ubicado más lejos que el SICA y la CAN de un umbral de supranacionalidad, quedándole mucho camino aun por recorrer. Pero en contraposición es el que más ha mutado y avanzado, el hecho es que partió desde muy atrás respecto de la línea de una integración global, como hemos recalcado ni siquiera se lo propuso, a diferencia del SICA y la CAN que se intentaron proyectar hacia esa zona desde el primer momento, es decir, las voluntades iniciales difieren.

En definitiva y si bien todos toman senderos — que aun pareciéndose - son concretamente diferentes, en ningún caso esta circunstancia los convierte en modelos excluyentes. Por el

\footnotetext{
${ }^{128}$ Vid. notas 98 y 99 de este capítulo. QUINDIMIL, 2006. BLANCO, 2014.

${ }^{129}$ Considerando 37, en Laudo del TPRM de 21 de julio de 2012, República Oriental del Uruguay, as. $1 / 2012$. 
contrario, nos parece perfecto apostar por mecanismos de integración sub-regionales que se nutran de antecedentes comunes, de sentimientos unitarios basados en las historias de vecindad y de coexistencia en territorios que muchas veces sus condiciones geográficas no reconocen fronteras políticas. En el fondo decimos que se complementan en línea utilitaria hacia el mejor bienestar de las personas.

Es más, para nosotros, desde una óptica global no deben porqué ser todos los modelos extra-UE tan similares. Ya que, si las experiencias en África, en Asia y en América Latina, logran ser eficientes dentro de sus realidades, no amerita pretender importar desde Europa el molde exacto y completo de la UE, que ya a los europeos les es difícil de manejar aunque se adapta a su realidad concreta. En tal eje estimamos que todos estos esquemas de integración son compatibles atendida la naturaleza de servicio que las organizaciones sui generis construidas en dichas zonas irrogan a sus destinatarios.

Ahora bien, si las naturalezas jurídicas de los modelos en Latino América se posicionan en coordenadas eclécticas entre las organizaciones internacionales clásicas o típicas y una organización de integración plena como la UE, a su vez la propia UE se asienta en otro punto ecléctico, aquel que se encuentra ahora entre una organización de integración intensa y una solución federal, sin que esta última sea su meta, en realidad su fórmula es a medio camino justo antes de una federación. Entonces en ningún caso la UE representa un Estado federal, de hecho la UE ni siquiera es un Estado. Su posición es anterior al federalismo, pero de carácter supranacional. A mayor dificultad el contenido del inciso $2^{\circ}$ del artículo 1 del TUE se sincera expresando que en realidad estamos ante una situación de tránsito, indicando «El presente Tratado constituye una 'nueva etapa' en el proceso creador de una unión cada vez más estrecha entre los pueblos de Europa». Para la doctrina ${ }^{130}$ dicho texto

\footnotetext{
${ }^{130}$ La noción de progresividad es siempre destacada en este tipo de empresas, no sólo por la doctrina, sino también por el legislador, positivizándolo en ocasiones bajo la noción de principio de progresividad o de gradualidad. Obsérvese un ejemplo para cada caso (doctrina y norma): A) MANGAS subraya, la idea de la progresividad, la idea del puente intergeneracional y la idea de que el futuro se construye poco a poco y entre todos, que no hay nada acabado ni cerrado y que las generaciones futuras están llamadas a ser protagonistas del proceso, condensa toda una filosofía política. La autora presiona en que ni siquiera la UE es la meta misma de la integración, sino que ésta es sólo una nueva etapa en el proceso creador de una Unión, para subrayarlo pone de relieve el contenido textual del inciso $2^{\circ}$ del art. 1 del TUE - ya transcrito arriba. Es decir, que la UE está en una dinámica hacia una mayor integración, pero sin definir su meta. MANGAS MARTÍN, 2014c, pp. 46-47. B) Ahora en cuanto a su conceptualización como principio y positivización normativa, vemos v.gr. que en América Latina el principio de progresividad o de gradualidad lo encontramos en el literal e) del art. 4 del Protocolo de Tegucigalpa a la Carta ODECA, norma contenedora de los denominados principios fundamentales por los que se regulan los Estados miembros, expresando «Para la realización de los propósitos citados, el SICA y sus Miembros procederán de acuerdo a los principios fundamentales siguientes: [...] e) La gradualidad, especificidad y progresividad del proceso de integración». Volveremos sobre la progresividad en los capítulos III y IV de esta tesis.
} 
deja en evidencia que ni siquiera la UE es la meta en sí misma, sino sólo reflejo de la época actual de la unión en Europa.

Asentar, o al menos consensuar su naturaleza jurídica, ha sido materia de diversos intentos por la doctrina, así para algunos la UE si bien va en línea con lograr relaciones cada vez más estrechas entre los miembros, no define su meta con claridad, en un despliegue de progresividad muy singular, sin ser un Estado federal, sino una organización internacional intergubernamental muy distinta de las clásicas, o más específicamente un «ente jurídicointernacional atípico» ${ }^{131}$. Otros en cambio, acentúan sus coordenadas eclécticas superadoras de lo intergubernamental pero anteriores al federalismo ${ }^{132}$. También encontramos a los que prefieren recurrir al campo de la fenomenología social, política y jurídica para explicarla, dado la imposibilidad de hacer encajar a la UE en estructuras conceptuales preexistentes $^{133}$.

Nosotros observamos que la naturaleza jurídica del proyecto europeo evidentemente cambió tras desarrollarse su proceso - como lo venimos viendo. En un principio las tres Comunidades Europeas daban cuenta de un inicial intento moderno de los Estados de trabajar conjuntamente. Pero la evolución del proyecto hizo que se complejizara su naturaleza, y en tal sentido actualmente la UE puede comprenderse bajo una noción de organización de integración supranacional plena. Pero dado que justamente la UE es un proyecto en movimiento que no define su meta — como lo señala la doctrina que ya apuntamos - se dirige entonces hacia un destino desconocido para la ciencia del derecho. Por tal motivo no cabe sino considerarla como una institución jurídica de frontera, dado que precisamente lo más claro, es lo que la UE no es. Simplemente no puede identificarse con precisión absoluta $^{134}$.

${ }^{131}$ MANGAS tras aclarar que la UE no es un Estado federal, que ni siquiera es un Estado, sino una organización internacional intergubernamental muy distinta de las clásicas, concluye entonces que la UE sería un «ente jurídico-internacional atípico». MANGAS MARTÍN, 2014c, pp. 46-47.

${ }^{132}$ En línea con lo que no es la UE, los autores RODRÍGUEZ y LÓPEZ expresan que la Unión Europea es una organización jurídico-política sui generis situada a caballo entre las organizaciones internacionales clásicas y los Estados federados. RODRÍGUEZ IGLESIAS \& LÓPEZ ESCUDERO, 2010a, p. 593.

${ }^{133}$ En líneas generales y concluyentes ALDECOA manifiesta que el proceso de integración europea constituye una de las actividades humanas más singulares y, quizás, el fenómeno social y político más deslumbrante de los que se han producido en el siglo XX. ALDECOA LUZÁRRAGA, F. (2002). La integración europea: Análisis histórico-institucional con textos y documentos - Tomo II génesis y desarrollo de la unión europea (1979-2002). Madrid: Tecnos. [Truyol y Serra, A. (1999). La integración europea: Análisis histórico-institucional con textos y documentos.- Tomo I génesis y desarrollo de la unión europea (1951-1979). Madrid: Tecnos], p. 25.

${ }^{134}$ Continúa por lo tanto, con plena vigencia la certera apreciación de JACQUES DELORS — presidente de la Comisión Europea entre los años 1985 a 1995 - la caracterizó a fines del s. XX como un OPNI «objeto político no identificado». 
En tal carencia conceptual, lo único zanjado sería que la UE sobrepasa lo intergubernamental con creces, sin llegar al umbral del federalismo y siendo la única construcción verdaderamente supranacional que existe en la actualidad, comportando «el espacio de libertad, desarrollo, justicia y paz, que ofrece las mejores condiciones de vida en el mundo» ${ }^{135}$.

${ }^{135}$ El Espacio de Libertad, Seguridad y Justicia (ELSJ) perfila un marco conceptual que engloba ámbitos competenciales muy extensos y que pertenece a uno de los objetivos de primera magnitud de la UE, pues afecta sectores muy sensibles tanto política como jurídicamente de la soberanía de los Estados miembros. El ELSJ se proyecta sobre temas centrales para el ciudadano, como la jurisdicción, el orden penal, las policías, las políticas de asilo, etc. En atención a estas características se le da un tratamiento académico triple $1^{\circ}$ ) Desde lo conceptual general, vid. et al. MÉNDEZ DE VIGO, I. \& OREJA AGUIRRE, M. (2007). ¿Qué fue de la constitución europea? : El tratado de lisboa: Un camino hacia el futuro ( $1^{\mathrm{a}}$ ed.). Madrid: Fundación Rafael del Pino., pp. 163-172. Otro, DEL VALLE GÁLVEZ, A. (2008). El espacio de libertad, seguridad y justicia. En J. Martín y Pérez de Nanclares (coord.), F. Aldeoca Luzurraga, N. Mariscal Berástegui, M. A. Alcoceba Gallego, M. Guinea Llorente, A. Fernández Tomás, ... M. Urrea Corres, El tratado de lisboa: La salida de la crisis constitucional : Jornadas de la Asociación Española de Profesores de Derecho Internacional y Relaciones Internacionales celebradas en madrid el 17 y 18 de diciembre 2007 ( $1^{\mathrm{a}}$ ed.). Madrid: Iustel., pp. 417-435. $2^{\circ}$ ) Se puede estudiar rigurosamente alguno de sus múltiples extremos o temas específicos, vid. et al. PI LLORENS, M., ZAPATER DUQUE, E. \& VILÁ COSTA, B. (2010). ¿Hacia una europa de las personas en el espacio de libertad, seguridad y justicia?. Madrid: Marcial Pons. Este texto comienza con una idea inicial sobre el Tratado de Lisboa y luego deviene en reflexionar sobre la política de inmigración, los DDHH en el ESLJ, finalizando con una mirada de la UE frente a Guantánamo y otros. $3^{\circ}$ ) Y desde el punto de vista normativo estricto, debe recurrirse al art. 3.2 del TUE, y en el TFUE al Título V. titulado Espacio de libertad, seguridad y justicia, arts. 67 y ss. 
CAPÍtULO II

\section{LAS VÍAS DE ACCESO A LA JURISDICCIÓN DE LOS TRIBUNALES DE LOS PROCESOS DE INTEGRACIÓN EN AMÉRICA LATINA: UN ANÁLISIS COMPARADO CON LA UNIÓN EUROPEA}




\section{CAPítulo II}

\section{LAS VÍAS DE ACCESO A LA JURISDICCIÓN DE LOS TRIBUNALES DE LOS PROCESOS DE INTEGRACIÓN EN AMÉRICA LATINA: UN ANÁLISIS COMPARADO CON LA UNIÓN EUROPEA}

\section{INTRODUCCIÓN}

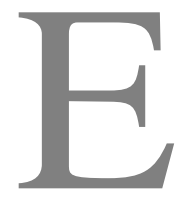

1 objeto del presente capítulo es efectuar un análisis estatutario de las Cortes de los procesos de integración latinoamericanos. Este análisis al ser directamente legislativo nos entregará una primera aproximación a dichos órganos jurisdiccionales, permitiéndonos visualizar el margen de acción real con que cuentan para desplegar sus ejercicios jurisdiccionales. Es decir, advertiremos con nitidez las condiciones y competencias de que disponen, cuestión relevante pues al ser tales herramientas procesales de menor entidad y cantidad que las de la Corte de Luxemburgo, todos los pasos que pueden dar las Cortes latinoamericanas por favorecer los proyectos regionales, vienen restringidos desde sus cimientos estatutarios, razón por la cual sus jurisprudencias expansivas en la dimensión integracionista serán altamente valorables. Con la base anterior acabada, pasaremos luego, en los capítulos III y IV, al análisis de sus respectivas jurisprudencias integracionistas y también del empleo de un tipo particular de dialogo judicial.

Para poder llevar adelante el objeto recién expuesto, comenzaremos por precisar algunos conceptos trascendentes de la jurisdicción integracionista, los cuales tienen la propiedad de presentarla como una clase muy singular de jurisdicción internacional, además observaremos la dimensión orgánica de las Cortes de integración y la correcta posición en 
que se ubican dentro de la triada compuesta por los tribunales estatales, internacionales y los de integración.

Luego nos enfocaremos en determinadas características muy específicas, que por su importancia, las hemos denominado en esta tesis «patrones centrales», los cuales cumplen con tres exigencias simultáneamente, uno, se presentan en el modelo europeo, dos, poseen su correlato en los estatutos latinoamericanos, y tres, son esenciales en un modelo de integración, según lo justificaremos destacando el desarrollo y efecto que esas singularidades han producido en el TJUE. Ahora bien, un aspecto diferente será la intensidad con que dichos patrones centrales se recepcionan y se desarrollan en América Latina, pues si bien en algunos casos parecen ser idénticos a ambos lados del Atlántico, su implementación y ejecución concreta en Latinoamérica son muy distantes del modelo europeo.

Finalizaremos este capítulo analizando otras características, las que sin llegar a ser patrones centrales — por no cumplir con las tres exigencias indicadas en el párrafo anterior — también se presentan en América Latina, a éstas las hemos denominamos «simples rasgos comunes». Es decir, dispondremos de dos conductos importantes de características.

Una vez analizadas las construcciones legislativas que rigen la orgánica y la funcionalidad de la Corte Centroamericana de Justicia (CCJ), del Tribunal de Justicia de la Comunidad Andina (TJCA) y del Tribunal Permanente de Revisión Mercosur (TPRM) más los Tribunales Arbitrales ad hoc Mercosur (TAAM), mediante un cotejo jurídico con el Tribunal de Justicia de la Unión Europea (TJUE) podremos, en primer lugar, organizar a las Cortes receptoras, en modelos de mayor o de menor cercanía con el europeo, y en segundo lugar, se nos hará posible conformar la base orgánica y la realidad estatutaria concreta de las Cortes latinoamericanas bajo análisis, para así lograr comprender en su justa medida la jurisprudencia integracionista y el diálogo judicial que efectúan dichas Cortes.

Para iniciar el desarrollo del planteamiento propuesto, retengamos cuatro ideas que nos serán útiles para el desarrollo del presente capítulo y que fluyen del anterior, en primer lugar, que de la institucionalidad de la reconstrucción política europea post Segunda Guerra Mundial nació el primer modelo de organización de integración, la actual Unión Europea (UE) y entre sus órganos encontramos al TJUE en carácter de Institución; en segundo lugar, el modelo de la UE se intentó replicar parcialmente en América Latina, África y Asia, siendo Latinoamérica la principal zona receptora con tres proyectos, el Sistema de la Integración Centroamericana (SICA) con la CCJ, la Comunidad Andina de Naciones (CAN) con el TJCA y el Mercado Común del Sur (MERCOSUR) con los TAAM y el TPRM; en tercer lugar, es un hecho objetivo que América Latina esperó la madurez del proceso europeo antes de intentar esquemas de integración más intensos, lo que implica que 98 
sus tribunales son bastante más recientes, obsérvese que en Europa los precedentes del TJUE son del año 1951 post Segunda Guerra Mundial, en cambio los tribunales en América Latina bajo análisis son prácticamente todos post Guerra Fría, la CCJ nace en 1991, el TJCA en 1984, los TAAM en 1991 y el TPRM en el año 2002, ya insertos en el concepto del nuevo regionalismo y en los efectos de la globalización; por último, y en cuarto lugar, lo anterior les permitió a los latinoamericanos aprovechar toda la experiencia de la UE, por tal motivo varias soluciones construidas en Europa mediante la actividad jurisprudencial de la Corte de Luxemburgo, en América Latina se incorporaron mediante el cauce estatutario.

También respetando nuestro marco teórico, retengamos para el desarrollo del presente capítulo que el derecho que regula este fenómeno se conoció en Europa como Derecho Comunitario, luego como Derecho de la Integración y hoy como Derecho de la UE. En América Latina se le identificó como Derecho Comunitario y más tarde como Derecho de la Integración. Regionalmente se habla de Derecho del SICA o centroamericano, Derecho de la CAN o andino y Derecho del MERCOSUR o mercosureño, y de modo amplio se hace referencia al Derecho de la Integración como un genérico para destacar las similitudes entre todos los modelos. Coincidiendo la noción de Derecho de la Integración que tienen los latinoamericanos, con los principios rectores del Derecho de la UE, tal como ya lo explicamos ${ }^{1}$.

\footnotetext{
${ }^{1}$ Vid. número 2 de la introducción de esta tesis.
} 


\section{LOS PRINCIPALES CONCEPTOS DE LA JURISDICCIÓN INTEGRACIONISTA \\ Y SU DIMENSIÓN ORGÁNICA: EN LA BÚSQUEDA DE UNA POSICIÓN JURÍDICA MÁS EXACTA DE LAS CORTES DE INTEGRACIÓN}

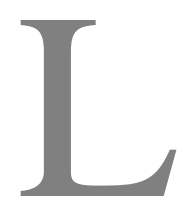

as Cortes de integración si bien pueden ser explicadas, prima facie, como una categoría especial de tribunales internacionales y por ende compartiendo determinadas similitudes en dicha relación de género a especie, sus campos se posicionan a distancias bastante considerables. El aspecto procesal más diferenciador es la densidad de las competencias que ostentan, en el sentido de que los tribunales internacionales típicos gozan de competencias de clases especiales en un área determinada, mientras que las Cortes de integración son mucho más ricas en su espectro competencial, tanto es así que incluso son consideradas como cuasi tribunales constitucionales del proyecto político al que cada una pertenece.

Esta alta densidad competencial recién anotada es la propiedad más nítida que las transforman en institutos jurídicos complejos, por lo tanto para lograr aproximarnos correctamente a estas Cortes comenzaremos por analizar un grupo de conceptos que hemos ordenado por dos cauces, primero nos centraremos en aspectos fundamentales que circulan por la dimensión orgánica de estas Cortes, y en segundo lugar continuaremos con otros aspectos que se aprecian al comparar de modo amplio a los tribunales estatales con los internacionales y a todos esos con las Cortes de integración, toda vez que nuestros objetos de estudio no se desarrollan en compartimentos estancos, sino que los tres niveles jurisdiccionales indicados se superponen en los territorios cubiertos por un proyecto de integración.

$1^{\circ}$. La dimensión ORgániCa de las CoRTes de inTEgRaCión. Por este primer conducto las Cortes de integración se comprenden como un órgano permanente de un tipo especial de organización internacional (OI) las denominadas organizaciones de integración. Aunque en realidad sólo nuestro referente la UE es una verdadera organización de integración, plena y supranacional, en cambio el SICA, la CAN y el MERCOSUR son más bien organizaciones de aspiraciones integracionistas. Sin embargo dichos modelos latinoamericanos tampoco pueden definirse como OI típicas, siendo precisamente esta realidad una arista central, pues dará paso en América Latina a Cortes que no siendo necesariamente de integración, tampoco serán tribunales internacionales clásicos, quedando por lo tanto dichos tribunales latinoamericanos ubicados orgánicamente en coordenadas eclécticas. 
La función jurisdiccional dentro del complejo campo jurídico y territorial creado por los Estados miembros de estas organizaciones de aspiraciones integracionistas, será de cargo mixto pues, primero, dicha función la llevará adelante la referida organización a través de sus Cortes de integración. Pero en segundo lugar, la función jurisdiccional del proyecto integracionista también se resuelve a través de los tribunales nacionales, mediante el principio de colaboración. Entonces si las Cortes de integración llevan adelante la función jurisdiccional en calidad de órganos permanentes de la organización, es importante comprender - al menos de modo amplio - a estas organizaciones en calidad de construcciones jurídicas modernas o relativamente recientes. Desde el campo jurisdiccional las OI han sido comprendidas como ciertas entidades que no son un Estado ${ }^{2}$ y la doctrina se ha aproximado a su noción con muchas dificultades, planteando incluso algunos autores que su conceptualización es imposible ${ }^{3}$.

\footnotetext{
${ }^{2}$ La conceptualización como, cierta entidad que no es un Estado, se ha usado por la Corte Internacional de Justicia (CIJ) para aproximarse a un concepto de OI. Obsérvese al respecto «Les sujets de droit, dans un système juridique, ne sont pas nécessairement identiques quant à leur nature ou à l'étendue de leurs droits ; et leur nature dépend des besoins de la communauté. Le développement du droit international, au cours de son histoire, a été influencé par les exigences de la vie internationale, et l'accroissement progressif des activités collectives des États a déjà fait surgir des exemples d'action exercée sur le plan international par 'certaines entités qui ne sont pas des États'.» CIJ, Sentencia de 11 de abril de 1949. Opinión consultiva. Reparación de daños sufridos. Vid. en COMPENDIO DE SENTENCIAS, OPINIONES Y ORDENES DE ASESORAMIENTO. REPARACIÓN DE DAÑOS AL SERVICIO DE LAS NACIONES UNIDAS, p. 178. Recogiendo esta noción, como «Entes que no son un Estado» vid. DE YTURRIAGA BARBERÁN, J. A. (1964). Las organizaciones internacionales y la soberanía de los estados. Revista de estudios políticos, (135), 83-106. Otra en GONZÁLEZ CAMPOS, SÁNCHEZ RODRÍGUEZ \& ANDRÉS SÁENZ DE SANTA MARÍA, 2008, pp. 11-12.

${ }^{3}$ Para WHITE es imposible construir un concepto preciso de OI, expresando al respecto «A precise definition of an international organisation is not posible. [...] an international organisation can be viewed very differently by different States, actors and writers. Even from the narrow perspective of international law, the sheer variety of institutional forms of co-operation between States belies the possibility of providing a precise legal definition». WHITE, N. D. (2005). The law of international organisations. Manchester: Manchester University press., p. 1. La dificultad radica entonces en la amplitud y diversidad del intituto, SEYERSTED subraya esta multiplicidad listando «international organizations of States - so-called intergovernmental organizations - as opposed to non-governmental organizations, which are compose of private individuals and/or of national associations of individuals or companies. [...]. There are many different types of intergovernmental organizations - inter alia according to: a) Size (membership)... b) Purposes... c) Functions and powers... d) Duration [...]». SEYERSTED, F. (2008). Common law of international organizations. Leiden, Boston: Martinus Nijhoff, p. 3 y 9-10. Ante tal cantidad SANTOS expresa que no ha de extrañar que el DI no haya adoptado una definición de OI. Precisando que todas ellas tienden a develarse tras el reconocimiento de su elemento más identificatorio por la Sociedad Internacional, cual es, la noción de función. SANTOS, 2002, pp. 33-34. HUICI insiste en la multiplicidad como principal escollo para conceptualizarlas. HUICI SANCHO, 2007, pp. 29-30 (apartado 2 Debates en torno al concepto de organización internacional).
} 
Anotada la dificultad e incluso la imposibilidad para definir a una OI, se vuelve aún más complejo arribar a una noción de organización de integración. Éstas últimas obedecen a proyectos cooperativos de mayor intensidad que las OI típicas, pues toman a su cargo algunas de las funciones y competencias de los Estados miembros sin detenerse siquiera en las más esenciales ${ }^{4}$, a diferencia de las OI típicas, las cuales dejan intacta la estructura Estatal de los países miembros. En ambas circunstancias - OI típicas, o de integraciónpodremos encontrar entre sus órganos permanentes a determinadas Cortes, verificándose que los fines, principios y normativa que emane de estas organizaciones serán cuestiones que afectarán directamente a sus tribunales. Ya que, desde la arista orgánica en que nos encontramos, las jurisdicciones y competencias de estas Cortes se establecen sintonizadas con los fines de la organización.

Tal sincronización o coherencia orgánica, que rige la relación organización/órgano, encuentra su razón de ser en el hecho de que el órgano queda dispuesto al servicio de los fines de la organización. Es decir, pasa a ser una herramienta de otra herramienta, pues las OI en sí mismas ya poseen una naturaleza de servicio ${ }^{5}$. El órgano nace entonces con el objeto de que la OI alcance sus fines ${ }^{6}$. De tal suerte, la razón organización/órgano se rige bajo el principio de coherencia orgánica ${ }^{7}$, por el cual, el proceder de los órganos debe

\footnotetext{
${ }^{4}$ Para algunos autores estas construcciones jurídicas serían una simple forma de clasificar a las OI, pero para otros son estructuras diferentes y con principios propios. Nosotros en el marco teórico de la tesis resaltábamos que la doctrina identifica de varios modos a las organizaciones de integración. Como por ejemplo: «organizaciones de integración o de unificación», «organizaciones internacionales de integración», u «organizaciones sui generis». Para VIRALLY las organizaciones de integración poseen su campo propio, alejado de las OI típicas, existiendo una frontera jurídica entre ellas. VIRALLY, 1998, p. 262. En cambio PASTOR a partir de un método de cooperación, estima que representan un nivel clasificatorio, concluyendo que serían «el supuesto de cooperación más intenso». PASTOR, 2010, pp. 664-667. Para DIEZ DE VELASCO quedan dentro de la clasificación que él denomina «organizaciones de integración o de unificación» las cuales —-según explica- se sitúan entre las OI clásicas y las estructuras federales, precisando que se ha extendido en la doctrina el uso de la categoría de «organizaciones internacionales de integración» para explicar a la CE y ahora a la UE. DIEZ DE VELASCO \& SOBRINO, 2010, pp. 47-53 y 593.

${ }^{5}$ El carácter de herramienta o de servicio que poseen las OI es evidente, de lo contrario éstas no se crearían. En tal línea v.gr. HUICI señala que la propia creación y existencia de las OI dependen de su naturaleza de servicio. HUICI SANCHO, 2007, p. 37.

${ }^{6}$ Positivizaciones de la condición utilitaria del órgano en favor de la organización —es decir, del para qué fue creado - pueden observarse por ejemplo en el SICA en el art. 12 del Protocolo de Tegucigalpa a la Carta de la Organización de Estados Centroamericanos (PTC-ODECA), el cual claramente lo responde del siguiente modo «Para la realización de los fines del SICA se establecen los siguientes Órganos». En la UE la respuesta también es directa y clara, en el art. 13.1 del Tratado de la Unión Europea (TUE) se explica la finalidad de su marco institucional así «La Unión dispone de un marco institucional que tiene como finalidad promover sus valores, perseguir sus objetivos».

${ }^{7}$ El principio de coherencia orgánica es el imperativo lógico que rige la relación organización/órgano. Por el cual la acción de los órganos tiene como fin el favorecer que la OI alcance sus metas. En menor medida en el 102
} 
guardar congruencia con las metas de la OI y con el derecho del grupo, en este caso con el Derecho de la UE, del SICA, de la CAN o del MERCOSUR.

En tal predicamento aparece un punto de equilibrio orgánico ya que, por un extremo, se observa que un órgano será el guardián del correcto proceder de los otros órganos, de los Estados miembros y de todos los concurrentes, siendo este guardián, el órgano jurisdiccional de la organización, y por otro extremo, el principio de coherencia orgánica recién anotado, presenta una contrapartida, ahora bajo el principio general de derecho accesorium sequitur principale, en el entendido de que la suerte que corra la organización impacta en el órgano — volveremos sobre este mutuo potenciamiento líneas más adelante.

En estas coordenadas gira un aspecto de alta relevancia para nuestra hipótesis, cual es que tales organizaciones — desde su ordenamiento originario o derivativo — orgánicamente al dotarse de tribunales, logran mejorar el estándar de todo el proyecto político, dado que se alcanza un doble beneficio, se robustece la institucionalidad de la OI, y redunda en una mayor responsabilidad para los Estados miembros. Es decir, se materializa una estrategia de fortificación del proyecto completo a través de un control judicial intenso ${ }^{8}$.

nivel nacional es una visión orgánica y administrativa, como por ejemplo el principio de coordinación y el principio de diligencia que rige el comportamiento del funcionario de velar por los intereses generales (de la administración local). Pero en el nivel internacional, y aplicado al marco institucional de una OI, el principio de coherencia o congruencia orgánica se encuentra positivizado en algunos Estatutos, v.gr. en el SICA lo recoge El PTC-ODECA en su art. 11 «El SICA velará por la eficiencia y eficacia del funcionamiento de sus órganos $e$ instituciones asegurando la unidad y la coherencia de su acción». En la UE encontramos a este imperativo afectando a sus órganos o marco institucional en general, el TUE lo recoge en su art. 13.1 «La Unión dispone de un marco institucional que tiene como finalidad promover sus valores, perseguir sus objetivos, [...], así como garantizar la coherencia, eficacia y continuidad de sus políticas y acciones». Políticas y acciones que se llevan adelante a través de dichos órganos. Este extremo no es menor, pues como vemos la UE y toda OI actúa y se despliega principalmente a través de sus órganos. Máxime si consideramos la precisión de parte de la doctrina que puntualiza que la delegación de soberanía se produce en los órganos de la UE, v.gr. DE YTURRIAGA al aproximarse jurídicamente a ella sostiene «El régimen de las comunidades europeas supone una verdadera limitación de la soberanía de los Estados al producirse la injerencia de la comunidad supranacional en el clásico reducto de la competencia doméstica de los Estados, injerencia consentida por éstos mediante la delegación 'en los órganos' de la Comunidad de algunos de sus atributos soberanos». DE YTURRIAGA BARBERÁN, J. A. (1964). Las organizaciones internacionales y la soberanía de los estados. Revista de estudios políticos, (135), 83-106 (p. 99, vid. apartado 3. Visión jurídica).

${ }^{8}$ Esta idea de fortificación de las OI mediante la incorporación de órganos jurisdiccionales es bastante antigua, de hecho ya vimos que en América en 1907 se incorpora la Corte de Cartago al proyecto organizativo Centroamericano, y luego analizamos toda la secuela para Europa, América y también lo observamos de modo global. En este lineamiento REUTER al referirse sobre los límites funcionales o desviación de poder de las OI, explica que la competencia de ellas está determinada por la función o fines que persigan, cuestión esencial de todo acto, especialmente en las organizaciones y en las Cartas que lo declaran expresamente, sin embargo, acota para nuestro máximo interés aquí: «si una tal concepción no ha sido admitida por todos, y ha sido discutida, ella supone en todo caso para ser eficaz un control judicial muy fuerte». Como se aprecia, lo 
Ahora bien — en particular - los tribunales de integración deberían por lógica, pertenecer al marco institucional de alguna organización de integración, pero esta simple idea inicial ya es doblemente dificultosa toda vez que, de un lado, únicamente nuestro referente la UE, es una organización de integración plena y supranacional, a diferencia de lo que ocurre con las latinoamericanas donde es discutible aquel sustrato, y de otro lado, porque según vimos líneas arriba, la doctrina no logra consensuar en una noción unívoca para las OI, por lo que menos lo harán para las organizaciones de integración o sui generis.

Con todo, es nítida la existencia de una frontera ya que se visualiza un exilio de las organizaciones de integración del conjunto de las OI típicas, el cual se centra en el paradigma de una confusión en sentido de unidad englobante de alta intensidad, que sólo ocurre en las primeras, pero sin llegar a ser la máxima intensidad, pues no se estructura un Estado federal, modelo ecléctico al que responden los patrones de la UE, dado que dicha construcción europea nada tiene que ver con un Estado federativo como tal, a pesar de que se le reconozcan algunos rasgos puntuales ${ }^{9}$.

Entonces desde la dimensión orgánica que venimos analizando en este apartado, los tribunales de integración son órganos permanentes que llevan adelante sólo una parte de la función jurisdiccional de la organización a la cual pertenecen. Porque la totalidad de la función jurisdiccional se satisface sumando al principio de cooperación, mediante el cual, procesalmente, el juez natural $^{10}$ para el ciudadano pasa a ser el juez nacional. Y este

que se sentencia no es sólo lo imperioso de un control judicial en la OI, circunstancia que se da por descontado, sino que la intensidad del control debe ser profunda (muy fuerte). REUTER, P. \& PUENTE EGIDO, J. (1978). Derecho internacional público. Barcelona: Bosch., p. 206 (vid. Cap. IV, Sección IV Teoría general de las organizaciones internacionales).

${ }^{9}$ Ya anotamos las diferencias en la doctrina al respecto, la UE representaría «el supuesto de cooperación más intenso» en PASTOR 2010, pp. 664-667, o bien la UE se encuadraría en el concepto de «organizaciones de integración o de unificación», entre las OI clásicas y las estructuras federales, bajo la categoría de «organizaciones internacionales de integración» en DIEZ DE VELASCO \& SOBRINO, 2010, pp. 47-53 y 593. Ahora bien, la importancia para el mundo del derecho, de tal diferenciación, radica en que las investigaciones comprenderían mejor a los órganos jurisdiccionales de dichas organizaciones, como objetos de estudio particularizado al interior de las ciencias sociales y jurídicas, ya que se facilita su correcta posición mostrándolos distantes de un tribunal internacional típico.

${ }^{10}$ Se aplica en estricto sentido procesal la noción de juez natural, es decir, aquel juez que cumple de modo propio y directo con todos los requisitos de la competencia para conocer y resolver el asunto, habitualmente en primera instancia, et. al. COUTURE, E. J. (1958). Fundamentos del derecho procesal civil. ( $3^{\mathrm{a}}$ ed.). Roque de Palma. Buenos Aires., p. 98. Otro, CHIOVEndA, G. [Gómez \& Greco, trans.] (2005). Instituciones de derecho procesal civil - Vol. II. ( $1^{a}$ ed.). Florida Buenos Aires: Valleta Ediciones., p. 135. Este juez, es el que en la compleja arquitectura jurisdiccional creada en la UE pasa a ser el magistrado que se enfrenta en el primer nivel local al conflicto (recordemos que no puede escalarse por vías de impugnación desde el sistema nacional al supranacional, por ello el siguiente nivel es interno, esto es, a las Cortes nacionales. SARMIENTO 104 
tribunal local puede comunicarse por conductos procesales establecidos en cada sistema regional con la Corte de integración. Ahora bien, las Cortes de integración sobrepasan la simple disolución del contencioso debido a sus densas competencias, cuestión sobre la que nos centraremos en este mismo capítulo. Y rebasan además las explicaciones puramente orgánicas, por tal motivo también tendremos presente la dimensión funcional y el ejercicio jurisdiccional $^{11}$.

\section{$2^{\circ}$. LA RELACIÓN EN LA TRIADA JURISDICCIONAL: TRIBUNALES ESTATALES,} INTERNACIONALES Y DE INTEGRACIÓN. El ejercicio de las Cortes de integración no se efectúa en un compartimento estanco, sino en un contexto jurídico-procesal global, donde se constatan tres grandes tipos de tribunales, los nacionales, los internacionales típicos y los de integración. Las Cortes objeto de la presente investigación, reconocen ese triple entramado y se desenvuelven en dicho entorno. El TJUE se vincula con los tribunales nacionales de los Estados miembros de la UE, pero además mediante el diálogo judicial toma razonamientos de tribunales internacionales, como del Tribunal Europeo de Derechos Humanos (TEDH).

Similar cuestión se constata en América Latina, v.gr. la CCJ se conecta con los jueces locales de los Estados miembros del SICA y además a través del diálogo judicial se vincula con tribunales internacionales típicos, como lo ha hecho con la Corte Internacional de Justicia, con la Corte Constitucional de Italia ${ }^{12}$ y también con la Corte Interamericana de Derechos Humanos (CIDH). Misma situación de conexión con tribunales internacionales clásicos se observar en el MERCOSUR donde un TAAM se ha conectado a criterios de la Corte Internacional de Justicia ${ }^{13}$.

RAMÍREZ-ESCUDERO, 2016, p. 360.) y para cuya disolución aplica directamente el Derecho de la UE. En tal ejercicio de jurisdicción primaria y local, el juez natural puede conectarse con los criterios de la Corte de Luxemburgo mediante las cuestiones prejudiciales — las que analizaremos en este mismo capítulo II- y ante la respuesta del TJUE únicamente le resta aplicar dichos criterios, bajo la posibilidad de incurrir en vulneración de derecho. Anomalía procesal que puede subsanarse con el recurso de casación ante las Cortes nacionales superiores del juez que no respetó la respuesta del TJUE.

${ }^{11}$ El análisis jurisprudencial con ejemplos y casos están desarrollados en los capítulos III y IV de esta tesis, referidos al análisis de jurisprudencia integracionista y al diálogo judicial respectivamente.

${ }^{12}$ Sentencia de la CCJ de 5 de marzo de 1998, Coto Ugarte c. Consejo Superior Universitario de la Universidad de El Salvador, expediente 05-11-1996, as. 05/96. En esta sentencia la CCJ recurre de forma expresa a la Corte Constitucional de Italia, al TJUE y al TJCA, y en su Considerando V hace expresa referencia a la Corte Internacional de Justicia. El análisis de este caso se encuentra en el capítulo IV de esta tesis.

${ }^{13}$ Laudo del TAAM (número 10) de 5 de agosto de 2005, República Oriental del Uruguay c. República Federativa del Brasil. En este laudo al hacer el análisis del derecho aplicable, pasa a apoyarse en construcciones de la Corte Internacional de Justicia, vid. en párrafo 6 del apartado Derecho aplicable. El análisis de este caso se encuentra en el capítulo IV de esta tesis. 
Como se aprecia las Cortes de integración no tienen reparos en buscar una conexión con los tribunales internacionales clásicos, los cuales son el antecedente jurídico de las Cortes de integración, por tal motivo su teoría general ya resolvió varios aspectos aplicables a todos. Y de entre las soluciones de jurisdicción transnacional, que aquí nos interesan, podemos apreciar que una de las más importantes, se refiere a la explicación sobre la fuente de la jurisdicción internacional. En el nivel interno se entiende a la jurisdicción nacional como una de las funciones estatales ${ }^{14}$. El punto radica en cómo y por qué ésta emigra del dominio Estatal absoluto, sobrepasando los denominados límites de la jurisdicción, en particular la frontera territorial. La respuesta es bastante compleja pero puede afrontarse del modo que sigue.

En términos iniciales la explicación comienza por el reconocimiento de un proceso de consenso entre los Estados como sujetos de derecho internacional, quienes a través de los Tratados Internacionales, dan origen a la señalada jurisdicción internacional. Sin embargo, lo anterior no explica la totalidad del fenómeno, pues inmediatamente sorteada la existencia de la jurisdicción, nos enfrentamos al campo competencial, punto desde donde se hace incluso necesario multiplicar estos órganos jurisdiccionales internacionales, dado el factor de distribución ${ }^{15}$ propio de las competencias de todo tipo de tribunal. Ante dicha dificultad,

\footnotetext{
${ }^{14}$ La potestad de administrar justicia nace en manos de los ancianos de las tribus, de los líderes del mundo antiguo, del emperador, del rey, y desde allí toma la deriva hacia el Estado, el cual se dota de órganos locales - los tribunales y Cortes - para llevarla adelante. Su noción cruza por comprender el deber poder del Estado para administrar justicia, con lo cual se mantiene la paz interna, y es la contrapartida para monopolizar el uso de la fuerza por parte del Estado. CHIOVENDA explica que la jurisdicción es la función pública desarrollada en el proceso, que pertenece al Estado, siendo esta una función jurisdiccional, y correspondiéndole actuar las normas que pone la función legislativa. CHIOVENDA [Casais y Santaló, y Alfredo Salvador], 1977, pp. 367-369. Para GUASP es una función específica estatal, por la cual, el poder público satisface pretensiones. GUASP, 1977, pp. 101-104. Por su parte WACH plantea que la jurisdicción es el poder estatal aplicado a conservar el ordenamiento jurídico. WACH [Banzhaf (trans.) \& Alcalá-Zamora y Castillo], 1977, p. 3.

${ }^{15} \mathrm{El}$ factor de distribución lo explica CHIOVENDA precisando que el poder jurisdiccional, en cada uno de los órganos investidos de él, se presenta limitado, correspondiendo a la ley efectuar una distribución de la parte de poder jurisdiccional que le corresponderá a cada órgano, atendiendo a su naturaleza, para lo cual sigue tres criterios de distribución: el objetivo, el funcional y el territorial, siendo este último el que se conecta a la circunscripción territorial para cada tribunal. CHIOVENDA, 1977, pp. 625-634. LORCA esquematiza el vínculo jurisdicción/competencia, indicando: que éstos se ordenan bajo la siguiente razón «todo juez posee jurisdicción, pero no en todas las competencias», ya que se distribuye la función jurisdiccional precisamente a través del concepto de competencia. LORCA, 1991, p. 36. Pues bien, esa es la explicación intra-muros, la cual en cierta medida se replica en el nivel internacional, pues hay tribunales internacionales de jurisdicciones globales como la CIJ, otros sub-continentales como el TJUE, etc., y si enfocamos directamente hacia la competencia, veremos que en general los tribunales internacionales son de competencias especiales, v.gr. Corte Penal Internacional (CPI), o el Tribunal del Derecho del Mar, etc. En cambio, las Cortes de integración tienen mucha más densidad competencial tal como ya veremos en este mismo capítulo.
}

106 
el consenso Estatal — aquí por medio de los Tratados Internacionales — presenta a lo menos dos caras:

Primero, en principio se produce una especie de cesión parcial o transferencias del ejercicio de competencias soberanas — aquí de jurisdicción-, cuestión que por ejemplo en la UE para los autores más clásicos pasa a ser una ficción ${ }^{16}$ jurídica sobre la cual dicho modelo construye su Poder Judicial sui generis. Esquema de transferencias que con la historia se consolidó al interior del proceso europeo, pasando a conocerse bajo el concepto de «desapoderamiento competencial».

Segundo, sin embargo, dicha cesión parcial o transferencia del ejercicio de competencias soberanas, no es capaz de mostrar la fuente de la jurisdicción internacional en toda su extensión. Ya que el desapoderamiento competencial es más bien utilitario de los procesos integracionistas, como en el caso de la UE o del SICA, donde — en parte - es posible ceder el ejercicio de algo que se tiene. En cambio hay otros ámbitos en que no es posible entender cesión alguna, pues jurídicamente nadie transmite más derechos que los que tiene, por lo tanto no puede aplicarse este esquema de transferencias para dotar de jurisdicción a los tribunales internacionales — no a los de integración — que ejercen competencias que ningún Estado poseía, v.gr. las potestades para resolver controversias y conflictos entre Estados no pertenecientes a ningún esquema de integración, o bien, para poder explicar las competencias consultivas, potestades que tampoco tenía ningún Estado, todo lo cual se observa claro por ejemplo a partir del estudio de las competencias de la CIJ, o de los tribunales híbridos ${ }^{17}$. Todas circunstancias competenciales que evidencian que no hay

\footnotetext{
${ }^{16}$ Esta metodología para otorgar jurisdicción en la UE al TJUE, en una primera aproximación es mediante la ficción de una cesión del ejercicio de soberanía. Construcción que para MONTERO es a lo menos peligrosa, pues no se marcan los límites con absoluta nitidez, manifestando que «en la UE se ha recurrido a una ficción que difícilmente podrá sostenerse y que aunque se apoye desde lo constitucional local, carecería de futuro para seguir explicando el cómo se ha roto el monopolio del Estado en calidad de titular único de la jurisdicción, abriéndose la puerta a algo que no sabe a dónde ha de conducir». MONTERO AROCA, J. (2013). Prólogo. En V. Pardo Iranzo, J. L. Iglesias Buhigues, M. Desantes Real, M. Jimeno Bulnes, C. Arangüena Fanego, F. J. Jimenez Fortea ... M. Cervera Vallterra, El sistema jurisdiccional de la unión europea ( $1^{\mathrm{a}}$ ed.). Navarra: Aranzadi., pp. 15-17.

${ }^{17}$ El punto aquí radica en que determinados tribunales internacionales, a través de la función jurisdiccional llevan adelante competencias no Estatales, como las referidas arriba. Ahora bien los Tribunales Híbridos o Mixtos en particular poseen una mezcla de lo nacional y lo internacional, producto del fenómeno denominado «reparto de la responsabilidad judicial» entre los Estados en los que funcionan y las OI que los auspician, particularmente NU. WILLIAMS, S. (2012). Hybrid and internationalised criminal tribunals: Selected jurisdictional issues. Oxford: Hart Publishing. pp. 58-65. Además del reparto de responsabilidad judicial recién anotado, también colaciona aquí el «principio de justicia universal» de remotos orígenes, se sostiene que el Corpus Iuris Civilis lo reconocía en determinada medida (C.3.15.1), y que luego GrociO en el siglo XVII defendió este título. Pero se desarrolló en el siglo XX y en materias penales propiamente. Está destinado a evitar que los delitos más graves, aquellos atentatorios contra la Comunidad Internacional, queden
} 
Estado que haya tenido tales competencias, por tal razón, mal podrían ceder sus ejercicios. Aquí entonces el consenso se conduce por crear del todo ex novo una jurisdicción.

Como vemos, la explicación sobre la fuente de la jurisdicción internacional no es ni lineal, ni obedece a un solo principio, ni solución. Pero sí revela que nace de las necesidades de convivencia internacional, las que no pueden ser satisfechas por los Estados aisladamente, de allí el desborde de los límites de la jurisdicción. Quedando construidos estos tribunales en el marco institucional de determinadas OI. Aunque hay algunas excepciones en que los tribunales internacionales no pertenecen a una OI sino que son híbridos como algunas soluciones de guerra y penales excepcionales v.gr. el Tribunal Especial para Sierra Leona, o bien incluso son en sí mismos una OI como el caso particular de la Corte Permanente de Arbitraje o la Corte Penal Internacional ${ }^{18}$.

Por su parte la relación de las Cortes de integración con los tribunales nacionales de los Estados miembros de la organización a la que pertenecen es bastante intensa, de hecho estos tribunales nacionales son los que más directamente se vinculan con los potenciales sujetos procesales. En primer lugar reconozcamos que en términos amplios, más allá de su vinculación con los procesos de integración, pudiese pensarse que los tribunales nacionales se encontrarían disociados de la realidad jurisdiccional transnacional, lo cual no es así, pues se reconocen unas cuantas aristas que los conectan con los tribunales internacionales en general y con los de integración en particular, y además llevan adelante un fáctico ejercicio internacional cada vez que conocen determinados asuntos de aristas transnacionales ${ }^{19}$.

impunes. Sin embargo desde antaño han existido otros principios y mecanismos que solucionaban este conflicto. MARTÍNEZ ALCAÑIZ, A. (2014). El principio de justicia universal y los crímenes de guerra. Madrid: Instituto Universitario General Gutiérrez Mellado-UNED., pp. 117-126.

${ }^{18}$ Las excepciones son de dos tipos, una se refiere a los tribunales híbridos como lo han sido varios casos, Núremberg, Sierra Leona y otros, y la otra excepción es que la Corte en sí misma sea una OI, tal es el caso de la Corte Penal Internacional (CPI) y de la Corte Permanente de Arbitraje (CPA). La historia de la CPI indica que en un primer momento la idea era que fuese un nuevo órgano o Corte de NU, pero finalmente se optó por constituirla como una OI en sí misma, manteniendo NU sólo una relación procesal intensa con la CPA. vid. QUESADA, 2005, pp. 35-101. TRUJILLO SÁNCHEZ, 2014, pp. 125 y ss. El texto del acuerdo de cooperación Relationship agreement between the United Nations and the International Criminal Court, A/58/874, se encuentra disponible en <http://www.un.org/en/ga/search/view_doc.asp?symbol=A/58/874> [última consulta, febrero 28, 2019]. Por su parte la CPA es en sí misma una organización intergubernamental independiente. VAN DEN HOUT, 2008, pp. 643-661.

${ }^{19}$ Los tribunales nacionales más allá de su participación en procesos de integración, históricamente han venido conociendo de temas de aristas internacionales debido a la existencia de múltiples principios procesales de jurisdicción aplicables a hechos no cometidos en sus territorios, a Tratados Internacionales especiales, a la colaboración internacional y a temáticas del derecho internacional privado. Todo, a través de diversos canales procesales.

108 
Es particularmente habitual que los esquemas nacionales tiendan a ser comparados con los internacionales, ejercicio en el que efectivamente se observa una cierta similitud entre ambos niveles, v.gr. la recurrencia a un proceso, la existencia de jueces, la producción de sentencias, diversos principios procesales y más. Lo trascendente es que se genera un efecto comparativo positivo, pues propicia una cultura de empleo o de recurrencia a los tribunales internacionales, lo que redunda en un aumento de confianza en el sistema jurídico internacional en general ${ }^{20}$.

Ahora bien, en particular los tribunales estatales de una zona de integración, son los primeros órganos jurisdiccionales llamados a hacer respetar el derecho de la integración, para lo cual se les dota de herramientas procesales específicas a efectos de ejecutar estas competencias, como por ejemplo los procedimientos de consultas prejudiciales, mediante las cuales se materializa la naturaleza cooperativa del juez nacional con el tribunal de integración $^{21}$.

En conclusión las Cortes de integración son un tipo especial de tribunal internacional, de altas competencias, que pertenecen a una organización de integración o sui generis, que tienen la capacidad de vincularse con los demás tribunales internacionales y los nacionales, pues se insertan en el contexto global y no en compartimentos estancos, y cuya gestación se remonta históricamente a la época post Segunda Guerra Mundial en Europa y post Guerra Fría en América Latina.

\footnotetext{
${ }^{20} \mathrm{La}$ semejanza entre ambos niveles de jurisdicción apareja efectos positivos, en dicha línea ESCOBAR destaca cuatro buenas consecuencias, que explica así «la sensible semejanza entre ellos no es baladí», pues, uno, introduce en el derecho internacional el criterio de objetivación y de alejamiento de las partes en la solución del conflicto dando paso al actuar del Tribunal Internacional en nombre de la Comunidad Internacional, dos, favorece el empleo de criterios políticos en la disolución del contencioso potenciando la juridificación, impulso idóneo para que el imperio del Derecho se posicione con brío en materia internacional, tres, todo ello redunda en un aumento de confianza en el sistema jurídico internacional, y cuatro, permite dar el salto desde el estrecho modelo de la solución pacífica de las controversias al servicio de los Estados, hacia la dimensión de un mecanismo amplio para la correcta aplicación del derecho internacional en beneficio de cualquier sujeto la Comunidad Internacional. ESCOBAR HERNÁNDEZ, 2013, pp. 965-966.

${ }^{21}$ A juicio de MAESO el concepto jurídico del sistema de remisión prejudicial, debe entenderse como un mecanismo procesal de naturaleza cooperativa, en cuya virtud el juez nacional inquiere al juez europeo sobre la interpretación o la validez de una norma o acto del derecho [de la unión]; pues así quedarían englobados los caracteres básicos de ella, a saber, su naturaleza cooperativa, la iniciativa del juez nacional, y su doble objeto, interpretación o validez. MAESO SECO, 2007, pp. 197-198.
} 


\section{Criterios para definir a Un tribunal INTERnACIONAL EN CARÁCTER DE UNA CORTE DE INTEGRACIÓN: los Patrones Centrales}

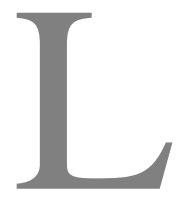

a dificultad para otorgarle a un tribunal internacional el carácter de integracionista sólo se presenta en los modelos extra-UE. En nuestro caso, la cuestión es determinar en qué medida podemos considerar que sean la CCJ, el TJCA y el TPRM tribunales de integración, pues dichas Cortes latinoamericanas siguen las lógicas de cada una de sus OI, y justamente en América Latina el ideario integracionista tiende a diluirse, por no comportar el SICA, la CAN y el MERCOSUR organizaciones de integración plenas, ni mucho menos supranacionales. La labor se dificulta pues será en dicha posición, desde donde deberemos pasar a determinar el rol que las Cortes bajo análisis juegan en cada uno de sus procesos regionales.

Complejidad que aumenta al considerar además el peso de la dimensión histórica de cada experiencia latinoamericana, pues en el proceso de desarrollo alguna de estas Corte puede reconocer que el proyecto político haya avanzado lo suficiente como para encuadrarse dentro del derecho de la integración - tal como veremos para el caso del MERCOSUR - o bien, la OI puede estimar necesario progresar y crear una Corte en calidad de nuevo órgano de la organización - como lo veremos para el caso de la CAN-o bien, la OI o los Estados miembros le otorgan más competencias a la Corte. Tales dinámicas permiten que alguno de estos tribunales latinoamericanos, que no fue concebido como un tribunal integracionista, varíe su finalidad y competencias, mutando su naturaleza jurídica y acercándose a los contenidos del derecho de la integración considerado éste de modo amplio.

La determinación final sobre el carácter integracionista o no de las Cortes bajo análisis y su rol en los procesos regionales, vendrá dado conjuntamente por tres conductos, primero, por la verificación de las competencias que se les atribuyeron estatutariamente, segundo, más lo que la doctrina especializada opina de esos Estatutos — estos dos ángulos los veremos en este capítulo II-, tercero, más sus propios aportes mediante la producción de jurisprudencia integracionista — capítulos III y IV. Para los dos primeros conductos recién indicados, seguiremos tres criterios técnicos procesales, uno, la aplicación del principio general de derecho accesorium sequitur principale; dos, nos enfocaremos en precisos patrones centrales, los cuales son características que cumplen simultáneamente con tres exigencias, se presentan en el modelo de la UE, poseen su correlato en los estatutos latinoamericanos y son de carácter esencial en un modelo de integración, según 
justificaremos en cada caso, y tres, analizaremos algunos simples rasgos comunes de dichas Cortes, los cuales les son bastante útiles a sus funciones.

\subsection{LA APLICACIÓN DEL PRINCIPIO GENERAL DE DERECHO ACCESORIUM SEQUITUR PRINCIPALE}

El principio general de derecho accesorium sequitur principale representa en nuestro caso la contrapartida al principio de coherencia orgánica ${ }^{22}$, toda vez que por el primer principio la suerte del órgano se sigue de la que corre la organización, y por el segundo principio, el órgano queda desde su génesis misma al servicio de la organización a la que pertenece. Bajo esta idea inicial es evidente que si una Corte pertenece a una organización de integración, por simple coherencia institucional será una Corte de integración.

Lamentablemente sólo el TJUE pertenece a una organización de integración propiamente tal, la UE, por lo tanto el problema recae de inmediato en los modelos de América Latina, pues en dicha realidad no estamos ante organizaciones de integración plenas, ni menos supranacionales, sino ante organizaciones de aspiraciones integracionistas. Motivo por el cual se hace insuficiente recurrir de modo aislado al principio accesorium sequitur principale, sino que metodológicamente en esta investigación requeriremos de más ángulos de análisis, ya que si sólo atendemos a dicho principio, ninguna de las experiencias latinoamericanas se encuadraría perfecta en las exigencias del derecho de la integración.

Entonces para poder superar la barrera anotada, que elimina in limine a todos los modelos de América Latina, llevaremos adelante dos ejercicios, de un lado, constataremos si se dan o no, estatutariamente los patrones centrales, como exigencias mínimas que el derecho de la integración impondría a un tribunal para reconocerlo como una Corte de integración, y de otro lado, únicamente si hay coincidencias estatutarias, consideraremos que el nivel de desarrollo, será un aspecto secundario, para de esa forma no sancionarlos con la fácil conclusión de que las Cortes latinoamericanas bajo análisis no son Cortes de integración.

\footnotetext{
${ }^{22}$ Retengamos que el principio de coherencia orgánica rige la relación organización/órgano, en sentido de que la acción de los órganos tiene como fin el favorecer que la OI alcance sus metas. El principio de coherencia o de congruencia orgánica se recoge en varios Estatutos, v.gr. en el SICA en el art. 11 del PTC-ODECA donde se establece «El SICA velará por la eficiencia y eficacia del funcionamiento de sus órganos e instituciones asegurando la unidad y la coherencia de su acción», en la UE en el art. 13.1 del TUE señalando «La Unión dispone de un marco institucional que tiene como finalidad promover sus valores, perseguir sus objetivos [...] así como garantizar la coherencia, eficacia y continuidad de sus políticas y acciones». Políticas y acciones que se llevan adelante a través de dichos órganos. DE YTURRIAGA 1964, p. 99. Vid. nota 6 de este capítulo.
} 
Es decir, que bajo las circunstancias de existir coincidencias en los patrones centrales, podría constatarse que únicamente no hubieran alcanzado un desarrollo pleno, en cuyo caso y después de los análisis jurisprudenciales, les reconoceríamos una mayor o menor cercanía con la naturaleza jurídica de una Corte de integración. Los criterios de selección de las características esenciales — que explicaremos para cada una - nos arrojan a nuestro juicio, a lo menos seis patrones centrales, los cuales indicaremos y analizaremos a continuación.

\subsection{LOS SEIS PATRONES CENTRALES SELECCIONADOS DESDE EL TJUE}

A COTEJAR ESTATUTARIAMENTE CON LAS

CORTES LATINOAMERICANAS

La selección de las características específicas que buscaremos constatar en los estatutos de las Cortes bajo análisis, siguen un criterio que les exige cumplir con tres requisitos simultáneamente, esto es, deben estar presentes en el modelo del TJUE, además es indispensable que posean su correlato en los estatutos de las Cortes latinoamericanas, y por último son esenciales en un modelo de integración, por las razones que daremos en cada caso.

Pues bien estos seis patrones centrales son $1^{\circ} \mathrm{La}$ función interpretativa de las cartas constitutivas, $2^{\circ}$ La función consultiva, $3^{\circ}$ El control de legalidad de los actos de las Instituciones y órganos en sus formatos de control de actividad e inactividad, $4^{\circ} \mathrm{El}$ carácter de cuasi tribunales constitucionales, $5^{\circ}$ La obligatoriedad de sus sentencias, y $6^{\circ} \mathrm{El}$ reconocimiento del auctoritas al sentenciar.

Al estudiar estas seis características esenciales, iremos justificando en cada caso el por qué motivo la hemos seleccionado, y en su caso, observaremos la presencia legislativa que se aplica a la Corte de Luxemburgo respecto de dicho patrón central, pero únicamente en carácter de referencia para el cotejo con las Cortes latinoamericanas enfocadas, por lo tanto no desarrollaremos un análisis del modelo europeo, dado que no es nuestro objeto de estudio, sino que su descripción en algunos aspectos cumple — de modo acotado - con la función metodológica recién indicada. 


\subsubsection{LA FUNCIÓN INTERPRETATIVA DE LAS CARTAS CONSTITUTIVAS:}

SU JUSTIFICACIÓN Y SU PRESENCIA

ESTATUTARIA

La selección de la función interpretativa en carácter de patrón central para las Cortes latinoamericanas se debe a que consideramos que los Estados miembros de una determinada organización, al actuar bajo el respeto del principio de igualdad de los países miembros, se verán forzados — para no vulnerarlo - a recurrir a un órgano imparcial, técnico y jurídico, para la compleja labor que supone obtener el sentido exacto de los mandatos contenidos en las Cartas que estructuran a la organización, afectando de modo central a todos los concurrentes.

En tal ritmo las Cortes latinoamericanas deberían propender a monopolizar la actividad hermenéutica de los Estatutos y de las Cartas Fundacionales de la organización a la cual pertenecen, o bien, asumir la posición de última instancia en su ejercicio, tal como sucede en la UE donde el TJUE posee de modo exclusivo las competencias necesarias para desplegar la referida función. En este aspecto el TUE presiona sobre el hecho de que la Corte de Luxemburgo debe garantizar el respeto del Derecho de la UE al interpretar y aplicar los Tratados ${ }^{23}$. Sin embargo esta es una cuestión que no se replica en América Latina con igual intensidad, y aún más, en el MERCOSUR este aspecto es bastante débil pues el Protocolo de Olivos para la Solución de Controversias en el Mercosur (POPSCM) no le otorgó la función interpretativa ni a los TAAM, ni al TPRM, dejando un flanco abierto que debilita el modelo de tribunales en el merco-sistema, cuestión que la doctrina destaca de modo negativo constantemente ${ }^{24}$.

Distinta es la situación que encontramos en los modelos SICA y CAN, aplicable a la CCJ y al TJCA respectivamente. En el SICA se le atribuye a la Corte centroamericana el carácter

23 La fuente estatutaria en el modelo europeo se aprecia tanto en el TUE como en el TFUE, cuerpos normativos que le otorgan el carácter exclusivo de supremo intérprete al TJUE respecto del Derecho de la UE. En tal sentido el art. 19.1 del TUE señala que el TJUE «Garantizará el respeto del Derecho en la interpretación y aplicación de los Tratados». Misma disposición que luego es reiterada en el 19.3 en su letra b) al precisar «sobre la interpretación del Derecho de la Unión».

${ }^{24}$ Esta carencia competencial impide que se hable de un verdadero derecho y menos un derecho de integración efectivo, por ejemplo CHEDIAK y BENÍTEZ recuerdan de modo conjunto, que inicialmente se sostenía que no podría decirse que existiera ni un derecho ni un Tribunal de Justicia Mercosur propiamente tal. CHEDIAK GONZÁLEZ, J. \& BENÍTEZ RODRÍGUEZ, P. (2014). Acerca de la competencia consultiva del tribunal permanente de revisión mercosur y de la experiencia del poder judicial del uruguay en la tramitación de opiniones consultivas. Revista de la secretaría del tribunal permanente de revisión 2(4), pp. 83-91. 
de último intérprete del Derecho centroamericano, tanto a partir del Protocolo de Tegucigalpa a la Carta de ODECA (PTC-ODECA), como en el propio Estatuto de la CCJ. En el PTC-ODECA se le otorgan las competencias hermenéuticas de modo imperativo respecto del contenido de dicho Protocolo ${ }^{25}$. Por su parte el Estatuto de la CCJ robustece dicha potestad ampliándola hacia el derecho derivativo, primero la reitera de forma exclusiva para la CCJ respecto del PTC-ODECA, pero la expande cubriendo también los instrumentos complementarios y los actos derivados de los mismos ${ }^{26}$.

En cambio en la UE el fortalecimiento normativo se efectúa de manera más intensa, así las disposiciones del TUE - ya anotadas - pasan a ser reforzadas por las del TFUE atribuyéndole competencia exclusiva al TJUE para la interpretación de los Tratados a través de la cuestión prejudicial y suma la interpretación de los actos adoptados por las instituciones, órganos $\mathrm{u}$ organismos de la UE, cerrando con una obligación de comportamiento negativo para los Estados miembros, forzándolos a no someter cuestiones interpretativas de los Tratados a un procedimiento de solución distinto de los previstos en los mismos instrumentos ${ }^{27}$. Incluso el TJUE en su respuesta en Slowakische Republik/Achmea $B V^{28}$, señaló claramente que se opone al Derecho de la UE

«una disposición de un acuerdo internacional celebrado entre Estados miembros, [...] conforme a la cual un inversor de uno de esos Estados miembros puede, en caso de controversia sobre inversiones realizadas en el otro Estado miembro, iniciar un procedimiento contra este último Estado miembro ante un tribunal arbitral cuya competencia se ha comprometido a aceptar dicho Estado miembro» ${ }^{29}$.

Como apreciamos, de los dos párrafos anteriores, en el SICA se intenta darle el carácter de supremo intérprete a la CCJ procurando acercarse a las potestades del TJUE, pero el

\footnotetext{
${ }^{25}$ El inciso final del art. 35 del Protocolo de Tegucigalpa a la Carta de ODECA establece que «Toda controversia sobre la aplicación o interpretación de las disposiciones contenidas en el presente Protocolo y demás instrumentos [...], deberá someterse a la CCJ».

${ }^{26}$ El Estatuto de la CCJ utiliza básicamente dos disposiciones para reiterar y ampliar el mandato del PTCODECA, su art. 2 indica «La Corte garantizará el respeto al derecho, tanto en la interpretación como en la ejecución del Protocolo de Tegucigalpa». Luego en su art. 22, literal e) le atribuye competencia a la CCJ precisamente en «la interpretación y aplicación del PTC-ODECA, y de los instrumentos complementarios y actos derivados de los mismos».

${ }^{27}$ El TFUE emplea la letra a) del art. 267 para atribuirle al TJUE competencia exclusiva para la interpretación de los Tratados mediante la cuestión prejudicial. Suma la parte del contenido de la letra b) del mismo art. 267, indicando «interpretación de los actos adoptados por las instituciones, órganos u organismos de la Unión». Y añade el art. 344 como norma de clausura, el cual reza «Los Estados miembros se comprometen a no someter las controversias relativas a la interpretación o aplicación de los Tratados a un procedimiento de solución distinto de los previstos en los mismos».

28 Sentencia del TJ de 6 de marzo de 2018, Slowakische Republik/Achmea BV, as. C-284/16, ECLI:EU:C:2018:158.

${ }^{29}$ Considerando 60 en sentencia ibídem.

114
} 
resultado legislativo es en menor medida. Tal intento disminuye aún más para el caso de la CAN, pues la concreción inicial de este patrón central bajo análisis — la función interpretativa- quedó en el proyecto andino circunscrito exclusivamente a las competencias del TJCA para responder cuestiones prejudiciales, según lo dispuso el Tratado de Creación del TJCA ${ }^{30}$. Sin embargo, esta limitada circunstancia inicial vino a ser ampliada, en parte, en la CAN siguiendo la línea de las Motivaciones del Tratado de Creación del TJCA, el cual expresa:

«SEGUROS de que la estabilidad del Acuerdo de Cartagena [...] deben ser salvaguardados por un órgano jurisdiccional [...], con capacidad de declarar el derecho comunitario, dirimir las controversias que surjan del mismo e interpretarlo uniformemente» ${ }^{31}$.

Por tal motivo se sumó el Estatuto del $\mathrm{TJCA}^{32}$, el cual vino a agregar diversa normativa en este sentido, ahora sí estableciendo que el TJCA está instituido para declarar, interpretar, asegurar y aplicar el Derecho andino. Aunque manteniéndose en este documento la vinculación de la función interpretativa a las cuestiones prejudiciales. Además se creó la obligación del juez nacional de consultar a la Corte andina cada vez que se esté conociendo en única instancia y se haya controvertido el derecho de la $\mathrm{CAN}^{33}$.

En contraste a todo lo anterior, tanto respecto del modelo de la UE como del SICA y de la CAN, en el MERCOSUR, como ya apuntamos en el segundo párrafo de este apartado, el POPSCM no le otorgó la función interpretativa ni a los TAAM, ni al TPRM, y ha debido ser el desarrollo y ejercicio de los mismos tribunales mercosureños los que han ido

${ }^{30}$ El Tratado de Creación del TJCA en su Sección Tercera, titulada De la Interpretación Prejudicial, puntualmente en su art. 32 acota el campo de aplicación de la potestad hermenéutica así: «Corresponderá al Tribunal interpretar por vía prejudicial las normas que conforman el ordenamiento jurídico de la CA». En tanto el art. 34 únicamente agrega, en lo pertinente, formalidades de dicha interpretación prejudicial, sin ampliarla a otros campos, expresando «En su interpretación, el Tribunal deberá limitarse a precisar el contenido y alcance de las normas que conforman el ordenamiento jurídico de la Comunidad Andina, referida al caso concreto».

${ }^{31}$ Párrafo quinto de las Motivaciones del Tratado de Creación del TJCA.

${ }^{32}$ El Estatuto del TJCA fue concretado por la Decisión 500.

${ }^{33}$ En el Estatuto del TJCA encontramos este nuevo desarrollo en su art. 4 el cual asume el cauce rector indicando que el TJCA está «instituido para declarar el derecho andino y asegurar su aplicación e interpretación uniforme en todos los Países Miembros». Reitera la potestad en el art. 121 «Corresponde al Tribunal interpretar las normas que conforman el ordenamiento jurídico de la CA». Manteniéndose en este documento la vinculación de la función interpretativa a las cuestiones prejudiciales, así se aprecia del art. 122 «Los jueces nacionales que conozcan de un proceso en el que deba aplicarse o se controvierta alguna de las normas que conforman el ordenamiento jurídico de la CA, podrán solicitar, [...], la interpretación del Tribunal acerca de dichas normas». La obligación del juez local de consultar al TJCA si conoce en única instancia y se ha controvertido el derecho de la CAN se encuentra en el art. 123 y debe seguir las condiciones del art. 125 . 
aminorando la carencia ${ }^{34}$, ésta es precisamente una de las cuestiones que abordaremos en los análisis jurisprudenciales en los capítulos III y IV de esta tesis. Pero lo que destacamos aquí es que, aun cuando dicha carencia se aminore a través del ejercicio jurisprudencial, igualmente la función interpretativa queda en segundo plano ante los Estatutos. Por tal razón, esta solución pasa a ser la causa por la cual la actividad hermenéutica del sistema jurisdiccional mercosureño sea considerada como tangencial, toda vez que debe utilizarse una compleja solución mediante el art. 3 del POPSCM, que le otorga al Consejo Mercado Común (CMC) la potestad para crear mecanismos de consulta. Por lo tanto en el MERCOSUR la función interpretativa se vincula fuertemente con la función consultiva.

Como apreciamos entonces, de este primer cotejo del marco estatutario y de las Cartas Fundacionales de los modelos latinoamericanos enfocados, sus respectivas Cortes desde el ángulo de sus bases legislativas, se ubican distantes del modelo europeo. Ahora bien, sus posiciones internas en América Latina ordenadas por cercanía con la UE dejan a la CCJ como la relativamente más próxima, luego le sigue la CAN y al final el TPRM y los TAAM.

El punto no es menor pues el patrón central aquí analizado - la función interpretativasimultáneamente implica a todas las demás competencias necesarias para ejecutar la función en análisis, generando una utilidad en otros aspectos, así por ejemplo pasan a ser uno de los afluentes que le da a la Corte de integración el carácter de cuasi tribunal constitucional, cuestión que analizaremos por separado más adelante ${ }^{35}$. Además hay que considerar la cercanía en que se ubica la función hermenéutica de las Cartas Fundacionales, con la función consultiva, las que van en razón de objeto/herramienta, y que también veremos por separado.

\footnotetext{
${ }^{34}$ Esta variación se produce mediante el ejercicio jurisprudencial, lo cual es muy relevante para nuestros intereses por tal motivo la estudiaremos en los capítulos III y IV. En esta línea FERNÁNDEZ destaca el cambio, expresando que el Mercosur «como esquema de integración del cono Sur de América, ha generado un ordenamiento jurídico propio», afirmación que la basa, precisamente, en la labor de sus Tribunales Mercosur. FERNÁNDEZ REYES, J. (2006). El orden jurídico del mercosur. Revista de derecho, 5(9), 27-51.

${ }^{35}$ Así por ejemplo SÁIZ lo pone de manifiesto señalando «Más importancia que todo cuanto hasta aquí se ha escrito tiene sin duda la propia percepción que el Tribunal estudiado tiene de sí mismo y de sus funciones como órgano de garantía constitucional en su calidad de 'último interprete' del ordenamiento comunitario y de primacía del derecho que lo integra (originario y derivado)». SÁIZ ARNÁIZ, A. (1999) "El tribunal de justicia de las comunidades europeas como tribunal constitucional”, Revista vasca de administración pública. 2, pp. 223-256 (p. 229).

116
} 


\subsubsection{LA FUNCIÓN CONSULTIVA EN LAS CORTES LATINOAMERICANAS:}

SU JUSTIFICACIÓN Y SU PRESENCIA

La importancia de que la función consultiva se encuentre presente en los esquemas de integración latinoamericanos, SICA, CAN y MERCOSUR, se justifica por varias razones concretas, primero, porque dicha función, en una de sus caras, posee una eminente naturaleza casacional, lo que evita una incoherencia legal entre la pretensión con el orden jurídico del SICA, de la CAN o del MERCOSUR según sea el caso, segundo, por lo estratégico de su carácter preventivo, es decir corre en ritmo de economía procesal, tercero, porque si hacemos uso de la experiencia del referente, en la UE esta función pasó a ser de gran relevancia, aplicándose mediante las cuestiones prejudiciales como pieza jurisdiccional esencial del sistema según apunta la doctrina ${ }^{36}$, y a través de la solicitud de dictámenes consultivos sobre acuerdos internacionales, de allí entonces que América Latina debiese poner sus esfuerzos por perfeccionar sus estructuras legales en este aspecto, y cuarto, porque tiene importantes y ricos desarrollos procesales al servicio del derecho material $^{37}, v \cdot g r$. sus cauces de manifestación pueden ser consultivo político-orgánica, o bien consultivo prejudicial, en cuyo caso, puede ser a su vez de interpretación o de validez.

La función consultiva se corresponde con una operación de cotejo previo sobre la compatibilidad de una cuestión de hecho o de derecho que se pretende realizar $v / s$ el Derecho de la organización respectiva. En el caso de las Cortes latinoamericanas tal función se presenta de modo diferente y contrastando bastante con el modelo europeo. En el SICA - a diferencia de la UE — hay hasta una triple diferenciación, distinguiéndose las consultas prejudiciales, las vinculantes y las ilustrativas. Las dos primeras fluyen sin grandes disensos del modelo europeo. Pero las ilustrativas son completamente propias del

\footnotetext{
${ }^{36}$ En el esquema jurisdiccional construido en la UE las cuestiones prejudiciales se transformaron en piezas claves. Por ejemplo LIÑÁN señala que las funciones consultivas vía las cuestiones prejudiciales son una manifestación del principio de cooperación y se han convertido en la pieza más importante de todo el sistema de control judicial. LIÑÁN, 2014d, p. 465. En misma línea RODRÍGUEZ expresa que la competencia prejudicial constituye, quizás, el elemento más importante del sistema judicial de la Unión. RODRÍGUEZ, 2010, p. 646. Por su parte MARTÍNEZ reconoce que, por esta vía la labor del juez local supera el ámbito interno. MARTÍNEZ LAFUENTE, A. (2016). La cuestión prejudicial en el derecho de la unión europea. Carta tributaria. Revista de opinión, (19), 11-34.

${ }^{37}$ En el caso de esta tesis el concepto de derecho material o sustancial coincide con del derecho de la integración comprendido en sentido amplio. Por su parte, tal sentido amplio del derecho de la integración, es comprendido como ya lo establecimos en nuestro marco teórico, por el cual para los latinoamericanos el derecho de la integración viene a ser un genérico cuya fuente de desarrollo es la UE. Vid. número 2 de la introducción de esta tesis.
} 
SICA y por dicho cauce aparece una singularidad de la CCJ, cual es que asume el rol de órgano de consulta para las construcciones legislativas nacionales y de Tratados vigentes.

Tal competencia se presenta desde las Motivaciones del Estatuto de la CCJ, donde se expresa «se le da atribución de Órgano de Consulta Permanente de la CCJ, conociendo las consultas que le formulen, así como emitiendo recomendaciones que propicie la emisión de leyes uniformes» ${ }^{38}$. Por su parte en la CAN también se presenta la función consultiva y con varias finalidades, incluso de modo bastante singular pues en algunos aspectos se aplica a cuestiones orgánicas que afectan a la misma Corte, así por ejemplo encontramos el uso de la consulta para modificar la cantidad de jueces, crear el cargo de Abogado General y la modificación del Estatuto del mismo TJCA, como se aprecia todos estos aspectos son netamente orgánicos y no jurisdiccionales ${ }^{39}$. Ambos modelos, el SICA y la CAN, contrastan absolutamente con el MERCOSUR, donde otra vez más constatamos que su construcción legislativa, en comparación a las de su entorno latinoamericano, es la más débil.

Dicha débil posición del MERCOSUR tiene su explicación en que el POPSCM sólo se aproximó a la función consultiva, otorgándole al CMC la potestad para crear algún mecanismo referido a consultas que pudiesen dirigirse al TPRM, sin desarrollar esta institución, es decir, que desde el ángulo estatutario sucede que el ordenamiento originario mercosureño sólo contempló la posibilidad de la existencia de las opiniones consultivas, más no así su procedimiento, ni especificó la legitimación activa ${ }^{40}$.

Las consultas prejudiciales son herramientas del derecho procesal de conexión entre tribunales intra-sistema, debido a que vinculan a dos tribunales pertenecientes a un mismo sistema, ya sea éste nacional — v.gr. en el derecho constitucional- o transnacional sui generis — SICA, CAN o MERCOSUR - o supranacional — en la UE —, todos gracias al mecanismo más amplio conocido como comunicación entre tribunales o colaboración judicial o auxilio judicial ${ }^{41}$. Nacen en el ámbito del Derecho Constitucional bajo la noción

\footnotetext{
${ }^{38}$ Párrafo quinto del apartado Competencias, de las Motivaciones del Estatuto de la CCJ.

${ }^{39}$ El Tratado de Creación del TJCA en el inciso $3^{\circ}$ del art. 6 establece «El Consejo Andino de Ministros de Relaciones Exteriores, en consulta con el Tribunal, podrá modificar el número de magistrados y crear el cargo de Abogado General». Luego el art. 13 añade «Las modificaciones al Estatuto del TJCA, aprobado mediante la Decisión 184, se adoptarán por [...] y en consulta con el Tribunal».

${ }^{40}$ El POPSCM en su art. 3 dejó en manos del Consejo Mercado Común la posibilidad para «establecer mecanismos relativos a la solicitud de opiniones consultivas al TPRM definiendo su alcance y procedimiento».

${ }^{41}$ La teoría de la comunicación entre tribunales, o los actos de comunicación con otros jueces, o el auxilio judicial, dan cuenta de la noción de conexión entre los órganos que ejercen jurisdicción, tanto desde las perspectivas orgánicas como extra-orgánicas. Nosotros entendemos que las consultas prejudiciales son herramientas procesales de conexión intra-sistema. Diferente de la conexión que veremos en el Capítulo IV 118
} 
de la técnica del reenvío, cuyo fin es tener una temprana comunicación entre el juez de la causa y el Tribunal Constitucional. Por lo tanto poseen un origen muy anterior a los modelos de jurisdicción de los esquemas de integración que estamos analizando.

La UE lo que hace es importar la técnica del reenvío para su singular sistema judicial, pero la dificultad en esta construcción, de aristas transnacionales, la torna más compleja que en un nivel nacional acotado al Derecho Constitucional, pues en el ámbito local el cotejo se efectúa intra-muros estatales, en un mismo sistema nacional donde todas las normas deberían obedecer a los principios y costumbres locales. En cambio en la UE hay mayor complejidad, pues cada Estado arrastra su propio sistema — common law o continental - y costumbres, a los que se les exige compatibilidad con uno externo y de superior jerarquía.

Otro aspecto relevante de este patrón central, y del cual pueden gozar el SICA, la CAN y el MERCOSUR, consiste en que también es una concreción del principio de economía procesal. Pues por intermedio de las consultas prejudiciales se evita tener que esperar un pronunciamiento de última instancia. Así, de modo anticipado se encauza la littis en coherencia con el Derecho del SICA, de la CAN o del MERCOSUR según corresponda. Si bien, dicha economía no va a impedirle a las partes que utilicen hasta la última instancia, cuando lo hagan y llegue el proceso a la sede judicial final, su arribo será ya encausado hacia el Derecho que en cada caso corresponda.

Por otra parte las consultas prejudiciales son una herramienta concreta y eficiente de que dispone el juez nacional, comprendido este juez, como el primer llamado a hacer cumplir el derecho de la integración, de ese modo fue concebido en el modelo europeo y con ese mismo tenor se expandió el concepto hacia América Latina cuestión que la doctrina ${ }^{42}$ lo resalta bajo el antiguo carácter del juez natural.

En simples términos comparativos, en Europa el TJUE recibe esta competencia por un doble cauce, mediante las consultas en cuestiones prejudiciales y por medio de la solicitud de dictámenes consultivos sobre acuerdos internacionales. Por las primeras el TJUE es

sobre diálogo judicial donde encontraremos conexiones extra-sistemas. GUASP explica que para la misión que se les está encargada a los tribunales, éstos pueden pedir asistencia a otros órganos, la que puede ser interjudicial o no, pero siendo inter-jurisdiccional se detecta un caso especial de asistencia, el auxilio jurisdiccional internacional o externo, que habitualmente toma el cauce de la diplomacia y de los Tratados Internacionales. GUASP, J. (1968). Derecho procesal civil : Tomo primero : Parte general ( $3^{\mathrm{a}}$ ed., $2^{\mathrm{a}}$ reimp.). Madrid: Instituto de Estudios Políticos., pp. 112-114.

${ }^{42}$ En el proyecto centroamericano SICA — al igual que en la UE- es el juez nacional el que procesalmente asume la naturaleza de juez natural. ULATE lo destaca así, el juez nacional, sigue siendo, el juez natural de la justicia comunitaria. ULATE, 2008. Sobre el concepto técnico de juez natural vid. COUTURE, 1958, p. 98. Otro, CHIOVENDA [Gómez \& Greco, trans.], 2005, p. 135. 
competente para pronunciarse por la validez o la interpretación de alguna norma, mediante la técnica del reenvío ${ }^{43}$, y la legitimación activa en su caso, se divide entre las que poseen los jueces locales para plantearlas, y la posibilidad de los litigantes de pedirle al juez que él las plantee, en sus versiones de interpretación y de validez. Por el segundo cauce — los dictámenes consultivos sobre acuerdos internacionales - el TJUE se conecta procesalmente con aquel tipo de competencia conocida como control de constitucionalidad a priori. Ejercicio de verificación de la compatibilidad del Derecho de la UE $v / s$ las normas del acuerdo en cuestión ${ }^{44}$, básicamente aquí los legitimados son los órganos permanentes de la organización y los Estados miembros.

En este último aspecto de la UE — sobre materias de nuevos acuerdos internacionalesencontramos una interesante diferencia con el SICA, ya que en el modelo Centroamericano se diferencia respecto de las solicitudes de dictámenes consultivos, estableciéndose en primer lugar que son vinculantes las respuestas de la CCJ a las consultas de los órganos y organismos del SICA en la interpretación y aplicación del PTC-ODECA y de los instrumentos complementarios y actos derivados, y en segundo lugar — aquí lo novedososon sólo ilustrativas las respuestas de la CCJ sobre un Tratado vigente ${ }^{45}$.

El carácter ilustrativo en el SICA no es una debilidad del sistema Centroamericano, sino un aporte adicional local, ya que no se vulnera la obligatoriedad que corre por ejemplo en la UE para las respuestas a las consultas, pues también son vinculantes en el proyecto de Centroamérica. Lo que sucede es que el SICA añade más tipos de consultas, por una parte

${ }^{43} \mathrm{El}$ art. 267 del TFUE es la norma que hace competente al TJUE para pronunciarse por la validez o la interpretación de alguna norma, a través del empleo del reenvío. El segundo párrafo de este artículo indica «Cuando se plantee una cuestión de esta naturaleza ante un órgano jurisdiccional de uno de los Estados miembros, dicho órgano podrá pedir al Tribunal que se pronuncie sobre la misma» y en el mismo sentido corren los incisos siguientes de dicha norma.

${ }^{44}$ Esta potestad se le atribuyó al TJUE en los arts. 207.3, 207.5 y, principalmente en el 218.11 del TFUE. El art. 218.1 del TFUE — dejando a salvaguarda las disposiciones del art. 217- anuncia un procedimiento de control previo, que luego detalla para la celebración de acuerdos en el cual participan diversos órganos e Instituciones de la UE, reservándose el punto final, el 218.11, para otorgar la potestad a cualquier Estado miembro e Institución de solicitar un dictamen consultivo al TJUE, así «Un Estado miembro, el Parlamento Europeo, el Consejo o la Comisión podrán solicitar el dictamen del TJ sobre la compatibilidad con los Tratados de cualquier acuerdo previsto». En tanto el art. 207 inmerso en la política comercial común de la UE remite, en lo no puntualizado por él, al art. 218, cerrándose de esta forma el marco normativo principal en esta materia para la UE.

${ }^{45} \mathrm{El}$ art. 23 del Estatuto de la CCJ dispone «Los Estados podrán formular consultas con carácter ilustrativo a La Corte sobre la interpretación de cualquier Tratado o Convención Internacional vigente; también, respecto a conflictos de los Tratados entre sí o con el Derecho Interno de cada Estado». Se suman como ilustrativas, las respuestas de la CCJ a las Cortes Supremas de los Estados miembros, según el literal d) del art. 22 del mismo Estatuto «Actuar como Tribunal de Consulta Permanente de las Cortes Supremas de Justicia de los Estados, con carácter ilustrativo».

120 
para Tratados vigentes y por otra para las Cortes Supremas no conociendo de un juicio, sino de modo permanente para otros aspectos. Son estos dos nuevos conductos los que reciben respuestas ilustrativas. Por lo tanto es en realidad una arista de desarrollo del SICA que observamos como muy positiva. Por su parte ni el esquema de la CAN, ni el del MERCOSUR contemplan consultas o dictámenes para el proceso de análisis de Tratados Internacionales futuros — ni menos vigentes como en el caso del SICA - distanciándose por completo en este aspecto de la UE y del SICA.

Pero la gran utilidad de la función consultiva y la de mayor tráfico procesal es la que se despliega por el cauce de las consultas prejudiciales, y en este aspecto, analizadas las tres respuestas latinoamericanas se observan diferencian entre sí. En el SICA las competencias para responder consultas en cuestiones prejudiciales le vienen dadas a la Corte centroamericana en el mismo Estatuto de la CCJ, instrumento que además les imprime el carácter de obligatorias $^{46}$. En tanto en el modelo de la CAN la concreción prejudicial de la función consultiva se contiene en varias disposiciones del Tratado de Creación del TJCA, convirtiendo en obligatoria la consulta en casos de recursos de inaplicabilidad ${ }^{47}$, y singularmente se otorga legitimación activa a los jueces locales de modo dual, por una parte, meramente potestativa, en un procedimiento cuya sentencia pueda recurrirse, y obligatoria, en caso de conocer en única instancia. Sumándose una segunda particularidad, cual es que, no se obliga al juez nacional a esperar la respuesta del TJCA si el proceso ya está en etapa de dictar sentencia, cuestión muy diferente en el esquema europeo donde evidentemente los jueces nacionales esperan la respuesta del TJUE y también en el SICA.

En todo caso en la CAN se establece la obligatoriedad de aplicar la respuesta del TJCA en la sentencia definitiva del juez local. Observamos entonces que se intenta equilibrar en el modelo de la CAN, la obligatoria suspensión del procedimiento $v / s$ la libertad para sentenciar sin esperar el criterio de la Corte andina, dependiendo de si, procesalmente, procede o no algún recurso y, si se encuentra la causa en estado de dictar sentencia, cuestión que hemos extraído del conjunto de normas ${ }^{48}$ del Estatuto del TJCA.

\footnotetext{
${ }^{46} \mathrm{El}$ art. 22 del Estatuto de la CCJ en su literal k) le atribuye la potestad a la CCJ indicando «Resolver toda consulta prejudicial requerida por todo Juez o Tribunal Judicial que estuviere conociendo de un caso». Y las respuestas son vinculantes, según se observa del art. 24 del Estatuto de la CCJ «Las consultas evacuadas por La Corte [...], relativas al SICA, serán obligatorias para los Estados que la integran».

${ }^{47}$ El Tratado de Creación del TJCA contempla en el inciso $3^{\circ}$ del art. 20, que «Presentada la solicitud de inaplicabilidad, el juez nacional consultará acerca de la legalidad de la Decisión, Resolución o Convenio, al TJCA». Y luego en su Sección Tercera en los arts. 32 al 35 le atribuye competencias al TJCA para responder consultas sobre el Ordenamiento Jurídico de la CAN.

${ }^{48}$ El cúmulo normativo al que nos referimos es el siguiente: El Estatuto del TJCA establece en su art. 104 «Presentada la solicitud de inaplicabilidad [...] el juez nacional consultará acerca de la legalidad de la Decisión, Resolución o Convenio al TJCA y suspenderá». En su Capítulo III se vincula la función consultiva con la función interpretativa — conexión habitual entre estas dos funciones, como ya lo comentamos- así el
} 
Respecto del MERCOSUR, como dijimos más arriba, desde el ángulo estatutario su ordenamiento originario sólo contempló la posibilidad de la existencia de las opiniones consultivas, pero no su procedimiento, ni la legitimación activa, por lo tanto todo lo referido a este patrón central - la función consultiva - quedó encargado a la norma derivativa. Cuestión que básicamente se resolvió diferenciando entre, si las opiniones consultivas son dirigidas por los Tribunales Superiores de Justicia de los Estados miembros, únicamente podrán referirse a la interpretación jurídica del Tratado de Asunción, del Protocolo de Ouro Preto, Decisiones CMC y otros, en cambio, las que procedan de los Estados miembros, actuando conjuntamente, o de los Órganos del Mercosur, se podrán referir a cualquier cuestión jurídica relativa a esas mismas fuentes del Derecho mercosureño $^{49}$.

Sin embargo la debilidad del merco-sistema ante este patrón central bajo análisis, se hace patente, toda vez que ninguna de las respuestas del TPRM son vinculantes ${ }^{50}$. El cúmulo de los precedentes aspectos técnico-procesales del merco-sistema, inciden en el real acceso al sistema de administración de justicia en el MERCOSUR, aparejando una evidente complejidad que afecta al ejercicio del TPRM. Cuestión sobre la que volveremos en los capítulos siguientes al abordar los análisis jurisprudenciales. Tal carencia hace que el MERCOSUR se distancie muchísimo de los otros proyectos latinoamericanos y del todo del europeo. Siendo un hecho que esta circunstancia se debe a la inicial naturaleza intergubernamental del MERCOSUR. En la actualidad, el referido infra desarrollo es una de las grandes debilidades del sistema mercosureño ${ }^{51}$ que debería superarse con el proyecto de la nueva Corte de Justicia Mercosur que está prevista.

En conclusión, la importancia de este patrón central - la función consultiva - en la dimensión de las respuestas a las consultas prejudiciales, no transita únicamente por el hecho de que sean vinculantes las respuestas, como lo son en la UE, en el SICA y en la

art. 122 titulado Consulta facultativa, le otorga competencia al juez local para efectuar la consulta de modo facultativo, si contra su sentencia procede recurso, y no le obliga a esperar la respuesta del TJCA si los autos están en etapa de sentenciar. En tanto el art. 123 Consulta obligatoria, le exige al juez local efectuar la consulta si conoce en única instancia, caso en que el art. 124 le obliga a suspender el procedimiento hasta recibir respuesta. Los requisitos formales se presentan en el art. 125 mediante las denominadas condiciones y requisitos para la formulación de la consulta.

${ }^{49}$ Artículo 4 de la Decisión 37/03 de la CMC.

${ }^{50}$ El Reglamento del POPSCM en su art. 11 denominado Efecto de las opiniones consultivas, hace evidente la debilidad expresando «Las opiniones consultivas emitidas por el TPR no serán vinculantes ni obligatorias».

${ }^{51}$ Para CIENFUEGOS esta es, precisamente, una de las aristas que deberían superarse tras la implementación de la nueva CJM, proyecto de futuro que nosotros abordaremos en el capítulo V. CIENFUEGOS MATEO, M. (2012b). Opiniones consultivas en el mercosur y cuestiones prejudiciales en la unión europea: Estudio comparativo. Revista de derecho comunitario europeo, 16(42), 433-476.

122 
CAN, sino además por las profundas implicancias conceptuales que conllevan. En este sentido consideramos que el sólo hecho de reconocer como fuente de consulta idónea al tribunal, en aristas tan sensibles de la vida de la organización, no puede sino ser un claro reflejo del reconocimiento del auctoritas del sentenciador y del consecuente sometimiento implícito a sus decisiones. De hecho tal labor es efectuada en los ordenamientos estatales por los respectivos Tribunales Constitucionales. Por todo lo anterior es trascendente que en América Latina se verifiquen estas competencias y además que sean robustas y eficientes.

\subsubsection{El CONTROL DE LEgALIDAD DE LOS ACtOS EN LAS CORTES}

LATINOAMERICANAS: SU JUSTIFICACIÓN Y

SU PRESENCIA ESTATUTARIA

Hemos seleccionado la función de control de legalidad de los actos en carácter de tercer patrón central que debiese presentarse en las Cortes latinoamericanas CCJ, TJCA y TPRM, pues consideramos que esto necesariamente implicaría que el SICA, la CAN y el MERCOSUR posean estatutariamente un ordenamiento jurídico lo suficientemente complejo y robusto como para que el tribunal tenga la necesidad de efectuar un control, además supondría que el tráfico de actividades de consecuencias jurídicas de los órganos e Instituciones latinoamericanas sea bastante intenso, como para que la necesidad de controlar la actividad o inactividad sea imperiosa, y todo lo anterior debería redundar en el lógico sometimiento obligatorio a la decisión de las Cortes latinoamericanas tras sus respectivos controles, de lo contrario toda fiscalización jurisdiccional carecería de sentido.

La respuesta nuevamente es dispar al interior del concierto latinoamericano, y a su vez todos estos modelos quedan muy alejados del esquema europeo construido para enfrentar el control de legalidad. En el SICA la respuesta viene dada por tres líneas, la acción de nulidad, la acción de incumplimiento y por el cauce de las consultas prejudiciales. Por su parte en la CAN se aumenta a cuatro herramientas, la acción de nulidad, la acción de incumplimiento, el recurso por omisión o inactividad y a través de las consultas prejudiciales. Pero el MERCOSUR, una vez más queda atrás, aunque esta vez del todo, ya que no posee ningún desarrollo especial para que sus tribunales puedan llevar adelante la función de control de legalidad, tan sólo se presenta de modo indirecto el uso de su singular mecanismo de consultas.

Entonces sólo dos de los tres modelos latinoamericanos construyeron herramientas específicas para afrontar el control de legalidad de los actos, sin embargo dichas respuestas legislativas del SICA y de la CAN se distancian considerablemente del modelo europeo, 
donde la función de control de legalidad de los actos que lleva adelante el TJUE se despliega en formatos de control de actividad y de inactividad de las Instituciones y órganos. Las competencias para llevar adelante tal función el TJUE las ejercita realizando una operación comparativa entre el bloque de legalidad de la UE $v / s$ la posición activa o pasiva asumida por el encausado. Pudiendo culminar en la anulación de un acto, o en la constatación de una omisión, o en la inaplicabilidad de un acto a un caso concreto.

Dicho control en la UE es de carácter amplio, pues de un lado, confirma actos equiparables a los administrativos de los Estados con las normas que los fundamentan, es decir, directamente de legalidad, y de otro, destaca un control del tipo constitucional, cada vez que revisa los actos normativos generales con los Tratados Constitutivos. Pero en definitiva el TJUE utiliza hasta cinco cauces, agrupables en tres criterios de intensidad, del siguiente modo, primero y principalmente, con tres herramientas, el recurso de anulación, el recurso por omisión y la excepción de ilegalidad. Luego por un conducto colaborativo continúa con las cuestiones prejudiciales de validez. Finalmente de manera indirecta concluye con la acción indemnizatoria.

Para el buen funcionamiento del SICA, de la CAN y del MERCOSUR es crucial su alineación con la legalidad vigente a efectos de cumplir con sus objetivos, por lo tanto el desarrollo para dejar a cubierto este patrón central se aprecia incompleto en los dos primeros, e inexistente en el tercero. En la UE la decisión de contar con un amplio espectro de herramientas utilitarias a la función de control de legalidad, da cuenta de la importancia que esto tiene para el mantenimiento del buen funcionamiento de su mega-sistema. En Latino América, cronológicamente, fue el SICA el primero en incorporar este tipo de herramientas para la CCJ, pues el TJCA nace con mucha posterioridad en la CAN, así entonces el proyecto andino contaba con dos precedentes para implementar su modelo de control, y efectivamente desarrolló una respuesta legislativa más robusta que la del SICA.

Ahora bien, y en su justa medida, en el SICA la existencia y ejercicio de sus tres herramientas dispuestas para el control de legalidad, es prueba del interés del plan Centroamericano por ser considerado como un proyecto integracionista serio, circunstancia destacada por la doctrina ${ }^{52}$. Esta función se le atribuyó a la CCJ estableciéndole la potestad de conocer de las acciones de nulidad y de incumplimiento de los acuerdos de los

\footnotetext{
${ }^{52}$ En este sentido de progreso en cuanto el proyecto Centroamericano se orienta hacia una verdadera dimensión integracionista, ULATE la destaca lo suficiente cuando ingresa al análisis del SICA y de la CCJ, remarcando que, una característica esencial - nosotros las hemos denominado patrones centrales en esta tesis- de las comunidades de derecho es la garantía del control jurisdiccional al que están sometidos los Estados miembros, las Instituciones, los órganos y los particulares. ULATE CHACÓN, E. (2008). El protocolo de tegucigalpa y la jurisdicción de la corte centroamericana de justicia. REIB: Revista electrónica iberoamericana, 2(2), 23-42.
}

124 
organismos del SICA y de resolver toda consulta prejudicial requerida por todo juez que estuviere conociendo de un caso pendiente, encaminada a obtener la aplicación o interpretación uniforme del derecho originario y derivativo centroamericano ${ }^{53}$. Por su parte en la CAN, la función en análisis se le encargó al TJCA, cuestión que fue considerado por la doctrina ${ }^{54}$ como muy idóneo, ya que únicamente el garante de la legalidad dentro de la estructura de la CAN es el que debe efectuar tal neurálgico control, siendo el mismo Estatuto del TJCA el que le otorgó las competencias a la Corte andina en estas materias fiscalizadoras a través de los cuatro ${ }^{55}$ cauces ya indicados.

\subsubsection{LA PRESENCIA LEGISLATIVA DE LAS ACCIONES DE NULIDAD Y DE INCUMPLIMIENTO DEL SICA V/S LA ACCIÓN DE INCUMPLIMIENTO Y EL RECURSO POR OMISIÓN O DE INACTIVIDAD DE LA CAN}

En el SICA y en la CAN no hay que confundir la denominada acción de incumplimiento, pues si bien en ambos esquemas legislativos se utiliza tal concepto, son diferentes en cada uno. Así, en el SICA la acción de incumplimiento comporta una herramienta al servicio de la función de control, pero muy poco especificada, únicamente bajo la fórmula legislativa que reza «Conocer de las acciones de nulidad y de incumplimiento de los acuerdos de los organismos del SICA» ${ }^{56}$. Tal reduccionismo legislativo permite dirigir dicha acción de modo amplio en contra de los Estados miembros, como de los órganos y organismos del SICA. A diferencia de lo que observamos en la CAN, donde el progreso estatutario es bastante superior al centroamericano desde dos perspectivas, primero, por el hecho de que posee dos tipos de acciones bien diferenciadas, una es la acción de incumplimiento ${ }^{57}$ y la

\footnotetext{
${ }^{53}$ El Estatuto de la CCJ en su Capítulo II titulado De la competencia y otras facultades, a través del art. 22, establece estas competencias, en su literal b) indica «Conocer de las acciones de nulidad y de incumplimiento de los acuerdos de los organismos del Sistema de la Integración Centroamericana». Se suma el literal k) el cual establece «Resolver toda consulta prejudicial requerida por todo Juez o Tribunal Judicial que estuviere conociendo de un caso pendiente de fallo encaminada a obtener la aplicación o interpretación uniforme de las normas que conforman el ordenamiento jurídico del "Sistema de la Integración Centroamericana", creado por el "Protocolo de Tegucigalpa", sus instrumentos complementarios o actos derivados del mismo").

${ }^{54}$ El carácter de garante de legalidad debe ser asumido por el órgano jurisdiccional que pretenda llegar a ser una Corte de integración. Así lo ha concluido la doctrina especializada, por ejemplo, y en este caso regional americano, VIGIL, estudiando a la CAN hace hincapié en que: la base de la integración regional reposa en que exista un garante de su legalidad, que no es otro que el Tribunal Andino. VIGIL TOLEDO, R. (2011). La estructura jurídica y el futuro de la comunidad andina ( $1^{\mathrm{a}}$ ed.). Madrid: Civitas Thomson Reuters., p. 71.

${ }^{55}$ El Estatuto del TJCA en su Título Tercero, denominado De las acciones en particular, a partir del art. 101 y ss., regula estos cuatro cauces: 1) la acción de nulidad, 2) la de incumplimiento, 3) las consultas prejudiciales, y 4) el recurso por omisión o inactividad.

${ }^{56}$ Art. 22, letra b) del Estatuto de la CCJ.

${ }^{57}$ La acción de incumplimiento se encuentra regulada entre los artículos 107 a 111 del Capítulo II del Título Tercero del Estatuto del TJCA.
} 
otra es el recurso por omisión o inactividad ${ }^{58}$, y segundo, porque en ambos casos, objetivamente hay mucho más desarrollo legislativo que en el SICA, toda vez que aquí en la CAN, se va explicando detalladamente el tipo de acción, sus efectos, la caducidad, los efectos de la sentencia y demás aspectos.

En la CAN el recurso por omisión o inactividad, está previsto para compeler al Consejo Andino de Cancilleres, o a la Comisión, o a la Secretaría General, cuando incumplan una actividad a la que están obligados por el Derecho andino. Aunque previamente es menester agotar el cauce administrativo ante el mismo órgano incumplidor, lo que es similar a la fase previa que se contempla en la UE. Entendiéndose en la CAN que, si se le ha dirigido por escrito el requerimiento al órgano en cuestión y éste no responde dentro de treinta días - y no dos meses como en la UE- dicho cauce queda agotado, abriéndose en ese momento la posibilidad de interponer esta acción por omisión o inactividad.

En contraste a lo anterior, en la UE el recurso por omisión comporta un test respecto de que una abstención sea contraria a los Tratados — no a que una actuación sea incorrecta, para eso existe el recurso de anulación - y viene a complementar el control de legalidad por el extremo de determinar si es o no legal una inacción de alguna Institución, órgano u organismo $^{59}$. Es relevante considerar que el TJUE solo dicta una sentencia declarativa - no de condena- por lo tanto la doctrina ${ }^{60}$ acusa que se le resta peso al recurso, pues no se obtiene de inmediato un resultado final, sino que posteriormente debe utilizarse otro procedimiento, v.gr. un recurso de nulidad. Así entonces, en realidad en la UE la pretensión del actor se resuelve mediante tres etapas: primero, una fase previa no contenciosa en la cual se interpela al posible requerido para que exponga su criterio, o ejecute el acto, otorgándole dos meses; segundo, luego de caducado dicho plazo, puede entonces interponerse el recurso por omisión, en un plazo también de dos meses ${ }^{61}$; y tercero, como la

\footnotetext{
${ }^{58}$ El recurso por omisión o inactividad se encuentra regulado entre los arts. 129 a 134 del Capítulo IV del Título Tercero del Estatuto del TJCA.

${ }^{59}$ El párrafo primero del art. 265 del TFUE expresa «En caso de que, en violación de los Tratados, el PE, el Consejo Europeo, el Consejo, la Comisión o el BCE se abstuvieren de pronunciarse, los Estados miembros y las demás instituciones de la Unión podrán recurrir al TJUE con objeto de que declare dicha violación. [...] se aplicará, en las mismas condiciones, a los órganos y organismos de la Unión que se abstengan de pronunciarse».

${ }^{60}$ La naturaleza de esta sentencia -meramente declarativa- es una circunstancia que desde temprano se ha detectado como insuficiente. En tal sentido VILLAMOR subraya que dicha característica procesal disminuye la efectividad del recurso por omisión, pues, no necesariamente se obtendrá de inmediato el resultado material final esperado por el demandante, y tal vez le será necesario deducir, después del pronunciamiento, un recurso de nulidad. VILLAMOR MORGAN-EVANS, L. (2001). El tribunal de justicia de las comunidades europeas como garante del derecho comunitario por las propias instituciones y órganos comunitarios. Anuario de la facultad de derecho, (19), 457-472.

${ }^{61}$ Párrafo segundo del art. 265 del TFUE.

126
} 
sentencia obtenida será meramente declarativa, para efectos de la consecución material final esperado por el actor, será necesario un nuevo recurso. En otro punto a destacar, en la UE los legitimados han sido restringidos ${ }^{62}$.

Como se aprecia, el recurso por omisión o inactividad en la CAN, si bien está más desarrollado que en el caso del SICA, igualmente se distancia de la respuesta de la UE. Ahora bien, dentro de la CAN la diferencia con la acción de incumplimiento, corre por el hecho de que ésta se encuentra exclusivamente dirigida en contra de un Estado miembro ${ }^{63}$ para los casos en que alguno vulnere el Derecho de la CAN, ya sea tanto en una dimensión positiva como negativa, cuestión que explica directamente el Estatuto del TJCA de la siguiente forma:

«La conducta objeto de la censura podrá estar constituida por la expedición de normas internas contrarias al ordenamiento jurídico andino, por la no expedición de normas que le den cumplimiento a dicho ordenamiento o, por la realización de cualesquiera actos $\mathrm{u}$ omisiones opuestos al mismo o que de alguna manera dificulten u obstaculicen su aplicación» ${ }^{64}$.

\subsubsection{LA PRESENCIA LEGISLATIVA DE LA ACCIÓN DE NULIDAD EN EL SICA Y EN LA CAN}

Si comparamos ahora la acción de nulidad en los sistemas confrontados, el SICA queda en la posición más débil —excluido el MERCOSUR que en nada desarrolló esta función-, circunstancia que se explica por la pequeña fórmula legislativa empleada en Centroamérica, la cual ya dijimos que rezaba así «Conocer de las acciones de nulidad y de incumplimiento de los acuerdos de los organismos del SICA» ${ }^{65}$ sin ningún otro desarrollo legislativo concreto. Ahora bien, esto no implica que la CCJ se encuentre tan limitada, sólo que el legislador deja al tribunal con un margen de acción muy amplio, debido a que no le acota el campo jurisdiccional, es decir, que igualmente hay muchos ejemplos de sentencias dictadas

\footnotetext{
${ }^{62}$ Los legitimados privilegiados están en el párrafo primero del art. 265 del TFUE, esto es, los Estados miembros y las demás instituciones de la UE (es decir que no fuesen el PE, el Consejo Europeo, el Consejo, la Comisión o el BCE). La restricción recae sobre los particulares, según indica ahora el párrafo tercero del mismo artículo, del siguiente modo «Toda persona física o jurídica podrá recurrir en queja al Tribunal, en las condiciones señaladas en los párrafos precedentes, por no haberle dirigido una de las instituciones, o uno de los órganos u organismos de la Unión un acto distinto de una recomendación o de un dictamen».

${ }^{63}$ El sujeto pasivo es un País miembro, así lo detalla el inciso $1^{\circ}$ del art. 107 del Estatuto del TJCA, «La acción de incumplimiento podrá invocarse ante el Tribunal con el objeto de que un País Miembro, cuya conducta se considere contraria al ordenamiento jurídico comunitario, dé cumplimiento a las obligaciones y compromisos contraídos en su condición de miembro de la Comunidad Andina».

${ }^{64}$ Inciso $2^{\circ}$ del art. 107 del Estatuto del TJCA.

${ }^{65}$ Art. 22, letra b) del Estatuto de la CCJ.
} 
con esta escasa normativa, puede verse el caso Brenes Pérez y Dougherty Liekens c/ Parlacem $^{66}$ causa en la cual los parlamentarios demandantes los señores Brenes Pérez y Dougherty Liekens solicitan la nulidad de la Resolución AP/5-CXCII-2007 emanada del PARLACEM, en la que se reconocía a los Parlamentarios Designados de la República Dominicana los mismos derechos y obligaciones que los diputados del Parlamento Centroamericano, y nombra Parlamentarios Titulares y Suplentes Designados por la República Dominicana en el PARLACEM, entre otros aspectos. El punto de interés aquí es que en definitiva, con la escueta fórmula normativa descrita, la CCJ termina declarando sin inconvenientes la nulidad ex nunc de la Resolución impugnada ${ }^{67}$, efectuando un análisis de las normativas del PARLACEM y del contexto afectado, quedando a la vista que la acción creada en el Estatuto de la CCJ tiene aplicación práctica.

En la CAN la acción de nulidad es la principal herramienta para ejercer el control de los actos comunitarios, por medio de la cual se sancionan con ineficacia las Decisiones, Resoluciones o Convenios, cuando colisionan con el ordenamiento andino. Los legitimados en esta acción judicial son los Estados miembros, el Consejo de Ministros de Relaciones Exteriores, la Comisión, la Secretaría General y las personas naturales o jurídicas, pero se limita a los Estados miembros y a los particulares, a los primeros con una lógica cortapisa de coherencia, pues no pueden dirigir la acción contra las Decisiones o Convenios que no hubieren sido aprobados con su voto afirmativo ${ }^{68}$, en cambio a los segundos - los particulares - se les pide demostrar que concretamente se afectan sus derechos subjetivos o sus intereses legítimos ${ }^{69}$. Este último aspecto observamos que guarda relación con la UE, en cuanto en este modelo europeo, pasaron a diferenciarse entre litigantes privilegiados y semi-privilegiados, debiendo los particulares sortear la denominada prueba de fuego ${ }^{70}$, consistente en que también deben probar que sus derechos se afectan directamente ${ }^{71}$. Por lo tanto, en la UE la legitimación para los particulares — sean personas físicas o jurídicas-

\footnotetext{
${ }^{66}$ Sentencia de la CCJ de 7 de octubre de 2009, Brenes Pérez y Dougherty Liekens c. Parlacem, expediente 88-07-07-10-2008.

${ }^{67}$ RESUELVE, CUARTO de la Sentencia ibídem «Declárase la nulidad ex nunc de la Resolución AP/5CXCII-2007, en las condiciones establecidas en el CONSIDERANDO XIII de ésta sentencia».

${ }^{68}$ Inciso $2^{\circ}$ del art. 102 del Estatuto del TJCA.

${ }^{69}$ Inciso $3^{\circ} \mathrm{del}$ art. ibídem.

${ }^{70}$ Como lo destaca LIÑÁN pasó a convertirse en indispensable tener que diferenciar entre demandantes privilegiados y no privilegiados, siendo los particulares precisamente los no privilegiados, porque los particulares deben afectarse directamente para poder adquirir legitimación, debiendo incluso sortear la que denomina prueba de fuego, por la cual tienen que demostrar que les afecta un acto de alcance general específicamente a ellos, o a un grupo reducido de personas, de una forma que no afecta al resto. LIÑÁN, 2014d, pp. 454-456.

${ }^{71}$ Inciso $4^{\circ}$ del art. 263 del TFUE «Toda persona física o jurídica podrá interponer recurso, [...], contra los actos de los que sea destinataria o que la afecten directa e individualmente y contra los actos reglamentarios que la afecten directamente y que no incluyan medidas de ejecución».
} 
si bien se resolvió legislativamente otorgándoles ius standi en este recurso, la doctrina ${ }^{72}$ detectó rápidamente su limitación tanto jurídica como fáctica, incluso después de Lisboa.

Pues bien, ambas respuestas latinoamericanas - SICA y CAN — contrastan con la profusa estructura legislativa que recibe el recurso de anulación en la UE, donde se le atribuyen las competencias necesarias al TJUE para controlar la legalidad de los actos jurídicos más importantes de las Instituciones ${ }^{73}$, esto es, del Consejo, de la Comisión y del BCE que no sean recomendaciones o dictámenes y de los actos del PE y del Consejo Europeo, extendiéndose para proteger las potestades del TCUE, del BCE y del Comité de Regiones ${ }^{74}$.

En cuanto a las condiciones que deben cumplir estos actos en la UE para ser recurridos, ha sido el TJUE y no el legislador, el que ha ido especificándolas jurisprudencialmente, resolviendo que debe haber un análisis sustancial sobre la naturaleza del acto, más que de lo meramente formal, buscándose verificar que el acto sea obligatorio, definitivo y que abandone lo puramente interno de la Institución, es decir, que afecte a terceros, según va explicando la doctrina ${ }^{75}$.

Pero los motivos concretos de anulación cruzan por la incompetencia, los vicios sustanciales de forma, la violación del Tratado o de cualquier norma jurídica sobre su ejecución, y por desviación de poder. Los dos primeros casos son impugnables de oficio

\footnotetext{
${ }^{72}$ Tras analizar los requisitos de admisión para los particulares, MONTESINOS concluye que, se tornaron tan limitados que resulta ser una cuestión más retórica que real. MONTESINOS PADILLA, C. (2015). A las puertas del TJUE. La frustrada flexibilización de las condiciones de acceso del particular. Civitas. Revista española de derecho europeo, (55), 37-65. Otro, en similar crítica MARTínEZ opina que, el TJUE se ha movilizado hacia una interpretación reduccionista que constriñe el espíritu de la reforma. MARTÍNEZ CAPDEVILA, C. (2014). El ius standi de los particulares frente a los "actos reglamentarios que no incluyen medidas de ejecución" (art. 263 TFUE) en la jurisprudencia del TJUE: Un análisis crítico. Civitas. Revista española de derecho europeo, 52, pp. 159-187.

${ }^{73}$ Las competencias se le otorgan al TJUE en los arts. 263, 264 y en los literales b) y c) del art. 271 del TFUE. El inciso $1^{\circ}$ del art. 263, establece «El TJUE controlará la legalidad de los actos legislativos, de los actos del Consejo, de la Comisión y del Banco Central Europeo (BCE) que no sean recomendaciones o dictámenes, y de los actos del PE y del Consejo Europeo destinados a producir efectos jurídicos frente a terceros. Controlará también la legalidad de los actos de los órganos u organismos de la Unión destinados a producir efectos jurídicos frente a terceros».

${ }^{74}$ Mediante el inciso $3^{\circ}$ del art. 263 del TFUE, esta competencia se extiende para proteger las potestades del TCUE, del BCE y del Comité de Regiones. Al tiempo que los literales b) y c) del art. 271 del TFUE amplían esta potestad contra los acuerdos del Consejo de Gobernadores y del Consejo de Administración del BEI.

${ }^{75}$ La lógica que subyace al recurso de anulación, como explica SARMIENTO, es que pone énfasis en su carácter objetivo y revisor, destinado a controlar la estricta legalidad de un acto, y no tanto a proteger los derechos subjetivos de sus destinatarios, como propio de una jurisdicción retenida, donde el tribunal se limita a enjuiciar y en su caso anular, pero no a restituir la situación jurídica afectada, ni a sustituir el acto por otro. Lo que se distingue de los recursos de plena jurisdicción, como los del art. 261 del TFUE que permite sustituir el acto declarado ilícito. SARMIENTO RAMÍREZ-ESCUDERO, 2016, p. 362.
} 
por el TJUE, los restantes, a través de la acción por los legitimados en un plazo de dos meses $^{76}$. Por último precisemos que la sentencia que declara la nulidad posee efectos $e x$ tunc generando una consecuencia retroactiva total, aunque la Corte podría acotarlo ${ }^{77}$.

\subsubsection{EL CAUCE INDIRECTO DE LAS CONSULTAS PREJUDICIALES}

EN LOS TRES MODELOS LATINOAMERICANOS

Las consultas prejudiciales también colaboran con el patrón central enfocado —el control de legalidad de los actos-, sin embargo, lo hacen de un modo secundario y centralmente cuando comporta nulidad, por tal razón su utilidad se presenta con más nitidez en el modelo de la UE, porque en él existe concretamente la faz de apreciación de validez que lleva adelante el TJUE, no así en la CAN, ni en el SICA, ni en el MERCOSUR.

Dicha dimensión de validez le imprime un carácter casacional a esta herramienta, toda vez que el TJUE, a requerimiento del juez nacional, se pronuncia sobre la compatibilidad de un acto normativo de la UE aplicable al litigio principal ${ }^{78}$, donde el cotejo de compatibilidad del acto normativo $v / s$ el bloque de legalidad de la UE es de carácter sustantivo, por ende, de idéntico rigor que en el caso del recurso de anulación, aunque aquí la particularidad es dual, debido a que de un lado se destaca la temprana oportunidad procesal en que se efectúa, y de otro, porque a diferencia de lo que ocurre con el recurso de anulación - en cuanto el acto declarado nulo no puede subsistir en el ordenamiento-, en la cuestión prejudicial de validez, el acto declarado nulo, únicamente debe ser considerado así, por los órganos jurisdiccionales, subsistiendo en el resto del sistema, así entonces, en la UE la eliminación o modificación debe hacerlo la Institución de la que ha emanado el acto.

En cambio en la CAN y en el SICA el cauce de las consultas prejudiciales no poseen tal carácter casacional, por lo tanto el apoyo de estas herramientas prejudiciales en favor de la función contralora enfocada, es aún más distante, aunque no inútil, sólo que giran en menor medida. Recordemos, tal como vimos en el apartado anterior, que en la CAN la consulta era facultativa para el juez nacional cuando solo conoce en primera instancia y obligatoria si actúa en única instancia o en última instancia, siempre que, se haya controvertido el Derecho de la CAN. En el SICA encontrábamos la diferenciación entre las vinculantes y las ilustrativas. Mientras que en el MERCOSUR ninguna es vinculante.

\footnotetext{
${ }^{76}$ Este plazo se computa desde la publicación del acto, o desde su notificación, o desde el día en que el recurrente tuvo conocimiento

${ }^{77}$ Art. 264 del TFUE.

${ }^{78}$ Esta potestad se encuentra en la letra b) del art. 267 del TFUE, el cual indica «El TJUE será competente para pronunciarse, con carácter prejudicial: [...] b) sobre la validez e interpretación de los actos adoptados por las instituciones, órganos u organismos de la Unión».
}

130 


\subsubsection{EL CONTROL DE LEGALIDAD INDIRECTO}

QUE DEBE EMPLEARSE EN EL

Mercosur

Muy diferente es la situación en el MERCOSUR ya que, en contraste con la minuciosa descripción del sistema de la UE y de lo que en menor medida ocurre en el SICA y en la CAN, en el merco-sistema el control de legalidad de los actos se ejerce indirectamente por medio de una demanda ordinaria del afectado, en la que lisa y llanamente éste acusa al demandado de incumplidor de una normativa mercosureña.

Ante tal acción el TAAM, o bien el TPRM según corresponda procesalmente, confronta los hechos denunciados $v / s$ el Derecho del Mercosur. Como vemos, entonces no es posible siquiera contrastar al MERCOSUR con el SICA, o con la CAN, ni mucho menos con la UE, dado que en el merco-sistema se genera un campo propio e inespecífico, sin normativa ni acciones especiales.

Ante tal panorama el asunto en el MERCOSUR pasa a ser bastante inestable e impreciso, tanto desde lo procesal como desde el ángulo sustantivo del DI, toda vez que se debe recurrir a una Corte mercosureña por conductos generales, relacionados con el cumplimiento del Derecho del Mercosur. Lo anterior origina que para enfrentar la acción - o recurso en terminología de la $\mathrm{UE}$ - , se superpongan o acumulen, todas las competencias de interpretación, aplicación y cumplimiento, pues no se está siguiendo una acción determinada, en carácter de cauce limpio o preciso que estuviese marcado por los requisitos puntuales de una acción.

Como se aprecia, la pretensión y la acción entran al juicio y se enfrentan a la globalidad de las competencias del TAAM o TPRM según corresponda, competencias que además fluyen de modo amplio desde el POPSCM, instrumento que en sus Motivaciones expresa que dicho Protocolo viene a satisfacer la necesidad de garantizar la correcta interpretación, aplicación y cumplimiento de los instrumentos fundamentales del proceso de integración y del conjunto normativo del Mercosur de forma consistente y sistemática ${ }^{79}$, es decir, se aplica en su totalidad pues nada en su interior filtra un conducto específico, pues no hay acción específica $\longrightarrow$ recurso en terminología de la UE.

Dado entonces ese impulso del POPSCM, los TAAM y el TPRM asumen como fin el garantizar la correcta interpretación, aplicación y cumplimiento de los instrumentos fundamentales del MERCOSUR, quedando el TPRM como máximo y último tribunal

\footnotetext{
${ }^{79}$ Párrafo titulado Considerando, en las Motivaciones del POSCOM.
} 
mediante el empleo del recurso de revisión ${ }^{80}$ procedente contra los laudos de los TAAM, o bien, si los litigantes fuesen Estados y estuvieren de acuerdo pueden, per saltum ${ }^{81}$, evitar el TAAM y llevar la cuestión directamente ante el TPRM.

En conclusión a diferencia de los esquemas del SICA y de la CAN, este patrón central —el control de legalidad de los actos - no existe en los Estatutos del MERCOSUR. Sistema en que debe seguirse un conducto procesal general, con todas las dificultades técnicas jurídicas que apareja el ejercicio jurisdiccional en materias tan específicas, sin contar ni con normas, ni con acciones especiales.

Para cerrar este apartado precisemos que ninguno de los sistemas SICA, CAN o MERCOSUR dispuso — para la función de control bajo análisis - de la excepción de ilegalidad, ni de la acción indemnizatoria presentes en la UE. La primera es muy particular, pues es formal, se le libera de todo plazo, y lo cierto es que el legislador no la bautizó como excepción de ilegalidad, sino que la presenta como una opción, según destaca la doctrina ${ }^{82}$.

Este cauce le permite al TJUE efectuar el control de legalidad de los actos, mediante el ejercicio de un derecho de las partes en el marco de un litigio, razón por la que su naturaleza es incidental, mediante el cual se ataca una medida de aplicación, del acto motivo del juicio. Y la estimación de esta excepción no genera efectos erga omnes, por lo tanto no conlleva la anulación del acto principal de forma general, solo produce el clásico efecto subjetivo entre las partes en litigio y respecto de la medida particular. Toma entonces el cariz de una opción de emergencia, lo que se explica por la reducida participación de los particulares, y por el corto plazo para deducir el recurso de anulación. Por lo cual se compensa liberando de plazo para ejercer la excepción de ilegalidad ${ }^{83}$.

\footnotetext{
${ }^{80}$ Art. 17 del POPSCM.

${ }^{81}$ Art. 23, en relación los arts. 4 y 5 del POPSCM.

${ }^{82}$ Para MARTÍN BAÑAS lo particular de este tercer conducto, viene dado por múltiples cuestiones, entre muchas v.gr. ella es una herramienta ritual, a la cual el legislador no la ha denominado excepción de ilegalidad, tampoco se le asignó plazo específico, a través de su uso se permite un control indirecto de legalidad mediante una Sentencia de efectos inter pares, pues esta herramienta ritual no se instituyó con el objetivo de tamizar el ordenamiento jurídico de la Unión, eliminando todas aquellas disposiciones de carácter general ilegales, [...] sino simplemente es un mecanismo alternativo. MARTÍN BAÑAS, C. (2013). La excepción de ilegalidad. En Pardo Iranzo, V., Iglesias Buhigues, J. L., Desantes Real, M., Jimeno Bulnes, M., Arangüena Fanego, C., Jimenez Fortea, F.J., ... Cervera Vallterra, M., El sistema jurisdiccional de la unión europea ( $1^{\mathrm{a}}$ ed.). Navarra: Aranzadi., pp. 119-134.

${ }^{83}$ El art. 277 del TFUE compensa con la siguiente fórmula «Aunque haya expirado el plazo previsto en el párrafo sexto del art. 263, cualquiera de las partes de un litigio en el que se cuestione un acto de alcance general adoptado por una institución, órgano u organismo de la Unión podrá recurrir al TJUE alegando la inaplicabilidad de dicho acto por los motivos previstos en el párrafo segundo del art. 263».
}

132 
Por último la acción indemnizatoria tampoco fue recepcionada directamente en los modelos latinoamericanos. En la UE se concreta mediante el recurso por responsabilidad extracontractual, el cual colabora de modo indirecto con el control de la legalidad de los actos. Su utilidad central consiste en permitirle a una persona física o jurídica, la reparación de los daños causados por las Instituciones de la UE o sus agentes en el ejercicio de sus funciones $^{84}$.

La razón por la cual este recurso puede ser considerado como un cauce indirecto para el control de legalidad, se basa en que no se requiere para su interposición, de una previa declaración judicial respecto de que el acto dañoso sea ilegal, sino que se permite la constatación durante la misma tramitación de este proceso, circunstancia procesal que lo conecta de modo oblicuo con el control de legalidad ${ }^{85}$.

\subsubsection{El CARÁCTER de CUASI TRIBUNAL CONSTITUCIONAL QUE PUDIERAN OSTENTAR LAS CORTES LATINOAMERICANAS: SU JUSTIFICACIÓN Y EL DESARROLLO ESTATUTARIO QUE LO RESPALDA}

El carácter de cuasi tribunal constitucional que una Corte de integración pudiese llegar a ostentar, se justifica de ser incorporado como un patrón central, para ser rastreado en los modelos de América Latina por dos motivos, en primer lugar, porque esta dimensión constitucional pasa a conformar una de las tantas cuestiones que distancian a una Corte de integración de un tribunal internacional típico, como sucede en la UE según subraya la doctrina $^{86}$. Lo que no es baladí para nuestra tesis, pues como nos enfocamos en las Cortes

\footnotetext{
${ }^{84} \mathrm{Su}$ marco legislativo lo encontramos centralmente en el art. 340.2 del TFUE, por el cual se consolida de modo sustantivo el derecho a ser indemnizado. Luego el art. 268 del TFUE le otorga la competencia necesaria al TJUE. Y el art. 256.1 del TFUE, le atribuye competencia en primera instancia al TGUE para la acción.

${ }^{85}$ En dicha línea PASCUAL pone de relieve que la admisibilidad no queda supeditada, a la previa declaración del Tribunal respecto de la ilegalidad del acto lesivo, a través de alguno de los otros cauces previstos en el Tratado. Sino que puede apreciarse la concurrencia de tal condición en el marco del propio procedimiento de responsabilidad. Ello, supone entonces - subraya este autor - que, la demanda puede interponerse sin que se solicite con carácter previo la anulación del acto ilegal causante del perjuicio, o sin haber planteado la vía del recurso por inacción. PASCUAL SERRATS, R. (2013). El recurso por responsabilidad extracontractual. En Pardo Iranzo, V., Iglesias Buhigues, J. L., Desantes Real, M., Jimeno Bulnes, M., Arangüena Fanego, C., Jimenez Fortea, F. J., ... Cervera Vallterra, M. El sistema jurisdiccional de la unión europea (1 ${ }^{\mathrm{a}}$ ed.). Navarra: Aranzadi., pp. 156-157.

${ }^{86}$ Tal distanciamiento entre las dos clases de tribunales, LIÑÁN lo remarca al resaltar que los recursos acciones - dispuestos para el control de la legalidad permiten al TJUE realizar a la vez funciones asimilables a un «control de constitucionalidad» de carácter material, mediante el [cual,] el Tribunal de Justicia actúa como tribunal constitucional de la UE, agregando este autor, que dicha función reviste una importancia cada vez mayor, ya que sirve para que el TJUE resuelva cuestiones fundamentales del ordenamiento jurídico de la
} 
de los esquemas de integración de América Latina, deberemos posicionarlas correctamente en las coordenadas jurídicas que les correspondan, según sea el nivel de desarrollo alcanzado en cada una de sus regiones. Y justamente, respecto de dichas Cortes latinoamericanas, el asunto se vuelve bastante más heterogéneo que en Europa; y en segundo lugar, la dimensión constitucional deja completamente al descubierto la doble funcionalidad de los tribunales de integración, en cuanto, por una parte obran como un tribunal internacional típico respecto de algunas materias resolviendo contenciosos, y por otra parte, despliegan las características propias de una Corte de integración, como precisamente lo es su dimensión constitucional $^{87}$.

Tan singular es este perfil constitucional, que ha pasado a ser un hecho prácticamente indiscutido en el modelo europeo, en cuanto efectivamente este carácter lo posee el TJUE. La conclusión europea recién apuntada, fluye de la suma de tres razones: primero, del hecho de reconocer a los Tratados Constitutivos de la UE como la Carta Magna de esta organización, es decir, habría efectivamente una especial codificación en sentido material, aunque algunos autores son del criterio de precisar que esta singular manera de codificación de la Constitución de la UE, en cuanto a no cumplir las formalidades y a no estar dirigida a un Estado, no obsta a que efectivamente establece los profundos principios políticos de la UE y de su Institucionalidad ${ }^{88}$, en segundo lugar, se advierte que lo anterior es una cuestión coherente con el tipo de competencias que recibe el TJUE, pues en varios aspectos - como analizaremos - es de claro carácter constitucional, y en tercer lugar, destaca el hecho de que en el ejercicio jurisprudencial del propio TJUE, este órgano jurisdiccional emplea una técnica hermenéutica finalista, propia de los tribunales constitucionales.

Unión. LIÑÁN NOGUERAS 2014d, p. 448. También vid. DÍEZ-HOCHLEITNER RODRÍGUEZ, J. (2013). El derecho a la última palabra: ¿Tribunales Constitucionales o Tribunal de Justicia de la Unión? En Tribunal Constitucional y diálogo entre tribunales: XVIII Jornadas de la Asociación de Letrados del Tribunal Constitucional. Instituto de derecho europeo e integración regional, universidad complutense, 17(2013), vid. apartado 2. El tribunal de justicia de la unión como tribunal constitucional europeo.

${ }^{87}$ Esta doble funcionalidad es un concepto amplio que podemos utilizar para analizar en un primer gran enfoque las competencias del TJUE, punto en el que advertiremos dos grandes campos de actuación de la Corte de Luxemburgo, por una parte resolviendo los contenciosos - como todo tribunal internacional típico-, y por otra parte, actuando como supremo interprete del Derecho de la UE, respondiendo consultas, etcétera, hasta llegar a comportar un cuasi tribunal constitucional de la UE. Así por ejemplo, SARMIENTO pone de relieve esta cuestión expresando: El Poder Judicial de la UE desempeña una labor crucial en la salvaguarda de la efectividad del Derecho de la Unión, pues por un lado ofrece pautas autorizadas de interpretación de dicho ordenamiento en todo el territorio de la Unión y, por otro lado, resuelve individualmente los pleitos que se plantean en el día a día. SARMIENTO RAMÍREZ-ESCUDERO, 2016, p. 357.

${ }^{88}$ SOTO-DÍAZ, D. (2014). Tribunales constitucionales y tribunal de justicia de la unión europea: el convulso vértice de la pirámide del sistema jurisdiccional europeo. Anuario da facultade de dereito da universidade da coruña, 18, pp. 363-390, vid. apartado 2.3 El TJUE como defensor de la constitución europea. 
Sin embargo hay detractores que defienden un derecho constitucional clásico o estricto, y por ende niegan rotundamente el símil, en atención a las carencias formales que advierten al cotejar la noción de Estado $v / s$ el concepto con el que se pueda intentar explicar a la UE. A lo que suman el análisis que hacen de sus respectivos máximos tribunales. Concluyendo que sería imposible empatar a la Corte de Luxemburgo con un Tribunal Constitucional, dado que este último tipo de órganos solo existen en una forma de poder político organizado bajo el nombre de Estado ${ }^{89}$, y la UE no es un Estado. Así las principales barreras serían: uno, la existencia de una declaración fundamental de derechos como conditio sine qua non para la existencia de una Constitución propiamente tal; dos, la garantía del principio democrático; y tres, la inexistencia de un proceso constituyente ${ }^{90}$.

Pero retomando la línea de análisis, que busca primero resaltar la condición de cuasi tribunal constitucional del TJUE para luego cotejarlo con las Cortes de Latino América, retengamos que para darle el carácter cuasi constitucional, se debe comenzar por reconocer la existencia de una Constitución en la UE, sin embargo, como esto no es un hecho positivo ni codificado ${ }^{91}$, se basa en dos teorías dóciles que reconocen que a pesar del fracaso normativo, la UE igualmente tendría una Constitución.

La primera es la teoría institucionalista, que sostiene que la Constitución europea existiría desde el momento en que tiene su propia organización institucional, independiente de los Estados miembros, con otros órganos regulados en los Tratados comunitarios, así la Constitución europea sería el derecho primario de la UE. Su debilidad es que — para afirmar la existencia de una Constitución moderna - requeriría que el principio democrático sea observado, en el sentido de una ratificación expresa por el pueblo.

La segunda teoría es la normativista, esta indica que tanto las constituciones modernas de los Estados como el derecho primario de la UE, juegan el mismo papel al regular funciones

\footnotetext{
${ }^{89}$ En tal línea reticente SÁIZ sostiene que no se puede pretender hacer del TJUE algo que no es y que no puede ser. Es decir, un tribunal constitucional o - más genéricamente- un órgano de justicia constitucional, dado que ésta y aquel solo existen en una forma de poder político organizado que conocemos con el nombre de Estado (Constitucional de Derecho). Es decir, de una realidad bien alejada por sus características y elementos conformadores de lo que en su día y en acertada - hoy ya clásica - descripción, JACQUES DELORS consideró como un «objeto político no identificado» a saber, las CE, o en terminología adecuada a las novedades introducidas desde el Tratado de la UE ha sido calificado por CURTIN como «la primera forma política de la posmodernidad», pero — sentencia SÁIZ - la UE no ha alumbrado un Estado (Federal), y como sin Estado no hay Constitución, en consecuencia no puede haber un supremo y último árbitro para garantizar la supremacía de aquella. SÁIZ ARNÁIZ, 1999, pp. 223-224.

${ }^{90}$ SOTO-DÍAZ, 2014.

${ }^{91}$ Recordemos — como ya lo vimos en el capítulo I- que el proyecto de una Constitución para la UE no prosperó, y fue el Tratado de Lisboa el que salvó el contenido sustantivo del proyecto. MÉNDEZ DE VIGO \& OREJA AGUIRRE, 2007. ALDEOCA LUZURRAGA, 2008, pp. 35-85. MILLÁN MORO, 2010.
} 
análogas. Lo cual remite al concepto kelseniano de «constitución material» según el cual, la Constitución es aquélla parte del sistema jurídico que establece el procedimiento para la creación del Derecho, y los fundamentos de los órganos encargados de esta función. La debilidad de esta teoría es que el concepto moderno de Constitución está estrechamente relacionado con el de Estado, y la UE, no es un Estado ${ }^{92}$.

Nosotros no creemos apropiado afrontar la tensión entre la existencia o la inexistencia de una Constitución en la UE desde una colisión irreconciliable de posturas. Sino más bien, de reconocer un tránsito en sentido de desarrollo transnacional. Es decir, no cruza por perturbar las bases del constitucionalismo moderno, sino por observar su evolución, tal como la doctrina ${ }^{93}$ va aclarando. Además debe tenerse presente que la mayoría de los autores $^{94}$ estudiosos de la Corte de Luxemburgo le han ido reconociendo este carácter.

${ }^{92}$ Estas son las dos posturas doctrinales que subraya RUIPÉREZ ALAMILLO referidas a la aceptación de que la UE sí tendría una Constitución, vid. SOTO-DÍAZ, 2014.

${ }^{93}$ En esta línea RODRÍGUEZ y BAQUERO expresan que no se trata como se ha afirmado, (citando a GREWE y RUIZ FABRI) de una «perturbación del edificio del constitucionalismo contemporáneo», sino más bien de una transformación o evolución del mismo, unida a una «constitucionalización» de las relaciones entre los Estados europeos, agregando estos autores, que tal evolución se debe en una buena medida a una reacción frente a las limitaciones del constitucionalismo tradicional aferrado al Estado-Nación, además señalan, que a los pesos y contrapesos internos, el nuevo orden público europeo añade toda una serie de pesos y contrapesos externos de naturaleza tanto normativa como institucional, que tienden a asegurar la estabilidad de los sistemas constitucionales nacionales y la del conjunto, concluyendo en que el constitucionalismo europeo se ve de esta forma completado por una dimensión supranacional. RODRÍGUEZ IGLESIAS, G. C. \& BAQUERO CRUZ, J. (2006). Funciones constitucionales del tribunal de justicia de las comunidades europeas. Fundamentos (Cuadernos monográficos de teoría del estado, derecho público e historia constitucional). 4, pp. 291-346.

${ }^{94}$ Por ejemplo CERVERA reflexiona al respecto y expresa «la jurisdicción comunitaria es sumamente innovadora y vanguardista en la medida en que en ella confluye un crisol de intereses contrapuestos [...], se encarga de administrar justicia asumiendo funciones heterogéneas (tan pronto hace las veces de un órgano contencioso-administrativo, actúa como un órgano constitucional o interviene como órgano consultivo)». Luego la misma autora — citando a COLIN — resalta «La doctrina llegó a caracterizar el sistema judicial comunitario como el Gobierno de los Jueces». CERVERA VALLTERRA, M. (2005). El tribunal de justicia de las comunidades europeas. En Bou, V. (coord.); Badenes, M., Torres, M., Quesada, C., \& (...). Nuevas controversias internacionales y nuevos mecanismos de solución ( $1^{\mathrm{a}}$ ed.) Tirant lo Blanch, p. 454. Su frase final la cita de V. COLIN, J. P., Le gouvernement des juges dans les communautés européennes, Parías, ed. LGDJ, 1966, p. 24. Por su parte los autores LENAERTS y GUTIÉRREZ-FONS refiriéndose al rol o el papel del TJUE, señalan que a su entender este tribunal está llamado a cumplir con la función de árbitro constitucional, en virtud de la cual debe asegurar que la UE sea una Unión de Derecho, destacando además que el TJUE actúa en un sistema complejo y con distintos niveles de gobernanza. LENAERTS, $\mathrm{K}$ \& GUTIÉRREZ-FONS, J. (2012). El papel del tribunal de justicia de la unión europea en el proceso de integración europea. En Beneyto, J. M., Maillo González-Orús, J., Becerril Atienza, B., \& Lenaerts, K. Tratado de derecho y políticas de la unión europea, Tomo V Sistema jurisdiccional de la ue (1 ${ }^{\mathrm{a}} \mathrm{ed}$.). Cizur Menor: Thomson Reuters Aranzadi, p. 106 y p. 108.

136 
En cuanto a la cercanía de las competencias y del ejercicio del TJUE, con algunas funciones desempeñadas por un tribunal constitucional, son relevantes ocho cauces de proximidad, a saber: 1) la potestad de decidir en definitiva las competencias de la UE $v / s$ los Estados y las Instituciones, 2) determinar el alcance de los Tratados, 3) mantener el equilibrio institucional, 4) controlar el respeto de los derechos humanos y de los principios de la UE, 5) el uso de una técnica interpretativa propia de los tribunales constitucionales, 6) la forma de intervención del TJUE en el proceso de institucionalización de la UE, 7) el carácter de supremo intérprete de los Tratados Constitutivos, y 8) el hecho de que el TJUE somete al Derecho de la UE a todo otro derecho nacional ${ }^{95}$. Para la doctrina ${ }^{96}$ el ejercicio mismo del TJUE demuestra fácticamente su similitud a un tribunal constitucional, entonces - para nosotros - de esto se desprende que habría un potencial funcional para los tribunales de integración, o de aspiraciones integracionistas como la CCJ, el TJCA y el TPRM, de actuar en alguna medida como un cuasi tribunal constitucional.

Por lo tanto, determinar si una Corte tiene o no perfiles constitucionales, no es un tema semántico, sino fáctico, que se colige de la noción de función del órgano jurisdiccional enfrentado, en tanto lo que efectúa y no como se denomina aquello que realiza. Por ejemplo, de entre todas las competencias próximas a materias constitucionales, la función consultiva de compatibilidad Estatutaria con un futuro acto pretendido por la UE, no puede

\footnotetext{
${ }^{95}$ Estos conductos SÁIZ los explica como los ocho ejes de cercanía. Este autor, si bien, y como ya anotamos, negaba la identidad constitucional propuesta, luego viene a matizar su planteamiento y reconoce similitudes funcionales entre las Cortes comparadas, justamente, a través de los ocho ejes de cercanía que hemos destacado en el texto. SÁIZ aclara que él, más bien, se centra en destacar que el TJUE no conecta con un Tribunal Constitucional estándar. Siendo enfático al decir que: más importancia que todo hasta cuánto aquí se ha escrito es la opinión que el TJUE tiene de sí mismo y de sus funciones como órgano de garantía constitucional en su calidad de último interprete del ordenamiento comunitario y de primacía del Derecho que lo integra, como el hecho de ser «el guardián de la legalidad de los actos y de la aplicación uniforme de las normas comunes» y que a estos efectos ejerce funciones que, en los ordenamientos jurídicos de los Estados incumben, según el caso, a los tribunales constitucionales, ordinarios o administrativos. SÁIZ ARNÁIZ, 1999, pp. 229-231.

${ }^{96}$ En este punto IGLESIAS BUHIGUES concluye que, el TJUE desempeña una función propia en el orden y sentido material de un Tribunal Constitucional, por lo que en términos generales podría estimarse que el control de constitucionalidad lo ejerce el TJUE, tanto cuando enjuicia la conformidad con el Tratado de un acto legislativo derivado, como cuando esa conformidad se plantea con relación a un acto legislativo nacional, si consideramos que el Tratado es la Carta Constitucional de la Unión de Estados. IGLESIAS BUHIGUES, J. L. (2013). El papel del tribunal de justicia de la unión europea en el proceso de integración. En Pardo Iranzo, V., Iglesias Buhigues, J. L., Desantes Real, M., Jimeno Bulnes, M., Arangüena Fanego, C., Jimenez Fortea, F.J.,...Cervera Vallterra, M. El sistema jurisdiccional de la unión europea (1 ${ }^{\mathrm{a}}$ ed.). Navarra: Aranzadi, pp. $24-$ 30. En cuanto al actuar fáctico como tribunal constitucional por los tribunales de integración, puede verse entre muchos en RODRÍGUEZ IGLESIAS, LIÑÁN NOGUERAS \& ABELLÁN HONRUBIA, 1993, pp. 396-399, y haciendo referencia expresa a la Corte de Luxemburgo GAMBINO, S. (2010). Jurisdicción y justicia entre tratado de lisboa, convenio europeo de derechos humanos y ordenamientos nacionales. Revista de derecho constitucional europeo, 13, 83-120 (100-101).
} 
ser más propio de una Corte Constitucional. A lo que se suma el hecho de que el TJUE le reconoce materialmente a los Tratados constitutivos el carácter de constitución material, así lo ha dejado ver en la causa Parti écologiste "Les Verts" contra Parlamento Europeo 97 , poniéndolo de relieve al expresar «es pertinente subrayar, en primer lugar, que la Comunidad Económica Europea es una comunidad de Derecho, en la medida en que ni sus Estados miembros ni sus instituciones pueden sustraerse al control de la conformidad de sus actos con la carta constitucional fundamental que constituye el Tratado» ${ }^{98}$. A la que se suma el Dictamen 1/91 ${ }^{99}$ donde el TJ expresó «el Tratado CEE, aunque haya sido celebrado en forma de Convenio internacional, no por ello deja de ser la carta constitucional de una Comunidad de Derecho» ${ }^{100}$, a lo que se añaden las diversas explicaciones de la doctrina ${ }^{101}$.

Ahora bien, para aproximarnos a la realidad latinoamericana, ha de considerarse que, más allá de lo estricto que podamos ser al intentar ubicar con máxima precisión a la CCJ, el TJCA y al TPRM en el compartimiento de los Tribunales nacionales Constitucionales, por una cara, pasa a ser indiscutible el hecho de que son formalmente diferentes. Pero de otro lado, hay trazas de significativa similitud entre estos, lo que hace imposible ocultar la singular posición en que quedan estas Cortes, cuestiones que analizaremos a continuación valiéndonos de los ya señalados ocho cauces de cercanía entre el TJUE y un Tribunal Constitucional nacional.

\footnotetext{
${ }^{97}$ Sentencia del TJ de 23 de abril de 1986. Parti écologiste "Les Verts" contra Parlamento Europeo. Recurso de anulación. Campaña de información para la elección del Parlamento Europeo, as. C-294/83, ECLI:EU:C:1986:166.

${ }^{98}$ Considerando 23 en sentencia ibídem.

${ }^{99}$ Dictamen del TJ de 14 de diciembre de 1991. Comisión. Dictamen emitido con arreglo al párrafo segundo del apartado 1 del art. 228 del Tratado CEE. Proyecto de Acuerdo entre la Comunidad, por una parte, y los países de la Asociación Europea de Libre Comercio, por otra parte, sobre la creación del Espacio Económico Europeo. Dictamen 1/91. ECLI:EU:C:1991:490.

${ }^{100}$ Considerando 21 en dictamen ibídem.

${ }^{101} \mathrm{Al}$ respecto FRUTOS y ESPÓSITO al analizar la naturaleza de la función consultiva que el TFUE le otorgó al TJUE señalan, conviene apuntar que más allá de la cuestión terminológica y su acierto, lo relevante es su carácter de Constitución en sentido material que el Tribunal atribuye a los Tratados. Para respaldar este aserto, los autores recurren a los Dictámenes 1/91 y 1/92 tildándolos como la manifestación más elocuente al respecto, en cuyo contexto el TJUE afirmó que el TCEE aunque haya sido celebrado en forma de Convenio Internacional, no por ello deja de ser la Carta Constitucional de una Comunidad de Derecho. FRUTOS MIRANDA, J \& ESPÓSITO, C. (2012). La función consultiva: los dictámenes previos a la conclusión de acuerdos internacionales. En Beneyto, J. M., Maillo González-Orús, J., Becerril Atienza, B., \& Lenaerts, K. Tratado de derecho y políticas de la unión europea, Tomo V Sistema jurisdiccional de la ue ( $1^{\mathrm{a}} \mathrm{ed}$.). Cizur Menor: Thomson Reuters Aranzadi., pp. 515-516.
}

138 


\subsubsection{ANÁLISIS DEL POSIBLE CARÁCTER DE CUASI TRIBUNAL CONSTITUCIONAL}

La CCJ fue creada en una posición privilegiada respecto del resto de los órganos del SICA, lo que en parte se debió a que el proceso centroamericano intentó economizar errores, razón por la cual se basó en la experiencia de la UE, de tal forma es que desde sus orígenes pudo ser más claro en el reconocimiento de una prelación entre sus órganos permanentes, a diferencia de los orígenes del proyecto de integración europeo y de la Corte de Luxemburgo. Esta elevada posición de la CCJ al interior del esquema SICA, fluye originariamente desde su propio Estatuto bajo la siguiente fórmula:

«La Corte representa la conciencia nacional de Centroamérica y se considera, además, depositaria y custodia de los valores que constituyen la nacionalidad centroamericana» $^{102}$.

Tal construcción estatutaria nos deja enfrentado de inmediato a una Corte latinoamericana de notable conexión con la dimensión constitucional, toda vez que ésta asume la condición de instituto orgánico donde - por voluntad directa de los fundadores - se pasan a domiciliar todas las aristas axiológicas del proyecto regional centroamericano en su conjunto, el cual en su actual etapa, se encauza a través del SICA. Sin embargo lo indicado en estos dos primeros párrafos requiere de una complementación histórica sobre dos aspectos:

El primer punto es comprender que la CCJ se impregna de este carácter constitucionalista directamente desde su Estatuto, lo que marca una diferencia concreta con el TJUE, quien no se vio enfrentado a tan ambicioso y complejo objetivo en sus inicios, sino que la Corte de Luxemburgo, asumiendo su posición pionera, en su primera época ${ }^{103}$ debió ir desarrollando y asumiendo este cariz constitucional. Estas y otras experiencias europeas son las que el modelo de integración Centroamericano al reorientarse hacia el derecho de la integración incorporó ya resueltas estatutariamente, a diferencia de lo sucedido en el proyecto de integración europeo donde varios de estos aspectos fueron inicialmente producto de la jurisprudencia, como por ejemplo la construcción de la Corte de Luxemburgo en cuanto a la protección en la dimensión jurisdiccional de los derechos humanos, efectuadas en sus

\footnotetext{
${ }^{102}$ Primera parte del art. 6 del Estatuto de la CCJ.

${ }^{103} \mathrm{Si}$ bien el TJUE sigue siendo de carácter único en el concierto mundial, pues ninguna construcción jurisdiccional transnacional se le parece completamente, hemos empleado el concepto de único, en el sentido de que en los primeros tiempos de la Corte de Luxemburgo — antes del fin del Guerra Fría - aún no se constataban recepciones del modelo de la UE ni del TJUE en el resto del planeta. Correlato histórico que ya analizamos en el capítulo I de esta tesis.
} 
clásicas sentencias del caso Stauder c/ Stadt Ulm - Sozialamt ${ }^{104}$, en el caso Internationale Handelsgesellschaft mbH c/ Einfuhr - und Vorratsstelle für Getreide und Futtermittel ${ }^{105}$, y en el caso Nold, Kohlen - und Baustoffgroßhandlung c/ Comisión de las CE ${ }^{106}$, estas sentencias han sido de profuso análisis por la doctrina ${ }^{107}$ y con el tiempo sus criterios fueron positivizados por el legislador de la UE. Puntualmente dicha experiencia de la UE es la que el SICA incorpora estatutariamente desde sus inicios, lo que se demuestra porque el Protocolo de Tegucigalpa a la Carta ODECA considera este objetivo concretamente, expresándolo así:

«EL SICA tiene por objetivo fundamental la realización de la integración de Centroamérica, para constituirla como Región de Paz, Libertad, Democracia y Desarrollo.

En ese sentido, se reafirman los siguientes propósitos:

Consolidar la democracia y fortalecer sus instituciones sobre la base [...] del irrestricto respeto a los Derechos Humanos» ${ }^{108}$.

Otro ejemplo es la concreción respecto de que la CCJ es la depositaria de la conciencia centroamericana — conforme ya indicamos ${ }^{109}$ — , cuestión que se complementa con la explicación histórica que hace de esa norma las mismas Motivaciones del PT a la Carta ODECA al señalar:

«cabe resaltar el contenido del art. 6 del Estatuto, que lo toma de lo establecido para La Corte de Justicia Centroamericana, o Corte de Cartago de 1907, y lo enriquece, al declarar a La Corte Centroamericana de Justicia, como representante de la conciencia nacional de Centroamérica y depositaria de los valores que integran la nacionalidad centroamericana, incorporando así a las nuevas reglas de convivencia de Centroamérica el aporte axiológico que deberá informar a las futuras generaciones de la nuestra Patria Centroamericana» ${ }^{110}$.

104 Sentencia del TJ de 12 de noviembre de 1969, Stauder c/ Stadt Ulm - Sozialamt, as. C-29/69, ECLI:EU:C:1969:57.

${ }^{105}$ Sentencia del TJ de 17 de diciembre de 1970, Internationale Handelsgesellschaft mbH c/ Einfuhr - und Vorratsstelle für Getreide und Futtermittel, as. C-11/70, ECLI:EU:C:1970:114.

${ }^{106}$ Sentencia del TJ de 14 de mayo de 1974, Nold, Kohlen - und Baustoffgroßhandlung c/ Comisión de las $C E$, as. C-4/73, ECLI:EU:C:1974:51.

${ }^{107}$ No es nuestro objeto analizar la dimensión protectora de los derechos humanos que poseen las Cortes de integración en esta tesis, sin embargo anotamos aquí que la construcción en la dimensión protectora de los derechos fundamentales mediante el triple fundamento del TJUE y la técnica que conlleva, puede revisarse entre varios en MORENO MOLINA, 2007, pp. 32-34. Otra, LIÑÁN NOGUERAS, 2014a, pp. 122-124.

${ }^{108}$ Art. 3 del Protocolo de Tegucigalpa a la Carta ODECA.

${ }^{109}$ Primera parte del art. 6 del Estatuto de la CCJ, ya citado, vid. nota 102 de este capítulo.

${ }^{110}$ Párrafo noveno del apartado Conclusiones de las Motivaciones del Protocolo de Tegucigalpa a la Carta ODECA, sección en que además de forma clara conecta a la Corte de Cartago con la actual CCJ. 
El segundo aspecto es que la CCJ, como dijimos, más que orientarse hacia la integración, lo que realmente hace es re-orientarse en un nuevo ciclo, pues no precisamente fue al nacer que se le inyectó este carácter constitucional, toda vez que la CCJ es en realidad la sucesora de la Corte de Cartago de $1907^{111}$, es decir, que al órgano jurisdiccional de Centroamérica se le reconocen raíces mucho más antiguas que las de la Corte de Luxemburgo.

El motivo por el cual nosotros destacamos esta circunstancia, es porque la propia CCJ lo subraya prácticamente en casi todas sus sentencias, conectando de ese modo el Derecho de la integración con un acervo jurídico de principios del siglo XX, y de lo cual hay múltiples casos, véase por ejemplo la sentencia recaída en Poder Ejecutivo de Nicaragua c. Asamblea Nacional de Nicaragua ${ }^{112}$, donde nítidamente se lee:

«Que previo [...] es necesario determinar con toda claridad el derecho a aplicarse [...] "Finalmente cabe resaltar el contenido del art. 6 del Estatuto, que lo toma de lo establecido para la CCJ, o Corte de Cartago de 1907 y, lo enriquece» ${ }^{113}$.

Y continuando en igual línea en la sentencia se expresa:

«Que en atención al derecho a aplicarse en este caso, se destaca [...]: "La Competencia de La Corte será: f) Conocer y resolver a solicitud del agraviado de conflictos que puedan surgir entre los Poderes u Órganos Fundamentales de los Estados, y cuando de hecho no se respeten los fallos judiciales." Esta atribución, que forma parte del acervo jurídico centroamericano, originada en similar que tuvo la Corte de Justicia Centroamericana (Corte de Cartago), que funcionó de 1908 a $1918 »^{114}$.

Sumándose el hecho de que el carácter constitucional de la CCJ es destacado mayoritariamente por la doctrina ${ }^{115}$ especializada en el proceso centroamericano, la cual

${ }^{111}$ La cronología jurisdiccional centroamericana comienza con el Tribunal de Justicia Centroamericano también conocido como Corte de Cartago de 1907 primer tribunal internacional en la historia de naturaleza jurisdiccional y permanente, posterior Corte de Justicia Centroamericana de 1962, y finalmente Corte Centroamericana de Justicia - CCJ con Estatutos desde 1992. La Corte de Cartago es primer tribunal internacional en la historia de naturaleza jurisdiccional y de extensión sub-continental, a diferencia de la Corte Permanente de Arbitraje de 1899 que es el tribunal internacional más antiguo que está en funcionamiento, pero es de naturaleza arbitral y de extensión global.

${ }^{112}$ Vid. et al. Sentencia de la CCJ de 29 de marzo de 2005, República de Nicaragua c/ Asamblea Nacional de la República de Nicaragua, expediente 69-01-03-01-2005.

${ }^{113}$ CONSIDERANDO (I) en sentencia ibídem.

${ }^{114}$ CONSIDERANDO (II) en sentencia ibídem.

${ }^{115}$ En dicho entendido GIAMMATTEI asevera con base en los criterios o funciones de justiciabilidad y que caracterizan a los Tribunales Constitucionales, la CCJ, desde el inicio de sus funciones y dentro del límite de sus competencias, ha actuado como Tribunal Constitucional, al determinar la jerarquía que corresponde al Protocolo de Tegucigalpa con respecto al conjunto de tratados, convenios, protocolos, acuerdos y otros actos 
hace hincapié en las concretas funciones de esta Corte y al modo coherente de aplicarlas cada vez que se requieren, en base a sus competencias atribuidas.

Buscando directamente la constatación de aquellos ocho cauces de cercanía ${ }^{116}$ que se utilizan para destacar esta singularidad en el caso del TJUE, se observa que la dimensión constitucional de la CCJ aflora tanto de las Motivaciones de su Estatuto, como positivamente de algunas potestades catalogadas en el art. 22 de dicho Estatuto. Esto es, no de todo el catálogo de esa norma, ya que en su conjunto da cuenta de la gran amplitud de competencias asignadas $^{117}$, dejando de paso al descubierto la doble funcionalidad de los tribunales de integración que ya mencionamos para el TJUE ${ }^{118}$.

Entonces, por lo dicho en el párrafo precedente, debemos seleccionar de entre todas las competencias que lista el extenso art. 22, sólo las pertinentes a esta materia, y que ya hemos mencionado al estudiar otros patrones centrales en la CCJ, como la función interpretativa de las Cartas Constitutivas, la función consultiva y el control de legalidad de los actos, pues a través de éstas se da salida a los comentados cauces de cercanía con un tribunal constitucional. Para no redundar en lo ya dicho, tengamos presente que del señalado artículo sirven para confrontar a la CCJ con su dimensión constitucional, los siguientes aspectos que hemos agrupamos en cuatro conjuntos para enfrentarlos a los ocho cauces, quedando así:

Uno, a través de su competencia en las acciones de nulidad ${ }^{119}$, da cuenta del cauce que se refería al sometimiento al Derecho del SICA a todo derecho nacional de los Estados miembros.

Dos, su potestad para efectuar un análisis de correspondencia o compatibilidad de la legislación local con los Tratados ${ }^{120}$, pudiendo conocer a petición de un interesado acerca de las disposiciones legales o de cualquier otra clase, dictadas por un Estado,

vinculatorios, anteriores y posteriores a la entrada en vigencia del referido Protocolo, y la relación normativa de los instrumentos complementarios o actos derivados. GIAMMATTEI AVILÉS, J. A. (2002). La corte centroamericana de justicia como tribunal constitucional de la comunidad centroamericana. Anuario de derecho constitucional latinoamericano, (2003), 507-522 (p. 516). Disponible en <https://revistascolaboracion.juridicas.unam.mx/index.php/anuario-derecho-constitucional/article-/view/3602/3361> [última consulta, diciembre 10, 2018].

${ }^{116}$ Nos referimos a los ocho cauces o ejes de cercanía que esquematiza SÁIZ para el caso del TJUE, y que ya vimos líneas atrás. Vid. nota 95 de este capítulo II. SÁIZ ARNÁIZ, 1999, pp. 229-231.

${ }^{117}$ Para una visión más amplia vid. CANO LINARES, M. A. (2009). La corte centroamericana de justicia: un órgano único con diversidad de competencias. En Fernández Liesa, C. R., \& Díez de Velasco Vallejo, M. Tribunales internacionales y espacio iberoamericano ( $1^{\mathrm{a}} \mathrm{ed}$.). Cizur Menor: Thomson Reuters.

${ }^{118}$ SARMIENTO RAMÍREZ-ESCUDERO, 2016, p. 357, vid. nota 85 de este capítulo.

${ }^{119}$ Literal b) del art. 22 del Estatuto de la CCJ.

${ }^{120}$ Literal c) del art. ibídem.

142 
cuando afecten los Convenios o Tratados y, de toda otra normativa del Derecho del SICA. Esta competencia reconoce el cauce por el cual la Corte está determinando el alcance de los Tratados, más el cauce que le reconoce el carácter de supremo intérprete de los mismos.

Tres, mediante las competencias consultivas ${ }^{121}$, para que actúe como Tribunal de Consulta Permanente de las Cortes Supremas de Justicia de los Estados lo sea también respecto de los órganos u organismos del SICA en la interpretación y aplicación del PTC-ODECA, y de los instrumentos complementarios y actos derivados. Por último, en carácter de pieza principal del sistema, se le dan competencias consultivas prejudiciales requeridas por el juez nacional para lograr la aplicación o interpretación uniforme del Derecho del SICA. Constatándose principalmente los cauces de supremo intérprete de los Tratados, el de determinar el alcance de los Tratados y el del sometimiento al Derecho del SICA.

Cuatro, por último a través de su función de apoyo a la legislatura, por una cara, se le reconoce su carácter de supremo intérprete del Derecho del SICA, y por otra cara, su carácter de activo partícipe en el proceso integracionista, indicándose del siguiente modo:

«Hacer estudios comparativos de las Legislaciones de Centroamérica para lograr su armonización y elaborar proyectos de leyes uniformes para realizar la integración jurídica de Centroamérica» ${ }^{122}$.

Aquí colacionan los cauces de la forma de intervención de la Corte en el proceso de institucionalización del SICA, más el de supremo intérprete de los Tratados.

Ahora bien, en calidad de competencia material constitucional de la CCJ, es reflejo nítido de esta cualidad del tribunal, cada vez que le corresponde conocer y resolver conflictos que puedan surgir entre los Poderes u órganos fundamentales de los Estados, y cuando no se respeten los fallos judiciales ${ }^{123}$.

En conclusión, del análisis estatutario realizado en este apartado y de lo apuntado en cada caso respecto de la doctrina y ejemplos de determinadas sentencias, se desprende con claridad que en la CCJ — a partir de sus Estatutos- el patrón central buscado sí está

\footnotetext{
${ }^{121}$ Literales d), e) y k) del art. ibídem.

122 Literal i) del art. ibídem.

${ }^{123}$ Este punto en particular ULATE lo conecta con el literal b) del art. 22 en estudio, para resaltar que el hecho de que le corresponde a dicha Corte, cuando así le sea requerido por los Estados partes, conocer y resolver a solicitud del agraviado, de conflictos que puedan surgir entre los Poderes u órganos fundamentales de los Estados, y cuando de hecho no se respeten los fallos judiciales, serían evidencia de una competencia material constitucional. ULATE CHACÓN, 2008.
} 
presente. Por lo tanto la Corte centroamericana posee el carácter de cuasi tribunal constitucional.

\subsubsection{ANÁLISIS DEL POSIBLE CARÁCTER DE CUASI TRIBUNAL CONSTITUCIONAL} DEL TJCA A PARTIR DE SU MARCO ESTATUTARIO

Si bien al TJCA se le atribuyeron competencias propias de un órgano constitucional, no fue con tanta nitidez como sí se hizo para la CCJ. Además, y como ya hemos visto, el TJCA nace desfasado del proyecto político, lo cual supuso un grave inconveniente para todo el proyecto regional, de hecho nace en medio de una crisis ${ }^{124}$. La dimensión constitucional de la Corte andina se sigue en sus Estatutos de la función hermenéutica que se le atribuyó respecto de las Cartas Constitutivas de la CAN, función que ejercita como último intérprete y sometiendo toda otra norma al Derecho andino. Además de reconocerse que el Acuerdo de Cartagena, en su condición de norma primaria, es el marco constitucional del proyecto andino, asumiendo el carácter de primario o constitucional, tal como apunta la doctrina ${ }^{125}$. Entonces, desde tales coordenadas es que el TJCA al interpretar esa clase de normas y siendo el garante de la legalidad de la CAN, se impregna efectivamente del carácter de cuasi tribunal constitucional.

Las competencias que colacionan con la dimensión constitucional son varias, comenzando por la potestad de declarar la nulidad de las Decisiones de otros órganos del Sistema Andino de Integración (SAI), norma que bajo una estructura englobante de los concurrentes al proyecto andino señala:

«Corresponde al Tribunal declarar la nulidad de las Decisiones del Consejo Andino de Ministros de Relaciones Exteriores, de la Comisión de la CA, de las Resoluciones de la Secretaría General y de los Convenios a que se refiere el literal

\footnotetext{
${ }^{124}$ Recordemos que la inexistencia del TJCA en el origen de la CAN, representó una severa debilidad orgánica. Circunstancia crítica y siempre realzada por la academia bajo metáforas como el pecado original de la CAN, o la cojera inicial. Este análisis lo vimos desde el cauce histórico en el capítulo I, y en el capítulo V lo abordaremos como un hecho relevante que nos permitirá analizar incluso su proyección. Vid. et al. ZELADA CASTEDO, 1985. Otro, VIGIL TOLEDO, 2011.

${ }^{125}$ En dicho cauce podemos destacar el razonamiento de VIGIL quien señala, para dicha experiencia de integración regional, el Acuerdo de Cartagena es la norma fundacional que creó la CAN, estableciendo cuales son los órganos e Instituciones que conforman el SAI, entre los que por cierto se encuentra el TJCA, según el claro tenor del art. 6 del referido Acuerdo de Cartagena, instrumento jurídico que posee el carácter de primario o Constitucional. Luego — este autor - refuerza la idea agregando que, desde un punto de vista teórico los Tratados de Creación de un organismo son su Constitución o Estatuto; y desde esa posición pasa a explicitar la dimensión constitucional del Tribunal Andino, observando que la adquiere cada vez que por vía pretoriana interpreta las normas comunitarias como garante de la legalidad de su ordenamiento jurídico. VIGIL TOLEDO, 2011, pp. 33-37.
} 
e) del Art. 1, dictados o acordados con violación de las normas que conforman el ordenamiento jurídico de la CAN, incluso por desviación de poder, cuando sean impugnados por algún País Miembro, el Consejo Andino de Ministros de Relaciones Exteriores, la Comisión de la Comunidad Andina, la Secretaría General o las personas naturales o jurídicas» ${ }^{126}$.

Le siguen en esta línea las competencias en las consultas prejudiciales ${ }^{127}$, las cuales si bien, presentan diferencias procesales con el modelo de la UE, su mera incorporación al Ordenamiento Andino da cuenta del carácter de supremo intérprete sobre los Tratados Constitutivos que asume el TJCA y del concluyente sometimiento al Derecho de la CAN a todo otro derecho. Pero la norma central en esta materia y la que con mucha mayor precisión le imprimió el perfil constitucional a la Corte andina, es la que le da el carácter de supranacional y el status de supremacía, del siguiente modo:

«El Tribunal es el órgano jurisdiccional de la Comunidad Andina, de carácter supranacional y comunitario, instituido para declarar el derecho andino y asegurar su aplicación e interpretación uniforme en todos los Países Miembros» ${ }^{128}$.

Ahora bien, es un hecho que el proyecto de la CAN no puede ser considerado un modelo supranacional, menos en las constantes circunstancias de crisis en que se moviliza. Por lo tanto, si bien en los Estatutos pueda indicarse como una estructura supranacional, en los hechos no lo es. Incluso en los albores de la CAN se tenían altas expectativas de este proyecto, tanto así que se consideraba a la UE y a la CAN como los modelos integracionistas más avanzados según recuerda la doctrina ${ }^{129}$, rotundo error que la historia se ha encargado de $\operatorname{aclarar}^{130}$.

\footnotetext{
${ }^{126}$ Art. 17 del Tratado de Creación del TJCA.

127 El art. 32 del Tratado ibídem, en lo pertinente indica «Corresponderá al Tribunal interpretar por vía prejudicial las normas que conforman el ordenamiento jurídico de la CA».

${ }^{128}$ Inciso $1^{\circ}$ del art. 4 del Estatuto del TJCA.

${ }^{129}$ Cuando nace definitivamente el órgano jurisdiccional de la CAN — desfasado como ya lo anotamos- se tenían grandes expectativas. Los análisis realizados sólo en papel, es decir en lo Estatutario del TJCA comparado al marco normativo del TJUE, los mostraban a ambos como muy modernos y casi idénticos. Fue significativa la aseveración de QUINDIMIL «el Tribunal de Justicia de las Comunidades Europeas en Europa y el Tribunal de Justicia de la CAN en el Continente americano. Salvando las distancias existentes entre ambos tribunales, 'puede afirmarse que constituyen, sin duda, los modelos más avanzados de justicia comunitaria'». QUINDIMIL LÓPEZ, 2006, p. 38. Volveremos sobre este aspecto con más detalle en el capítulo $\mathrm{V}$.

${ }^{130}$ Volveremos sobre esta realidad que toma distancia de lo pretendido por los Estatutos, al hacer las proyecciones de futuro de los modelos latinoamericanos en el capítulo V, y también al observar en el capítulo IV referido al diálogo judicial, como, los esquemas de América Latina solo operan extractivamente, sin grandes aportes locales al desarrollo de un derecho de la integración aplicado al Cono Sur de América - CAN y MERCOSUR. Aunque una mejor situación iremos observando, prácticamente en todas las aristas analizadas en esta tesis, para el caso de Centroamérica - SICA.
} 
Sin embargo, tampoco es absolutamente indispensable poseer una tan desarrollada estructura normativa sobre un patrón central para concluir que la Corte en análisis lo posea, pues, como hemos puesto de manifiesto, existen diferentes intensidades en cada proceso integracionista. Por lo cual, la singularidad que buscamos se puede verificar, tanto en los procesos más avanzados, como en los de menos desarrollo, así en estos últimos, se constatará en menor medida. Justamente este reconocimiento y valoración de la existencia de procesos de integración de distintas intensidades - y no la negación absoluta sobre todos los que no sean la UE- es remarcado por buena parte de la doctrina ${ }^{131}$. Pues bien, a la luz del análisis realizado en este apartado se deduce que el TJCA presenta el carácter de cuasi tribunal constitucional.

\subsubsection{ANÁLISIS DEL POSIBLE CARÁCTER DE CUASI TRIBUNAL CONSTITUCIONAL DEL TPRM A PARTIR DE SU MARCO ESTATUTARIO}

Resulta bastante complejo buscar un posible carácter constitucional en los tribunales del MERCOSUR - TAAM y TPRM - por diversas dificultades que podemos agrupar en los siguientes tres tipos de razones:

El primer obstáculo es la génesis intergubernamental del MERCOSUR. Este proyecto obedeció en su origen a objetivos de sesgos comerciales, más que sociales o políticos. Sin perjuicio de que su desarrollo lo ha llevado por un nuevo camino mucho más conectado a lo socio-político. Pero dicha impronta comercial aún es muy preponderante, cuestión que lo hace colacionar con más facilidad en el concepto de integración económica, según va categorizando la doctrina ${ }^{132}$.

${ }^{131}$ Tal diferenciación CIENFUEGOS la explica en los siguientes términos «en los procesos de integración más avanzados la solución de controversias se radica en el Tribunal o Corte de Justicia al que se le atribuyen prerrogativas mиy amplias, toda vez que generalmente puede anular los actos de sus órganos, [...], resolver en vía prejudicial las dudas acerca de la interpretación y, en su caso, la validez del ordenamiento de la organización, [...] etcétera, —agregando que- es el caso de la UE y, en menor medida, de la Comunidad Andina, entre otros». CIENFUEGOS MATEO, M. (2013). Cuestiones prejudiciales en la unión europea y consultas prejudiciales en la comunidad andina: Similitudes, diferencias e influencias. Revista electrónica de estudios internacionales (REEI), (25).

${ }^{132}$ La doctrina categoriza a los esquemas de integración porque no es un fenómeno jurídico homogéneo, sino recepciones del modelo de la UE con sendas carencias. Ningún proceso en América Latina es puro, ni podría ajustarse a sólo una clase de integración. ARCARO destaca dos grandes tipos de integración, una básica denominada integración estructural, identificada por formalismos y vinculada al desarrollo económico o comercial, $v / s$ una integración profunda, la denominada integración sustancial, más desarrollada contemplando la protección a los derechos humanos y no por ello con más orgánica, sino que decantan en lo sustantivo; por esta razón sería parte de una integración jurídica. ARCARO CONCI, L. G. (2015). Mercosur, 146 
En segundo lugar se concentran negativamente tres razones propias del sistema orgánico de los tribunales mercosureños: uno, la naturaleza arbitral de los TAAM y del TPRM; dos, la falta de continuidad de sus jueces, pues como vimos, los árbitros son sólo de convocatoria permanente; y tres, respecto a la fuerza estructural, observamos que, si ya es bastante dificultoso para los tribunales latinoamericanos de naturaleza jurisdiccional el asumir un carácter constitucional, imposible será entonces, pretender que estructuras menores, como las arbitrales no permanentes, soporten el peso específico de un cuasi tribunal constitucional.

Por último, en tercer lugar, el TPRM carece de importantes competencias, aquí destaca el hecho de que no tiene atribuciones para conocer de una acción de nulidad de normas, ni originarias ni derivativas, lo que constituye una carencia sustantiva del merco-sistema. Por lo que, de modo paliativo, el TPRM recurre a la denominada «facultad para declarar la incompatibilidad», la cual es una noción propia del MERCOSUR nacida jurisprudencialmente en la respuesta a la opinión consultiva República Oriental del Uruguay $^{133}$. En dicha oportunidad el TPRM para sortear la inexistencia de la acción de incumplimiento, recurrió a competencias generales y construyó la institución que pasó a conocerse como la «apreciación de compatibilidad», mediante la cual se hace factible, el apreciar la compatibilidad de las normas de los Estados Partes con las mercosureñas. Así, en su respuesta señaló:

«en la actual etapa del proceso de integración, tanto los Tribunales Ad Hoc como el TPR, aunque carecen de competencia para declarar de forma directa la nulidad o la inaplicabilidad de la norma interna [...], pueden declarar la incompatibilidad de la norma interna con el derecho del Mercosur. Son los órganos estatales competentes los que deben derogar o modificar la norma interna incompatible, habilitando medidas que pueden ser adoptadas por el Estado Parte afectado en caso de incumplimiento» ${ }^{134}$.

\footnotetext{
integración regional y derechos humanos en un proceso multinivel. Estudios constitucionales: Revista del centro de estudios constitucionales, 13(2), 125-152. Con mayores detalles DOBOVSEK y SABAT distinguen entre varias, una, según la forma histórica de la integración habrían dos tipos, la autoritaria y la por coordinación, otra, según su finalidad estaría la integración militar, la económica, la política, o la cultural, y finalmente, según la actitud de ella, reconocen una integración de sistema cerrado y estanco, o una de apertura y flexibilidad intelectual. DOBOVSEK \& SABAT, 1999, vid. en particular apartado II, números 3.1., 3.2. y 3.3. Clases de integración (...), pp. 241-243.

${ }^{133}$ Laudo del TPRM de 24 de abril de 2009, Opinión consultiva, República Oriental del Uruguay, as. OC. 01/2008.

${ }^{134}$ Considerando 33 en laudo ibídem.
} 
Esta fue una construcción jurisprudencial en base a un proceso hermenéutico finalista de la totalidad del Derecho del MERCOSUR, apoyándose en la estructura piramidal de las normas y del principio de seguridad jurídica ${ }^{135}$, al tiempo de que el TPRM ha aplicado el concepto de Comunidad de Derecho acuñado por la Corte de Luxemburgo.

Se suma a esta carencia en materia de competencias, el hecho de que tampoco posee atribuciones para efectuar un control previo de los Acuerdos Internacionales que el MERCOSUR pretenda suscribir. Así por ejemplo, con las actuales estructuras jurídicas, el Acuerdo de Asociación UE - MERCOSUR ${ }^{136}$ tendrá un diferente control a ambos lados del Atlántico. En la UE el control preventivo será — de existir dudas - jurisdiccional a cargo del TJUE, en cambio en el MERCOSUR será a todo evento intergubernamental.

Bajo tales circunstancias el resultado que obtuvimos tras analizar al MERCOSUR en cuanto a esta característica, es negativa, pues aún persisten sendos obstáculos que impactan, de tal modo en la orgánica y en la funcionalidad del Sistema Resolutor de Controversias Mercosur (SSCM), que nos impiden reconocerle un carácter constitucional al TPRM, sin perjuicio de que es el máximo intérprete del Derecho mercosureño.

En conclusión, por todo lo analizado en este apartado orientado a lograr probar el cariz constitucional que las Cortes latinoamericanas enfocadas pudiesen tener —al igual como previamente lo vimos para el TJUE_-, deducimos dos conclusiones, primero que en ningún caso las Cortes de los modelos receptores, se encuentran plenamente imbuidas del cariz constitucional, a diferencia del TJUE quien sí lo ostenta notoriamente, y en un segundo plano, esto es, sí dichas Cortes latinoamericanas son únicamente analizadas respecto de la cercanía con el cariz constitucional - y no con el hecho efectivo o absoluto de poseerlose ubican en el siguiente orden: primero y con más intensidad la CCJ, siguiéndole luego el TJCA, y al TPRM lo excluimos del todo.

\footnotetext{
${ }^{135}$ Ahondaremos en esta construcción jurisprudencial del TPRM al efectuar el análisis de la jurisprudencia integracionista en el capítulo III.

${ }^{136}$ El proyecto de Acuerdo de Asociación UE - MERCOSUR tardó más de 20 años para concretarse y recientemente en junio de 2019 se arribó a un texto. El camino fue muy lento pero en los últimos años se aceleró y al parecer se estarían dando las condiciones para concretarlo. LUCÁNGELI, J., SANGUINETTI, M. \& ZAMORANO, A. L. (2010). Mercosur: La consolidación de la expansión de la economía del bloque. Revista del CEI. Comercio exterior e integración, (18), pp. 19-45 (24, vid. en particular apartados 1.2. El relacionamiento externo del MERCOSUR, y 1.2.1. Las negociaciones MERCOSUR - Unión Europea). En julio del 2018 EDITA HRDA, directora para América del Servicio Europeo de Acción Exterior de la UE auguraba que el ACUERDO DE ASOCIACIÓN UE-MERCOSUR ya avanzaba muy rápido. Fuente, Portal oficial de la Comisión de la UE. Disponible en 〈https://ec.europa.eu/spain/news/180706_hrda-mercosur_es> [última consulta, diciembre 31, 2018]. Y recientemente en junio del 2019 se cerró un texto entre la UE y MERCOSUR, pasando ya a la fase final. Disponible en <https://www.mercosur.int/todos-los-datos-sobre-elhistorico-acuerdo-mercosur-ue/> [última consulta, septiembre 26, 2019].
} 


\subsubsection{LAS ESTRUCTURAS LEGISLATIVAS Y CONDICIONES QUE FAVORECEN}

EL RESPETO A LA RES IUDICATA PARA LAS SENTENCIAS

DE LAS CORTES LATINOAMERICANAS

La res iudicata y el imperium en sedes transnacionales han sido un foco de estudio que ha ido variando con el desarrollo de la teoría general de la jurisdicción internacional. Pero siempre manteniéndose el carácter obligatorio de los fallos de los tribunales internacionales como un tema sensible para el DI y, en particular, muy propio de las Cortes de integración, sobre todo, de las que se encuentran inmersas en procesos de integración maduros. En términos amplios, la comunidad jurídica comparte la idea de que los Estados cumplirán los fallos internacionales de buena fe y voluntariamente ${ }^{137}$, quedando el cumplimiento prendado al Honor de las Naciones. Pero si atendemos con detención al fenómeno histórico de la judicialización transnacional, veremos que la voluntariedad en el cumplimiento de las sentencias internacionales era más propia del pasado, cuando las soluciones procesales en tal dimensión sólo se aposentaba en sedes arbitrales ${ }^{138}$, las cuales no se encontraban conectadas estructuralmente a una OI.

Sin embargo, se ha venido produciendo una mutación desde lo voluntario hacia lo obligatorio por diversas razones históricas, entre las cuales destaca el hecho de que los sujetos con capacidad de ser partes han ido aumentando, pues a los Estados se les han sumado las OI, Instituciones, órganos de OI y las personas físicas y jurídicas. Por otra parte

${ }^{137}$ HERSCH LAUTERPACHT «It is a canon of international law that the jurisdiction of international tribunals is one voluntarity accepted by States». LAUTERPACHT, H. (1933). The function of law in the international community. Oxforf: Clarendon Press, vid. en particular Cap. I, apartado 1 The limitation of the place of law as an expression of the theory of sovereignty., pp. 3-4.

${ }^{138}$ Recordemos que la sede arbitral internacional precede históricamente — con mucha distancia — a la jurisdiccional internacional. El arbitraje ya existía en el mundo griego antiguo, en cambio la dimensión jurisdiccional nace en América en 1907 con la Corte de Cartago. El arbitraje internacional nació sin jueces especializados, siendo los Emperadores, el Papa y luego importantes Jefes de Estados los que llevaban adelante tal misión. Más tarde el arbitraje se profesionaliza, siendo un claro ejemplo de su desarrollo la Corte Permanente de Arbitraje (CPA) de 1899 que fue la primera institución global creada para resolver disputas internacionales. La CPA es en sí misma una Organización Intergubernamental Independiente, constituyendo un mecanismo opcional para la Comunidad Internacional en múltiples materias. Nació hace más de un siglo y continúa vigente hasta nuestros días compartiendo sede con la CIJ en el Palacio de la Paz en la ciudad de la Haya. Un valioso reconocimiento a la CPA puede verse en VAN DEN HOUT, T. T. (2008). Resolution of international disputes: The role of the permanent court of arbitration - reflections on the centenary of the 1907 convention for the pacific settlement of international disputes. Leiden journal of international law, 21(3), 643661. (Este artículo es una adaptación de los discursos pronunciados con motivo del sexagésimo aniversario de la Sociedad Telders para el Derecho Internacional -Universidad de Leiden- el 17 de febrero de 2007 y la Conferencia del Foro Mundial legal el 10 de diciembre de 2007). 
los tribunales internacionales en general pertenecen a una OI en cuyos esquemas ya se establecieron estatutariamente las sanciones a los incumplimientos. Luego se suman casos especialísimos, como los tribunales de jurisdicciones globales $v . g r$. en la CIJ ante el incumplimiento de uno de sus fallos, pueden ser enviados los antecedentes al Consejo de Seguridad de NU para que éste tome las medidas conducentes al cumplimiento, en un claro código de imperium $^{139}$. Y a todo lo anterior se agrega el complejo Sistema Penal Internacional, el cual nace con los tribunales híbridos de Núremberg y Tokio, casos en que las sentencias a muerte fueron cumplidas sin más. Con posterioridad se han venido desarrollando este tipo de jurisdicción penal internacional bajando la intensidad de sus sanciones. Este es entonces el contexto teórico referido al cumplimiento de las sentencias internacionales que rodea a la UE y al modelo del TJUE, claramente muy singulares ante dicho entorno.

En nuestro modelo de referencia — la UE — se estableció legislativamente la obligatoriedad en el cumplimiento de las sentencias del TJ, cuestión que fue muy trascendente para los modelos de América Latina que observaban el esquema europeo, toda vez que una de las dificultades propias de dicha región es precisamente la seriedad y el cumplimiento de los acuerdos. Así entonces, era evidente que ante un modelo jurisdiccional transnacional a implementar, sería central el tema del respeto a lo resuelto por el tribunal, de lo contrario se estaría añadiendo un mecanismo de inseguridad jurídica para las regiones cubiertas por los proyectos SICA, CAN y MERCOSUR, y carecería de todo sentido la presencia de la CCJ, del TJCA y del TPRM si sus fallos no fuesen obligatorios. Justamente esta es la debilidad más sensible del MERCOSUR respecto de las respuestas del TPRM a las consultas prejudiciales, pues ninguna es vinculante ${ }^{140}$. Esta consecuencia negativa es la que se supera con estructuras legislativas pertinentes que robustezcan a las Cortes latinoamericanas bajo análisis, razón por la cual hemos incorporado como patrón central entre dichos tribunales, el respeto a la res iudicata.

${ }^{139}$ El sistema de las NU creado para el respeto de la res iudicata de las Sentencias de la CIJ, se articula mediante tres normas, en primer lugar, es el art. 59 del Estatuto de la CIJ el que establece la obligatoriedad de la sentencia para las partes del litigio, en segundo lugar, dicha norma es complementada por el art. 94.2 del Reglamento de la CIJ, el cual indica que la sentencia tendrá fuerza obligatoria para las partes desde el día de su lectura, y en tercer lugar, mediante el art. 94.2 de la Carta de NU se cierra el marco legislativo de respeto a la res iudicata en el sistema de NU, generando la posibilidad de informar al Consejo de Seguridad ante el incumplimiento de una sentencia de la CIJ, disponiéndolo del siguiente modo «Si una de las partes en un litigio dejare de cumplir las obligaciones que le imponga un fallo de la Corte, la otra parte podrá recurrir al Consejo de Seguridad, el cual podrá, si lo cree necesario, hacer recomendaciones o dictar medidas con el objeto de que se lleve a efecto la ejecución del fallo».

${ }^{140}$ Art. 11 del Reglamento del POPSCM, titulado Efecto de las opiniones consultivas, el cual señala «Las opiniones consultivas emitidas por el TPR no serán vinculantes ni obligatorias».

150 
La fórmula europea para salvaguardar el imperium de la Corte de Luxemburgo se basa en reconocerles a sus fallos la condición de título ejecutivo perfecto, tras la simple constatación de su autenticidad, ejecutándose mediante el principio de colaboración por el juez nacional ${ }^{141}$. Como vemos la obligatoriedad del cumplimiento de las sentencias del TJ es un tema zanjado, acatándose la autoridad de cosa juzgada por los Estados miembros y por todo litigante, cuestión motivo de orgullo y además realzado por la doctrina ${ }^{142}$.

Igual fuerza vinculante tienen las respuestas del TJ a las cuestiones prejudiciales, y su autoridad en este último caso, se respeta mediante los conductos procesales de impugnación recursivos nacionales, por incurrir en error de derecho, cuestión destacada por la doctrina $^{143}$. Así resueltas las cosas en Europa, el foco de interés recae ahora sobre los proyectos latinoamericanos, pues hay modelos receptores en Latino América que parecen disonantes, pues no recepcionan con tanta fuerza el modelo de referencia, sino que hacen particulares diferenciaciones, incluso en ocasiones, no son obligatorias algunas sentencias. En este sentido podemos apreciar significativos contrastes entre los modelos latinoamericanos en el respeto a la res iudicata a partir del cotejo estatutario de cada sistema, según veremos a continuación.

${ }^{141}$ Tal construcción se basa en dos artículos, primero, mediante el art. 280 del TFUE el cual expresa «Las sentencias del TJUE tendrán fuerza ejecutiva en las condiciones que establece el art. 299». El señalado art. 299 manifiesta — para nuestro interés aquí - en sus incisos $2^{\circ}, 3^{\circ}$ y $4^{\circ}$, en general las siguientes ideas: uno, que la ejecución forzosa se rige por las normas del procedimiento civil del Estado en cuyo territorio se lleve a cabo, dos, que la orden de ejecución será consignada sólo tras la comprobación de la autenticidad del título, tres, que el interesado podrá promover la ejecución conforme al derecho interno, cuatro, que eventualmente podría suspenderse la ejecución por el TJUE, y cinco, reserva un control de conformidad a derecho, de las medidas de ejecución, a la competencia de las jurisdicciones nacionales.

${ }^{142}$ Como lo concluye IGLESIAS BUHIGUES señalando «en fin, las sentencias del Tribunal de Justicia forman título ejecutivo sin más trámite que el de la comprobación de su autenticidad». IGLESIAS BUHIGUES, 2013, p. 25.

${ }^{143}$ Esta arista de obligatoriedad de las resoluciones de la Corte de Luxemburgo, es una diferencia respecto de los modelos clásicos de jurisdicción internacional, o con más precisión, diferente a los esquemas anteriores al creado para la UE. Lo más particular es que también las sentencias prejudiciales del TJUE son obligatorias (veremos que hay modelos receptores latinoamericanos que no lo recepcionan así, incluso en ocasiones hacen algunas diferenciaciones) por tal singularidad la doctrina habitualmente destaca este punto del modelo europeo. SARMIENTO subraya que «la obligación de dar cumplimiento a la sentencia prejudicial dictada por el Tribunal de Justicia recae en primer lugar sobre el órgano jurisdiccional remitente. Por lo tanto, las sentencias prejudiciales no son resoluciones consultivas, sino sentencias obligatorias en todos sus extremos, cuyo incumplimiento por el órgano jurisdiccional remitente justifica un recurso contra la sentencia nacional por incurrir en error de Derecho» (precisemos que el autor se está refiriendo a un recurso interno dentro de la estructura nacional, es decir, dirigido al superior jerárquico del juez nacional — no hacia el TJUE ni al TGUE). SARMIENTO RAMÍREZ-ESCUDERO, 2016, p. 414. 
1. En términos generales, referidos a la estructura normativa dirigida al respeto de la cosa juzgada, comencemos señalando que en el SICA se establece el efecto relativo ${ }^{144}$ de las sentencias de la CCJ haciéndolas obligatorias para las partes del litigio. Mientras que el efecto vinculante se lo otorga a tres clases de resoluciones de la CCJ, las interlocutorias, a los laudos y a las sentencias definitivas ${ }^{145}$.

En el SICA constatamos una singularidad, que lo diferencia de la UE, de la CAN y del MERCOSUR, pues en el sistema centroamericano deben hacerse algunas precisiones en cuanto al tipo de resoluciones de la CCJ referidas a las respuestas a las consultas prejudiciales y a algunos dictámenes consultivos, del siguiente modo: primero, son obligatorias las respuestas de la CCJ a las consultas provenientes de los órganos y organismos SICA en la interpretación y aplicación del PTC-ODECA y de los instrumentos complementarios y actos derivados, y también son vinculantes para el juez nacional las respuestas a las consultas prejudiciales tras haberse planteado ${ }^{146}$; segundo, sin embargo, son ilustrativas las respuestas de la CCJ sobre un tratado vigente ${ }^{147}$, y las que la CCJ dé a las Cortes Supremas de los Estados miembros ${ }^{148}$.

En contraste con lo explicado en el párrafo anterior, en el modelo de la UE no existen estas conexiones, ya que en el caso europeo la consulta es por Tratados «aún no vigentes», siendo de carácter previa. Tampoco hay en la UE un canal de comunicación objetivo y amplio de las Cortes Supremas de los Estados miembros de la UE con el TJUE, sino que es subjetivo y acotado a un caso específico, conducido por el cauce de la consulta prejudicial en carácter de juez nacional. Por lo tanto el efecto ilustrativo que reciben algunas respuestas de la CCJ, son en realidad un desarrollo positivo y novedosos del SICA, e inexistentes en la UE, en la CAN y en el MERCOSUR.

\footnotetext{
${ }^{144} \mathrm{El}$ efecto relativo de las sentencias de la Corte centroamericana fue recogido en el Estatuto de la CCJ, en su Cap. III titulado De la sentencia y su cumplimiento, art. 37 el cual establece «El fallo [...] será obligatorio únicamente para las partes, respecto al caso decidido».

${ }^{145}$ Art. 39 del Estatuto de la CCJ «Las resoluciones interlocutorias, laudos y sentencias definitivas que dicte La Corte no admitirán recurso alguno, son vinculantes $[\ldots]$ y se ejecutarán como $[\ldots]$ sentencias de un tribunal nacional [...] para lo cual bastará la certificación extendida por el Secretario General de La Corte. En el caso de incumplimiento de los fallos [...] por parte de un Estado, La Corte lo hará saber a los otros Estados para que, utilizando los medios pertinentes, aseguren su ejecución».

146 Son dos las normas pertinentes del Estatuto de la CCJ, el art. 22, literal k) «Resolver toda consulta prejudicial requerida por todo Juez o Tribunal Judicial que estuviere conociendo de un caso pendiente», y el art. 24 da el carácter vinculante con la fórmula «Las consultas evacuadas por La Corte con arreglo al presente Estatuto, ordenanzas y reglamentos, relativas al SICA, serán obligatorias para los Estados que la integran».

${ }^{147}$ Art. 23 del Estatuto de la CCJ «Los Estados podrán formular consultas con carácter ilustrativo a la Corte sobre la interpretación de cualquier Tratado o Convención Internacional vigente; también, respecto».

${ }^{148}$ Art. 22, literal d) del Estatuto de la CCJ «Actuar como Tribunal de Consulta Permanente de las cortes Supremas de Justicia de los Estados, con carácter ilustrativo».
}

152 
El proyecto de la CAN también contempló estructuras normativas para el respeto a la cosa juzgada en todo el espectro de las decisiones de la Corte andina, pero sin hacer diferenciaciones como ocurre en el MERCOSUR donde se excluyen las respuestas a opiniones consultivas, por lo tanto lo supera en ese sentido, sin embargo al mismo tiempo, queda por debajo del SICA al no disponer de las respuestas ilustrativas adicionales que incorporó dicho modelo Centroamericano, el cual tampoco se ha implementado en la UE.

En tanto el campo normativo del merco-sistema, si bien da cuenta de la decisión de sus fundadores de dotar de fuerza vinculante a los laudos de los TAAM y del TPRM, la construcción concreta es mucho más débil en comparación a los modelos de su entorno latinoamericano, y por cierto, en extremo lejano del campo normativo de la UE. Respecto del hecho de que el modelo en el merco-sistema es complejo — toda vez que posee tribunales inferiores más un superior jerárquico - se puntualiza en el MERCOSUR que el efecto de cosa juzgada se produce a partir de que el laudo se encuentre firme, ya sea porque no se recurrió ${ }^{149}$ al TPRM, o bien, si se utilizó un recurso, entonces desde su notificación $^{150}$. Como vemos en el MERCOSUR se ha resuelto en código de jerarquía hacia el TPRM, puesto que, por una parte, la decisión de este último tribunal pone fin a la instancia, declarándose la inapelabilidad del segundo laudo, y por otra parte, se refuerza el respeto al laudo final otorgándole el carácter de obligatorio para las partes. Y ambos extremos, concomitantes sobre el respeto al instituto de cosa juzgada.

2. Ahora bien, en cuanto a la posibilidad de ejecutar los fallos, esto es, la concreción del imperium del tribunal, las decisiones de la CCJ se hacen valer siguiendo una fórmula bastante similar a la empleada en la UE, esto es, mediante los tribunales nacionales tras la certificación de autenticidad extendida por el Secretario de la Corte, la mayor diferencia con el modelo de la UE es que en el SICA, si el ejecutado fuese un Estado, lo deja en manos de todos los Estados miembros del SICA, en una solución de carácter más político. Por su parte en la CAN las sentencias del TJCA tienen autoridad de cosa juzgada desde el día siguiente de su notificación, e igualmente se emplea la solución administrativa de

\footnotetext{
${ }^{149}$ Párrafo $1^{\circ}$ del art. 26 titulado Obligatoriedad de los laudos del POPSCM «Los laudos de los TAAM son obligatorios para los Estados partes en la controversia a partir de su notificación y tendrán, con relación a ellos, fuerza de cosa juzgada si transcurrido el plazo previsto en el Art. 17.1 para interponer el recurso de revisión, éste no fuere interpuesto».

${ }^{150}$ En el párrafo $2^{\circ}$ del art. ibídem, se expanden los criterios para los TAAM hacia el TPRM estableciéndose «Los laudos del TPRM son inapelables, obligatorios para los Estados partes en la controversia a partir de su notificación y tendrán, con relación a ellos, fuerza de cosa juzgada».
} 
ejecutarla por el juez nacional sin necesidad de homologación o exequatur ${ }^{151}$. Como vemos el esquema andino va siguiendo en este tema las respuestas de la UE y del SICA, lo que guarda coherencia con la cronología histórica de aparición del TJUE, la CCJ y el TJCA.

3. En cuanto a la fuerza obligatoria de las respuestas a las consultas prejudiciales, observamos que en la CAN esta cuestión también encuentra un sólido respaldo estatutario, por ejemplo, incluso respecto de la acción de nulidad se ordena la suspensión del proceso hasta recibirse la respuesta que es obligatoria ${ }^{152}$. En tanto en el SICA debe estarse a la diferenciación que ya indicamos arriba, acusando un correcto desarrollo. Pero en el MERCOSUR el tema de la fuerza obligatoria a las respuestas a las consultas prejudiciales, simplemente no existe, siendo este punto la gran carencia del sistema, tal como ya hemos anotado $^{153}$, sin embargo precisamente este bache debería ser superado con la implementación de la nueva Corte de Justicia Mercosur ${ }^{154}$.

4. En lo referido al incumplimiento concreto de las sentencias, se han desarrollado algunas soluciones en los modelos bajo análisis, así en la CAN hay una singularidad en el cumplimiento de las sentencias, que dice relación con la acción especial de incumplimiento, mediante la cual se acusa el desacato del vencido a la misma Corte andina, la que inicia un proceso especial que culmina en una nueva sentencia. Este nuevo fallo también queda cubierto, pues se le otorga al particular afectado, un título perfecto para iniciar en su país una acción por indemnización de daños y perjuicios ${ }^{155}$. Entendemos que este es un desarrollo particular de la CAN que se ubica por sobre el SICA y el MERCOSUR.

De hecho observamos que la construcción legislativa de la CAN referida al incumplimiento es muy profusa en detalles y posibilidades, lo que da cuenta de la particular atención que puso la CAN y los Estados miembros al momento de crear a la Corte andina. Se regula por ejemplo el incumplimiento de los fallos directamente por algún Estado miembro ${ }^{156}$. Se

${ }^{151}$ Art. 91 titulado Fuerza obligatoria y cosa juzgada, del Estatuto del TJCA «La sentencia tendrá fuerza obligatoria y carácter de cosa juzgada a partir del día siguiente al de su notificación y es aplicable en el territorio de los Países Miembros sin necesidad de homologación o exequátur».

${ }^{152}$ Art. 20 del Tratado de Creación del TJCA «Presentada la solicitud de inaplicabilidad, el juez nacional consultará acerca de la legalidad de la Decisión, Resolución o Convenio, al TJCA y suspenderá el proceso hasta recibir la providencia del mismo, la que será de aplicación obligatoria en la sentencia de aquél».

153 Art. 11 titulado Efecto de las opiniones consultivas, del Reglamento del POPSCM señala «Las opiniones consultivas emitidas por el TPR no serán vinculantes ni obligatorias».

${ }^{154}$ Sobre el proyecto para la nueva Corte de Justicia Mercosur nos referiremos en el capítulo V.

${ }^{155}$ Art. 110, titulado Mérito ejecutivo de la sentencia, del Estatuto del TJCA «La sentencia de incumplimiento dictada por el Tribunal en acción promovida por un particular, constituirá título legal y suficiente para que éste pueda solicitar al juez nacional la indemnización de daños y perjuicios que correspondiere».

${ }^{156}$ Art. 111, titulado Efectos de la sentencia de incumplimiento, del Estatuto del TJCA «El País Miembro cuya conducta haya sido declarada en la sentencia como contraria al ordenamiento jurídico andino, quedará 154 
añaden hipótesis que permiten a los otros Estados miembros limitar ventajas comerciales ${ }^{157}$. Para nosotros, esto último va por el ritmo de las típicas medidas de apremio nacionales civiles, es decir, de pérdidas de ventajas comerciales, lo que entendemos como una eficaz interpelación al cumplimiento, toda vez que las ventajas obtenidas a partir de la existencia de la OI no podrá alcanzarlas aisladamente el país remiso.

En el mismo aspecto del incumplimiento concreto, ahora en el MERCOSUR, debe analizarse enfocando la norma de clausura del merco-sistema, la cual exige que los laudos se cumplan en la forma dictada, y aclara que la adopción de medidas compensatorias no exime del cumplimiento de tales laudos ${ }^{158}$, de lo que se siguen dos ideas de trascendencia, la primera es la presencia del principio de la buena fe en el cumplimiento de las decisiones de los tribunales, y la segunda, es la prohibición de confusión entre la retaliación y la obligación constituida, declarada o condenada mediante el laudo. En efecto, un tema es la retaliación con su típica naturaleza sancionatoria, que va por el cauce del apremio a nivel de castigo, la cual es del todo diferente a la obligación incumplida, y que se espera que el Estado remiso cumpla, para no aumentar las sanciones, cuestión resaltada por la doctrina ${ }^{159}$.

obligado a adoptar las medidas necesarias para su debida ejecución [...]. El Tribunal, de conformidad con lo dispuesto en el art. 27 del Tratado y lo que se regula al respecto en este Estatuto, velará por el cumplimiento de las sentencias dictadas en ejercicio de esta competencia».

${ }^{157}$ Art. 119 del Estatuto del TJCA «Si un País Miembro no acatare [...] la sentencia de incumplimiento, el Tribunal podrá sumariamente determinar como sanción, y conforme a lo previsto en el párrafo segundo del art. 27 del Tratado, los límites dentro de los cuales el país reclamante o cualquier otro País Miembro podrá restringir o suspender, total o parcialmente, las ventajas del Acuerdo de Cartagena que beneficien al País Miembro remiso». La remisión es al art. 27 del Tratado de Creación del TJCA, el cual en lo pertinente establece «Si la sentencia del Tribunal fuere de incumplimiento, el País Miembro cuya conducta haya sido objeto de la misma, quedará obligado a adoptar las medidas necesarias para su cumplimiento [...]. Si dicho País Miembro no cumpliere la obligación [...], el Tribunal [...] determinará los límites dentro de los cuales el país reclamante o cualquier otro País Miembro podrá restringir o suspender, total o parcialmente, las ventajas del Acuerdo de Cartagena que beneficien al País Miembro remiso. [...], el Tribunal podrá ordenar la adopción de otras medidas si la restricción o suspensión [...] agravare la situación [...] o no fuere eficaz».

158 Art. 27 titulado Obligación del cumplimiento de los laudos, del POPSCM cubriendo ambas fuentes TAAM y TPRM - señala «Los laudos deberán ser cumplidos en la forma y con el alcance que fueron dictados. La adopción de medidas compensatorias en los términos de este Protocolo no exime al Estado parte de su obligación de cumplir el laudo».

${ }^{159}$ El tema del cumplimiento de los laudos en el MERCOSUR lo destaca CENTURIÓN señalando que en este campo las medidas retaliativas se entienden como un mecanismo compulsivo de cumplimiento, lo que en definitiva haría caer al Estado remiso en una doble situación de desventaja, exponiendo «El Protocolo de Olivos, en el Cap. IX, art. 31, [contempla a las] "Medidas Compensatorias" o "medidas de retaliación", prevé un mecanismo por el cual el Estado que se vea afectado por el incumplimiento de un laudo, puede solicitar autorización al Tribunal para aplicar medidas retaliativas contra el Estado remiso. Agrega que: si ante tales medidas retaliativas el remiso no cumple — escenario poco probable pero no imposible — la situación se tornaría compleja para dicho Estado, por las consecuencias políticas de esa postura ante la Comunidad Internacional y ante el MERCOSUR, en futuras negociaciones donde el mismo Estado Parte infractor estará 
En un aspecto similar a la CAN en el MERCOSUR también existen pronunciamientos por incumplimientos, pero no directamente como cauces de apremio, sino que en el mercosistema se refieren a divergencias ocurridas dentro de las dinámicas del cumplimiento concreto, por ejemplo en el caso Divergencia sobre el cumplimiento del Laudo $N^{\circ} 1 / 05$ iniciada por la República Oriental del Uruguay ${ }^{160}$ se lleva adelante la discusión precisa sobre el modo en que se acataba el laudo previo. Por cierto, este tipo especial de proceso se encuentra regulado legislativamente ${ }^{161}$.

5. A la luz del análisis realizado en este apartado sobre el patrón central enfocado —el respeto a la res iudicata de las Cortes latinoamericanas - podemos concluir lo siguiente, en cuanto al SICA se advierte que posee un esquema normativo orientado a la obligatoriedad de los fallos dictados por la CCJ, sumándose el hecho de que en materia de respuestas a las cuestiones prejudiciales difiere del esquema de la UE y de su entorno, al contemplar respuestas de carácter ilustrativas, lo que entendemos es un positivo desarrollo. Respecto de la CAN, ésta también contempla la característica central, mediante múltiples disposiciones que giran por otorgar fuerza vinculante a las sentencias del TJCA, incluyéndose las respuestas a las cuestiones prejudiciales, buscando con esto, dotar de la seriedad y de una efectividad jurídica concreta a todo el proyecto regional. Por último, en cuanto al MERCOSUR resultó ser éste, el modelo más débil en relación al patrón central buscado, pues si bien posee una estructura normativa general para el respeto a la cosa juzgada, su gran carencia es que las respuestas a las consultas prejudiciales no son obligatorias.

necesariamente presente. Agrega: de llegar el caso a estos extremos, es dable suponer que el Estado Parte renuente a cumplir el laudo estaría ante una doble situación desventajosa, de un lado, el Estado Parte reclamante ya le habrá aplicado las medidas retaliativas, y de otro, el infractor quedaría en franco deterioro de su imagen ante la comunidad internacional. Concluye en que, las medidas retaliativas siempre terminan afectando al mismo sector o incluso a otros sectores donde las medidas aplicadas generan consecuencias socio-económicas severas que perjudican a segmentos comerciales y/o productivos. CENTURIÓN GONZÁLEZ, C. H. (2017). Aporte del tribunal permanente de revisión al proceso de integración del Mercosur: Reflexiones orientadas hacia la sociedad civil del mercosur. Revista da secretaria do tribunal permanente de revisão, 5(9), 78-100.

${ }^{160}$ Laudo del TPRM de 25 de abril de 2008, "Divergencia sobre el cumplimiento del Laudo $N^{\circ} 1 / 05$ iniciada por la República Oriental del Uruguay (artículo 30 - Protocolo de Olivos)”, Laudo 01/2008, as. 1/2005. Volveremos sobre este laudo en el capítulo IV referido al diálogo judicial.

${ }^{161}$ El art. 29 titulado Plazo y modalidad del cumplimiento, más el art. 30 denominado Divergencias sobre el cumplimiento del laudo, ambos del POPSCM, cierran desde lo formal y lo administrativo, el tema de la obligatoriedad y de cumplimiento de los laudos en el sistema mercosureño.

156 


\subsubsection{LOS SISTEMAS DE SELECTIVIDAD DE JUECES FAVORECEN LA CONSTRUCCIÓN DEL AUCTORITAS: LA SOLUCIÓN DE LA UE Y LA DE LAS CORTES LATINOAMERICANAS}

Un buen mecanismo de selección de jueces va en beneficio del reconocimiento de un auctoritas tras el ejercicio jurisdiccional de un tribunal, cuestión de tan alta importancia, que será nuestro último patrón central para cotejar a las Cortes latinoamericanas con el modelo europeo. La razón que tuvimos para escoger a este ángulo de análisis se fundamenta en el hecho de que, al implicar la noción del auctoritas un reconocimiento social o autoridad moral de un tribunal, emanado del constante y correcto ejercicio de quienes fueron seleccionados como jueces, se vuelve central su verificación para las Cortes de integración, toda vez que éstas no se vinculan jerárquicamente con los tribunales nacionales, sino que lo hacen a través del principio de colaboración, por lo tanto es indispensable que las sentencias de las referidas Cortes sean robustas y convincentes para que los jueces nacionales estén dispuestos, de buena manera - y no por jerarquía-, a seguir las pautas que va marcando la Corte de cada esquema de integración latinoamericano y además para que sus fallos sean cumplidos buenamente por todos.

En ocasiones se han visto críticas a determinadas sentencias del TJUE a nivel nacional, lo que se supera con una buena selección de jueces que fortalezca el auctoritas del tribunal según ha remarcado parte de la doctrina ${ }^{162}$ pues en realidad el desafío no cruza por imponer nada a nadie, sino convencer a todos. Es decir, que el cumplimiento no se fundamente sólo en que los estatutos establezcan como obligatorias las sentencias, sino porque dichas decisiones jurisdiccionales comporten razonamientos que redunden en el convencimiento efectivo de las partes y de todo el resto de los concurrentes, fortaleciendo así el proyecto de integración en su globalidad.

\footnotetext{
${ }^{162}$ En este sentido GASCÓN refiriéndose a la selección de jueces señala que un problema común es que las sentencias del TJUE se critican a nivel nacional, por lo que al menos para luchar parcialmente contra esas críticas se debería seleccionar a las personas más cualificadas para el puesto de juez, reforzando así el auctoritas del Tribunal. La autora recuerda además a COSTA, el Presidente del TEDH, quien subraya que la autoridad de la jurisprudencia es indisociable de la razón, la credibilidad y en última instancia de la capacidad de convencer, más que el derecho de imponer nada. GASCÓN MARCEN, A. (2019). Réplica de mecanismos institucionales del TJUE en el TEDH ¿inspiración positiva o fuerza de la realidad? En J. Martín y Pérez de Nanclares, R. Bustos Gisbert, C. González Beilfuss, C. Martínez Capdevila, M. E. Salamanca Aguado, ... C. E. Oriozola Mariscal, El diálogo judicial internacional en la protección de los derechos fundamentales. Valencia. Tirant lo Blanch, vid. en particular el apartado 2. La selección de jueces: (...), pp. 348-349.
} 
El auctoritas se sigue técnicamente de la noción procesal que podemos denominar estabilidad de la sentencia ${ }^{163}$, esto es, que la decisión final de un tribunal condense adecuadamente la norma decisoria litis con el caso específico, en forma armónica con el bloque de legalidad, permitiendo así que los valores, principios y normas del grupo se articulen en la sentencia de manera sólida, de modo tal, que no sea solo el acto de proceso final que resuelve la controversia, o en su caso la consulta, sino que la sentencia pase a integrar con brío el acervo jurídico de la organización.

Para lograr lo precedentemente indicado, es requisito sine qua non, que los jueces sean de la más alta calidad. Claro que no es la única condición, o la que por descontado generará el auctoritas, sino que la selectividad de jueces es el prerrequisito que mejor favorece que la Corte adquiera el reconocimiento buscado. Resultando esencial que legislativamente se impongan exigencias de idoneidad y capacidad para los candidatos a los cargos de magistraturas internacionales. Lo que es lógico en el campo de la seguridad jurídica internacional, pues las soluciones jurisprudenciales en dicho nivel, no sólo deben satisfacer el principio de efecto relativo de las sentencias, sino que además deben revestir utilidad para disolver futuros conflictos o consultas, extendiéndose en carácter de disuasivas como lo explica la doctrina ${ }^{164}$, ante posibles contenciosos, pues el ejercicio de toda jurisdicción, conlleva implícita una función social y jurídica de carácter educativa que el derecho procesal conoce bajo la noción del criterio de la Corte, dado que la sentencia no es puramente lógica y norma, sino que supera dichos umbrales, tal y como subrayan las fuentes ${ }^{165}$ clásicas.

No es fácil alcanzar una posición de liderazgo para una Corte de integración, pues éstas, como lo es el TJUE, están al servicio de un todo mayor bastante complejo —al caso, el

${ }^{163}$ La estabilidad de la sentencia es una noción de eficacia y resultado de todo proceso, que para algunos gravita sobre la estabilidad de los efectos de la sentencia, en el sentido de que dicha resolución final sea armónica con el marco jurídico en que se dicta, y que tiende a aproximarse al valor justicia. De allí el respeto con que se impone, pues está perfectamente construida. POZO la explica como aquella permanencia o prolongación en el tiempo, en sentido de que sea imposible su derogación, pues se afianza en la autoridad de cosa juzgada. Por lo tanto, la falta de estabilidad supone la ausencia de la autoridad de res iudicata. POZO SILVA, N. (1993). La sentencia. El juez y la sentencia. Santiago, Chile. Ediciones jurídicas. (vid. en particular Cap. VIII, apartado I Estructura del proceso y estabilidad de la sentencia., pp. 93 y ss.).

${ }^{164}$ Sobre el factor disuasivo QUINDIMIL, recordando los procesos de génesis de la Corte andina pone de relieve la parte de un Informe preliminar en que se subraya «una de las funciones del órgano jurisdiccional debe ser la de actuar como factor disuasivo de los conflictos, para evitar que la tensión política [que] de ellos deriva rompa el vínculo asociativo». Lo que entrecomilla el autor, es una cita textual de la p. 17 del Informe de la Junta sobre el Establecimiento de un Órgano Jurisdiccional del Acuerdo de Cartagena, COM/X-E/di 5 de 12-12-1972. QUINDIMIL, 2006, pp. 326-327.

${ }^{165} \mathrm{Al}$ razonar sobre el juez, COUTURE explica «La sentencia no es un pedazo de lógica, ni es tampoco una pura norma. La sentencia es una obra humana, una creación de la inteligencia y de la voluntad, es decir, una criatura del espíritu del hombre». COUTURE, 1949, p. 73.

158 
proyecto de la UE. Por lo tanto dentro de las labores cruciales estas singulares Cortes también deberán servir de tensor interno, orientadas a evitar el abandono de los socios del proyecto político, puesto que la seguridad jurídica, es la base de todo desarrollo económico o social que se pretenda estructurar en una región. El auctoritas de la Corte de Luxemburgo - así como el de todo tribunal — proviene evidentemente de su campo exógeno, esto es, de la doctrina, de los tribunales estatales de los países de la UE, de otros tribunales internacionales, o de integración. Estos dos últimos casos se comprobarán cuando recurran, mediante el diálogo judicial, a las soluciones del TJUE, pues por intermedio de ese acto estarán reconociéndole autoridad jurídica a la Corte de Luxemburgo.

Un modelo exitoso en auctoritas, como lo es el TJUE, quedará demostrado cuando simultáneamente se logren tres objetivos: primero, que los tribunales nacionales pertenecientes al proceso de integración, a través del principio de colaboración $-\mathrm{y}$ no jerárquico- estén llanos a aplicar las guías rectoras de las Cortes de integración; segundo, que las Cortes foráneas al proyecto reconozcan el auctoritas de la Corte mediante el empleo del diálogo judicial; y en tercer lugar, que la doctrina especializada lo valore positivamente.

Por los motivos recién indicados en la UE se asegura un excelente nivel jurídico, creando rigurosos mecanismos de selectividad de jueces, en razón de lo cual se exige que los candidatos ofrezcan garantías de independencia ${ }^{166}$, y que reúnan las condiciones para las más altas magistraturas, o bien que sean jurisconsultos de reconocida competencia ${ }^{167}$. Esta fórmula de opción entre el cumplimiento de requisitos formales para ser jueces en las Cortes nacionales o bien que provengan del mundo de la doctrina, permite ampliar el campo de participación de los especialistas, lográndose un buen equilibrio al interior de la Corte de Luxemburgo.

En el mecanismo de selección europeo, juega un rol central el Comité especial para el estudio de los candidatos, toda vez que se conforma por notables personalidades como ex jueces del TJ, Cortes superiores nacionales y juristas ${ }^{168}$. Como se aprecia, la UE es exigente

${ }^{166}$ El art. 19.2 del TUE indica «Los jueces [...] serán elegidos de entre personalidades que ofrezcan plenas garantías de independencia y que reúnan las condiciones contempladas en los arts. 253 y 254 del TFUE». Dichos artículos a que envía la norma anterior, exigen el cumplimiento de las denominadas condiciones para los candidatos.

${ }^{167}$ El inciso $1^{\circ}$ del art. 253 del TFUE detalla «Los jueces [...] [serán] elegidos entre personalidades que ofrezcan absolutas garantías de independencia y que reúnan las condiciones requeridas para el ejercicio, en sus respectivos países, de las más altas funciones jurisdiccionales o que sean jurisconsultos de reconocida competencia, [...]». Se suman las normas del inciso $2^{\circ}$ del art. 254 y el art. 255 del Tratado supra incorporando la fórmula de un Comité de expertos para valorar a los candidatos.

${ }^{168}$ El art. 255 del TFUE puntualiza sobre este Comité especial para evaluar preventivamente la idoneidad de los candidatos, en los siguientes términos «Se constituirá un comité para que se pronuncie sobre la idoneidad de los candidatos para el ejercicio de las funciones de juez [...], antes de que [...] procedan a los 
y clara al establecer sus mecanismos de selectividad, sumándose a todo aquello, la buena labor desplegada por el TJ, en términos de tener por probada la eficacia de los mecanismos de selección. Esta evaluación positiva $-\mathrm{y}$ amplia, salvo contadas excepciones- que se hace de la Corte de Luxemburgo, es prácticamente uniforme por la doctrina ${ }^{169}$.

Ahora, dirigiendo nuestra atención hacia las Cortes latinoamericanas bajo análisis, el tema del auctoritas también resulta ser esencial para el éxito de cada proceso de integración, pero ingresado a un análisis comparativo con el modelo europeo, éstos resultan diferentes. Sin embargo se ubica en primer plano la importancia y el deseo de contar con jueces de alta calidad. En este sentido los tres modelos que cobijan a las Cortes analizadas, se han dotado de algún tipo de mecanismo de seguridad en esta materia, los cuales analizados en detalle presentan notorias disparidades entre sí, aunque existe un deseo subyacente común de lograr el mejor funcionamiento posible de los órganos jurisdiccionales.

1. En primer lugar se observan diferencias estructurales en los tres modelos. Así en el SICA advertimos que la exigencia para integrar el cuerpo de jueces de la CCJ es de menor rigurosidad que la prevista tanto para la CAN como para el TJUE, pero mejor que en el MERCOSUR, lo que se debe a que en Centroamérica la responsabilidad queda entregada a cada Estado miembro, prescindiendo de la figura del Comité especial que existe en la UE, de tal modo en el SICA únicamente se crea una exigencia genérica para los candidatos, en cuanto deben cumplir las condiciones para que en sus propios países ejerzan altas funciones judiciales ${ }^{170}$. En realidad en el SICA toda la decisión queda dentro del mecanismo judicial local, incluso la designación misma la debe hacer cada Corte Suprema ${ }^{171}$. Mientras que en

nombramientos [...]. El comité estará compuesto por siete personalidades elegidas de entre antiguos miembros del TJ y del TGUE, miembros de los órganos jurisdiccionales nacionales superiores y juristas de reconocida competencia».

${ }^{169}$ La doctrina especializada es abundante en elogios y además muy precisa en reconocer el auctoritas del TJUE, así por ejemplo, entre muchos, RODRÍGUEZ IGLESIAS sentencia que «el Tribunal de Justicia es una pieza esencial de la construcción europea». RODRÍGUEZ IGLESIAS et al., 1993, p. 647. Por su parte LIÑÁN destaca que «este tribunal ha contribuido con su jurisprudencia a la consolidación de dicho sistema [de control jurisdiccional de la UE]». LIÑÁN NOGUERAS, 2014d, p. 448. En tanto ZAPATER pone de relieve que «el Tribunal ha desempeñado una función determinante en el desarrollo de una integración jurídica y en la defensa del cumplimiento de los objetivos». ZAPATER DUQUE, 2005a, p. 101. Por su parte IGLESIAS BUHIGUES concluye que «no cabe duda de que la aportación del Tribunal de Justicia a la causa de la integración europea por medio de su jurisprudencia coadyuvante a la realización de los objetivos de la Unión, es verdaderamente relevante y significativa». IGLESIAS BUHIGUES, 2013, p. 30.

${ }^{170}$ El art. 9 del Estatuto de la CCJ preceptúa «Los Magistrados deberán ser personas que gocen de alta consideración moral y reunir las condiciones requeridas en su país para el ejercicio de las más altas funciones judiciales».

${ }^{171}$ El art. 10 del Estatuto de la CCJ «Los Magistrados titulares y suplentes de La Corte serán electos por las Cortes Supremas de Justicia de los Estados».

160 
la CAN observamos un mayor progreso, de hecho, comparativamente es la mejor solución de los tres modelos latinoamericanos.

Esta mejor posición de la CAN en el concierto latinoamericano se debe a dos causas: primero porque que su modelo recurre a un mecanismo de selectividad que contempla a un Panel de Plenipotenciarios convocado por el gobierno del país sede, y sus integrantes deben escoger por unanimidad, de una terna propuesta por cada país miembro ${ }^{172}$. Sin embargo los integrantes del Panel de Plenipotenciarios no son, como en la UE exjueces del TJUE, miembros de tribunales nacionales superiores o juristas de reconocida competencia, sino que simplemente es conformado a criterio del país sede; y la segunda causa, es que impone la exigencia para los candidatos en cuanto deben gozar de alta consideración moral y tener las condiciones para ejercer en sus países altas funciones judiciales o ser juristas de notoria competencia. Como se aprecia la disposición de la CAN es una copia ${ }^{173}$ de la norma de la UE. Por el contrario el MERCOSUR posee la solución más débil de los tres esquemas, sin ningún tipo de seguridad de calidad previa a la designación, sino que sólo contempla reacciones de los Estados intentando objetar a los árbitros.

En particular el método del merco-sistema se basa en que cada Estado miembro designa libremente candidatos a árbitros, los cuales pasan a conformar la denominada lista de magistrados disponibles ${ }^{174}$ para el evento de que se les llegase a convocar para integrar un TAAM o el TPRM, como vemos, sin verificarse ningún mecanismo de selectividad previo, ni técnico, ni menos objetivo, sólo se exige de modo general que sean juristas de reconocida competencia ${ }^{175}$. Para intentar controlar dicha exigencia, el merco-sistema se dota de un método ex post a la selección, es decir, corre con una naturaleza de impugnación, evidentemente al otro lado de la prevención, como sucede en la UE, en la CAN y en el SICA. Dicho mecanismo ex post del merco-sistema usa dos conductos, por un extremo, los Estados del Mercosur pueden pedir aclaraciones ${ }^{176}$ a los otros Estados respecto de alguna designación, y por otro extremo, los Estados mercosureños también pueden

172 Esta solución orgánica se estructura en el art. 7 del Tratado de Creación del TJCA del siguiente modo «Los magistrados serán designados de ternas presentadas por cada País Miembro y por la unanimidad de los Plenipotenciarios acreditados para tal efecto. El Gobierno del país sede convocará a los Plenipotenciarios».

${ }^{173}$ El inciso $1^{\circ}$ del art. 6 del Tratado de Creación del TJCA es una copia del inciso $1^{\circ}$ del art. 253 del TFUE.

${ }^{174}$ Art. 11.1 del POPSCM «Cada Estado parte designará doce (12) árbitros, que integrarán una lista que quedará registrada en la Secretaría Administrativa del Mercosur».

${ }^{175}$ La solución en el merco-sistema comienza en el art. 35.1 del POPSCM, el cual genera la única exigencia del modelo, indicando que «Los árbitros de los TAAM y los del TPRM deberán ser juristas de reconocida competencia en las materias que puedan ser objeto de las controversias y tener conocimiento del conjunto normativo Mercosur».

${ }^{176}$ El literal i) del art. 11.1 del POSCOM «Cada Estado Parte podrá solicitar aclaraciones sobre las personas designadas por los otros Estados Partes para integrar la lista». En tanto el art. 10 del POPSCM se refiere al listado para los TAAM. 
presentar objeciones justificadas contra los candidatos basadas en la falta de idoneidad de los $\operatorname{mismos}^{177}$.

2. Otro aspecto relevante para favorecer el auctoritas que va un poco más lejos del mecanismo mismo de selectividad, es la exigencia de dedicación exclusiva, tema que conecta directamente con el carácter de permanente del tribunal. En el SICA como una norma indirecta que facilita la mejor calidad en el trabajo de quienes ya son jueces, se impone a estos magistrados la exigencia de dedicación exclusiva ${ }^{178}$. Por su parte en la CAN también se contempla dicha disposición de exclusividad ${ }^{179}$ para los jueces del TJCA. Sin embargo, la nota discordante la vuelve a tocar el MERCOSUR, toda vez que ninguno de sus tribunales son de carácter permanente, sino de convocatoria permanente ${ }^{180}$, por lo tanto no se puede siquiera pensar en una dedicación exclusiva, lo único que se le puede exigir a los tribunales de convocatoria permanente es una concentración en las funciones durante el proceso mismo.

Claramente en el MERCOSUR no solo hay una carencia en el sentido anotado en el párrafo anterior, sino que además se constata en este punto, una desconexión en el uso del lenguaje técnico, pues denomina como permanente, a un tribunal que no lo es. Aunque reconozcamos que desconexiones del lenguaje técnico jurídico con la realidad material, las hay en abundancia, así por ejemplo podemos sumar al bautizo de permanente para esta Corte, la designación de recursos en la UE a instituciones que son acciones $v$.gr. recurso de nulidad $v / s$ acción de nulidad, ni que decir cuando en Europa se intentó emplear el concepto de Constitución, o el hecho de que en el SICA se designe en sus estatutos a la CCJ como un tribunal supranacional ${ }^{181}$. Deducimos entonces, en atención al estudio del marco normativo de todos los modelos de integración analizados en esta tesis, el hecho de que aparentemente

${ }^{177}$ El literal ii) del art. 11.2 del POPSCM, genera la posibilidad de presentar objeciones justificadas contra los candidatos, basándose en los criterios establecidos en el art. 35.1 del mismo Protocolo.

${ }^{178}$ Art. 15 del Estatuto de la CCJ «Los Magistrados no podrán desempeñar otras actividades profesionales, remuneradas o no, excepto las de carácter docente».

${ }^{179}$ El inciso $2^{\circ}$ del art. 6 del Tratado de Creación del TJCA establece «Los magistrados gozarán de plena independencia en el ejercicio de sus funciones, no podrán desempeñar otras actividades profesionales, remuneradas o no, excepto las de naturaleza docente».

${ }^{180} \mathrm{Se}$ crea la figura de la disponibilidad permanente, según indica el art. 19 del POPSCM «Los integrantes del TPRM, una vez que acepten su designación, deberán estar disponibles de modo permanente para actuar cuando se les convoque». El art. 18.2 del POPSCM apunta a la integración del tribunal para cuando sea necesario su funcionamiento, pues no es permanente, estableciendo que cada país designará un árbitro «Cada Estado Parte del Mercosur designará un (1) árbitro y su suplente». En tanto en el art. 18.3, refiriéndose al quinto árbitro — dado que son sólo cuatro Estados miembros en Mercosur - tampoco establece criterios de calidad, simplemente lo entrega al acuerdo de los Estados, así «El quinto árbitro [...] será elegido por unanimidad de los Estados»y de no haber acuerdo, se sorteará el quinto árbitro del listado.

${ }^{181}$ Cada uno de estos ejemplos de incorrecciones de lenguaje, y otros tantos más, los hemos ido señalando y analizando oportunamente en esta tesis. En este punto sólo hemos agrupado las que más destellan. 
se filtra lenguaje político en los Estatutos y Protocolos para crear más bien expectativas, que para definir instituciones jurídicas propiamente tal.

3. En conclusión, de todo lo analizado en este apartado, y en el anterior, se desprende que es muy lamentable que la arquitectura del MERCOSUR, en esta materia, en nada contribuya a la calidad y robustecimiento de los jueces, como para lograr el auctóritas buscado, básicamente por las siguientes tres razones: primero, se pierde el criterio de la Corte, toda vez que en cada oportunidad estará conformada por nuevos jueces; segundo, los árbitros no se concentran en la labor de la Corte al no exigírseles dedicación exclusiva; y tercero, su selectividad no cruza por mecanismos de exigencia técnica, tan sólo políticos al ser designados por los Estados miembros. Campo fértil para la aparición de giros copernicanos en la jurisprudencia de los TAAM y del TPRM — tal como lo veremos al analizar sus laudos en los capítulos III y IV - complotando este cumulo de dificultades, contra el esperado auctoritas que debieran lograr los tribunales mercosureños. Esta problemática debería superarse con la nueva CJM — proyecto que analizaremos en el capítulo $\mathrm{V}$.

Por su parte el SICA queda ubicado en segunda posición, pues cuenta con un mecanismo de selectividad mucho mejor que lo visto para el MERCOSUR, aunque sin incorporar alguna solución similar al Comité que existe en la UE o al Panel de Plenipotenciarios que se presenta en la CAN, tampoco se expande hacia la posibilidad de que los candidatos sean jurisconsultos de reconocida competencia, como sí lo hace el esquema de la UE y de la CAN. Pero rescatemos que el mecanismo del SICA no ha sido obstáculo para que la CCJ haya desarrollado una destacada actividad jurisprudencial en su región, tal como veremos al analizar algunas de sus sentencias en los capítulos siguientes.

Sin duda la CAN, en el aspecto analizado, ocupa la mejor posición dentro del contexto latinoamericano, pues posee un sistema de selección previo, contempla al Panel de Plenipotenciarios, exige exclusividad, y en general se observa mucha más robusta toda su construcción que sus vecinos SICA y MERCOSUR, aunque siempre distante del todo del sistema de la UE que ya vimos. Ahora bien — y tal como lo señalamos para la CCJ— es claro que la selección de jueces representa solo el pazo inicial para un correcto desempeño del tribunal, porque el auctoritas en sí, es un resultado concreto, que fluye de las tres dimensiones ${ }^{182}$ que vimos al iniciar esta temática aplicada al TJUE. La última de dichas tres dimensiones, se refería a lo relevante que es la opinión positiva de la doctrina especializa

${ }^{182}$ Las tres dimensiones que colegimos al referirnos al TJUE implicaban que simultáneamente se logre: $1^{\circ}$ que los tribunales locales del proceso de integración, mediante el principio de colaboración y no jerárquico, estén llanos a aplicar las guías de las Cortes de integración, $2^{\circ}$ que las Cortes foráneas al proyecto reconozcan el auctoritas de la Corte, mediante el empleo del diálogo judicial, y $3^{\circ}$ que la doctrina especializada valore expresamente la labor del tribunal. 
sobre la jurisprudencia emanada del tribunal que se analice, la cual en el caso del TJCA le ha sido bastante favorable ${ }^{183}$.

Lo anterior, no significa que los árbitros de las Cortes mercosureñas no cumplan con los estándares internacionales, pero lo que sí implica es que el MERCOSUR deberá avanzar hacia esquemas de selectividad de jueces más acordes a los mecanismos de su entorno y, por cierto del europeo. De hecho hasta ahora, los laudos de los TAAM y TPRM han sido muy valiosos y han ido conformando una base jurisprudencial propia de dicho proyecto del Cono Sur de América tal como lo destaca la doctrina ${ }^{184}$, y como nosotros lo analizaremos en los capítulos III y IV.

183 Así por ejemplo refiriéndose directamente al TJCA, QUINDIMIL manifiesta «puede valorarse la jurisprudencia de su Tribunal de Justicia como "muy importante a favor de la consolidación de la integración, contribuyendo a la formación de un ordenamiento jurídico muy completo, formalmente avanzado, y desarrollando un trabajo progresivo, de carácter en buena medida creativo, que ha ido cristalizando en una sólida infraestructura jurídica que permite atribuir a la CAN la calificación de Comunidad de Derecho». QUINDIMIL LÓPEZ, J. A. (2012). El acceso a tribunales de justicia supranacionales: aportes desde la comunidad andina y su incipiente ciudadanía comunitaria. En M. HERNÁNDEZ RAMOS, A. SÁIZ ARNÁIZ, A. TORRES PÉREZ, y M. ZELAIA GARAGARZA (Dirs.), Tribunales en organizaciones supranacionales de integración: mercosur, comunidad andina y unión europea ( $1^{\mathrm{a}}$ ed.), Cizur Menor: Thomson Reuters Aranzadi. pp. 122-123.

${ }^{184} \mathrm{Si}$ bien la producción de laudos en el Mercosur es muy baja, tal como lo veremos en gráficos y tablas al final del capítulo $\mathrm{V}$, los que se han dictado, han recibido en general y de modo amplio una positiva valoración. Por ejemplo CENTURIÓN al referirse al Mercosur expresa «Cada laudo arbitral hace aportes relevantes al proceso integracionista. Cada laudo arbitral, cada fallo que se ha dictado en el MERCOSUR, ha dejado elementos de suma relevancia jurídica que van dando aportes en pro del avance y desarrollo de nuestro proceso integracionista». CENTURIÓN GONZÁLEZ, 2017. 


\subsection{LOS SIMPLES RASGOS COMUNES DE LAS CORTES LATINOAMERICANAS}

A LA LUZ DE LA CORTE DE LUXEMBURGO

Además de los seis patrones centrales que recién finalizamos de analizar, detectamos otro pequeño conjunto de cuatro características comunes, pero de menor intensidad, a éstas las hemos denominado simples rasgos comunes, los cuales se corresponden con rasgos que en términos amplios, es habitual y lógico que se manifiesten en este tipo de Cortes. Éstos son, las competencias negativas, las políticas de impugnación jerárquicas, la exclusión de los votos disidentes, y la mayor amplitud del locus standi en comparación a un tribunal internacional clásico. Todos los cuales analizaremos a continuación.

\subsubsection{LA PRESENCIA DE LAS COMPETENCIAS NEGATIVAS EN LOS MODELOS DE LAS CORTES LATINOAMERICANAS}

Procesalmente las competencias negativas son una prohibición expresa de injerencias que establece el legislador para limitar la jurisdicción de un tribunal. Pero se hace necesario resaltar dos aspectos, en primer lugar, es evidente que cada órgano actuará válidamente dentro de sus competencias, a contrario sensu será nulo su accionar, porque sobrepasaría las potestades asignadas a través del principio de atribución competencial.

Esta clásica solución de atribución de competencias es la usada por regla general en todo sistema, v.gr. en la CAN para el TJCA se enfatiza legislativamente que «El Tribunal ejerce su jurisdicción sobre la CA dentro del marco de competencias establecido en el ordenamiento jurídico comunitario» ${ }^{185}$, pero en segundo lugar, resaltemos que el asunto es más complejo, pues si lo anterior - la amenaza de incompetencia por no obrar dentro de las potestades atribuidas - fuese suficiente, no se entendería la necesidad de establecer competencias negativas. Su razón de ser es intentar impedir que mediante un análisis global de los objetivos del tribunal y/o de los fines de la organización, a la que pertenece la Corte, eventualmente éste órgano jurisdiccional, asumiera o entendiera que posee competencias en determinadas materias.

Entendemos entonces que mediante las competencias negativas se crea un mecanismo jurídico de doble cerradura, pues, de un lado, a la Corte no se le asigna una determinada potestad mediante el principio de atribución competencial, y luego, de otro lado, se le agrega una prohibición expresa de intervención mediante la técnica de las competencias

${ }^{185}$ Art. 5 del Estatuto del TJCA. 
negativas. A modo de ejemplo podemos apreciar que en la UE se usa esta técnica de las competencias negativas limitando al TJUE básicamente en dos aspectos, uno referido a la prohibición para enjuiciar a los Estados miembros en materias de Policía y Orden Público $^{186}$, y otro en materia de Política Exterior y de Seguridad Común (PESC), pues legislativamente se establece que no tendrá competencia respecto de tales materias ${ }^{187}$-no ingresaremos en mayores detalles pues las dos menciones al modelo de la UE las efectuamos únicamente para visualizar la existencia del uso de la técnica legislativa comentada. En Latino América también constatamos la presencia de esta técnica de competencias negativas, y en términos comparativos se presenta en temas más relevantes en el SICA, en cambio en la CAN y en el MERCOSUR las detectamos en temas más bien menores.

En el SICA se utilizó la técnica de las competencias negativas en dos aspectos, uno bastante estricto y otro que gira en código de derecho renunciable para las partes. La primera manifestación dice relación con la introducción de una prohibición en materias de derechos humanos, disponiéndose de forma concreta y directa que «la competencia de la Corte no se extiende a la materia de derechos esenciales, la cual corresponde exclusivamente a la Corte Interamericana de Derechos Humanos» ${ }^{188}(\mathrm{CIDH})$, decisión legislativa que se basa en criterios de orden procesal, respetando el principio de especialidad, pues en América se monopoliza esta sensible temática en el sistema dual de la OEA conformado por la Comisión y la $\mathrm{CIDH}$, lo que es diferente a la solución en Europa donde coexisten competencias en estas cuestiones entre el TJUE y el Tribunal Europeo de Derechos Humanos.

\footnotetext{
${ }^{186}$ En las normas para ambos casos subyace un claro tenor impeditivo, el art. 276 del TFUE, señala «En el ejercicio de sus atribuciones respecto de las disposiciones de los capítulos 4 y 5 del título $\mathrm{V}$ de la tercera parte relativas al espacio de libertad, seguridad y justicia, el TJUE no será competente para comprobar la validez o proporcionalidad de operaciones efectuadas por la policía u otros servicios con funciones coercitivas [...], $n i$ para pronunciarse sobre el ejercicio de las responsabilidades que incumben a los Estados miembros respecto del mantenimiento del orden público y de la salvaguardia de la seguridad interior».

${ }^{187}$ En materia de PESC el inciso $2^{\circ}$ del número 1 del art. 24 del TUE, estableció que «La PESC se regirá por reglas y procedimientos específicos. La definirán y aplicarán el Consejo Europeo y el Consejo, [...]. Queda excluida la adopción de actos legislativos. La política exterior y de seguridad común será ejecutada por el Alto Representante de la Unión para Asuntos Exteriores y Política de Seguridad y por los Estados miembros, [...]. El TJUE no tendrá competencia respecto de estas disposiciones, con la salvedad de su competencia para controlar el respeto del art. 40 del presente Tratado y para controlar la legalidad de determinadas decisiones». Como señalamos no ingresaremos al análisis de las interpretaciones más o menos restrictivas que el TJUE haya efectuado de estas normas o bien las opiniones de la doctrina, pues el objeto aquí es subrayar la existencia de la técnica legislativa de las competencias negativas.

${ }^{188}$ Art. 25 del Estatuto de la CCJ.
} 
La segunda manifestación de competencias negativas se genera al eliminar del ámbito de las competencias de la CCJ las controversias de naturaleza fronterizas ${ }^{189}$, aunque este impedimento gira más bien en código de derecho renunciable para las partes, más que en una prohibición absoluta, pues si los Estados en disputa aceptan la competencia de la CCJ, éste tribunal sí podrá conocer. Es decir, no es absoluta esta segunda prohibición, a diferencia de la primera.

En cambio en la CAN no hay competencias negativas de relevancia, lo cual no es extraño, dado lo excepcional de esta técnica prohibitiva, toda vez que de ordinario lo único necesario es no otorgar competencias positivas. En el modelo andino sólo detectamos un par de limitantes menores en contra de las competencias del TJCA, una es la prohibición expresa de registro de votos de disidencias en las sentencias de la Corte andina ${ }^{190}$, y otra se refiere a la prohibición al TJCA efectuar interpretaciones sobre normativa nacional ${ }^{191}$ al momento de efectuar los ejercicios de interpretación prejudicial. Esta segunda prohibición es una cuestión lo suficientemente compleja de llevar delante de modo absoluto, pues las Cortes de integración constantemente están efectuando análisis de compatibilidad entre las normas internas de cada país miembro, con las del proyecto de integración, en un ejercicio orientado a proteger al bloque de legalidad de la organización.

Dicha protección, recién mencionada en el párrafo anterior, se explica en la línea de que los ordenamientos de los proyectos de integración latinoamericanos, no sean neutralizados al interior de cada país recurriendo estas naciones a normativas locales, por lo tanto, en tal dinámica siempre habrá algo que observar de los derechos internos de cada país. Ejercicio en el cual se ha desarrollado por el TJCA determinada jurisprudencia para abordarlo, v.gr. en la sentencia dictada en el caso Cavelier, consulta de la Corte Suprema de Justicia de la República de Colombia ${ }^{192}$, en lo pertinente a este punto la Corte andina va explicando detalladamente el fenómeno de desplazamiento de la normativa local incompatible con la comunitaria, pero para tal conclusión es evidente que el tribunal de integración debe conocer la norma nacional. En lo pertinente aquí, el TJCA destacó:

${ }^{189}$ El literal a) del art. 25 del Estatuto de la CCJ señala «La competencia de La Corte será: a) Conocer, a solicitud de cualquiera de los Estados miembros, de las controversias que se susciten entre ellos. Se exceptúan las controversias fronterizas, territoriales y marítimas, para cuyo conocimiento se requiere la solicitud de todas las partes concernidas».

${ }^{190}$ En el inciso final del art. 90 del Estatuto del TJCA lo prohíbe del siguiente modo «Las sentencias del Tribunal deberán [...], y en ellas no podrán expresarse votos salvados ni opiniones disidentes».

${ }^{191}$ El art. 34 del Tratado de Creación del TJCA dispone en lo pertinente «En su interpretación, el Tribunal deberá limitarse a precisar el contenido y alcance de las normas [...] de la CA [...]. El Tribunal no podrá interpretar el contenido y alcance del derecho nacional ni calificar los hechos».

192 Sentencia del TJCA de 25 de mayo de 1988, Interpretación prejudicial, Germán y Ernesto Cavelier, consulta de la Corte Suprema de Justicia de la República de Colombia, as. 2-IP-88. GOAC N³3 de 1988. 
«De tal suerte, la norma interna que sea contraria a la norma comunitaria [...] $s i$ bien no queda propiamente derogada, dejará de aplicarse automáticamente, bien sea anterior o posterior a la norma integracionista» ${ }^{193}$.

Por su parte en el MERCOSUR casi no se usa la técnica de las competencias negativas, sólo existe la prohibición para los árbitros de emitir votos particulares en los laudos dictados en procesos contenciosos ${ }^{194}$, lo cual es relativamente similar a la primera prohibición que recién vimos para la $\mathrm{CAN}$, dos párrafos atrás, con la diferencia de que aquí en el modelo mercosureño no se abarca a todo su sistema judicial, pues sí están permitidos los votos particulares en las respuestas a las opiniones consultivas, aunque - como ya analizamos - ninguna de estas respuestas son vinculantes en el merco-sistema.

Es muy importante resaltar, que la temática de las competencias negativas ha sido abordada jurisprudencialmente con trascendentes repercusiones para el merco-sistema. Así en el MERCOSUR encontramos un análisis directo al respecto en el laudo del caso República Oriental del Uruguay ${ }^{195}$. En dicha oportunidad se interpuso una excepción de incompetencia contra el TPRM, fundamentada en que se ventilaban materias de derechos humanos y al TPRM no se le habían atribuido tales potestades. Sin embargo el TPRM la repele destacando centralmente que no habían competencias negativas que le impidan avanzar en su desarrollo jurisprudencial. Es decir, para la Corte no había obstáculo alguno que le impidiera generar su nuevo criterio sobre sus propias competencias. En aquella ocasión la Corte mercosureña empleó el concepto de exclusión de jurisdicción —aquí competencias negativas-, indicándolo con toda precisión del siguiente modo:

«esta jurisdicción se conforma sobre controversias entre los Estados Partes referidas a la interpretación o incumplimiento de la normativa MERCOSUR. No hay, de forma implícita o explícita en el texto del Protocolo de Ouro Preto, exclusión de jurisdicción con base a la materia objeto de la controversia» ${ }^{196}$.

En conclusión fluye de lo visto en este apartado que en los tres modelos latinoamericanos se presenta el uso de la técnica de las competencias negativas, al igual como primeramente

\footnotetext{
${ }^{193}$ Párrafo tercero, del apartado 4) en TJCA, Sentencia ibídem —el análisis acabado de este caso y de otros importantes pronunciamientos, los veremos en el capítulo III esta tesis.

${ }^{194}$ El art. 25 del POPSCM lo prohíbe así «Los árbitros no podrán fundar votos en disidencia y deberán mantener la confidencialidad de la votación». Prohibición reforzada en el art. 21 del Reglamento del POPSCM el cual indica «Una vez designados los árbitros [...], les presentará una declaración del siguiente tenor, [...] Me comprometo a mantener bajo reserva la información y actuaciones vinculadas a la controversia, así como el contenido de mi voto».

${ }^{195}$ Laudo del TPRM de 21 de julio de 2012, República Oriental del Uruguay, as. 1/2012.

${ }^{196}$ Considerando 36 en laudo ibídem. Este es un laudo bastante trascendente por el avance concreto que se genera para el MERCOSUR desde el TPRM, claramente es un aporte del tribunal al proceso de integración mercosureño, y su análisis acabado más otros importantes pronunciamientos, los veremos en el capítulo III.
} 168 
fueron estatuidas en el modelo europeo. En el concierto latinoamericano el SICA las emplea en materias muy sensibles, cuales son, temáticas de derechos humanos, privilegiando la competencia del tribunal internacional especialista. En cambio en la CAN y en el MERCOSUR se emplean para prohibir los votos disidentes, además en la CAN se añade la prohibición expresa de interpretar derecho local nacional de los Estados miembros. En el fondo nosotros entendemos que este tipo de herramientas comportan un mecanismo de doble cerradura para intentar evitar el desborde competencial de las Cortes de integración. Decimos doble, porque se suma al simple hecho del respeto al principio de atribución de competencias, ya que de ordinario, sólo es necesario no otorgar competencias a una Corte en determinadas materias, razón por la cual al sumarle una prohibición respecto de dicha materia no atribuida, queda a la vista un doble seguro.

\subsubsection{LA PRESENCIA DE POLÍTICAS DE IMPUGNACIÓN JERÁRQUICAS EN LOS MODELOS DE LAS CORTES LATINOAMERICANAS}

Las vías de impugnación son un instituto procesal que ofrece una gama de herramientas para la corrección del proceso. Sin embargo, en el nivel internacional casi nunca operan recursos procesales jerárquicos, dado que los esquemas de justicia transnacionales, no son complejos orgánicamente, sino que la mayoría de las veces el mecanismo es simple, es decir, compuesto de una sola Corte. En nuestro tema únicamente la UE con el TJUE y el TGUE, y el MERCOSUR con el TPRM y los TAAM son procesalmente esquemas complejos en razón de pluralidad de Cortes. En cambio el SICA con la CCJ y la CAN con el TJCA, son modelos orgánicos simples, esto es, de tribunal único.

Un tema del todo diferente es verificar si existe o no la posibilidad de impugnar resoluciones judiciales dictadas por tribunales nacionales ante tribunales internacionales. La respuesta es que - en general - esto no es posible, debido a que la conexión entre ambos niveles de justicia — nacional/internacional — no es jerárquica, por lo tanto la necesidad de aplicar mecanismos procesales de justicia revisora, se conduce mediante las denominadas competencias primarias y secundarias, modelo que exige agotar los cauces locales para luego accionar en sede internacional, jamás deducir recursos de impugnación jerárquicos.

Pues bien, el criterio recién indicado en el párrafo anterior, es el que viene a sufrir algunas leves modificaciones en los esquemas jurisdiccionales de integración. La UE es la organización que posee la estructura jurisdiccional de mayor desarrollo y complejidad que existe, conformada por dos Cortes, más la posibilidad de añadir un tercer nivel, los 
tribunales especiales ${ }^{197}$ aunque en la actualidad no hay tribunales especiales en la UE. Lo primero que debemos destacar que dichos tres niveles, sí se vinculan a través del principio jerárquico. Y simultáneamente todo, en conexión a través del principio de colaboración con los jueces nacionales. Dicha mega construcción es la que lleva a la doctrina ${ }^{198}$ a reconocer un cuasi Poder Judicial de la UE. La creación de la estructura jurisdiccional de la UE constituyó la primera experiencia procesal orgánica de jurisdicción transnacional de carácter compleja, posición bien destacada por la doctrina ${ }^{199}$, a lo que se suma que su política impugnativa es dicotómica, por las siguientes razones.

1. Por una parte, entre los tribunales nacionales y las Cortes de la UE hay dos sub herramientas indirectas, el principio de colaboración, más la introducción de elementos jerárquicos por la jurisprudencia de Luxemburgo, pues el TJUE es el último intérprete del Derecho de la UE, proceso donde su auctoritas juega un papel central. Pero en concreto los fundadores no permitieron la impugnación directa de las resoluciones judiciales nacionales ante las Cortes de la $\mathrm{UE}^{200}$.

${ }^{197}$ El número 1 del art. 19 del TUE, señala «El Tribunal de Justicia de la Unión Europea comprenderá el Tribunal de Justicia, el Tribunal General y los tribunales especializados». Esta redacción también es la causa por la cual en algunas oportunidades el acrónimo TJUE es el significante de Poder Judicial de la UE, y no respecto de la literalidad Tribunal de Justicia de la UE, por lo cual muchas veces se utilizan las siglas «TJUE versus $\mathrm{TJ} »$.

${ }^{198}$ La noción de un cuasi Poder Judicial de la UE, es resaltada por la doctrina desde varios ángulos, por ejemplo SARMIENTO enfocándose en la composición de la estructura jurisdiccional de la UE, señala que el Poder Judicial de la Unión lo componen el TJUE y los tribunales nacionales; y más adelante expresándose ahora bajo el apartado que el autor tituló «El Poder Judicial de la Unión» expresa que, como en todo sistema político basado en el reparto de competencias, el Poder Judicial de la Unión se estructura en dos niveles, por un lado los Tribunales de la Unión, y por otro los Tribunales de los Estados miembros, por lo que concluye que se trata de un «Poder Judicial Híbrido». SARMIENTO RAMÍREZ-ESCUDERO, 2016, p. 89, pp. 357358 y p. 437. Ahora en una línea comparativa del sistema de la UE -el cual como dijimos no alcanza, ni pretende, el umbral del federalismo- LENAERTS y GUTIÉRREZ-FONS cotejan que: a diferencia de otros sistemas federales la UE tiene un «Poder Judicial Integrado», pues el TJUE lo comparte con los órganos jurisdiccionales nacionales, pero aclaran que el TJUE ha introducido elementos jerárquicos en una relación que en todo caso gira en torno al entendimiento y fortalecimiento mutuos. LENAERTS \& GUTIÉRREZFONS, 2012, pp. 86-88.

${ }^{199}$ Dicho carácter pionero es destacado por PESCATORE quien expresa, por primera vez una jurisdicción ha sido realmente insertada en un sistema institucional internacional. PESCATORE, P. \& INSTITUT UNIVERSITAIRE DE HAUTES ÉTUDES INTERNATIONALES (1972). Le droit de l'intégration : Emergence d'un phénomène nouveau dans les relations internationales selon l'expérience des Communautés Européenes. Leiden: Sijthoff., p. 73.

${ }^{200}$ Tal imposibilidad la destaca SARMIENTO al señalar «a diferencia de los sistemas judiciales federales, no existen vías procesales que unan el nivel jurisdiccional de la Unión con el nivel nacional. Por tanto las resoluciones judiciales nacionales no pueden ser recurridas ante los Tribunales de la Unión, pues no existe un recurso específico que lo permita». SARMIENTO RAMÍREZ-ESCUDERO, 2016, p. 360.

170 
Para evitar confusiones semánticas, precisemos que la técnica legislativa de la UE, mencionando como «recursos» a institutos que procesalmente son «acciones», es poco acertada, tal como lo ha puesto de manifiesto parte de la doctrina ${ }^{201}$. Así por ejemplo el recurso de incumplimiento, o el recurso de anulación, o el recurso por omisión, son en realidad acciones, pues no están dirigidos a impugnar una resolución judicial, cual es la finalidad de los recursos procesales. En un análisis de derecho comparado - como lo es este caso- debe considerarse tal circunstancia técnico-gramatical.

En tal exigencia, respecto de un lenguaje jurídico más preciso, constatamos que en América Latina se logra de mejor manera pues, en el SICA, en la Ordenanza de Procedimientos de la CCJ su Cap. VI se pasa a titular De la acción de nulidad, y en el artículo 89 reza, «La acción... podrá incoarse...», luego su Capítulo VII se titula, De la acción de incumplimiento, y su artículo 94 precisa «La acción...» ${ }^{202}$. En la CAN, en el Estatuto del TJCA su Título Tercero se denominó De las acciones en particular, y va singularizándolas en el Capítulo I, II y siguientes bajo los nombres, en cada caso, «De la acción de....». Por último en el MERCOSUR se habla de reclamo, o de escrito de presentación, reservándose el concepto de recurso para las impugnaciones ${ }^{203}$.

2. En segundo lugar, si pasamos al análisis interno del Poder Judicial de la UE, sí encontraremos políticas recursivas jerárquicas entre el TGUE y el TJUE. Ejemplos hay varios, entre éstos el recurso de casación contra la sentencia del TGUE al resolver una acción o recurso de anulación interpuesto por el legitimado ${ }^{204}$, también el recurso de casación contra las resoluciones que pongan fin al proceso ${ }^{205}$, más otros tantos ejemplos que se constatan en el modelo europeo.

\footnotetext{
${ }^{201}$ El fallo lingüístico lo explica DESANTES y PARDO reconociendo que en realidad se emplea el término «recurso» en la UE sólo por ser una denominación comúnmente usada y de aceptación generalizada en la normativa europea. DESANTES REAL, M. \& PARDO IRANZO, V. (2013). "El sistema jurisdiccional de la ue: aspectos orgánico y procedimental”, en: Pardo Iranzo, V., Iglesias Buhigues, J. L., Desantes Real, M., Jimeno Bulnes, M., Arangüena Fanego, C., Jimenez Fortea, F.J.,...Cervera Vallterra, M., El sistema jurisdiccional de la unión europea ( $1^{\mathrm{a}}$ ed.). Navarra: Aranzadi., p. 49.

${ }^{202}$ En la Ordenanza de Procedimientos de la CCJ, a los nombres de los Capítulos VI y VII, y a los artículos 89 y 94 , se les suman los arts. 24, 27, 28, 35 y 51, los cuales hacen clara mención a la demanda, sin confundir con recursos.

${ }^{203}$ En dicho ritmo los arts. 14, 17 y 28 del POPSCM, el art. 48 del Reglamento del POPSCM y el art. 18 literal (D) de Las Reglas de Procedimiento del TPRM.

${ }^{204}$ Vid. inciso $2^{\circ}$ del número 1 del art. 256 del TFUE «Contra las resoluciones dictadas por el TGUE en virtud del presente apartado podrá interponerse recurso de casación ante el TJ».

${ }^{205} \mathrm{El}$ art. 56 del Estatuto del TJUE, el cual se hace cargo de determinadas resoluciones especiales en los siguientes términos «Contra las resoluciones del TGUE que pongan fin al proceso, así como contra las que resuelvan parcialmente la cuestión de fondo o pongan fin a un incidente procesal relativo a una excepción de incompetencia o de inadmisibilidad, podrá interponerse recurso de casación ante el TJ».
} 
Pues bien en Latino América en tanto, observamos que en el SICA, al igual que en la UE, no está permitido impugnar las decisiones de los tribunales nacionales ante la $\mathrm{CCJ}^{206}$. Además, como la construcción orgánica jurisdiccional del SICA es simple — con sólo una Corte - se imposibilitan políticas recursivas jerárquicas intra Poder Judicial. A diferencia de lo que sucede en el MERCOSUR y en la UE dado sus construcciones complejas de más de una Corte. En el SICA además de la circunstancia orgánica anotada, se refuerza procesalmente esta imposibilidad, pues los fundadores establecieron el estado de firmeza de la sentencia de tipo ipso facto $^{207}$ al tiempo de imposibilitar el uso de recursos ${ }^{208}$ en contra de los principales tipos de resoluciones de la CCJ. Por similar cauce se conduce la CAN pues tampoco se permite en el modelo andino la impugnación de las sentencias de los tribunales nacionales ante el TJCA. Y como también en la CAN sólo existe una Corte, es imposible un análisis interno de recursos. Aunque con un cariz díscolo, el Estatuto del TJCA contempla una antigua vía impugnativa, ya purgada de diversos sistemas jurídicos, y en otros, muy limitada, nos referimos a la acción de revisión, la cual permite ventilar un nuevo juicio, con la finalidad de modificar lo resuelto en el primer juicio ${ }^{209}$. Sin embargo

206 Al respecto destaca CANO, haciendo referencia a la jurisprudencia de la CCJ, que el proceso de integración centroamericano cuenta con dos responsables de impartir justicia. Por un lado la CCJ como Tribunal Regional y, por otro los jueces nacionales [...]. Ambos conforman el sistema jurisdiccional regional sin que exista una relación de jerarquía entre ambos pues, la CCJ no es, como ha manifestado ella misma, un tribunal de alzada para conocer de las resoluciones jurisdiccionales o administrativas pronunciadas de acuerdo a su derecho interno por los Estados miembros del SICA. CANO LINARES, M. A. (2009). La corte centroamericana de justicia: un órgano único con diversidad de competencias. En Fernández Liesa, C. R., \& Díez de Velasco Vallejo, M., Tribunales internacionales y espacio iberoamericano ( $1^{\text {a }}$ ed.). Cizur Menor: Thomson Reuters., p. 132.

${ }^{207} \mathrm{El}$ art. 38 del Estatuto de la CCJ establece el estado de firmeza ipso facto de la sentencia, decretando «El fallo será definitivo e inapelable».

${ }^{208}$ Art. 39 del Estatuto de la CCJ «Las resoluciones interlocutorias, laudos y sentencias definitivas que dicte La Corte no admitirán recurso alguno».

${ }^{209}$ Respecto de la acción de revisión, el art. 95 Recurso extraordinario de revisión del Estatuto del TJCA dispone «Únicamente las sentencias pronunciadas en acciones de incumplimiento son susceptibles de revisión con arreglo a las previsiones del 'art. 29 del Tratado' [*no se indica a qué Tratado se refiere]. La demanda de revisión podrá intentarse por quienes hayan sido parte en el proceso, siempre que esté fundada en algún hecho que hubiere podido influir decisivamente en el resultado del mismo y hubiere sido desconocido en la fecha de la expedición de la sentencia...». A esta vía impugnativa se le da un claro tratamiento de acción, de hecho el art. 96 se titula Contenido de la 'demanda' de revisión, y el 97, Trámite de la 'demanda' de revisión. Ahora, respecto de la remisión que hace el art. 95 del Estatuto del TJCA es hacia el art. 29 del Tratado de Creación del TJCA [*lo aclaramos pues no se indica a qué cuerpo normativo pertenece el art. 29] el cual le asigna competencia a la misma Corte, así «Las sentencias dictadas en acciones de incumplimiento son revisables por el mismo Tribunal, a petición de parte, fundada en algún hecho que hubiere podido influir decisivamente en el resultado del proceso, siempre que el hecho hubiere sido desconocido en la fecha de la expedición de la sentencia...».

172 
esta acción de revisión en el nivel de la jurisdicción internacional no es exclusiva de la CAN también se encuentra presente para la $\mathrm{CIJ}^{210}$.

En cambio en el MERCOSUR la situación está más desarrollada que en sus vecinos la CAN y el SICA, lo que se explica en su actual estructura orgánica jurisdiccional compleja, con dos tipos de tribunales, pues contempla - al igual que la UE, guardando todas las proporciones - recursos procesales jerárquicos entre los TAAM y el TPRM, básicamente mediante el recurso de revisión, cauce impugnativo que forma parte del nombre del mismo tribunal. Dicho recurso se restringe a las cuestiones de derecho ventiladas en la litis y a las interpretaciones jurídicas desarrolladas en el laudo impugnado ${ }^{211}$, por lo tanto, y como justamente ambas restricciones le imprimen un carácter casacional al recurso de revisión, éste se vuelve inidóneo respecto de los laudos resueltos ex aequo et bono ${ }^{212}$.

En conclusión, en Latino América sólo en el MERCOSUR se implementaron políticas recursivas jerárquicas al interior de su sistema, dado su construcción orgánica basada en dos niveles de tribunales — como en la UE, con las reservas del caso-, a diferencia de la CAN y del SICA pues éstos son modelos de tribunal único. Ahora bien, más allá de lo meramente orgánico y que pudiese mirarse incluso como evidente, en lo central, éste esquema del merco-sistema comporta un punto concreto de desarrollo en favor de su proyecto de integración, por dos razones, en primer lugar, porque viene a fortalecer la decisión final del sistema judicial mercosureño dado las versatilidades propias de todo esquema de recursos jerárquicos, y en segundo lugar, porque además, este desarrollo se muestra como un punto de equilibrio ante todos los demás ángulos de análisis que hemos empleado para enfocar nuestros objetos de estudio - hasta aquí (cap. I) con lo histórico y (cap. II) en lo estatutario con los seis patrones centrales, más lo que llevamos recorrido de los cuatro rasgos comunes - en todos los cuales las estructuras del MERCOSUR se vienen presentando como las más débiles, en cambio ésta, comporta precisamente todo lo contrario.

\footnotetext{
${ }^{210}$ Art. 61 del Estatuto de la CIJ. Esta norma permite la acción de revisión si se funda en el descubrimiento de un hecho decisivo que al dictarse la sentencia no era conocido de la Corte ni de la parte que la pida. La caducidad es de 6 meses desde llegado a conocimiento de la parte el hecho, y con todo no puede superar los 10 años desde la fecha de la sentencia.

${ }^{211}$ Números 1 y 2 del art. 17 del POPSCM «1. Cualquiera de las partes en la controversia podrá presentar un recurso de revisión al TPMR, contra el laudo del TAAM [...]. 2. El recurso estará limitado a las cuestiones de derecho tratadas en la controversia y a las interpretaciones jurídicas desarrolladas en el laudo». Reiterándose la procedencia de este recurso en los párrafos 1 y 2 del art. 26 del POPSCM.

${ }^{212}$ Número 3 del art. 17 del POPSCM «Los laudos de los TAAM dictados en base a los principios ex aequo et bono no serán susceptibles del recurso de revisión».
} 


\subsubsection{LA EXCLUSIÓN DE LOS VOTOS DISIDENTES EN LOS MODELOS DE}

LAS CORTES LATINOAMERICANAS CONFRONTADO AL

PRINCIPIO DE PUBLICIDAD Y TRANSPARENCIA

Como los tribunales internacionales poseen por regla general, una integración habitualmente colegiada, se requiere lograr acuerdo entre los jueces para dictar la sentencia. Actividad en que la unanimidad sería lo ideal, pero en los hechos esto es poco probable, surgiendo por tal razón las opiniones particulares. Dichas opiniones se presentan en variadas intensidades, unas más y otras menos compatibles con la opinión de la mayoría de los jueces, aunque esta circunstancia no obstaculiza al acto de juzgamiento, sino que lo enriquece, toda vez que permite compartir y debatir en torno a las diferentes apreciaciones. En todo caso, tales episodios los previene el legislador, quien resuelve ex antes qué hacer con los votos particulares, enfrentados al principio de publicidad de los actos del proceso, dándose al respecto diversas soluciones.

El tratamiento del voto disidente en los sistemas nacionales contrasta con el que recibe en los transnacionales, pues en los primeros tienden a equilibrarse entre opciones restrictivas y los que privilegian la transparencia, en cambio en el nivel internacional esto no es así, pues por regla general se privilegia el principio de transparencia, cuestión que la doctrina ${ }^{213}$ va destacando. Este es un hecho concreto, así por ejemplo hay varios casos que siguen el principio de publicidad, como la $\mathrm{CIJ}^{214}, \mathrm{CPI}^{215}, \mathrm{TEDH}^{216}, \mathrm{CIDH}^{217}$, la Corte Africana de Derechos Humanos y de los Pueblos ${ }^{218}$, entre otros más. Como vemos el principio de publicidad impera en el nivel transnacional, siendo muy contados los casos de restricción y precisamente el TJUE es una excepción ya que opta por el secretismo.

Es particularmente curioso que ni el Estatuto del TJUE, ni el Reglamento de Procedimiento del TJUE, posean disposiciones sustantivas sobre las disidencias. Sólo hay una obligación

\footnotetext{
${ }^{213} \mathrm{Al}$ respecto LYNCH acota «The ambiguous origins of dissent in domestic tribunals may be contrasted with the situation in respect of international law courts which, being a phenomenon of the 20th century and the outcome of vigorous diplomacy, make no such assumptions and any ability to dissent is indeed a right enshrined in those documents which establish them». LYNCH, A. (2004). Is judicial dissent constitutionally protected?. Macquarie Law Journal, 5, vid. apartado "II The possibility of dissent", <http://www5.austlii.edu.au/au/journals/MqLJ/2004/5.html> [última consulta, abril 29, 2019].

${ }^{214}$ Art. 57 del Estatuto de la Corte Internacional de Justicia.

${ }^{215}$ Número 4 del art. 83 del Estatuto de Roma.

${ }^{216}$ Art. 52.2 del Reglamento del Tribunal Europeo de Derechos Humanos.

${ }^{217}$ Número 3 del art. 24 de su Estatuto de la Corte Interamericana de Derechos Humanos.

${ }^{218}$ Número 5 de la Regla 60 de la Corte «Any Member of the Court who heard the case may deliver a separate or dissenting opinion».
}

174 
para los jueces de no revelar las deliberaciones, pero entre las opiniones particulares y las deliberaciones hay bastantes diferencias ${ }^{219}$. En realidad todo gira por el carácter unitario de la decisión judicial, la cual se extrae del hecho de que las conclusiones de la mayoría de los jueces comportan la decisión del tribunal mismo $^{220}$, lo que finalmente se refleja en el criterio en la UE, cual es no registrar los votos de disidencia por ser colectiva la decisión. Y como anunciamos, sólo respecto de las deliberaciones, se precisa lo siguiente:

«Los Jueces, en la primera audiencia pública del Tribunal a la que asistan tras su nombramiento y antes de su entrada en funciones, prestarán el siguiente juramento: "Juro ejercer mis funciones en conciencia y con toda imparcialidad; juro que guardaré el secreto de las deliberaciones"» ${ }^{221}$.

La solución europea intenta desperfilar las diferencias de los sentenciadores y presentar a la Corte como un tribunal de mayor convicción, cuestión que es destacada en el documento Tribunal de Justicia, Composición, Competencias y Procedimientos, en el cual se señala «Las decisiones del Tribunal de Justicia se adoptan por mayoría, sin que sea posible hacer constar votos particulares» ${ }^{222}$. En el momento histórico en que surge la idea restrictiva, no sólo se caminó en sentido contrario a la mayoría de los sistemas internacionales vigentes a la época del nacimiento de la Corte de Luxemburgo, sino que además, se fue en contra de la solución interna de los seis Estados miembros primigenios, intentando fortalecer un naciente Derecho Comunitario, buscando apoyo en las versatilidades del secreto, como que al no mostrar cismas jurídicos se observa la sentencia con un mayor respeto, se crea una sensación de cohesión y se evitan secuelas de discusión sobre las que ya impera cosa juzgada. Esquivando un clima divisorio al interior de un proyecto en formación.

Pero para nosotros el punto es que tras todo el desarrollo alcanzado, ya debería haberse modificado tal situación, alineando al proyecto de la actual UE con los estándares de los principios de publicidad y democrático propios de una Comunidad de Derecho moderna que reconoce al principio de publicidad como un contenido central del due process of law, en el sentido de que, si los actos de proceso son públicos, el principal acto debe también ser público en su integridad, esto es, en la forma en que fue construido, ya que la decisión de

\footnotetext{
${ }^{219} \mathrm{Ni}$ en el art. 27, ni entre los arts. 63 a 68 del Reglamento de Procedimiento del TJUE, se otorga la facultad de emitir votos particulares.

${ }^{220}$ El carácter unitario se observa prevalente en el número 5 del art. 27 del Reglamento indicado «Las conclusiones adoptadas por la mayoría de los Jueces tras el debate final constituirán la decisión del Tribunal». ${ }^{221}$ Art. 3 del Reglamento de Procedimiento del TJUE.

${ }^{222}$ TRIBUNAL DE JUSTICIA, COMPOSICIÓN, COMPETENCIAS Y PROCEDIMIENTOS (Dic. 2010 , doi: 10.2862/39016, ISBN 978-92-829-1015-3), apartado Sentencia, p. 8. Disponible en <https://curia.europa.eu/jcms/upload/docs/application/pdf/2012-05/cjue_es.pdf> Portal oficial del TJUE. [última consulta, julio 12, 2017] y en <https://studylib.es/doc/5394670/el-tribunal-de-justicia---curia> [última consulta, diciembre 7, 2019].
} 
cada magistrado habría sido la sentencia definitiva de haber servido dicho juez en un tribunal unipersonal. Por otro extremo, se está limitando individualmente al juez a que efectúe su principal misión, emitir su decisión sobre el asunto controvertido, y poder disentir públicamente ${ }^{223}$, mezclándose aquí la figura de tribunal con la de juez, de un modo inapropiado para el principio de transparencia.

Esta circunstancia de hacer públicos los votos particulares, genera múltiples beneficios, como el hecho de que la sentencia resulta ser más sólida, pues estará en tensión desde su origen con un criterio diferente, por lo tanto se pone más énfasis en su argumentación, y obliga al juez disidente a justificar su pensamiento jurídico, ya que el voto particular no está dirigido ni conversa con los jueces del voto de mayoría a quienes ya no convenció, sino que está direccionado a otras instituciones de la Organización Internacional, a los Estados, a los pensadores del derecho, a las partes, a todos menos a los jueces del voto de mayoría con los cuales ya se deliberó ${ }^{224}$. En este camino comienzan muchas veces a cambiar los criterios de la Corte. Además se presenta una mayor cercanía con los destinatarios al conocer el criterio de la disidencia, favorece la discusión de la doctrina, se conecta con las exigencias democráticas modernas, precisamente con el principio de transparencia. Por ende, todo lo anterior contribuye a la madurez del sistema de justicia, razón por la cual creemos que sería un buen desafío para el TJUE.

En América Latina, no se siguió de modo homogénea la prohibición europea, sino que se presenta una gama de soluciones, así en la CCJ se permiten los votos disidentes, cuestión que se arrastra históricamente desde la Corte de Cartago de 1907, para el TJCA no se permiten los votos disidentes, en línea con el TJUE pero con la diferencia de que en la CAN hay norma expresa, y en el MERCOSUR se presenta una dicotomía, pues de un lado se prohíben en los laudos de contenciosos, mientras que del otro, sí se permiten en las respuestas a las consultas prejudiciales. Así las cosas, es nuevamente el SICA quien muestra el mayor grado de desarrollo en este punto, incluso por sobre la UE pues Centroamérica apuesta por la transparencia desde el año 1907, lo que hemos verificado históricamente en los Anales de la Corte ${ }^{225}$. Pero en la era actual, es el Estatuto de la CCJ el

\footnotetext{
${ }^{223}$ LYNCH, A. (2004). Is judicial dissent constitutionally protected?. Macquarie Law Journal (5), vid. apartado «II The possibility of dissent».

${ }^{224}$ CASSESE S. (2009). Lezione sulla cosiddetta opinione dissenziente. Quaderni di diritto costituzionale, 4 , p. 15 de la versión ampliada, disponible en <http://www.irpa.eu/area-bibliografica/scritti/lezione-sullacosiddetta-opinione-dissenziente/> [última consulta, abril 5 de 2018]; versión impresa: Cassese, S. (2009). Una lezione sulla cosiddetta opinione dissenziente. Quaderni Costituzionali, 4, 973-983.

${ }^{225}$ Subrayamos, manteniendo, pues la cultura de la publicidad de los votos disidentes en la Corte del istmo centroamericano, nace junto a la Corte de Cartago de 1907, y desde ese momento, la tradición se ha mantenido en cada nueva época del proyecto, lo que fluye hacia la actual era del SICA y de la CCJ. Pueden verificarse votos razonados registrados, en LOS ANALES DE LA CORTE DE CARTAGO, Mayo a 176
} 
contenedor de esta temática, manteniendo la competencia a los jueces integrantes para consignar sus criterios, tanto concurrentes como disidentes:

«Todas las decisiones de La Corte [...] se tomarán con el voto favorables de al menos la mayoría absoluta de los que las integran. El Magistrado o Magistrados disidentes o concurrentes tendrán derecho a que se consigne su criterio. La resolución será motivada» ${ }^{226}$.

La CAN en cambio, se aproxima al secretismo de la UE en la materia bajo análisis, recurriendo a la excepción a la publicidad. Pero a diferencia del modelo europeo, en la CAN se usan las competencias negativas para construir una prohibición directa y clara, no tan oblicua como en la UE, sino que el modelo andino lo hace expresamente así:

«Las sentencias del Tribunal deberán ser suscritas por el Presidente, por los demás Magistrados que participaron en su adopción y por el Secretario, y en ellas no podrán expresarse votos salvados ni opiniones disidentes» ${ }^{227}$.

El MERCOSUR a diferencia de todos los esquemas anteriores, se ubica en una posición intermedia lograda por tres condiciones: en primer lugar, por una parte adscribe a la excepción al principio de publicidad, siguiendo en esto a la UE, pero empleando el mecanismo de la CAN, es decir, valiéndose de la técnica de las competencias negativas como vimos esta técnica no se usó en la UE para esta materia, pero en Europa se logra el mismo efecto, mediante una interpretación ajustada al principio de atribución de competencias-, prohibiéndole a los árbitros divulgar sus votos y sus deliberaciones ${ }^{228}$. En el modelo legislativo mercosureño se observa un claro tratamiento diferenciado entre votos disidentes $v / s$ deliberaciones, en línea con lo ya comentado para la UE, donde la prohibición directa recae solo en las deliberaciones, el resto es una exégesis restrictiva ante el principio de atribución; en segundo lugar, se genera una atenuante del secreto en los laudos de los contenciosos toda vez que se va indicando si cada decisión fue adoptada por mayoría $v / s$ unanimidad, pero sin expresar más datos ni precisiones; y finalmente, en tercer lugar, sí se permiten votos disidentes en las respuestas en las cuestiones prejudiciales ${ }^{229}$.

Diciembre de 1913, Tomo III, pp. 36 y ss., disponible en <http://portal.ccj.org.ni/ccj/wp-content/uploads/009T-3-N-1-8-1.pdf> [última consulta, abril 7 de 2018].

${ }^{226}$ Inciso $1^{\circ}$ del art. 36 del Estatuto de la CCJ.

${ }^{227}$ Inciso final del art. 90 del Estatuto del TJCA.

${ }^{228}$ La situación restrictiva está en el art. 25 del POPSCM de la siguiente forma «Los laudos del TAAM y del TPRM, se adoptarán por mayoría, [...]. Los árbitros no podrán fundar votos en disidencia y deberán mantener la confidencialidad de la votación. Las deliberaciones también serán confidenciales», norma reforzada luego en el art. 21 del Reglamento del POPSCM.

${ }^{229}$ Letra c) del número 1 del art. 9 Contenido de las opiniones consultivas, del Reglamento del POPSCM «c. el dictamen del TPR con la opinión de la mayoría y las opiniones en disidencia, si las hubiera». 
En conclusión el SICA presenta el mayor desarrollo en materia de votos disidentes al optar por la transparencia, superando con esto incluso a la UE, y a sus vecinos la CAN y el MERCOSUR. Tal posición del SICA, no sólo es reflejo de una opción técnica procesal novedosa para las Cortes de integración, sino que además, es notable en cuanto a no calcar el modelo europeo, como si fuese un esquema exportable sin acomodo alguno. Demostrándose que la incorporación de tradiciones jurídicas propias de las regiones latinoamericanas, es factible y positivo, pues no se expone al destinatario a un instituto jurídico al cual no está acostumbrado, acusando de paso, plena confianza en la transparencia, tan propia de nuestra era democrática. Por otro extremo no comprendemos cómo aún la UE — atendido el nivel de desarrollo que ha alcanzado - no se alinee con la regla general, esto es dando preferencia al principio de transparencia, propio de los esquemas democráticos modernos, con todos los beneficios que aquello trae - y que detallamos en el párrafo quinto de este apartado. La CAN por su parte, se mantiene completamente en la prohibición, por lo mismo sería esperable un avance. En cambio el MERCOSUR tiene una mejor posición que el proyecto andino y menor que el centroamericano, toda vez que en el mercosureño se dan las tres situaciones descritas restrictivo para contenciosos, pero indicándose el quorum de cada decisión y con transparencia para las respuestas a las consultas prejudiciales - lo que le dejan en una posición intermedia, desde la cual deducimos que le será más fácil avanzar hacia la transparencia completa.

\subsubsection{LA MAYOR AMPLITUD DEL LOCUS STANDI EN LOS ESQUEMAS DE LAS}

CORTES LATINOAMERICANAS EN COMPARACIÓN A LOS MODELOS

DE JURISDICCIÓN INTERNACIONAL CLÁSICOS

El último ángulo de análisis que seleccionamos para cotejar a las Cortes latinoamericanas, es el locus standi, entendido éste como el derecho a ser oído por un tribunal. El locus standi afecta a los que pretendan ser partes y también a determinados terceros. Nuestra justificación para utilizar este último ángulo de análisis se basa en que, el locus standi es un componente central para el acceso efectivo a la justicia, toda vez que si se le niega a alguien la capacidad para participar en un juicio, obviamente se le está alejando del tribunal, lo que generará el distanciamiento del afectado, no sólo de dicha Corte, sino también, se sentirá desafectado de todo el proyecto integracionista, y tales ánimos negativos siempre se intentan evitar al implementar un plan de integración intenso.

El estatus de participación ante un tribunal internacional ha ido evolucionado y además se resuelve de forma diferente según sea el tipo de Corte transnacional enfocada. Al gestarse el DI el Ser Humano gozaba de derechos en una posición privilegiada, como centro de las 
construcciones jurídicas $^{230}$, pero esas primeras ideas fueron suplantadas por el positivismo jurídico que personificó al Estado, dotándolo de voluntad propia, reduciendo los derechos de las personas a los que el Estado concedía, negando jus standi a los particulares ${ }^{231}$. Hacia 1899 la CPA consideraba como partes solo a los Estados. Lo mismo ocurrió en Latino América con la Corte de Cartago de 1907, aunque hoy en día se ha venido ampliando fuertemente el acceso a los particulares a los modelos de administración de justicia transnacionales.

Los nuevos fenómenos, como el fin de la Segunda Guerra Mundial dan paso a un hecho procesal inédito en la dimensión internacional, consistente en haber comenzado a enjuiciar a personas físicas $^{232}$. Al mismo tiempo el DI contemporáneo comenzó a dar respuestas más serias a las nuevas ideas que los Estados manifestaban mediante la institucionalización de la Sociedad Internacional apareciendo de tal suerte más Sujetos de DI, como las OI y sus Instituciones y órganos, a lo que se suman los desarrollos en derechos humanos, en el derecho penal internacional y otros, conjunto total de desarrollos que pasarían a consolidar la idea moderna de acceso a los particulares ${ }^{233}$. Aunque aún no hay un locus standi

${ }^{230}$ Tras el impulso de los españoles Francisco De Vitoria y de Francisco Suárez la idea era que el Ser Humano gozaba como centro de las construcciones jurídicas, para SUÁREZ el Derecho de Gentes revelaba la universalidad del género humano, DE VITORIA planteaba el concepto de totus orbis DE VITORIA, F., PEREÑA, L., PÉREZ-PRENDES Y MUÑOZ DE ARRACO, JOSÉ MANUEL, \& BELTRÁN DE HEREDIA, V. (1967). Relectio de indis o libertad de los indios [Relectio de Indis. Español-Latín]. Madrid: Consejo Superior de Investigaciones Científicas, vid. en particular: Estudios de Introducción, acápite IV Vitoria en la perspectiva de nuestro tiempo, pp. CXLVI-CXLIX.

${ }^{231}$ A las ideas de SUÁREZ y DE VITORIA, se sumaron las de GROTIUS en cuanto el Estado es un medio para asegurar el ordenamiento social en conformidad con la inteligencia humana para perfeccionarse, sociedad común que abarca a toda la humanidad. En misma línea ALBERICO GENTILE, SAMUEL PUFENDORF, CRISTIAN WOLFF, pero absolutamente todas las reflexiones de los fundadores del DI fueron suplantadas por la fuerza del positivismo jurídico que personificó al Estado dotándolo de voluntad propia, reduciendo los derechos de los Seres Humanos a los que el Estado concedía. Así el consentimiento o voluntad de los Estados se convirtió en el criterio predominante del DI negando jus standi al Ser Humano. Lo que redundó en la dificultad para comprender a la Sociedad Internacional y debilitó al DI mismo, que pasó a reducirse a un simple derecho interestatal. De tal suerte que la idea de Estado Super-Poderoso propia de la filosofía de HEGEL traería consecuencias nefastas para toda la Humanidad, siendo muy lento el camino emancipador. TRINDADE, A. A. C. (2001). El acceso directo del individuo a los tribunales internacionales de derechos humanos. Bilbao: Universidad de Deusto, vid. en especial Cap. I El rescate histórico del individuo como sujeto de derecho internacional, pp. 19-28.

${ }^{232}$ Como lo fueron los tribunales especiales de Núremberg y Tokio, luego siguieron los Tribunales penales híbridos y hasta llegar a la CPI.

233 Vid. nuevas nociones et al. CARVALHO DE VASCONCELOS, R. (2015). Organizaciones internacionales y tratados asociativos: Por una nueva clasificación de los sujetos de derecho internacional. Revista da secretaria do tribunal permanente de revisão, 3(6), 178-206. Otras múltiples conclusiones en la doctrina afirman el indispensable locus standi para los particulares. TRINDADE y VENTURA consideran que: la personalidad jurídica internacional del ser humano en virtud de la cual es 
completo en la dimensión transnacional, sino que siguen existiendo, por una faz, diferenciaciones lógicas, y por otra, se materializa una concreta carencia ${ }^{234}$. En dicha ausencia de una solución homogénea se distinguen tres situaciones, una muy restrictiva con acceso sólo a los Estados, esta es la más típica, v.gr. ante la CIJ, otra intermedia, donde hay avances pero con limitaciones, v.gr. respecto del TJUE, y la más permisiva, v.gr. ante el TEDH, o ante la CIDH y respecto de la CCJ.

Ahora bien, ingresando únicamente a la dimensión integracionista, observamos que ante el TJUE el locus standi presenta un lúcido desarrollo, aunque no llega a ser absoluto, ya que si bien, se permite el acceso a los particulares, a los Estados y a los órganos e Instituciones de la UE, se genera una restricción que la doctrina ${ }^{235}$ ha venido explicando y clasificando con

titular de derechos inherentes como persona humana emanados directamente del derecho internacional, es indisociable de su capacidad procesal. TRINDADE, A. A. C. \& VENTURA ROBLES, M. E. (2003). El futuro de la corte interamericana de derechos humanos. San José, C. R.: Corte Interamericana de Derechos Humanos; Alto Comisionado de Naciones Unidas para los Refugiados, vid. apartado VI. El fortalecimiento de la capacidad procesal internacional del ser humano bajo la convención americana sobre derechos humanos., pp. 70-78. FERIA TINTA expresa, el individuo ha irrumpido en el sistema de derecho internacional como un sujeto más dentro de él, cristalizándose su rol de sujeto bajo el derecho internacional no sólo como sujeto de derechos (tanto sustantivos como procesales en los diferentes regímenes de petición individual bajo el sistema internacional) sino también como sujeto de deberes. FERIA TINTA, M. (2006). La víctima ante la corte interamericana de derechos humanos a veinticinco años de su funcionamiento. Revista IIDH, (43), 159-203. Y fluyendo hacia las Cortes de integración CARVALHO DE VASCONCELOS y MAIA TAVARES razonan sobre el Mercosur así, conviene reflexionar si habría algún fundamento en excluir a los particulares como sujetos activos de la generación de cuestiones que envuelvan dudas en torno al derecho del Mercosur. Debido a que es el ciudadano el destinatario de la integración, sujeto y titular del derecho internacional. CARVALHO DE VASCONCELOS, R. \& MAIA TAVARES, S. (2014). La competencia consultiva del tribunal permanente de revisión del MERCOSUR: Legitimación y objeto. Revista da secretaria do tribunal permanente de revisão, 2(4), 117-134.

${ }^{234} \mathrm{La}$ falta de acceso de los particulares a los tribunales internacionales BIACCHI lo vincula además con un déficit democrático mitigado, explicando: A pesar de que los fundamentos y presupuestos de la validez del derecho internacional son diferentes de los establecidos en el derecho interno, están cada vez más presente en los ordenamientos jurídicos internos de los Estados. Se trata de una tendencia prevista en muchas constituciones contemporáneas, con el fin de regular temas relevantes y de interés común, como los derechos humanos. De aquí resulta el llamado déficit democrático mitigado del Derecho Internacional, porque los nacionales no poseen el debido acceso a los tribunales internacionales pues les falta el supuesto procesal elemental — capacidad jurídica - para actuar en el foro internacional (excluyendo este autor el caso de las Cortes de Derechos Humanos). BIACCHI GOMES, E. (2014). La democratización del acceso al tribunal permanente de revisión del mercosur a través de las opiniones consultivas. Revista da secretaria do tribunal permanente de revisão, 2(4), 49-63.

${ }^{235}$ Los conceptos de litigantes privilegiados, semi-privilegiados y no privilegiados surgen ante el estudio de precisas acciones o recursos del sistema de la UE. V.gr. para el caso del recurso de anulación del art. 263 del TFUE se introducen importantes diferenciaciones para los que pretendan legitimación activa. Así de su párrafo 2 se entiende que los Estados miembros, el Parlamento Europeo, el Consejo y la Comisión serían litigantes privilegiados. En cambio del párrafo 3 se entiende que el TCUE, al BCE y al Comité de Regiones 180 
las nociones de litigantes privilegiados, semi-privilegiados y no privilegiados, ideas que se extraen de diversas normas discriminatorias, unas de simple naturaleza formal, o si se desea de mero orden, pero otras son cortapisas sustanciales. Como ejemplo del primer tipo, en la UE los Estados miembros, Instituciones y otros órganos son representados ante el TJ por un agente, mientras que las personas por un abogado ${ }^{236}$. En el Estatuto del TJUE se ubica la norma inicial, que le imprime a los Estados miembros y a las Instituciones de la UE el carácter de sujetos procesales preponderantes, idea que según la doctrina ${ }^{237}$ se infiere de dicho Estatuto, cuerpo normativo en el cual no sólo se presenta la recién señalada diferencia entre las partes, sino que además se agregan disposiciones limitantes para terceros bajo el estatus procesal de interviniente coadyuvante, generalizado como «cualquier tipo de persona» ${ }^{238}$. Pero ejemplos del nivel de restricción sustancial, los encontramos en el hecho de que determinados intervinientes deben demostrar interés o perjuicio efectivo, esto es ya un evidente requisito-obstáculo de superior talaje para los potenciales litigantes $^{239}$. Del lado inverso, se presentan otras varias normas que giran ahora a favor de la participación de los particulares, bajo la noción de toda persona natural o jurídica $^{240}$.

serían litigantes semi-privilegiados. Y del párrafo 4 fluiría que los particulares, personas físicas y jurídicas serían litigantes no privilegiados. SARMIENTO RAMÍREZ-ESCUDERO, 2016, pp. 365-366.

${ }^{236}$ Art. 19 del Estatuto del TJUE «Los Estados miembros, así como las instituciones de la Unión, estarán representados ante el TJ por un agente designado para cada asunto; el agente podrá estar asistido por un asesor o un abogado.- Los Estados parte en el Acuerdo sobre el Espacio Económico Europeo, distintos de los Estados miembros, y el Órgano de Vigilancia de la AELC, previsto por dicho Acuerdo, estarán representados de la misma manera.- Las otras partes deberán estar representadas por un abogado».

${ }^{237}$ La diferenciación de clases de sujetos se va dando cada vez que la normativa genera desniveles mediante la imposición de requisitos particulares, así por ejemplo DÍAZ refiriéndose a la representación de los litigantes partiendo del art. 19 del Estatuto del TJUE explica que quedan como partes privilegiadas los Estados miembros y las Instituciones, quienes estarán representadas por Agentes, versus los otros litigantes que serán representadas por un Abogado, a los que — este autor - señala como partes no privilegiadas. DÍAZ ABAD, N. (2012). La defensa jurídica ante el tribunal de justicia de la unión europea. En Beneyto, J. M., Maillo González-Orús, J., Becerril Atienza, B., \& Lenaerts, K., Tratado de derecho y políticas de la unión europea, Tomo V Sistema jurisdiccional de la ue ( $1^{\mathrm{a}}$ ed.). Cizur Menor: Thomson Reuters Aranzadi., p. 198.

${ }^{238}$ Según se indica en los párrafos uno y dos del art. 40 del Estatuto del TJUE «[1] Los Estados miembros y las instituciones de la Unión podrán intervenir como coadyuvantes en los litigios [...]. [2] El mismo derecho tendrán los órganos y organismos de la Unión y cualquier otra persona siempre que puedan demostrar un interés».

${ }^{239}$ Párrafo tres del art. 40 del Estatuto del TJUE «Las personas físicas y jurídicas no podrán intervenir en los asuntos entre los Estados miembros, entre instituciones de la Unión, o entre Estados miembros, por una parte, e instituciones de la Unión, por otra».

${ }^{240}$ Dicho tipo de normas que potencian el locus standi en la UE se encuentran en los arts. 42 y 46 del Estatuto del TJUE y en el 265 del TFUE, este último establece «En caso de que, en violación de los Tratados, el PE, el CE, el Consejo, la Comisión o el BCE se abstuvieren de pronunciarse, los Estados miembros y las demás instituciones de la Unión podrán recurrir al TJ [...] Toda persona física o jurídica podrá recurrir en queja al Tribunal, [...], por no haberle dirigido una de las instituciones, o uno de los órganos u organismos de la Unión 
Este ángulo de análisis final que estamos utilizando aquí - el mayor desarrollo del locus standi en las Cortes latinoamericanas - es de alta trascendencia, toda vez que el principio de igualdad de las partes se ve alterado, produciéndose una anomalía procesal y sustancial en la dimensión internacional, irregularidad que materializa una afectación directa a los contenidos del due process of law. Desde esa perspectiva es notable que en el SICA — en contraste a la UE y también al MERCOSUR - el locus standi goce de un tratamiento bastante preponderante, pues estatutariamente se garantizó en el modelo Centroamericano que siempre estará expedito a la CCJ el acceso de todo tipo de persona ${ }^{241}$. Esto representa una diferencia significativa con la UE, circunstancia que demuestra nuevamente que —al menos en lo Estatutario - el SICA vuelve a apostar por soluciones más modernas, propias y ajustadas a la realidad de Latino América. Empero no solamente ésta, es una cuestión normativa en el SICA, sino que lo eleva a una dimensión esencial, pues además de desarrollarlo en normativas concretas, lo encripta en las Motivaciones del Estatuto de la CCJ, posicionándolo así como noción central ${ }^{242}$, además la doctrina ${ }^{243}$ va resaltando este mejor desarrollo de locus standi ante la CCJ.

En cambio en la CAN, si bien apreciamos una cierta laxitud en materia de locus standi, igualmente el modelo andino adscribe a la opción restrictiva de la UE. La normativa para el acceso al TJCA se encuentra básicamente en el Estatuto del tribunal, y la regla general aborda el tema desde el ángulo de la necesidad, o no, del otorgamiento de representación ${ }^{244}$,

un acto distinto de una recomendación o de un dictamen». Otro ejemplo lo vemos en el Reglamento de Procedimiento del TJ que permiten que personas o empresas adquieran locus standi, según se sigue de su art. 106 el cual remite a los arts. 104 y 105 TCEEA.

${ }^{241}$ El art. 10 del PTC-ODECA bajo su apartado titulado Estructura Institucional, prescribe con toda claridad «Los Órganos e Instituciones del SICA [...] deberán garantizar siempre la publicidad de sus resoluciones y el procedimiento abierto al acceso de las personas».

${ }^{242}$ El Estatuto de la CCJ desde su Exposición de Motivos vuelve a recalcar un locus standi amplio. En el apartado Un Poder Jurisdiccional Para Los Países Centroamericanos, en su párrafo tres, indica «Su competencia se establece como una competencia de atribución [...] y, además, de los conflictos entre los Estados, conocer de los litigios entre las personas naturales o jurídicas». Luego en el apartado Competencia, en su párrafo tres expresa «las disputas surgidas entre las personas naturales o jurídicas y un Estado o con alguno de los Organismos». Finalmente en ritmo de norma de clausura, bajo su apartado Conclusiones, en su párrafo seis estableció «Desde luego también tiene acceso a esta jurisdicción, las personas naturales o jurídicas afectadas en sus derechos, por actos de algunos de los Estados o de los Órganos del SICA».

${ }^{243}$ Por ejemplo GUERRERO enfatiza «este record jurisprudencial no tiene parangón con otros Tribunales Internacionales y "de Integración" y refleja que el "Locus Standi" ante la CCJ, continuará fortaleciendo la institucionalidad del SICA y su Seguridad Jurídica a fin de cristalizar los anhelos unionistas por convertir Centroamérica en una región de Paz, Libertad, Democracia y Desarrollo». GUERRERO MAYORGA, O. (2002). Esfuerzos históricos y perspectivas del locus standi ante la corte centroamericana de justicia. Revista de derecho, (2), 175-188, p. 185.

${ }^{244}$ Art. 39 del Estatuto del TJCA titulado Capacidad para ser parte y comparecer al proceso. 182 
pero luego el sistema en la CAN va resolviendo el locus standi conforme va presentando a cada una de las acciones procesales ${ }^{245}$. Sin embargo, y como ya lo anunciamos, se repite aquí la prueba del interés ${ }^{246}$ que se emplea en la UE. Pero en una línea de equilibrio por otra parte la CAN genera una importante singularidad en comparación a la UE, al SICA y al MERCOSUR, la cual consiste en la construcción normativa que establece una acción de naturaleza impugnativa, otorgando locus standi ante el TJCA para los particulares, previo error de derecho del juez nacional ${ }^{247}$. Es muy notable en la CAN esta incorporación de dicha acción de sustrato impugnativo, toda vez que se condice con una especie de acción de incumplimiento en contra de un tribunal nacional y no de otro órgano, como ocurre en la UE, por tal motivo es que asume la naturaleza procesal impugnativa conectando el nivel nacional con el internacional.

Pero todo lo anterior contrasta profundamente con el umbral del MERCOSUR en materia de locus standi para los particulares, pues esta materia en el merco-sistema es en extremo tímida. Sin embargo, debemos reconocer que se han producido avances concretos, pues en el año 2002 los particulares fueron incluidos como legitimados procesales mediante el POPSCM bajo el concepto de reclamantes particulares, a través de los siguientes dos cauces.

La primera concreción se denomina los reclamos de los particulares ${ }^{248}$, sin embargo se les generan dos importantes obstáculos a esta creación, en primer lugar, se les hace obligatorio concurrir al procedimiento ante el GMC, no así para los Estados miembros, quienes podrían omitirlo $^{249}$, adicionalmente es muy restrictiva la fórmula por la cual los particulares únicamente tienen derecho a solicitar ante sus propios gobiernos para que estos impulsen el proceso, ya que la Sección Nacional puede aprobar o rechazar el iniciar ese trámite, y tan

\footnotetext{
${ }^{245} \mathrm{El}$ art. 45 del Estatuto del TJCA establece en lo pertinente «cuando el demandante sea una persona natural o jurídica». En igual línea la letra b) del art. 47. Se añaden en ritmo permisivo la letra c) del art. 49, la letra b) del art. 57, y los arts. 102 número 3, 108 y 130, todos del Estatuto supra.

${ }^{246}$ En la letra b) del art. 48 del Estatuto del TJCA se establece la carga de probar el interés en los siguientes términos «b) Si el actor es una persona natural o jurídica, las pruebas que demuestren que la Decisión, la Resolución o el Convenio impugnado afecta sus derechos subjetivos o sus intereses legítimos».

247 El art. 128 del Estatuto del TJCA contiene esta acción de sustrato impugnativo en los siguientes términos «Los Países Miembros y los particulares tendrán derecho a acudir ante el Tribunal en ejercicio de la acción de incumplimiento, cuando el juez nacional obligado a realizar la consulta se abstenga de hacerlo, o cuando efectuada ésta, aplique interpretación diferente a la dictada por el Tribunal».

${ }^{248}$ En el Cap. XI del POPSCM titulado Reclamos de particulares, su art. 39 denominado Ámbito de aplicación, indica «El procedimiento [...] se aplicará a los reclamos efectuados por particulares (personas físicas o jurídicas) con motivo de la sanción o aplicación, por cualquiera de los Estados Partes, de medidas [...] de efecto restrictivo, discriminatorias, o de competencia desleal, en violación del Tratado».

249 Número 1 del art. 40 del POSCOM «1. Los particulares afectados formalizaran los reclamos ante la Sección Nacional del GMC del Estado Parte donde tenga su residencia habitual o la sede de sus negocios».
} 
solo si lo acepta, tal vez pueda llegar el asunto del particular ante un TAAM y luego al TPRM, y ya en un punto extremo, se torna muy complejo si el particular se ve afectado por su propio Estado, pues únicamente le restaría acudir a sus propios tribunales locales, en busca de que éstos hagan valer el Derecho mercosureño; y en segundo lugar, se les exige la prueba del perjuicio ${ }^{250}$ en igual ritmo que en la UE y en la CAN, aunque en este esquema, el umbral puede ser previo, es decir, basta la amenaza del perjuicio, no necesariamente un daño consumado.

El segundo cauce por el cual se intentó favorecer la participación de particulares, fue a través del desencadenamiento de opiniones consultivas. Aunque en realidad el POPSCM lo que hizo fue no negar la legitimación de los particulares para impulsar opiniones consultivas, dejando la cuestión regulatoria y la implementación local, en manos de cada Estado mercosureño ${ }^{251}$, lo que ha generado un gran problema pues los países lo permiten o no, usando diferentes criterios para que las partes en un litigio impulsen una opinión consultiva. En la práctica se produce entonces un nuevo escollo de acceso, discriminando al particular, ahora en función de su nacionalidad o residencia. Por lo tanto la solución es débil y hace complejo el ejercicio de este derecho por los particulares, tal como viene destacando la doctrina ${ }^{252}$.

En conclusión, fluye de todo lo visto en este último apartado, que es el SICA el que se encuentra en una mejor posición que el resto de los concurrentes, porque en concreto es el sistema que posee la política más laxa en materia de locus standi, dejando claramente establecida una amplia apertura para todas las personas residentes en los territorios sobre los que ejerce jurisdicción la CCJ, solución que tampoco se detiene en la nacionalidad, sino que avanzó hacia un concepto aún más amplio, el de residente. La CAN en cambio da cuenta de una dicotomía, pues de un lado mantiene la restricción empleada en la UE, con lo cual se distancia de la solución centroamericana, pero de otro lado, genera ius standi de modo amplio incorporando la acción de sustrato impugnativo, lo que además es relevante porque se condice con una especie de acción de incumplimiento dirigida en contra de un tribunal nacional, y no en contra de un órgano de la de la organización. Finalmente el MERCOSUR es el esquema más débil, de hecho no tenía incorporado en nada a los

\footnotetext{
${ }^{250}$ Número 2 del art. 40 del POSCOM «2. Los particulares deberán aportar elementos que permitan determinar la verosimilitud de la violación y la existencia o amenaza de un perjuicio».

${ }^{251}$ Según disponen el art. 3 del POPSCM y los arts. 3 y 4 del Reglamento del POPSCM.

${ }^{252}$ En tal línea CARVALHO DE VASCONCELOS y MAIA TAVARES razonan así, la normativa Mercosur y las reglamentaciones nacionales rigen la materia, problematizando en especial las hipótesis acerca de la legitimación activa de los particulares; la cual no desarrolló una formulación referidas a si las opiniones consultivas debían ser de oficio por los jueces y por las instancias ad quem, o si también podrían ser detonadas por los ciudadanos; únicamente determinó que la solicitud debía ser hecha por los tribunales superiores. CARVALHO DE VASCONCELOS \& MAIA TAVARES, 2014.
} 
particulares, y su tímida reforma legislativa que les permitió el acceso, lo hizo de modo tan restringido - exigiéndoles prueba de un posible perjuicio; obligándolos a recurrir ante su propia Sección Nacional; enfrentándolos a los diversos criterios en cada Estado mercosureño; y si son vulnerados por sus propios países sólo pueden recurrir al juez nacional—, que en definitiva el mecanismo no solo los coarta, sino que además generó un nuevo problema. 


\section{CAPÍTULO III}

EL ROL DE LOS TRIBUNALES DE INTEGRACIÓN LATINOAMERICANOS EN EL MARCO DE LOS PROCESOS REGIONALES A LOS QUE PERTENECEN: UN ANÁLISIS DE SUS JURISPRUDENCIAS INTEGRACIONISTAS 


\section{CAPÍtulo III}

\section{EL ROL DE LOS TRIBUNALES DE INTEGRACIÓN LATINOAMERICANOS EN EL MARCO DE LOS PROCESOS REGIONALES A LOS QUE PERTENECEN: UN ANÁLISIS DE SUS JURISPRUDENCIAS INTEGRACIONISTAS}

\section{INTRODUCCIÓN}

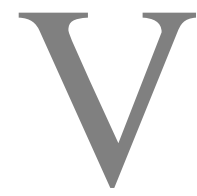

imos en los capítulos anteriores que las organizaciones de integración son una clase de organización internacional a través de las cuales determinados proyectos políticos transnacionales se dotan de una determinada orgánica y se fijan objetivos orientados a lograr el éxito de dichos procesos, los cuales tienden a generar vínculos de alta intensidad entre las naciones partícipes. Estas sui generis organizaciones se ubican en una zona intermedia, no bien definida, entre la cooperación y el federalismo ${ }^{1}$, siendo útiles para optimizar el desarrollo de una región y hacer frente de

\footnotetext{
${ }^{1}$ En las organizaciones de integración se produce una vinculación mucho más intensa que en las OI típicas, convirtiéndose en proyectos de mayor cercanía entre los Estados miembros, mediante el fenómeno del desapoderamiento competencial, a través del cual, ceden el ejercicio de determinadas funciones en favor de la organización. Pero una organización de integración, no busca conformar un Estado Federal, a pesar de algunas similitudes con dicho modelo. La denominación organización de integración — tal como hemos destacado en los capítulos anteriores - encuentra su génesis y apogeo en el modelo, denominado actualmente: Unión Europea, la cual se ha intentado emular en parte y con sendas carencias, por los tres proyectos americanos en estudio. La doctrina se ha venido haciendo cargo de este concepto desde la aparición del fenómeno, SOBRINO se refiere a estas organizaciones denominándolas directamente como «organizaciones de integración o de unificación», diferenciándolas de las OI típicas así «nos encontramos, ante unas Organizaciones que se sitúan entre las Organizaciones Internacionales clásicas y las estructuras Federales», [...] «se basan en las transferencias de competencias soberanas hacia las instituciones». SOBRINO HEREDIA, 2010b, pp. 47-53. RODRÍGUEZ IGLESIAS y LÓPEZ ESCUDERO, señalan que «se ha extendido en la doctrina el uso de la categoría de 'organizaciones internacionales de integración' para explicar a la actual UE». RODRÍGUEZ IGLESIAS \& LÓPEZ ESCUDERO, 2010a, p. 593. PASTOR RIDRUEJO refuerza el concepto señalando «la Unión Europea es el supuesto de cooperación más intenso que existe en la actualidad». PASTOR RIDRUEJO, 2010, pp. 664-667.
} 
mejor manera a los efectos de la globalización. El ejercicio de las funciones de este tipo de organizaciones incide en el quehacer de los Estados miembros y, en esta tesis, estamos observando tal incidencia únicamente a través de la función jurisdiccional, la cual llevan adelante mediante sus singulares Cortes, en carácter de órgano o Institución permanente ${ }^{2}$. Cuestiones que ya analizamos desde el ángulo estatutario, resultando que desde ese punto la Corte Centroamericana de Justicia (CCJ), el Tribunal de Justicia de la Comunidad Andina (TJCA) y los Tribunales Arbitrales ad hoc Mercosur (TAAM) y el Tribunal Permanente de Revisión Mercosur (TPRM), en teoría se observarían similares al modelo europeo, efecto que se produce porque los Estatutos de las Cortes latinoamericanas indicadas —en lo medular - siguen las estructuras normativas de la Unión Europea (UE), en particular de las que afectan al Tribunal de Justicia de la UE (TJUE).

Pero a pesar de la similitud estatutaria, las Cortes latinoamericanas analizadas, difieren notablemente del sistema de la UE, dado las carencias de competencias que ya destacamos en el capítulo II, más, por su bajo grado de influencia efectiva en los procesos nacionales de ajustes a los respectivos esquemas de integración. Dicho de otro modo, del cómo las naciones en América Latina obedecen a los criterios jurisdiccionales de sus Cortes, y del

\footnotetext{
${ }^{2}$ La doctrina ha resaltado la importancia de que existan «órganos permanentes» en los entes supranacionales para poder identificarlos como Organizaciones Internacionales, SANTOS VARA, J. (2002). La participación de la unión europea en las organizaciones internacionales. Madrid: Colex. Intr., vid. en particular apartado 1 Una aproximación a los elementos que identifican a las organizaciones internacionales, pp. 33-34. Otra en PASTOR RIDRUEJO, 2010, pp. 661-669, vid. en particular el apartado 69 El concepto de organización internacional. Entre estos órganos permanentes, encontramos al órgano jurisdiccional, tanto en las OI como en las organizaciones de integración, ejemplo del primer caso lo es la Corte Internacional de Justicia (CIJ), vid. CARTA DE NACIONES UNIDAS, Capítulo XIV, La Corte Internacional de Justicia, artículo (art.) 92 «La CIJ será el órgano judicial principal de las $N U$ », ejemplos del segundo caso lo son los tribunales estudiados en esta tesis (TJUE, CCJ, TJCA y TPRM). Además las Cortes pertenecientes a las OI y a las de integración, van siendo calificadas tanto de: Instituciones, de Órganos, e incluso en ocasiones la misma Corte es una Organización Internacional en sí misma, como el caso tan singular de la Corte Penal Internacional (CPI) que durante su gestación se discutió si sería un órgano de NU o una OI en sí misma, optándose por la última idea, pero con un matiz de conexión con el auspiciador (NU) a través de un Acuerdo de cooperación, mandato establecido en el art. 2 del Estatuto de Roma para la CPI, Relación de la Corte con las NU: «La Corte estará vinculada con las NU por un acuerdo que deberá aprobar la Asamblea de los Estados Partes en el presente Estatuto y concluir luego el Presidente de la Corte en nombre de ésta». Dicho documento es el Acuerdo de Relación entre la CPI y las NU, depositado en la CPI como: Documento ICC-ASP/3/25, Parte III, resolución ICC-ASP/3/Res.1, anexo; y en ONU con la nomenclatura: A/58/874, Relationship agreement between the United Nations and the International Criminal Court, vigente de octubre 2004. En la UE el TJUE pasa a ser parte de las denominadas Instituciones según el art. 13.1 del TUE el cual lista las siete Instituciones. En cambio en América, v.gr. la CCJ se identifica como un Órgano permanente del SICA según el inciso $2^{\circ}$ de art. 1 del Estatuto de la CCJ en relación al art. 12 del Protocolo de Tegucigalpa (PT) a la Carta de ODECA. El TPRM es sólo un Órgano de convocatoria permanente según el art. 19 del Protocolo de Olivos para la Solución de Controversias Mercosur (POPSCM).
}

190 
cómo los ciudadanos puedan verse afectados por las consecuencias de dicha labor jurisdiccional. Cuestiones que en derecho conocemos como el auctoritas del tribunal.

Por tales razones ingresaremos al análisis de la producción jurisprudencial de la CCJ, del TJCA y de los TAAM y TPRM enfocándonos en el rol y valoración de tales Cortes latinoamericanas en sus propios procesos regionales. Para lo anterior atenderemos a aquellas sentencias que aborden y resuelvan aspectos y principios claves de un verdadero sistema de integración, para lo cual tomaremos como referente inexcusable la jurisprudencia del TJUE. Luego en el capítulo IV analizaremos cómo, determinadas respuestas de estas Cortes latinoamericanas se construyeron recurriendo al diálogo judicial, básicamente extrayendo soluciones del TJUE.

El complejo marco de la jurisprudencia integracionista se inserta en el contexto general de cada proyecto regional de integración. Desde ese punto se aprecia que la función legislativa tiende a ir un tanto rezagada respecto de la realidad social. Aquí estamos empleando un concepto amplio para legislador, abarcando de este modo al creador originario, como lo son los Estados a través de los Tratados fundacionales u otros, y a los órganos o Instituciones que crean derecho derivativo, que en el caso de la UE lo son el Consejo más el PE.

Lo central que destacamos es que las construcciones jurídicas son per se estáticas, como todo derecho material. Lo que contrasta con la esencia dinámica de un proceso de integración. Desfase que de tanto en tanto, se nivela - en parte - mediante la labor jurisprudencial de las Cortes, y por cierto a través de la actividad legislativa, que es lo propio. Presentándose en muchas oportunidades la singularidad de que un determinado tema, que fue solucionado primero por medio de la labor jurisdiccional, después el legislador se hace cargo de la situación y la positiviza ${ }^{3}$, por ejemplo y entre varias, está el caso de la creación del concepto de mercado común que previamente construye el TJ y que más tarde se positiviza ${ }^{4}$, o como sucedió en materia de derechos humanos que previamente fue el TJ quien le dio el respaldo necesario en la dimensión jurisdiccional y solo posteriormente el legislador lo positivizó ${ }^{5}$.

\footnotetext{
${ }^{3}$ En dicha línea y además en el contexto de un proceso de integración, LIÑÁN expresa «No es extraordinario, así, que alguno de los principios formulados por el TJ en este contexto hayan después pasado, por decisión de los Estados miembros, a las normas constitutivas para formar parte de aquella primera categoría». LIÑÁN NOGUERAS, 2014e, p. 370.

${ }^{4}$ Este ejemplo del desfase se refiere al caso de la construcción del concepto de mercado común, fue el TJ el que primero la crea y después se positiviza en el Acta Única Europea (AUE) tal como lo veremos más adelante.

${ }^{5}$ Otro ejemplo del desfase destacado se refiere a la protección de los derechos humanos en la dimensión jurisdiccional, pues resultó que sin normativas expresas el TJ debió enfrentar esta sensible temática en el proyecto europeo, lo cual hizo mediante su conocido triple fundamento, en una secuencia de fallos (Sentencia del TJ de 12 de noviembre de 1969, Stauder c/ Stadt Ulm - Sozialamt, as. C-29/69, ECLI:EU:C:1969:57,
} 
Lo que destacamos es que este desfase, como fenómeno propio de todo sistema Estatal, se acentúa en uno integracionista debido a las peculiaridades del Derecho de la Integración ${ }^{6}$, entre las cuales destaca el hecho de que, tal como se ha observado para el Derecho de la UE, éste se encuentra en constante formación y adecuación a la realidad de cada época por la que va transitando el proyecto europeo, por tal motivo ha sido considerado como un derecho incompleto, evolutivo y heteronormativo, según precisa y explica la doctrina ${ }^{7}$, y también se alinean los criterios jurisprudenciales latinoamericanos, así por ejemplo en República Argentina c/ República Federativa de Brasil ${ }^{8}$ la misma idea de incompleto o inacabado lo resaltan las Cortes del Mercosur al expresar:

Sentencia del TJ de 17 de diciembre de 1970, Internationale Handelsgesellschaft mbH c/ Einfuhr - und Vorratsstelle für Getreide und Futtermittel, as. C-11/70, ECLI:EU:C:1970:114, y Sentencia del TJ de 14 de mayo de 1974, Nold, Kohlen - und Baustoffgroßhandlung c/ Comisión de las CE, as. C-4/73, ECLI:EU:C:1974:51) en los que básicamente reconoció que los derechos fundamentales forman parte del proyecto de integración europeo en calidad de principios generales del derecho. Pero mucho más tarde el legislador se haría cargo de esto, primero, por el Tratado de Amsterdam (vigor, 1999) el que le reconoció competencias al TJUE en materia de derechos humanos (MANGAS, 2014a, p. 40) y luego sería superado con más detalles gracias al Tratado de Lisboa 2007 (LIÑÁN, 2014a, p. 124).

${ }^{6}$ En esta tesis — como ya indicamos y justificamos en nuestro planteamiento y marco teórico que incluimos en la introducción - estamos empleando un concepto amplio para el Derecho de la integración, y acotado para Derecho de la UE, Derecho del SICA, Derecho de la CAN y Derecho del MERCOSUR. Además, en los proyectos latinoamericanos de las Cortes en estudio, se emplea la noción de Derecho de la Integración como un genérico que coincide en su totalidad con el Derecho de la UE, pues los esquemas latinoamericanos se miden y se evalúan respecto de dicho referente europeo, en un exacto sentido de pauta a seguir. Hay varios ejemplos de esta situación, et al. vid. Sección: Resuelve: Primero, párrafo: Décimo Punto — segunda parte(p. 5), en CCJ, Sentencia de 5.8.1997, expediente 13-02-01-05-1997, punto donde la CCJ lingüísticamente diferencia entre Derecho de Integración v/s Derecho Comunitario Centroamericano «En el Derecho de Integración y Comunitario Centroamericano».

${ }^{7}$ Como los proyectos latinoamericanos enfocados intentan aproximarse a un modelo de derecho que no es de creación propia, sino recepcionado desde el esquema de la UE, asumen las críticas y cualidades que se le hacen al Derecho de la UE y las analizan para sus realidades locales. En tal sentido, entre los múltiples ángulos el derecho de la integración —en sentido amplio para los latinoamericanos, y concreto para los europeos en cuanto Derecho de la UE - presenta una realidad dicotómica, ya que, por una parte diagnostica sus características fácticas, y por otra, desarrolla sus aspiraciones u objetivos. Entonces: A) por un extremo se analiza y perfila empíricamente, por esto, y por ejemplo LIÑÁN refiere las mencionadas tres características -incompleto, evolutivo y heteronormativo - en cuanto éstas reflejan el carácter de proceso en que se encuentra inmerso este tipo de derecho. LIÑÁN NOGUERAS, 2014e, p. 370. B) Del otro lado encontramos el objetivo de llegar a conformar un derecho único, uniforme y homogéneo. Sobre este objetivo se alinea el criterio del TJCA al expresar «se haría imposible la existencia de un derecho comunitario único, uniforme y homogéneo» frase final del párrafo cuarto, del apartado 6 en TJCA, Sentencia de 25-5-1988, Interpretación prejudicial, Germán y Ernesto Cavelier, consulta de la Corte Suprema de Justicia de la República de Colombia, as. 2-IP-88. GOAC 33 de 1988.

${ }^{8}$ Laudo del TAAM de 28 de abril de 1999, República Argentina c. República Federativa de Brasil, as. 1/1999. 
«Es que no se trata de 'un derecho acabado' al decir de Lecourt, sino de un proceso dinámico, dentro de una realidad en cambio»? ${ }^{9}$

Esas tres características indicadas en el párrafo anterior, que como recién anotamos resalta la doctrina y la jurisprudencia, identifican a un proceso de integración en su dimensión fáctica. Como contrapartida, uno de los lógicos objetivos jurídicos de la integración es superar la triada anterior, por lo que se intenta construir un derecho único, uniforme y homogéneo, según ha explicado con toda claridad el TJCA en el caso Germán y Ernesto Cavelier, consulta de la Corte Suprema de Justicia de la República de Colombia ${ }^{10}$ ocasión en que razonando sobre el objetivo de un derecho de la integración pleno, expresó en su sentencia que de existir normas nacionales sustantivas contrapuestas a las comunitarias:

«...se haría imposible la existencia de un derecho comunitario único, uniforme y homogéneo» ${ }^{11}$.

En igual cauce insiste la Corte andina, quien apoyándose en criterios europeos, deja a la vista su criterio en cuanto se aspira a conseguir imprimirle un carácter común y uniforme a este tipo de derecho. Cuestión que el TJCA explica de la siguiente forma:

«Se estableció así un régimen común y uniforme, de especial significación dentro del proyecto integracionista, cuyas características principales, en cuanto ordenamiento comunitario, son las de constituir una regulación autónoma, coercitiva, de efecto directo y que constituye un derecho único para toda la Subregión, que ha de aplicarse en toda ella de manera homogénea y que ha de prevalecer por lo tanto, en todo caso, sobre el derecho nacional» ${ }^{12}$.

Como se aprecia entonces, la jurisprudencia integracionista, partiendo de una realidad que reconoce al derecho de la integración como incompleto, evolutivo y heteronormativo, intenta hacer progresar esas tres aristas orientándose a lograr un derecho de la integración único, uniforme y homogéneo. De hecho esta es la razón por la cual el trabajo del TJUE se ha orientado por ejemplo, a la unidad jurídica, construyendo grandes conceptos como la aplicabilidad directa, la supremacía y varios más que veremos. En definitiva se ha ido allanando la diversidad local en pos de un proyecto común, cuestión que también se observa y se razona al otro lado del Atlántico por las Cortes de los proyectos de integración en América Latina, como lo analizaremos en el presente capítulo.

En esta tesis intentamos demostrar que el logro del objetivo recién explicado en los dos párrafos anteriores, corresponde en gran medida al rol del tribunal de integración - aunque

\footnotetext{
${ }^{9}$ Párrafo 57 en laudo ibídem.

10 Sentencia del TJCA de 25 de mayo de 1988, Interpretación prejudicial, Germán y Ernesto Cavelier, consulta de la Corte Suprema de Justicia de la República de Colombia, as. 2-IP-88. GOAC N 33 de 1988.

${ }^{11}$ Párrafo cuarto del apartado 6. La norma nacional acusada y la decisión 85, en sentencia ibídem.

${ }^{12}$ Párrafo segundo del apartado 4 en sentencia ibídem.
} 
también le compete a otros participes, como el resto de los órganos e Instituciones, los Estados miembros, etcétera - y tal rol, no puede ser otro para estos singulares tribunales bajo análisis, que actuar como un constante motor de avance para la madurez del proyecto de integración, a través de la única forma que les compete, la producción de jurisprudencia integracionista — motivo del presente capítulo.

Dicho tipo de jurisprudencia intentará nivelar de forma más rápida que el legislador, los desfases entre las carencias normativas y la realidad regional. Generando conceptos y principios que fortificarán el proceso de integración, aportando así, al acervo jurídico del respectivo proyecto. Entonces el motivo de nuestra exploración y análisis, es identificar en las Cortes latinoamericanas enfocadas, sentencias que puedan establecer un nuevo modelo interpretativo de alguna norma, o establecer un modo más sofisticado para comprender el alcance de un concepto o crear uno nuevo. De tal modo, que impulsen el avance de todo el proyecto socio-político hacia un nivel más maduro.

La jurisprudencia integracionista es mucho más compleja que la jurisprudencia de un típico tribunal nacional o internacional. Esto se debe a que en su totalidad conlleva dos grandes funciones, de un lado resuelve los contenciosos y de otro interpreta el derecho del grupo de la UE, o del SICA, de la CAN o del MERCOSUR - responde consultas, construye soluciones jurídicas muchas veces mediante nuevos principios o reacomodando los anteriores, e incluso llega a posicionarse en una dimensión constitucional. Competencias que en el nivel nacional se resuelven por dos órganos diferentes — tribunales ordinarios, para el primero, y constitucionales para el segundo. Ambas funciones dan cuenta de un equilibrio dual de la Corte de integración, que evidencian un fenómeno de alta densidad competencial. Dicha circunstancia es identificable en el TJUE, pues por una cara interpreta el nuevo ordenamiento creado entre los Estados miembros, con todos los extremos que ya hemos destacado en el capítulo II, y por otra parte, resuelve contenciosos ${ }^{13}$.

Simultáneo a esa doble funcionalidad general, la jurisprudencia expansiva conlleva una triple dimensión, primero, puede tener una naturaleza de fuente jurídica, a través de sentencias de carácter constitutivas, segundo, o bien podrá ser reorientadora, v.gr. la Corte puede reconducirnos a una ampliación de un determinado concepto, el cual pasa a modificarse, esto por medio de sentencias de carácter declarativas o constitutivas o con dosis de ambas; o, en tercer lugar, puede ser sólo reconocedora de costumbres, normas, principios y valores, por ejemplo reconociendo que determinado sujeto tiene una específica

\footnotetext{
${ }^{13}$ Este equilibrio, o dicotomía, que hemos anotado, es identificable en nuestro modelo jurisdiccional europeo, cuestión resaltada por la doctrina. SARMIENTO subraya que el Poder Judicial de la UE desempeña una labor crucial en la salvaguarda de la efectividad del Derecho de la Unión, pues por un lado ofrece pautas autorizadas de interpretación de dicho ordenamiento [...] y, por otro lado, resuelve individualmente los pleitos que se plantean en el día a día. SARMIENTO RAMÍREZ-ESCUDERO, 2016, p. 357.
} 
condición desde hace mucho tiempo atrás, recurriendo a sentencias de carácter declarativas. Estos aspectos conforman lo que ha sido considerado por las fuentes clásicas del derecho procesal como uno de los problemas fundamentales de las sentencias, según explica Couture, quien medita profundamente sobre este aspecto, cuestionándose en definitiva lo siguiente:

«Si la jurisdicción y la sentencia son actividades meramente declarativas de derecho o si son funciones de carácter creativo y productor de nuevas normas jurídicas ${ }^{14}$.

Precisamente este es uno de los puntos centrales que nos impactan de modo rotundo en todos los análisis que componen esta tesis doctoral, toda vez que nosotros estamos analizando la forma en que las Cortes de los procesos de integración latinoamericanos hacen sus aportes a los esquemas de integración sub-regional a que pertenecen, ejercicio que en definitiva implica que esos criterios se incorporan al bloque de legalidad.

Empezaremos por posicionar resumidamente a nuestro referente el TJUE, sin entrar en extensos detalles pues éste no es nuestro objeto de estudio, sino los tribunales latinoamericanos, pero sería inexcusable no referirnos a la Corte de Luxemburgo en los

${ }^{14}$ En esta tesis el rol de las sentencias es central, pues representan el modo o la forma concreta en que las Cortes hacen sus aportes al proceso de integración, y dichas construcciones jurisdiccionales deben pasar a formar parte del acervo jurídico de cada proyecto regional. Pero la naturaleza o modalidad en que lo efectúan ha sido discutido por la doctrina desde un ángulo general y para cualquier ordenamiento. Para COUTURE este tema es uno de los problemas fundamentales al valorar sentencias, en atención a que la principal distinción que se hace de los fallos, diferencia entre sentencias declarativas, constitutivas o de condena. COUTURE explica entonces que «es necesario determinar qué significación tiene la sentencia dentro del sistema jurídico. Se trata de saber si se está en presencia de una pura actuación o aplicación de la ley al caso decidido, o. si, por el contrario, la sentencia es una nueva norma que nace en el sistema jurídico, distinta de la ley en su esencia y en su contenido. En otros términos, si la jurisdicción y la sentencia son actividades meramente declarativas de derecho o si son funciones de carácter creativo y productor de nuevas normas jurídicas». COUTURE, E. J. (1958). Fundamentos del derecho procesal civil ( $3^{\text {a }}$ Ed. póstuma), Buenos Aires: De Palma., p. 304, vid. B) La sentencia y el derecho. Lo habitual es que exista una dosis de cada noción declarativas, constitutivas o de condena - en cada sentencia. Para nuestro interés, el orden que utilizamos sigue así, $1^{\circ}$ ) Reconocemos el tipo de función general de la Corte ya sea, i) disolviendo el contencioso o, ii) interpretando el derecho del grupo, al caso el Derecho de la de la UE, o del SICA, de la CAN o del MERCOSUR, respondiendo consultas, e incluso pudiendo adoptar una dimensión constitucional. $2^{\circ}$ ) Luego la sentencia podrá ser declarativa, constitutiva o, de condena, y $3^{\circ}$ ) Finalmente su naturaleza se presenta por tres cauces o dimensiones: i) puede tener una naturaleza de fuente jurídica — a través sentencias constitutivas - o bien, ii) podrá ser re-orientadora — a través sentencias declarativas o constitutivas o con dosis de ambas-o, iii) puede ser sólo reconocedora de costumbres, normas, principios y valores —a través sentencias declarativas. Por ejemplo ya vimos en el capítulo anterior las críticas que la doctrina hacía al hecho de que la sentencia del TJUE en el recurso por omisión sea meramente declarativa. VILLAMOR destacaba que tal cualidad procesal de la sentencia del TJUE disminuye la efectividad del recurso por omisión, pues, no necesariamente se obtendrá de inmediato el resultado material final esperado, debiendo deducir después un recurso de nulidad. VILLAMOR MORGAN-EVANS, 2001. 
aspectos que nos atañen. Hecho lo anterior, abordaremos a la CCJ, el TJCA y el TPRM ${ }^{15}$ en relación a sus organizaciones de pertenencia, el SICA, la CAN y el MERCOSUR respectivamente.

\section{LA JURISPRUDENCIA DEL TRIBUNAL DE JUSTICIA DE LA UNIÓN EUROPEA COMO MODELO DE REFERENCIA EN AMÉRICA LATINA}

La Corte de Luxemburgo ha producido un amplio campo de jurisprudencia integracionista contribuyendo con esto al proceso global de la integración europea, cuestión reconocida y valorada constantemente por la mayoría de la doctrina ${ }^{16}$. En tal sentido el TJUE ha efectuado construcciones ya clásicas para Europa, todas muy bien conocidas y perfectamente estudiadas en el concierto europeo, tanto es así, que en la actualidad dichas sentencias no reportan novedad alguna al interior de Europa. Sin embargo, para el análisis comparativo que haremos con las Cortes de los procesos de integración de América Latina, nacidos históricamente con bastante posterioridad al esquema europeo, nos reportan la

15 Retengamos que enfrentaremos —orgánicamente- construcciones jurisdiccionales complejas y otras simples. En esta perspectiva, en la UE y en el MERCOSUR se desarrollaron modelos complejos, pues presentan estructuras jerárquicas instanciales y casacionales entre sus Cortes. El art. 19.1 del TUE muestra la composición estructural del modelo europeo bajo la siguiente fórmula «El Tribunal de Justicia de la Unión Europea comprenderá el Tribunal de Justicia, el Tribunal General y los tribunales especializados». En el MERCOSUR, según el art. 17 del POPSCM, puede recurrirse de un laudo de un TAAM al TPRM. Estas circunstancias orgánicas y procesales recursivas no pueden confundirse con la especial vinculación de los tribunales de integración con los tribunales nacionales, entre los cuales la conexión es dual, por una parte colaborativa y por otra, de competencias secundarias (no instanciales). SARMIENTO refiriéndose a la UE señala que, el Poder Judicial de la Unión, como en todo sistema político basado en el reparto de competencias, precisa de una estructura en dos niveles, por un lado los Tribunales de la Unión, y por otro los Tribunales de los Estados miembros, signándolo de «Poder Judicial Híbrido»; explicando que, «a diferencia de los sistemas judiciales federales, no existen vías procesales que unan el nivel jurisdiccional de la Unión con el nivel nacional. Por tanto las resoluciones judiciales nacionales no pueden ser recurridas ante los Tribunales de la Unión, pues no existe un recurso específico que lo permita». SARMIENTO RAMÍREZESCUDERO, 2016, p. 360. En cambio en el SICA y la CAN sus sistemas jurisdiccionales son simples, pues sólo lo conforman una corte: la CCJ en el primer caso, y el TJCA para el segundo.

${ }^{16}$ La alta valoración del TJUE es un hecho en que converge casi toda la doctrina, en esta línea RODRÍGUEZ IGLESIAS, LIÑÁN NOGUERAS, ZAPATER DUQUE, IGLESIAS BUHIGUES, entre otros. Para RODRÍGUEZ el TJ ha venido a ser una pieza esencial de la construcción europea. RODRÍGUEZ IGLESIAS, LIÑÁN NOGUERAS \& ABELLÁN HONRUBIA, 1993, p. 647. LIÑÁN resalta que este tribunal, ha contribuido con su jurisprudencia a la consolidación del sistema de control jurisdiccional de la UE. LIÑÁN NOGUERAS, 2014d, p. 448. Para ZAPATER el TJ ha desempeñado una función determinante en el desarrollo de una integración jurídica y en la defensa del cumplimiento de los objetivos. ZAPATER DUQUE, 2005a, p. 101. A IGLESIAS BUHIGUES no le cabe duda de que la aportación del TJ a la causa de la integración europea por medio de su jurisprudencia coadyuvante a la realización de los objetivos de la Unión, es verdaderamente relevante y significativa. IGLESIAS BUHIGUES, 2013, p. 30.

196 
máxima utilidad aquellos clásicos fallos de la Corte de Luxemburgo pues las Cortes latinoamericanas bajo análisis las utilizan hasta estos días como referencias concretas.

Adicionalmente al mantener dichas sentencias del TJUE como referencia, podremos medir los desarrollos jurisprudenciales de la CCJ, del TJCA y del TPRM y los TAAM, precisamente respecto de las mismas temáticas que, ex profeso hemos seleccionado para lograr la conexión de criterios jurisprudenciales a ambos lados del Atlántico, pudiendo sólo entonces, comprobar las cercanías o distancias de las Cortes de Latino América con la Corte de Luxemburgo.

La selección que hemos llevado adelante, tras testear la multiplicidad de materias de que conocen este tipo de tribunales latinoamericanos, y que además cumplan con la exigencia de poseer su correlato en la base jurisprudencial del TJUE, se compone de nueve bloques temáticos muy concretos, todos los cuales siguen un criterio netamente utilitario para el cotejo jurídico anunciado.

\section{LOS NUEVE BLOQUES TEMÁTICOS QUE ABORDAN LAS JURISPRUDENCIAS} DE LAS CORTES LATINOAMERICANAS QUE FUERON CREADOS POR EL TJUE

Tanto en el presente capítulo como en el siguiente, analizaremos diversas jurisprudencias de las Cortes latinoamericanas en que estamos enfocados. En dicho ejercicio advertiremos que hay determinada coincidencia en nueve grandes temas, los cuales han sido solucionados previamente por creaciones del TJUE. En el presente capítulo veremos algunas de estas conexiones destacando directamente jurisprudencia integracionista emanada de la CCJ, del TJCA y de los TAAM y TPRM, mientras que en el capítulo siguiente, continuaremos observando estas materias, pero mediante el uso del diálogo judicial.

Los nueve grupos temáticos que hemos seleccionado, a partir de las creaciones del TJUE, y que usaremos para el trabajo comparativo que efectuaremos en este y en el siguiente capítulo, son los siguientes: 1) el efecto directo y la primacía del Derecho de la UE, 2) el principio de la responsabilidad patrimonial de los Estados miembros y, de la UE misma, por violación al Derecho de la UE, y al subsecuente derecho a ser indemnizado, 3) el principio de proporcionalidad, 4) el principio de la igualdad de los Estados miembros, 5) el principio de la aplicación uniforme del Derecho de la UE, 6) la contribución al desarrollo del mercado común, 7) el principio de la no discriminación por razón de la nacionalidad en 
materias económicas, 8) la libre circulación, y la influencia para el principio de la igualdad de trato, y 9) la precisión del principio de no discriminación, en su ampliación y restricción.

De modo simultáneo, en este análisis se conectan con intensidad los dos cauces centrales por los que nos vamos movilizando, uno el sustantivo, asumido aquí por el derecho de la integración más el derecho internacional, y otro adjetivo, el derecho procesal básicamente en su dimensión internacional. En tal dicotómico avance, lo primero fue establecer los nueve bloques temáticos recién acotados, pero en segundo lugar, debemos mantener presente que desde el punto de vista procesal, dichos nueve temas sustantivos - los cuales son propios del derecho de la integración-, se concretan a través de alguna de las tres clases de sentencias ya explicadas, esto es, variando entre sentencias del tipo declarativas, o bien constitutivas o de condena, más todas sus posibles mezclas ${ }^{17}$.

En el orden metodológico reconoceremos el tipo de función general que esté desplegando la Corte en cada caso, ya sea disolviendo el contencioso, o interpretando el Derecho de la de la UE, o del SICA, o de la CAN, o del MERCOSUR según corresponda, respondiendo consultas, e incluso pudiendo adoptar una dimensión constitucional. Al hilo de lo anterior, la sentencia podrá ser de tipo declarativa, constitutiva o de condena. Finalmente advertiremos la naturaleza de la sentencia en cuanto ésta orbite en carácter de fuente jurídica - a través sentencias constitutivas - o bien, podrá ser reorientadora — a través sentencias declarativas o constitutivas, o con dosis de ambas - o puede ser sólo reconocedora de costumbres, normas, principios y valores - a través sentencias declarativas.

Retengamos entonces que los principios y normas contenidos en las sentencias que analizaremos en el presente y en el siguiente capítulo, no se desarrollan en compartimentos estancos, sino que en muchas ocasiones se presentan simultáneamente variados principios y criterios en cada una de ellas, por tal motivo, en cada caso destacaremos el tema central que corresponda. Además tengamos presente que las sentencias del TJUE a las que hacen referencia la CCJ, el TJCA, los TAAM y el TPRM, corresponden a sentencias clásicas e históricas de la Corte de Luxemburgo, todas ya muy bien conocidas aquí en Europa, pero que en Latino América han sido, y continúan siendo, de alta recurrencia, tal como lo analizaremos en detalle a continuación.

\footnotetext{
${ }^{17}$ Vid. nota 14 de este capítulo. COUTURE, 1958, p. 304, vid. B) La sentencia y el derecho. 198
} 


\section{LA JURISPRUDENCIA INTEGRACIONISTA DE LAS CORTES CREADAS}

EN LOS PROCESOS DE INTEGRACIÓN REGIONAL

EN AMÉRICA LATINA

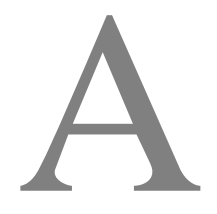

1 posicionarnos desde América Latina la circunstancia fáctica de ir a la zaga de la UE queda en evidencia tan solo con observar las temáticas abordadas por la CCJ, el TJCA y el TPRM, sobre todo al detenernos en el análisis de la manera en que dichas Cortes latinoamericanas lo hacen. En tal ejercicio hay un aparente parecido en las construcciones jurisprudenciales desarrolladas a ambos lados del Atlántico, aunque se aprecian algunas pocas soluciones jurisdiccionales propiamente latinoamericanas. Este último signo de singularidad se acrecienta, al añadirle las particularidades estatutarias, también propias de América Latina que ya vimos en el capítulo II.

Aquí nos enfocaremos en aquellas aportaciones de la CCJ, el TJCA y el TPRM que han favorecido el robustecimiento de sus respectivos esquemas de integración, SICA, CAN y MERCOSUR. Teniendo presente que, a pesar de que la labor jurisprudencial latinoamericana se genera en menor medida que en Europa, igualmente observaremos que circula por las tres dimensiones que en general cubren este tipo de sentencias, que como ya explicamos operan como fuente de derecho, o bien re-orientan algunas nociones y criterios jurídicos, y otras reconocen derechos, todo esto, mediante sentencias de naturalezas declarativas o constitutivas, según corresponda ${ }^{18}$.

Para el ejercicio anunciado en el párrafo precedente, hemos seleccionado de cada una de las Cortes latinoamericanas, sentencias que se encuadran con alguno de los nueve bloques temáticos escogidos desde el TJUE y que acabamos de terminar de presentar en el apartado anterior. Ahora bien, no todas las Cortes latinoamericanas poseen jurisprudencias en la totalidad de las nueve temáticas, pero en su conjunto — la CCJ, el TJCA y el TPRM- sí lo cubren por completo. Es decir, puede acontecer por ejemplo que la CCJ toque cuatro de los nueve temas, y luego el TJCA repita algunos y toque otros más, etcétera. Además advertimos desde ya, que en América Latina se utiliza en muchas ocasiones el concepto de derecho comunitario como sinónimo de derecho de la integración, aunque en la mayoría de los casos hay precisión al respecto, conforme iremos apreciando. Todo lo cual analizaremos ordenadamente a continuación.

\footnotetext{
${ }^{18}$ Ídem.
} 


\subsection{LA PRODUCCIÓN DE JURISPRUDENCIA INTEGRACIONISTA DE LA} Corte Centroamericana de Justicia

Durante el período moderno de la CCJ (Estatuto de 1992) esta Corte ha ido dejando a la vista la notoria influencia del TJUE, aunque también la CCJ ha construido su propio camino en el cual incluso va citando ${ }^{19}$ a la antigua Corte de Cartago. Todo esto ha hecho posible que se haya ido moldeando fuertemente hacia el Derecho de la integración considerado en su sentido amplio, sin abandonar la cultura jurídica propia del istmo centroamericano, logrando importantes aportaciones jurisprudenciales y respondiendo así a su actual carácter de un tribunal de aspiraciones integracionistas. Dicho nuevo enfoque de la Corte centroamericana - considerando sus antiguos antecedentes, 1907- es lo que la doctrina ${ }^{20}$ especializada en el estudio histórico de esa sub-región viene destacando.

Pues bien, para el siguiente análisis hemos efectuado una selección de sentencias de la CCJ que se encuadran en algunas de las dimensiones de las nueve temáticas que ya vimos para el caso de la Corte de Luxemburgo, y que consideramos representan las principales aportaciones de la Corte centroamericana en favor del SICA, las cuales ahora pasamos a presentar en tres bloques temáticos: el primero abarca jurisprudencia de la CCJ referida a la jerarquía, vigencia, reforma y derogación del derecho interno, del internacional y del comunitario; en el segundo bloque analizaremos jurisprudencia de la CCJ referida al desapoderamiento competencial, al principio de atribución de competencias, al concepto de comunidad y a la responsabilidad que todo aquello implica; por último, en el tercer bloque, analizaremos jurisprudencia de esta Corte, referida al concepto de desarrollo progresivo del proceso de integración centroamericano.

${ }^{19}$ Por ejemplo puede verse el CONSIDERANDO (II) en la Sentencia de la CCJ de 29 de marzo de 2005, Poder Ejecutivo de Nicaragua c. Asamblea Nacional de Nicaragua, expediente 69-01-03-01-2005.

${ }^{20}$ Entre éstos ARAYA, CANO y RIPLEY. Esta Corte transitó desde una naturaleza jurisdiccional típica, hacia una de integración, dicho desplazamiento es fruto del más extenso proceso histórico de la Jurisdicción Internacional, comenzado en 1907 con el nombre de Tribunal de Justicia Centroamericano, o Corte de Cartago, remitiéndonos en todos los detalles cronológicos al capítulo I sobre análisis histórico. RIPLEY, C. (2018). The central american court of justice (1907-1918): rethinking the word's first court. Diálogos: Revista electronica de historia, 19(1), 47-68. Otra, ARAYA, 1992. En su «nueva etapa» como CCJ, apreciamos que, si bien, ha desarrollado creaciones jurisdiccionales propias y ha recepcionado el acervo histórico señalado, efectivamente se ve muy influenciada por el TJUE. CANO lo destaca así, la CCJ tomando como referente la jurisprudencia del TJUE ha hecho trascendentales aportaciones jurisprudenciales como tribunal de integración. CANO LINARES, 2009, pp. 129-132.

200 


\subsubsection{LA JURISPRUDENCIA DE LA CCJ}

RELACIONADA A LA JERARQUÍA Y VIGENCIA DEL

En la sentencia de la causa Rodas Melgar, Secretario General de la SIECA ${ }^{21}$, la CCJ presenta las ideas centrales de los mismos principios que previamente desarrolló en Europa el TJ en los casos Van Gend \& Loss $^{22}$ y Costa/Enel ${ }^{23}$, oportunidad en que el TJ declaró tanto el efecto directo del Derecho de la Unión, como su primacía, y en parte los del caso Neumann $^{24}$ donde abordó el principio de la aplicación uniforme del Derecho de la integración. Es decir, que de entre los bloques temáticos que definimos en el apartado tres de este capítulo, en este caso concreto, se observa en determinada medida el tema uno, sobre el efecto directo y la primacía del Derecho de la UE, y en una dosis menor el tema cinco, referido al principio de la aplicación uniforme del Derecho de la UE, los cuales ahora veremos en la jurisprudencia de la CCJ aplicados, en parte, al ordenamiento jurídico del SICA.

El primer tema, como es bien sabido, proviene de la construcción del TJ en Van Gend \& Loss y Costa/Enel, pero aquí, comparativamente con América Latina, contrasta el hecho de que esas tempranas soluciones europeas, se discutan décadas después en el nuevo continente. En Van Gend \& Loss el TJ confirmó que los Estados han reconocido al Derecho Comunitario una eficacia susceptible de ser invocada por los ciudadanos ${ }^{25}$, y además pasó a asentar que la Comunidad conformaba un nuevo ordenamiento jurídico de derecho internacional, a favor del cual los Estados miembros han limitado su soberanía, cuyos sujetos son, no sólo los Estados, sino también los nacionales ${ }^{26}$. En Costa/Enel, complementó, añadiendo que se trata de un ordenamiento jurídico propio, que nace de una

\footnotetext{
${ }^{21}$ Sentencia de la CCJ de 5 de agosto de 1997. Opinión consultiva. Haroldo Rodas Melgar, Secretario General de la Secretaria Permanente del Tratado General de Integración Económica Centroamericana (SIECA), expediente 13-02-01-05-1997. En el SICA es procedente que los órganos y organismos de éste le dirijan opiniones consultivas a la CCJ, tal como lo vimos al analizar los tipos de competencias de este tribunal en el capítulo II. En este caso, el SIECA es un órgano técnico del SICA, por lo que posee legitimación para dirigir consultas a la CCJ. Esta sentencia es la que posteriormente sería citada en la «Sentencia de la CCJ de 5 de marzo de 1998, Coto Ugarte c. Consejo Superior Universitario de la Universidad de El Salvador, expediente 05-11-1996, as. 05/96» para reiterar la prohibición de los Estados miembros de dictar normativa incompatible o que pretenda desconocer a la de origen comunitario.

${ }^{22}$ Sentencia del TJ de 5 de febrero de 1963, Van Gend \& Loos, as. C-26/62, ECLI:EU:C:1963:1.

${ }^{23}$ Sentencia del TJ de 15 de julio de 1964, Costa/Enel, as. C-6/64, ECLI:EU:C:1964:66.

${ }^{24}$ Sentencia del TJ de 14 de noviembre de 1985, Neumann, as. C-299/84, ECLI:EU:C:1985:463.

${ }^{25}$ Párrafos $3^{\circ}, 4^{\circ}$ y $6^{\circ}$ del apartado B. En cuanto al fondo, en Sentencia del TJ de 5 de febrero de 1963, Van Gend \& Loos, as. C-26/62, ECLI:EU:C:1963:1.

${ }^{26}$ Párrafo $7^{\circ}$ del apartado y sentencia ibídem.
} 
fuente autónoma, dotado de naturaleza específica y original ${ }^{27}$. Así el principio del efecto directo en la UE se consolidaría con aquellos dos fallos más una secuencia de sentencias que les seguirían, como Simmenthal ${ }^{28}$, Walt Wilhelm ${ }^{29}$, Reyners ${ }^{30}$, Van Duyn ${ }^{31}$, Rewe ${ }^{32}$, Comet $^{33}$, Demirel ${ }^{34}$, Kreil ${ }^{35}$ y Masterfoods ${ }^{36}$. Estableciéndose así, mediante el cauce pretoriano, el efecto directo, a través del cual las disposiciones de la UE generan derechos y obligaciones para cualquier ciudadano de un Estado miembro, el que ahora posee acción, y puede invocar las disposiciones de la UE directamente ante el juez nacional, sin necesidad de que exista una norma local que reconozca la normativa de la UE.

En cuanto al tema número cinco, el principio de la aplicación uniforme del Derecho de la UE, éste fue asentado por el $\mathrm{TJ}^{37}$ en el caso Neumann, oportunidad en que se consultaba por un tribunal alemán sobre la pertinencia de aplicar el principio de inequidad objetiva, que en términos generales tiene por finalidad no aplicar alguna ley cuando causa un perjuicio, y así preservar la confianza de los ciudadanos en las instituciones legales, afinándose todo en una correspondencia entre la ley y la justicia, si bien el juez nacional reconocía que este principio no había sido aceptado con anterioridad por el TJ en el caso Balkan-ImportExport $^{38}$, lo consultaba para confirmar si hubiese alguna evolución de criterio. Sin embargo

${ }^{27}$ Párrafo 11 del apartado Argumento basado en la obligación del Juez de aplicar la ley interna, de la sección Sobre la aplicación del artículo 177, del capítulo Fundamentos de derecho, en la Sentencia del TJ de 15 de julio de 1964, Costa/Enel, as. C-6/64, ECLI:EU:C:1964:66.

${ }^{28}$ Sentencia del TJ de 9 de marzo de 1978, Simmenthal, as. C-106/77, ECLI:EU:C:1978:49.

${ }^{29}$ Sentencia del TJ de 13 de febrero de 1969, Walt Wilhelm, as. C-14/68 ECLI:EU:C:1969:4.

${ }^{30}$ Sentencia del TJ de 21 de junio de 1974, Reyners, as. C-2/74, ECLI:EU:C:1974:68.

${ }^{31}$ Sentencia del TJ de 4 de diciembre de 1974, Van Duyn, as. C-41/74, ECLI:EU:C:1974:133.

${ }^{32}$ Sentencia del TJ de 16 de diciembre de 1976, Rewe-Zentralfinanz, as. C-33/76, ECLI:EU:C:1976:188.

${ }^{33}$ Sentencia del TJ de 16 de diciembre de 1976, Comet, as. C-45/76, ECLI:EU:C:1976:191.

${ }^{34}$ Sentencia del TJ de 30 de septiembre de 1987, Demirel, as. C-12/86, ECLI:EU:C:1987:400.

${ }^{35}$ Sentencia del TJ de 11 de enero de 2000, Kreil, as. C-285/98, ECLI:EU:C:2000:2.

${ }^{36}$ Sentencia del TJ de 14 de diciembre de 2000, Masterfoods y HD, as. C-344/98, ECLI:EU:C:2000:689.

${ }^{37}$ Con precisión la creación pretoriana fue del Tribunal de Primera Instancia (TPUE, hoy TGUE).

${ }^{38}$ Sentencia del TJ de 28 de junio de 1977, Balkan-Import-Export, as. C-118/76, ECLI:EU:C:1977:111. Mediante cuestiones prejudiciales se intentó averiguar cuáles eran los principios jurídicos aplicables en materia de condonación, por motivos de equidad (de montantes compensatorios monetarios percibidos sobre la importación de productos agrícolas de terceros países, al caso, sobre la importación de queso de oveja de Bulgaria). La Corte se refirió expresamente a su sentencia de 24-10-1973 Balkan Import Export GmbH (ECLI:EU:C:1973:109), en la cual rechazó la solicitud del actor Hauptzollamt Berlin-Packhof que pedía se condonaran los montantes compensatorios monetarios que se le reclamaban, basado en que: el pago de dichos montantes conducía, en ese caso, a un resultado contrario a los objetivos de la normativa comunitaria, que debía ser corregido mediante la aplicación de los principios de equidad consagrados en su normativa local. El rechazo de la Corte se fundó en que la cuestión giraba en función del reparto de competencias entre la Comunidad y los Estados miembros (relativo al establecimiento y percepción del canon objeto del litigio), así todas las cuestiones referidas al canon objeto del litigio, fueron determinadas por el Derecho Comunitario, sólo su recaudación y formalidades derivadas, se confiaron a las Administraciones locales. Por tanto estas 202 
el TJ procedió a subsumir el criterio de justicia nacional alemán en las múltiples dimensiones del principio de proporcionalidad de la UE, por lo tanto, mantuvo su criterio asentando así, y de modo definitivo, el principio de aplicación uniforme del Derecho de la UE.

Pues bien, en América Latina, en la sentencia de la Corte centroamericana dictada en la causa Rodas Melgar, Secretario General de la SIECA, se observan algunas conexiones con los dos criterios europeos recién precisados. En el caso concreto, el señor Haroldo Rodas Melgar, Secretario General de la Secretaria Permanente del Tratado General de Integración Económica Centroamericana, dirigió una opinión consultiva a la CCJ por diversos problemas de aplicación e interpretación de disposiciones del Convenio sobre el Régimen Arancelario y Aduanero Centroamericano. A efectos de evitar confusiones, aclaramos que a estas consultas la sentencia de la CCJ los denomina «puntos», y de entre estos únicamente nos implican los puntos sexto y décimo ${ }^{39}$, los cuales eran:

«Sexto Punto ¿Pueden los organismos legislativos de los Estados parte modificar los derechos arancelarios a la importación (DAI) o la clasificación oficial de las mercancías (SAC) del Arancel Centroamericano de Importación, que han sido aprobados de conformidad con los arts. 6, 7, 9, 12, 22, 23 y 24 del Convenio y 18 del Protocolo de Tegucigalpa?

Décimo Punto: ¿Tienen potestad los Estados Parte para modificar unilateralmente las materias que los Órganos Regionales competentes de la integración centroamericana han regulado en sus resoluciones con fundamento en las competencias que les atribuyen los Tratados de Integración Centroamericana como el Convenio?».

últimas no pueden modificar el alcance de las disposiciones del Derecho Comunitario. Concluyendo «Una Administración nacional de Aduanas no puede aplicar a una solicitud de condonación de cánones adeudados en virtud del Derecho comunitario, basadas en motivos de equidad, las disposiciones de su Derecho nacional». Resolutorio número 1, en la Sentencia del TJ de 24 de octubre de 1973, Balkan-Import-Export, as. C-5/73, ECLI:EU:C:1973:109.

${ }^{39} \mathrm{Si}$ bien nos hemos centrado aquí en las consultas $6^{\mathrm{a}}$ y $10^{\mathrm{a}}$, fueron en total 14 extensas cuestiones, de entre las cuales, y a efectos de contextualizar, podemos destacar las siguientes: $8^{\circ}$ ) ¿Qué efectos producen las modificaciones constitucionales de los Estados en las disposiciones del Convenio, si aquellas son posteriores al inicio de vigencia de éste? $9^{\circ}$ ) ¿Qué validez tienen las modificaciones que los Estados Parte pretendan hacer unilateralmente a los convenios de Integración Centroamericana, incluyendo el Convenio, a través de leyes nacionales o reformas constitucionales? $11^{\circ}$ ) ¿Qué relación guardan las disposiciones de los convenios centroamericanos de Integración y en general el Derecho Comunitario Centroamericano con las de los instrumentos nacionales? $13^{\circ}$ ) [...] ¿qué efectos tienen las leyes nacionales que tergiversen, modifiquen o

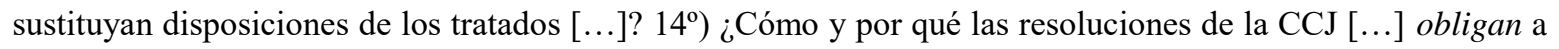
los Estados Parte, a los Órganos y Organismos Regionales y a los particulares? 
Abordado el conjunto de las cuestiones en términos amplios ${ }^{40}$ tal como lo resaltó la Corte, el señor Rodas solicitaba la opinión consultiva en relación con la tergiversación y, por consiguiente, la violación de principios fundamentales de la integración centroamericana postulados en el Protocolo de Tegucigalpa (PT) y demás instrumentos que señala, los cuales sirven de base al compromiso de los Estados Parte para adoptar un arancel centroamericano uniforme y así lograr una unión aduanera, como medio para el establecimiento del Mercado Común Centroamericano. Todo con el fin último, la Unión Económica Centroamericana.

La Corte centroamericana recordó que su jurisprudencia ya había sustentado tres doctrinas relevantes: uno, que el PT es el Tratado constitutivo marco de la integración centroamericana, y por lo tanto el de mayor jerarquía y base de cualquier otra norma, dos, que el PT en relación a sus instrumentos complementarios o actos derivados, es el de mayor jerarquía, y juntos, estos últimos con el primero, de conformidad al art. 35 del mismo, prevalecen sobre cualquier Convenio, Acuerdo o Protocolo entre los Estados Miembros, y tres, que los actos normativos obligatorios de los órganos e Instituciones del SICA entran en vigencia en la forma, fecha, plazo o término, que se establezca en estos. A partir de estos razonamientos respondió las dos cuestiones destacadas. Indicando primero, que los Estados no pueden crear normativa que tenga por objeto obstaculizar o dejar sin valor actos jurídicos del SICA, por ser simplemente contrarios al derecho y a la lógica jurídica. Explicándolo así:

«Sexto Punto: [...] Los Poderes Legislativos, no pueden emitir leyes para desconocer el carácter obligatorio de los actos jurídicos válidos realizados por los Órganos y Organismos de la Integración Centroamericana, que han ejercido las facultades conferidas por Convenios y Tratados vigentes, porque sería contrario a derecho y a la lógica jurídica que después de que éstos hayan ratificado ese Convenio, aprueben disposiciones que frustren su finalidad, salvo las excepciones contempladas en el Art. 26 del mismo» ${ }^{41}$.

Aún más clara observamos que es la CCJ al abordar el denominado «décimo punto», pues, únicamente apoyada en el principio de buena fe, pasó a resaltar que los Estados no pueden desconocer las resoluciones de los Órganos Regionales, sino que deben respetarlas y cumplirlas, porque no tienen la potestad de evadir su cumplimiento con modificaciones hechas unilateralmente, precisando:

\footnotetext{
${ }^{40}$ Considerando III de la Sentencia de la CCJ de 5 de agosto de 1997. Opinión consultiva. Haroldo Rodas Melgar, Secretario General de la Secretaria Permanente del Tratado General de Integración Económica Centroamericana (SIECA), expediente 13-02-01-05-1997.

${ }^{41}$ Sección: Resuelve: Primero, párrafo Sexto Punto (p. 4) en sentencia ibídem. 204
} 
«Décimo Punto: [...] los Estados deben cumplir sus obligaciones internacionales de buena fe, de conformidad con el principio jurídico universalmente reconocido "pacta sunt servanda”. Si los Órganos Regionales han aplicado correctamente, desde el punto de vista jurídico, los Tratados, Convenios y Acuerdos mediante las resoluciones que emitan, los Estados deben respetarlas y cumplirlas; y, definitivamente, no tienen la potestad de evadir su cumplimiento con modificaciones hechas en forma unilateral o irregular» ${ }^{42}$.

Si se observa con detención, en la sección de la respuesta recién transcrita, ya quedaba clara la prohibición en análisis, pero en la continuación del texto la CCJ pasa a efectuar la justificación jurídica en base a la buena $\mathrm{fe}^{43}$, y para nuestro interés aquí, lo relevante de destacar es que en su primera frase hace un distingo semántico entre «Derecho de Integración $v / s$ Comunitario Centroamericano», es decir, se sigue claramente que la Corte no los considera idénticos. Circunstancia que puede observarse en su primera frase:

«En el Derecho de Integración y Comunitario Centroamericano, de manera especial en el Art. 4 del PT, se establece que los Estados miembros se obligan a proceder de acuerdo a principios fundamentales ahí establecidos, entre los que se encuentra el de la "buena fe" $\gg$ ".

Apreciamos entonces, que aquí el uso del lenguaje técnico-jurídico queda al servicio de la idea que pivota por distinguir entre el Derecho de la integración comprendido de modo amplio $v / s$ el Derecho Comunitario Centroamericano, tal como ya lo señalamos en nuestro marco teórico en la introducción de esta tesis y como lo hemos recordado al inicio de este capítulo, en cuanto las Cortes latinoamericanas consideran la existencia de un derecho de la integración como una sección formal del derecho, cuyo contenido coincide perfecto con el Derecho de la UE, en sentido de reconocerle a la UE el carácter de creador de tal rama del derecho y el líder autorizado para aplicar las modificaciones estructurales y sus nuevos desarrollos, mientras que en calidad de receptores incompletos quedan el Derecho del SICA, el de la CAN, y el del MERCOSUR, los cuales intentan aproximarse a ese ideal de Derecho de la integración poco a poco conforme sus realidades se los van permitiendo, ejercicio durante el cual, si bien importan las ideas de tal derecho de la integración, le van

\footnotetext{
${ }^{42}$ Sección: Resuelve: Primero, párrafo: Décimo Punto — primera parte- (p. 5) en sentencia ibídem.

${ }^{43}$ Explica la aplicación de la buena fe aquí, en la dimensión del cumplimiento de los Estados miembros para con el proyecto de integración del siguiente modo «h) La buena fe de los Estados miembros en el cumplimiento de sus obligaciones, absteniéndose de establecer, convenir o adoptar medida alguna que sea contraria a las disposiciones de este Instrumento o que obstaculice el cumplimiento de los principios fundamentales del Sistema de la Integración Centroamericana o la consecución de sus objetivos». Parte final del párrafo Décimo Punto, de la sección Resuelve Primero en sentencia ibídem.

${ }^{44}$ Sección: Resuelve: Primero, párrafo: Décimo Punto —-segunda parte— (p. 5) en sentencia ibídem.
} 
aplicando modificaciones propias con más o con menos énfasis, todo según venimos analizando en esta tesis.

En conclusión, de esta sentencia se sigue nítida la línea que marca la CCJ para hacer respetar la jerarquía, vigencia, reforma y derogación de las normas de derecho interno, internacional y, de modo singular el Comunitario, pues, de lo contrario se produciría una directa violación de los principios fundamentales de la integración centroamericana. De hecho - y como ya lo analizamos en la primera parte de este capítulo - las ideas centrales de estos mismos principios, son las que previamente desarrolló en Europa la Corte de Luxemburgo en los casos Van Gend \& Loss y Costa/Enel, oportunidad en que el TJ declaró tanto el efecto directo del Derecho de la Unión, como su primacía. Observándose también una dosis del principio de la aplicación uniforme del Derecho de la integración, asentado igualmente en Europa a través del caso Neumann.

\subsubsection{LA JURISPRUDENCIA DE LA CCJ REFERIDA AL DESAPODERAMIENTO COMPETENCIAL, AL PRINCIPIO DE ATRIBUCIÓN DE COMPETENCIAS, AL CONCEPTO DE COMUNIDAD Y A LA RESPONSABILIDAD QUE TODO AQUELLO IMPLICA}

En cuanto al fenómeno de desapoderamiento competencial, al principio de atribución de competencias, al concepto de Comunidad y a la responsabilidad que todo aquello implica, la CCJ los ha abordado y desarrollado con algunas particularidades aplicables al SICA en casos como Nicaragua/Honduras y Honduras/Nicaragua ${ }^{45}$. Lo más significativo del primer caso es que la Corte centroamericana debió retroceder hasta los conceptos básicos del Derecho de la integración — entonces conocido como Comunitario - los cuales habían sido construidos en Europa por el TJ. El camino de la CCJ se debía a que se intentaban desconocer por Honduras los más elementales principios y reglas de un proceso de integración, ubicándose las partes en las antípodas jurídicas al interpretar las consecuencias que se siguen del hecho de adherir a un proyecto integracionista.

Dada las circunstancias se condensan en la sentencia de la Corte centroamericana diversos elementos y principios de alto interés, pero básicamente este caso lo analizaremos porque, de entre los nueve bloques temáticos ya precisados, en determinada medida la CCJ se conecta con el tema uno, referido al efecto directo y la primacía del Derecho de la UE,

\footnotetext{
${ }^{45}$ Sentencia de la CCJ de 27 de noviembre de 2001, Nicaragua c. Honduras, expediente 25-05-29-11-1999, as. 69/01, y Sentencia de la CCJ de 28 de noviembre de 2001, Honduras c. Nicaragua, expediente 26-06-0312-1999. Analizaremos el primero de estos casos, porque en él se muestran más claramente todos los principios e instituciones del Derecho de la Integración que recién anunciamos. En cambio, en el segundo fallo, sólo se reiteran. Estimamos prudente hacer la salvedad de mencionarlo, pues es habitual encontrar referencias sobre ambas sentencias.
}

206 
desarrollado por el TJUE, y que lo recordamos recién en el apartado anterior, motivo por el cual nos remitimos a aquella sección. Pero además la sentencia de la CCJ también se relaciona con el tema dos, esto es, sobre el principio de la responsabilidad patrimonial de los Estados miembros por violación al Derecho de la UE y al subsecuente derecho a ser indemnizado, según analizaremos.

Respecto de ese segundo tema, recordemos que fue creado por el TJ mediante varias sentencias desde 1960, con antecedentes como el caso Humblet ${ }^{46}$ en que se comprendía, en determinado sentido la reparación de perjuicios, pero aquel fallo no era por sí solo una creación sólida, más bien fue incipiente su aporte al derecho de indemnización. Le seguiría en 1976 la causa Carmine Antonio Russo/AIMA ${ }^{47}$ donde el TJ dejó claro que el Estado debía asumir las consecuencias del perjuicio causados por violación del derecho comunitario $^{48}$. Pero definitivamente en diciembre de 1991, en las causas acumuladas Francovich y Bonifaci ${ }^{49}$ el TJ estableció el principio de la responsabilidad de los Estados, ahora complementaba con una idea más precisa, puntualizando que la responsabilidad procede cuando el particular no puede invocar un derecho subjetivo ante sus tribunales nacionales, y ubicó al principio de la responsabilidad en el actual art. 10 TCE (ex art. 5 TCEE) que obliga a los Estados a adoptar todas las medidas para asegurar el cumplimiento de las obligaciones que les incumben del Derecho Comunitario. Así el criterio se consolidó, incluso con otras varias sentencias como Brasserie du Pêcheur, ex parte Factortame ${ }^{50}$ y en Transportes Urbanos y Servicios Generales S.A.L. ${ }^{51}$.

Pues bien, en América Latina en el año 1986, Honduras había suscrito el Tratado LópezRamírez con Colombia, cuya ratificación implicaría una cesión de espacios marítimos en favor de Colombia, nación extra-comunitaria, pero el Estatuto de la CCJ (1992) era posterior al Tratado que ahora se intentaba ratificar. El 29 de noviembre de 1999, Nicaragua demandó ante la CCJ a Honduras y pidió medidas cautelares, fundada en violación de normativa y principios comunitarios, ya que la ratificación del mentado Tratado significaría despojar a Centroamérica, en beneficio de un país ajeno al proceso de integración, de una extensa zona marítima, lesionando el desarrollo económico y social del conglomerado humano centroamericano. La medida cautelar buscaba evitar la ratificación,

\footnotetext{
${ }^{46}$ Sentencia del TJ de 16 de diciembre de 1960, Humblet/Etat belge, as. C-6/60-IMM, ECLI:EU:C:1960:48.

${ }^{47}$ Sentencia del TJ de 22 de enero de 1976, C. A. Ruso, as. C-60/75, ECLI:EU:C:1976:9.

${ }^{48}$ Vid. número 9, del Capítulo del derecho, y letra c) de la parte decisoria, en sentencia ibídem.

${ }^{49}$ Sentencia del TJ de 19 de diciembre de 1991, A. Francovich y D. Bonifaci, as. Acumulación C-6/90 y C9/90, ECLI:EU:C:1991:428.

${ }^{50}$ Sentencia del TJ de 5 de marzo de 1996, Brasserie du Pêcheur, ex parte Factortame, as. C-48/93, ECLI:EU:C:1996:79.

${ }^{51}$ Sentencia del TJ de 26 de enero de 2010, Transportes Urbanos y Servicios Generales, as. C-118/08, ECLI:EU:C:2010:39.
} 
la cual fue acogida al día siguiente el 30 de noviembre de ese año, notificándole a Honduras, ese mismo día, que suspendiera la ratificación hasta que se pronunciara la sentencia, pero Honduras no acató y el mismo día 30 de noviembre de 1999 ratificó $^{52}$.

Honduras planteó que era imposible vincular la aprobación del Tratado de límites a violaciones de instrumentos de la integración, porque los Tratados integracionistas eran posteriores al Tratado sublite ${ }^{53}$, y que Honduras al participar del SICA no limitó su soberanía para concluir Tratados de límites. Agregó que la CCJ era incompetente ${ }^{54}$, que el Derecho del SICA no tendría supremacía sobre el nacional, que no existe el patrimonio territorial centroamericano, y que el término integración como se usa en el SICA es relativo y diferente al de la UE, donde hay poderes legislativos, ejecutivos y judiciales a los que se les transfirió competencias propias de los países. Pero para Nicaragua tal concepción de la soberanía estatal evocaba las teorizaciones clásicas de Jean Bodin, cuestión incompatible con los compromisos comunitarios, que la facultad de celebrar Tratados es retenida por los Estados miembros, pues dichos Tratados deben ejercerse de forma compatible con los fines de la integración, respetando el hecho de que el Derecho del SICA sí identifica la integridad del patrimonio colectivo centroamericano y el principio de solidaridad. Pero la ratificación quebranta todo lo anterior y destruye el presupuesto moral de todo proceso de integración y la piedra angular de la estrategia única de la política exterior y de seguridad común centroamericana. Agregando que este derecho se basa en los principios de progresividad, irreversibilidad y de respeto al acervo comunitario.

Pues bien, en primer lugar la CCJ desechó la incompetencia ajustándose a su marco competencial y articulando el principio kompetenz-kompetenz ${ }^{55}$. En segundo lugar y ahora

${ }^{52}$ Honduras no acató la medida cautelar, así se observa en la Gaceta Diario Oficial del Gobierno de la República de Honduras del 1 de diciembre de 1999 en que se publicó el Decreto Legislativo No 2-99-E de aprobación del Tratado. Nicaragua alegó desacato y pidió dirigir un oficio a las Oficinas de Registro de Tratados de NU y de OEA solicitándoles se abstengan de inscribir o registrar el Tratado. Por su parte Honduras, en cuanto a esta medida cautelar, sostuvo que la resolución de la CCJ era ilegal por dictarse en infracción de las disposiciones que regulan las actuaciones de la CCJ; que la resolución no era obligatoria porque fue dictada en materia excluida de su competencia. Por lo que pidió la nulidad de la medida cautelar. Solicitud rechazada por la CCJ, quien comunicó al resto de los Estados miembros del SICA, el incumplimiento.

${ }^{53}$ Lo que implicaría vulnerar el art. 28 de la Convención de Viena sobre el Derecho de los Tratados.

${ }^{54} \mathrm{La}$ incompetencia se basaba en que el art. 22, literal b) del Estatuto de la CCJ solo comprende las leyes secundarias, y no los actos soberanos, los cuales, por su naturaleza serían indelegables.

${ }^{55}$ El rechazo se basó en tres aspectos, primero en las ideas centrales de la motivación del Tratado de Tegucigalpa; segundo, en sus normas concretas; y en tercer lugar, articulando procesalmente el principio kompetenz-kompetenz. Considerandos IX a XII en la Sentencia de la CCJ de 27 de noviembre de 2001, Nicaragua c. Honduras, expediente 25-05-29-11-1999, as. 69/01. El principio kompetenz-kompetenz, o compétence sur la compétence, da la potestad a determinados jueces para decidir sobre su propia competencia. Si bien nace vinculado a la sede arbitral, se extendió hasta los Tribunales Internacionales con 208 
en cuanto al fondo, la Corte debió comenzar por recordar que el PT es el Tratado constitutivo marco de la integración centroamericana, por lo tanto el de mayor jerarquía y base fundamental de cualquier otra normativa centroamericana, sean estos, Tratados, Convenios, Protocolos, Acuerdos u otros actos jurídicos vinculantes «anteriores o posteriores» a la entrada en vigencia del PT. Entonces la CCJ reiteró la jerarquía, primacía y aplicación directa de la normativa comunitaria, en los mismos términos ya asentados mediante su respuesta en la opinión consultiva Rodas Melgar y también en Coto/Universidad ${ }^{56}$.

Adicionalmente la Corte centroamericana se vio forzada hacer un ejercicio conceptual, señalando que es menester distinguir entre un Tratado suscrito con otro Estado sujeto al DI Convencional, $v / s$ un Tratado que tiene como propósito crear, establecer o reconocer la existencia de una Comunidad de Estados en proceso de Integración. Y para la CCJ el PT a la Carta ODECA pertenece a esta última clase, por lo tanto tiene mayor jerarquía que cualquier otro instrumento suscrito con un Estado extracomunitario.

Para nosotros es sorprendente que la CCJ — forzada por los argumentos de la defensahaya debido retroceder hasta los conceptos iniciales del Derecho de la integración, pues se intentaban desconocer sus más elementales principios y reglas. Por tal motivo analizó lo que representa y lo que es una Comunidad de Estados y la forma en que sus Estados miembros deben de conducirse en sus relaciones entre sí, con la Comunidad y sus Órganos $\mathrm{y}$, con otros Estados extracomunitarios.

El criterio de la Corte es que los Estados que han optado libremente por pertenecer a una Comunidad que se le reconoce vida propia, y se le dota de un Sistema para la realización de su integración, entran — dichos Estados — en una etapa de desarrollo de mayor nivel y

gran naturalidad dado que habitualmente estas Cortes carecen de un superior jerárquico que resuelva alguna contienda de competencias, o bien que escale en apelación. La noción inicial es que el árbitro posee competencia para decidir sobre su propia competencia. Esta idea la presentó BöHLAU en su obra KompetenzKompetenz (1876), teoría decantada luego por SCHMITT en Verfassungslehre (1928). Principio que sería morigerado por la escuela francesa que establece el árbitro decide sobre su propia competencia pero el juez estatal tiene competencia en segunda instancia. Hay muchos ejemplos legislativos del principio kompetenzkompetenz, en materia de TI v.gr. el Estatuto de la CIJ lo contempla en el núm. 6 del art. 36; la CPI en la Regla 133 de las Reglas de Procedimiento y Prueba; el TJUE, la CCJ y el TPRM también lo despliegan de manera natural cada vez que un litigante pone en duda sus competencias. Para el TJCA se contempla vinculado al rechazo in limine en el art. 53 de su Estatuto.

${ }^{56}$ Ambos casos ya los mencionamos, Sentencia de la CCJ de 5 de agosto de 1997. Opinión consultiva. Haroldo Rodas Melgar, Secretario General de la Secretaria Permanente del Tratado General de Integración Económica Centroamericana (SIECA), expediente 13-02-01-05-1997; y Sentencia de la CCJ de 5 de marzo de 1998, Coto Ugarte c. Consejo Superior Universitario de la Universidad de El Salvador, expediente 05-111996, as. 05/96. 
compromiso, en el que sus facultades soberanas quedan entrelazadas con todos los que integran la Comunidad, con sus propósitos y principios. Por esto sus actos deben dirigirse en forma tal que impulsen y fortalezcan a dicha Comunidad, y también, a sus integrantes.

Además, y en lo que resulta ser todo un acierto, la CCJ haciéndose cargo de lo que la Carta de NU pudiese indicar sobre las OI, lo pasa a estimar únicamente en carácter de supletorio, toda vez que para aquella época en que se dictó dicha Carta, las organizaciones de integración no existían, y esta clase de organizaciones son en esencia sui generis, o bien, un «ente político con vida propia» ${ }^{57}$. En definitiva, la Corte centroamericana, por mayoría ${ }^{58}$, resolvió que Honduras infringió el PT a la Carta ODECA y, en consecuencia, incurrió en responsabilidad, sin embargo la CCJ se abstuvo de determinar la cuantía para la justa reparación, pues faltó incorporar pruebas para aquello, no porque no fuese procedente la justa indemnización.

${ }^{57}$ Vid. estos desarrollos en el literal C) del Considerando XIX en la Sentencia de la CCJ de 27 de noviembre de 2001, Nicaragua c. Honduras, expediente 25-05-29-11-1999, as. 69/01, donde se indica «el proceso de integración de Estados que crean o reconocen: la existencia de una Comunidad entre ellos, un ente político con vida propia [...], que puede denominarse OI sui-géneris, se aleja de las concepciones existentes al momento de darse la Carta de NU, en consecuencia: la realidad de los hechos ha desbordado cualquier previsibilidad [...], aunque quienes estén involucrados en este nuevo ente hagan referencia a la misma en sus conceptos generales, para encontrar una fundamentación que legitime su creación o posterior desarrollo, v.gr. las CE, hoy UE. [...], en la Carta de NU no se considera en forma expresa la existencia de Comunidades de Estados, tal como hoy se encuentran desarrolladas, por tanto la referencia que se haga a la misma, en relación con la Comunidad Centroamericana, deberá atenderse como una alusión supletoria al propio derecho que rige esta Comunidad».

${ }^{58}$ Esta sentencia se dicta sólo por mayoría de votos, recordemos que la CCJ es la única Corte de Integración en que se permiten las dissenting opinions o votos particulares, a diferencia del TJUE y TGUE, del TJCA y del TPRM y TAAM donde no se emplean (excepto en el procedimiento de consultas prejudiciales en Mercosur). En cuanto al cotejo estatutario que de este extremo se visualiza con la UE, nos remitimos en todo a lo ya visto en el capítulo II, apartado 3.3.3. La exclusión de los votos disidentes en los modelos de las cortes latinoamericanas confrontado al principio de publicidad y transparencia. Pero en este caso concreto hubieron dos opiniones particulares, el voto razonado del Magistrado ADOLFO LEÓN GómEZ, que disiente de la Sentencia; y el voto particular del Magistrado José EdUARDo GAUGGEL RIVAS quien estaba en desacuerdo con los razonamientos contenidos en la parte motivada de la sentencia, y disentía de su parte resolutiva. Por cierto es deseable que todos los modelos integracionistas se alinearan con el principio de transparencia y registrasen y publicasen las dissenting opinions, pues además aquello fortalece el principio democrático. Sobre lo positivo de la existencia de las dissenting opinions en los diversos tipos de tribunales, vid. et al. LYNCH, A. (2004). "Is judicial dissent constitutionally protected?", Macquarie law journal, 5, apartado "II The possibility of dissent”, <http://www5.austlii.edu.au/au/journals-/MqLJ/2004/5.html> IBÁÑEZ GARCÍA, I. (1998). "Los votos particulares en el proceso judicial comunitario; el contenido mínimo del derecho de petición ante el parlamento europeo y la protección de este derecho por el defensor del pueblo", Noticias de la unión europea, 156, 25-36.

210 
En conclusión, para nosotros el mayor aporte de este extenso fallo, es dar una lección de coherencia en las actitudes de los Estados miembros, en el sentido de que no pueden desconocer el nivel de desarrollo alcanzado por el esquema de integración del SICA, sino que por el contrario, los Estados miembros deben asumir la responsabilidad que conlleva haber conformado toda una estructura de integración en una determinada sub-región, debiendo actuarse en coherencia con los objetivos que libremente se pactaron. En ese entendido es que la Corte centroamericana exprese que la soberanía no debe ser entendida como una búsqueda y prosecución de sólo el propio interés nacional, sino como la compatibilización entre los intereses propios y los de la Comunidad de que forma parte ${ }^{59}$.

En definitiva, esta extensa y rica jurisprudencia, precisó tres aspectos trascendentes, en primer lugar, entregó una noción amplia del concepto de una comunidad, identificándola como un ente político con vida propia, en segundo lugar, resolvió que el SICA es una OI sui generis, por último, en tercer lugar, respecto ahora del marco jurídico que la Carta NU pudiese llegar a otorgarles a estas organizaciones sui generis, consideró que en atención a que tal tipo de OI - v.gr. la actual UE - no existían al momento de dictarse dicha Carta, toda referencia que se haga a la Carta de NU en relación con la Comunidad Centroamericana es supletoria al derecho particular que la rige. De este modo la jurisprudencia analizada, por todos sus extremos resulta ser un aporte concreto de la CCJ al proyecto global del SICA, aflorando nuevamente el rol central de una Corte de integración en cada proyecto al que pertenezca.

\subsubsection{LA JURISPRUDENCIA DE LA CCJ REFERIDA AL CONCEPTO DE DESARROLLO PROGRESIVO DEL PROCESO DE INTEGRACIÓN CENTROAMERICANO}

A continuación, veremos como la Corte centroamericana para responder a una consulta prejudicial —en la UE denominada cuestión prejudicial-, recurrió al concepto de desarrollo progresivo del proceso de integración, también identificado como el principio de progresividad, o directamente bajo la noción de progresividad o de transitoriedad del

\footnotetext{
59 Considerando XV en la Sentencia de la CCJ de 27 de noviembre de 2001, Nicaragua c. Honduras, expediente 25-05-29-11-1999, as. 69/01. Además del considerando anotado, y en coherencia con éste, la CCJ razonó que al pertenecer ambos Estados a la Comunidad Centroamericana, lo que marca una distancia sustantiva y procesal con el país extracomunitario (Colombia), quedan sujetos a la normativa que rige al SICA. Por lo tanto deben sujetar su forma de obrar entre sí, con la Comunidad y con otros Estados, a dicha normativa. Que en atención a las obligaciones que deben guardar los Miembros del SICA y que se relacionan con lo demandado, están las contenidas en el PT, art. 6 «Los Estados miembros se obligan a abstenerse de adoptar medidas unilaterales que pongan en peligro la consecución de los propósitos fundamentales del SICA».
} 
proceso por la doctrina ${ }^{60}$, el cual se presenta por múltiples conductos, v.gr. aquí lo veremos para el SICA aplicado a través del crecimiento de la organización de integración mediante la incorporación de nuevos Estados, pero también se puede observar por el cauce del cambio de calidad de la organización, como lo analizaremos luego para el caso del MERCOSUR, y por otros múltiples extremos, como por ejemplo a través del crecimiento normativo, el desarrollo orgánico, etcétera.

En la sentencia de la Corte centroamericana que analizaremos, se presenta en determinada medida el tema cuatro de los bloques temáticos que estamos usando para este y el siguiente capítulo, y que se refiere al principio de la igualdad de los Estados miembros. Recordemos brevemente que este principio fue asentado por el TJ en el caso Comisión/Reino Unido ${ }^{61}$, oportunidad en que Reino Unido e Italia intentaba continuar con las condiciones para el mercado agrario establecidas para un período de transición, ante lo cual, y en lo pertinente para nuestro análisis, el TJ sentenció que:

«el Acta de adhesión no puede ser interpretada en el sentido de que ha establecido en favor de los nuevos Estados miembros, durante un período indefinido, una situación jurídica diferente a la que establece el Tratado para los Estados miembros originarios; [...] que, en efecto, si [...] fuera considerado como una «disposición particular» [...] establecería una desigualdad persistente entre los Estados miembros originarios y los nuevos Estados miembros, [...]; que si bien se justifica que los Estados miembros originarios acepten provisionalmente tales desigualdades, sería contrario al principio de igualdad de los Estados miembros ante el Derecho comunitario admitir que tales desigualdades continúen indefinidamente» ${ }^{62}$.

\footnotetext{
60 PANAYOTIS SOLDATOS habla del continuum integratif como visión de conjunto de una realidad ordenada en función de un proceso de integración. PANAYOTIS SOLDATOS (1989). Le Système Institutionelle et Politique des Communautées Européennes Dans un Monde en Mutation, Bruylant, Bruxelles, pp. 115 a 117. DA SILVA, expresa: el modelo europeo puede ser tomado como ejemplo, pero teniendo en cuenta las profundas diferencias [...]. Sin embargo, es interesante considerar que la CE se ha construido progresivamente, en un lapso extenso de tiempo, y que aún hoy sigue evolucionando. Un desarrollo progresivo parece, entonces, más prudente a la hora de la integración regional de Estados diversos. DA SILVA, 1998, p. 131. MANGAS emplea la noción de progresividad con el objeto de ubicar a la UE en un contexto de avance para lograr relaciones cada vez más estrechas entre los pueblos, avanzando hacia una mayor integración sin definir la meta final, subraya que: la idea de la progresividad, la idea del puente intergeneracional y la idea de que el futuro se construye poco a poco y entre todos, que no hay nada acabado ni cerrado y que, las generaciones futuras están llamadas a ser protagonistas del proceso: condensa toda una filosofía política. MANGAS, 2014c, pp. 46-47. La idea de progresividad es recogida en innumerables sentencias de las Cortes latinoamericanas en análisis, y varios de esos casos los indicaremos más adelante, y también en el capítulo IV.

${ }^{61}$ Sentencia del TJ de 24 de marzo de 1979, Comisión c. Reino Unido, as. C-231/78, ECLI:EU:C:1979:101.

${ }^{62}$ Considerando 17 , en sentencia ibídem.
}

212 
Pues bien, en América Latina observamos algunos de estos criterios pretorianos en la respuesta que dio la Corte centroamericana en los autos Consulta Parlacem/República Dominicana $^{63}$, oportunidad en que estimó que, si bien existe el principio de progresividad, éste debe llevar un correlato formal de parte de los Estados respecto del cumplimiento de objetivos y de adscripción material a los Tratados por parte de los Estados - de lo contrario habría una desigualdad. Aclarando la posición precisa que ocupan las naciones miembros del proyecto SICA las cuales — como analizamos en el capítulo anterior - se agrupan en el esquema centroamericano en cuatro categorías. En dicho contexto, no pueden determinados Estados miembros, asumir roles o funciones propias de otro tipo de Estado miembro. La opinión consultiva la dirigió el Parlamento Centroamericano, preguntando:

«¿Puede el Estado de República Dominicana incorporarse como parte del Estatuto de la CCJ? Y ¿para el caso de que el Estado de República Dominicana se pueda incorporar como miembro pleno de la CCJ, cuáles serían los procedimientos y formalismos que deben desarrollarse por parte del gobierno de dicho país para lograr su incorporación?».

Como apreciamos, la consulta no versaba por la incorporación total de un nuevo Estado, sino por una aproximación parcial. Consistente en poder participar del órgano jurisdiccional del SICA, en un contexto de acercamiento progresivo hacia dicha organización. Pero como veremos, fluye de la sentencia que la Corte ubicó a la progresividad, en una dimensión formal, rechazando la incorporación, mientras la República Dominicana, no adscribiera totalmente a la Carta constitutiva del SICA. En cierta medida, la Corte resguardó celosamente la intervención en su propia orgánica — pues la referida nación deseaba ser parte del Estatuto de la CCJ sin ingresar del todo al SICA — por lo tanto el rechazo pasa a implicar que la participación directa en el colegio de jueces con poder de decisión, es un privilegio reservado para los Estados miembros plenos. Tal cuestión hace fuerza, sobre el carácter central que juega una Corte de Integración en el proyecto completo, idea sobre la cual estamos desarrollando la hipótesis de esta tesis.

Observando todos los modelos de integración que venimos analizando, se advierte que la exigencia que se les imponen a los candidatos para ser Estados miembros, y para adscribir de forma completa al proyecto, no son cuestiones ni absolutas ni homogéneas en cada modelo de integración, sino que cada esquema establece sus propios requisitos de ingreso y sus particulares estándares de compenetración entre los socios, para poder ser parte de la Corte respectiva, o bien para participar en otro órgano específico, o para calificar en algún nivel superior de Estado participante. Así por ejemplo en el MERCOSUR se dispusieron de dos tipos, los Estados partes y los asociados; en la CAN se distinguen los propios; y otro

\footnotetext{
${ }^{63}$ Sentencia de la CCJ de 10 de noviembre de 2006, Consulta Parlacem/República Dominicana, expediente 76-03-12-09-2006, as. 76/06.
} 
tanto en el SICA. En cambio respecto de la UE el factor de diferenciación no afecta a los miembros, sino a los no miembros. A éstos últimos aplica un criterio de mayor o menor cercanía para su incorporación, diferenciando entre Estados miembros $v / s$ Países candidatos y Candidatos potenciales.

El método de la UE le permite exigir un estándar de calidad democrática y de compatibilidad de la nación candidata, con los principios y valores del proyecto de integración europeo ${ }^{64}$, desplegando una inteligente estrategia de nivelación previa, tras un proceso de cumplimiento de metas. A lo que se suma, pero sólo desde un ángulo histórico, el hecho de que en ocasiones se destaquen los Estados originarios de la Europa de los seis, los de la primera ampliación, de la segunda, y así sucesivamente ${ }^{65}$. Además la UE posee casos en que algunos Estados miembros, no asumen idénticas obligaciones que el resto en determinadas áreas, por ejemplo, no todos adscriben a la moneda única, el euro, e igualmente dichos Estados miembros pueden tener jueces dentro del Tribunal de Justicia.

Entendemos entonces que cada proyecto define cuál es su núcleo político, omitiendo determinadas áreas o sub-áreas. Cuestiones que no antagonizan con otras reglas, como el principio de la igualdad de los Estados miembros, matriz asentada por el TJ mediante la

\footnotetext{
${ }^{64} \mathrm{El}$ art. 49 del TUE incardina el estándar básico de los candidatos al expresar «Cualquier Estado europeo que respete los valores mencionados en el artículo 2 y se comprometa a promoverlos podrá solicitar el ingreso como miembro en la Unión», el art. 2 mencionado por el art 49, ambos del TUE, es uno de los receptáculos axiológicos iniciales de la UE, indicando «La Unión se fundamenta en los valores de respeto de la dignidad humana, libertad, democracia, igualdad, Estado de Derecho y respeto de los derechos humanos, incluidos los derechos de las personas pertenecientes a minorías. Estos valores son comunes a los Estados miembros en una sociedad caracterizada por el pluralismo, la no discriminación, la tolerancia, la justicia, la solidaridad y la igualdad entre mujeres y hombres».

${ }^{65}$ La idea de la Europa de los seis, realza el protagonismo de los primeros Estados miembros del proyecto europeo (Francia, Alemania, Italia, Bélgica, Países Bajos y Luxemburgo), a los cuales les siguen las diversas ampliaciones. El concepto de la Europa de los seis, el complejo despegue y desarrollo del proyecto europeo de referencia mediante una acabada relación de todo el proceso histórico e institucional para arribar a la UE, abarcando desde la cristiandad europea hasta el año 2002, más cronología hasta el año 2015, y un anexo de los principales instrumentos de la UE, puede revisarse en: TRUYOL \& SERRA (1999, Tomo I). Génesis y desarrollo de la unión europea (1951-1979), y ALDECOA LUZÁRRAGA, F. (2002, Tomo II). La integración europea: Análisis histórico-institucional con textos y documentos - Tomo II génesis y desarrollo de la unión europea (1979-2002). Otro, AHIJADO QUINTILLÁN, M. (2000). Historia de la unidad europea: Desde los precedentes remotos a la ampliación al este ( $1^{\mathrm{a}} \mathrm{ed}$.). Ediciones Pirámide, en esta obra en su primera parte se exponen ejemplos unificadores de carácter federalista y de origen alemán, mientras que su segunda parte se orienta a la génesis y desarrollo del proceso comunitario. Actualmente la UE cuenta con 28 Estados miembros, aunque debemos considerar el desenganche de Reino Unido tras el Brexit. En tanto Países candidatos, son cinco: Albania, Antigua República Yugoslava de Macedonia, Montenegro, Serbia y Turquía. Y Candidatos potenciales, son dos Bosnia y Herzegovina, y Kosovo. Información y datos en el Portal oficial de la UE. Disponibles en <http://europa.eu/about-eu/countries/index_es.htm\#goto_2> [última consulta, julio $8,2018]$.
} 
articulación del principio de la igualdad de los Estados miembros —al que se refiere el bloque temático cuatro de nuestra selección - materia que desarrolló el TJ en el caso Comisión/Reino Unido ${ }^{66}$, ni tampoco antagoniza con el principio de la cooperación reforzada, por medio del cual, algún grupo de Estados miembros de la UE, pueden ir más allá del nivel de exigencia impuesto por los centros de decisión de la UE.

Pues bien, aclarado el concepto anterior - en cuanto cada modelo de integración impone sus propias exigencias a quienes pretendan ser miembros del proyecto- en el caso concreto la CCJ exigió, para permitir el acceso al colegio de jueces a magistrados propuestos por la República Dominicana, que dicha nación previamente ingresara al núcleo político central del SICA. Recordemos que el proyecto centroamericano comenzó con cinco naciones, Costa Rica, El Salvador, Guatemala, Honduras y Nicaragua ${ }^{67}$. Actualmente cuenta con ocho Estados miembros, entre los cuales, desde el año 2013, la República Dominicana lo hace en plenitud. Pero al momento de la opinión consultiva, esto no era así, razón por la cual la CCJ construyó este criterio interpretativo sobre las normas del SICA que le permitirían eventualmente a un Estado, ingresar al Estatuto de la CCJ. Primero valoró positivamente las acciones de la República Dominicana, reconociéndole su colaboración con el SICA. Entonces alineándose con el principio de progresividad, la CCJ subrayó que su incorporación ha sido gradual al proceso de integración centroamericana, y agregó que mediante el Acuerdo de Asociación de 2003 ya se le concedió la calidad de Estado asociado del SICA.

Inmersa en este ejercicio, la CCJ explicó que en el SICA se distinguen cuatro categorías de Estados, primero, los Estados miembros fundadores $\mathrm{u}$ originales, que son los que suscribieron y ratificaron el PT, y que, a estos se refiere el art. 1 del PT, segundo, los Estados miembros por adhesión, como Belice el cual depositó (2000) el correspondiente

\footnotetext{
${ }^{66}$ Sentencia del TJ de 24 de marzo de 1979, Comisión c. Reino Unido, as. C-231/78, ECLI:EU:C:1979:101.

${ }^{67} \mathrm{La}$ integración del Istmo Centroamericano es producto de una evolución histórica que ya vimos en el capítulo I, al cual nos remitimos en todos los detalles. Sólo recordemos aquí que la idea unitaria es prehispánica, y tras la independencia la Capitanía General de Guatemala se dividió en las actuales naciones de Costa Rica, El Salvador, Guatemala, Honduras y Nicaragua, las que en 1823 conformaron la Federación Provincias Unidas Centroamericanas. En 1838 se disuelve en naciones. En 1903 Panamá se independiza de Colombia. En 1907 nace la Confederación Centroamericana más el Tribunal de Justicia Centroamericano, o Corte de Cartago. En 1951 se firma la Carta Constitutiva de ODECA por las mismas 5 naciones. En 1980 los 5 Estados miembros de ODECA más Panamá estudiaron la revitalización de ODECA, y en 1990 firman la Declaración de Antigua abogando por la reestructuración. Ahora, los seis países, en 1991 firmaron el PT de la Carta de ODECA naciendo el SICA, en funcionamiento desde 1993. El SICA sufrió dos ampliaciones, la primera en el año 2000 uniéndose Bélize, y la segunda en 2013 sumándose República Dominicana. Actualmente el SICA está conformado por ocho Estados miembros, a los que se adicionan una serie de países observadores regionales y extra-regionales.
} 
instrumento, tal como el PT lo permite en el inciso final de su art. 36, tercero, los Estados asociados, como República Dominicana, cuya situación la comprende el inciso primero del art. 31 del PT, y cuarto, los Estados observadores como España, México y la República de China, calidad contemplada en el art. 17 del PT. De lo anterior interpretó que es evidente que aquellas cuatro categorías de Estados, conllevan un diferente grado de intervención, los fundadores u originales y los por adhesión tienen plena participación dentro de los órganos e instituciones comunitarias - entre los cuales se encuentra justamente la CCJ_, en cambio, la intervención de los asociados y los observadores, es restringida y, han de circunscribirse a las modalidades que se establezcan en los instrumentos que se acuerden al respecto. Concluyendo que la República Dominicana, desde su posición de Estado asociado no puede pasar a ser parte del Estatuto de la CCJ.

Advertimos que el modo en que la CCJ ubicó al principio de progresividad en una concreta dimensión formal - como lo explicamos líneas arriba - fue precisando que el Acuerdo Complementario sobre la participación de la República Dominicana en el SICA, por el cual podría participar en los subsistemas económico, social, ambiental y de seguridad, y en sus órganos e Instituciones «quedaba supeditada su participación a la gradualidad, pertinencia y requisitos formales y económicos que estableciera en cada caso el SICA y, en tanto dure la transitoriedad, se evaluaría su participación como observador» ${ }^{68}$. A lo cual se suma el hecho de que en el Acuerdo Marco de Cooperación entre la CCJ y la Suprema Corte de Justicia de la República Dominicana, sólo se determinó que la CCJ consideraría a los magistrados dominicanos como observadores de la misma, en tanto el Estado dominicano suscribiera y ratifique el Convenio de Estatuto de la CCJ de 1992.

Si comparamos este punto específico con la solución de la CAN, observamos una cuestión diferente, pues en el proyecto andino la normativa aplicable al TJCA no distingue para el caso de investir a un magistrado, entre un nacional de un País miembro pleno, o de uno asociado. Más aún, en la CAN, dado que se integra el TJCA en razón de un juez por cada Estado miembro, se produce una composición par del tribunal, lo que se soluciona, invitando a un juez de un País miembro asociado a integrar el TJCA. Por consiguiente el juez de un País asociado, no es un mero juez observador, como en la Corte centroamericana, sino que actúa con voz y voto pleno al interior de la Corte andina.

En el asunto bajo análisis, la CCJ resolvió que, previo a incorporarse, más allá de todo lo valorado en cuanto a su progresivo acercamiento, deben cumplirse las formalidades, decretando lo siguiente, «para que República Dominicana se incorpore a la CCJ en calidad

\footnotetext{
${ }^{68}$ Considerando VIII en la Sentencia de la CCJ de 10 de noviembre de 2006, Consulta Parlacem/República Dominicana, expediente 76-03-12-09-2006, as. 76/06.

216
} 
de Miembro Pleno, deberá adherirse al PT y al Convenio de Estatuto de la $\mathrm{CCJ}{ }^{69}$. Aunque le reconoció el derecho de nivel intermedio que ostenta, recordando que «Mientras se cumplen los procedimientos anteriores incluyendo la adhesión, República Dominicana puede designar observadores en esta Corte» ${ }^{70}$. Así entonces, de todo lo anterior se sigue que el principio de progresividad aplicado a la expansión del proyecto, requiere de una formalidad en carácter de complemento eficaz.

En conclusión, de todo lo analizado en este apartado destinado exclusivamente al ejercicio jurisprudencial de la CCJ, se demuestra empíricamente que este tribunal sí produce jurisprudencia integracionista de valor claramente positivo, cuestión que ha fortalecido al SICA, toda vez que las sentencias analizadas incorporan aportes significativos y concretos al desarrollo del esquema centroamericano, entre los cuales ha aclarado las metodologías interpretativas, ha realzado la primacía del Derecho del SICA, resuelve con amplias competencias diversos contenciosos, absolviendo consultas prejudiciales y opiniones consultivas en variados temas del Derecho del SICA. Sin embargo, aun cuando el SICA confrontado con los modelos de integración de su entorno - CAN y MERCOSUR - es mucho más robusto, tanto en lo legislativo (capítulo II de esta tesis), como en el desarrollo jurisprudencial que hemos analizamos, la CCJ no alcanza en ningún caso el nivel de progreso, ni de intensidad del TJUE, pues el ejercicio de la Corte de Luxemburgo, es abrumadoramente abundante y más sustancioso, involucrando toda aquella complejidad de materias que seleccionamos al inicio de este capítulo y que clasificamos en nueve bloques temáticos ${ }^{71}$, y como vemos la Corte centroamericana no ha cubierto siquiera dichos nueve temas centrales que fluyen de las clásicas construcciones jurisprudenciales de la Corte de Luxemburgo.

\footnotetext{
${ }^{69}$ Vid. parte final del Decisorio Primero en sentencia ibídem.

${ }^{70}$ Decisorio Segundo en sentencia ibídem.

${ }^{71}$ Los nueve bloques temáticos que seleccionamos desde el ejercicio del TJUE eran: 1. el efecto directo y la primacía del Derecho de la UE, 2. el principio de la responsabilidad patrimonial de los Estados miembros y, de la UE misma, por violación al Derecho de la UE, y al subsecuente derecho a ser indemnizado, 3. el principio de proporcionalidad, 4. el principio de la igualdad de los Estados miembros, 5. el principio de la aplicación uniforme del Derecho de la UE, 6. la contribución al desarrollo del mercado común, 7. el principio de la no discriminación por razón de la nacionalidad en materias económicas, 8. la libre circulación, y la influencia para el principio de la igualdad de trato, y 9. la precisión del principio de no discriminación, en su ampliación y restricción.
} 


\subsection{LA PRODUCCIÓN DE JURISPRUDENCIA INTEGRACIONISTA POR EL TRIBUNAL DE JUSTICIA DE LA COMUNIDAD ANDINA}

Para centrarnos en el análisis de la jurisprudencia integracionista del TJCA es importante tener presente dos aspectos, uno, recordar que en la génesis de la CAN se constata una carencia orgánica, pues el proyecto originario no contó con una Corte en carácter de órgano permanente cuestión que trajo múltiples problemas, circunstancias que forzaron la aparición del TJCA ${ }^{72}$, y dos, el hecho de que en la actualidad la CAN es observada un tanto debilitada por razones multifactoriales ${ }^{73}$. Sin embargo se justifica hacernos cargo en esta tesis del desarrollo del TJCA pues, por una parte esta Corte se encuentra vigente, y por otra, su ejercicio jurisdiccional desde sus primeros fallos, ha dado cuenta de un aporte positivo y sustantivo para la región del Cono Sur de América.

En tal sentido y siguiendo nuestro criterio de selección, analizaremos a continuación jurisprudencia integracionista del TJCA que aborda la primacía del Derecho de la CAN, la interpretación de la ley comunitaria derogada, la cierta dosis jerárquica del TJCA ante los tribunales nacionales, razona sobre el complemento indispensable, la inaplicabilidad de determinada norma nacional y aborda la función de la Corte en cuanto evita el caos

\footnotetext{
${ }^{72}$ La CAN o CA, presentó la carencia orgánica señalada, en circunstancias de que a esa altura del desarrollo del Derecho Comunitario ya se encontraba resuelto como, indispensable el contar con un órgano jurisdiccional. Al decir de VIGIL, el proyecto CAN venía con un pecado original, el acuerdo nació cojo, al no haberse establecido desde el mismo momento en que renacía ese embrión de la integración subregional, un garante de legalidad. Lo cierto es que únicamente contenía un pobre mecanismo de solución de controversias que se basaba en negociaciones, buenos oficios, mediación y conciliación. VIGIL TOLEDO, R. (2011). La estructura jurídica y el futuro de la comunidad andina ( $1^{\mathrm{a}}$ ed.). Madrid: Civitas Thomson Reuters, p. 39. Es constante en la doctrina el hecho insistir en que es menester la existencia de un tribunal internacional o de integración, para lograr una sólida permanencia de una determinada OI o de Integración, cuestión que ya hemos apuntado. En ese contexto es que la CAN en 1978 comienza a subsanar el error orgánico, declarando los Estados miembros la imperiosa necesidad de contar con un órgano jurisdiccional, lo cual condujo al Tratado respectivo (vigor 1983), creándose el TJ del Acuerdo de Cartagena, pero más tarde tras el Protocolo de Cochabamba (1996, vigente 1999) cambió su nombre por el actual TJ de la Comunidad Andina.

${ }^{73}$ Este proceso regional enfrentado a la actual realidad mundial se encuentra debilitado, así lo observa la doctrina. CAETANO manifiesta que en tiempos recientes muchos de los procesos de integración en América Latina han ingresado en situaciones críticas de diversa índole, lo que ha llevado a quiebres que en algunos casos han puesto en riesgo la continuidad de algunas de esas experiencias de integración. Para él, esto último es lo que estaría ocurriendo con la CAN, aseverando que las razones que explican el desgaste son multicausales [...], pero en parte, pueden explicarse por los efectos de un cambio en el paradigma global de integración, en el marco de nuevos escenarios a los que no todos los procesos han sabido adaptarse. CAETANO, G. (2015). ¿Hacia un nuevo paradigma integracionista en el mercosur? contextos y desafíos de la encrucijada actual. Relaciones internacionales: Revista académica cuatrimestral de publicación electrónica, 30.
} 
jurisprudencial. Dicha selección temática sigue el criterio ya establecido, en cuanto va coincidiendo con algunos de los nueve bloques temáticos extraídos del ejercicio jurisdiccional del TJUE, criterio de selección de sentencias que ya explicamos en el apartado tres de este capítulo.

\subsubsection{LA CONSOLIDACIÓN FORMAL DE LA PRIMACÍA DEL DERECHO DE LA CAN} GRACIAS AL EJERCICIO DE LA CORTE ANDINA

Fue muy interesante la respuesta de la Corte andina a la consulta prejudicial en el caso Aktiebolaget Volvo/Volmo ${ }^{74}$, porque el tribunal recorrió tres importantes temáticas para el derecho de la integración, en primer lugar, puso de relieve el principio de legalidad y el principio de primacía del derecho de la integración por sobre el nacional, en segundo lugar, precisó que el método teleológico es el más idóneo para la interpretación de las normas integracionistas y por último, en tercer lugar, destacó la importancia del derecho a la marca comercial, el cual opera y se articula en un mercado común, propio del derecho de la integración.

Al desarrollar aquellas temáticas la Corte andina va coincidiendo con varias materias ya resueltas por la Corte de Luxemburgo, presentándose en primer lugar una conexión con el tema uno de nuestra selección, esto es, con el efecto directo y la primacía del Derecho de la UE, proveniente de la creación del TJ en los casos Van Gend \& Loss y Costa/Enel, según ya lo recordamos, y por ende nos remitimos al correspondiente apartado ${ }^{75}$. En segundo lugar, se relaciona con el tema cinco, el principio de la aplicación uniforme del Derecho de la UE, que el TJ desarrolló en el caso Neumann, según ya lo recordamos ${ }^{76}$. En tercer lugar, la sentencia de la CCJ también se vincula con el tipo de interpretación teleológico propio del TJUE. Por último, y en cuarto lugar, se presentan elementos del tema seis, esto es, la contribución al desarrollo del mercado común, al respecto recordemos que fue fundamental la jurisprudencia del TJ partiendo por la creación del concepto mismo, pues en un inicio los Tratados no lo definían, siendo en el caso $S c h u l^{77}$ donde el TJ efectúa esta contribución pretoriana pasando a construir un concepto de mercado común, expresando:

«El concepto de mercado común tal y como lo ha desarrollado este TJ en una jurisprudencia constante, tiene por objeto la eliminación de todos los obstáculos a

\footnotetext{
${ }^{74}$ Sentencia del TJCA de 3 de diciembre de 1987, Interpretación prejudicial, Aktiebolaget Volvo c. Volmo, consulta de Consejo de Estado de la República de Colombia, Sala de lo Contencioso Administrativo, Sección Primera, as. 1-IP-87.

${ }^{75}$ Vid. en este capítulo el apartado 4.1.1. La jurisprudencia de la CCJ relacionada a la jerarquía y vigencia del derecho interno, internacional y comunitario.

${ }^{76}$ Ídem.

${ }^{77}$ Sentencia del TJ de 5 de mayo de 1982, Schul, as. C-15/81, ECLI:EU:C:1982:135.
} 
los intercambios intracomunitarios con el fin de fundir los mercados nacionales en un mercado único estableciendo condiciones lo más próximas posibles a las de un auténtico mercado interior» ${ }^{78}$.

La relevancia de la respuesta del TJ se basa en que desarrolló un concepto de mercado común en un momento histórico en que aún no había sido establecido uno legislativamente. Sólo más tarde, y de modo retrasado a esta actividad jurisprudencial niveladora, llegaría la función legislativa positivizando un concepto en el AUE, ahora eso sí, bajo la idea de mercado único, por el cual se entendería como un espacio sin fronteras interiores, en que la libre circulación de mercancías, personas, servicios y capitales estará garantizada ${ }^{79}$.

Aprovechemos de subrayar que en ese caso se observa nítido aquel desfase ${ }^{80}$ sobre el que ya hemos comentado, entre la realidad concreta del proyecto de integración y las normas imperantes. Pues tales normas, no satisfacen todas las necesidades legislativas de la integración. Carencia muy propia de este derecho incompleto, evolutivo y heteronormativo, que aspira a ser único, uniforme y homogéneo ${ }^{81}$. Desfase que la Corte de integración va nivelando de modo más rápido que el legislador ante el caso concreto, y de paso, efectúa su aporte concreto al proyecto.

Pues bien, estando entonces los antecedentes jurisprudenciales europeos dispuestos como recién recordamos y resumimos, en América Latina los hechos en la causa Aktiebolaget Volvo/Volmo daban cuenta de que en Colombia se había solicitado el registro de la marca Volvo, a la que se opuso otra muy similar, Volmo S.A., resultando denegada la solicitud para Volvo, y su reclasificación también se rechazó. Aktiebolaget Volvo apeló al Consejo de Estado de Colombia quien dirigió a la Corte andina una interpretación prejudicial de

\footnotetext{
${ }^{78}$ Considerando 33 en sentencia ibídem.

${ }^{79} \mathrm{El} \mathrm{AUE}$ viene, con posterioridad a la labor jurisprudencial del TJ, a desarrollar un concepto legislativo de mercado común, señalándose en su art. 13, que el Tratado CEE será complementado con el Art. 8-A el cual en su inciso $2^{\circ}$ señala «El mercado interior implicará un espacio sin fronteras interiores, en el que la libre circulación de mercancías, personas, servicios y capitales estará garantizada de acuerdo con las disposiciones del presente Tratado».

${ }^{80} \mathrm{El}$ fenómeno de desfase, que en ocasiones se presenta entre la realidad dinámica del proyecto de integración $v / s$ la respuesta legislativa, ya lo precisamos en la primera parte de este capítulo, y dimos ejemplos en las notas 4 y 5 .

${ }^{81}$ En cuanto a que es incompleto, evolutivo y heteronormativo, vid. LIÑÁN, 2014e, p. 370, y párrafo 57 en el Laudo del TAAM de 28 de abril de 1999, República Argentina c. República Federativa de Brasil, as. 1/1999, y respecto de la idea de llegar a ser único, uniforme y homogéneo, vid. Sentencia del TJCA de 25 de mayo de 1988, Interpretación prejudicial, Germán y Ernesto Cavelier, consulta de la Corte Suprema de Justicia de la República de Colombia, as. 2-IP-88. GOAC Nº 33 de 1988.
}

220 
normativa específica ${ }^{82}$. La Corte respondió la consulta abordando las tres áreas que anunciamos al inicio de la siguiente forma.

1. Primero recordó lo indispensable que es su función interpretativa para tutelar la vigencia del principio de legalidad en el proceso de integración y para adaptar funcionalmente su complejo ordenamiento jurídico, permitiendo su aplicación uniforme en los Países miembros, objetivo que está fuera de las competencias de los jueces nacionales, tarea que compete exclusivamente al Tribunal comunitario.

Respecto de la primacía ${ }^{83}$ del Derecho andino, la Corte recordó que ésta es una cuestión zanjada «legislativamente». Justamente aquí — como lo explicamos en los capítulos I y IIdetectamos otro caso en que construcciones jurídicas que en el proyecto europeo fueron creados jurisprudencialmente, en Latino América se incorporan legislativamente, esto es, ya resueltas, lo cual ocurre — según vimos - dado la época en que se produce la recepción del fenómeno integracionista en América Latina (post Guerra Fría, a diferencia de Europa post Segunda Guerra Mundial). Es interesante advertir la forma en que la Corte destaca esta circunstancia pues destaca que la «incorporación legislativa» se produjo incluso antes a la entrada en funcionamiento de la misma Corte, prevaleciendo sobre las normas nacionales, sin que puedan oponerse a él, medidas o actos unilaterales de los Países Miembros. Explicándolo de la siguiente manera:

«el ordenamiento jurídico de la integración andina prevalece en su aplicación sobre las normas internas [...], por ser característica esencial del Derecho Comunitario, como requisito básico para la construcción integracionista. Así lo reconoció la Comisión del Acuerdo de Cartagena [...] cuando declaró la "validez plena" de los siguientes conceptos: a) el ordenamiento jurídico del Acuerdo de Cartagena tiene identidad y autonomía propias, constituye un derecho común y forma parte de los ordenamientos jurídicos nacionales, b) el ordenamiento jurídico del Acuerdo prevalece, $[\ldots]$, sobre las normas nacionales sin que puedan oponerse a él medidas o actos unilaterales de los Países Miembros» ${ }^{84}$.

\footnotetext{
${ }^{82}$ La consulta era puntualmente por los arts. 58, 62 y 64 de la Decisión 85 de la Comisión del Acuerdo de Cartagena.

${ }^{83}$ Tal como ya aclaramos en el punto 2 de la introducción de esta tesis, recordemos que existe una diferencia entre supremacía y primacía del derecho de la integración. Supremacía gira en torno al carácter supranacional de la UE, en cambio primacía, es un concepto posterior que surge para dejar a salvo la terminología referida a la supremacía constitucional, entendiendo que el derecho de la integración prima sobre el nacional en las materias abordadas por él. Lo aclaramos porque los autores y determinadas sentencias no hacen siempre la diferencia, y nosotros tampoco hemos procurado dibujar la frontera de estos conceptos en la presente tesis.

${ }^{84}$ Párrafo primero del Considerando 2 Preeminencia del derecho andino, en Sentencia del TJCA de 3 de diciembre de 1987, Interpretación prejudicial, Aktiebolaget Volvo c. Volmo, consulta de Consejo de Estado de la República de Colombia, Sala de lo Contencioso Administrativo, Sección Primera, as. 1-IP-87.
} 
Ahora bien, nosotros entendemos que dicha norma emanada de la función legislativa, únicamente se convierte en una realidad empírica al apoyarse en la función jurisdiccional de la Corte de integración. Pero como anotamos, el TJCA no existía a la fecha de dictarse y entrada en vigor de la norma a que se refiere la Corte, lo que originó el evidente desfase orgánico que ya hemos analizado en los capítulos anteriores, pero que además aquí concretamente implica la inexistencia del derecho, pues comprendemos que un derecho sin acción y sin tribunal, solo es ilusorio, o bien una mera expectativa. Esta es a nuestro juicio la razón de fondo que justifica la siguiente declaración de la Corte en su sentencia:

«Estos criterios alcanzan plena vigencia como norma jurídica con la entrada en vigor del Tratado constitutivo del tribunal, a partir del 19 de mayo de 1983 -en que este cuerpo legal comenzó a regir en la subregión» ${ }^{85}$.

En conclusión, en la CAN la declaración de la supremacía del Derecho de la integración se efectuó de modo diferente a Europa, donde se usó el cauce jurisprudencial debiendo la Corte de Luxemburgo efectuar su construcción explicando aquello que parecía evidente que, el Derecho de la UE gozaba de supremacía ante el nacional (1964, Costa/Enel ${ }^{86}$ ). Y por otra parte, la Corte del modelo europeo ${ }^{87}$ participó desde la génesis organizativa en el complejo proyecto del viejo continente (1952) no así el tribunal de la CAN.

2. Ahora por el segundo aspecto, esto es, la interpretación de las normas que componen el derecho de la integración, es muy destacable que la Corte andina explique cuál es el mejor método y además, qué es lo que ha de tenerse prioritariamente en cuenta. En este sentido manifestó lo esencial que resulta respetar las características propias del derecho integracionista para efectuar una interpretación correcta, destacándolo de la siguiente manera:

«En cuanto a los métodos de interpretación que debe utilizar el Tribunal, ha de tenerse presente la realidad y características esenciales del nuevo Derecho de la Integración y la importante contribución que en esta materia tiene ya acumulada la experiencia europea, sobre todo por el aporte de la jurisprudencia de la Corte de Justicia, Tribunal único de las CE, en la aplicación de este Derecho, que se está

\footnotetext{
${ }^{85}$ Párrafo segundo del Considerando 2 Preeminencia del derecho andino, en sentencia ibídem.

${ }^{86}$ Sentencia del TJ de 15 de julio de 1964, Costa/Enel, as. C-6/64, ECLI:EU:C:1964:66.

${ }^{87}$ Nuestra Corte de referencia participa en la génesis del proyecto europeo desde la Europa de los seis, de hecho la Comunidad Europea del Carbón y el Acero (CECA, 1951) ya poseía a su TJCE del Carbón y el Acero (1952), tribunal que luego sería una de las denominadas instituciones comunes de la CECA, la Comunidad Económica Europea y la Comunidad Europea de la Energía Atómica (1957) identificadas las tres bajo la noción de Las Comunidades Europeas, conociéndose su Corte bajo el nombre de: Tribunal de justicia de las Comunidades Europeas - TJCE, el cual desde el Tratado de Lisboa (vigor 2009) adopta su estructura y nombre actual: TJUE. Vid. et al. ABELLÁN HONRUBIA, 2005, pp. 22-25.
} 
haciendo constantemente en beneficio de la construcción comunitaria, sin perder de vista el fin permanente de la norma» ${ }^{88}$.

Nosotros apreciamos, del recién transcrito considerando, que la Corte andina está impidiendo las interpretaciones desconectadas de la globalidad del proyecto integracionista, y precisamente para evitar tales desconexiones el TJCA llama a considerar tres aspectos, primero, las características del derecho de la integración, segundo, la jurisprudencia europea, y tercero, la dimensión finalista para sus normas comunitarias. Por el segundo aspecto - el llamado a considerar la jurisprudencia europea - nuevamente se aprecia como los modelos Latino Americanos le otorgan una completa posición de fuente autorizada a las construcciones jurisprudenciales del TJUE en un carácter directo, de hecho más aun lo observaremos en el capítulo IV al analizar el diálogo judicial. En cuanto al tercer aspecto - la dimensión finalista - al igual que ha hecho el TJUE prestando especial atención al método teleológico, la Corte andina justifica su utilización atendiendo a que éste es el más idóneo de todos los componentes hermenéuticos para responder consultas prejudiciales en un esquema de integración. Señalando al respecto:

«corresponde el empleo preferente de los métodos de interpretación llamados "funcionales", como los métodos sistemáticos y de interpretación teleológica, sin dejar de utilizar, si fuese el caso, los demás universalmente admitidos, con la advertencia de que el método teleológico, que adquiere connotación especial en el derecho comunitario como normativa de un proceso de realizaciones conjuntas para el logro de un objetivo común, es el que mejor se adapta a la naturaleza propia de la decisión prejudicial en cuanto tiene en cuenta el "objeto y fin" de la norma, o sea, en último término, el proceso de integración de la Subregión Andina que es el propósito que inspira la suscripción del Acuerdo de Cartagena» ${ }^{89}$.

A nuestro juicio resalta, en lo referido a la extensión competencial para interpretar las normas comunitarias, la advertencia que hace la Corte andina, consistente en que, «a pesar de que una norma comunitaria pase a ser parte de un Estado miembro, esta Corte sigue siendo competente en su interpretación» ${ }^{90}$. Es decir, lo llamativo es que la Corte advierta, o más bien tenga temor de que «un Estado miembro incorpore una norma comunitaria en su

\footnotetext{
${ }^{88}$ Primera parte del párrafo único del Considerando 3.5 Métodos de interpretación, en la Sentencia del TJCA de 3 de diciembre de 1987, Interpretación prejudicial, Aktiebolaget Volvo c. Volmo, consulta de Consejo de Estado de la República de Colombia, Sala de lo Contencioso Administrativo, Sección Primera, as. 1-IP-87.

${ }^{89}$ Segunda parte del párrafo único del Considerando 3.5 Métodos de interpretación, en sentencia ibídem.

${ }^{90}$ Señala textual la Corte «Conviene advertir que, en el caso de que la norma comunitaria, objeto de la consulta, haya sido adoptada como norma interna en el País Miembro de donde proviene dicha consulta, no por ello pierde su competencia el Tribunal Comunitario, ya que la norma continúa perteneciendo al ordenamiento jurídico del Acuerdo, sin perjuicio de que también sea norma nacional». Último párrafo del Considerando 3.4 Alcance de la interpretación, en sentencia ibídem.
} 
sistema nacional y luego se intente desconectar del control jurisdiccional del órgano comunitario alegando incompetencia para interpretar ley nacional». Para nosotros esta circunstancia es una clara advertencia de la Corte andina, ante cualquier intento de nacimiento de alguna particular teoría jurídica en el sentido señalado, pues dicho criterio es incompatible, dañino y autodestructivo de la lógica del derecho de la integración.

También consideramos muy interesante y bueno el hecho de que la Corte pase a autoexigirse en el proceso de interpretación, que sus propias conclusiones jurídicas al evacuar consultas prejudiciales revistan realmente utilidad para juez nacional. Así el tribunal considera:

«La exigencia del Estatuto, de que tales hechos se informen al Tribunal de manera sucinta, ha de entenderse entonces no en el sentido de que éste se ha de pronunciar sobre ellos, lo cual le está vedado, sino para que, conociéndolos, pueda el Tribunal enfocar u orientar la doctrina de suerte que su interpretación resulte útil para el juez nacional que debe fallar. De otro modo, la interpretación que adopte el Tribunal podría resultar demasiado general y abstracta, en el inagotable universo de la teoría jurídica e inútil» ${ }^{91}$.

Finalmente sobre la aportación al derecho de marca en la CAN, lo más significativo para nuestro análisis, es el hecho de que la Corte andina detectando la dificultad de armonización en esta materia, que entiende que debe desarrollarse y desplegarse en un mercado común andino, fue capaz de generar importantes avances muy útiles al proyecto completo de la CAN, en el sentido de que desarrolló un concepto general de marca aplicable a la sub-región andina, es decir, por este aspecto la sentencia asume un carácter constitutivo $^{92}$, luego intentó homogenizar determinadas clasificaciones, y confirmó que en la CAN la marca notoria está especialmente protegida, por lo que no requiere de prueba quedando amparada por el aforismo notoria non egent probatione.

Ahora bien, más allá de la temática concreta del caso analizado - la marca comercial, cuestión recién condensada en el párrafo anterior-, resultó que absolutamente toda esta

\footnotetext{
${ }^{91}$ Parte final del párrafo primero, del Considerando 3.4 Alcance de la interpretación, en sentencia ibídem.

${ }^{92} \mathrm{Al}$ crear un concepto jurídico que imperará en la región, la sentencia asume, en ese aspecto, una naturaleza constitutiva (ya vimos las tres posibilidades: constitutivas, declarativas y de condena, así como la gran problemática respecto de si las sentencias crean o no normativa. COUTURE, 1958, p. 304, vid. B) La sentencia y el derecho). En este caso concreto el concepto creado fue el de marca. Estableciendo la Corte andina que «la marca pasa a ser información básica destinada al consumidor potencial para facilitar y propiciar su libertad de elección, debe contribuir a que sea "transparente" la oferta pública de productos y servicios. Y cumple una función indicadora de la calidad, alta o baja, de determinado producto o servicio». Párrafo primero del Considerando 6.3 La marca frente a los consumidores, en la Sentencia del TJCA de 3 de diciembre de 1987, Interpretación prejudicial, Aktiebolaget Volvo c. Volmo, consulta de Consejo de Estado de la República de Colombia, Sala de lo Contencioso Administrativo, Sección Primera, as. 1-IP-87.
} 
construcción jurisprudencial del TJCA giró en sentido inverso a lo que habían resuelto los tribunales y organismos nacionales, por lo tanto queda demostrado que la Corte andina logra efectivamente reconducir el proceso de integración en esta materia específica, cuestión que ha de ser lo propio en todos los tribunales de los procesos latinoamericanos, porque aquello da cuenta de rol central que juegan las Cortes bajo análisis en cada uno de los procesos regionales a que pertenecen, alineándose entonces con nuestra hipótesis planteada en la introducción de esta tesis.

\subsubsection{Un CAMBIO de CRITERIO COMPLetAMENTE EVOlUtivo de LA CORTE ANDINA SOBRE LA INTERPRETACIÓN DE LA LEY COMUNITARIA DEROGADA y LA SUPREMACíA DEL DERECHO DE LA CAN}

Es evidente que cada vez que los procesos de integración ensanchan sus límites asumiendo nuevos desafíos o perfeccionando determinados aspectos, es a todas luces un buen acierto, y en tal derrotero el apoyo ágil de cada uno de los órganos de la organización es fundamental, pero para nosotros es aún más lúcido cuando la evolución se ubica en un sólo órgano o Institución, como resultado del auto-análisis crítico del mismo órgano o Institución, toda vez que esto se condice con un afinado ritmo de auto-exigencia, reflejando que el órgano está atento en detectar la forma en cómo servir mejor a la organización a la que pertenece, y en nuestro caso, centramos la búsqueda de tal comportamiento en el órgano jurisdiccional.

La idea expuesta en el párrafo anterior se reflejó con toda claridad en la ocasión en que el TJCA se auto impuso la exigencia de que sus respuestas a una consulta prejudicial —en la UE denominada cuestión prejudicial—, debían ser concretamente útiles al juez nacional, circunstancia que, si bien, ya pudimos apreciar en el aspecto final del caso anterior Aktiebolaget Volvo c. Volmo ${ }^{93}$, ahora lo podremos observar con mucho más énfasis en la sentencia dictada en la causa Mac Pollo ${ }^{94}$, mediante la cual generó jurisprudencia integracionista en dos aspectos, en primer lugar, la Corte cambió su criterio sobre la interpretación de ley comunitaria derogada, que en una primera etapa entendía que eliminada una norma del Derecho de la CAN, simultáneamente la Corte perdía su competencia para interpretarla, sin embargo, ahora evoluciona y se reorienta, importando determinadas soluciones Estatales que diferencian entre la vigencia de la ley in abstracto $v /$ s in $_{\text {concreto }}{ }^{95}$, es decir, en este aspecto $-\mathrm{y}$ en lo que venimos rastreando- estamos ante

\footnotetext{
${ }^{93}$ Parte final del párrafo primero, del Considerando 3.4 Alcance de la interpretación, en sentencia ibídem.

${ }^{94}$ Sentencia del TJCA de 11 de octubre de 1994, Interpretación prejudicial, Marca: Mac Pollo, as. 1-IP-94.

${ }^{95}$ La noción entre la vigencia de la ley in abstracto $v / s$ in concreto, es propia del estudio de los efectos de la ley en el tiempo al interior de un derecho nacional, diferenciándose entre, 1) la vigencia de la ley in abstracto,
} 
una jurisprudencia integracionista del tipo reorientadora ${ }^{96}$, y en segundo lugar, el TJCA recalcó la correcta posición que un tribunal de integración ostenta ante los tribunales nacionales. Pues bien, tal posición gira teóricamente por el cauce del principio de colaboración, pero las consecuencias prácticas dejan a la vista que cuando una Corte de integración asume el rol de último intérprete se posiciona como propietaria de un lógico carácter jerárquico.

Como se aprecia, los anteriores aspectos anunciados justifican sobradamente la selección que hemos hecho de esta jurisprudencia para proceder a analizar sus principales aspectos, la cual se conecta con el tema uno del bloque temático, el efecto directo y la primacía del Derecho de la UE, y con el tema cinco, el principio de la aplicación uniforme del Derecho de la UE.

La empresa Avidesa solicitó en Colombia el derecho de la marca Mc Pollo Su Pollo Rico, y se le concedió el 30 de octubre de 1984 por 5 años, pero debía ser inscrita y publicada, lo que ocurrió recién el 24 de febrero de 1992 más allá incluso del plazo de concesión del derecho. Ante esto la empresa Comidas Rápidas Mc Pollo S.A. en Colombia, y bajo sus leyes, demandó la nulidad del acto que había fijado vigencia a la marca desde el 24 de febrero de 1992, pues el plazo estaba caducado ${ }^{97}$. La defensa sostenía que la nulidad solo pretendía favorecer a la actora, para que ésta continuara utilizando, sin autorización, la marca de su propiedad. A su juicio el plazo de 5 años que le otorga la Decisión $85^{98}$ no habría vencido, pues el derecho le nacería desde el registro y publicación, lo cual había sucedido en 1992 y no en 1984, o bien, el plazo sería de 10 años según la Decisión $313^{99}$ que reemplazó la 85 .

que es aquella que se ubica entre la entrada en vigor y su derogación, $v / s$ b) la vigencia de la ley in concreto, que se refiere i) al estudio de la determinación de las situaciones de hecho a las que no se aplica, a pesar de estar vigente, y ii) al estudio de las que se aplican a pesar de haber cesado de estar vigente. Esta es la idea que expone la Corte citando a SANCHEZ-COVISA HERNANDO tal como veremos pocas líneas adelante.

${ }^{96}$ COUTURE, 1958, p. 304, vid. B) La sentencia y el derecho.

${ }^{97}$ Los desfases de plazos, la norma derogada y la vigencia se observa así: El acto administrativo de concesión, como se observa, lleva fecha 30-10-1984, dictado bajo el imperio de la Decisión 85, la cual fijaba en 5 años el plazo de vigencia de una concesión de marca; pero su inscripción en el Registro, sólo ocurrió el 24-2-1992, es decir, seis años después de la emisión del referido acto administrativo de concesión, y diez días más tarde de haber entrado en vigor la Decisión 313 publicada en la Gaceta Oficial del Acuerdo de Cartagena.

${ }^{98}$ Decisión de la Comisión del Acuerdo de Cartagena $N^{\circ}$ 85, Reglamento para la aplicación de las normas sobre propiedad industrial, publicada en la Gaceta Oficial del Acuerdo de Cartagena (GOAC) el 5 de junio de 1974. Disponible en el Portal oficial de la CAN en el enlace <http://www.comunidadandina.org/Normativa.aspx?GruDoc=07> apartado Decisiones [última consulta, octubre 1, 2019].

${ }^{99}$ Decisión de la Comisión del Acuerdo de Cartagena $N^{\circ} 313$, Régimen común sobre propiedad industrial, publicada en la GOAC, año IX, $\mathrm{N}^{\circ} 101$, del 14 de febrero de 1992. Disponible en el Portal oficial de la CAN 226 
En el anterior contexto descrito, el Consejo de Estado de Colombia ${ }^{100}$ dedujo una extensa consulta a la Corte andina por múltiples artículos de las Decisiones 85 y $313^{101}$. Respecto de dicha consulta, nosotros nos centraremos aquí sólo en dos extremos, de un extremo, respecto de la interpretación de normas derogadas de la CAN por el TJCA, y de otro extremo, respecto de una cierta dosis jerárquica, propia de las Cortes de integración ante los tribunales nacionales, emanada de su condición de último intérprete, todo según sigue a continuación.

\subsubsection{LA INTERPRETACIÓN DE NORMAS DEROGADAS DE LA CAN POR EL TJCA: UN CAMBIO DE CRITERIO}

En lo relativo al «criterio interpretativo de normas comunitarias derogadas» ${ }^{102}$ la consulta revestía bastante importancia pues la Decisión 85 que confería derecho por 5 años había sido derogada y reemplazada primero por la Decisión $311^{103}$ y luego por la 313, estableciéndose en esta última, 10 años, luego la Decisión $344^{104}$ mantuvo los mismos 10 años. Sucedía que se concedió el derecho en 1984, pero la inscripción y publicación fue en 1992. Para la Corte fue crucial determinar el sentido y alcance de las normas de la CAN destinadas a regir el acto impugnado, así advierte que la primera norma relevante es el art. 69 de la Decisión 85 la cual «si bien no está vigente, sí lo estaba al momento de expedirse el acto demandado, por lo cual en el análisis de legalidad debe ser tenida en cuenta».

en el enlace <http://www.comunidadandina.org/DocOficialesFiles/Gacetas/gace101.pdf> [última consulta, octubre 1, 2019].

${ }^{100}$ Sala de lo Contencioso Administrativo, Sección Primera.

${ }^{101}$ La extensa consulta abarcaba la interpretación de los arts. 56, 58, 69, 70 y 71 de la Decisión 85 de la Comisión del Acuerdo de Cartagena, y de los arts. 87, 98 y 102 de la Decisión 313 de la misma Comisión.

${ }^{102}$ Con precisión las normas sobre las que se solicitaba interpretación prejudicial eran el art. 85 de la Decisión 85 que indicaba «Todo derecho de propiedad industrial válidamente concedido de acuerdo en la legislación de los respectivos Países Miembros anterior a la vigencia del presente Reglamento subsistirá por el tiempo que fue concedido. En cuanto a su uso y goce, obligaciones y licencias, renovaciones y prórrogas, se aplicarán las normas que este Reglamento contiene». El art. 87 de la Decisión 313 que expresaba «El registro de una marca tendrá una duración de diez años contados a partir de la fecha de su concesión y podrá renovarse por períodos sucesivos de diez años». Y en idénticos términos el art. 98 de la Decisión 344.

103 Decisión de la Comisión del Acuerdo de Cartagena $\mathrm{N}^{\circ} 311$, Régimen comunitario sobre propiedad industrial, publicada en la GOAC, año VIII, $\mathrm{N}^{\circ}$ 96, del 12 de diciembre de 1991. Disponible en el Portal oficial de la CAN en el enlace <http://www.comunidadandina.org/DocOficialesFiles/Gacetas/gace096.pdf> [última consulta, octubre 1, 2019].

${ }^{104}$ Decisión de la Comisión del Acuerdo de Cartagena $\mathrm{N}^{\circ} 344$, Régimen común sobre propiedad industrial, publicada en la GOAC, año X, N 142, del 29 de octubre de 1993. Disponible en el Portal oficial de la CAN en el enlace <http://www.comunidadandina.org/DocOficialesFiles/Gacetas/gace142.pdf> [última consulta, octubre 1, 2019]. 
Enfrentaba entonces la Corte un impedimento mayúsculo, cual era, determinar sí podía o no llevar a cabo el análisis de normativa comunitaria derogada. Obstrucción de gran talaje, pues aquello, en principio no sería posible, debido a que el criterio imperante de la propia Corte andina era que se habría producido su pérdida de competencia, mediante el fenómeno que la Corte denomina sustracción competencial, lo cual explicó del siguiente modo:

«se ha venido considerando que cuando la interpretación solicitada se refiere a una norma como la Decisión 85, que ya fue sustituida, el Tribunal no podría emitir criterio, porque la Decisión dejó de pertenecer al ordenamiento jurídico del AC. En tal sentido, esta Alta Jurisdicción Andina ha venido consecuentemente declarando improcedente el requerimiento, en razón de que no puede producirse la interpretación por haber sobrevenido una sustracción de materia» ${ }^{105}$.

La importancia para nuestra investigación, se centra en la reorientación que hace el TJCA del proceso completo de la CAN un una materia específica, mediante una jurisprudencia integracionista del tipo reorientadora — es decir de las características procesales que ya hemos explicado varias veces. De tal modo que la frontera, o el marco de competencia restringido que antaño la misma Corte andina se había autoimpuesto, ahora debía desarmarlo paso a paso, pues se hacía imperioso evolucionar y cambiar el antiguo criterio, de lo contrario el asunto de fondo no tendría ninguna solución y quedaría al arbitrio del demandado.

Pues bien, bajo las circunstancias expuestas en los párrafos anteriores, la Corte plantea la posibilidad de materializar la interpretación, pero salvando las siguientes distinciones de rigor, primero, la Corte tendrá presente la sentencia del caso Noel ${ }^{106}$ la cual había dictado

${ }^{105}$ La sustracción de materia, causante de la incompetencia para los procesos hermenéuticos del órgano jurisdiccional de la CAN, es un motivo condensado por la Corte en su jurisprudencia sentada desde el 6 de abril de 1992 en las interpretaciones prejudiciales: 01, 02 y 03-IP-92 y 01, 02, 04, 05 y 06-IP-93, publicadas en la GOAC números 106, 112, 122, 137, 140, 147 y 150. Considerando 1 del apartado a) La primera norma relevante, tema B. En relación con los hechos y el derecho debatidos, del Capítulo III Normas comunitarias pertinentes, en la Sentencia del TJCA de 11 de octubre de 1994, Interpretación prejudicial, Marca: Mac Pollo, as. 1-IP-94.

${ }^{106}$ Sentencia del TJCA de 4 de julio de 1994, Interpretación prejudicial, Noel, as. 2-IP-94. Aquí la Corte analizó la aplicación de la ley en el tiempo, destacando que: desde la obra de PAUL ROUBIER solían referirse al problema del derecho transitorio, para enunciar tres posiciones de la acción de una ley en el tiempo: la retroactividad misma, su efecto inmediato y la supervivencia de la ley antigua. En el caso Noel, se estaba frente a las dos últimas: A) La supervivencia de los efectos de la ley antigua, los enfrentó citando un curso dictado en la Academia de Derecho Internacional de la Haya, titulado «Los Conflictos de Leyes en el Tiempo» precisando que M. E. SZASZY desde 1935 señalaba que el sistema de la supervivencia de la ley parte del postulado de la «unidad de tratamiento de una situación jurídica concreta». Fenómeno explicado por la necesaria confianza que la norma jurídica debe otorgar para la estabilidad de los derechos individuales. Así se llega a la regla generalmente aceptada de que «las leyes nuevas no puedan surtir efecto sobre un hecho cumplido»-tempus regit factum- o, a juicio de la Corte: sobre una situación jurídica concreta. En términos de 228 
recién hacía tres meses, en la que se planteaba un problema en términos de aplicación de la ley en el tiempo, y segundo, destacó que

«la supervivencia de los efectos de la ley antigua, la ultra-actividad de la ley, y el principio de no retroactividad de la ley, son sólo aspectos parciales del más general de los conflictos de leyes en el tiempo, al que también se lo conoce como el problema de la aplicación de la ley en el tiempo» ${ }^{107}$.

En el fondo la Corte andina reconoce lo necesario de la interpretación de la norma comunitaria derogada, pero en esta ocasión justifica el análisis, explicando que las leyes nacen y mueren, pero que en el momento del nacimiento y de la muerte, suscitan problemas específicos, ya que «su personalidad tiende a veces a rebasar el instante preciso en que se verifican esos dos acontecimientos» ${ }^{108}$. En este punto la Corte pasa a importar soluciones y estudios de los efectos de la ley en el tiempo para sistemas Estatales, aplicándolas ahora al nivel internacional del sistema andino. Nosotros no observamos obstáculo alguno desde la lógica jurídica como para haberse mantenido en aquella imposibilidad de interpretar normativa derogada autoimpuesta por la misma Corte, pues esto ya lo apreciamos bastante mermado desde el caso Noel, oportunidad en que ingresó al análisis de norma derogada, aunque en tal ocasión advirtió en forma categórica, que la mención de la disposición derogada obedecía al fenómeno de supervivencia del efecto de la norma anterior. Pero ambas sentencias, Noel (julio 1994) y Mac Pollo (octubre 1994) son casi simultáneas.

la aplicación de la ley, esta tendencia refleja el fenómeno denominado «ultra-actividad de la ley». B) Sobre el tránsito legal frente a una expectativa de derecho, la Corte consideró que en este caso, sí se materializaba, del momento en que hay una expectativa de derecho constituida por la solicitud de inscripción de una marca en trámite y con oposición, el cual estando pendiente se expidieron las nuevas normas. Y como era menester la interpretación prejudicial de la primera, estimó que ingresaría a su interpretación, advirtiendo en forma categórica que la mención a disposición derogada: obedecía al fenómeno de supervivencia del efecto de la norma anterior.

${ }^{107}$ Número 3 del literal a), del apartado Considerando, del apartado B) En relación con los hechos y el Derecho debatidos, del Cap. III. Normas comunitarias pertinentes, en la Sentencia del TJCA de 11 de octubre de 1994, Interpretación prejudicial, Marca: Mac Pollo, as. 1-IP-94.

${ }^{108}$ La Corte construye este cambio de dirección utilizando, primero, algunas aristas del caso Noel -ya mencionado-, y luego, con la importación de soluciones o estudios de los efectos de la ley diseñados para sistemas Estatales. Por tales circunstancias el tribunal expresa y cita a SANCHEZ-COVISA de la forma señalada arriba en el texto y además agrega «El estudio de la vigencia temporal de la ley es, por consiguiente, la determinación del período de tiempo durante el cual tiene la ley carácter obligatorio. Pretendemos investigar cuándo entra en vigor una ley, cuándo cesa de estarlo y en virtud de qué circunstancias rige a veces relaciones jurídicas nacidas fuera de su período de vigencia o, a la inversa, no rige relaciones jurídicas que nacieron en el período mencionado". (SANCHEZ-COVISA HERNANDO, Joaquín: "La vigencia temporal de la ley en el ordenamiento jurídico venezolano". Ediciones de la Contraloría General de la República. Caracas, 1976. Páginas 95, 118 y siguientes)». Considerando 3 del apartado a) La primera norma relevante, tema B. En relación con los hechos y el derecho debatidos, del Capítulo III Normas comunitarias pertinentes, en la Sentencia del TJCA de 11 de octubre de 1994, Interpretación prejudicial, Marca: Mac Pollo, as. 1-IP-94. 
En conclusión, esta jurisprudencia es altamente relevante para nosotros por dos aspectos, en primer lugar, porque se materializa una evolución de la misma Corte impulsando el proyecto completo al darle seguridad jurídica en uno de los aspectos que cubre el modelo de integración andino, explicando de modo prolijo la diferencia entre la vigencia de la ley in abstracto $\mathrm{v} / \mathrm{s}$ in concreto en el plano internacional integracionista de la CAN, aclarando que la primera - in abstracto - se ubica entre la entrada en vigor y su derogación, mientras que la segunda - in concreto - se refiere al estudio de la determinación de las situaciones de hecho a las que no se aplica, a pesar de estar vigente, o bien a las que se aplica a pesar de haber cesado de estar vigente ${ }^{109}$, así entonces el TJCA salvó el obstáculo jurídico pasando a interpretar la norma derogada en la dimensión in concreto, concluyendo que desde el momento que se otorgó el derecho debe computarse el plazo de 5 años de la norma vigente a esa época.

En segundo lugar, porque ante las características propias del derecho de la integración que ya vimos, en cuanto es incompleto, evolutivo y heteronormativo, pero que aspira a ser único, uniforme y homogéneo ${ }^{110}$ _, el tribunal de integración trabaja por dicha mutación ante la carencia normativa, cuestión que en este caso concreto el TJCA lo resalta al poner de manifiesto que detecta una indeseable falta de normativa, circunstancia que justifica su trabajo jurisprudencial. Ambos aspectos la Corte andina los explica de la siguiente manera: «una interpretación diferente conduciría a que se dejara al libre arbitrio del beneficiario de marca en cada país y en el área andina, la fijación del comienzo y el término del plazo de duración de la misma [...]. Semejante interpretación no traduciría, por lo demás, el espíritu de la legislación comunitaria, que podría en esa forma quedar comprometido ante el hecho real y concreto de la inexistencia de unas deseables soluciones expresas en el ordenamiento andino, a falta de las cuales ha de mediar una interpretación como la que realiza el Tribunal a través del presente

\footnotetext{
${ }^{109}$ Sería la in abstracto, sobre la que la Corte tenía la doctrina de no poder abocarse, por ya no pertenecer al Ordenamiento de la CAN, es decir, por la referida «sustracción de materia». La in concreto, en cambio, es diferente, y es a la que ahora pasa a hacerse cargo, para lo cual vuelve en apoyarse en doctrina (citando en extenso a SANCHEZ COVISA, 1976) subrayando que, vigencia "in abstracto", vigencia "in concreto": "Una y otra cuestión tienen, sin embargo, un profundo nexo sistemático, que es, en sustancia, la dimensión temporal de la fuerza obligatoria de la ley". Aspectos ambos de un mismo y único problema relativo a la "dimensión temporal de la fuerza obligatoria de la ley".

${ }^{110}$ En cuanto es incompleto, evolutivo y heteronormativo, vid. LIÑÁN, 2014e, p. 370, y párrafo 57 del Laudo del TAAM de 28 de abril de 1999, República Argentina c. República Federativa de Brasil, as. 1/1999, y respecto de la idea de único, uniforme y homogéneo, vid. Sentencia del TJCA de 25 de mayo de 1988, Interpretación prejudicial, Germán y Ernesto Cavelier, consulta de la Corte Suprema de Justicia de la República de Colombia, as. 2-IP-88. GOAC N 33 de 1988. Nos remitimos en todo a lo ya explicado en la Introducción de este capítulo III.
}

230 


\section{fallo, destinada a desentrañar los principios implícitos en las normas comunitarias» $^{111}$.}

Por lo tanto el principal aporte de esta sentencia al modelo andino de integración, radica en que la Corte asume que su labor jurisprudencial también conlleva actuar y dar solución a las problemáticas del grupo aún a falta de normativa, lo que tilda de indeseable, pero lo asume como necesario, y de otro lado, se suma que ella misma evoluciona y cambia de criterio de ser necesario. Todo lo cual deja a la Corte andina robustecida como órgano al servicio del desarrollo del proyecto de integración al cual ella pertenece, circunstancias que se alinean nuevamente con nuestra hipótesis.

\subsubsection{El CRITERIO DE LA CORTE ANDINA RESPECTO DE UNA CIERTA}

DOSIS JERÁRQUICA DE LAS CORTES DE INTEGRACIÓN SOBRE LOS TRIBUNALES NACIONALES

El segundo aspecto de trascendencia de la sentencia Mac Pollo ${ }^{112}$ que estamos analizando, es el referido a una cierta dosis jerárquica de que se impregnan los tribunales de integración, mostrándose un tanto por encima de los tribunales nacionales. En realidad éste es un fenómeno que se ha identificado a partir del análisis de las formas en que el TJUE aborda las temáticas sometidas a su decisión en la UE cuestión que va destacando la doctrina $^{113}$. Dicha percepción jerárquica no obedece a la clásica estructura orgánica que en el nivel nacional existe entre el juez de primera instancia o inferior, respecto del tribunal superior — pues el vínculo entre el TJUE y los tribunales nacionales se satisface por medio del principio de colaboración-, por tal razón es que nosotros lo comprendemos posicionado en la dimensión sustancial del derecho de la integración. Es decir, justamente a nivel de interpretación del derecho de la integración en línea con la uniformidad del mismo en toda la UE o en su caso en todo el SICA, la CAN o el MERCOSUR. Así entonces al ser

${ }^{111}$ Párrafo tercero, del segundo Considerando, del apartado c), tema B. En relación con los hechos y el derecho debatidos, del Capítulo III Normas comunitarias pertinentes, en la Sentencia del TJCA de 11 de octubre de 1994, Interpretación prejudicial, Marca: Mac Pollo, as. 1-IP-94.

${ }^{112}$ Sentencia del TJCA de 11 de octubre de 1994, Interpretación prejudicial, Marca: Mac Pollo, as. 1-IP-94.

${ }^{113}$ La doctrina detecta esta posición jerárquica — no orgánica sino sustancial— a partir del análisis de las formas en que el TJUE aborda las temáticas sometidas a su decisión, más allá del acuerdo formal de la relación tribunal local-TJUE, a través del principio de la cooperación. Así por ejemplo, en un análisis particular, LENAERTS y GUTIÉRREZ-FONS son del criterio de que esta dosis jerárquica la introduce directamente la Corte de Luxemburgo, afirmando al respecto lo siguiente: a diferencia de otros sistemas federales la UE tiene un "Poder Judicial Integrado», pues el TJUE lo comparte con los órganos jurisdiccionales nacionales, [aclarando que en dicha dinámica] el TJUE ha introducido elementos jerárquicos en una relación que en todo caso gira en torno al entendimiento y fortalecimiento mutuos. LENAERTS \& GUTIÉRREZ-FONS, 2012, Tomo V, pp. 86-88. 
una cuestión del derecho sustancial, se conecta estrechamente con la supremacía del derecho de la integración y con el auctoritas de una Corte de integración, tal como ya lo analizamos en el capítulo II, precisamente al abordar el patrón central del auctoritas en las Cortes de integración.

El principio de cooperación entre el juez nacional con la Corte de integración es un tema zanjado en la UE y en todos los modelos extra-UE ${ }^{114}$ surgidos en América Latina, y puntualmente en la CAN el mismo TJCA lo ha reconocido en varias ocasiones, v.gr. en el caso Louis Vuitton ${ }^{115}$ refiriéndose a la acción de incumplimiento y a la de interpretación prejudicial, explicó que una de las maneras de garantizar los derechos individuales, es gracias al principio de cooperación entre el juez nacional y el comunitario. Expresándolo su criterio del siguiente modo:

«Por la vía de la acción de incumplimiento de que gozan los particulares, en armonía con la acción de interpretación prejudicial contemplada en el art. 28 del Tratado del Tribunal, se garantiza la salvaguardia de los derechos individuales mediante la cooperación entre el juez nacional y el comunitario» ${ }^{116}$.

Sin embargo, a pesar del principio anotado, simultáneamente se detecta la introducción de elementos jerárquicos por parte de las propias Cortes de integración, así al analizar sus ejercicios se comprueba empíricamente una dosis o matiz jerárquico ${ }^{117}$ que las elevaría un tanto por encima de los ejercicios de los tribunales nacionales. Hablamos sólo de dosis o

\footnotetext{
${ }^{114}$ Tengamos presente que en esta tesis estamos analizando únicamente a los modelos extra-UE americanos, pues el fenómeno expansivo de la teoría de la integración, que tuvo su génesis en la Europa de post-guerras, tiene correlatos de diversas intensidades en Asia, África y América. En África todos los modelos organizativos poseen notoria influencia de la UE, comenzando por la propia Unión África, o la Unión Económica y Monetaria del Oeste Africano (UEMOA), en la cual encontramos al TJ UEMOA y al Tribunal de Cuentas UEMOA, y varias Organizaciones africanas más que poseen singulares tribunales. En Asia, luego del desplome de la URSS, y tras el fenómeno de atomización surge la Comunidad de Estados Independientes (CEI), la que también presenta influencia de la UE, siendo destacable que habiendo nacido la CEI sólo con objetivos paliativos, ella fue desarrollando diversos contenidos integracionistas, fenómeno sobre el cual BLANC ALTEMIR efectúa un interesante análisis enmarcado en la disolución de la ex URSS ubicando a la CEI como un intento por paliar el vacío dejado por la ex megapotencia. BLANC ALTEMIR, A. (2004). La herencia soviética : La comunidad de estados independientes y los problemas sucesorios. Madrid: Tecnos. Y en América, como venimos estudiando, se desarrollan los modelos SICA, CAN y MERCOSUR. Ahora bien, todos los proyectos extra-UE presentan mayor o menor cercanía con el modelo pionero. Pero más allá de esa distancia, que académicamente pueda tabularse $-\mathrm{y}$ que en esta tesis hacemos sólo respecto de un tipo de órganos de 'algunas' de estas OI: los tribunales de integración americanos - es un hecho que en términos absolutos, todos se ubican muy distantes de los impresionantes desarrollos alcanzados por la UE.

${ }^{115}$ Sentencia del TJCA de 17 de febrero de 1994, Interpretación prejudicial, Louis Vuitton, as. 6-IP-93. GOAC No 150 .

${ }^{116}$ Párrafo segundo, bajo el apartado Alcance del artículo 27 del Tratado, en sentencia ibídem.

${ }^{117}$ Vid. nota 113 de este capítulo. LENAERTS \& GUTIÉRREZ-FONS, 2012, Tomo V, pp. 86-88.

232
} 
matiz, porque no existe una concreción sobre aquello, pues los sistemas de integración no establecen construcciones autoritarias de jurisdicción, ni de forma orgánica, ni de forma procesal directa. Lo más cercano, o si se prefiere, la prueba concreta del cariz jerárquico en la UE, es el hecho de que dentro del nivel nacional es posible recurrir de casación sobre una sentencia de un juez nacional que no aplicó correctamente la respuesta del TJUE en una cuestión prejudicial, argumentando evidente error de derecho, pero se recurre al superior jerárquico del juez nacional dentro de su propio país, sencillamente las sentencias nacionales no pueden recurrirse directamente ante el TJUE ${ }^{118}$.

Por ejemplo esta imposibilidad procesal para interponer recursos directos al TJCA, es una realidad legislativa porque no existe dicha construcción, sin embargo fue aclarada en la sentencia Louis Vuitton — que recién señalamos dos párrafos atrás- oportunidad en que el TJCA lo explica del siguiente modo:

«La interacción de las 'dos' competencias debe entenderse que se ejerce dentro de un marco de cooperación en el que no se establece estructura jerárquica alguna entre el juez nacional y el comunitario, sino que es el resultado de una distribución de competencias que permite interpretar de manera uniforme la regla comunitaria y paulatinamente crear un cuerpo de doctrina aplicable en el ámbito nacional por el juez de cada país. El juez nacional en cada caso específico se convierte en ejecutor del derecho comunitario» ${ }^{119}$.

En este orden de ideas, y volviendo a la causa Mac Pollo, observamos que en dicha oportunidad la Corte andina puso de relieve un cúmulo de institutos jurídicos que tienen la virtud de otorgarle a la Corte misma el cariz jerárquico que estamos analizando en este apartado, los cuales corren por tres cauces, uno, por la mejor prelación que poseen las normas Comunitarias Andinas, sobre las nacionales, dos, la Corte subrayó que el orden para responder las consultas lo determina la misma Corte, tres, incluso destacó la libertad absoluta que posee para pronunciarse por normativa no señalada, ni por las partes ni por el

\footnotetext{
${ }^{118}$ En los sistemas de integración -y en otros- no existen competencias instanciales, ni casacionales, sino que para ingresar a las Cortes de integración, se sigue el cauce de las denominadas competencias secundarias. Es decir, primero (competencias primarias) deben agotarse los conductos y recursos procesales nacionales, y luego (mediante competencias secundarias) se emplaza generalmente al Estado. O bien, otra forma de llegar a estas Cortes es mediante la remisión de consultas prejudiciales y opiniones consultivas. En particular en la UE no existen recursos procesales para impugnar resoluciones judiciales locales ante el TJ. Distinto es el hecho de que aquí en Europa se hable de recursos, pues en realidad estos cauces son acciones. Destaca SARMIENTO, refiriéndose a la UE, a diferencia de los sistemas judiciales federales, no existen vías procesales que unan el nivel jurisdiccional de la Unión con el nivel nacional. Por tanto las resoluciones judiciales nacionales no pueden ser recurridas ante los Tribunales de la Unión, pues no existe un recurso específico que lo permita. SARMIENTO RAMÍREZ-ESCUDERO, 2016, p. 360.

${ }^{119}$ Párrafo quinto, bajo el apartado Alcance del artículo 27 del Tratado, en la Sentencia del TJCA de 17 de febrero de 1994, Interpretación prejudicial, Louis Vuitton, as. 6-IP-93. GOAC No 150.
} 
juez nacional. Este conjunto de institutos los desarrolló comenzando por despejar un concepto, al caso concreto, definir la palabra «otorgamiento» la cual era relevante para ese caso, en dicho punto es que puso de relieve el primer cauce, esto es, la preferencia del Ordenamiento Comunitario Andino, señalando que éste siempre es preferente sobre el derecho interno, lo que manifestó de la siguiente forma:

«CONSIDERANDO el Tribunal que, tal como lo ha dejado expuesto, debe determinarse entonces previamente, qué se entiende a nivel de las normas comunitarias - siempre prelatorias sobre el derecho interno- por "otorgamiento", ya que, es a partir de la fecha de éste cuando rige el plazo de cinco años» ${ }^{120}$.

En cuanto al segundo y tercer cauces, referente a la selección de la normativa a interpretar y el orden para responder las consultas, la Corte lo resuelve así:

«Requerida por un juez nacional al juez comunitario la interpretación prejudicial, pasa a ser de exclusiva competencia de este Alto Tribunal el determinar cuáles son, en definitiva, las normas pertinentes a interpretar, sugeridas o no por el requirente y todo con el fin de lograr una comprensión global del caso consultado; le corresponde también absolver la consulta en el orden de prelación que el mismo estime conducente» $^{121}$.

En conclusión, respecto de esta dosis jerárquica de un tribunal de integración, vínculo que no es orgánico, que detecta la doctrina y que explica la jurisprudencia del TJCA que hemos analizado aquí, nosotros apreciamos que en definitiva tales consideraciones de la Corte andina podrían quedar comprendidas únicamente dentro de las múltiples manifestaciones de la supremacía del derecho de la integración tal como lo han hecho el TJUE, la CCJ y el TPRM. Entendemos que este fenómeno de cuasi posición jerárquica que se produce entre la Corte de integración y el tribunal nacional, tiene su explicación teórica en tres causas simultáneas:

Primero, en que es claramente una manifestación del principio general del derecho procesal iuria novit curia, aumentando el auctoritas de la Corte de integración. Segundo, en que en el ejercicio entre ambos niveles — nacional e internacional- se generan muchas veces importantes efectos procesales que trasuntan en una cuasi visión jerárquica, como lo son, si la respuesta a una consulta o cuestión prejudicial no es respetada por el juez nacional, puede legitimarse - internamente, dentro del nivel nacional - a las partes en el recurso de casación ante el superior nacional del juez de primera instancia, contra la sentencia que no respete la respuesta de la Corte de integración, basando el recurso en error de derecho, es

\footnotetext{
${ }^{120}$ Último Considerando del apartado a) La primera norma relevante, tema B. En relación con los hechos y el derecho debatidos, del Capítulo III Normas comunitarias pertinentes, en la Sentencia del TJCA de 11 de octubre de 1994, Interpretación prejudicial, Marca: Mac Pollo, as. 1-IP-94.

${ }^{121}$ Concluyente $1^{\circ}$, en sentencia ibídem. 
decir, la intervención de la Corte de integración tiene la «potencialidad» de generar un impacto procesal efectivo al «interior de la judicatura nacional», toda vez que puede terminar alterando lo decidido por el juez nacional de primera instancia; por otra parte se suma el hecho de que para un caso diferente al de los fallos recaídos en consultas prejudiciales, la Corte de integración puede declarar el incumplimiento y la subsecuente responsabilidad de un Estado, después de que los tribunales nacionales le hubieren incluso exculpado. Tercero, por sí solos, la supremacía del derecho de la integración, o la forma de interpretación, o el modo en que la Corte construye sus sentencias en cuanto al orden para responder las consultas y otros extremos más, no son, en sí mismos singularidades capaces de demostrar una jerarquía «orgánica». Sino que comportan consecuencias jurídicoprocesales propias del hecho de interpretar un derecho superior, bajo el principio general de la supremacía del derecho internacional, y en particular aquí, la supremacía del derecho de la integración.

Aclaremos eso sí dos cuestiones para evitar confusiones, nosotros hemos hablado de supremacía, pero también en un lenguaje más preciso o explicativo se habla de primacía del derecho de la integración, dejando a salvaguarda la supremacía constitucional; y por otra parte en el punto en análisis, esto es la jerarquía orgánica (que no existe entre la Corte de integración y el tribunal nacional) $v / s$ la jerarquía sustancial (que es la analizada aquí), no cabe confundir el fundamento de la supremacía o primacía del Derecho de la integración, que en particular en la UE reside en la atribución del ejercicio de competencias por los Estados miembros, explicación que está muy clara, sólo que lo analizado en este apartado, es una dimensión precisa y particular de aquello.

Por tales tres razones, a nosotros nos parece más acertado comprender que no hay una supremacía jerárquica del órgano jurisdiccional de integración sobre el tribunal nacional, sino lo que existe, es una supremacía del derecho de la integración sobre el derecho local. De allí que a nuestro juicio sólo podamos hablar de un cariz jerárquico.

\subsubsection{El Robustecimiento del Derecho de la CAN GRACIAS AL EJERCICIO DE LA CORTE ANDINA}

Por último hemos seleccionado cuatro jurisprudencias integracionistas de la Corte andina de alta relevancia en materia de respeto al derecho de la integración, en las cuales se observa nítido como ha contribuido a robustecer el Derecho de la CAN abordando principalmente tres aspectos, primero, el principio del complemento indispensable, según el cual no es posible la expedición de normas nacionales sobre un asunto regulado comunitariamente, a menos que sea forzoso para la función nacional ejecutiva de la norma 
comunitaria, en segundo lugar, el alcance positivo y negativo de la supremacía del derecho comunitario andino, y en tercer lugar, respecto de la intrascendencia, para la prevalencia del derecho comunitario sobre las leyes internas, el rango que éstas últimas posean. Estos tres aspectos los analizaremos a través de las siguientes cuatro sentencias.

\subsubsection{LA INAPLICABILIDAD DE LA NORMA NACIONAL} CONTRARIA AL DERECHO DE LA CAN

El derecho de la integración, al caso el derecho de la CAN, por su característica de ser incompleto $^{122}$, se dificulta que coincida con un estándar de autosuficiencia normativa, es decir, que en varias ocasiones será necesario un complemento para su ejecución en el nivel nacional, cuestión que apareja la dificultad y la precaución de que dicho apoyo no vulnere al derecho de la integración en concreto. Es en esta dinámica hemos seleccionado dos valiosas jurisprudencia del TJCA, una es la sentencia dictada en el caso Cavelier $^{123}$, y la otra es la respuesta del TJCA en la consulta de la Corte Constitucional de la República de Colombia ${ }^{124}$, las cuales — solo en lo pertinente-veremos a continuación.

1. En el caso Cavelier los señores Germán y Ernesto Cavelier demandaban la inconstitucionalidad del art. 454 de la Ley $9^{\text {a }}$ de 1979 del derecho colombiano, pues consideraban que dicha norma desbordaba las atribuciones contenidas en el art. 84 de la Decisión $85^{125}$, violando los arts. 56, 58, 76 y 77 de la misma. En ese contexto la Corte Suprema de Justicia de la República de Colombia dirigió al TJCA una solicitud de interpretación prejudicial sobre los artículos recién señalados ${ }^{126}$.

\footnotetext{
${ }^{122}$ Ya vimos la condición del derecho de la integración de ser incompleto, evolutivo y heteronormativo, y aspira a ser único, uniforme y homogéneo. Nos remitimos en todo a lo ya explicado en la Introducción de este capítulo.

${ }^{123}$ Sentencia del TJCA de 25 de mayo de 1988, Interpretación prejudicial, Germán y Ernesto Cavelier, consulta de la Corte Suprema de Justicia de la República de Colombia, as. 2-IP-88. GOAC N 33 de 1988.

${ }^{124}$ Sentencia del TJCA de 20 de abril de 1995, Interpretación prejudicial, consulta de la Corte Constitucional de la República de Colombia, as. 10-IP-94. GOAC 177 de 1995.

${ }^{125}$ Ya nos habíamos referido en el caso anterior a esta Decisión de la Comisión del AC N 85 Reglamento para la aplicación de las normas sobre propiedad industrial, GOAC del 5 de junio de 1974. Disponible en el Portal oficial de la CAN en el enlace <http://www.comunidadandina.org/Normativa.aspx?GruDoc=07> apartado Decisiones [última consulta, octubre 1, 2019].

${ }^{126}$ La norma impugnada, el art. 454 de la Ley $9^{\text {a }}$ de 1979 de Colombia, señalaba «El Ministerio de Desarrollo no podrá registrar un producto farmacéutico sin informe previo permisible del Ministerio de Salud sobre su aceptación. Asimismo podrá cancelar todo registro que solicite éste». La consulta era: «Lo que específicamente desea la Corte que se interprete es si a) el derecho interno de cada uno de los Países Miembros puede señalar, tratándose de productos farmacéuticos, requisitos adicionales a los que se desprenden de los arts. 56 y 58 mencionados para el registro de una marca, y si b) el derecho interno de cada uno de los Países Miembros puede señalar, tratándose de productos farmacéuticos, causales adicionales a las 236
} 
Centrándonos únicamente en lo que interesa a nuestra investigación, resaltemos que la Corte para abordar la interpretación, primero reflexionó sobre el derecho de la integración y su desarrollo normativo interno. En sentido de que la Decisión 85 tiene en principio, la vocación de regular íntegramente la materia agotando su reglamentación, sin que se precisen medidas complementarias de los Estados miembros que la deben aplicar. Es decir plantea una autosuficiencia normativa, pero no de tesis absoluta, pues la función nacional ejecutiva de la norma comunitaria no puede excluirse de plano, ya que existe excepcionalmente y de modo restrictivo, siguiendo la noción del principio del complemento indispensable, propio de soluciones estatales, que aquí pasa a destacar el TJCA para el nivel integracionista, a la zaga de las soluciones europeas, siendo del siguiente criterio:

«ante la posibilidad de alguna injerencia nacional para complementar, ejecutar o adaptar la norma comunitaria, la doctrina y la jurisprudencia suelen aplicar criterios muy restrictivos, tales como el principio del "complemento indispensable" que tradicionalmente se utiliza en el derecho interno para verificar hasta dónde pueden llegar las innovaciones normativas que se incorporan a un reglamento con el fin de complementarlo. De esta suerte, sólo suelen legitimarse las medidas complementarias adoptadas por los Países Miembros que resulten ser estrictamente necesarias para la ejecución de la norma comunitaria y, por tanto, que favorezcan su aplicación y que de ningún modo lo entraben o desvirtúen» ${ }^{127}$.

Para el TJCA la norma en estudio, como se caracteriza por su aplicación directa y homogénea en toda la sub-región, siendo así de simple ejecución, pasa a ser del tipo selfexecuting —clase de normas que si bien existen hace bastante tiempo en el derecho internacional, aquí se les analiza respecto del derecho de la integración-, por lo tanto, los países no pueden efectuar reservas de ningún tipo. Noción que la Corte explica en paridad a la obligación negativa o de abstención de desplegar medidas contrarias al Derecho de la CAN, indicándolo así:

«el reglamento sobre marca contenido en la Decisión 85 corresponde a la categoría de las resoluciones que han sido llamadas "self-executing" y que se caracterizan por ser aplicables directamente y en términos de absoluta igualdad en todos los Estados Miembros. Estos, frente a la norma comunitaria, no pueden formular reservas ni desistir unilateralmente de aplicarla, ni pueden tampoco escudarse en disposiciones vigentes o en prácticas usuales de su orden interno para justificar el incumplimiento o

que se desprenden de los arts. 76 y 77 mencionados para la cancelación de un registro de marca, todo ello en virtud del entendimiento que se dé al art. 84 citado».

${ }^{127}$ Párrafo primero, del apartado 3. El derecho comunitario y su desarrollo normativo interno, del Capítulo Considerando, en Sentencia del TJCA de 25 de mayo de 1988, Interpretación prejudicial, Germán y Ernesto Cavelier, consulta de la Corte Suprema de Justicia de la República de Colombia, as. 2-IP-88. GOAC N 33 de 1988. 
la alteración de obligaciones resultantes del derecho comunitario. No debe olvidarse que en la integración regida por las normas del ordenamiento jurídico andino, los Países Miembros están comprometidos "a no adoptar ni emplear medida alguna que sea contraria a dichas normas o que de algún modo obstaculicen su aplicación”, como de modo expreso preceptúa el art. 5, segunda parte, del Tratado de 26 de mayo de 1979, constitutivo de este Tribunal» ${ }^{128}$.

El aporte central de esta sentencia es que aclara, para el mejor desarrollo del Derecho de la CAN que, si los reglamentos self-executing no agotan la materia a la cual se refieren, entonces permiten y exigen, un complemento legislativo de parte del derecho interno. Incluso cuando la normativa comunitaria agota la materia regulada, podrían resultar inevitables determinadas normas nacionales de implementación o de adaptación. Todas estas aclaraciones que va haciendo la Corte andina, si bien en Europa pudieran parecer evidentes, en realidad en el proyecto andino no lo eran, por lo que el ejercicio de la Corte en materia de jurisprudencia integracionista pasa a ser el carril central para forjar el sentido correcto y unitario del ordenamiento jurídico andino.

2. Luego mediante la respuesta del TJCA en la consulta de la Corte Constitucional de la Rep. de Colombia ${ }^{129}$ fueron robustecidas las implicancias del principio del complemento indispensable que recién vimos en el caso anterior. En esta ocasión el TJCA dinamiza el concepto del principio sublite con las obligaciones de hacer y no hacer que pesan sobre los Estados miembros de la CAN. Para lo cual justamente cita su fallo anterior, recién visto por nosotros - Cavelier - señalando lo siguiente:

«El desarrollo de la ley comunitaria por la legislación nacional, es empero excepcional y por tanto a él le son aplicables principios tales como el del "complemento indispensable", según el cual no es posible la expedición de normas nacionales sobre el mismo asunto, salvo que sean necesarias para la correcta aplicación de aquellas. Este régimen de excepción [...] debe ser aplicado en forma restringida [...]. Significa esto que para que tenga validez la legislación interna se requiere que verse sobre asuntos no regulados en lo absoluto por la comunidad [...]. Como lo ha dicho el Tribunal en [...] (caso 2-IP-88 -Cavelier), no es posible que la legislación nacional modifique, agregue o suprima normas sobre aspectos regulados por la legislación comunitaria "o que se insista en mantener la vigencia de leyes nacionales [...] incompatibles con ella", debiendo únicamente legislar sobre lo no comprendido en la Decisión Comunitaria» ${ }^{130}$.

\footnotetext{
${ }^{128}$ Párrafo segundo, en apartado, capítulo y sentencia ibídem.

${ }^{129}$ Sentencia del TJCA de 20 de abril de 1995, Interpretación prejudicial, consulta de la Corte Constitucional de la República de Colombia, as. 10-IP-94. GOAC 177 de 1995.

${ }^{130}$ Párrafo sexto, del apartado 15 . Relaciones entre el derecho comunitario y el derecho interno, en sentencia ibídem.
} 
En el fallo al que la Corte se refiere - Cavelier - se había enfocado hacia el principio de la aplicación preferente del derecho comunitario para aproximarse a su supremacía, explicando de forma rigurosa el fenómeno de desplazamiento de la normativa nacional incompatible con la comunitaria. Reacción dinámica que no coincide con la noción de derogación tácita, sino con el concepto de inaplicabilidad que toma la Corte andina de las construcciones jurisprudenciales de la Corte de Luxemburgo en los casos Costa/Enel ${ }^{131}$, consulta del Finanzgericht Hamburg ${ }^{132}$ y Simmenthal ${ }^{133}$, a través de un tipo de diálogo judicial que abordaremos en el capítulo IV. Esta notable diferencia es exclusiva del derecho de la integración, ya que éste — explica la Corte - no posee la versatilidad de derogar leyes nacionales, sino que su supremacía se afina en el sentido de desplazar la normativa local momentáneamente. Así la ley local no se aplica en nada contrario al orden comunitario. Pero si éste último cambia o se deroga, entonces el derecho nacional sigue aplicable, pues no lo obstaculiza. Cuestión que la Corte expone del siguiente modo:

«Este pretendido efecto derogatorio, [...] no se compagina sin embargo con el derecho de la integración [...]. La doctrina prevaleciente, por ello mismo, se inclina con toda decisión por el principio de la aplicación preferente del derecho comunitario, siempre que con él entre en conflicto el derecho interno [...]. De tal suerte, la norma interna que sea contraria a la norma comunitaria [...] si bien no queda propiamente derogada, dejará de aplicarse automáticamente, bien sea anterior o posterior a la norma integracionista» ${ }^{134}$.

En conclusión, en ambas sentencias analizadas - Cavelier y Consulta de la Corte Constitucional de la Rep. de Colombia - se aprecia la clara contribución del TJCA al robustecimiento del Derecho de la CAN respecto de aclarar el principio del complemento indispensable y sus limitaciones, entendiendo que si los reglamentos self-executing no agotan la materia a la cual se refieren, entonces exigen un complemento legislativo del derecho interno, además la Corte potencia este principio del complemento indispensable vinculándolo con las obligaciones de hacer y de no hacer que pesan sobre los Estados miembros, ejercicio durante el cual la Corte andina no duda en recurrir a los precedentes de la Corte de Luxemburgo en calidad de fuente autorizada para marcar las pautas del derecho de la integración, comprendido éste, de modo amplio.

\footnotetext{
${ }^{131}$ Sentencia del TJ de 15 de julio de 1964, Costa/Enel, as. C-6/64, ECLI:EU:C:1964:66.

${ }^{132}$ Sentencia del TJ de 11 de febrero de 1971, Norddeutsches Vieh- und Fleischkontor - Finanzgericht Hamburg, as. C-39/70, ECLI:EU:C:1971:16.

${ }^{133}$ Sentencia del TJ de 9 de marzo de 1978, Simmenthal, as. C-106/77, ECLI:EU:C:1978:49.

${ }^{134}$ Párrafo tercero, del apartado 4. El reglamento para la aplicación de las normas sobre propiedad industrial (Decisión 85), en Sentencia del TJCA de 25 de mayo de 1988, Interpretación prejudicial, Germán y Ernesto Cavelier, consulta de la Corte Suprema de Justicia de la República de Colombia, as. 2-IP-88. GOAC N 33 de 1988.
} 


\subsection{LA CORTE ANDINA EVITA EL CAOS JURISPRUDENCIAL}

La tercera sentencia integracionista que hemos seleccionado posee un rico y complejo contenido que robustece al derecho de la CAN desde múltiples aristas, incluso en este fallo la Corte andina declaró que su propio ejercicio pretoriano evita el caos jurisprudencial en la zona andina, nos estamos refiriendo a la sentencia dictada en la causa Louis Vuitton ${ }^{135}$.

Sucedía que la sociedad dueña de la marca Louis Vuitton en atención a que su marca era notoriamente conocida, pidió la cancelación del registro de otra marca idéntica, pero la autoridad local no acogió la cancelación, por lo que demandó al Estado colombiano basándose en el art. XXVII del Tratado que creó el TJ del Acuerdo de Cartagena, para que se declarara que el Estado de Colombia había incumplido el art. V de dicho Tratado y que debe restituirle su derecho conculcado. En tal contexto el Consejo de Estado de la Rep. de Colombia solicitó al TJCA una interpretación prejudicial de diversas normativas ${ }^{136}$.

El TJCA para elaborar su respuesta procedió a establecer determinadas bases jurídicas ${ }^{137}$, y en lo que nos interesa, señaló que han de respetarse dos principios cardinales del Derecho de la CAN, el de su aplicación directa y el de su preeminencia. Del primero surge el derecho a la acción ante los tribunales nacionales, y del segundo se sigue su carácter imperativo y de primacía sobre la ley nacional, explicándolo del siguiente modo:

${ }^{135}$ Sentencia del TJCA de 17 de febrero de 1994, Interpretación prejudicial, Louis Vuitton, as. 6-IP-93. GOAC No 150 .

${ }^{136}$ La consulta prejudicial la dirigió en particular la Sala de lo Contencioso Administrativo del Consejo de Estado de la Rep. de Colombia y se acotaba «por la interpretación prejudicial de los arts. a) 5 y 27 del Tratado de Creación del Tribunal, b) 80 del Estatuto del TJ del Acuerdo de Cartagena y c) los arts. 56, 58 literales a), h), i) y g) y 76 de la Decisión 85 de la Comisión del Acuerdo de Cartagena».

${ }^{137}$ La Corte andina —en lo que a nosotros interesa aquí- respondió «1) Los Países Miembros [...] al ratificar su Tratado Constitutivo, así como los Protocolos [...] se han comprometido a cumplir las obligaciones contenidas en ellos, y de acatar los principios de aplicación directa y de preeminencia del derecho comunitario sobre el derecho interno. Con tal fin el art. 5 del Tratado del Tribunal impone la obligación de adoptar las medidas necesarias para asegurar el cumplimiento del ordenamiento jurídico comunitario contenido en el art. 1 del mismo Tratado y la obligación de no adoptar ni emplear medida alguna contraria a dichas normas o que obstaculice su aplicación. [...]. 3) La acción por incumplimiento [...] otorga una garantía a las personas naturales y jurídicas para que con arreglo a las normas procesales establecidas en el derecho interno de cada país, puedan acudir a los tribunales nacionales para exigir el cumplimiento del derecho que llegare a establecerse como violado. 4) En la acción por incumplimiento [...] la responsabilidad del Estado se circunscribe exclusivamente al ámbito nacional, y puede generar reparación del derecho individual que se comprobare violado [...]. 5) Corresponde al juez nacional decidir de conformidad con [el] derecho interno, sobre aplicación de la ley procesal en el tiempo, si el órgano nacional competente debió proseguir o no con el trámite [...] frente a la situación de tránsito legislativo». 
«Dos principios fundamentales del derecho comunitario están llamados a ser tutelados por el art. 5 del Tratado de Creación del Tribunal, la aplicación directa y la preeminencia del ordenamiento jurídico del Acuerdo de Cartagena. Por el primero se entiende la capacidad jurídica de la norma comunitaria para generar derechos y obligaciones que los ciudadanos de cada país puedan exigir ante sus tribunales nacionales.

La preeminencia que se deriva de la aplicación directa conlleva la virtud que tiene el ordenamiento comunitario de ser imperativo y de primar sobre una norma de derecho interno, de manera que allí donde se trate de aplicar normas legales en actos jurídicos contemplados en el derecho de integración deberá acudirse al ordenamiento jurídico comunitario, con prevalencia sobre el derecho interno» ${ }^{138}$.

Observamos entonces, que de ambos principios fluye una obligación de doble dimensión, positiva y negativa. Entendemos que esta circunstancia se aproxima a la idea de un estándar de comportamiento para los Estados, el cual debe superar el umbral de lo meramente compatible con el derecho del grupo, llegando a un nivel en que se aprecie que lo favorece cómodamente — si fuese aún más intenso que este último, ya hablaríamos del principio de la cooperación reforzada ${ }^{139}$, el cual no es el nivel de exigencia aquí. La Corte lo explicó recurriendo al clásico binomio que distingue entre obligaciones de hacer $v /$ s de no hacer $^{140}$. Criterio sobre el cual insistiría luego en el fallo de la causa Secretaría General de la CA

\footnotetext{
${ }^{138}$ Párrafos primero y segundo, del apartado Alcance del artículo 5 del Tratado de Creación del Tribunal, del Capítulo Considerando, en Sentencia del TJCA de 17 de febrero de 1994, Interpretación prejudicial, Louis Vuitton, as. 6-IP-93. GOAC $\mathrm{N}^{\circ} 150$.

${ }^{139}$ Nos estamos refiriendo a la noción por la cual algunos Estados de la UE, que lo deseen, pueden avanzar más allá de los objetivos que homogéneamente están establecidos para dicha organización, cuestión que se regula principalmente en el TUE en su Preámbulo, Título IV denominado Disposiciones sobre las cooperaciones reforzadas, art. 20, también en la Sexta Parte del mismo TUE, en su Título III denominado Cooperaciones reforzadas, arts. 326 y ss. Es decir, es un nivel de compromiso superior al que marca el principio de cooperación leal, indicado en el art. 4.3 del TUE.

${ }^{140}$ Este clásico distingo del derecho civil (que más estrictamente diferencia entre obligaciones y prestaciones, y éstas últimas a su vez son de dar, hacer, o no hacer, y la de entregar contenida en la de dar) es importado hacia los modelos transnacionales. En este caso el TJCA expresó «Tales características se cumplen en su integridad y se materializan cuando el art. 5 del Tratado impone a los países [...] dos obligaciones básicas: una de hacer, consistente en adoptar las medidas necesarias para asegurar el cumplimiento del ordenamiento jurídico comunitario [...], y la obligación de no hacer, consistente en no adoptar ni emplear medida alguna contraria a dichas normas o que obstaculice su aplicación. Por la [...] de hacer, los Países [...] se vinculan jurídicamente al compromiso de adoptar toda clase de medidas -sean legislativas, judiciales, ejecutivas, administrativas o de cualquier otro orden- que contengan manifestaciones de voluntad del Estado expresadas en leyes, decretos, resoluciones, decisiones, sentencias o en general actos de la administración, destinados a garantizar el cumplimiento del ordenamiento jurídico comunitario. Por la [...] de no hacer [...] deben abstenerse de adoptar toda medida [...] que pueda contrariar u obstaculizar dicho ordenamiento». Párrafos tercero y cuarto, ídem.
} 
contra República del Perú ${ }^{141}$, oportunidad en que explicó que dicha diferenciación fluye de la primacía del Derecho de la CAN, preeminencia que es respecto de todos los tipos de normas del derecho interno, es decir, comprende:

«cualquiera que sea el rango de éstas, lo cual en la práctica se traduce en que el hecho de pertenecer al acuerdo de integración le impone a los Países Miembros dos obligaciones fundamentales dirigidas la una, a la adopción de medidas que aseguren el cumplimiento de dicho Ordenamiento dentro de su ámbito territorial; y la otra, $a$ que no se adopten medidas o se asuman conductas o se expidan actos, sean de naturaleza legislativa, judicial, o administrativa, que contraríen u obstaculicen la aplicación del derecho comunitario» ${ }^{142}$.

Por último, es notable y de alto interés para nosotros, la forma en que la Corte razona sobre la importancia de la «existencia» de un tribunal de integración, y del inminente caos que generaría la inexistencia de interpretaciones prejudiciales. El tribunal plantea que «su propia existencia es una garantía de seguridad jurídica», sino el caos jurisprudencial se detonaría, pues se presentarían tantos criterios, como jueces nacionales hubiese. Explicando su criterio de la siguiente forma:

«De no producirse la interpretación prejudicial por ausencia de un órgano jurisdiccional permanente o por omisión del juez nacional que deba solicitarla, se llegaría a una situación de caos jurisprudencial para la comunidad, pues al momento de aplicar una norma comunitaria, el juez nacional se vería en la necesidad de establecer su propio criterio y sus propias bases de interpretación, llegándose al extremo de contar con tantas jurisprudencias distintas, cuantos casos estuvieren ajenos a la interpretación prejudicial del Tribunal.

\footnotetext{
${ }^{141}$ Sentencia del TJCA de 28 de septiembre de 2001, Acción de incumplimiento, Secretaría General de la CA / República del Perú, as. 89-AI-2000. GOAC 722.

142 Párrafo séptimo del apartado 4.1.3. Preeminencia del ordenamiento jurídico andino respecto de las normas internas de los países miembros y autonomía de aquél frente a otros ordenamientos internacionales, en sentencia ibídem. En este mismo fallo, la Corte criticó fuertemente el hecho de que algún Estado miembro de la CA que pertenezca además a otra OI, pretenda ajustar el Derecho de la CAN para compatibilizarlo con otro proyecto internacional al que adscriba tal nación. Enfatizando «pretende[r] la convalidación, a contrapelo de lo que expresan las normas comunitarias, de la facultad de emitir normas de derecho interno con la finalidad de ajustar o hacer compatibles las normas comunitarias a los otros ordenamientos internacionales a los que también estén sujetos, de manera individual o conjuntamente con los otros países andinos, cuando, a su juicio, se presente entre tales ordenamientos alguna incongruencia o discordancia. El razonamiento es inaceptable porque vulnera dos de los principios esenciales de la naturaleza jurídica del ordenamiento comunitario andino como son el de autonomía y el de preeminencia, sobre los cuales el Tribunal ha venido, con fundamento en las normas constituyentes del Acuerdo de Cartagena, elaborando copiosa jurisprudencia».
} 
La existencia de un órgano judicial que, al interpretar el derecho comunitario, permita la aplicación uniforme del mismo en todos los países que forman la CA, es garantía de seguridad jurídica» ${ }^{143}$.

La existencia del tribunal de integración es un aspecto lógicamente central para nosotros, de hecho, recordemos las grandes problemáticas que debió enfrentar el proyecto andino justamente por no poseer un tribunal de integración, el cual se incorporó bastante retrasado a la institucionalidad de la CAN. Desfase que también se produjo en MERCOSUR. No así en el SICA ni en la $\mathrm{UE}^{144}$. Si bien estamos gravitando sobre la importancia de los ejercicios jurisdiccionales de las Cortes integracionistas, su mera existencia es trascendental para el éxito de la organización y de sus objetivos ${ }^{145}$.

En conclusión, por todo lo analizado en este apartado exclusivamente destinado al análisis del tipo y calidad de jurisprudencia integracionista del TJCA observamos claramente que esta Corte ha aportado dicha clase de jurisprudencia y de alta calidad, mostrando sólidas técnicas de construcción jurídica, además de abarcar a las principales aristas del derecho de

${ }^{143}$ Párrafos séptimo y octavo del apartado Alcance del artículo 27 del Tratado, del capítulo Considerando, en Sentencia del TJCA de 17 de febrero de 1994, Interpretación prejudicial, Louis Vuitton, as. 6-IP-93. GOAC $N^{o}$ 150. Para llegar a esta conclusión la Corte comienza por el análisis del art. 28 del Tratado constitutivo del mismo Tribunal, y cita en su fallo los asuntos 1-IP-87 (Sentencia del TJCA de 3 de diciembre de 1987, Interpretación prejudicial, Aktiebolaget Volvo c. Volmo, consulta de Consejo de Estado de la República de Colombia, Sala de lo Contencioso Administrativo, Sección Primera, as. 1-IP-87) expresando «Al alcance de este artículo le son pertinentes las consideraciones recogidas por este Tribunal en su sentencia de 3.12.1987 (Proceso 1-IP-87, Gaceta Oficial 28, de 15.2.1988), según las cuales la interpretación prejudicial 'Es función básica..., indispensable para tutelar el principio de legalidad en el proceso de integración andina y para adaptar funcionalmente su complejo ordenamiento jurídico, a fin de asegurar su aplicación uniforme en el territorio de los Estados miembros' (art. 28 del Tratado de Creación), objetivo fundamental que está lógicamente fuera de las competencias de los jueces nacionales».

${ }^{144}$ Este desfase entre la creación de la organización y su órgano jurisdiccional, es una anomalía que debió enfrentar la CAN y el MERCOSUR. La CAN lo vivió traumáticamente casi ad-portas de su desaparición, y en el MERCOSUR se presenta una extensa nivelación por etapas que aún no termina de concluir encontrándose aún pendiente el nacimiento de la Corte de Justicia del Mercosur (CJM). A diferencia del modelo sincrónico que se siguió en las CE hoy UE y en el SICA. Todas singularidades que ya las hemos analizado, por lo que nos remitimos en todo al capítulo I, referido al análisis histórico. VIGIL TOLEDO, 2011, p. 39. Otro, QUINDIMIL LÓPEZ, 2006.

${ }^{145}$ En cuanto a la importancia de que las OI en general, y por cierto para las de Integración, posean órganos jurisdiccionales con la capacidad efectiva de efectuar controles judiciales intensos ante el desacuerdo de los socios, en el entendido de que sus posturas ya fueron sometidas a las vías ordinarias de solución, es un reflejo del típico fenómeno local de convivencia y de la forma de resolver los conflictos al interior de las Naciones. En tal línea REUTER analizando a las OI, expresa si una tal concepción no ha sido admitida por todos, y ha sido discutida, ella supone en todo caso para ser eficaz un control judicial muy fuerte. REUTER, P. \& PUENTE EGIDO, J. (1978). Derecho internacional público. Barcelona: Bosch. Cap. IV, Sección IV Teoría general de las organizaciones internacionales, p. 206. 
la integración. Además la Corte andina se deja ver como un tribunal intenso al resaltar los principios matrices que deben respetarse para el éxito de un proyecto que la misma Corte identificó primero de comunitario y hoy de integracionista.

Se suma a lo anterior una profusa técnica de reiteración de las conclusiones y criterios del TJCA que hemos analizado hasta este punto, reiteración muy singular en cuanto a lo detallado de las explicaciones de cada principio y criterio, mostrando una técnica de construcción de sentencias muy propia de la Corte andina cuestión que la hacen diferenciarse de otras Cortes que dan por descontado los antecedentes jurisprudenciales. Así por ejemplo el TJCA en su sentencia de la causa Pfizer/Invima ${ }^{146}$ nuevamente recordó la preeminencia del derecho de la integración, las obligaciones positivas y negativas de los Estados, la aplicación directa de la norma comunitaria, etcétera. En lo particular, aclaró el efecto de la ley comunitaria en el tiempo, cuestión que es vital tener resuelto en un sistema jurídico en constante construcción, por tal razón el TJCA, en línea con la seguridad jurídica, expresó que las normas sustanciales del Derecho de la CAN no conllevan efecto retroactivo, sino que las situaciones de derecho nacidas con normas anteriores, se sujetan a tales leyes, explicando su criterio del siguiente modo:

«En principio, y con el fin de garantizar el respeto a las exigencias de seguridad jurídica y de confianza legítima, la norma comunitaria de carácter sustancial no surte efectos retroactivos; por tanto, las situaciones jurídicas disciplinadas en ella se encuentran sometidas, en sí y en sus efectos, a la norma vigente al tiempo de su constitución. Y si bien la nueva norma comunitaria no es aplicable, salvo previsión expresa, a las situaciones jurídicas nacidas con anterioridad a su entrada en vigencia, procede su aplicación inmediata a los efectos futuros de la situación nacida bajo el imperio de la norma anterior» ${ }^{147}$.

Sin embargo, y a pesar de todo lo constatado, es un hecho que actualmente la globalidad del proyecto político de la CAN se encuentra debilitado, y que requiere de nuevas fuerzas capaces de asumir y valorar lo construido, al tiempo de proyectarlo hacia el futuro. Volveremos sobre esta penosa situación de debilitamiento en el capítulo $\mathrm{V}$ referido a las perspectivas de futuro de las Cortes bajo análisis.

\footnotetext{
${ }^{146}$ Sentencia del TJCA de 30 de noviembre de 2004, Interpretación prejudicial, Pfizer/Invima, as. 105-IP2004.

${ }^{147}$ Párrafo primero, del apartado I. De la aplicación de la ley comunitaria en el tiempo, en sentencia ibídem. Y en su Conclusión Primera — en lo que nos interesa - condensa el criterio del siguiente modo «Primero: La Decisión comunitaria que rige para sus efectos, es la que se encontraba vigente al momento de la presentación de la solicitud. La norma comunitaria no tiene carácter retroactivo». En el resto, reitera las construcciones históricas previas.
} 
Pero a pesar del debilitamiento anotado - tal como explicamos al iniciar el análisis del TJCA - era imposible obviar en esta investigación a la Corte andina por tres razones, primero, porque el TJCA se encuentra vigente y en funcionamiento, segundo, porque este órgano jurisdiccional se reconoce a sí mismo como plenamente integracionista, y tercero, porque mediante su ejercicio acabamos de probar que efectivamente se ha esmerado con creces en fortalecer el proyecto andino en su totalidad, aportando la jurisprudencia integracionista de notable valor que recién hemos terminado de analizar. Derrotero que si bien se ha ido inspirando fuertemente en el modelo de la UE, también ha dejado su sello propio para el desarrollo del Derecho de la CAN. 


\subsection{LA JURISPRUDENCIA EXPANSIVA} DE LOS TRIBUNALES ARBITRALES AD HOC y del Tribunal Permanente de ReVisión Mercosur

Las Cortes del merco-sistema fueron las últimas en aparecer en el Latino América y lo hicieron en un proceso de robustecimiento del Sistema de Solución de Controversias Mercosur (SSCM), el cual ya analizamos en el capítulo anterior, referido a las bases estatutarias y normativas que en general afectan a las Cortes mercosureñas, tal análisis previo nos permite ahora, considerar las particularidades orgánicas y estatutarias que resaltamos en el capítulo I, pues tales singularidades explican en gran medida las formas y los resultados de los laudos de estos tribunales. Actualmente en el SSCM el proceso comienza con un conducto administrativo en general ante la CMC, o bien puede hacerse valer la tan discutida opción de foro que la doctrina ${ }^{148}$ tacha como ajena a los modelos de integración, de hecho en la UE una pretendida opción de foro está claramente prohibida ${ }^{149}$, y además incluso, recientemente en la respuesta prejudicial en el caso Slowakische Republik/Achmea $B V^{150}$ - que ya habíamos mencionado- el TJUE resolvió que es incompatible con el Derecho de la UE una disposición de un acuerdo internacional celebrado entre Estados miembros, conforme a la cual un inversor de uno de esos Estados pueda, en caso de controversia, iniciar un procedimiento contra este último Estado miembro ante un tribunal arbitral ${ }^{151}$.

En el MERCOSUR vencida la etapa administrativa las partes pueden seguir hacia los TAAM y luego escalar al TPMR, o ir directamente al TPRM si son Estados miembros y están de acuerdo o se utiliza el procedimiento especial de urgencia. Estos tribunales son órganos de naturaleza arbitral y con jueces de convocatoria permanente. Todo inmerso en un modelo orgánico de carácter complejo, pues permite apelaciones y canales casacionales entre los inferiores TAAM y el superior TPRM. En esto último el modelo jurisdiccional del MERCOSUR se aproxima aparentemente al modelo orgánico de la UE (TJUE y el TGUE).

\footnotetext{
${ }^{148}$ Recordemos que mediante la opción de foro se puede recurrir a un sistema externo al Mercosur, como la OMC u otro. Posibilidad altamente criticada por la doctrina pues debilita las construcciones del mercosistema. Para SILGUERO la opción de foro es completamente ajeno a los sistemas de integración, y afecta negativamente al Mercosur. SILGUERO, 2013.

${ }^{149}$ Art. 344 del TFUE «Los Estados miembros se comprometen a no someter las controversias relativas a la interpretación o aplicación de los Tratados a un procedimiento de solución distinto de los previstos en los mismos».

150 Sentencia del TJ de 6 de marzo de 2018, Slowakische Republik/Achmea BV, as. C-284/16, ECLI:EU:C:2018:158.

${ }^{151}$ Vid. Considerando 60 en sentencia ibídem.

246
} 
A todo se añade que los TAAM (1991) y el TPRM (2002) emergen de un proceso internacional de origen intergubernamental, construido por etapas y aun inacabado ${ }^{152}$.

Por lo anterior y a priori, podría pensarse que los TAAM y el TPRM no pueden, ni menos, han producido jurisprudencia integracionista, pero no es así, lo cual ha sido posible, tanto por el singular ejercicio de estos tribunales, como por el hecho de que el proyecto completo del MERCOSUR ha ido incorporando otras temáticas diferentes a lo meramente económico, tales como, la cooperación en educación, la promoción de la cultura, los derechos humanos, las cuestiones laborales, de género, ambientales y muchas más. Gracias a este contexto progresivo, es que la labor de los TAAM y TPRM sobrepasó la mera disolución de los contenciosos e irrumpió en dimensiones integracionistas.

Tal irrupción en materias integracionistas es lo que justifica nuestra investigación sobre determinados laudos. Además, y a pesar de que comparativamente con los otros esquemas latinoamericanos y con el referente europeo, los laudos de las Cortes mercosureñas se han dictado en muy baja cantidad ${ }^{153}$, sustantivamente, se presentan llenos de contenidos del derecho de la integración. Ahora bien, atendiendo a la realidad cuantitativa que hemos podido advertir tras nuestro proceso investigativo, sólo hemos podido seleccionar los siguientes casos, que se condicen con determinadas dimensiones de los nueve bloques temáticos que establecimos como criterios de selección de las sentencias que estamos analizando. Todo según veremos a continuación.

${ }^{152}$ El SSCM se sigue de cinco etapas, estando inconclusa la última, que es justamente la que lo haría abandonar el umbral arbitral, desplazándose a la zona jurisdiccional. La etapa 1 está constituida por el Tratado de Asunción (TA - marzo 1991) el que en su Anexo III abordó las controversias entre Estados partes y la interpretación del TA más otros instrumentos, básicamente a través de la negociación. La etapa 2 es marcada por el Protocolo de Brasilia para la Solución de Controversias (diciembre 1991) estableció algunos procedimientos y añadió un tímido sistema para los reclamos de los particulares, se definieron los instrumentos de la negociación, de la mediación y del arbitraje naciendo los TAAM. La etapa 3 está representada por el Protocolo de Ouro Preto (1994, vigente dic. 1995) solo tipificó más materias arbitrables y estableció algunas reclamaciones. La etapa 4 se inicia con el POPSCM (2002, vigor 2004) se estableció dos instancias arbitrales naciendo el TPRM, e introdujo la cuestionada opción de foro que ya comentamos. Las etapas 1, 2 y 3 pueden verse en ARBUET-VIGNALI, 1999, pp. 153-156. Compleméntese con AMIN FERRAZ \& PICART GARCÍA, 2005, pp. 562-565. La etapa 4 en FABBRICATORE, 2011, pp. 19-22. La etapa 5 se identifica con el Proyecto de la Corte de Justicia del Mercosur. Vid. Proyecto de Norma 02/10 del Parlamento del MERCOSUR (MERCOSUR/PM/PN 02/2010) aprueba el «Proyecto de Protocolo Constitutivo de la Corte de Justicia del MERCOSUR» volveremos sobre este proyecto en el capítulo V.

${ }^{153}$ Tras tabular toda la producción de sentencias en la UE desde 1952, en el SICA aquí incluso desde la Corte de Cartago 1907, en la CAN y en el MERCOSUR, hemos podido levantar resultados cuantitativos que presentamos en tablas y gráficos en el capítulo $\mathrm{V}$ de esta tesis doctoral. En ellos podrán visualizarse de modo global una comparativa que hemos confeccionado respecto de la efectiva producción jurisprudencial de las Cortes bajo análisis. 


\subsubsection{UnA INTEGRACIÓN SINGULAR Y PROPIA PARA EL MERCOSUR}

EN LA QUE COLABORAN LOS TAAM

En la causa Argentina/Brasil ${ }^{154}$ el TAAM respectivo, dejó a la vista determinadas nociones integracionistas aplicables al MERCOSUR, las cuales podemos ordenar por dos cauces, primero se extrae que el MERCOSUR no es un proyecto enclaustrado en lo comercial y coaptado por su génesis intergubernamental, y en segundo lugar el laudo acoge y concreta el denominado principio in dubio pro communitate.

Argentina accionando ante un TAAM reclamó que Brasil imponía restricciones al tráfico de mercaderías sobre licencias automáticas y licencias no automáticas a la importación, indicando que diversos Comunicados de Brasil establecían medidas equivalentes a restricciones, incumpliendo los compromisos contraídos por el Tratado de Asunción (TA) y otros. Argentina destacaba que el TA expresa que el mercado común implica eliminar los derechos aduaneros y las restricciones no arancelarias y cualquier otra medida equivalente, añadiendo múltiples detalles. Brasil, por su parte, pidió el rechazo señalando que sólo se estaría ante un modelo de licenciamiento más moderno que condensa perfeccionamientos de la normativa adecuándola al nuevo contexto internacional, más otros aspectos. Pues bien, tras extensas consideraciones el TAAM pronunció un laudo unánime constatando que Brasil debía ajustar el régimen de licenciamiento, dándole para esto, un año de plazo ${ }^{155}$.

Acotándonos a lo que nos interesa, destaquemos la claridad del TAAM para perfilar al proyecto mercosureño como del tipo integracionista, explicando los árbitros que en el proceso hermenéutico de la normativa que converge al caso, debe utilizarse el modelo teleológico, pues es éste el que le corresponde a los procesos de integración, expresando su criterio de la siguiente forma:

«El enfoque teleológico resulta más patente aún en los Tratados e instrumentos que conforman organismos internacionales o configuran procesos o mecanismos de integración. A diferencia de otros instrumentos en cierto modo estáticos, donde los

\footnotetext{
${ }^{154}$ Laudo del TAAM de 28 de abril de 1999, República Argentina c. República Federativa de Brasil, as. $1 / 1999$.

${ }^{155}$ En términos más detallados, Argentina primero agotó la vía administrativa dispuesta en el SSCM, tras no prosperar su pretensión, es que demandó ante el TAAM. Consideraba que los Comunicados de Brasil $\mathrm{N}^{\mathrm{o}} 37$, $\mathrm{N}^{\circ} 7$ y $\mathrm{N}^{\circ} 23$ establecían medidas administrativas equivalentes a restricciones, lo que implica un incumplimiento de los compromisos establecidos en el Tratado de Asunción, su Anexo I y el Acuerdo de Complementación Económica $\mathrm{N}^{\circ}$ 18; las Decisiones CMC No 3/94 y 17/97. Para Brasil su moderno sistema SISCOMEX no violaba el Derecho mercosureño, y el Comunicado $\mathrm{N}^{\circ} 37$ sólo condensa los perfeccionamientos de la normativa Mercosur, todo bajo los criterios de transparencia aceptados por la Comunidad Internacional sin establecer reglas nuevas, y que se ajusta a los criterios de la OMC.
} 
derechos y obligaciones se agotan en algunos pocos actos de ejecución, [...], donde la valoración teleológica de las obligaciones y de las actividades ocupa un lugar central so pena de perder todo sentido» ${ }^{156}$.

Lo cual remata finalizando del siguiente modo:

«Los instrumentos internacionales que configuran procesos de integración y las obligaciones que resultan de ellos han de ser interpretados en forma teleológica, teniendo en cuenta los fines, objetivos y principios del sistema de integración, aun en ausencia de normas de carácter supranacional» ${ }^{157}$.

Entendemos que la importancia de la conjunción con el modelo teleológico radica en que al ser transversal y propia de los modelos de integración, refleja que el TAAM al optar por su incorporación se desplaza hacia esa zona, subsumiendo de facto las estructuras normativas intergubernamentales del MERCOSUR en formatos exegéticos integracionistas. Operación sustantiva que es más osada que la materializada en sistemas que autodefinen su naturaleza integracionista desde sus propios Estatutos, como ya lo vimos legislativamente en el capítulo anterior para el SICA y la CAN, y por cierto en el caso de la UE.

En este orden de ideas, el impulso de los laudos mercosureños también pasa a dar cuenta del fenómeno de nivelación jurisprudencial, ante el desfase existente entre el legislador y la realidad social - ya explicado-, y en este caso, tal realidad sería el reconocimiento fáctico integracionista en múltiples áreas. En nuestra opinión, este encuadre jurisprudencial de estructuras normativas intergubernamentales en moldes integracionistas, efectuados por órganos de naturaleza arbitral son realidades empíricas altamente valorables para la movilización completa del merco-sistema hacia la zona jurídica de la integración.

La opción del TAAM por la exégesis teleológica nos traslada hasta exactamente la misma conclusión que pudimos constatar al analizar el modelo de la CAN a partir de la sentencia del TJCA en Aktiebolaget Volvo/Volmo. Oportunidad en que el TJCA resolvió que corresponde el empleo preferente de los métodos de interpretación llamados funcionales, como los métodos sistemáticos y de interpretación teleológica ${ }^{158}$, metodología también

\footnotetext{
${ }^{156}$ Párrafo 57 del Laudo del TAAM de 28 de abril de 1999, República Argentina c. República Federativa de Brasil, as. 1/1999.

${ }^{157}$ Numeral (iii), del párrafo 85, del capítulo Conclusiones, en laudo ibídem.

${ }^{158}$ Sentencia del TJCA de 3 de diciembre de 1987, Interpretación prejudicial, Aktiebolaget Volvo c. Volmo, consulta de Consejo de Estado de la República de Colombia, Sala de lo Contencioso Administrativo, Sección Primera, as. 1-IP-87.
} 
seguida en el SICA. Circunstancias que incluso - como ya lo vimos- le imprimen al TJUE y a determinadas Cortes de América Latina un sello constitucional ${ }^{159}$.

Otro aspecto que consideramos muy relevante de este laudo es el hecho de que establece que siendo la Corte un elemento más del ordenamiento mercosureño, su labor es eminentemente de carácter cooperativo para lograr el objetivo de la integración misma. Es decir, nuevamente se demuestra que este tipo de tribunales, se encuentran al servicio de la organización a que pertenecen, bajo la lógica del principio de coherencia orgánica entre órgano y organización ${ }^{160}$. Tal vinculación utilitaria entre los objetivos fijados y la labor del tribunal de la organización, lo expresó nítidamente el laudo del siguiente modo «Los fines y objetivos no son un adorno de los instrumentos de integración sino una guía concreta para la interpretación y para la acción» ${ }^{161}$. Además los árbitros razonan de la siguiente forma: «el Tribunal habrá de buscar e identificar las reglas jurídicas aplicables, guiado por los fines y objetivos del orden normativo creado por las Partes y siendo el propio Tribunal un elemento del ordenamiento que las Partes conformaron para regular sus relaciones recíprocas con vistas a lograr el objetivo compartido 'de su integración', en el ámbito de los fines y principios del sistema» ${ }^{162}$.

Como se observa de la última frase destacada, «de su integración», se extrae que este laudo dejó a la vista otro aspecto que se ha venido poniendo de relieve, cual es el hecho de que el MERCOSUR posee su propio «tipo» de integración. Lo que se conecta con la múltiple categorización de los procesos de integración que hace la doctrina distinguiendo en términos amplios entre la integración estructural y la sustancial $^{163}$ y en términos

\footnotetext{
${ }^{159}$ En este aspecto nos remitimos en todo a lo ya analizado en el capítulo II en su apartado 3.2.4. El carácter de cuasi Tribunal Constitucional que pudieran ostentar las Cortes Latinoamericanas: Su justificación y el desarrollo estatutario que lo respalda.

${ }^{160}$ Recordemos que la sincronización o coherencia orgánica, es el principio cardinal que rige la relación organización/órgano. Principio que encuentra su razón de ser en el hecho de que el órgano queda dispuesto al servicio de los fines de la organización. Es decir, pasa a ser una herramienta de otra herramienta, pues las OI en sí mismas ya poseen una naturaleza de servicio. Esta circunstancia la estudiamos en el capítulo II, pueden verse las notas 4 y 5 de aquel capítulo y también HUICI SANCHO, 2007, p. 37.

${ }^{161}$ Párrafo 58, en Laudo del TAAM de 28 de abril de 1999, República Argentina c. República Federativa de Brasil, as. 1/1999.

${ }^{162}$ Párrafo 51 en laudo ibídem.

${ }^{163}$ Las categorías de integración reflejan toda la complejidad de la teoría de la integración, dado que no es un fenómeno jurídico homogéneo, sino recepciones incompletas del modelo de la UE manifestando por esto sendas carencias. Ningún proceso en América Latina es puro, ni podría ajustarse a sólo una clase de integración. Este aspecto ya lo destacamos en el capítulo II, v.gr. ARCARO presenta 2 grandes tipos de integración, una básica, la integración estructural, identificada por formalismos y vinculada al desarrollo económico o comercial, $v / s$ una profunda, la integración sustancial, más desarrollada contemplando la protección a los derechos humanos y no por ello con más orgánica, sino que decantan en lo sustantivo; por esta razón sería parte de una integración jurídica. ARCARO CONCI, 2015, 125-152. Con mayores detalles 250
} 
particulares identificando otras múltiples clases. Cuestión que ocurre cada vez que se intenta explicar la naturaleza jurídica del MERCOSUR, que como lo vimos, en su génesis fue de una clara naturaleza intergubernamental, pero luego pasa a discutirse sobre su tránsito hacia la integración, punto que precisamente analizamos en esta investigación, pero sólo desde el aporte de sus tribunales.

Para un correcto análisis, además de las categorías de integración, se debe observar el nivel de intensidad de dicha integración. Así por ejemplo, nuestro modelo de referencia - entre otros aspectos - es el más intenso, porque cubre una gran cantidad de áreas del quehacer de los Estados miembros y de los particulares, y su aporte es sustantivo y constante. Ahora bien, como ambos distingos — categorías y nivel— se despliegan y desarrollan paulatinamente, debemos focalizar los análisis considerando el contexto de madurez o la noción de continuum integratif, o más ampliamente el denominado factor de progresividad $^{164}$.

DOBOVSEK y SABAT distinguen otras varias, una, según la forma histórica de la integración habrían dos tipos, la autoritaria y la por coordinación, otra, según su finalidad estaría la integración militar, la económica, la política, o la cultural, y por último, una según la actitud de ella reconocen una integración de sistema cerrado y estanco, o una de apertura y flexibilidad intelectual. DOBOVSEK \& SABAT, 1999, pp. 241-243.

${ }^{164}$ El factor de progresividad, como ritmo de avance que sugiere la doctrina, ya lo hemos abordado, pueden verse las notas 129 del capítulo I y la 119 de este capítulo III. El problema es que en muchas ocasiones hay involuciones, retrocesos o extensas detenciones, aunque esto es propio de todo proyecto asociativo, véanse sólo las múltiples ampliaciones de la UE $v / s$ el actual Brexit, o la reconducción de los contenidos del proyecto de Constitución para Europa, etc. La progresividad entonces es inmanente al despliegue de la ejecución de los objetivos. PANAYOTIS SOLDATOS habla del «continuum integratif» como visión de conjunto de una realidad ordenada en función de un proceso de integración, citado en el mismo Laudo en su párrafo 50 (Le Système Institutionelle et Politique des Communautées Européennes Dans un Monde en Mutation, Bruylant, Bruxelles, 1989, p. 115 a 117). En esta línea, DA SILVA, en un estudio coetáneo al Laudo que estamos estudiando, comparó justamente la realidad de Mercosur con la CE (hoy UE), señalando: el modelo europeo quizás el más eficiente de los bloques regionales- puede ser tomado como ejemplo, pero teniendo en cuenta las profundas diferencias [...]. Sin embargo, es interesante considerar que la CE se ha construido progresivamente, en un lapso extenso de tiempo, y que aún hoy sigue evolucionando. Un desarrollo progresivo parece, entonces, más prudente a la hora de la integración regional de Estados diversos. DA SILVA, 1998, p. 131. 


\subsubsection{EL PRINCIPIO IN DUBIO PRO COMMUNITATE Y LA TENDENCIA PRO INTEGRATIONE} INCORPORADOS POR UN TAAM AL ACERVO DEL MERCOSUR

Otro aspecto de gran interés para el robustecimiento del MERCOSUR y que surge a partir del laudo bajo análisis — Argentina/Brasil ${ }^{165}$ _, es el hecho de que el TAAM incorporó jurisprudencialmente el concepto académico referido al principio in dubio pro communitate. Esta regla matriz explica que debe mantenerse constante una postura o tendencia en favor de la integración. Es decir, favorecer las interpretaciones de los Tratados conduciéndolas hacia el logro de la integración, también es útil para medir las exigencias a los socios en base a la lealtad para con la integración, entre otros aspectos en que también puede aplicarse. El tribunal realzó este principio en carácter de herramienta conceptual idónea para un proceso de integración. Aunque advirtió que es del todo improcedente si por su utilización se llegase a producir una contradicción con los textos expresos:

«Los fines y objetivos no son un adorno de los instrumentos de integración sino una guía concreta para la interpretación y para la acción. Aun sin llegar a una aplicación absoluta de la regla que Quadros define como 'in dubio pro communitate', y en tanto no haya contradicción con textos expresos, la interpretación de las disposiciones en un conjunto normativo cuyo fin es la integración debe guiarse por este propósito y hacerlo posible» ${ }^{166}$.

La materialización del principio in dubio pro communitate, es a nuestro juicio un ejercicio jurisdiccional de gran relevancia, porque permite materializar aquella dualidad que señalamos en el capítulo anterior, en cuanto a que, una Corte de integración, por una parte resuelve los contenciosos, y por otra, colabora con la construcción misma del proyecto a través, precisamente, de este tipo de jurisprudencia integracionista que en este capítulo venimos analizando ${ }^{167}$.

${ }^{165}$ Laudo del TAAM de 28 de abril de 1999, República Argentina c. República Federativa de Brasil, as. $1 / 1999$.

${ }^{166}$ Por esta vía el TAAM le otorga utilidad concreta a los fines y objetivos de la Organización, pues resalta que ellos no son decorativos, sino aplicables. Es decir, pasa a dinamizar estructuras matrices originarias, para de esa forma impregnar de un ritmo unitario a todo el sistema. Se apoya para esto, citando a QUADROS y a LECOURT [en el párrafo 58 del Laudo]. Referencias hechas a DE QUADROS, F. (1984). Direito das comunidades europeias e direito internacional público - contributo para o estudo da natureza jurídica do direito comunitário europeu. Lisboa: Almedina, pp. 429-430, y a LECOURT, R. (1976). L'Europe des juges. Bruxelles: Bruylant, p. 241 a 247. Párrafo 58 en el laudo ibídem.

${ }^{167}$ Tal dicotomía funcional de los tribunales de integración, que fluye desde su ámbito competencial, es detectada ampliamente por la doctrina. CENTURIÓN GONZÁLEZ recalca —al comentar este mismo Laudo - lo siguiente «la labor de un Tribunal Arbitral no se limita a resolver un caso de controversia, sino a ser un actor que, desde su esfera de acción jurisdiccional, haga aportes a la consolidación del proceso de integración, en base a objetivos y principios que fueron negociados y establecidos por las mismas Partes». CENTURIÓN GONZÁLEZ, C. H. (2017). Aporte del tribunal permanente de revisión al proceso de 252 
En los sistemas de diseños procesales complejos, es decir, con más de una Corte - como la UE y aquí el MERCOSUR - la jurisprudencia integracionista puede provenir de cualquiera de sus tribunales siguiendo las normas de competencias, tal como por ejemplo ya lo vimos en el caso Neuman donde la creación pretoriana provino del TPUE, hoy TGUE, asentando el principio de aplicación uniforme del Derecho de la $\mathrm{UE}^{168}$, y justamente ahora en el caso bajo análisis, el aporte jurisprudencial proviene de un órgano inferior, un TAAM, cuyo laudo fue trascendente para el desarrollo del merco-sistema, en el marco de un fenómeno posterior emergido durante el desarrollo práctico de este modelo de justicia del MERCOSUR, consistente en una dinámica por la cual varios TAAM reutilizan soluciones de otros anteriores.

Como es sabido, en términos generales, no es extraño que muchos tribunales de diversos tipos y materias citen a otras Cortes, sentencias o laudos arbitrales, esto es una costumbre procesal habitual. Sin embargo, se presenta una cierta singularidad en el MERCOSUR cuando los TAAM citan a otros TAAM, porque en dicho ejercicio subyace la intención de proyectar una idea unitaria de un aparente Poder Judicial que en términos formales no existe, pero que se desea que se visualice en una dimensión sustantiva, cuestión que ha pasado a identificarse bajo la noción que la doctrina denomina tendencia pro integratione $^{169}$.

Mediante el concepto de tendencia pro integratione, se destaca el hecho de que los TAAM al ser sólo de convocatoria permanente, todas sus referencias a otros laudos previos, intentando en particular generar una sensación unitaria y/o la percepción de la existencia de un cuerpo jurisdiccional con una historia o precedentes comunes, pasan a ser muy

integración del Mercosur: Reflexiones orientadas hacia la sociedad civil del mercosur. Revista da secretaria do tribunal permanente de revisão, 5(9), 78-100. SARMIENTO destaca esta circunstancia, refiriéndose al concepto de Poder Judicial de la UE, especifica: En consecuencia el poder judicial desempeña una función crucial en la salvaguarda de la efectividad del Derecho de la Unión, pues, por un lado, ofrece pautas autorizadas de interpretación de dicho ordenamiento en todo el territorio de la Unión y, por otro lado, resuelve individualmente los pleitos que se plantean en el día a día. SARMIENTO RAMÍREZ-ESCUDERO, D. (2016). El derecho de la unión europea. Madrid, Barcelona, Buenos Aires, Sao Paulo: Marcial Pons, p. 357.

${ }^{168}$ Sentencia del TJ de 14 de noviembre de 1985, Neumann, as. C-299/84, ECLI:EU:C:1985:463.

169 La doctrina detecta este fenómeno en el MERCOSUR como un fruto positivo del ejercicio de los tribunales arbitrales dispuestos en el sistema de solución de controversias del modelo, así por ejemplo para OLMOS el fenómeno que se ha venido produciendo en el MERCOSUR, respecto de las referencias de los TAAM a laudos de arbitrajes anteriores, es una cuestión que da cuenta de que habría una cierta tendencia pro integratione emanando precisamente del impulso del órgano resolutor de controversias mercosureño. Esta autora destaca la tendencia pro integración impulsada desde la sede arbitral al tiempo de citar para ello a ZLATA DRNAS DE CLÉMENT. OLMOS GIUPPONI, 2009, p. 141. 
especiales. Nosotros entendemos que dicha singularidad se basa en que la mentada comunicación horizontal entre los TAAM con el propósito unitario destacado, toma una notoria distancia de los cuatro cauces clásicos para incorporar precedentes a una sentencia, esto es, primero, una Corte puede auto-citarse arrastrando de ese modo su propio criterio anterior, o bien, en segundo lugar, un tribunal puede considerar sentencias de Cortes que orgánicamente son superiores suyos, o en tercer lugar, las Cortes que se citan están en su mismo nivel jerárquico pero siempre dentro de un sistema orgánico de carácter permanente, o por último, en cuarto lugar, y en una dimensión más osada, es factible que un tribunal recurra al fenómeno del dialogo judicial con Cortes foráneas. Pero ninguna de esas cuatro técnicas coincide con la singular práctica horizontal entre los TAAM, por lo tanto nosotros también consideramos que es más próxima al concepto de la tendencia pro integratione, toda vez que en la técnica detectada entre los TAAM subyace la idea de cuerpo jurisdiccional estable, lo que en la práctica no existe en el merco-sistema. Ahora bien, esta práctica de los TAAM, la consideramos claramente evolutiva, pues genera una fuerza unitaria especial entre órganos que ya no están constituidos, toda vez que se disuelven tras cada caso, y se constituyen otros nuevos para el siguiente.

En conclusión, el aporte de este laudo es sustancial para el proceso de integración mercosureño, pues impulsó un desplazamiento desde el original modelo intergubernamental meramente económico, hacia una zona integracionista, ya que razonó en cuanto su labor es eminentemente cooperativa para lograr el objetivo de la integración, además le inyectó conceptos nuevos, como el principio in dubio pro communitate, también incorporó el criterio en cuanto debe aplicarse el modelo de interpretación teleológica, insertando la estructura normativa intergubernamental del MERCOSUR en moldes integracionistas, por otra parte el laudo recalcó que los fines y objetivos son una guía concreta para la integración, y por último dejó a la vista que el MERCOSUR posee su propio tipo de integración. 


\subsubsection{El TEST DE COMPATIBILIDAD DEL DERECHO NACIONAL CON EL MERCOSUREÑO} ANTE LA INEXISTENCIA DEL RECURSO DE INCUMPLIMIENTO, $Y$ EL FACTOR DE PROGRESIVIDAD APLICADOS POR EL TPRM

El TPRM presenta un ejercicio de fuerte cercanía con el derecho de la integración generado progresos en varios campos, de entre los cuales y por poseer el carácter de jurisprudencia integracionista, hemos seleccionado la respuesta a la opinión consultiva en la causa República Oriental del Uruguay ${ }^{170}$, ya que en esa oportunidad el TPRM generó importantes aportaciones, en primer lugar hubo una notable creación reactiva, ante la inexistencia del recurso de incumplimiento, dando paso a una solución propia para superar dicha carencia; además el TPRM se alineó con el factor de progresividad; también advirtió del riesgo de convertir al Derecho del Mercosur en un mero derecho lírico; por otra parte explicó que las normas mercosureñas no son de aplicación directa, sino que cada Estado debe incorporarlas - muy diferente a la UE-; y subrayó la existencia de normas derivativas en el MERCOSUR emanadas de órganos propios con capacidad legislativa, alejándose de su inicial naturaleza intergubernamental.

Las empresas Suceción Schneck S.A., Galisur S.A. y Cesim Co Ltda. demandaron al Estado uruguayo, solicitando la devolución de montos que entendían ilegítimamente cobrados más otros por el concepto de tasa consular, además pedía que se declarara prohibido su cobro, y finalmente pedía el desaplique del art. 585 de la ley nacional $17.296^{171}$, pues reimplantando dicho tributo se habría violado normativa MERCOSUR. La Suprema Corte de Justicia uruguaya consultó dos aspectos al TPRM, primero, si las normas mercosureñas primaban o no, sobre la nacional y, en segundo lugar, para el caso afirmativo, cuál sería la que debería aplicar el juez, la nacional o la del MERCOSUR ${ }^{172}$.

Sin duda el mayor aporte de esta sentencia fue su creación reactiva ante la inexistencia del recurso de incumplimiento, haciendo factible el pasar a apreciar la «compatibilidad» de las

\footnotetext{
${ }^{170}$ Laudo del TPRM de 24 de abril de 2009, Opinión consultiva, República Oriental del Uruguay, as. OC. $01 / 2008$.

${ }^{171}$ Ley uruguaya $\mathrm{N}^{\circ} 17.296$ Publicada D.O. 23 de feb/001 - $\mathrm{N}^{\mathrm{o}} 25714$, y en su artículo 585 dispuso "Reimplántese la tasa consular, derogada por el artículo 473 de la Ley No 16.226 de 29 de octubre de 1991.

${ }^{172}$ Este juicio se ventiló ante el Juzgado Letrado de Primera Instancia en lo Civil de $1^{\circ}$ Turno IUE 2-32247/07 de Uruguay. Demandaron 3 empresas: Suceción Schneck S.A., Galisur S.A. y Cesim Co Ltda., y detallaban en extenso que el art. 585 de la Ley 17.926 había «reimplantado» el tributo llamado tasa consular, la cual ya había sido derogada por el art. 473 de la Ley 16.226 por violar la misma norma Mercosur que por esta acción judicial se intentaba hacer respetar, las cuales eran: el TA art $1^{\circ}$; Anexo I, arts. $1^{\circ}$ y $2^{\circ}$; Decisiones CMC 7/94, 22/94 y 22/00; Decisión GMC 36/95; Protocolo de Ouro Preto, arts. 38 y 42; y la Convención de Viena del Derecho de los Tratados, arts. 26 y 27.
} 
normas de los Estados Partes con las mercosureñas. Para su estudio consideremos dos cuestiones, uno, que el cumplimiento de las obligaciones de los Estados miembros se vincula con el principio de cooperación leal, pues no tiene sentido que un Estado asuma libremente obligaciones para el logro de objetivos que aisladamente no podría alcanzar o lo haría en menor medida, para luego, desentenderse de la suerte del grupo, incumpliendo con tales compromisos; y dos, que una carencia procesal de la magnitud anotada, en cuanto a no otorgar acción para hacer valer el cumplimiento de una obligación, simplemente, en todo sistema y en todo nivel, transforma al derecho material, en ilusorio.

El recurso de incumplimiento como garantía procesal destinada a hacer valer determinados derechos fue desarrollado en la UE y luego recepcionado en los modelos SICA y CAN, a diferencia del MERCOSUR donde no se incorporó legislativamente — según vimos en el capítulo II-, y en la UE comporta uno de los medios para controlar el cumplimiento de las obligaciones que le incumban a los Estados miembros en virtud de los Tratados, ya sea por acciones u omisiones ${ }^{173}$. Además, y como ya lo vimos, esta herramienta no es precisamente un recurso, pues no es una vía de impugnación, sino que en realidad es una acción ${ }^{174}$. Por tal motivo la recepción latinoamericana se produjo bajo el nombre de acción de incumplimiento tanto en el SICA $^{175}$ como en la $\mathrm{CAN}^{176}$. Por otra parte la acción de incumplimiento se conecta con la legitimación activa, pudiendo ser ésta, más o menos amplia, en cada uno de los modelos que tenemos bajo análisis. Comparativamente observamos que la legitimación en la UE es más bien restrictiva con los particulares y sólo están legitimados la Comisión y los Estados miembros, y excepcionalmente el Consejo de Administración del BEI, o el Consejo de Gobierno del BCE. En cambio en América Latina la apreciamos más amplia, toda vez que se incluyen además a las personas físicas y jurídicas de modo más amplio, tanto en la $\mathrm{CAN}^{177}$ como en el $\mathrm{SICA}^{178}$, todo según ya lo analizamos en el capítulo II.

Desprovisto entonces el MERCOSUR de la acción indicada, pero disponiendo del mecanismo de las opiniones consultivas el TPRM articuló los contenidos del principio de primacía del derecho de la integración y los pasó a encuadrar en el modelo del MERCOSUR. Señaló que eventualmente las normas nacionales pueden colisionar con el Derecho mercosureño, y que tal situación — explica el TPRM- da paso a lo que en

\footnotetext{
${ }^{173}$ Arts. 258, 259 y 260 del TFUE, nos remitimos en todo al capítulo II.

${ }^{174}$ La técnica legislativa en la UE de bautizar como «recursos» a institutos que en realidad son «acciones» es muy poco técnica, y ya lo abordamos en el capítulo anterior. DESANTES REAL \& PARDO IRANZO, 2013, p. 49. SARMIENTO RAMÍREZ-ESCUDERO, 2016, p. 360.

${ }^{175}$ Literal b) del art. 22 del Estatuto de la CCJ.

${ }^{176}$ Arts. 107 y siguientes del Estatuto del TJCA.

177 Art. 108 del Estatuto del TJCA.

${ }^{178}$ Art. 95 de la Ordenanza de Procedimiento de la CCJ.

256
} 
terminología de la integración se justifica como indagar si hay o no compatibilidad entre el derecho de la integración y el nacional, momento preciso en que surge la interrogante de si el Derecho del Mercosur es jerárquicamente superior al nacional.

La respuesta a dicha interrogante comienza a aclararse teniendo presente en primer lugar la construcción gradual de las normas mercosureñas, interpretadas a la luz de las relaciones recíprocas en el contexto de un proyecto integrador común. Es decir, hace referencia directa al continuum integratif lo que además es reflejo de la tendencia pro integratione según analizamos en el laudo del TAAM dictado en la causa República Argentina c. República Federativa de Brasil $^{179}$, pero ahora el TPRM viene en complementar basándose en el hecho de que incluso desde el simple contexto internacional tiene solución, aplicando el principio pacta sunt servanda, cuestión que explica del siguiente modo:

«teniendo presente el principio pacta sunt servanda, los acuerdos de integración del Mercosur y las normas derivadas se van convirtiendo en "un conjunto normativo de formación sucesiva, por acumulación de disposiciones tomadas en el curso de un complejo proceso de decisiones políticas y jurídicas, insertas en una realidad económica cambiante"» ${ }^{180}$.

Pero el nudo más complejo —y que lo reconoce el TPRM en los Considerandos 31, 34 y 48 del laudo - es que la primacía de la normativa del MERCOSUR se materializa sólo desde su incorporación o internalización en cada Estado miembro. Por lo que en este aspecto, se constata que el proyecto mercosureño se aleja totalmente de la UE, donde opera el principio de aplicación directa, y de los modelos latinoamericanos del SICA y de la CAN. Por esto es que el TPRM declara la primacía sólo en términos generales:

«De modo general, el Tribunal afirma la primacía de la normativa del Mercosur desde su ratificación, incorporación o internalización, según sea el caso, respecto de toda disposición interna de los Estados Parte que le sea contrapuesta sobre materias de la competencia legislativa del Mercosur» ${ }^{181}$.

Acto seguido los árbitros se conectan con la dimensión obligatoria de los laudos. Considerando que, como estos son vinculantes, entonces los Estados están obligados a derogar o modificar sus normativas que por tales laudos —obligatorios - se declaren

\footnotetext{
${ }^{179}$ En cuanto a la «tendencia pro integratione», vid. nota 179. Sobre el «continuum integratif» el TPRM está haciendo referencia a la noción de PANAYOTIS SOLDATOS, y a la imposibilidad de disociación de las normas de un régimen de integración que explica REMIRO BROTONS, a quienes citó el TAAM en el laudo que ya analizamos (Laudo del TAAM de 28 de abril de 1999, República Argentina c. República Federativa de Brasil, as. 1/1999).

${ }^{180}$ Considerando 28, en Laudo del TPRM de 24 de abril de 2009, Opinión consultiva, República Oriental del Uruguay, as. OC. 01/2008.

${ }^{181}$ Considerando 34 en laudo ibídem.
} 
incompatibles con el Derecho del Mercosur - recordemos que solo los laudos son obligatorios, las respuestas a las consultas no lo son. Con el razonamiento expuesto el tribunal logró crear un conducto indirecto de control de legalidad y de cumplimiento, mediante la obligación de acatar un laudo que declare la desconexión de las normas nacionales con las del merco-sistema.

A nuestro juicio estamos ante una interpretación amplia de las normas del MERCOSUR por dos razones, primero, porque los derechos, acciones y recursos deben contemplarse expresamente por el legislador, en cambio aquí, la solución del tribunal es oblicua toda vez que en algún momento el legislador debiese consolidar estatutariamente una acción de incumplimiento, y en segundo lugar, en términos generales la inexistencia de una acción por una parte, produce la pérdida del derecho, tornándolo ilusorio, o como lo adjetivó el mismo tribunal, lo transforma «en lírico», y por otro extremo, deja a la Corte en un inestable campo por una posible incompetencia. Pero esta jurisprudencia al ser de carácter amplio, superó los referidos problemas, permitiéndole sortear la inexistencia de la acción de incumplimiento gracias al uso de competencias generales, construyendo la institución que pasó a conocerse como la «apreciación de compatibilidad», mediante la cual se hace posible apreciar la compatibilidad de las normas de los Estados miembros con las mercosureñas. Así, en su respuesta el TPRM señaló:

«Es importante recordar que en la actual etapa del proceso de integración, tanto los Tribunales Ad Hoc como el TPR, aunque carecen de competencia para declarar de forma directa la nulidad o la inaplicabilidad de la norma interna [...], pueden declarar la incompatibilidad de la norma interna con el derecho del Mercosur. Son los órganos estatales competentes los que deben derogar o modificar la norma interna incompatible, habilitando medidas que pueden ser adoptadas por el Estado Parte afectado en caso de incumplimiento» ${ }^{182}$.

La amenaza de cumplimiento mediante el respeto a la autoridad de cosa juzgada emanada de un laudo, que declare la incompatibilidad, la entendemos en posición de ultima ratio. De hecho, el tribunal expresó que la compatibilidad surge como consecuencia general de las obligaciones asumidas por los miembros, indicando «En general, la compatibilidad o no de la normativa interna con una norma del Mercosur surge como consecuencia de la obligatoriedad asumida por los Estados Partes» ${ }^{183}$. Extrayéndose entonces que, antes de la autoridad de cosa juzgada y de sus consecuencias, se encuentran la buena fe en el obrar y en la lealtad hacia el proyecto común. Todo lo cual impulsa el avance concreto de la Corte en cuanto a asumir potestades para efectuar el cotejo jurídico entre el Derecho del Mercosur y el nacional, cuestión que expresa directamente «El Tribunal considera, en suma, que es de

\footnotetext{
${ }^{182}$ Considerando 33 en laudo ibídem.

${ }^{183}$ Considerando 46 en laudo ibídem. 258
} 
su competencia efectuar un análisis jurídico de la normativa Mercosur con relación a la normativa uruguaya» ${ }^{184}$.

En conclusión, fluye de este laudo su evidente naturaleza integracionista ${ }^{185}$, pues el TPRM ha promovido el éxito del proceso integracionista, ya que si bien reconoció su incompetencia para declarar la nulidad o el incumplimiento, buscó y encontró una buena solución para la el conflicto concreto y para el robustecimiento del proyecto completo, estimando su plena potestad para advertir desconexiones de leyes nacionales con el Derecho del Mercosur, señalando en tales casos una posible incompatibilidad. Ejercicio pretoriano que es de plena lógica jurídica ${ }^{186}$.

La importancia de este laudo la observamos como un doble impulso de ajuste a la realidad, pues, de un lado, motiva al legislador del MERCOSUR para que genere la acción inexistente - de incumplimiento - y le atribuya esas competencias al tribunal, y de otro lado, motiva al legislador nacional a alinearse con el Derecho del Mercosur, so pena de declararse la incompatibilidad.

En cuanto a los otros contenidos del laudo que aquí nos influyen, destaca el hecho de que la Corte ponga de relieve que el Derecho del Mercosur es un cuerpo normativo vivo, establecido por la voluntad de los Estados el cual incluye instrumentos originarios que forjan la estructura del MERCOSUR, delinea los principios que lo rigen, fija objetivos y crea órganos, e incluso dota a algunos de capacidad normativa, de cuyo ejercicio surgen las normas denominadas derivadas ${ }^{187}$. Tal reconocimiento sobre algunos órganos mercosureños que poseerían capacidad de gestar normativa derivativa, denota un tímido intento de avance hacia la zona supranacional. Sin embargo, es muy discutible que tales órganos sean efectivamente de tipo integracionista y con capacidad normativa desconectada de los gobiernos nacionales. De hecho éste es uno de los aspectos más criticados del MERCOSUR, e identificado como la causa para mantenerlo atrapado en su naturaleza intergubernamental. Pero claramente la Corte tiene una visión más optimista.

${ }^{184}$ Considerando 42 en laudo ibídem.

${ }^{185}$ En especial de los párrafos 33, 42 y 46 en laudo ibídem.

${ }^{186}$ En esta línea, para CIENFUEGOS el concepto «amplio de interpretación» del TPRM que le permite apreciar la mencionada compatibilidad de las normas locales con las de Mercosur, es de buena lógica. Además destaca este autor que, el punto neurálgico de la argumentación fue la supremacía de las normas del Derecho del Mercosur sobre los ordenamientos internos, de tal suerte que este procedimiento está siendo utilizado para sancionar de modo indirecto (a través de las jurisdicciones internas) las infracciones de sus Estados Parte, dado que el recurso directo de incumplimiento no existe en el Cono Sur. CIENFUEGOS MATEO, M. (2012b). Opiniones consultivas en el mercosur y cuestiones prejudiciales en la unión europea: Estudio comparativo. Revista de derecho comunitario europeo, 16(42), 433-476.

${ }^{187}$ Considerando 24, en Laudo del TPRM de 24 de abril de 2009, Opinión consultiva, República Oriental del Uruguay, as. OC. 01/2008. 
En conclusión, sobre la actividad jurisprudencial completa de los TAAM y TPMR, consideramos que las complejas construcciones jurisdiccionales que impulsan hacia los contenidos del derecho de la integración, son más valiosas que las de su entorno, atendida la dificultad que conlleva reorientar procesos de integración nacidos dentro de un esquema de integración económica, que se dota de una débil institucionalidad enfocada a dicho fin, lo que configura una limitante de origen que obstaculiza el ejercicio de la Corte a modo de freno constante. En ese cauce, no sólo el MERCOSUR es un caso de integración económica en que existiendo dichas limitantes, igualmente evolucione, sino que en general las integraciones de tipo económicas tienden a ampliar sus fines ${ }^{188}$ porque sus Cortes, sin haber sido creadas en el contexto de una Organización de integración plena — sino por OI basadas en otros fines - pueden impulsar al grupo completo hacia una integración socio-política y sustancial, o bien, porque la Organización genera el desplazamiento del proyecto, atribuyéndole más competencias a su Corte. Aunque ambos extremos se sincronizan.

Visto lo visto, queda demostrada con creces la producción concreta de jurisprudencia integracionista de relevancia por parte de la CCJ, del TJCA y del TPRM y TAAM. Pero para el caso del MERCOSUR se observa menos intensa. De hecho, incluso, los TAAM y TPRM son los que cuantitativamente menos sentencias dictan, en comparación a la CCJ y al TJCA - y todos absolutamente lejanos del TJUE y TGUE. Pero, pese a esta menor intensidad y menor cantidad que se observa en la Cortes mercosureñas, su ejercicio es bien destacable, ya que rompe el molde intergubernamental y comercial en que se encontraba encapsulado originariamente.

\footnotetext{
${ }^{188}$ Por ejemplo en la ex-URSS y en África, para los casos del Tribunal Económico CEI y la ECOWAS Court, se constatan avances similares, pudiendo observarse comparativamente diversas particularidades. Por una parte, el Imperio Ruso se construyó por un cauce integracionista del tipo fenomenológico mediante una integración autoritaria. La revolución hacia la URSS repitió el modelo autoritario para la unificación, pero al disolverse afloraron diversas problemáticas, como las económicas, lo que motivó la creación de la Comunidad de Estados Independientes (CEI) como una OI orientada a una integración económica usando el esquema de una integración por coordinación. Se le dotó entre sus órganos del Tribunal Económico atribuyéndole competencias en esas materias. Pero la Corte y la CEI inmersas en el proceso cooperativo tomaron un rumbo de ampliación de competencias alcanzando extremos políticos e integracionistas más globales. Los procesos herederos de la ex URSS donde se enmarca el surgimiento de la CEI y su intento por paliar el vacío dejado por la ex megapotencia, vid. en BLANC ALTEMIR, 2004. Por otra parte, la Economic Community of West African States (ECOWAS) agrupa Estados francófonos, anglófonos y lusófonos de África. Su objeto inicial era la cooperación internacional económica, social y cultural, sin embargo las económicas no tuvieron logros importantes. En cambio, las no establecidas, las políticas, se desarrollaron mucho más. Así en 1993 su Tratado Constitutivo se amplió y la Ecowas Court recibe competencias interpretativas, consultivas y contenciosas, incluso luego pasó a tener competencias en derechos humanos, siendo significativo que no se exija agotar las vías nacionales. Así hoy esta OI se encuadra en un modelo más próximo al de integración sustancial. El Protocolo de la Ecowas Court es de 1991 (vigor 1996), en 2001 juraron sus primeros jueces y en 2007 dictó su primera sentencia. SOBRINO HEREDIA, 2010a, p. 874.
}

260 
EL DIÁLOGO JUDICIAL ENTRE LOS TRIBUNALES DE INTEGRACIÓN 


\section{Capítulo IV}

\section{EL DIÁLOGO JUDICIAL \\ ENTRE LOS TRIBUNALES DE INTEGRACIÓN}

\section{INTRODUCCIÓN}

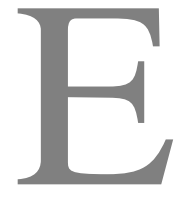

ste capítulo tiene por objeto demostrar que importantes sentencias de la Corte Centroamericana de Justicia (CCJ), del Tribunal de Justicia de la Comunidad Andina (TJCA) y del Tribunal Permanente de Revisión Mercosur (TPRM) comprendiendo en este último caso a los Tribunales Arbitrales ad hoc Mercosur (TAAM), han sido dictadas basadas en las soluciones del Tribunal de Justicia de la Unión Europea (TJUE o TJ) mediante el empleo de una clase de diálogo judicial. Para tal labor seguiremos el siguiente esquema, primero, contextualizaremos el fenómeno del diálogo judicial, justamente en esta introducción, en segundo lugar, nos aproximaremos a un concepto del mismo, y en tercer lugar, nos adentraremos en el análisis de determinadas sentencias de cada una de las Cortes latinoamericanas bajo análisis, dejando a la vista, no sólo una influencia notoria de la UE como lo vimos en el capítulo anterior, sino un empleo directo y concreto de precisas jurisprudencias del TJUE, sumado a un incipiente diálogo judicial interamericano.

En cuanto al primer aspecto señalado en el párrafo anterior, el contexto del dialogo judicial en sentido amplio se subsume en el ejercicio de la función jurisdiccional, la cual en ocasiones exige que los tribunales se conecten entre sí por diversos motivos, cuestión que efectúan mediante cauces procesales u orgánicos, como peticiones nacionales e internacionales, consultas, respuestas, órdenes y en una dimensión más específica a través de diversos recursos procesales se aplican soluciones jurisdiccionales impuestas por los superiores jerárquicos intra-sistemas. Esta vinculación que permite el flujo de variada 
información entre tribunales se conoce en el derecho procesal como la teoría de la comunicación entre tribunales o del auxilio judicial ${ }^{1}$.

En particular, las Cortes de integración se enfrentan a dicha teoría o auxilio judicial, de forma mucho más compleja que en un modelo clásico. Pues orgánicamente los sistemas a que pertenecen se caracterizan, en general, porque se conectan con el nivel nacional a través del principio de colaboración - tal como ya lo hemos analizado en los capítulos anteriores, y en particular, porque en aquellos pocos modelos diseñados orgánicamente con pluralidad de Cortes, como el caso de la Unión Europea (UE — con el TJUE y el TGUE) y del Mercado Común del Sur (MERCOSUR — con los TPRM y los TAAM) se produce entre dichas Cortes, una comunicación jerárquica intra-sistema. Ahora bien, si consideramos ambos aspectos orgánicos, tanto el principio de colaboración como la comunicación jerárquica (intra-sistema), la máxima complejidad la observaremos en la UE

\footnotetext{
${ }^{1}$ La teoría de la comunicación entre tribunales, o los actos de comunicación con otros tribunales, o el auxilio judicial, dan cuenta de la noción de conexión entre los órganos que ejercen jurisdicción, tanto desde las perspectivas orgánicas como extra-orgánicas, mediante vehículos procesales idóneos. Esquematizando sus contenidos encontraremos: $1^{\circ}$ En una posición intra-sistema hay dos realidades, una al interior de una estructura piramidal donde se manifiesta básicamente por medio de recursos procesales jerárquicos y algunos tipos de oficios, y otra cuando no hay comunicación jerarquía dentro del sistema, sino horizontal, se recurre a herramientas como: otros oficios especiales, exhortos nacionales, el suplicatorio, la carta orden, etcétera. Por ejemplo en España (sistema del cual derivan múltiples americanos) tanto en la Ley de Enjuiciamiento Civil (LEC) como en la Ley Orgánica del Poder Judicial (LOPJ) se contiene el «auxilio judicial», en términos de colaboración entre tribunales. Así se aprecia del art. 169.1 LEC, del art. 273 LOPJ, y el art. 276 LOPJ se explaya hacia el nivel internacional así: Las peticiones de cooperación internacional se tramitarán de conformidad con lo previsto en los tratados internacionales, las normas de la Unión Europea y las leyes españolas que resulten de aplicación. $2^{\circ}$ En este último caso -internacional- quedamos expuestos a la dimensión extra-sistema, donde se usan herramientas como los oficios, solicitudes, exhortos internacionales y el excecuatur. Esta clase extra sistema refleja una dimensión extra-orgánica de comunicación, explicándose aquí la teoría de la comunicación entre tribunales en código de colaboración internacional a través de los filtros del Poder Ejecutivo. Estos dos primeros niveles clásicos, son hasta donde las estructuras formales del derecho han avanzado con claridad. GUASP explica que para la misión que se les está encargada a los tribunales, éstos pueden pedir asistencia a otros órganos, la que puede ser inter-judicial o no, pero siendo inter-jurisdiccional se detecta un caso especial de asistencia, el auxilio jurisdiccional internacional o externo, que habitualmente toma el cauce de la diplomacia y de los Tratados Internacionales. GUASP, J. (1968). Derecho procesal civil : Tomo primero : Parte general ( $3^{\mathrm{a}}$ ed., $2^{\mathrm{a}}$ reimp.). Madrid: Instituto de Estudios Políticos., pp. 112-114. $3^{\circ}$ ) Pero al emigrar por completo de lo local, posicionándonos en la Jurisdicción Internacional, la visión horizontal y la desconexión estatutaria imperante entre las Cortes Transnacionales, devela un campo irresoluto para la clásica teoría de la comunicación entre tribunales. $4^{\circ}$ ) Este plano internacional, es precisamente donde se ubican las Cortes de Integración, en el cual, si enfocamos en particular hacia la dinámica de comunicación entre Cortes de un sistema con las de otro diferente, aparece utilitariamente la «teoría del diálogo judicial» que es hacia donde nos dirigimos en este capítulo IV.
} 
— como ya lo hemos destacado-, por tal razón se concluye por la doctrina ${ }^{2}$ que estaríamos ante un Poder Judicial híbrido o integrado.

Pero abandonando ese campo de conexión orgánica — que afecta a las Cortes de Integración, como ya lo analizamos en los capítulos anteriores - y avanzando por medio de una observación amplia, se constata una conexión extra-orgánica ${ }^{3}$ entre Cortes pertenecientes a diferentes sistemas. Fenómeno que en ningún caso es privativo de las Cortes de integración, sino que se materializa entre los más diversos tipos tribunales, el cual se ha venido en identificar bajo el concepto de diálogo judicial.

\footnotetext{
${ }^{2}$ Ya hemos destacado la especial vinculación de las Cortes de integración con los tribunales nacionales, subrayando que entre éstos la conexión era dicotómica, pues por un extremo opera bajo el principio de colaboración, y por otro se articulan las competencias secundarias (no instanciales, ni casacionales). SARMIENTO explica que el Poder Judicial de la UE, como en todo sistema político basado en el reparto de competencias, precisa de una estructura en dos niveles, por un lado los Tribunales de la UE, y por otro los Tribunales de los Estados miembros, refiriéndose al todo como un «Poder Judicial Híbrido». SARMIENTO RAMÍREZ-ESCUDERO, D. (2016). El derecho de la unión europea. Madrid, Barcelona, Bs. Aires, Sao Paulo: Marcial Pons, p. 360. LENAERTS y GUTIÉRREZ-FONS hablan de un «Poder Judicial Integrado» indicando que, a diferencia de otros sistemas federales la UE tiene un «Poder Judicial Integrado» pues el TJ lo comparte con los órganos jurisdiccionales nacionales — aclarando que en dicha dinámica- el TJ ha introducido elementos jerárquicos. LENAERTS, K. \& GUTIÉRREZ-FONS, J. (2012). El papel del TJUE en el proceso de integración europea. En Beneyto, J. M., Maillo González-Orús, J., Becerril Atienza, B., \& Lenaerts, K., Tratado de derecho y políticas de la unión europea, Tomo V Sistema jurisdiccional de la ue ( $1^{\mathrm{a}}$ ed.). Cizur Menor: Thomson Reuters Aranzadi., pp. 86-88.

${ }^{3}$ La conexión es de tipo orgánica cuando los tribunales están conectados al mismo sistema y obedecen a estructuras jerárquicas. Pero cuando fluyen razonamientos entre tribunales desconectados jerárquicamente, sin vínculo orgánico, hablamos de comunicación extra-orgánica, en estos casos su herramienta de comunicación es el diálogo judicial. NANCLARES identifica esta desconexión orgánica como una «manifestación de la cooperación no reglamentada entre tribunales». MARTÍN Y PÉREZ DE NANCLARES, J. (2017). El TJUE como actor de la constitucionalidad en el espacio jurídico europeo: La importancia del diálogo judicial leal con los tribunales constitucionales y con el TEDH. Teoría y realidad constitucional, (39), 235-269. Vid. apartado 1. El diálogo judicial como viejo concepto actualmente en boga, p. 239.
} 


\section{APROXIMACIÓN AL CONCEPTO DEL DIÁLOGO JUDICIAL}

Comprender de un modo apropiado el concepto del diálogo judicial como un elemento técnico del derecho, es en sí una operación bastante compleja ${ }^{4}$. Lo agreste de la labor se debe a que convergen en su noción demasiadas aristas, unas provenientes desde las vinculaciones voluntarias que sobrepasan las conexiones orgánicas y jerárquicas entre los tribunales, y otras que más bien verifican las condiciones de contexto para que suceda el diálogo judicial y se robustezca, $v . g r$. el aspecto tecnológico. También existen nociones descriptivas y otras valóricas. Pero su núcleo es sustantivo, ya que la homogenización de criterios jurídicos, en cada una de las áreas del derecho en que se aplica el diálogo judicial, conlleva el fortalecimiento de los cimientos de la justicia ${ }^{5}$.

La teoría del dialogo judicial emerge desde la perspectiva general de la labor jurisdiccional, la cual pasó a observar a determinadas materias del derecho como inmersas en una dimensión internacional que justificó la importación de soluciones jurisprudenciales de Cortes foráneas, para aplicarlas a problemas similares, y en ocasiones se constata entre tribunales nacionales desconectados entre sí. Este fenómeno se desarrolla desde hace muchísimo tiempo, pero académicamente se detecta y organiza a partir del año 1994 por

\footnotetext{
${ }^{4}$ La dificultad para consolidar una noción de diálogo judicial proviene de diversos aspectos, así por ejemplo para NANCLARES es compleja una conceptualización previa del diálogo judicial. Es más, este autor subraya el hecho de que todavía pervive cierta indeterminación dogmática $-\mathrm{y}$ añade - existe controversia doctrinal incluso a propósito de la cuestión terminológica: mientras en nuestro entorno más próximo parece imponerse la referencia a diálogo judicial. MARTÍN Y PÉREZ DE NANCLARES, 2017, pp. 239-240. A BUSTOS le parece conveniente una teoría general que ofrezca mínimamente las pautas definidoras de lo que sea un diálogo judicial. Luego este autor, hace un punto de inflexión —en conexión a la dificultad de conceptualización - señalando: lo cierto es que la comunicación transjudicial engloba fenómenos y formas de muy variada naturaleza. BUSTOS GISBERT, R. (2012). XV proposiciones generales para una teoría de los diálogos judiciales. Revista española de derecho constitucional, 32(95), 13-63 (p. 4 y 7).

${ }^{5}$ El centro valórico del diálogo judicial se manifiesta en todas las áreas del derecho, y muy nítido en derechos humanos. PROVIN y DOS SANTOS se cuestionan así: $O$ diálogo entre as cortes pode contribuir para fortalecer os alicerces da justiça?. Frente a esto —apoyándose en ARAÚJO \& MACEDO - destacan que esta nueva concepción del proceso judicial se ve reflejada en decisiones tomadas por diversas Cortes alrededor del globo, reproduciendo una perspectiva de justificación de la racionalidad argumentativa de las cortes locales por el paradigma decisional de las cortes transnacionales. Concluyendo - PROVIN y DOS SANTOS - que el diálogo internacional, como fuente auténtica del derecho, fomenta un derecho globalizado [... a amplitude da discussão acerca do diálogo internacional como fonte autêntica do direito, de forma a fomentar um direito globalizado], entonces la migración de ideas y fundamentos extranjeros llevan al conocimiento de lo que pasa en otros lugares, pudiendo así los tribunales, establecer parámetros para sus decisiones. PROVIN, A. F. \& DOS SANTOS QUEIROZ, Y. A. (2017). O diálogo entre as cortes. Anuario iberoamericano de justicia constitucional, (21), 111-127 (113, 124-126).
} 
Slaughter quien denominó el fenómeno como transjudicial communication ${ }^{6}$. Mediante el cual, un tribunal no vinculado ni orgánica ni jerárquicamente con otro, toma los fundamentos de sus decisiones, mencionando dicha fuente en su sentencia. Para lo cual recurre a jurisprudencia de Cortes que tengan un indiscutido auctoritas. Además esta autora organizó y clasificó el fenómeno presentando las

«Forms of transjudicial communication, $1^{\circ}$ ) The geometry of transjudicial communication varies according to the national or supranational status of the courts talking to one another: horizontal communication, vertical communication, mixed vertical-horizontal communication. $2^{\circ}$ ) A second way of distinguishing between different types of transjudicial communication is according to the degree of reciprocal engagement manifested by the court involved: direct dialoge, monologue» ${ }^{7}$.

El mentado ejercicio clasificatorio la doctrina lo continúa desarrollando, derrotero por el cual ha ido incorporado otros tantos puntos de análisis para enfrentar el fenómeno del diálogo judicial, v.gr. se introduce el dialogo regulado $v /$ s espontáneo, diálogo integrado, dialogo convencional, y en otro extremo el diálogo libre, desenfrenado o desbocado. Todos en relación al vertical u horizontal ${ }^{8}$. Pero además de las diferencias formales que puedan identificarse, también la intensidad de la comunicación transjudicial juega un rol diferenciador, ya que es muy diferente y variable, pudiéndo en tales circunstancias hablarse de comunicación ad exemplum, a fortiori, ad ostentationem, ad auctoritatis y de ex lege 9 .

\footnotetext{
${ }^{6}$ El fenómeno del diálogo judicial es bastante antiguo, SLAUGHTER lo que hace es constatarlo, para lo cual conduce su estudio bajo la idea, Courts are talking to one another allover the world. Mostrando diversos ejemplos y desarrollando una nutrida clasificación (sobre la cual volveremos). Pone de relieve la velocidad con que está aumentando en todo el mundo, expresando: Transjudicial communication is not a new phenomenon, but anecdotal evidence suggests that it is increasing. Y lo valora como instrumento, aun cuando si bien éste se pudiese apreciar pequeño ante otras instituciones más desarrolladas o formales del mundo del derecho, él tiene su lugar y posee determinada importancia en la interacción de los órganos jurisdiccionales a nivel global, expresándolo así: Transjudicial communication, while a seemingly small phenomenon in the face of such a grand vision, is nevertheless an important instance of interaction among judicial institutions around the world. Many of these institutions are bound by multiple ties, both formal and informal, but ultimately by none so powerful as a common commitment to the rule of law. SLAUGHTER, A. M. (1994). A typology of transjudicial communication. 29 University of richmond law review, 29, 99-137 (99, 129 y 137).

${ }^{7}$ SLAUGHTER, 1994.

${ }^{8}$ BURGORGUE-LARSEN, L. (2013). La formación de un derecho constitucional europeo a través del diálogo judicial. En E. Ferrer Mac-Gregor, A. Herrera García, D. García Sayan, D. Valdés, L. Pegoraro, A. Bogdandy, ... A. A. Cancado Trindade. Dialogos jurisprudenciales en derechos humanos : entre tribunales constitucionales y cortes internacionales. México. Tirant lo Blanche.

${ }^{9}$ Esta es la línea de BUSTOS para quien la intensidad de la comunicación es un tema central. BUSTOS GISBERT, 2012.
} 
Desde un ángulo transnacional, cuestión que es de la mayor relevancia para nuestra investigación, se construyó una clasificación atendiendo a la estructura de las interacciones, punto en cual se observaría, en el ámbito exclusivamente internacional diálogos verticales (v.gr. TJUE y TGUE); semiverticales (v.gr. TJUE-TEDH, TJUEÓrgano de Apelación de la OMC, TJUE-CIJ); horizontales (v.gr. TJUE y EFTA Court); competititvos o superpuestos (v.gr. CIJ y Tribunal Internacional del Mar), o de relaciones especiales (v.gr. TJUE y Tribunales Constitucionales estatales) ${ }^{10}$. Su importancia trasunta hacia nuestros análisis porque las conexiones de las que nos haremos cargo se aposentan presisamente en la dimensión internacional, pero acotada a los tribunales de integración de América Latina —CCJ, TJCA y TPRM y TAAM—, es decir, horizontalmente en un perfil interamericano, y luego entre dichas Cortes latinoamericanas y la Corte de Luxemburgo, en un muy particular sentido de verticalidad. Estos sentidos o direcciones las justificaremos en el desarrollo de este capítulo.

La clasificación anterior se conecta con una de las dimensiones más llamativas, cual es aquella que hace presión por las consideraciones jerárquicas, coordenadas en que justamente se visualiza la verticalidad $v / s$ la horizontalidad de los tribunales concurrentes en el fenómeno del diálogo judicial, y como anunciamos, en el párrafo precedente, nosotros hablaremos de un incipiente dialogo judicial interamericano de sesgos horizontales, mientras que el más contundente tráfico jurisprudencial fluye en una posición de cuasi verticalidad con el TJUE de cariz jerárquico o bien de una autoridad sustantiva, basada en el auctoritas que posee la Corte de Luxemburgo para las Cortes Latinoamericanas bajo análisis, cuestión que se materializa y justifica por diversas razones que analizaremos en el presente capítulo. En cuanto a esta clasificación Bengoetxea destaca la complejidad de la dinámica vertical/horizontal explicando:

«hay dos grandes dimensiones del diálogo judicial, el diálogo vertical en situaciones jerárquicas y el diálogo horizontal entre jueces y tribunales en posiciones jerárquicamente equivalentes en la misma jurisdicción o en una diferente. Verticalmente el diálogo judicial se lleva a cabo entre los diferentes niveles en direcciones hacia arriba y hacia abajo. Se rige por principios como la jerarquía, reparto de competencias, Kompetenz-Kompetenz y jurisdicción. Los niveles que pueden involucrarse en estas relaciones verticales abarcan desde lo internacional, lo transnacional, lo supranacional, el Estado (centralizado en el Estadonación/compuesto en el Estado plurinacional/ descentralizado en el Estado federal) a

\footnotetext{
${ }^{10}$ ROSAS, 2007. The european court of justice in context: forms and patterns of judicial dialogue, European journal of legal studies, vol. 1, número 2. 
los niveles sub-estatales, regionales (que pueden ser también nacionales) y locales» ${ }^{11}$.

El diálogo judicial transnacional encuentra su parcela entre los efectos de la globalización, pues los tribunales se observan entre sí al momento de dar respuestas a problemáticas comunes, en un ejercicio pretoriano de evaluación comparativa, que da cuenta de la globalización del derecho mismo, el que muchas veces requiere de determinados patrones de justicia, que se conviertan en matrices homologadas - deseadas y por esto buscadasen materias específicas del mundo jurídico, como por ejemplo en el campo del derecho de la integración, o en el de los derechos humanos, o en el derecho constitucional, comercial, etcétera. Por tal razón y en términos amplios, hoy es común encontrar intercambios y aperturas del conocimiento hacia diversos mundos jurídicos ${ }^{12}$.

Pero la globalización no es en sí misma portadora del diálogo judicial per se, sino más bien lo acelera. Incluso, antes de los avances técnicos que permitieron la dinámica global, también los jueces se conectaban a otras soluciones foráneas. Lo que ocurre es que ahora el fenómeno se intensificó, acelerándose su ritmo gracias a nuevas herramientas tecnológicas que permiten verificar con un alto grado de certeza, documentación de todo el planeta. Dicho de otro modo, hoy las condiciones para el diálogo judicial son en extremo fértiles ${ }^{13}$.

11 BEngoetxeA, J. (2014). Judicial and interdisciplinary dialogues in european law. En B. Hess \& S. Ménetrey. Les dialogues des juges en europe. Bruxelles: Larcier., pp. 19-49. [Trans. Serna Hernández, A. J. (2015). Diálogos judiciales e interdisciplinarios en el derecho europeo. Sortuz: oñati journal of emergent socio-legal studies, 7(1), 160-183 (175)].

12 La globalización apareja infinitas consecuencias, entre estas, la globalización del derecho -en determinados aspectos y materias del mundo jurídico - para lo cual el diálogo judicial es la herramienta ideal, toda vez que las Cortes que se conectan voluntariamente, se encuentran desconectadas orgánicamente. VIVAS y CUBIDES destacan «La era de la globalización [...], también involucra sensiblemente las respuestas de la justicia ante problemáticas comunes». VIVAS BARRERA, T. G. \& CUBIDES CÁRDENAS, J. A. (2012). Diálogo judicial transnacional en la implementación de las sentencias de la corte interamericana. Entramado, 8(2), 184-204 (p. 187). La doctrina que adscribe al diálogo judicial, lo resalta como una consecuencia de esta globalización, bajo la lógica de que ante similares situaciones ya no se toleran soluciones diferentes. BRITO MELGAREJO explica que ha surgido la exigencia general de intercambio de ideas, incluso entre civilizaciones y culturas del planeta en el marco de los procesos de integración global; y que, estos macro-procesos implican también fenómenos relevantes de interacción en el ámbito jurídico [...]. Este hecho que se ha acentuado en las últimas décadas, ha sido producto de una serie de fenómenos que favorecen la circulación de principios comunes y, al mismo tiempo, dotan a estos principios de una fuerza expansiva. BRITO MELGAREJO, R. (2011). Derecho comparado y actividad jurisdiccional: Los factores que favorecen el diálogo judicial transnacional. Quid iuris, (13), 39-60 (pp. 41-42).

${ }^{13}$ Lo que una parte de la doctrina va aclarando es que técnicamente la red mundial de ordenadores $-\mathrm{y}$ agreguemos nosotros, los sofisticados motores de búsquedas de textos - posibilitan obtener rápidamente información útil sobre el contenido, duración e interpretación del derecho extranjero, que es precisamente lo que le ha dado gran velocidad al fenómeno. RECHSTEINER expresa «Com o auxílio da rede mundial de computadores (internet), é possível que se obtenha rapidamente informações úteis com relação ao teor, à 
Prácticamente en todas las materias el diálogo judicial se ha comenzado a identificar y a estudiar pues atrae en todos los continentes, no siendo en nada privativo ni de Europa ni menos de una materia en concreto, aunque sí es reconocible su alto empleo en materia de derecho fundamentales del ser humano, y por otra parte, contribuye también a su gran uso la alta proliferación de tribunales internacionales existentes en la actualidad, en definitiva para los más entendidos contemporáneos el diálogo judicial ha llegado a ser una de las manifestaciones más significativas ${ }^{14}$.

Sin embargo el concepto de dialogo judicial sigue inacabado, y sobre el cual, recaen múltiples investigaciones que dan cuenta de las más variadas posiciones. Reconociéndose por una parte, a fervientes seguidores, y por otra, negacionistas absolutos. Posturas eclécticas sin embargo, refieren que el diálogo judicial existiría sólo bajo determinados requisitos, los cuales podemos sintetizar como condiciones de tráfico sustantivo entre dos Cortes que pudiesen retroalimentarse.

Para algunos de estos moderados ${ }^{15}$, el concepto de diálogo judicial sería sólo una metáfora para referirse únicamente a determinados análisis comparativos que en ocasiones poseen

vigencia e à interpretação do direito estrangeiro». RECHSTEINER, B. W. (2008). Direito internacional privado: teoria e prática. São Paulo: Saraiva, p. 242. MARTín Y PÉREZ DE NANCLARES, subraya: el actual florecimiento del diálogo judicial es consecuencia inevitable de 3 fenómenos fundamentales que concurren en el tiempo y en el espacio: la globalización (con el crecimiento exponencial de las relaciones transnacionales y la internacionalización de los ordenamientos jurídicos nacionales), la tecnificación del contenido de los ordenamientos jurídicos (con la especialización inevitable de los operadores jurídicos y, por tanto, también de los mecanismos de resolución de controversias) y la llamada fragmentación del DI (con la correlativa proliferación de tribunales internacionales en el marco de los diferentes subsistemas del DI). MARTÍN Y PÉREZ DE NANCLARES, 2017, pp. 240-241.

${ }^{14}$ Para MARTÍN Y PÉREZ DE NANCLARES el diálogo judicial es una de las manifestaciones más significativas e interesantes del espacio jurídico europeo. Este autor es enfático en aclarar que el fenómeno del diálogo judicial está presente en todo el mundo, y respecto del ámbito americano pone de relieve que, gracias al uso del diálogo judicial, se está produciendo un apasionante proceso transformador de la sociedad en materia de derechos humanos, cuestión que probablemente no haya merecido entre nosotros la atención doctrinal que merece. MARTÍN Y PÉREZ DE NANCLARES, J. (2019). El diálogo judicial internacional en la protección de los derechos fundamentales. Valencia. Tirant lo Blanch., pp. 21-36.

${ }^{15}$ Las posturas intermedias, si bien advierten lo errado de la denominación diálogo judicial, pues no toda comunicación supone dialogar, sí reconocen el fenómeno de comunicación entre tribunales (recordemos que SLAUGHTER habla puntualmente de transjudicial communication - lo que parece ser un término más amplio), midiendo su intensidad o clasificándolo. LAW y CHANG plantean que no se condice la definición del diccionario con la terminología técnica. Ellos se refieren a una metáfora, pues notan la distancia con el concepto lingüístico «The use of dialogue as a metaphor for the comparative analysis found in constitutional decisions is problematic on multiple levels. A threshold problem is that of whether comparative analysis can be characterized as "dialogue" as a purely conceptual or definitional matter. "Dialogue" is defined by the Oxford English Dictionary in the following ways: [...]», y ninguna de tales conceptualizaciones se 272 
mayor o menor intensidad. También hay nociones que destacan la cualidad práctica o metodológica del fenómeno, para los cuales, el concepto de diálogo judicial no les reporta tanta importancia, sino más bien se centran en sus consecuencias. Es decir, dependiendo de si la intensidad es lo suficientemente fuerte como para dar por sentados determinados criterios jurídicos ${ }^{16}$. Otras nociones siguen un cauce descriptivo y de baja exigencia sustancial, a éstas les basta con que se verifiquen simples referencias hacia sentencias de tribunales externos al sistema para tildarlo de diálogo judicial ${ }^{17}$. Y otras son del todo amplias, e incluso se presentan conceptualizaciones valóricas ${ }^{18}$.

observarían en los ejercicios de diálogo judicial. Siguiendo en su crítica, expresan que hay muy pocos casos de verdadero diálogo judicial, y no comportan una práctica generalizada [salvemos que esto sería en su área -el derecho constitucional - pues v.gr. en el ámbito de los derechos humanos es profuso] «The use of the metaphor of dialogue to describe judicial comparativism is not only contrary to ordinary definition and political logic, but also lacking in empirical support. The handful of high-profile cases that tend to be recycled as evidence of dialogue do not appear to be representative of overall practice». LAW, D. S. \& CHANG, W. (2011). The limits of global judicial dialogue. Washington law review, 86(3), 523-577.

${ }^{16}$ Para BUSTOS la noción de diálogo judicial es una práctica de creación exclusivamente pretoriana buscando, de modo pragmático, solucionar conflictos no previstos por sus ordenamientos. Sin embargo, para él, hay que centrarse en el diálogo judicial cuándo la comunicación es la propia del uso del Derecho comparado y, cuando es de una 'intensidad' superior, capaz de obligar jurídicamente, a los tribunales a acercar la propia jurisprudencia a la dictada por un órgano judicial externo. Y si se centra en el ámbito constitucional, el diálogo judicial, es la comunicación entre tribunales derivada de una obligación de tener en cuenta la jurisprudencia de otro tribunal (extranjero o ajeno al propio ordenamiento jurídico) para aplicar el propio Derecho. Esto es, el diálogo es un tipo de comunicación obligatoria entre tribunales porque actúan en un contexto de pluralismo constitucional. BUSTOS GISBERT, 2012, pp. 3, 8-9, 20.

${ }^{17}$ MIRANDA explica en estricto sensu que el término «diálogo judicial» viene utilizado cada vez que en una sentencia se encuentran referencias a otras provenientes de un ordenamiento diverso, por lo tanto externo, respecto del ordenamiento en que la sentencia debe explicar su eficacia. MIRANDA BONILLA, H. (2017). Dialogo judicial interamericano: una visión teórico práctica. En A. Milano Sánchez, A. Garro Vargas, C. Hines Céspedes, E. Briones Briones, E. Jinesta Lobo, F. Castillo Viquez, ... V. Orozco Solano. Constitucionalismo Costarricense. Libro en homenaje al prof. rubén hernández valle. Ed. Juricentro., pp. 535-570 (p. 5 interna).

${ }^{18}$ Los conceptos laxos crean un campo de estudio posible de clasificar internamente. BURGORGUELARSEN reconoce una noción amplia que él critica inmediatamente, señalando: El diálogo es la búsqueda de un equilibrio constante, no establece, una vez por todas, una posición firme y estable respetada por todos los actores. BURGORGUE-LARSEN, 2013, p. 136. Otro caso de concepto amplio lo presentan FERRER MACGREGOR y HERRERA GARCÍA indicando «por definición el "diálogo jurisprudencial” — como lo es la propia idea sustantiva de los derechos_-, refleja un fenómeno jurídico transterritorial, incluso de alcances globalizantes». Agregan «el "diálogo jurisprudencial" constituye una suma de espacios de interlocución de los tribunales». FERRER MAC-GREGOR, E. \& HERRERA GARCÍA, A. (2013). La formación de un derecho constitucional europeo a través del diálogo judicial. En E. Ferrer Mac-Gregor, A. Herrera García, D. García Sayan, D. Valdés, L. Pegoraro, A. Bogdandy, ... A. A. Cancado Trindade. Dialogos jurisprudenciales en ddhh : entre tribunales constitucionales y cortes internacionales. México. Tirant lo Blanche., p. 13. 
Como se aprecia, la dificultad para conceptualizar al diálogo judicial queda en evidencia ${ }^{19}$. Pero para el campo hacia el cual nosotros nos estamos conduciendo —el fenómeno del diálogo judicial en las Cortes de integración latinoamericanas - debemos tomar una posición más exigente. Por lo tanto, para nosotros el concepto de diálogo judicial, debe buscarse dentro de los métodos pretorianos de aplicación de justicia, bajo la singularidad de que su ejercicio es siempre voluntario de parte de los jueces - de hecho esta es una característica que anotaremos como una debilidad del método- y además debe comportar retroalimentación ${ }^{20}$, pues no toda referencia a sentencias foráneas es diálogo judicial, debiendo entonces superarse un umbral de intensidad y retroalimentación mínimo entre las Cortes bajo análisis, tal como lo veremos en este capítulo.

${ }^{19}$ Vid. nota 4 de este capítulo. MARTÍN Y PÉREZ DE NANCLARES, 2017, pp. 239-240.

${ }^{20}$ Varios autores precisan que debe haber intercambio recíproco para estar en presencia de un dialogo judicial propiamente tal. Por ejemplo DE VERGOTTINI subraya, solo si estamos en presencia de interacción, parece sensato recurrir al tema de diálogo. DE VERGOTTINI G. (2010a). Oltre il dialogo tra le Corti. Giudici, diritto straniero, comparazione. Bolonia. Ed. Il Mulino., p. 10. 


\section{EL DIÁLOGO JUDICIAL AL SERVICIO DE LOS DESARROLLOS Y APORTES DE LAS CORTES LATINOAMERICANAS EN CADA UNO DE LOS PROCESOS DE INTEGRACIÓN REGIONAL}

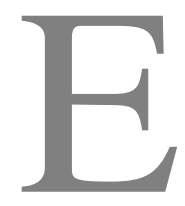

1 diálogo judicial presenta singularidades y fines bastante utilitarios para el desarrollo de la CCJ, el TJCA y el TPRM, toda vez que dichas Cortes intentan replicar las soluciones del TJUE en América Latina, aunque tal recurso jurídico es transversal a todos los sistemas de jurisdicción internacional, debido a que éstos modelos no pueden esperar ante la lentitud del diálogo de fuentes ${ }^{21}$, sino que frente al caso concreto, aplican soluciones inmediatas importándolas justamente a través del diálogo judicial. Y habitualmente más tarde, llega el legislador a positivizar esas soluciones jurisprudenciales, intentando nivelar al derecho material con la realidad del proceso de integración, y casi siempre la ley se termina alineando con aquella construcción pretoriana.

Es cierto que los tribunales internacionales en general, siguen la técnica de la comparación, inclinándose a conceptualizar la jurisprudencia de otros sistemas jurídicos ${ }^{22}$, pudiendo incluso llegar a afirmarse que los tribunales internacionales por su naturaleza son comparatistas $^{23}$. Pero la noción del diálogo judicial se distancia de un simple análisis de

${ }^{21} \mathrm{El}$ «diálogo de fuentes» fluye del antiguo fenómeno de homogenización normativa entre grupos de Estados que en el proceso creador de sus normas recurren a la técnica del derecho comparado. Pero el diálogo de fuentes precisa una operación no necesariamente interestatal, sino que pudiese ser entre un Estado y una OI, o bien entre diversas OI. Nosotros lo estamos destacando en aplicación hacia las construcciones jurídicas integracionistas. También es posible que esta noción se aplique a fenómenos jurídicos del DI privado que se desarrollen en un ámbito espacial integrado, SCOTTI lo destaca para el Mercosur, resaltando que diversa normativa nacional argentina tiene sus antecedentes en normativa mercosureña. Subrayando esta autora que, para que la integración se logre, también se requiere del DI Privado (DIPr). SCOTTI, L. B. (2016). Diálogo de fuentes: Las normas regionales del mercosur y las nuevas disposiciones del derecho internacional privado argentino. Revista da secretaria do tribunal permanente de revisão, 4(7), 152-184. En el mismo ámbito (DIPr) para JAYME, el fenómeno más importante para la resolución de conflictos de ley, es un diálogo entre los derechos más heterogéneos, considerados éstos, como fuentes no excluyentes, pero que no conversan fácilmente, por ello, los jueces están obligados a coordinar estas fuentes escuchando lo que dicen. JAYME, E. (1995). "Identité culturelle et intégration : Le droit international privé postmoderne", in: Collected courses of the hague academy of international law. Vol. 251. Brill. Nijhoff, Leiden. Boston.

${ }^{22}$ GROPPI, T. \& LECIS COCCO-ORTU, A. M. (2014). Las referencias recíprocas entre el tribunal europeo y la corte interamericana de derechos humanos: ¿de la influencia al diálogo? Revista de derecho político, (91), $185-230$ (p. 190).

${ }^{23}$ DE VERGOTTINI, G., GARCÍA ROCA, F. J. (prol.) \& TENORIO SÁNCHEZ, P. J. (trad.). (2010b). Más allá del diálogo entre tribunales: Comparación y relación entre jurisdicciones ( $1^{\mathrm{a}}$ ed.). Madrid: Civitas Thomson Reuters., p. 11. 
derecho comparado y encuentra su parcela propia. Pues cuando se desarrolla plenamente se produce retroalimentación entre las Cortes. En cambio, el derecho comparado es una herramienta más amplia que el diálogo, pero más pequeña que el recurso a lo extranjero.

Ahora bien, si sólo gravitamos sobre el uso diálogo judicial — y ya no sobre su concepto-, constatamos que se manifiesta de modo muy diferente según sea la materia en cuestión y el tipo de tribunales que se comuniquen. Detectándose mucho más intenso entre Cortes protectoras de los derechos humanos, pues en tales aspectos se busca una contundente unidad jurídica universal. Pero entre las Cortes de integración objeto de la presente investigación, lo que apreciamos, es más bien una hegemonía de la fuente por parte de la UE, a diferencia de América Latina, donde se observan tres sistemas receptores incompletos que sólo extraen algunas soluciones desde la fuente, tal como lo veremos con todo detalle en este capítulo.

En este orden de ideas retengamos que las Cortes de integración enfrentan la comunicación por un cauce orgánico y otro extra-orgánico. Es orgánica la que se conduce mediante las cuestiones prejudiciales, las consultas, las competencias secundarias y, además, cuando el sistema sea complejo - conformado por más de una Corte v.gr. TGUE/TJUE o TAAM/TPRM — se materializará mediante las competencias recursivas jerárquicas. En cambio, será extra-orgánica la comunicación cuando las Cortes abandonan por completo su sistema sub-regional dejando atrás todo vínculo colaborativo y jerárquico ${ }^{24}$. Por esto para nosotros, una de sus aristas centrales, es el pleno y libre voluntarismo de los jueces, quienes por decisión propia se comunican con otras Cortes, totalmente exógenas a su sistema, sean o no de integración ${ }^{25}$. Para lo cual, el vehículo idóneo es el diálogo judicial.

${ }^{24}$ En la desvinculación orgánica radica la voluntad y la libertad de los jueces, pues no están siendo influenciados por patrones de jerarquía, sino por matrices de lógica jurídica, fenómeno acelerado por los efectos de la globalización. MARINHO Y SILVA, enfocándose hacia la globalización y a la carencia jerárquica, sostienen que el diálogo judicial permite un examen del fenómeno de la globalización «O estudo do diálogo entre juízes permite um exame do fenômeno da globalização do direito a partir do papel desempenhado pelos juízes. Foi dado a estes um papel de destaque no proceso de integração normativa em razão da proliferação dos tratados e da necessidade de efetividade das normas negociadas». Y en cuanto a las características propias del diálogo judicial, destacan la carencia jerárquica de modo central «O diálogo entre juízes reflete um alto grau de troca de precedentes judiciais entre cortes que não guardam necessariamente entre si vínculo formal de hierarquia. Entretanto, é possível a existência de um intercâmbio entre Cortes sem que haja necessariamente diálogo». MARINHO, M. E. \& OLIVEIRA, L. P. S. (2014). O uso de precedentes judiciais de jurisdições estrangeiras em matéria de propriedade intelectual. En Marihnho, Silva, Oliveira, et al. Diálogos entre juízes. Brasilia: UniCEUB., pp. 30-32.

${ }^{25}$ Las conexiones de las Cortes de integración hacia sentencias foráneas 'no' se limitan a una dinámica inter tribunales de integración, sino que se expanden a otras clases de Cortes. Pues las soluciones que buscan fluyen en razón de la materia. Así veremos casos en que la CCJ se ha conectado con la Corte Constitucional de Italia (CCi), o el TPRM con la Corte Internacional de Justicia (CIJ) y además el TJUE presenta un rico diálogo judicial con el Tribunal Europeo de Derechos Humanos (TEDH), cuando en ocasiones actuando 276 
La particularidad del diálogo judicial, considerando sólo su centro sustantivo -el fortalecimiento de los cimientos de la justicia ${ }^{26}$ — aplicado a las Cortes de Integración, es dicotómico, pues de un lado, por su intermedio se busca la importación de soluciones jurisdiccionales «sustantivas» con el fin de fortalecer y desarrollar «lo más homogéneo posible» del derecho de la integración en las diversas regiones en que se aplican sus principios, y de otro lado, y al mismo tiempo, se intenta generar un mejor nivel de convencimiento en los justiciables, a quienes —en nuestro caso, los latinoamericanos - les es muy significativo el apoyo buscado en el modelo europeo.

Este segundo objeto del diálogo judicial requiere de una correcta selección de las fuentes de importación que nutrirán la operación de comunicación. Puesto que tal selección incide directamente en el proceso subjetivo y objetivo de persuasión en la población destinataria. Ya que si bien las respuestas de los jueces integracionistas siguen el cauce del efecto relativo de las sentencias, son ineluctables los efectos expansivos irradiados hacia todo el resto de la comunidad, sumándose, además, todos aquellos casos que aparejan efectos erga omnes. Por tal razón los sentenciadores deben dirigirse con altos niveles de persuasión efectiva, no sólo para resolver el caso concreto, sino para fortalecer el proceso integracionista en su totalidad, evitando así las desmotivaciones de los ciudadanos ${ }^{27}$.

Por esas razones las Cortes de América Latina bajo análisis, recurren de modo insistente a las construcciones europeas, intentando satisfacer dos objetivos, por una parte, la aplicación lo más homogénea posible del derecho de la integración, y por otra, lograr un alto grado de convencimiento en la comunidad a que pertenecen. En tal sentido el uso de las soluciones

dentro de sus competencias, resuelve en estas materias. Sobre el diálogo judicial entre el TJUE y el TEDH existen los más diversos estudios, v.gr. MARTÍN Y PÉREZ DE NANCLARES, J. (2013). El diálogo judicial entre el TJUE y el TEDH: Algo más que el derecho a la última palabra en el triángulo judicial europeo. Tribunal constitucional y diálogo entre tribunales : XVIII jornadas de la asociación de letrados del tribunal constitucional. $1^{\mathrm{a}}$ ed. Centro de Estudios Políticos y Constitucionales, pp. 161-208. Otro: ahora en materia tributaria en MARTÍN JIMÉNEZ, A. J. (2013). El impacto de la jurisprudencia tributaria del TJUE en los tribunales latinoamericanos (o acerca del nacimiento de un nuevo "diálogo judicial global" en materia tributaria. Civitas. Revista española de derecho financiero (160)35-54.

${ }^{26}$ PROVIN \& DOS SANTOS QUEIROZ, 2017. Vid. nota 5 de este capítulo.

${ }^{27}$ Para nosotros es claro que debe existir un subyacente nivel de convencimiento en cada sentencia de un tribunal de integración, en sentido expansivo dirigido hacia toda la comunidad. Por tal razón se hace presión en la elección de las Cortes desde dónde serán importadas las soluciones a través del diálogo judicial. Al respecto GROPPI y LECIS razonan del siguiente modo «Dado que la motivación de las decisiones judiciales tiene como objetivo principal el volverlas 'persuasivas' y mejor aceptadas a los ojos de sus destinatarios, la 'selección' de los argumentos por parte de los tribunales está fuertemente influenciada por la percepción que tienen de la sensibilidad y de la preferencia de su público de referencia. [...] Estas consideraciones implican diferenciaciones no sólo entre tribunales constitucionales nacionales y cortes internacionales, sino también entre las diferentes cortes internacionales». GROPPI \& LECIS COCCO-ORTU, 2014, pp. 191-192. 
del TJUE son por naturaleza las más idóneas, dado que dicha Corte administra la fuente del derecho de la integración, logrando un alto auctoritas en su acometido, siendo respetadas sus creaciones por todos los destinatarios (a lo que se suma que dichas sentencias son incluso estudiadas en zonas extra-UE, como en los esquemas de integración de América Latina y África, circunstancia que precisamente ocasionará que sean importados sus contenidos mediante un tipo de diálogo judicial). Quedando nuevamente demostrado el célebre apotegma de Couture, las sentencias valdrán lo que valgan los hombres que las dicten $^{28}$.

Estas ideas se alinean perfectamente con nuestra hipótesis. Es decir, el rol de los tribunales de integración en sus sistemas regionales es precisamente, favorecer el desarrollo del proyecto político completo, evitando que los socios lo abandonen, o surja la desafección del ciudadano. Por esto, colegimos que, es vital la existencia de un subyacente nivel de convencimiento en cada sentencia dictada por un tribunal de integración, en un sentido expansivo hacia toda la comunidad, y en tal esquema, el diálogo judicial, es una excelente herramienta para contribuir a la meta fijada.

Por su parte, el interés de aplicación homogénea del derecho de la integración, o al menos, lo más similar posible en cada proyecto integracionista, debemos comprenderlo como un robustecimiento en carácter de conjunto del derecho de la integración, en el sentido de que sus principios y reglas básicas sean lo más similares posibles en cada esquema, o en términos negativos, que no se vaya en contra de sus criterios centrales. Esta es la razón que impulsa a las Cortes de América Latina bajo análisis a usar el diálogo judicial con el TJUE. Es decir, dichas Cortes latinoamericanas, se amparan en la concepción grupal, o en los

\footnotetext{
${ }^{28} \mathrm{Al}$ escoger la fuente para la importación, deben valorarse a las Cortes foráneas y a sus jueces. COUTURE centra el ejercicio valorativo de los jueces en sus sentencias [materia prima del diálogo judicial] su razonamiento es notable porque para llegar al apotegma referido [las sentencias valdrán lo que valgan los hombres que las dicten] primero se sacude del pensamiento de MONTESQUIEU explicando que, para éste, el centro del derecho era la ley, y el proceso una simple prolongación de esa ley [aquí entonces ubica a la sentencia], pero MONTESQUIEU - explica COUTURE - es como ciertas figuras del arte o la ciencia, un límite entre dos épocas como Dante, Cervantes, Beethowen o Pasteur, Montesquieu es, en su ciencia, el último de los antiguos y el primero de los modernos (p. 67). Pero COUTURE avanza más allá del entendimiento de una sentencia asentada únicamente en la ley [al igual que el TJUE cuando repleta de nuevos contenidos al derecho de la integración, allí se ancla el utilitarismo del diálogo judicial integracionista], para COUTURE la sentencia 'no' es un pedazo de lógica, 'ni' es tampoco pura norma. La sentencia es una obra humana, una creación de la inteligencia y de la voluntad, es decir, «una criatura del espíritu del hombre» (p. 73). Desde esas coordenadas pivota hacia su corolario, no se ha inventado todavía una máquina de hacer sentencias. El día en que sea posible... la concepción constitutiva del proceso carecerá de sentido y la sentencia será una pura declaración como quería Montesquieu. Pero mientras no pueda lograrse esa máquina de hacer sentencias, el contenido humano, profundo y entrañable del derecho, no puede ser desatendido ni desobedecido y «las sentencias valdrán lo que valgan los hombres que las dicten» (p. 77). COUTURE, E. J. (1949). Introducción al estudio del proceso civil. Buenos Aires, Argentina. Depalma., pp. 67-77.
}

278 
criterios y lógicas aceptadas en Europa, para copiar esas líneas en todas aquellas cuestiones que favorecen el cohesionar al grupo, intentando evitar las implicancias perjudiciales que implicaría el fracaso de cualquier experiencia en América Latina.

Entonces para el análisis que estamos haciendo de las Cortes indicadas, debemos tener presente que, por una parte, sus Estatutos copian una sección significativa de las normas aplicables al TJUE, y por otra parte, luego, adicionalmente, durante su ejercicio jurisdiccional mediante un diálogo judicial del tipo monólogo y extractivo incorporan determinados criterios y soluciones del TJUE. Por estos dos motivos la CCJ, el TJCA y el TPRM se ubican en una posición receptora - incompleta- del modelo europeo. Dicha realidad nos deja, fácticamente, ante una razón bipolar en el sentido de que, por una cara, tenemos un sistema pionero, la UE, que lógicamente hegemoniza la fuente con el TJUE, y por otra cara, analizamos tres sistemas receptores incompletos, el Sistema de la Integración Centroamericana (SICA) con la CCJ, la Comunidad Andina de Naciones (CAN) con el TJCA y el Mercado Común del Sur (MERCOSUR) con los TPRM y los TAAM. Estas Cortes latinoamericanas usan un diálogo judicial monólogo extrayendo soluciones desde el TJUE. Y, en una tenue dimensión, se comunican entre sí, mediante un incipiente diálogo judicial inter-americano de carácter horizontal.

Por los motivos expuestos, el fenómeno no muestra un real intercambio entre dichos polos (Europa/América Latina). Realidad que nos hace concluir que sería más exacto hablar de influencia $^{29}$ del modelo europeo sobre los latinoamericanos, más que de diálogo propiamente tal. De hecho la teoría del diálogo judicial presupone un nivel de intercambio de criterios. Pero si obedecemos a las tipologías originarias de la teoría del diálogo judicial, podemos encuadraros en el denominado monólogo ${ }^{30}$, por el cual únicamente se extraen

\footnotetext{
${ }^{29}$ La idea de influencia deja fuera muchos intentos amplios de conceptualización del diálogo judicial. Para nosotros es acertado y útil para la mejor explicación del fenómeno en las zonas latinoamericanas en que nos enfocamos. MIRANDA lo pone de relieve expresando: Al respecto, es muy útil la distinción entre «influencia»e «interacción». La primera es simplemente unidireccional, por su parte, la segunda implica una plausible reciprocidad que conlleva a una «cross fertilization». MIRANDA, 2017, p. 5 interna.

${ }^{30}$ La circunstancia de no verse involucrado realmente el emisor, en el sentido de que pudiese incluso ignorar que sus ideas fueron tomadas en préstamo por un tribunal exógeno al sistema, habitualmente extranjero, lo desarrolla SLAUGHTER bajo la noción conceptual de «monologo». Por el cual, el grado correlativo de compromiso entre los tribunales en cuestión es muy bajo, caracterizándose por la inexistencia de un autoaprendizaje recíproco, quedándonos exclusivamente en un umbral extractivo. Esta autora señala «II. DEGREE OF RECIPROCAL ENGAGEMENT: A second way of distinguishing between different types of transjudicial communication is according to the degree of reciprocal engagement manifested by the court involved. The examples discussed above neatly illustrate the potential range of such involvement; the discussion here will thus be relatively brief. [...]. B.- Monologue: The examples of horizontal communication discussed above are more readily conceptualized as monologue than dialogue, in the sense that a court whose ideas or conclusions are borrowed by foreign court, whether on the national or supranational level, is not a self-conscious participant in an ongoing conversation. The originating court may indeed have little idea that
} 
soluciones desde otra sede, sin que podamos constatar un diálogo horizontal internacional o el denominado genuino.

Sin embargo hay que manejar con mucha precaución la idea de influencia, pues es demasiado cercana a la negación del diálogo judicial, tesis a la cual se adscribe una pequeña parte de la doctrina ${ }^{31}$. Aunque, para nosotros, tal extremismo se suscita únicamente si se simplifica todo al mero campo linguístico, donde por cierto, un diálogo implicaría intercambio de opiniones. Y como esto no se verifica entre los tribunales aquí analizados — al ordenarse del modo bipolar apuntado - es que en ocasiones se pretende explicar esta circunstancia únicamente extractiva, en línea con el clásico recurso al derecho extranjero, a la comparación jurídica y —en algunos casos - a la necesidad de legitimación del juzgador cuando está en el inicio de su actividad, o cuando administra un nuevo ordenamiento, tendiendo a disminuir la intensidad de la técnica al salvar dicha etapa ${ }^{32}$.

La particularidad de la influencia, es que por una cara, ya es un tipo de diálogo judicial monólogo - y por otra es intrínsecamente potencial, pues puede detonar un diálogo verdaderamente recíproco. Esta circunstancia de progresión hacia la retroalimentación ha ocurrido empíricamente entre tribunales internacionales, como lo ha sido el notable caso entre el Tribunal Europeo de Derechos Humanos (TEDH) y la Corte Interamericana de Derechos Humanos (CIDH), en que por muchísimo tiempo el diálogo fue sólo desde América meramente extractivo respecto de las construcciones europeas, pero luego, tal mono-locus se torna bi-frontal, y la Corte europea comenzó a citar a la americana ${ }^{33}$.

its views have a foreign audience. It speaks to the litigants in the case before it, and perhaps also to the courts and the political branches in a particular national legal system. Its ability to communicate to foreign listeners depends on the initiative of the listeners themselves». SLAUGHTER, 1994, p. 112-113.

${ }^{31}$ En la doctrina hay algunas pocas opiniones de escepticismo respecto de que el diálogo judicial fuese un nuevo fenómeno jurídico, negando su entidad. Por ejemplo para DE VERGOTTINI la teoría misma sencillamente no es tal. Según él, no existiría la efectividad del diálogo judicial, sino sólo el recurso a la jurisprudencia extranjera. En otros casos respondería a la satisfacción de una exigencia de legitimación del juzgador cuando un tribunal está en el inicio de su actividad o cuando deba aplicarse un nuevo ordenamiento. Disminuyendo este recurso con la consolidación del papel del tribunal. Agrega que, la retórica del diálogo queda enmarcada en el ámbito de la apertura hacia lo externo. En ese contexto la posibilidad que tienen los tribunales al recurso al derecho extranjero y a la comparación sería sólo un apéndice de las relaciones de influencia e interacción que los afectan, pudiendo ocurrir que utilicen el argumento comparativo. DE VERGOTTINI, et al., 2010b., pp. 197-198, y pp. 207 y ss.

32 Ídem.

${ }^{33}$ Este singular caso de mutación progresiva en el tipo de diálogo judicial se apreció entre el TEDH y la $\mathrm{CIDH}$, lo cual ha aparejado notables investigaciones. Al respecto GROPPI y LECIS en su estudio ¿de la influencia al diálogo?, lo destacan así «Por muchos años, la relación ha ido exclusivamente "en un sentido", en el momento en que sólo la CIDH, en cuanto jurisdicción de nueva constitución, miraba al más antiguo e influente TEDH. Se podía hablar entonces de "influencia" entre una corte y otra, más que de "diálogo". Es a partir de la primera década de este siglo cuando el TEDH comienza también a citar a su homóloga 280 
Son precisamente todas las ideas anteriores, los intentos de conceptualización y de clasificación, los que demuestran lo inacabado del concepto del diálogo judicial. El cual, para algunos es amplio, para otros debe acotarse y, al mismo tiempo, una minoría lo niega del todo ${ }^{34}$. Pero para nuestro caso puntual, en esta investigación, las nociones de influencia y de diálogo monólogo, parecieran ser las más acertadas en atención a la bipolaridad referida ${ }^{35}$.

A pesar de que veremos que entre las Cortes latinoamericanas bajo análisis, se ha concretado un incipiente diálogo judicial interamericano de un carácter más horizontal. Por lo tanto en el análisis de los modelos latinoamericanos enfocados, utilizaremos el concepto amplio de diálogo judicial para aproximarnos a cada caso, luego precisaremos si estamos en presencia de un diálogo monólogo o simple influencia, si es meramente extractivo o no. Además consideraremos la casi verticalidad en el flujo de soluciones desde el TJUE hacia las Cortes de América Latina en análisis, sumado el incipiente dialogo judicial interamericano de carácter horizontal ${ }^{36}$.

americana en un conjunto de decisiones que, si bien exiguo, no parece irrelevante desde el punto de vista cualitativo». GROPPI \& LECIS COCCO-ORTU, 2014, p. 192.

${ }^{34} \mathrm{Tal}$ cúmulo de consideraciones son en general las que justifican aplicar determinados requisitos o límites a la noción del diálogo judicial. En estos términos DÍAZ CREGO plantea la imperiosa necesidad de acotar el concepto de diálogo judicial. DÍAZ CREGO, M. (2015). Diálogo judicial. Eunomía: Revista en cultura de la legalidad, (9), 289-299. Para FERRERES la idea de diálogo ha de ser precisada, para que no se convierta en una idea vacía, compatible con las más variadas prácticas judiciales. FERRERES COMELLA, V. (2005). El juez nacional ante los derechos fundamentales europeos. Algunas reflexiones en torno a la idea de diálogo. En A. Saiz Arnaiz y M. Zelaia (coords.). Integración europea y poder judicial. Oñati. IVAP.

${ }^{35}$ La influencia en Latino América de la aplicación del Derecho de la Integración modelado por la jurisprudencia europea, se produce únicamente de modo voluntario a través del diálogo judicial. Pues, si bien a nivel de Estatutos, éstos fueron reacondicionados legislativamente para los esquemas latinoamericanos según vimos en el capítulo II - su interpretación y ejercicio han sido articulados, en gran medida, mediante una permanente referencia a las sentencias de la Corte de Luxemburgo. MEJÍA HERRERA destaca este fenómeno de «influencia y referencia» así "Es un hecho notorio [...] la 'influencia' de la doctrina jurisprudencial del antiguo TJCE, ahora llamado TJUE, en las sentencias [...] de los tribunales [...] de las principales organizaciones internacionales de integración subregional existentes en América Latina y el Caribe.- Basta una simple observación de la parte considerativa de las resoluciones de estos tribunales para comprobar la 'continua referencia' que en muchos casos hacen de la jurisprudencia comunitaria europea». MEJÍA HERRERA, O. (2011). El diálogo entre tribunales: la jurisprudencia del tribunal de justicia de la unión europea como fuente de inspiración para los tribunales de los sistemas de integración latinoamericanos. Boletín electrónico sobre integración regional del CIPEI, (1), 14-34. Disponible en el Portal oficial CIPEI <http://www.boletincipei.unanleon.edu.ni/articulos.html> [última consulta, diciembre 13, 2018].

${ }^{36}$ Retengamos que, $1^{\circ}$ ) por la casi verticalidad no sólo se presenta una extracción desde el TJUE en carácter de monologo, sino se suma, el hecho de que las Cortes americanas en estudio valoran en tan alto nivel el auctoritas del TJUE que se someten sin obstáculo sus construcciones, posicionando al TJUE casi como un 


\section{EL USO CONCRETO DE CONEXIONES EXTRA-ORGÁNICAS COMO CRITERIO DE SELECCIÓN DE LA JURISPRUDENCIA LATINOAMERICANA PARA EL ANÁLISIS DEL DIÁLOGO JUDICIAL EMPLEADO POR LA CCJ, EL TJCA Y EL TPRM Y TAAM}

El punto de partida para llevar adelante los análisis que efectuaremos en las siguientes secciones del presente capítulo, es establecer y explicar el método o criterio que hemos empleado para la selección de las sentencias en que nos vamos a concentrar. Pues bien, a diferencia del criterio que seguimos en el capítulo II para efectuar los análisis estatutarios en que nos guiamos por los que denominamos «seis patrones centrales», y también diferente al criterio que utilizamos en el capítulo III para analizar la producción de jurisprudencia integracionista, que en dicha ocasión fue en base a los «nueve bloques temáticos», los cuales seguiremos advirtiendo en el presente capítulo, ahora el criterio central que nos inspira para la selección de las sentencias, no se refiere a detectar la presencia de determinados temas o principios — que igualmente se presentarán-, sino que nos concentraremos en comprobar si en una determinada sentencia «se verifica concretamente algún tipo de conexión extra-orgánica con el criterio de un tribunal ajeno al sistema de integración de la Corte enfocada».

Entonces, en el ejercicio que nos espera, no atenderemos — en carácter de criterio o filtroa la materia de fondo que las Cortes latinoamericanas estén conociendo — sin perjuicio de

pseudo superior jerárquico, en sentido de pauta autorizada a seguir, y $2^{\circ}$ ) la incipiente horizontalidad interamericana, se refiere a una naciente comunicación extra-orgánica entre la CCJ, el TJCA y el TPRM en carácter de diálogo judicial integracionista inter-americano horizontal. Por tanto no debemos confundir dicho planteamiento, con la diferenciación de SLAUGHTER entre la horizontal que sucede entre cortes del mismo estatus; la vertical, entre tribunales nacionales con internacionales; y la vertical-horizontal, que mezcla el dialogo horizontal y vertical: «I. Forms of Transjudicial Communication. The geometry of transjudicial communication varies according to the national or supranational status of the courts talking to one another. I identify three distinct forms of such communication: horizontal, vertical, and mixed vertical-horizontal. [...]. A. Horizontal Communication: takes place between courts of the same status, whether national or supranational, across national or regional borders. [...]. B. Vertical Communication: takes place between national and supranational courts. The most developed form of such communication has emerged within the framework of a treaty establishing a supranational tribunal with a specialized jurisdiction that overlaps the jurisdiction of national court. The Treaty of Rome granted the ECJ jurisdiction over particular categories of suits between member states of the European Community and between European Commission and member states. [...]. C. Mixed Vertical-Horizontal Communication: The vertical and horizontal forms of transjudicial communication described about can also combine in several different ways. First, supranational tribunals can serve as a conduit for horizontal communication. Among states party to the European Convention on Human Rights, for instance, national legal rules and principles are spreading through the medium of ECHR decisions». SLAUGHTER, 1994, p. 103-112.

282 
que algunas materias que engloban los nueve bloques temáticos ${ }^{37}$ continúen presentándose. Tal exclusión la justificamos en que el diálogo judicial no se vincula con un tal o cual tema en concreto, sino que por su naturaleza de herramienta procesal al servicio del tráfico de soluciones jurisprudenciales entre distintos tribunales, tiene precisamente la versatilidad de estar disponible para múltiples materias y cauces del derecho sustantivo. Por lo tanto, ni las materias, ni los principios específicos comportan indicios de la presencia de alguna clase de dialogo judicial. Pues bien, bajo este marco metodológico, pasaremos a efectuar el análisis que nos convoca para la CCJ, el TJCA y el TPRM y los TAAM.

${ }^{37}$ Vid. en el capítulo III el apartado 3. Los nueve bloques temáticos que abordan las jurisprudencias de las Cortes latinoamericanas que fueron creados por el TJUE. 


\section{LA CCJ RECURRE AL DIÁLOGO JUDICIAL PARA CONTRIBUIR}

\section{AL FORTALECIMIENTO DEL SICA}

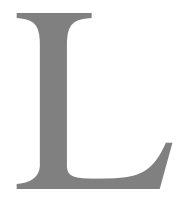

a Corte Centroamericana de Justicia ha desarrollado una intensa labor orientada a consolidar el Derecho del SICA, tal como lo vimos en los capítulos II y III. Pero lo que ahora destacaremos es que en dicho esfuerzo, la CCJ extrae soluciones jurisprudenciales foráneas reacondicionándolas a su realidad regional, y luego las va reiterando en diversas secuencias de sentencias, casi, en carácter de técnica de justificación ${ }^{38}$.

Para apreciar tal reiteración y evidenciar el particular código de justificación que la Corte centroamericana utiliza - siguiendo el criterio de selección de jurisprudencia para este capítulo explicado recién en el apartado anterior-, hemos procedido a analizar cuatro sentencias que fueron dictadas en una secuencia temporal que corre por los años 1998, 2005, 2008 y 2018, la cual hemos organizado en tres etapas de desarrollo. De lo anterior podremos observar que fluyen básicamente dos cuestiones, primero, que la CCJ importa soluciones mediante un diálogo judicial extractivo o monólogo desde el TJUE y en menor medida de otros tribunales — de la Corte Constitucional de Italia (CCi) y también del TJCA—, y segundo, que en el proceso de reiteración la CCJ disminuye la intensidad de sus razonamientos hacia las soluciones importadas, en un ritmo muy cercano con los fundamentos de la teoría negacionista del diálogo judicial. Aunque nosotros consideramos que más bien sería una paulatina incorporación al acervo propio. Y el fenómeno completo se repite cuando la CCJ enfrenta nuevas materias.

${ }^{38}$ CANO entiende que la reiteración constante de la jurisprudencia del TJUE le imprime mayor autoridad a las sentencias de la CCJ, explicando «En su condición de Tribunal de Integración, la CCJ ha tomado como modelo la labor jurisprudencial del TJUE cuyas sentencias no tiene problema en incorporar en sus decisiones como argumento de autoridad». CANO LINARES, M. A. (2009). La corte centroamericana de justicia: un órgano único con diversidad de competencias. En M. Diez de Velasco Vallejo (prol.), C. R. Fernández Liesa, S. Astete Muñoz, F. González Morales, M. A. Cano Linares, B. Olmos Giupponi, ... P. Zapatero Miquel, Tribunales internacionales y espacio iberoamericano $\left(1^{\mathrm{a}}\right.$ ed.). Cizur Menor: Thomson Reuters., p. 129. Para AIZENSTATD la abundante referencia que la CCJ hace a la jurisprudencia del TJUE, al efectuarse sin considerar las realidades locales, pudiese afectar el dialogo judicial con los tribunales de la región. AIZENSTATD LEISTENSCHNEIDER, A. (2011). Reflejos del derecho comunitario europeo en las decisiones de la corte centroamericana de justicia. Revista general de derecho europeo, (25). Otro, bajo la idea de influencia, en OLMOS GIUPPONI, M. B. \& ULATE CHACÓN, E. (2011). Diálogo judicial y gobernanza global: La influencia del derecho comunitario europeo en la jurisprudencia de la corte centroamericana de justicia ( $1^{\text {a }}$ ed.). España: Universidad Rey Juan Carlos. Editorial Dykinson, S. L. 


\subsection{LA PRIMERA ETAPA:}

EL DIÁLOGO JUDICIAL, UN CASO DE TRIPLE CONEXIÓN EFECTUADA POR LA CCJ Y UN INCIPIENTE DIÁLOGO INTERAMERICANO

En 1998 encontramos la sentencia del caso Coto Ugarte/Consejo Superior Universitario de la Universidad de El Salvador ${ }^{39}$, la cual representa la principal utilización del dialogo judicial en cuanto a la materia y a los efectos generados. Sirvió para precisar la limitación estatal tras el desapoderamiento competencial, cuestión que impacta positivamente en los particulares. Fue una clara oportunidad en que utilizando el diálogo extractivo, la CCJ se apoyó en soluciones de tres tribunales, dos internacionales - el TJUE y el TJCA- y uno nacional - la CCi.

Por lo que se refiere a los hechos que dieron lugar a esta interesante sentencia, se trataba de un nacional salvadoreño que había obtenido sus títulos de médico general y especialista en cirugía, en la Universidad (Univ.) de San Carlos de Guatemala, pero le eran desconocidos en El Salvador. Por esto tenía en trámite la solicitud respectiva ante la Univ. de El Salvador, y además había recurrido ante la Sala de lo Contencioso-Administrativo de la Corte Suprema de Justicia de El Salvador. Pero sin esperar a que vencieran tales instancias locales, demandó ante la CCJ, al Consejo Superior Universitario de la Univ. de El Salvador, por desconocimiento del Convenio sobre el Ejercicio de Profesiones Univ. y Reconocimiento de Estudios Univ. y del Protocolo al Tratado General de Integración Económica. La CCJ decretó que se oyera al Consejo Superior Univ. Centroamericano, el cual respondió e incorporó las opiniones de los Rectores de las Universidades de El Salvador y de San Carlos de Guatemala. Pero de todo, lo más contundente que produjo que la CCJ rechazara la acción, era que no se habían agotado las instancias nacionales ${ }^{40}$.

39 Sentencia de la CCJ de 5 de marzo de 1998, Coto Ugarte c. Consejo Superior Universitario de la Universidad de El Salvador, expediente 05-11-1996, as. 05/96. En esta tesis ya nos hemos referido a esta sentencia de la CCJ, pero para destacar otros aspectos que fluyen de su texto. Aquí en cambio, analizaremos la dinámica del diálogo judicial que de forma expresa acusa en su contenido la recurrencia al TJUE, al TJCA y a la CCi.

${ }^{40}$ Es decir no se respetaron las denominadas competencias secundarias, sobre las que ya nos referimos en el capítulo II. Así las cosas y constatando la CCJ que estaba aún pendiente de resolverse la cuestión en el nivel local, en su Considerando V concluyó que no se habían agotado racionalmente las instancias nacionales, y reiterando su Resolución No 6-1-12-96 (Nicolás Urbina Guerrero c/ el Estado de Nicaragua) reafirmó que «el peticionario debe dirigirse a todas y cada una de las instancias internas que le ofrece su respectivo Sistema jurídico nacional, [...], hasta agotar las últimas posibilidades que éste contempla, antes de presentar su demanda o petición a este Tribunal Regional, y que los casos en los que los particulares puedan tener acceso como sujetos activos procesales a esta Corte, deben ser, en forma genérica, siempre que éstos hayan agotado racionalmente los medios que les confiere la legislación común para solucionar sus problemas, y, que, sea evidente que el agotamiento de los recursos ordinarios no coloque al solicitante en una clara situación de denegación de justicia». Es decir, «debe accederse no con la pretensión de hacer de éste un Tribunal de 
A pesar de lo simple que resultaba rechazar la acción, únicamente, por las causales procesales de vulneración a las lógicas de las competencias secundarias, tal como lo hizo expresando: «Primero: No ha lugar por ahora, a la demanda [...], por no haber agotado los procedimientos internos» ${ }^{41}$, es notable que la CCJ haya decidido continuar, e ingresar a las dimensiones sustantivas del derecho de la integración, advirtiendo a los Estados, lo insuficiente que era solamente respetar el Derecho del SICA como simples actores tolerantes, pues lo que se les exige, es que respeten dicho derecho como facilitadores activos de él. Subrayando además, la responsabilidad que acarrea para los Estados miembros ante los particulares, el incumplimiento del Derecho del SICA, manifestándolo del siguiente modo:

«Segundo: Los Estados Miembros del SICA, ya sea directamente o por medio de sus instituciones oficiales [...], están, especialmente, en la obligación de cumplir 'no solo' con lo que el espíritu y letra de lo que la normativa comunitaria dispone, sino de 'facilitar' el ejercicio y cumplimiento de los derechos que en dicho ordenamiento se otorgan a sus destinatarios, ya que, de no hacerlo, se incurre en responsabilidad por parte de dichos Estados» ${ }^{42}$.

Ingresando al fenómeno del diálogo judicial, la CCJ se conectó con tres tribunales ajenos al sistema SICA con el objeto de mostrar coherencia jurisdiccional en la reafirmación de los principios del derecho de la integración, de autonomía, aplicabilidad inmediata, supremacía y de la responsabilidad de los Estados miembros, intentando lograr unidad en los contenidos centrales de este tipo de derecho, mostrándolo como un objeto único de estudio, cuyas características centrales se respetarían en Europa y en Latino América. Lo que justamente es el principal problema, toda vez que dichas realidades son bien diversas. Nosotros consideramos que el deseo de que el Derecho de la Integración se observe como una teoría jurídica unitaria, idéntica, aplicable sin adecuaciones y de modo global, colisiona con las realidades regionales, diferentes en historias, madurez democrática, etcétera ${ }^{43}$.

quejas o de instancias», precisando que ello es doctrina corroborada por esta Corte (la CCJ) y por la CIJ. Proceder de otra forma sería desnaturalizar a este Tribunal, en tal sentido este tribunal «no lo convierten, como ya se dijo, en un Tribunal de quejas o de instancias de los Tribunales Comunes de la Región».

${ }^{41}$ Resolutivo Primero, en Sentencia de la CCJ de 5 de marzo de 1998, Coto Ugarte c. Consejo Superior Universitario de la Universidad de El Salvador, expediente 05-11-1996, as. 05/96.

${ }^{42}$ Resolutivo Segundo, en sentencia ibídem.

${ }^{43}$ Esta diferencia es en esencia la dificultad que detecta la doctrina, et al. AIZENSTATD (2011). Otra, ACCIOLY PINTO DE ALMEIDA, E. (1998). Integración europea e integración latinoamericana: dos realidades distintas. En E. Accioly, M. A. Ciuro, C. da Silva, W. Faria, G. Losfeld, F. Mariño, ... G. Zanin, El MERCOSUR en el siglo XXI. Buenos Aires: Ediciones Ciudad Argentina., p. 309. 
Creemos que las metas y los logros de un conjunto de países desarrollados europeos, no pueden extrapolarse sin más, a grupos de naciones latinoamericanas en vías de desarrollo ${ }^{44}$, las que de tanto en tanto presentan serios problemas de madurez democrática. Sin embargo es innegable que los esquemas de integración bajo análisis, han generado objetivamente beneficios. Por tal razón observamos más bien, que las críticas que se le dirigen se basan en que no se logran todas las metas, desconociéndoles injustamente otros tantos beneficios que si han sido alcanzados. Es decir, es un inconformismo ante las expectativas, más no porque estén vacíos de desarrollos. Entonces, ante los euro-escépticos y los americano-escépticos nosotros consideramos que no es que los esquemas de integración y el Derecho de la Integración considerado en forma amplia, le haya hecho mal a las regiones en las que se despliega, sino que, aún no ha generado todo lo bueno a que puede llegar a generar.

La CCJ al analizar el Derecho del SICA destaca su primacía, la imposibilidad de la derogación unilateral, la pertenencia a dicho estatuto de las normas acusadas las que están plenamente vigentes para El Salvador y Guatemala. Hasta aquí el razonamiento podría entenderse emergido intra-sistema (SICA), sin embargo la CCJ da un paso más intentando imprimirle aquel carácter unitario y global del derecho de la integración ${ }^{45}$. Tal carácter unitario es al que la CCJ, el TJCA y el TPRM tanto esfuerzo dedican, a diferencia del TJUE, que ni siquiera se plantea el fenómeno, pues como se empodera de la fuente, su mayor esfuerzo corre por no perder coherencia con sus propios precedentes. La CCJ en cambio busca legitimidad y además desea destacar su compatibilidad con las soluciones del TJUE, para lo cual, la mejor — sino la única - herramienta que tiene a su alcance, es el diálogo judicial extractivo.

La Corte centroamericana insiste en las conexiones con la Corte de Luxemburgo pues, tras identificar las principales características del derecho de la integración —que ya indicamos párrafo atrás - se detiene en el principio de responsabilidad, destacando que éste existe

\footnotetext{
${ }^{44}$ La dificultad de implementación de esquemas creados por países desarrollados en otros que no lo son, conlleva evidentemente una gran dificultad. ACOSTA analizando este punto para el caso de la CAN razona expresando, la CAN constituía una opción para construir economías de escala de distinto tipo, políticas, productivas, sociales y de conocimiento. Pero 'el subdesarrollo a veces acaba con los sueños'. ACOSTA PUERTAS, J. (2006). La desintegración andina. Nueva sociedad, (204), 4-13.

${ }^{45}$ Recordemos - tal como lo precisamos en nuestro marco teórico - que en los modelos latinoamericanos bajo análisis, se refieren de modo amplio, primero al concepto de «Derecho Comunitario» y más tarde al de «Derecho de la Integración», el cual para los latinoamericanos coincide totalmente con los principios e ideas centrales del Derecho de la UE. Así cuando se refieren al Derecho de la Integración, lo que intentan, es respetar los conceptos básicos de ese nuevo derecho creado en Europa, pues en América Latina se intenta replicar en parte el esquema de la UE, por cierto arrojando como resultado, modelos integracionistas del todo incompletos. Y de modo preciso o concreto nos estamos refiriendo al Derecho de la UE, Derecho del SICA o centroamericano, Derecho de la CAN o andino y Derecho del MERCOSUR o mercosureño.
} 
exclusivamente gracias a la labor pretoriana del TJUE, lo que la CCJ subraya de la siguiente forma:

«finalmente, el Principio de Responsabilidad del Estado, formulado por el Tribunal de Justicia de las Comunidades Europeas, que afirma que los Estados están obligados a reparar los daños causados a los particulares como consecuencia de la violación de las normas comunitarias. Este principio se genera sobre la base de que los particulares son sujetos del derecho comunitario» ${ }^{46}$.

Añadiendo al respecto que la Corte de Luxemburgo mantiene vigente este principio de responsabilidad, pues lo ha ido reiterando en varios fallos desde su creación, expresándolo la Corte centroamericana del siguiente modo:

«El Tribunal de Justicia de las CE o Tribunal de Luxemburgo, lo ha corroborado reiteradamente a partir de la sentencia COSTA-ENEL, [...] en donde no solo reafirma y desarrolla los principios anteriormente señalados, sino que además indica la obligatoriedad de las jurisdicciones nacionales de asegurar dichos principios, y ha establecido que cualquier pretensión de los Estados Miembros de hacer que sus criterios constitucionales prevalezcan sobre las normas de Derecho Comunitario es un fermento de dislocación, contrario al principio de adhesión al que los Estados se han sometido libre y soberanamente ${ }^{47}$.

Pero la CCJ no se detiene ahí, sino que continuando con el uso del diálogo judicial, inmediatamente dirige su atención sobre la sentencia Van Gend en $\operatorname{Loos}^{48}$, para insistir sobre el beneficio recaído en favor de los particulares, argumentando en que éste fue reafirmado por el TJUE en el desarrollo del principio, expresándolo así:

«Además, el Tribunal de Luxemburgo en su histórica sentencia Van Gend en Loos dejó claramente establecido que los Tratados Comunitarios confieren a los particulares derechos que las jurisdicciones nacionales deben salvaguardar no solamente cuando las disposiciones en cuestión los consideren expresamente como sujetos de derechos, sino también cuando imponen a los Estados Miembros una obligación bien definida».

Lo particularmente curioso que observamos, es que si bien el razonamiento anterior, parece ser suficientemente convincente, para la CCJ no lo fue, y continuó buscando más bases de

\footnotetext{
${ }^{46}$ Todas estas motivaciones dirigidas a visibilizar al Derecho de la Integración como un instituto unitario del derecho (en aquel entonces denominado Derecho Comunitario), la CCJ los desarrolla en su extenso Considerando I, en Sentencia de la CCJ de 5 de marzo de 1998, Coto Ugarte c. Consejo Superior Universitario de la Universidad de El Salvador, expediente 05-11-1996, as. 05/96.

${ }^{47}$ Parte final del Considerando I, en sentencia ibídem. La referencia interna es a la Sentencia del TJ de 15 de julio de 1964, Costa/Enel, as. C-6/64, ECLI:EU:C:1964:66.

${ }^{48}$ Sentencia del TJ de 5 de febrero de 1963, Van Gend \& Loos, as. C-26/62, ECLI:EU:C:1963:1. 
legitimidad pretoriana por el camino de la correspondencia extra-sistema, enfocando ahora su atención en otros dos tribunales completamente foráneos al SICA, el TJCA y la CCi.

A nuestro criterio resulta particularmente relevante la conexión que hace con la jurisprudencia del TJCA, por dos motivos, uno, porque la forma en que lo expone, reservándolo para el cierre de sus razonamientos, lo deja ver como ejemplo a seguir, planteándolo así «El Tribunal de Justicia del Acuerdo de Cartagena también lo ha tenido por doctrina reiterada en los Procesos 1-IP-87, 2-IP-88 y 2-IP-90», bajo aquella técnica demostrativa que va en la siguiente razón, si el TJCA lo pudo hacer, nosotros también, y dos, porque a pesar de lo acotada que es la referencia — sin más análisis que lo recién transcrito - su impacto no es menor, pues al conectarse con una Corte de su entorno, impulsa la aplicación de este tipo de comunicación, para importar soluciones regionales más cercanas a las culturas jurídicas de América Latina, materializando un incipiente «diálogo judicial inter-americano».

Aunque en este caso concreto, la mirada horizontal que efectúa la CCJ hacia su entorno, no cobija soluciones propiamente latinoamericanas, ya que las tres ${ }^{49}$ causas a que hace referencia, contienen a su vez construcciones del TJUE, que el TJCA había incorporado previamente mediante un diálogo judicial extractivo ${ }^{50}$. Lo que no alcanza a opacar lo notable del fenómeno, ya que representa un excelente conducto para potenciar soluciones

\footnotetext{
${ }^{49}$ Los tres procesos a que se refiere la CCJ —y sobre los que volveremos, al momento de estudiar el diálogo judicial en el TJCA - son 1) Sentencia del TJCA de 3 de diciembre de 1987, Interpretación prejudicial, Aktiebolaget Volvo c. Volmo, consulta de Consejo de Estado de la República de Colombia, Sala de lo Contencioso Administrativo, Sección Primera, as. 1-IP-87, 2) Sentencia del TJCA de 25 de mayo de 1988, Interpretación prejudicial, Germán y Ernesto Cavelier, consulta de la Corte Suprema de Justicia de la República de Colombia, as. 2-IP-88. GOAC N 33 de 1988, y 3) Sentencia del TJCA de 20 de septiembre de 1990, Interpretación prejudicial, Germán Cavelier y Alexandre Vernot, consulta de la Corte Suprema de Justicia de la República de Colombia, as. 2-IP-90. GOAC N 69, de 11-10-1990. En términos concretos la CCJ se refiere a estos tres fallos del TJCA porque también están gravitando sobre los conceptos y características centrales del derecho de la integración.

${ }^{50}$ En las tres causas no hay soluciones originarias de América Latina, sino importadas desde el modelo europeo, en términos generales — pues en el capítulo anterior ya vimos algunos aspectos y, además un poco más adelante volveremos en su análisis - en el primer proceso a que hace referencia la CCJ es a la consulta en el caso Aktiebolaget Volvo c. Volmo, en el cual el TJCA estableció que atendiendo a las características propias de este derecho, el ejercicio exegético recaído en él, debe ser el teleológico. El segundo, la consulta en el caso Germán y Ernesto Cavelier, el TJCA señaló que «no es posible que la legislación nacional modifique, agregue o suprima normas sobre aspectos regulados por la legislación comunitaria», planteando una autosuficiencia normativa, aunque la función nacional ejecutiva de la norma comunitaria podría existir excepcionalmente y de modo restrictivo, siguiendo la noción del principio del complemento indispensable. Y el tercero, Germán Cavelier y Alexandre Vernot, el TJCA aseveró, entre otras precisiones, lo siguiente «El derecho de la integración, como tal, no puede existir si no se acepta el principio de su primacía o prevalencia sobre los derechos nacionales o internos de los Países Miembros».
} 
regionales, abogando para que estas manifestaciones dejen de ser solo destellos superficiales y pasen a ser construcciones o adaptaciones propiamente latinoamericanas.

Ahora bien, en cuanto a la conexión de la CCJ con la sentencia del caso Frontini ${ }^{51}$ dictada por la $\mathrm{CCi}$, la consideramos bastante singular y todo un acierto por varios aspectos procesales y sustantivos. Este órgano de control de constitucionalidad italiano, no solo es ajeno al SICA — como prerrequisito para hablar de diálogo judicial — sino que, además es un tribunal de nivel nacional, lo que da cuenta de un dialogo judicial vertical si nos conducimos por las ideas clasificatorias ya mencionadas ${ }^{52}$. Además la construcción de la CCi precede en 25 años (1973) al fallo de la CCJ (1998), siendo esto un reflejo del retardo latinoamericano no sólo en la creación de modelos integracionistas, sino en la solución jurisdiccional aplicada. Máxime si consideramos que, precisamente la aparición posterior de los modelos latinoamericanos, permitían - y así fue en otros aspectos - incorporar estatutariamente varios institutos creados por la jurisprudencia europea, pero, para el caso concreto no era así, razón por la cual se abordó su desarrollo a través del diálogo judicial.

Tras analizar en detalle la sentencia italiana estimamos que la CCJ debió destacar con más énfasis los contenidos de dicha sentencia, de hecho — al igual que para el caso del TJCAla CCJ fue muy escueta, indicando únicamente lo siguiente:

«Esto, además, según lo ha considerado la Corte Constitucional Italiana en el caso Frontini, en el año de mil novecientos setenta y tres, es un derecho que por su propia naturaleza debe tener vigencia en todas partes al mismo tiempo y conseguir aplicación igual y uniforme en las confrontaciones de todos los destinatarios» ${ }^{53}$.

Esta falta de énfasis, desaprovecha el rico contenido del fallo de la Corte italiana el cual presentaba una relación directa con las materias tratadas por la CCJ. De hecho, para comprender realmente el fondo de lo que la CCJ estaba intentando destacar, debemos apreciar en términos más amplios el caso Frontini, el cual era producto de los ajustes nacionales que el proyecto europeo de integración causaba al interior de cada Estado miembro en sus primeras décadas. En aquel contexto es que la $\mathrm{CCi}$ se pronunció en las

\footnotetext{
${ }^{51}$ Sentenza Corte Costituzionale (Italia) de 18-12-1973, Frontini. Deposito in cancelleria 27-12-1973. Pubblicazione in Gazz. Uff. N ${ }^{\circ}$ 2, del 2 gennaio 1974.

${ }^{52}$ Como vimos hay diversas maneras de clasificar la concreción del dialogo judicial, v.gr. el diálogo judicial vertical. «Vertical Communication: takes place between national and supranational courts». SLAUGHTER, 1994, p. 106. Otros, ROSAS, 2007. BUSTOS GISBERT, 2012. BURGORGUE-LARSEN, 2013. BENGOETXEA, 2014.

${ }^{53}$ Parte final del Considerando I, en Sentencia de la CCJ de 5 de marzo de 1998, Coto Ugarte c. Consejo Superior Universitario de la Universidad de El Salvador, expediente 05-11-1996, as. 05/96.

290
} 
denominadas «questione di legittimità costituzionale» ${ }^{54}$ provenientes de los tribunales de Turín y Génova. La CCJ extrajo la referencia recién apuntada, desde el siguiente razonamiento contenido en la sentencia constitucional italiana, que expresa:

«Los requisitos básicos de igualdad y seguridad jurídica postulan que las normas comunitarias, que no pueden calificarse de fuente de derecho internacional, ni de derecho extranjero ni de derecho interno de los Estados individuales, deben tener una aplicación directa y obligatoria en todos los Estados miembros, sin la necesidad de leyes de recepción y adaptación, como actos que tienen la fuerza y el valor de la ley en todos los países de la Comunidad, para poder entrar en cualquier lugar en vigor al mismo tiempo y lograr una aplicación igual y uniforme para todos los destinatarios. [...] los reglamentos de la CEE, siempre que tengan una plenitud de contenido $[\ldots]$ son una fuente inmediata de derechos y obligaciones [...], no deben estar sujetos a medidas estatales [...] que puedan diferir o condicionar su entrada en vigor, ni $[\ldots]$ reemplazarlos, derogarlos total parcialmente» ${ }^{55}$.

\footnotetext{
${ }^{54}$ Estas metodologías de comunicación orgánica-procesal intra-sistemas nacionales, fueron creadas en sedes locales constitucionales para desarrollar los controles de constitucionalidad en cada país. Luego fueron importadas por los sistemas procesales del nivel internacional, $v . g r$. las consultas prejudiciales existentes entre los tribunales nacionales y el TJUE, modelos replicados en América Latina y en África. En particular, en Italia, por medio de una «questione di legittimità costituzionale» se hace factible que la Corte Constitucional italiana (CCi) efectúe un control de constitucionalidad de forma concreta cada vez que un juez, en el curso de un proceso judicial, le remita la señalada cuestión de legitimidad constitucional. Este procedimiento también se conoce en dicho país, bajo el nombre de juicio de legitimidad constitucional en vía incidental. Si bien a través del protocolo descrito la CCi garantiza el orden constitucional in concreto, se viene a sumar otra dimensión, mediante los controles in abstracto, por medio de los recursos directos que pueden accionar el Estado o de las Regiones. SCHILlACI, A. \& CALAHORRO A. A. (trans.) (2010). El sistema constitucional de italia. Revista de derecho constitucional europeo, 14, 75-115 (p. 97).

${ }^{55}$ El texto italiano, expresa «il diritto di questa e il diritto interno dei singoli Stati membri possono configurarsi come sistemi giuridici autonomi e distinti, ancorché coordinati secondo la ripartizione di competenze stabilita e garantita dal Trattato. Esigenze fondamentali di eguaglianza e di certezza giuridica postulano che le norme comunitarie, - non qualificabili come fonte di diritto internazionale, né di diritto straniero, né di diritto interno dei singoli Stati -, debbano avere piena efficacia obbligatoria e diretta applicazione in tutti gli Stati membri, senza la necessità di leggi di recezione e adattamento, come atti aventi forza e valore di legge in ogni Paese della Comunità, sì da entrare ovunque contemporaneamente in vigore e conseguire applicazione uguale ed uniforme nei confronti di tutti i destinatari. Risponde altresì alla logica del sistema comunitario che i regolamenti della C.E.E., - sempreché abbiano compietezza di contenuto dispositivo, quale caratterizza di regola le norme intersoggettive -, come fonte immediata di diritti ed obblighi sia per gli Stati sia per i loro cittadini in quanto soggetti della Comunità, non debbano essere oggetto di provvedimenti statali a carattere riproduttivo, integrativo o esecutivo, che possano comunque differirne o condizionarne l'entrata in vigore, e tanto meno sostituirsi ad essi, derogarvi o abrogarli, anche parzialmente». Apartado 7, en Corte Costituzionale, Sentenza de 18-12-1973, Frontini. Deposito in cancelleria 27-12-1973. Pubblicazione in Gazz. Uff. № 2, del 2 gennaio 1974.
} 
Todas las causas que desembocaban en las «questione di legittimità costituzionale» planteadas por los tribunales de Turín y Génova a la CCi, en lo medular, venían solicitando controlar la existencia coherente de diversa normativa nacional con el Derecho de las CEE, por tal motivo la $\mathrm{CCi}$ resume uno de los argumentos centrales que esgrimían los actores ante los tribunales inferiores, por el cual se sostenía que:

«no era infundado dudar de que hubiera una peligrosa limitación de la soberanía nacional, pues se introducía una herramienta de producción legislativa supranacional capaz de afectar a todos los campos y sin límites precisos sobre los derechos de los ciudadanos, posiblemente también socavando sus derechos esenciales y los principios fundamentales de la estructura estatal» ${ }^{56}$.

Como vemos, estas cuestiones eran de gran calado y de evidente interés para Centroamérica, en una época en que recién estaban siendo asimiladas —es más, aún no terminan de serlo. La histórica respuesta de la CCi, corrió por considerar que Italia se había unido libremente al proyecto de integración, y que a través de su participación en los órganos e Instituciones, se compensaba la sesión parcial de soberanía, por lo tanto el criterio de la CCi fue que «las limitaciones encuentran su contraparte en los poderes adquiridos dentro de la comunidad más amplia de la que Italia forma parte y con la que se inició de manera concreta el proceso de integración de los Estados de Europa» ${ }^{57}$.

\footnotetext{
${ }^{56}$ Párrafo cuarto, del número 1, del apartado Considerando de hecho, en sentencia ibídem.

${ }^{57}$ El tribunal de Turín planteó una cuestión de legitimidad constitucional en los ass. Frontini Franco y Soc. de Resp. Ltda Comercio de productos alimenticios c/ el Ministerio de Finanzas y contra el duplicado Vincenzo, Tommasoni Guido y Manganello Angelo, en relación con la medida establecida en algunas regulaciones de la CEE, de gravámenes agrícolas relacionados con ciertas operaciones de importación. El tribunal de Génova planteó una cuestión de legitimidad constitucional en el marco de tres procesos (1. Cía. Fratelli Pozzani, Rusconi \& C., 2. Liguori Costantino, y 3. Cía. Divella Vincenzo c/ la Administración de las finanzas estatales): Se sostenía que habría una limitación de la soberanía. La conclusión de la CCi -que apuntamos arriba en el texto- se basó en el art. 11 de la Constitución: «Italia permite, en condiciones de igualdad con otros Estados, las limitaciones de soberanía necesarias para un orden que garantice la paz y la justicia entre las naciones» $\mathrm{y}$, por tanto, «promueve organismos internacionales destinados a tal efecto». Para la CCi esto marca una dirección política precisa, y aunque se refiere a la adhesión de Italia a la ONU, se inspiró en principios programáticos de valor general, de los cuales la Comunidad Económica y las otras Organizaciones Regionales Europeas constituyen una implementación concreta. Agregó que, se concibe como un instrumento de integración entre los Estados, para el logro de objetivos comunes de desarrollo económico y social y, por tanto, también con el propósito de defender la paz y la libertad, razón por la cual Italia y otros Estados han conferido y reconocido ciertos poderes soberanos, constituyéndola como una institución con un sistema legal autónomo e independiente. Y por tanto resolvió que no había inconstitucionalidad alguna.
}

292 


\subsection{LA SEGUNDA ETAPA:}

\section{EL PROCESO DE REITERACIÓN MEDIANTE UN DIÁLOGO MENOS INTENSO DE LA CCJ}

Luego de las tres conexiones recién analizadas que efectuó la CCJ con el TJUE, el TJCA y la $\mathrm{CCi}$, observamos que la Corte centroamericana ingresa en una segunda etapa caracterizada por un ritmo de reiteración de dichas construcciones, el cual posee la particularidad de ir paulatinamente decayendo e incluso tiende a desaparecer. Así, en relación a la materia que venimos tratando, podemos verificar al interior de esta segunda etapa, una fase inicial bastante más álgida en la reiteración durante los primeros años, lo que se extiende aproximadamente hasta el 2005 con la sentencia Reyes Wyld c/ Rep. de Guatemala $^{58}$, luego en el año 2008 se contrae un poco en el fallo Consulta del Parlacen ${ }^{59}$. Y más adelante, ya en el año 2018 y en carácter de tercera etapa, ubicamos la sentencia en Consulta del Administrador del Mercado Mayorista ${ }^{60}$ donde la CCJ elimina absolutamente toda reiteración de los detalles. Como estos ejemplos sólo los utilizaremos para observar las secuencias del proceso de reiteración y su cadencia, los analizaremos en lo únicamente pertinente a dicho fin, de la forma que sigue.

1. En el primer ejemplo de reiteración, Reyes Wyld c/ Rep. de Guatemala, los hechos corrían por hacer respetar la inmunidad de jurisdicción de los integrantes del PARLACEN, al caso, del diputado Reyes Wyld quien enfrentaba una investigación penal, y en Guatemala se le había suspendido su inmunidad mediante cauces ajenos a la diplomacia ${ }^{61}$. Frente a esto la CCJ fue enfática al valorar al PARLACEM como un órgano autónomo del SICA: «[1a] condición de órgano autónomo del SICA, que visto desde la perspectiva del Derecho Comunitario de Integración Centroamericana [...] se estructuró como una entidad superior, supranacional, con capacidad suficiente para atender las necesidades que aisladamente no logran sus integrantes ${ }^{62}$.

\footnotetext{
${ }^{58}$ Sentencia de la CCJ de 13 de enero de 2005, Reyes Wyld c. República de Guatemala, expediente 01-30-042004 , as. $01 / 04$.

${ }^{59}$ Sentencia de la CCJ de 8 de enero de 2008, Consulta Parlacen, expediente 81-03-05-12-2007, as. 07/07.

${ }^{60}$ Sentencia de la CCJ de 25 de enero de 2018, en Consulta del Administrador del Mercado Mayorista, expediente 03-08-06-2017.

${ }^{61}$ El actor alegó inmunidad de jurisdicción como diputado del PARLACEN y que la suspensión de esa prerrogativa, debía efectuarse por las vías diplomáticas habituales, no por las judiciales internas de Guatemala. Pidió a la CCJ que declarare la responsabilidad en que habría incurrido Guatemala por violar normativa SICA y también de DI (Convención de Viena sobre el Derecho de los Tratados, la Convención de Viena sobre Relaciones Diplomáticas, y Convención sobre Prerrogativas e Inmunidades de las NU). Solicitó el respeto del Derecho del SICA por Guatemala y que deje sin efecto la resolución de la Corte de Constitucionalidad de 17.2.2004 en los acumulados 012-2004 y 213-2004.

${ }^{62}$ Considerando VI en Sentencia de la CCJ de 13 de enero de 2005, Reyes Wyld c. República de Guatemala, expediente 01-30-04-2004, as. 01/04.
} 
La CCJ acogió la demanda y declaró que el actor, mientras sea diputado del PARLACEN y no sea privado de sus inmunidades y privilegios por el referido Parlamento, no puede ser obstaculizado en el desempeño de sus funciones como diputado centroamericano, ni restringido en su libertad, ni procesado por ningún tipo de autoridad.

La reiteración de la doctrina, afianzada mediante el diálogo judicial - y que debemos subrayar nosotros - lo hace la CCJ recordando las características del derecho de la integración, para lo cual se vale nuevamente del TJUE, de la CCi y del TJCA, replicando lo que ya analizamos en el caso anterior, pero aquí lo ajusta y resume, indicando que el Derecho Comunitario posee gran penetración en el orden interno de los Estados dado su aplicabilidad inmediata, efecto directo y primacía, que la Comunidad constituye un nuevo orden jurídico internacional, que hace surgir derechos y obligaciones para los Estados y ciudadanos, y que la CCi en el caso Frontini (1973) consideró que entra en vigor en todas partes al mismo tiempo con aplicación uniforme, cuestión corroborada reiteradamente por el TJUE desde Costa/ENEL (1974), donde se reafirman y desarrollan los principios señalados, indica la obligatoriedad de los jueces locales de asegurarlos, y que toda pretensión de los Estados de hacer que sus criterios constitucionales prevalezcan sobre el derecho comunitario, es un fermento de dislocación contrario al principio de adhesión, y que todo esto, ha sido doctrina reiterada del TJCA (1-IP-87; 2-IP-88 y 2-IP-90) ${ }^{63}$.

En particular observamos como muy singular el hecho de que la CCJ en esta sentencia explique que en Centroamérica no habría precisamente una cesión de soberanía que irrogue una limitación de las mismas para cada Estado, pues en esa región hay más bien, un ejercicio solidario y armonioso de las mismas. Tan particular apreciación lo explica de la siguiente forma:

«en la Comunidad Centroamericana como está definida en el art. $1^{\circ}$ del referido Protocolo, los Estados que la integran, en opinión de esta Corte, más que ceder o limitar sus soberanías, han decidido ejercerlas solidaria y armoniosamente, en forma conjunta y coincidente, en propósitos de bienestar común regional e individual, por lo que aunados en esos nobles y laudables propósitos, los Estados y sus habitantes alcanzan mayores cuotas de jerarquía» ${ }^{64}$.

2. El segundo ejemplo de reiteración se produce llegado el año 2008, en la sentencia Consulta del Parlacen ${ }^{65}$. En esa ocasión el PARLACEN le dirigió a la CCJ siete consultas, las que en general se refrían a (i) si el PARLACEN estaba sujeto al ordenamiento jurídico del DI o a los nacionales de sus Estados parte, (ii) si un tribunal nacional podía emitir fallos

\footnotetext{
${ }^{63}$ Considerando VII en sentencia ibídem.

64 Ídem.

${ }^{65}$ Sentencia de la CCJ de 8 de enero de 2008, Consulta Parlacen, expediente 81-03-05-12-2007, as. 07/07. 294
} 
que posibiliten la derogatoria parcial o total de Tratados, convenios o normativa SICA, (iii) si ocurriese lo anterior, si tales actuaciones eran nulas ipso jure, y (iv) si el PARLACEN debía o no, acatar fallos de tribunales nacionales que atenten contra su naturaleza, violenten su ordenamiento regional y que hagan primar el derecho interno sobre el DI público ${ }^{66}$.

En cuanto a la reiteración del criterio formado gracias al diálogo judicial que venimos resaltando, la CCJ destacó que en algunos procesos anteriores ya se había referido a una parte de las cuestiones que aquí se le consultan, precisando que así lo hizo en la sentencia de la causa Reyes Wyld/República de Guatemala donde a su vez citó el fallo de la causa Coto Ugarte/Consejo Superior Universitario de la Universidad de El Salvador. En lo central la CCJ ratifica sus doctrinas reconociendo los principios ya asumidos en esas dos sentencias. Aunque ahora disminuye notablemente la intensidad de la explicación, y no los detalla. Por tal razón, si nos remitimos a ese par de sentencias, identificaremos que tales principios serían, su autonomía, aplicabilidad inmediata, su efecto o aplicabilidad directa, su primacía y el principio de responsabilidad. Lo cual efectúa la Corte centroamericana a través de un complejo esquema de reiteración y encadenamientos, exponiéndolo así:

«Que La Corte ha fallado [...] en el Exp. 01-30-04-2004 [...]: “CONSIDERANDO IX) Que también en el caso promovido por el doctor J. V. Coto Ugarte (Exp. 05-111996) en contra del Consejo Superior Universitario de la Univ. de El Salvador [...] se ratificaron doctrinas jurisprudenciales así: en su Considerando I, principios reconocidos, contenidos en las resoluciones relacionadas en los Considerandos anteriores, ...principio que este Tribunal ratifica como lo ha hecho el TJUE en diversas ocasiones a partir de Costa/Enel, en donde no solo reafirma y desarrolla estos principios, sino que también establece la obligatoriedad de las jurisdicciones nacionales de asegurarlos, y que cualquier pretensión de los Estados miembros de hacer que sus criterios jurisdiccionales o constitucionales prevalezcan sobre las normas de Derecho Comunitario [...] es un fermento de dislocación contrario al principio de adhesión voluntaria a la Comunidad» ${ }^{67}$.

\footnotetext{
${ }^{66}$ Las 7 consultas que le dirigió el PARLACEN a la CCJ, contenían muy amplias temáticas, pero en lo que nos respecta, las señaladas arriba, son las más importantes. La CCJ las transcribe en la parte expositiva entre los literales A, a la G, en la sentencia ibídem.

${ }^{67} \mathrm{El}$ complejo esquema de reiteración materializa el dialogo judicial en el Considerando XXI de la sentencia en estudio, donde la CCJ pasa a «recordar el Considerando IX del expediente 01-30-04-2004 - Reyes Wyld», el que a su vez «retrotrae al expediente 05-11-1996 - Coto Ugarte». En lo central la CCJ reiteró todo, entre lo cual, pone de relieve que el art. 3 del Convenio de Estatuto de La CCJ, tiene efectos vinculantes para todos los Estados Miembros, Órganos, Organismos e Instituciones que formen parte del SICA, y para sujetos de Derecho Privado, principio que la Corte centroamericana ratifica — señala textual la CCJ «como lo ha hecho el TJUE o Tribunal de Luxemburgo, en reiteradas ocasiones a partir de la sentencia Costa-Enel», reiterando lo indeseado del denominado fermento de dislocación, que es contrario al principio de adhesión voluntaria a la Comunidad.
} 
En conclusión la técnica de reiteración que utiliza la CCJ se estructura mediante un complejo método de referencias históricas encadenadas retroactivamente, pues recuerda sentencias que a su vez, internamente, se basan en otras previas. Esquema que en el fondo demuestra el interés de la CCJ por evidenciar coherencia histórica con el criterio originalmente importado desde el TJUE, apreciándose además que en la jurisprudencia de la CCJ hay una referencia constante a las sentencias Costa/Enel y Van Gend en Loos, pero el tribunal no se adentra en los desarrollos posteriores de la primacía y eficacia directa del Derecho de la UE, lo que evidencia estadios de desarrollo diferentes.

\subsection{LA TERCERA ETAPA:}

\section{EL RECURSO AL DIÁLOGO JUDICIAL SE HACE MENOS PERCEPTIBLE}

Finalmente llegado 2018 encontramos el tercer ejemplo de reiteración, en Consulta del Administrador del Mercado Mayorista ${ }^{68}$, donde la CCJ, ya no expresa ningún detalle sobre los principios, y sólo remite de modo muy acotado a las sentencias previas, por tal razón es que hemos ubicado a este precedente en una tercera etapa. Siendo muy importante destacar que tal debilitamiento, no se justifica porque el caso fuese irrelevante, sino todo lo contrario. De hecho, lo primero que plantea la CCJ es que estima como de alta importancia su respuesta en este asunto, subrayándolo de la siguiente forma:

«Que la CCJ estima de alta importancia establecer las bases sobre las cuales evacuará esta consulta, la cual tendrá un carácter vinculante por tratarse de consultas sobre instrumentos complementarios y actos derivados que afectan al SICA» ${ }^{69}$.

De las características de esta jurisprudencia resulta muy oportuno analizar una posible cercanía con la tendencia negacionista ${ }^{70}$ del dialogo judicial. Pues al responder, la Corte ya no da mayores detalles sobre la construcción y desarrollo de los principios que hemos destacado en esta sección. Circunstancia que se podría traducir como un eventual abandono del diálogo judicial. En ese sentido observamos una cierta razón a la noción negacionista del diálogo judicial que explicaba este fenómeno de comunicación, sólo como una

\footnotetext{
68 Sentencia de la CCJ de 25 de enero de 2018, en Consulta del Administrador del Mercado Mayorista, expediente 03-08-06-2017.

${ }^{69}$ Considerando Primero, en sentencia ibídem.

70 Recordemos que la corriente negacionista del diálogo judicial aunque minoritaria, existe. Para DE VERGOTTINI no hay tan mentado diálogo judicial, sino sólo el uso del recurso a la jurisprudencia extranjera, y en ocasiones respondería a la satisfacción de una exigencia de legitimación del juzgador cuando un tribunal está en el inicio de su actividad o al aplicar un nuevo ordenamiento, disminuyendo este recurso con la consolidación del tribunal. DE VERGOTTINI, et al., 2010b., pp. 197-198, y pp. 207 y ss. Vid. nota 31 de este capítulo.
}

296 
manifestación del típico recurso a lo extranjero, que se acentúa en la etapa inicial del tribunal, quien lo emplea por necesidad de legitimación y que tiende a decaer al consolidarse su labor ${ }^{71}$.

Sin embargo, estimamos que sólo sería una posible cercanía a la postura negacionista del diálogo judicial, más no una constatación empírica ya que en realidad, la lenta disolución del recurso a lo extranjero en la medida que se asienta la Corte, debería darse en nuevas temáticas que fuesen resueltas por los tribunales receptores con soluciones propias, a pesar de que su primigenia fuente - aquí el TJUE - los abordase de distinto modo, lo cual no se constata. En realidad observamos un fenómeno de importación de soluciones. Lo que sucede es que la CCJ justifica con más ahínco la primera importación en una materia y luego sólo va reiterando esos conceptos de un modo más simple.

Entonces, en dicha reiteración hay una disminución de intensidad en su uso - como se observa de los tres ejemplos 2005, 2008 y 2018 - , pues primero importa la construcción europea, luego la absorbe y finalmente le suma más elementos como doctrina, otras jurisprudencias y normativa local - con lo cual amalgama una solución a una determinada necesidad del proyecto SICA, incorporando entonces el total resultante a su acervo. Operación que puede volver a repetir mediante el diálogo judicial, al enfrentar otra nueva materia. Por lo tanto, no es que no exista el referido diálogo judicial monólogo y extractivo, por el contrario sí lo hay, pero sólo al inicio de cada materia. Luego lo que decae es el énfasis para explicar los motivos por el cual se importó al modelo centroamericano una determinada solución europea o cualquier otra externa al SICA.

De hecho en este ejemplo reciente del año 2018, la CCJ se refiere únicamente a los números de los expedientes, en los que ya abordó la misma materia, sin dar, ni reiterar mayores explicaciones sobre los criterios o principios contenidos en esas causas, considerándolo a esa altura «su doctrina», bajo la siguiente formula:

«La Corte 'en su' doctrina que es vinculante para todos los Estados, órganos y organizaciones que forman parte o participan en el SICA y para sujetos de derecho privado, ha consagrado la primacía del Protocolo de Tegucigalpa que es: “...el tratado constitutivo marco de la integración centroamericana, y por tanto el de mayor jerarquía y la base fundamental de cualquier otra normativa centroamericana [...]. (Expediente $N^{o}$ 03-04-1995). También, La Corte ha resuelto que el Principio de Primacía ya reiterado en su jurisprudencia, [...] (Expediente $N^{o}$ 03-04-1995)» ${ }^{72}$.

\footnotetext{
${ }^{71}$ Ídem.

${ }^{72}$ Considerando Segundo en la Sentencia de la CCJ de 25 de enero de 2018, en Consulta del Administrador del Mercado Mayorista, expediente 03-08-06-2017.
} 
En conclusión, la CCJ efectivamente usa un diálogo judicial extractivo y monólogo respecto del TJUE, pero a lo anterior se añaden dos aspectos destacables, primero, la CCJ despliega un singular y complejo esquema de reiteración de sus precedentes, y segundo, que la operación de importación que efectúa la CCJ, si bien se logra tras conexiones preferentemente con el TJUE, también recurre a otras fuentes, como el TJCA, circunstancia que refleja un incipiente dialogo inter-americano de carácter horizontal, y excepcionalmente con algún tribunal nacional, como lo fue con la $\mathrm{CCi}$.

Entonces, si — tal como vimos al inicio de este capítulo - el centro del diálogo judicial es sustantivo y valórico ${ }^{73}$, aplicado al SICA el objeto último tendrá que ser el lograr la mayor uniformidad posible entre el Derecho del SICA y el derecho de la integración, comprendido este último en sentido amplio, tal como ya lo hemos explicado, y a la vez, tendrá por finalidad generar un mejor nivel de convencimiento en los justiciables centroamericanos, a quienes les es muy significativo el apoyo buscado en el modelo europeo ${ }^{74}$.

Ahora bien, si al singular diálogo que usa la CCJ le sumamos — como vimos en el capítulo anterior - el hecho de que la CCJ presenta la mayor cantidad de instrumentos propios, diferentes a los europeos — comparada con la CAN y el MERCOSUR - y que, además desde lo estatutario es la de mayor desarrollo, se produce el efecto de que los desarrollos del TJUE incorporados mediante el tipo de diálogo visto, no irrumpen sin filtros en el modelo del SICA. Por el contrario, las soluciones europeas sufren un freno y una posterior amalgama muy particular, a diferencia de lo que acaece en la CAN y en el MERCOSUR, según veremos a continuación.

\footnotetext{
${ }^{73}$ PROVIN \& DOS SANTOS QUEIROZ, 2017, pp. 113, 124-126, vid. nota 5 de este capítulo.

${ }^{74}$ GROPPI \& LECIS COCCO-ORTU, 2014, pp. 191-192, vid. nota 27 de este capítulo. 


\section{EL DIÁLOGO JUDICIAL EMPLEADO POR EL TJCA PARA CONTRIBUIR AL FORTALECIMIENTO DE LA CAN}

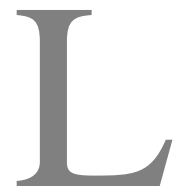

a Corte andina, en algunas determinadas sentencias, también ha recurrido a un diálogo judicial monólogo y extractivo para importar soluciones jurisprudenciales desde los precedentes de la Corte de Luxemburgo. Dicha importación le ha sido de gran utilidad en diversas materias, tal como lo veremos en esta sección. Para efectuar el análisis y siguiendo nuestro criterio de selección ${ }^{75}$ hemos identificado una secuencia de sentencias que dan cuenta de la evolución del fenómeno en la CAN. Las cuales organizamos en tres etapas, la primera a fines del siglo XX con sentencias dictadas en 1987, 1988 y 1990, una segunda etapa referida al inicio del siglo XXI con una sentencia de 2005, y una tercera etapa con la muestra del fenómeno en sentencias más recientes.

\subsection{LA PRIMERA ETAPA:}

EL DIÁLOGO JUDICIAL A FINES DEL SIGLO XX EN EL Tribunal de Justicia del ACUerdo de CARTAgena

Esta primera etapa, como recién indicamos en el párrafo anterior, la observamos desplegarse a fines del siglo XX, centralmente con tres importantes sentencias dictadas por la Corte andina en los años 1987, 1988 y 1990, triada que analizaremos a continuación.

\footnotetext{
${ }^{75}$ El criterio de selección de las sentencias que empleamos para este capítulo, dice relación con que en éstas «se verifique algún tipo de diálogo judicial», más no con un tema en particular, toda vez que por las características propias del diálogo judicial lo presentan como una herramienta de comunicación entre tribunales al servicio de diversas materias. Aunque igualmente se seguirán observando las temáticas que seleccionamos en el capítulo III, mediante los «nueve bloques temáticos» ya explicados. En cambio en el capítulo II recurrimos a los «seis patrones centrales». Vid. en el capítulo II el apartado 3.2. Los seis patrones centrales seleccionados desde el TJUE a cotejar estatutariamente con las Cortes Latinoamericanas. Vid. en el capítulo III el apartado 3. Los nueve bloques temáticos que abordan las jurisprudencias de las Cortes Latinoamericanas que fueron creados por el TJUE. Vid. en este capítulo IV el apartado 4. El uso concreto de conexiones extraorgánicas como criterio de selección de la jurisprudencia latinoamericana para el análisis del diálogo judicial empleado por la CCJ, el TJCA y el TPRM y TAAM.
} 
1. El primero de los precedentes jurisprudenciales que conforman esta fase inicial, es la respuesta de la Corte andina en el marco de la causa Aktiebolaget Volvo c. Volmo ${ }^{76}$ de 1987. Si bien analizamos esta sentencia en el capítulo III, aquello únicamente lo efectuamos como ejemplo de la producción de jurisprudencia integracionista. Sin embargo, ahora analizaremos aquellos extremos de la sentencia que la Corte andina construyó mediante el empleo del diálogo judicial. Los hechos daban cuenta de que la marca Volvo no había podido inscribirse en Colombia, debido a la oposición con éxito de otra muy similar Volmo. Lo que derivó en que el Consejo de Estado de la República de Colombia, solicitara al TJCA una interpretación prejudicial ${ }^{77}$.

El TJAC (posteriormente denominado TJCA, y de modo amplio la Corte andina) para responder la consulta se conectó y apoyó expresamente en el aporte que previamente había hecho el TJUE en la construcción y aplicación del derecho de la integración. La operación de conexión con la jurisprudencia de la Corte de Luxemburgo la efectúa el TJAC de forma muy incipiente, empleando una técnica de amplio enfoque, sin centrarse en ningún fallo europeo en particular. Por tal razón, nosotros consideramos que esta sentencia representa el despegue del uso de algún tipo de diálogo judicial en la zona andina. En el siguiente considerando podemos observar la laxitud con que el TJAC dirige su atención hacia el TJUE:

«En cuanto a los métodos de interpretación que debe utilizar el Tribunal, ha de tenerse presente la realidad y características esenciales del nuevo Derecho de la Integración y la importante contribución que en esta materia tiene ya acumulada la experiencia europea, sobre todo por el aporte de la jurisprudencia de la Corte de Justicia, Tribunal único de las Comunidades Europeas en la aplicación de este derecho, que se está haciendo constantemente en beneficio de la construcción comunitaria, sin perder de vista el fin permanente de la norma. Por estas consideraciones corresponde el empleo preferente de los métodos de interpretación llamados "funcionales", como los métodos sistemáticos y de interpretación teleológica, sin dejar de utilizar, si fuese el caso, los demás» ${ }^{78}$.

Si bien la Corte andina no citó de modo puntual ninguna sentencia de la Corte de Luxemburgo, sí se constata la clara importación de sus soluciones jurisprudenciales, en

\footnotetext{
${ }^{76}$ Sentencia del TJCA de 3 de diciembre de 1987, Interpretación prejudicial, Aktiebolaget Volvo c. Volmo, consulta de Consejo de Estado de la República de Colombia, Sala de lo Contencioso Administrativo, Sección Primera, as. 1-IP-87.

${ }^{77}$ La interpretación prejudicial recaía sobre los arts. 58, 62 y 64 de la Decisión 85 de la Comisión del Acuerdo de Cartagena.

${ }^{78}$ Considerando 3.5 Métodos de interpretación, en Sentencia del TJCA de 3 de diciembre de 1987, Interpretación prejudicial, Aktiebolaget Volvo c. Volmo, consulta de Consejo de Estado de la República de Colombia, Sala de lo Contencioso Administrativo, Sección Primera, as. 1-IP-87.
} 300 
cuanto a establecer las metodologías hermenéuticas que un órgano jurisdiccional integracionista debe privilegiar, para así lograr una coherencia con la finalidad del proceso mismo.

Con idéntica técnica, la Corte andina efectúa simultáneamente una referencia general al derecho de la integración, para lo cual tampoco mencionó ninguna sentencia del TJUE en particular. Tal consideración la realiza con el fin de resaltar la dificultad que entraña la materia de que trataba la consulta:

«La regulación del derecho a la marca comercial, [...], reviste señalada importancia para el derecho de la integración, especialmente ante la necesidad de armonizar el derecho exclusivo a una marca con las normas protectoras de la libre competencia y con el principio de la libre circulación de mercancías. El derecho comunitario europeo ha encontrado muy serias dificultades, aún en vía de superación, para resolver esos conflictos y el que plantea además la subsistencia de las marcas nacionales en el seno del mercado común» ${ }^{79}$.

En realidad fluye de esta sentencia sólo una estimación general hacia el modelo de la UE, pues en el primer considerando transcrito - tres párrafos atrás-, observamos solo una valoración amplia al ejercicio pretoriano del TJUE, y en el segundo considerando recién transcrito en el párrafo anterior, lo que hay es más bien un enfoque valorativo respecto de la importancia del derecho de marca para el derecho de la integración, pues se vincula con la libre competencia y con la libre circulación de mercancías, por cierto en un claro carácter de transición conceptual, ya que en el mismo considerando, lo singulariza primero como derecho de la integración y luego de comunitario. Pero en ninguna de las dos motivaciones la Corte andina se conecta con alguna jurisprudencia concreta de la Corte de Luxemburgo. Circunstancia que nos desplaza hacia la teoría negacionista del diálogo judicial, en similares términos a lo que analizábamos en el apartado anterior para el caso de la Corte centroamericana $^{80}$, aunque allí, lo que apreciábamos era una disminución en las argumentaciones sobre las construcciones foráneas, en cambio aquí, al no haber ninguna conexión con una sentencia concreta, sí podríamos centrarnos sobre el argumento referido a la mera recurrencia al derecho extranjero ${ }^{81}$.

\footnotetext{
${ }^{79}$ Considerando 4, La legislación comunitaria sobre propiedad industrial, en sentencia ibídem.

${ }^{80}$ La cercanía de las circunstancias fácticas con las argumentaciones de la teoría que niega la noción de diálogo judicial, la analizamos en la Sentencia de la CCJ de 25 de enero de 2018, en Consulta del Administrador del Mercado Mayorista, expediente 03-08-06-2017.

${ }^{81}$ Nos referimos al argumento que afirma que la retórica del diálogo quedaría enmarcada en el ámbito de la apertura hacia lo externo. A la posibilidad que tienen los jueces de emplear el recurso al derecho extranjero y a la comparación. Lo cual sería un apéndice de las relaciones de influencia e interacción que los afectan, pudiendo ocurrir que utilicen el argumento comparativo. DE VERGOTTINI, et al., 2010b. Vid. nota 30 de este capítulo.
} 
Aunque debemos precisar varios aspectos, pues podría producirse una confusión al hablar de derecho extranjero en el plano en que nos estamos movilizando. Pues las Cortes latinoamericanas bajo análisis, se esfuerzan demasiado por darle un matiz unitario al derecho de la integración, tal como ya lo hemos analizado en varias secciones de esta tesis. Sin embargo, y siendo estrictos, el derecho de la integración, desde el ángulo que se emplee para su análisis, resulta ser un derecho extranjero, ya que el Ordenamiento Jurídico de la UE no es idéntico al del SICA, ni al de la CAN, ni al del MERCOSUR.

Justamente por lo recién indicado en párrafo precedente, consideramos que en cada región hay una manifestación diferente de una misma rama del derecho, es decir, que la unidad del derecho de la integración, deviene centralmente de la confirmación de sus principios rectores -o patrones centrales-, más no de una igualdad geométrica entre los ordenamientos jurídicos pertenecientes a un tal o cual proyecto de integración, ya que si no fuese así, no se entendería en absoluto que buena parte de las soluciones jurisprudenciales del TJUE sean compatibles con los tres modelos latinoamericanos que los importan, y que además una parte considerable de los contenidos de los estatutos de la UE sean replicados de modo también compatible con los estatutos de los proyectos latinoamericanos. Por lo tanto, si bien objetivamente son realidades diferentes, al mismo tiempo, y también objetivamente, guardan notables semejanzas que no podemos desconocer, de hecho las hemos ido destacando una a una, en esta investigación.

2. Diferente fue lo sucedido al año siguiente en la sentencia que respondió a una consulta de la Corte Suprema de Justicia de la República de Colombia; Germán y Ernesto Cavelier $^{82}$. Aquí el TJAC mediante un diálogo judicial extractivo, a diferencia del anterior caso, sí se conectó con tres sentencias específicas del TJUE [Costa/Enel (1964), consulta del Finanzgericht Hamburg (1971) y Simmenthal (1978)] de las cuales la Corte andina seleccionó algunos determinados contenidos para construir su respuesta. Los señores Germán y Ernesto Cavelier habían deducido una acción de inconstitucionalidad contra ley interna colombiana ${ }^{83}$ por considerar que desbordaba las atribuciones contenidas en la Decisión $85^{84}$ que era una norma comunitaria dictada con posterioridad. En ese contexto la Corte Suprema colombiana solicitó al TJAC que interpretara si el derecho interno de los

\footnotetext{
82 Sentencia del TJCA de 25 de mayo de 1988, Interpretación prejudicial, Germán y Ernesto Cavelier, consulta de la Corte Suprema de Justicia de la República de Colombia, as. 2-IP-88. GOAC N 33 de 1988.

${ }^{83}$ La norma local impugnada era el art. 454 de la Ley 9\%/1979 de Colombia.

${ }^{84}$ Decisión de la Comisión del Acuerdo de Cartagena $\mathrm{N}^{\circ}$ 85, Reglamento para la aplicación de las normas sobre propiedad industrial, publicada en la Gaceta Oficial del Acuerdo de Cartagena (GOAC) el 5 de junio de 1974. Disponible en el Portal oficial de la CAN en el enlace <http://www.comunidadandina.org/Normativa.aspx?GruDoc=07> apartado Decisiones [última consulta, octubre 1, 2019].
}

302 
Estados podía señalar «en casos de productos farmacéuticos» requisitos adicionales y causales diferentes a los que establecía el Derecho de la CAN para registrar una marca ${ }^{85}$.

El TJCA destacó que el conflicto entre la norma andina con la del derecho interno tenía la particularidad de que la ley nacional era anterior a la comunitaria. Luego, recordó el TJCA que su jurisprudencia ya había afirmado que las Decisiones obligan a los Países miembros desde la fecha en que sean aprobadas por la Comisión del Acuerdo de Cartagena (CAC), y que bajo la normativa vigente, serán directamente aplicables a partir de su publicación en la Gaceta Oficial del Acuerdo de Cartagena (GOAC) ${ }^{86}$.

Asentado lo anterior el TJAC desarrolla los efectos de la ley comunitaria sobre la nacional, lo que en resumen - pues ya lo analizamos en el capítulo III - produce el efecto de que la norma comunitaria no deroga la nacional, sino que mediante el principio de aplicación preferente solo la desplaza. La nacional no es eliminada del sistema, quedando en una latencia durante el imperio de la comunitaria, y las naciones verán si las derogan o no, pero no pueden aplicarlas. En este punto el TJAC recurre al diálogo judicial para reforzar la idea, pero no para una aplicación absoluta sobre la región andina. Si bien la conexión es en concreto hacia las sentencias Costa/Enel y Simmenthal, la referencia a su sustancia, es en términos muy amplios. Únicamente refiriendo que los contenidos de esos fallos —en el punto pertinente- estarían en concordancia con el espíritu de las normas de la integración andina. Efectuando la conexión del siguiente modo:

«Así lo ha señalado reiteradamente el Tribunal de Justicia de las Comunidades Europeas (ver principalmente Sentencias Costa/Enel, 15.6.1964, y la Sentencia Simmenthal, 9.3.1978) en concordancia, en este punto, con el espíritu de las normas de la integración andina. Este efecto de desplazamiento de la norma nacional, como resultado del principio de aplicación preferente, resulta

\footnotetext{
${ }^{85}$ Las estructuras jurídicas y los artículos que estaban en colisión en aquella época entre la normativa local previa y una comunitaria posterior, que conformaban el Proceso Judicial $\mathrm{N}^{\circ} 1772$, eran $1^{\circ}$ ) Por el nacional, el art. 454 de la Ley 9 ${ }^{a}$ de 1979 que indicaba «el Ministerio de Desarrollo deberá acatar los informes o conceptos del Ministerio de Salud cuando se trate del registro de una marca de productos farmacéuticos, bien sea para aceptarlo o cancelarlo», ley nacional que el TJCA no podía interpretar, expresando «No asume este Tribunal, en cambio, ni podría hacerlo, la tarea de interpretar el art. 454 supra, puesto que la precisión del contenido de esta norma interna y el señalamiento de su alcance corresponden exclusivamente al Juez nacional, [...]. El Tribunal tendrá en cuenta la citada ley colombiana tan sólo de acuerdo con su significación material expresa y obvia, prima facie, a manera de simple punto de referencia hipotético y únicamente con el fin de orientar la interpretación solicitada». $2^{\circ}$ ) La norma comunitaria posterior, con la que se acusaba su incompatibilidad era el art. 84 de la Decisión 85, con violación de sus arts. 56, 58, 76 y 77.

${ }^{86}$ Las excepciones entonces debían ser expresas, según dispone el art. 2 en relación al 3 y 5 todos del Tratado Constitutivo del TJAC. Por lo que el TJAC recuerda que otras fechas de entrada en vigor, se deben circunscribir a los casos en que las mismas normas comunitarias lo señalen. Y, sólo cuando su texto claramente así lo disponga, requerirán de incorporación al derecho interno, mediante acto expreso.
} 
especialmente claro cuando la ley posterior -que ha de primar sobre la anterior $[\ldots]-$ es precisamente la norma comunitaria» ${ }^{87}$.

Luego, este tipo de diálogo judicial se vuelve más específico para ayudar a visualizar la estrecha conexión entre el principio de aplicación preferente -que desplaza la norma interna y no la deroga - con el principio de la preeminencia. Estos dos principios son tan similares que pareciesen anidar la misma matriz central, esto es, la supremacía del derecho de la integración. E incluso podríamos comprender el fenómeno de esta prelación, desde una tercera dimensión, como una manifestación más del principio general de derecho de la primacía del derecho internacional aplicado de modo amplio a los modelos integracionistas. Sin embargo, debemos remarcar sus contornos, en tal sentido sus diferencias radican en que el primero es específico para salvar colisiones de leyes, el segundo en cambio es de aplicación general en todo ámbito al interior de un esquema integracionista, y el tercero, comporta una matriz transversal del derecho en sí.

La sentencia de la Corte andina - consulta de la Corte Suprema de Justicia de la Rep. de Colombia; Germán y Ernesto Cavelier - vuelve a enfocarse hacia la Corte de Luxemburgo para poner de relieve el principio de preeminencia - denominado principio de primacía en la UE - lo cual efectúa la Corte andina, haciendo referencia directa a la sentencia Simmenthal — dice, última de las sentencias mencionadas - de la siguiente forma:

«El Tribunal de Justicia de las Comunidades Europeas, en las sentencias antes citadas, ha afirmado la preeminencia absoluta del derecho comunitario sobre el interno, tesis que resulta ser también aplicable en el ordenamiento jurídico de la integración andina conforme antes se indicó. En la 'última de las sentencias mencionadas' se concluye que 'todo Juez nacional que tenga que decidir en el marco de su competencia, tiene la obligación de aplicar íntegramente el derecho comunitario y de proteger los derechos que éste confiere a los particulares, dejando inaplicada toda disposición eventualmente contraria de la ley nacional, sea ésta anterior o posterior a la regla comunitaria"» ${ }^{88}$.

Ahora bien, si los principios anteriores están presentes y se articulan es porque evidentemente está conviviendo el ordenamiento integracionista con los nacionales, bajo la noción de desplazamiento de la ley nacional y no por un efecto derogatorio automático. Por lo tanto, resultará indispensable tener claridad respecto del rol exacto de la ley nacional ante la normativa comunitaria. En tal arista encontramos una regla lógica y dicotómica

\footnotetext{
${ }^{87}$ Parte final del párrafo uno del Considerando 2 titulado Efecto de la norma comunitaria sobre la norma nacional, en Sentencia del TJCA de 25 de mayo de 1988. Interpretación prejudicial, Germán y Ernesto Cavelier, consulta de la Corte Suprema de Justicia de la República de Colombia, as. 2-IP-88. GOAC N 33 de 1988.

${ }^{88}$ Párrafo final, en considerando y sentencia ibídem.

304
} 
consistente en que, por una cara negativa y principal, se imposibilita desarrollar una actividad legislativa nacional contraria a la comunitaria, y por una cara positiva y secundaria, se permite la existencia de un complemento legislativo de derecho interno y, en algunos casos, de implementación ${ }^{89}$. Tal como dieciocho años antes el TJUE ya lo había resuelto.

En dichas coordenadas el TJAC se conectó ahora con los contenidos de la sentencia que la Corte de Luxemburgo había dictado en 1971 en la consulta prejudicial del Finanzgericht Hamburg de Alemania ${ }^{90}$, para aclarar el rol exacto de la ley nacional ante la norma comunitaria, aspecto en el cual la Corte andina pone especial interés, expresándose así: «merece citarse la sentencia del TJCE [...] — Caso 39/70 - en el cual se afirma que la aplicación uniforme de las normas comunitarias no permite que se expidan normas nacionales sobre el mismo asunto, a menos que éstas sean necesarias para la correcta aplicación de aquellas. "Cuando el derecho comunitario -dijo ese Tribunal [TJCE] - establece un sistema especial [...] que contempla condiciones y sistemas de supervisión... las autoridades nacionales no pueden sujetar a los importadores a requisitos adicionales provenientes de la ley nacional, especialmente si tales requisitos resultan incompatibles con los criterios que inspiran la norma comunitaria" [...]. "La implementación se regula por la ley nacional — señaló el Tribunal [TJCE] — ... sin embargo la aplicación uniforme de las normas comunitarias excluye la regulación nacional sobre los mismos temas, a menos que ésta resulte necesaria para la aplicación de aquellas". Y agrega [el TJCE] "las autoridades nacionales están en libertad para usar todos los métodos que resulten apropiados [...] para asegurar el cumplimiento del derecho comunitario... y para impedir fraudes... utilizando siempre criterios compatibles con los comunitarios"»»

\footnotetext{
${ }^{89}$ La Corte andina efectúa su conclusión en los siguientes términos «En resumen y de acuerdo con la doctrina contenida en el fallo citado [se refiere a la Sentencia del TJ de 11 de febrero de 1971, Norddeutsches Viehund Fleischkontor - Finanzgericht Hamburg, as. C-39/70, ECLI:EU:C:1971:16] y que resulta aplicable en el ordenamiento andino los Reglamentos de la naturaleza del que se examina no siempre agotan la materia a la cual se refieren, por lo cual permiten, y aun exigen en ciertos casos, un complemento legislativo de parte del derecho interno. Incluso cuando la normativa comunitaria agota el asunto, lo cual no es frecuente, podrían resultar necesarias normas nacionales de implementación o de adaptación al sistema nacional, pero siempre sin vulnerar el citado art. 5 del Tratado en referencia». Parágrafo final, del Considerando $3^{\circ}$, en Sentencia del TJCA de 25 de mayo de 1988, Interpretación prejudicial, Germán y Ernesto Cavelier, consulta de la Corte Suprema de Justicia de la República de Colombia, as. 2-IP-88. GOAC Nº 33 de 1988.

90 Sentencia del TJ de 11 de febrero de 1971, Norddeutsches Vieh- und Fleischkontor - Finanzgericht Hamburg, as. C-39/70, ECLI:EU:C:1971:16.

91 Parágrafo quinto, en considerando $3^{\circ}$ en Sentencia del TJCA de 25 de mayo de 1988, Interpretación prejudicial, Germán y Ernesto Cavelier, consulta de la Corte Suprema de Justicia de la República de Colombia, as. 2-IP-88. GOAC N 33 de 1988.
} 
Claramente este segundo caso analizado (Cavelier, de 1988) presentó una aplicación más concreta del diálogo judicial que el caso anterior (Volvo c. Volmo, de 1987), pues ahora hubo mucha mayor precisión y detalles para el despliegue de la operación de conexión jurídica que la Corte andina efectúo con los precedentes del TJUE, aunque, es menor, en consideración al tercero (Cavelier y A. Vernot, de 1990) el cual analizaremos a continuación.

3. El tercer caso que viene a cerrar esta primera etapa se produjo en 1990 en la respuesta del TJAC a la consulta de la Corte Suprema de Justicia de la Rep. de Colombia; Germán Cavelier y Alexandre Vernot ${ }^{92}$, ocasión en que nuevamente la Corte andina recurrió al diálogo judicial. Los señores Cavelier y Vernot habían interpuesto acción de inconstitucionalidad en contra de determinadas secciones de la Ley 81/1988, acusando que el Congreso de Colombia al dictarla, le usurpó competencia a la Comisión del Acuerdo de Cartagena. Vulnerándose el art. 27 del Acuerdo de Cartagena (AC) que impulsa a una regulación común en materia de propiedad industrial, colisionando las normas locales con las Decisiones 84 y 85 y la 220 del AC. En ese contexto la Corte Suprema colombiana solicitó la interpretación del art. 27 supra y de las demás normas que lo desarrollaban ${ }^{93}$.

La Corte andina respondió reiterando el principio de supremacía en carácter de ineluctable y como requisito de existencia sine qua non del Derecho de la Integración, enfatizando:

«El derecho de la integración, como tal, no puede existir si no se acepta el principio de su primacía o prevalencia sobre los derechos nacionales o internos de los Países Miembros» ${ }^{94}$.

En el caso concreto el TJAC hizo referencia a su jurisprudencia en el asunto 2-IP-88 el cual analizamos anteriormente. Precisando que no sólo hay un conflicto entre leyes - nacional $v / s$ integracionista - sino que aquí se presenta un conflicto de fuentes. Problemática que

\footnotetext{
${ }^{92}$ Sentencia del TJCA de 20 de septiembre de 1990, Interpretación prejudicial, Germán Cavelier y Alexandre Vernot, consulta de la Corte Suprema de Justicia de la República de Colombia, as. 2-IP-90. GOAC N 69, de 11-10-1990.

${ }^{93}$ En el Proceso Judicial No 2006 la Procuraduría General de la Nación [colombiana] al rendir Concepto Fiscal, precaviendo una negativa a tramitar la consulta, emitió su opinión, la cual se alinea con el espíritu integracionista, señalando «el derecho de integración andino es 'superior' al derecho nacional sólo cuando el Estado respectivo ha transferido competencias soberanas sobre una materia a los órganos comunitarios, no da lugar a intervención de nuevo derecho interno, y no cabe invocar disposiciones constitucionales o legales internas para impedir su aplicación. El derecho de integración ha 'llenado' el sector, y el Estado carece de competencias en esa materia. Salvo que se hubiera reglamentado el punto en forma parcial».

${ }^{94}$ Párrafo primero, número 1 El derecho nacional frente al derecho comunitario, del apartado Considerando, en Sentencia del TJCA de 20 de septiembre de 1990, Interpretación prejudicial, Germán Cavelier y Alexandre Vernot, consulta de la Corte Suprema de Justicia de la República de Colombia, as. 2-IP-90. GOAC Nº 69, de 11-10-1990.
}

306 
enfrenta nuevamente con la regla de que el derecho de la integración no deroga leyes nacionales, sino que genera el efecto de desplazamiento - que vimos en el punto anterior.

Hasta aquí la sentencia ya estaba incardinada en su totalidad, por lo que en estricto rigor no necesitaba importar soluciones exógenas a la CAN. Lo lógico, para mostrar madurez, era que rodara exclusivamente en sentido de reiteración de la jurisprudencia ya asentada. Sin embargo la Corte andina volvió a conectarse con las sentencias de la Corte de Luxemburgo en los casos Costa/Enel y Simmenthal. Tan insistente necesidad de conexión la consideramos casi como una condición de justificación, lo que en cierta medida debilita la imagen de la Corte andina, pues trasluce una falta de aplomo individual. A diferencia de lo que vimos en el SICA, donde la CCJ internaliza la solución europea, la adapta a su realidad y finaliza amalgamándolo todo, generando efectivamente su propio criterio sub-regional. Pero en este caso, sólo hay una reiteración de la siguiente forma:

«El principio de la aplicación preferente del derecho comunitario, según el cual éste debe aplicarse de todos modos, no obstante lo que disponga el derecho nacional, fue consagrado en la Comunidad Económica Europea gracias al histórico fallo Costa/ENEL de 15.6.1964, ratificado en la sentencia Simmenthal de 9.3.1978. Este principio, junto con el del efecto directo, contribuyó de modo decisivo al espectacular éxito hasta ahora alcanzado por el proceso de integración en Europa. Se trata de una concepción jurídica fundamental, consagrada también dentro del ordenamiento jurídico andino, que hace posible la existencia de un verdadero derecho de la integración, por lo cual este Tribunal no ha vacilado en acogerla» ${ }^{95}$.

También es cierto que este diálogo lo usa la Corte andina solo para orientar su solución técnica, pues, el contenido europeo extraído, no es parte sustantiva de la respuesta del TJAC. En realidad — como lo indicamos más arriba - este tipo de comunicación era perfectamente prescindible, pero la Corte andina insiste en mostrar una coherencia de base con el TJUE. Lo cual queda en evidencia pues en la conclusión del asunto el TJAC efectúa un completo análisis normativo sin emplear el diálogo judicial, y resuelve que la regulación comunitaria, al caso concreto, «es de cubrimiento parcial y de alcance indicativo», por consiguiente los Estados miembros conservan su competencia para legislar sobre aspectos no regulados, o bien para desarrollar o complementar los que no lo hayan sido de modo exhaustivo $^{96}$.

\footnotetext{
${ }^{95}$ Parágrafo tres del Considerando $1^{\circ}$, en sentencia ibídem.

${ }^{96}$ Número 1, del apartado El tribunal de justicia del acuerdo de cartagena, concluye, en sentencia ibídem.
} 


\subsection{LA SEGUNDA ETAPA:}

El Renovado Tribunal de Justicla de LA COMUNIDAD ANDINA

Y EL DIÁLOGO JUDICIAL

Quince años después, en 2005, la Corte andina actuando ya bajo su nueva denominación, Tribunal de Justicia de la Comunidad Andina ${ }^{97}$, dio respuesta a la consulta en la causa Envíos de dinero BBVA Bancomer más Gráfica a color ${ }^{98}$. En tal ocasión se conectó con dos sentencias europeas Viking-Umwelttechnick $G m b H^{99}$ y SAT.1 SatellitenFrensehen $G m b H^{100}$ en ambos casos contra la Oficina de Armonización del Mercado interior, dictadas por el antiguo Tribunal de Primera Instancia de las Comunidades Europeas (TPCE, hoy TGUE).

BBVA Bancomer S.A. había presentado en Colombia una solicitud de registro de la marca Envíos de Dinero BBVA Bancomer más Gráfica a color, con la autorización del BBVA S.A. del mismo grupo empresarial, pero le fue denegada por la División de Signos Distintivos de la Superintendencia pues era similar a la marca BBVA, por lo tanto confundibles, y la autorización que el actor invocaba solo resguardaría los intereses de los empresarios, más no los de los consumidores. Elevada en apelación el Consejo de Estado de la Rep. de Colombia pidió interpretación prejudicial al TJCA de diversos artículos de la Decisión 486 de la Comisión de la $\mathrm{CA}^{101}$.

\footnotetext{
${ }^{97}$ Para esta etapa (2005) la Corte andina ya contaba con su estructura y nombre actual, Tribunal de Justicia de la Comunidad Andina - TJCA. Recordemos, tal como lo vimos en el capítulo I sobre análisis histórico, que el proyecto político de la CAN nació sin contemplar un tribunal comunitario. Pero en 1978 se comienza a superar esta circunstancia, tras reconocer expresamente los Estados miembros de la CAN, la necesidad imperiosa de contar con un órgano jurisdiccional propio. Esta Corte se gesta mediante el Tratado de Creación del TJAC de 1983, y comenzó su funcionamiento en enero de 1984, bajo la denominación Tribunal de Justicia del Acuerdo de Cartagena - TJAC. Luego a través del Protocolo de Cochabamba de 1996 (vigente 1999) fue rebautizado como TJCA, también conocido como Corte andina, o Tribunal andino. Este desfase entre el nacimiento de la OI y el de su órgano jurisdiccional, es - como lo vimos en el capítulo I referido al análisis histórico- un error sustancial del proceso andino. QUINDIMIL, 2006, pp. 328-330, 334 y 338.

${ }^{98}$ Sentencia del TJCA de 20 de julio de 2005, Interpretación prejudicial, Marca: Envíos de dinero BBVA Bancomer más Gráfica a color, as. 89-IP-05.

${ }^{99}$ Sentencia del TPCE de 25 de septiembre de 2002 (Sala Cuarta), Viking-Umwelttechnick GmbH c. Oficina de Armonización del Mercado interior, as. T-316/00, ECLI:EU:T:2002:225.

${ }^{100}$ Sentencia del TPCE de 2 de julio de 2002 (Sala Segunda), SAT.1 SatellitenFrensehen GmbH c. Oficina de Armonización del Mercado interior, as. T-323/00, ECLI:EU:T:2002:172.

${ }^{101}$ Se conoció por la Sala de lo Contencioso Administrativo, Sección Primera, quien solicitó puntualmente la interpretación sobre los arts. 134, 135 literal b), 136 literales a) y f), 150 y 159 de la Decisión 486 de la Comisión de la CA.
}

308 
En lo que nos interesa — esto es detectar el diálogo judicial ${ }^{102}$ — el actor pretendía la inscripción de la marca porque contaba con la autorización del otro participante que era de su mismo grupo económico. Planteó que la confusión de marcas genera rechazo, cuando irroga una dimensión nociva, y aquí no la habría. Pero la Administración consideró que la mentada autorización sólo protegía a los empresarios y no a los consumidores. Así las cosas, lo que debía hacer el TJCA, era resolver el alcance de dichas autorizaciones ${ }^{103}$, para lo cual recurrió al diálogo judicial conectándose nuevamente con el modelo europeo. Primero extrajo una sección del razonamiento que el TPCE (hoy TGUE) hizo en su sentencia del caso Viking-Umwelttechnick $G m b H$ bajo la siguiente fórmula:

«En la jurisprudencia europea se destaca que, cuando los productos designados en la solicitud de registro van destinados a los consumidores en general, "se supone que el público correspondiente es un consumidor medio normalmente informado y razonablemente atento y perspicaz. No obstante, ha de tenerse en cuenta la circunstancia de que el consumidor medio debe confiar en la imagen imperfecta que conserva en la memoria. Procede, igualmente, tomar en consideración el hecho de que el nivel de atención del consumidor medio puede variar en función de la categoría de productos contemplada ..." (Sentencia del Tribunal de Justicia de las Comunidades Europeas del 25 de septiembre de 2002, asunto T-136/00)» ${ }^{104}$.

\footnotetext{
${ }^{102}$ El criterio de selección de las sentencias analizadas en este capítulo lo justificamos oportunamente en el apartado 4. El uso concreto de conexiones extra-orgánicas como criterio de selección de la jurisprudencia latinoamericana para el análisis del diálogo judicial empleado por la CCJ, el TJCA y el TPRM y TAAM.

${ }^{103} \mathrm{El}$ actor se basaba en que el art. 136 se refería a las causales de irregistrabilidad relativas, el cual fue interpretado erróneamente por la Superintendencia, pues se pretextaba un interés del consumidor, pero la norma se refiere a un derecho de un tercero. Que el literal a) de dicho art. pretende evitar el riesgo de confusión bajo un concepto nocivo. Que la Superintendencia erró al interpretar dicha causal a), pues al decidir sobre el registro, no se refirió a la comparación de los signos, los cuales, si bien son semejantes, no son confundibles, pues aunque comparten la expresión BBVA, son diferenciables. Que el literal $f$ ) impide registrar signos que afecten derechos de un tercero, salvo que medie consentimiento de éste, y la Superintendencia desconoció dicha autorización. Finalmente que la Superintendencia habría violado el art. 150, en el cual se establece que vencido el plazo para presentar oposiciones sin que así hubiese ocurrido, la Oficina Nacional realizará el examen de registrabilidad, y que la facultad registral de la Administración no puede extralimitarse hacia una función protectora que corresponde a otras esferas del Estado».

${ }^{104}$ Párrafo 6 del apartado I La marca y sus elementos constitutivos. Requisitos de un signo para ser registrado como marca, en Sentencia del TJCA de 20 de julio de 2005, Interpretación prejudicial, Marca: Envíos de dinero BBVA Bancomer más Gráfica a color, as. 89-IP-05. Nosotros advertimos que habría un error de transcripción al interior de los paréntesis de dicho párrafo, pues el texto al que se cita, se indica pertenecer a TJCE Sentencia de 25-9-2002, as. T-136/00, sin embargo ésta no existe (la más cercana es la C-136/00 pero es de fecha 2-10-2002 y su texto 'no' coincide con el citado). Suponemos — con asidero- que el error estaría en el número «136» siendo en realidad «316», y además el acrónimo es impreciso, pues dice «TJCE» siendo más exacto «TPCE». Concluimos entonces que se quiso citar a la Sentencia del TPCE de 25 de septiembre de 2002 (Sala Cuarta), Viking-Umwelttechnick GmbH c. Oficina de Armonización del Mercado interior, as. T316/00, ECLI:EU:T:2002:225. Esto lo corroboramos porque «el texto transcrito» por el TJCA en realidad corresponde al «Párrafo 28» de la última sentencia señalada.
} 
Es decir, el TJCA incorporó mediante un diálogo judicial monólogo y extractivo, la preponderancia de la protección del consumidor en estos contextos. Lo relevante de esta sentencia es que por medio del dialogo el TJCA extrapola y hace aplicable a toda la región andina el mismo criterio de la UE. Pasando ahora a comprender que, si bien el consumidor es un sujeto medio y perspicaz, éste no es inmune a la confusión respecto de los orígenes de quienes le prestan servicios $\mathrm{u}$ ofrecen productos. $\mathrm{Y}$ precisamente para hacer factible el distingo, vuelve a recurrir al mismo tipo de diálogo, reflexionando ahora respecto de la sentencia del TPCE en la causa SAT.1 SatellitenFrensehen GmbH del siguiente modo:

«En definitiva, se trata de analizar "si la marca solicitada permitirá que el público correspondiente distinga los productos o servicios designados con dicha marca de los que tengan otro origen comercial cuando tenga que elegir al adquirir tales productos u obtener tales servicios" (Sentencia del Tribunal de Primera Instancia de las Comunidades Europeas, del 2 de julio de 2002, asunto T-323/00)» ${ }^{105}$.

Entonces, influenciado el TJCA por los razonamientos del modelo europeo, procedió a elaborar su respuesta - y en aquello que nos interesa aquí - señaló que debe primar la protección del consumidor por sobre las referidas autorizaciones ${ }^{106}$. Modificándose de esta forma el criterio respecto del alcance de aquellas autorizaciones — como la alegada por el actor - pasando a quedar limitadas en la región andina, bajo el mismo criterio europeo de la protección de los consumidores, y no sólo protegiéndose a terceros.

En conclusión queda demostrado nuevamente el apoyo que busca la Corte andina en los desarrollos europeos, a través del diálogo judicial unidireccional analizado, y que en este caso lo observamos del siguiente modo, primero, lo utilizó el TJCA a efectos de lograr mayor legitimidad para introducir en la región andina el nuevo concepto de protección analizado, segundo, por su intermedio el TJCA también intenta mostrar aquella coherencia

${ }^{105}$ Párrafo 7 del apartado y sentencia ibídem. El fallo que el TJCA cita entre paréntesis es la Sentencia del TPCE de 2 de julio de 2002 (Sala Segunda), SAT.1 SatellitenFrensehen GmbH c. Oficina de Armonización del Mercado interior, as. T-323/00, ECLI:EU:T:2002:172, y se refiere a su Párrafo 35.

${ }^{106}$ Dicha conclusión la obtenemos tras descomponer la respuesta de la Corte andina por los siguientes cauces $1^{\circ}$ ) por el llamado de atención respecto de que la comparación entre los signos debe realizarse considerando la impresión unitaria que cada uno producirá en la sensorialidad igualmente unitaria del destinatario, y $2^{\circ}$ ) asentándose en el hecho de que, de haber acuerdo entre los titulares de los signos para la comercialización de los productos o servicios identificados con una marca idéntica o semejante a otra, la eficacia de ese acuerdo, en todo caso, estará supeditada a la tutela del interés general de los consumidores por parte de la autoridad administrativa o judicial correspondiente. Por lo tanto, el límite fundamental del consentimiento de las partes viene dado por el riesgo de confusión, y en modo alguno, el acuerdo alcanza a dejar sin efecto el interés general de los consumidores o usuarios. Este compacto del corolario de lo resuelto por el TJCA lo extraemos de los numerales 4, 5 y 6 en Sentencia del TJCA de 20 de julio de 2005, Interpretación prejudicial, Marca: Envíos de dinero BBVA Bancomer más Gráfica a color, as. 89-IP-05.

310 
que tanto buscan los modelos latinoamericanos con la UE, y tercero la Corte andina pretende colaborar con la unidad del derecho de la integración, lo que se concreta al resolver de modo similar, conflictos similares, justificándose los jueces del TJCA en que a ambos lados del Atlántico se ampararían bajo el mismo tipo de derecho.

\subsection{LA TERCERA ETAPA:}

\section{EL DIÁLOGO JUDICIAL SE HACE MENOS} PERCEPTIBLE AL AGOTAR DETERMINADAS MATERIAS

Conforme la CAN va transitando hacia épocas más actuales el diálogo judicial se va haciendo menos perceptible y desaparece aquella insistente reiteración que acusábamos líneas atrás, circunstancia que supone un nuevo estadio de desarrollo. Aunque si bien, decaen sus referencias directas hacia las construcciones europeas, éstas no desaparecen del todo porque el TJCA comienza a efectuar reiteraciones consistentes en una referencia de tipo indirecta hacia el TJUE. Esta cuestión la hemos confirmado al estudiar sus sentencias más recientes que cumplen con nuestro criterio de selección ${ }^{107}$ de las mismas. El esquema de reiteración indirecto que analizaremos a continuación, guarda sintonía con el fenómeno del freno del diálogo judicial, que ya evidenciamos para la $\mathrm{CCJ}^{108}$.

Para el TJCA esta técnica de referencia indirecta es apreciable con facilidad en su sentencia del año 2018 dictada en el caso Caracol Televisión S.A. y RCN Televisión S.A. c/ República de Colombia ${ }^{109}$, donde el tribunal genera un complejo sistema de referencias indirectas mediante un encadenamiento interno hacia otras tres sentencias propias de la Corte andina $^{110}$. En aquella ocasión se interpusieron dos procesos por incumplimiento, uno por Caracol Televisión y otro por RCN Televisión —acumulados—, a los que además se les

107 Vid. apartado 4. El uso concreto de conexiones extra-orgánicas como criterio de selección de la jurisprudencia latinoamericana para el análisis del diálogo judicial empleado por la CCJ, el TJCA y el TPRM y TAAM.

${ }^{108}$ Como lo analizamos en la Sentencia de la CCJ de 25 de enero de 2018, en Consulta del Administrador del Mercado Mayorista, expediente 03-08-06-2017, la CCJ en esa oportunidad ya no expresó ningún detalle sobre los principios del derecho de la integración involucrados, y sólo se remitió de modo indirecto y muy acotado, a las sentencias previas. Recordemos que en el modelo SICA la CCJ toma el camino de la simple reiteración (como ya lo analizamos empleando los tres casos seleccionados de los años 2005, 2008 y 2018).

${ }^{109}$ Sentencia del TJCA de 19 de octubre de 2018, Acción de incumplimiento, Caracol Televisión S.A. y RCN Televisión S.A. / República de Colombia, as. acumulados 01 y 02-AI-16.

${ }^{110}$ Estas tres sentencias eran (1) Sentencia del TJCA de 24 de septiembre de 1998, Acción de incumplimiento, Secretaría General de la CA c/ la República del Ecuador, as. 02-AI-97, (2) Sentencia del TJCA de 12 de noviembre de 1999, Acción de incumplimiento, Secretaría General de la CA c/ la República del Perú, as. 07AI-99, y (3) Sentencia del TJCA de 24 de marzo de 1997, Acción de incumplimiento, Junta del Acuerdo de Cartagena c/ República de Venezuela, as. 03-AI-96. GOAC 261 de 29-4-97. 
unieron como terceros coadyuvantes Directv Colombia y UNE EPM Telecomunicaciones, todos, en contra de Colombia por desacato de obligaciones comunitarias, las cuales se verificarían porque la Autoridad Nacional de Televisión de Colombia (ANTC) había dictado determinadas normas de las que fluía, a juicio de los demandantes, un incumplimiento al Derecho de la CAN, pues se generaba un tratamiento diferente con los operadores de televisión (TV) abierta no colombianos, vulnerándose el principio de trato igualitario y equitativo, porque a los actores no se les permitía negociar plenamente las condiciones de retransmisión, también el principio de consolidación de statuo quo, al incumplir Colombia con su obligación de no hacer, y los principios de no discriminación, equivalencia y de trato igualitario, ya que Colombia desconocía sus obligaciones de hacer y no hacer, adoptando medidas en contra del Derecho de la $\mathrm{CAN}^{111}$.

El marco de estos litigios acumulados es en extremo extenso, pero a efectos de visualizar el fenómeno anotado - de simple referencia indirecta — destacamos que el TJCA al abordar la acción de incumplimiento explicó que tiene como finalidad el que un país, cuya conducta se considere contraria al ordenamiento jurídico andino, dé cumplimiento efectivo a sus obligaciones. En este punto el TJCA se conectó de modo indirecto con el TJUE, pues sólo hizo referencia a dos sentencias del mismo TJCA, recaídas en acciones de incumplimiento, una del año 1998, en la causa Secretaría General de la CA c/ la República del Ecuador ${ }^{12}$, y la otra del año 1999 en la causa Secretaría General de la CA c/ la República del Perú ${ }^{113}$. Lo singular es que esas dos sentencias el TJCA las había construido mediante un diálogo judicial de extensas referencias al TJUE ${ }^{114}$, pero la Corte andina no transparentó el origen

${ }^{111}$ Para los actores la Circular $N^{\circ} 45$ de 12 de junio de 2014, la Resolución $\mathrm{N}^{\circ} 2291$ de 22 de septiembre de 2014 y la Circular N 10 de 23 de abril de 2015 de la ANTC incumplían el art. 4 del Tratado de Creación del TJCA, vulneraban el principio de la nación más favorecida del art. 7, el principio de trato nacional del art. 8, y el principio de la consolidación del statuo quo del art. 10 todos de la Decisión 439. Planteaban que la ANTC habría hecho una errada interpretación, de la exégesis que previamente la Corte Constitucional de Colombia efectuó del art. 11 de la Ley nacional $\mathrm{N}^{\circ}$ 680. Estas normas locales, más los ejercicios hermenéuticos que los tribunales nacionales hacían de las mismas, les impedían a los actores, negociar el pago de una contraprestación económica por la retransmisión de su señal abierta con los operadores de televisión por suscripción, permitiendo así, que otros operadores de televisión abierta, no colombianos, sí pudiesen negociar sus retransmisiones. Generando las normas nacionales señaladas, un grado de discriminación contrario al Derecho de la CAN.

${ }^{112}$ Sentencia del TJCA de 24 de septiembre de 1998, Acción de incumplimiento, Secretaría General de la CA c/ la República del Ecuador, as. 02-AI-97.

${ }^{113}$ Sentencia del TJCA de 12 de noviembre de 1999, Acción de incumplimiento, Secretaría General de la CA c/ la República del Perú, as. 07-AI-99.

114 Así entonces en este fallo de 2018 (Sentencia del TJCA de 19 de octubre de 2018, Acción de incumplimiento, Caracol Televisión S.A. y RCN Televisión S.A. / República de Colombia, as. acumulados 01 y 02-AI-16) se refiere a 2 precedentes propios, $1^{\circ}$ ) uno de 1988 (Sentencia del TJCA de 24 de septiembre de 1998, Acción de incumplimiento, Secretaría General de la CA c/ la República del Ecuador, as. 02-AI-97), en el cual se producía un diálogo judicial directo, del tipo monólogo con tres sentencias europeas (Sentencia del 312 
europeo en la sentencia aquí analizada (Caracol Tv. y otros c/ Rep. de Colombia, 2018), en la cual solo se enviaba — aparentemente — a dos precedentes propios de la Corte andina.

Ahora bien, el que nosotros destaquemos el hecho de que la Corte andina no mencione del todo el origen de los criterios, no significa en caso alguno que esto sea una incorrección. Únicamente estamos reflotando la «técnica procesal de encadenamientos internos en formato de muñecas rusas», para dar cuenta del fenómeno de conexión extra-orgánico bajo análisis —el diálogo judicial—, que es el horizonte de este capítulo. Todo según veremos a continuación, pero separando las dos conexiones a efectos de una mejor comprensión para el lector.

\subsubsection{EL PRIMER PRECEDENTE CITADO COMO PROPIO} SIN REVELAR LA FUENTE EUROPEA

En la sentencia principal bajo análisis -Caracol Televisión S.A. y RCN Televisión S.A. c/ República de Colombia ${ }^{115}$ (ac. 01 y 02-AI-16) - el primer precedente citado como propio por el TJCA sin revelar la fuente europea, fue su sentencia dictada en el caso Secretaría General de la CA c/ la República del Ecuador ${ }^{116}$ (02-AI-97) el cual sólo lo menciona de la siguiente forma:

«con la sentencia recaída en el Proceso 02-AI-97, el TJCA ha destacado la importancia de la acción de incumplimiento como pieza clave en la construcción, desarrollo y vigencia del orden jurídico comunitario andino, en los siguientes términos:

"El recurso de incumplimiento es una pieza clave en la construcción, desarrollo y vigencia del orden jurídico comunitario y mediante el cual se

TJ de 14 de junio de 1988, Dansk Denkavit, as. C-29/87, ECLI:EU:C:1988:299, Sentencia del TJ de 5 de junio de 1997, Comisión/Francia, as. C-223/96, ECLI:EU:C:1997:287, y Sentencia del TJ de 29 de mayo de 1997, Comisión/Francia, as. C-282/96, ECLI:EU:C:1997:271), refiriéndose también a las conclusiones del abogado general (en este último caso Conclusiones del Abogado General Sr. Dámaso Ruiz-Jarvo Colomer de 27 de febrero de 1997, ECLI:EU:C:1997:100) más un sin número de citas a doctrina europea, y $2^{\circ}$ ) el otro fallo, ahora de 1999 (Sentencia del TJCA de 12 de noviembre de 1999, Acción de incumplimiento, Secretaría General de la CA c/ la República del Perú, as. 07-AI-99) el cual también fue construido en base al diálogo judicial conectándose con la Sentencia del TJ de 5 de febrero de 1963, Van Gend \& Loos, as. C-26/62, ECLI:EU:C:1963:1 y con la Sentencia del TJ de 9 de marzo de 1978, Simmenthal, as. C-106/77, ECLI:EU:C:1978:49.

${ }^{115}$ Sentencia del TJCA de 19 de octubre de 2018, Acción de incumplimiento, Caracol Televisión S.A. y RCN Televisión S.A. / República de Colombia, as. acumulados 01 y 02-AI-16.

${ }^{116}$ En estas sub-secciones, indicaremos — arriba en el texto- de qué sentencia se trata en cada situación, usando los códigos del TJCA, ya sea «02-AI-97», o en su caso «07-AI-99», a efectos de facilitar la lectura y la comprensión del complejo encadenamiento interno de las sentencias. 
ejerce el control del comportamiento de los Estados. El sistema andino de integración presupone la existencia de un orden de derecho, un ordenamiento normativo comunitario frente al cual los Países Miembros [...] tienen dos órdenes de obligaciones: las de hacer [...] y las de no hacer» ${ }^{117}$.

Pero tras aplicar nuestro criterio de selección ${ }^{118}$ de la jurisprudencia que estamos analizando, pudimos constatar que el TJCA omitió señalar que la anterior sentencia, a la que hace referencia [02-AI-97, Secrt. Grl. de la CA c/ la Rep. del Ecuador, 1998] había sido construida gracias a un diálogo judicial, que en aquella época le permitió extraer y absorber una amplia diversidad de contenidos jurisprudenciales desde el TJUE al conectarse con tres sentencias europeas, Dansk Denkavit ApS y Ministerio danés de Agricultura $^{119}$ de 1987, Comisión de las CE c/ la Rep. Francesa (1) ${ }^{120}$ de 1996, y con Comisión de las CE c/ Rep. Francesa (2) ${ }^{121}$ también de 1996, además de utilizar en el último caso las Conclusiones del Abogado General ${ }^{122}$, sumando diversas referencias hacia la doctrina europea. Aunque en el fondo esto refleja una mayor madurez de la Corte andina, al no seguir reiterando innecesariamente los desarrollos europeos, intentando así, mostrarse en un nuevo estadio de desarrollo. En concreto en esta causa (02-AI-97) se solicitaba el pronunciamiento del TJCA respecto de la aplicación unilateral del gobierno del Ecuador de medidas de retorsión a los licores de Colombia, en contravención expresa de normativa $\mathrm{CAN}^{123}$.

En lo pertinente el TJCA expresó en esa oportunidad que «elaborado un Acuerdo, los países suscriptores no pueden apartarse de las reglas comunes, sin destruir la esencia misma del sistema de derecho». Agregó que las medidas de retorsión sólo pueden aplicarse entre países no sujetos a un ordenamiento común, libremente aceptado, como era el caso de las partes que pertenecían a la CAN, por lo tanto debían recurrir al TJCA. Concluyó que los actos del Ecuador eran una restricción al comercio, coincidiendo con la Resolución $\mathrm{N}^{\circ} 454$ de la Junta Monetaria, y que el infractor, en cumplimiento de dicha Resolución — norma

${ }^{117}$ Párrafo 3.1.2.2, del apartado Finalidad de la acción de incumplimiento, en Sentencia del TJCA de 19 de octubre de 2018, Acción de incumplimiento, Caracol Televisión S.A. y RCN Televisión S.A. / República de Colombia, as. acumulados 01 y 02-AI-16.

${ }^{118}$ Vid. en este capítulo IV, el apartado 4. El uso concreto de conexiones extra-orgánicas como criterio de selección de la jurisprudencia latinoamericana para el análisis del diálogo judicial empleado por la CCJ, el TJCA y el TPRM y TAAM.

${ }^{119}$ Sentencia del TJ de 14 de junio de 1988, Dansk Denkavit, as. C-29/87, ECLI:EU:C:1988:299.

${ }^{120}$ Sentencia del TJ de 5 de junio de 1997, Comisión/Francia, as. C-223/96, ECLI:EU:C:1997:287.

${ }^{121}$ Sentencia del TJ de 29 de mayo de 1997, Comisión/Francia, as. C-282/96, ECLI:EU:C:1997:271.

${ }^{122}$ Conclusiones del Abogado General Sr. Dámaso Ruiz-Jarvo Colomer de 27 de febrero de 1997, ECLI:EU:C:1997:100.

${ }^{123}$ Se alegaba el incumplimiento de los arts. 47, 71, 75 y 155 del AC, los arts. 5 y 33 del Tratado de Creación del TJCA, y la Resolución 454 de la Junta de 23-1-1997.

314 
preeminente - debió adaptar su conducta al ordenamiento CAN y a sus objetivos. En este punto fue que para subrayar tal preeminencia, la Corte andina recurre a la herramienta del diálogo judicial en su dimensión monólogo y extractivo, de la siguiente forma:

«En el Derecho Comunitario Europeo, una medida de autorización previa para importaciones, también ha sido considerada como una restricción. Así la Corte Europea ha dicho: "El art. 30 del Tratado debe interpretarse en el sentido de que una medida nacional que sujete a autorización previa la importación de alimentos para animales que contienen aditivos constituye una medida de efecto equivalente a las restricciones cuantitativas a la importación, en el sentido del art. 30 del Tratado". (Recopilación de la Jurisprudencia del Tribunal, 1988-6 p. 2993, as. 29/87, caso: Dansk Denkavit ApS y Ministerio danés de Agricultura)» ${ }^{124}$.

Acto seguido, vuelve a emplear el mismo tipo de diálogo, concluyendo que no hay una demostración de que las medidas restrictivas contenidas en las regulaciones de la Junta Monetaria hayan sido derogadas internamente, luego de que la Junta emitiera el Dictamen de incumplimiento 02-97 de 23-1-1997 en el que calificó a la medida aplicada por la Junta Monetaria de Ecuador como una «restricción al comercio», señalando el TJCA:

«De ello debía producirse una conducta del País acusado suficiente para cesar dicho incumplimiento. Pero su omisión, ha traído la misma consecuencia que se cita en la siguiente Jurisprudencia europea:

[...], la Comisión precisó el marco jurídico y los hechos que la llevaron al convencimiento de que la República Francesa había incumplido las obligaciones que le incumben en virtud de la Directiva 91/156, a saber, la adaptación completa del derecho interno a la Directiva y la comunicación de las disposiciones de adaptación. [...], no tiene ninguna relevancia el hecho de que, para demostrar el incumplimiento, la Comisión se haya referido a un escrito de las autoridades francesas en el cual éstas reconocían que la adaptación del derecho interno a la Directiva [...] había resultado insuficiente. (Recop. Jurisp. Tribunal de Justicia de las Comunidades Europeas, 1997-6 p. 3210, as. C-223/96, Comisión de las Comunidades Europeas c/ la Rep. Francesa)" ${ }^{125}$.

\footnotetext{
${ }^{124}$ Párrafos 7 y 8 del apartado Preeminencia de la norma comunitaria, en Sentencia del TJCA de 24 de septiembre de 1998, Acción de incumplimiento, Secretaría General de la CA c/ la República del Ecuador, as. 02-AI-97, y se está refiriendo a la Sentencia del TJ de 14 de junio de 1988, Dansk Denkavit, as. C-29/87, ECLI:EU:C:1988:299.

${ }^{125}$ Párrafos 23 y 24 del apartado titulado Preeminencia de la norma comunitaria, en Sentencia del TJCA de 24 de septiembre de 1998, Acción de incumplimiento, Secretaría General de la CA c/ la República del Ecuador, as. 02-AI-97, y se está refiriendo a la Sentencia del TJ de 5 de junio de 1997, Comisión/Francia, as. C223/96, ECLI:EU:C:1997:287.
} 
Al abordar la noción del incumplimiento flagrante, el TJCA encontró coincidencia en ambos modelos (CAN y UE) precisando que la aceptación de un País miembro de su incumplimiento, o la deducción clara de una actitud de tal incumplimiento «ha conducido a que este Tribunal, el Europeo y la propia Secretaría General, traten de lo que es el "incumplimiento flagrante"». Pasando a conectarse con la sentencia del TJUE en Comisión de las CE c/ Rep. Francesa ${ }^{126}$ y además con las Conclusiones del Abogado General ${ }^{127}$, absorbiendo prácticamente todo el desarrollo europeo, del siguiente modo:

«Remitiéndose a la Jurisprudencia europea, cabe anotar:

“...Por tanto, los recursos interpuestos [...] deben considerarse fundados, al haber quedado demostrado, sin discusión alguna, que la República Francesa no ha adoptado en el plazo establecido las disposiciones legales, reglamentarias y administrativas necesarias para conformarse a la Directiva 91/157 y a la Directiva 93/86". (Recop. Jurisp. del Tribunal de Justicia de las Comunidades Europeas, 1997-5 p. 2932, as. acum. C-282/96 y C-283/96, Comisión de las Comunidades Europeas c/ República Francesa Conclusiones del abogado general Sr. Damaso Ruíz-Jarabo Colomer).

En el fallo referido el Tribunal Europeo se pronunció sobre lo que puede calificarse de "incumplimiento no discutido". Al efecto [...] dijo:

"10.- [...] el Gobierno francés informó a la Comisión de que había desistido de la redacción del proyecto de Decreto cuya finalidad era adaptar el derecho interno a la Directiva 93/86 [...]. De dicho escrito se deducía asímismo, que el citado proyecto de Decreto se encontraba pendiente de firma".

“12.- En su contestación, el Gobierno francés no niega el hecho de no haber adaptado su Derecho interno a las Directivas de que se trata dentro de los plazos señalados para ello. [...]".

"13.- Dado que la adaptación del Derecho interno a las Directivas [...] no se ha llevado a cabo dentro de los plazos [...], deben considerarse fundados los recursos $[\ldots]$ ".

"14.- Procede, pues, declarar que la República Francesa ha incumplido las obligaciones que le incumben [...]".

El "incumplimiento no discutido", puede asimilarse con el mismo alcance, a lo que el Reglamento de Procedimientos Administrativos de la Secretaría General de la Comunidad Andina, (Decisión 425, publicada en la G.O. № 314 de 18-12-1997) define como el incumplimiento "flagrante"»" 128.

\footnotetext{
${ }^{126}$ Sentencia del TJ de 29 de mayo de 1997, Comisión/Francia, as. C-282/96, ECLI:EU:C:1997:271.

127 Conclusiones del Abogado General Sr. Dámaso Ruiz-Jarvo Colomer de 27 de febrero de 1997, ECLI:EU:C:1997:100.

${ }^{128}$ Párrafos 28, 29, 30 (números internos: 10, 12, 13 y 14) y 31 del apartado Preeminencia de la norma comunitaria, en Sentencia del TJCA de 24 de septiembre de 1998. Acción de incumplimiento, Secretaría General de la CA c/ la República del Ecuador, as. 02-AI-97, en la cual se hace referencia a la sentencia en los 316
} 


\subsubsection{EL SEGUNDO PRECEDENTE CITADO COMO PROPIO}

SIN REVELAR LA FUENTE EUROPEA

A continuación de lo recién expuesto por TJCA —último párrafo del apartado anterioréste continúa en la sentencia bajo análisis —Caracol Televisión S.A. y RCN Televisión S.A. c/ República de Colombia ${ }^{129}$ (ac. 01 y 02-AI-16) - pasando a citar ahora otra sentencia propia, la del caso Secretaría General de la CA c/ la República del Perú130 (07-AI-99) y nuevamente sin revelar que el contenido sustantivo lo había extraído de la Corte de Luxemburgo. Su mención es sencillamente superficial y sin referencia alguna a la UE, indicándose de la siguiente manera:

«En la misma línea, en la Sentencia emitida en el Proceso 07-AI-99 se recalcó que al TJCA le corresponde garantizar que los países miembros cumplan las normas que integran el ordenamiento jurídico comunitario andino, respeten su intangibilidad y se abstengan de adoptar medidas que lo contraríen. Textualmente se dispuso lo siguiente:

"Requisito fundamental para la existencia y logro de las finalidades del proceso de integración [...] es el control de la legalidad del sistema, cuya salvaguardia ha sido encomendada a este Tribunal [...] como órgano jurisdiccional exclusivo con capacidad de declarar el derecho comunitario, dirimir controversias $[\ldots]$, e interpretarlo uniformemente. [...] le corresponde $[\ldots]$ velar por la recta aplicación del ordenamiento jurídico comunitario $[\ldots]$ y $[\ldots]$ garantizar que los Países Miembros cumplan [...].

Esta acción [...] constituye el instrumento por excelencia, mediante el cual el Tribunal está llamado a vigilar el cumplimiento de las obligaciones adquiridas por los Países Miembros» ${ }^{131}$.

En dicho precedente propio que el TJCA citaba, no se aprecia en lo absoluto una influencia directa del modelo europeo ${ }^{132}$, sin embargo, tras nuestra búsqueda en el proceso de

acumulados C-282/96 y C-283/96 resueltos en la Sentencia del TJ de 29 de mayo de 1997, Comisión/Francia, as. C-282/96, ECLI:EU:C:1997:271, y a las Conclusiones del Abogado General Sr. Dámaso Ruiz-Jarvo Colomer de 27 de febrero de 1997, ECLI:EU:C:1997:100.

${ }^{129}$ Sentencia del TJCA de 19 de octubre de 2018, Acción de incumplimiento, Caracol Televisión S.A. y RCN Televisión S.A. / República de Colombia, as. acumulados 01 y 02-AI-16.

${ }^{130}$ Sentencia del TJCA de 12 de noviembre de 1999, Acción de incumplimiento, Secretaría General de la CA c/la República del Perú, as. 07-AI-99.

${ }^{131}$ Párrafo 3.1.2.3, del apartado Finalidad de la acción de incumplimiento, en Sentencia del TJCA de 19 de octubre de 2018, Acción de incumplimiento, Caracol Televisión S.A. y RCN Televisión S.A. / República de Colombia, as. acumulados 01 y 02-AI-16.

${ }^{132}$ Así lo verificamos del texto completo del párrafo 3.1.2.3 de la sentencia ibídem, a pesar de los cortes «[...]» que introdujimos por economía y facilidad para el lector. 
selección aplicado ${ }^{133}$, advertimos que al igual que en el caso visto en el apartado anterior (02-AI-97), éste segundo fallo (07-AI-99) también había sido construido utilizando la técnica del diálogo judicial extractivo y monólogo, en dicha causa la sentencia había recaído en una acción de incumplimiento interpuesta por la Secretaría General de la CA contra la República del Perú, y por lo que se refiere a los hechos, éstos daban cuenta de que en la CAN se había dictado la Decisión 344 relativa al régimen común sobre propiedad industrial — reemplazando a la Decisión 313. Ante esta circunstancia Perú dictó el Decreto Supremo 010-97-ITINCI en el cual, a su juicio, sólo habría precisado algunos términos que garantizarían la correcta aplicación de los derechos consagrados en la norma CAN, sin agregar nuevas exigencias, ni requisitos. Pero la Secretaría General de la CA mediante su Dictamen de Incumplimiento $\mathrm{N}^{\circ}$ 06-98 concluyó que algunas disposiciones del referido Decreto peruano contravenían normativa CAN, configurándose un incumplimiento del Perú, lo que motivó la acción de incumplimiento ante la Corte andina ${ }^{134}$.

Pero en lo que nos compete, el TJCA al centrarse en la aplicabilidad directa y preeminencia del Derecho de la CAN, recurrió una vez más al acervo del TJUE mediante el diálogo judicial extractivo usando las sentencias Van Gend \& Loos y Simmenthal. Aunque con la particularidad de que en esta ocasión observamos una técnica de transición, antecesora del desaparecimiento total de las referencias hacia las fuentes foráneas.

Pues en esta oportunidad, si bien vuelve a referirse a un precedente propio, en el interior de dicha sentencia (07-AI-99), tampoco se desvelaba la fuente europea, sino que en un juego de muñecas rusas, reenvía ahora a la causa Junta del Acuerdo de Cartagena c/ República de

133 Vid. en este capítulo el apartado 4. El uso concreto de conexiones extra-orgánicas como criterio de selección de la jurisprudencia latinoamericana para el análisis del diálogo judicial empleado por la CCJ, el TJCA y el TPRM y TAAM.

${ }^{134}$ Puntualmente la Secretaría Gral. de la CAN le imputaba al Perú que su Decreto Supremo No 019-97ITINCI contravenía el art. 5 del Tratado de Creación del TJCA, los arts. 38 y 42 de la Decisión 344 de la Comisión y las Resoluciones 079 y 106 de la Secretaría General. Pero para Perú sus normas solo tenían por fin asegurar la explotación en determinados casos del producto patentado. Agregaba que la Decisión 344 dota al concepto importación de un contenido amplio, en línea con los convenios internacionales y con la legislación interna peruana «al definirlo como el ingreso legal al territorio nacional de mercancías extranjeras para su consumo en el país». Definición compatible con el art. 38, pues es congruente con el criterio de que lo más importante es el consumo del producto patentado cuando se está frente a un requisito de explotación de la patente. En cambio para la Secretaría General de la CA se incumplía el referido art. 38 cuando se suprime o restringe elementos intrínsecos en la definición legal de «explotación» de la patente: distribución y comercialización, los que, junto con la importación, son indispensables para determinar la satisfacción de la demanda del producto, y que el art. 38 era claro, y no admite interpretación para «aclarar» su alcance. Máxime, que la interpretación dentro de la CAN corresponde exclusivamente al TJCA, no a un País Miembro.

318 
Venezuela $^{135}$ (03-AI-96), donde finalmente sí aparece la conexión que buscábamos, justamente a través de un diálogo judicial extractivo y monólogo, pues se conectó con dos sentencias de la Corte de Luxemburgo, las ultra-referidas Van Gend \& Loos y Simmenthal.

Entonces en tal orden de encadenamientos, en este segundo fallo (07-AI-99) el TJCA vuelve a dirigirse hacia otro precedente propio (03-AI-96) en el cual sí se explica que el contenido de esa sentencia, había sido construido siguiendo los lineamientos europeos, lo cual expone de la siguiente forma:

«El Tribunal, con apego a los más autorizados criterios doctrinarios ha destacado la importancia de estas características hasta el punto de considerar que la existencia misma del derecho comunitario andino depende de la presencia de tales atributos. Así se expresó en relación con el tema en una de sus sentencias:

"En el área europea el principio de la aplicabilidad directa es reconocido a partir de la sentencia Van Gend \& Loos, 1963, del Tribunal de Justicia de las Comunidades Europeas, y precisado en la sentencia Simmenthal, 1978, en la que se sostuvo que la aplicabilidad directa “... significa que las reglas del derecho comunitario deben desplegar la plenitud de sus efectos de manera uniforme en todos los Estados miembros, a partir de su entrada en vigor y durante toda la duración de su validez; que de esta manera, estas disposiciones son una fuente inmediata de derechos y obligaciones para todos aquellos a quienes afectan, ya se trate de Estados miembros o de particulares que son parte en relaciones jurídicas que entran en el ámbito del derecho comunitario..." [nota 4$]$

[nota 4] TRIBUNAL DE JUSTICIA DE LA COMUNIDAD ANDINA. Sentencia del 24-III-97. Proceso 03-AI-96. En G.O.A.C. No. 261 de 29-IV$97 \gg^{136}$.

Además de esta incorporación de la referida jurisprudencia europea, también es relevante destacar que el TJCA recurrió a una multiplicidad de doctrina europea. Lo que por cierto no colaciona en el compartimento de diálogo judicial, sino en el espectro más general del recurso a la doctrina, pero en el fondo es otro cauce más de cercanía que busca la Corte andina para aproximarse al modelo europeo. En este caso concreto el enfoque del TJCA es hacia los autores que analizan al modelo europeo, indicando al respecto:

«"El profesor Gil Carlos Rodríguez Iglesias, Presidente del Tribunal de las Comunidades Europeas, define la aplicabilidad directa de la norma comunitaria “como la capacidad de la misma para producir efectos jurídicos en un País Miembro

\footnotetext{
${ }^{135}$ Sentencia del TJCA de 24 de marzo de 1997, Acción de incumplimiento, Junta del Acuerdo de Cartagena c/ República de Venezuela, as. 03-AI-96. GOAC 261 de 29-4-97.

${ }^{136}$ Párrafo $6^{\circ}$ del apartado IV Aplicabilidad directa y preeminencia del ordenamiento jurídico comunitario, en sentencia ibídem.
} 
sin que se requiera ningún complemento normativo de derecho interno". "Para el derecho europeo, dice, Muñoz Machado, una regla o norma "goza de aplicabilidad directa cuando no precise que los Estados Miembros dicten normas de incorporación, transposición o desarrollo para darle efectividad dentro de su territorio". "El profesor Dámaso Ruiz-Jarabo Colomer, define el principio manifestando que "La aplicabilidad inmediata significa que la norma comunitaria adquiere, automáticamente, de por sí, estatuto de derecho positivo en el orden interno [...], sin necesidad de ninguna fórmula de introducción» ${ }^{137}$.

Volviendo a la sentencia 07-AI-99 apreciamos que aborda otro aspecto de alta relevancia - y que ya hemos subrayado-, cual es, el beneficio de que gozaron los modelos integracionistas latinoamericanos por el hecho de ir a la zaga del europeo, ya que pudieron incorporar «estatutariamente» algunas problemáticas que debió enfrentar el sistema europeo mediante la articulación «jurisprudencial» en sus primeras décadas. Cuestión propia de los ajustes de la empresa europea que carecía de precedentes en los que apoyarse. Circunstancia completamente diferente a América Latina, donde, casi únicamente se han basado en experiencia foránea, positivizando las principales creaciones pretorianas del TJUE, en los Estatutos y demás normas de los modelos SICA, CAN y MERCOSUR. Justamente esta diferenciación en el «modo de incorporación» a los sistemas en cotejo, de algunas matrices centrales del derecho de la integración, es la que se destaca a través del engarce de los siguientes dos párrafos consecutivos que se presentan en esta sentencia (07AI-99), en los cuales es muy claro el TJCA al comparar entre sentencias $v / s$ normas positivas:

«En el área europea el principio de la aplicabilidad directa es reconocido a partir de la 'sentencia' Van Gend \& Loos [...] del Tribunal de Justicia de las Comunidades Europeas, y precisado en la 'sentencia' Simmenthal, [...].

Pues bien, en la Comunidad Andina de Naciones la aplicabilidad directa del derecho comunitario deriva de las propias 'normas positivas' de carácter constitutivo $u$ originario» $^{138}$.

Concepto que también es realzado en el MERCOSUR mediante el Laudo 1/2006 del TPRM, el cual — sólo en lo pertinente a este punto — destaca lo 'provechoso' de la labor institucional realizada por la jurisdicción europea, de la siguiente manera:

«A mayor abundamiento, la experiencia histórica del derecho de integración y del derecho comunitario, nos demuestra que inclusive la mayor parte de las

\footnotetext{
${ }^{137}$ Párrafo $2^{\circ}$ en apartado y sentencia ibídem.

${ }^{138}$ Párrafos 8 y 9 del apartado 2.3.2. Aplicabilidad directa y preeminencia del ordenamiento jurídico comunitario, en Sentencia del TJCA de 12 de noviembre de 1999, Acción de incumplimiento, Secretaría General de la CA c/ la República del Perú, as. 07-AI-99.
}

320 
características fundamentales de tal derecho fueron originariamente elaboraciones 'jurisprudenciales' en razón de la 'proficua' labor institucional realizada por los tribunales en cuestión cumpliendo su responsabilidad histórica e institucional dentro de un proceso de integración» ${ }^{139}$.

En conclusión, conforme lo analizado hasta aquí, y si ponemos atención a la forma en que culminan las incorporaciones de las soluciones europeas en los modelos SICA y CAN, queda en evidencia que el decaimiento del diálogo judicial empleado por sus respectivas Cortes, en las diversas materias que han abordado, es del todo natural, pues no se puede pretender un diálogo judicial permanente para una misma temática.

El modelo de incorporación mediante el cual las Cortes latinoamericanas se conectan con una solución europea, consiste en que en una determinada materia primero la realzan y la explican minuciosamente, para luego ingresar en una reiteración jurisprudencial que va en una singular cadencia, hasta que la incorporan al acervo propio. Este es precisamente el patrón que se repite en la CCJ y en el TJCA, siendo esta última etapa del debilitamiento del proceso de importación, la que corresponde a la época actual, la cual hemos analizado con las secuencias conformadas por las sentencias del año 2018, tanto para la CCJ en el SICA, como para el TJCA en la CAN. Aspecto que ahora analizaremos en el modelo del MERCOSUR respecto de sus TAAM y TPRM.

${ }^{139}$ Considerando XXIX del Laudo del TPRM de 13 de enero de 2006, Recurso de aclaratoria, as. 1/2006. Fallo pronunciado desestimando el recurso de aclaración presentado por Argentina en contra del Laudo del TPRM de 20 de diciembre de 2005, República Oriental del Uruguay c. República de Argentina, as. 1/2005. Este Considerando XXIX se hace cargo puntualmente del numeral 27 de la presentación del recurrente, desestimándolo del todo. 


\section{EL DIÁLOGO JUDICIAL EMPLEADO POR LOS TAAM Y POR EL TPRM PARA FORTALECER EL MERCOSUR}

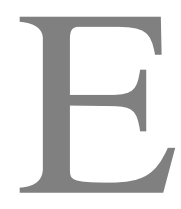

n contraposición a los anteriores dos modelos latinoamericanos recién analizados - SICA y CAN-, los tribunales del MERCOSUR, si bien han ido utilizado el diálogo judicial, esto ha ocurrido en menor medida, circunstancia que de acuerdo a nuestra investigación tendría sus causas en dos tipos de razones, una de índole estadística y otra de naturaleza sustantiva, las que en su conglomerado generan tal escasez.

Sobre la visión estadística, constatamos que el conjunto total de laudos dictados por los tribunales del merco-sistema es extremadamente escaso, sólo veintiséis publicados hasta la fecha, además el TPRM es relativamente reciente, su institucionalización aparece en el año 2002 como resultado del Protocolo de Olivos, inaugura su primera sede en 2004 en Asunción, en 2005 dicta su primer laudo y desde esa fecha hasta hoy en día, sólo ha dictado seis laudos y tres opiniones consultivas. Por otra parte, los TAAM sólo han publicado doce laudos y cinco aclaraciones ${ }^{140}$. Como se aprecia el total de posibles laudos a analizar es abordable en su totalidad, motivo por el cual los analizamos todos, y el resultado fue que sólo en ocho casos se contiene algún tipo de conexión de los tribunales del merco-sistema con jurisdicciones foráneas. De las cuales, realmente cinco aparejan un nivel de diálogo judicial monólogo en que las Cortes mercosureñas se conectan con una determinada

\footnotetext{
${ }^{140}$ La visión estadística sobre el ejercicio de los Tribunales del Mercosur refleja la escasa producción de estos órganos arbitrales. Si desagregamos los 26 pronunciamientos, observaremos (i) al TPMR únicamente con 6 laudos y 3 respuestas sobre opiniones consultivas, y (ii) a los TAAM con 12 laudos y 5 aclaraciones. Los que en detalle van en el siguiente orden cronológico: Los 6 laudos del TPRM son identificados como: 1/2005 (de 20-12-2005), 1/2006 (de 13-1-2006, Aclaración del 1/2005), 2/2006 (de 6-7-2006), 1/2007 (de 8-6-2007), 1/2008 (de 25-4-2008) y 1/2012 (de 21-6-2012). Las 3 opiniones consultivas son: 1/2007 (de 3-4-2007), 1/2008 (de 24-4-2009) y 1/2009 (de 15-6-2009). En tanto los 12 laudos y las 5 aclaraciones de los TAAM son: Laudo 1 (de 28-4-1999), Laudo 2 (de 27-9-1999) más Aclaración (de 27-10-1999), Laudo 3 (de 10-32000) más Aclaración (de 7-4-2000), Laudo 4 (de 21-5-2001) más Aclaración (de 18-6-2001), Laudo 5 (de 29-9-2001) más Aclaración (del laudo 5, publicación sin fecha), Laudo 6 (de 9-1-2002), Laudo 7 (de 19-42002), Laudo 8 (de 21-5-2002) más Aclaración (de 19-6-2002), Laudo 9 (de 4-4-2003), Laudo 10 (de 5-82005). Estos 10 primeros laudos fueron dictados conforme al Protocolo de Brasilia del año 1991, a los cuales se les suman otros 2 laudos más, que quedan comprendidos dentro de la nueva etapa, posterior al Protocolo de Olivos del año 2002 en vigor desde el año 2004, identificados estos dos como: Laudo de 25-10-2005 y Laudo de 6-9-2006. Fuente: Portal Oficial del Tribunal Permanente de Revisión del Mercosur <http://www.tprmercosur.org/es/sol_contr_laudos.htm> [última consulta, noviembre 23, 2018].
}

322 
sentencia de algún tribunal de integración ${ }^{141}$. Las tres restantes giran en sentido contrario a la esencia del diálogo judicial, las cuales serán objeto de análisis más adelante.

A lo anterior se añade el ángulo sustantivo, por el cual la carencia anotada se explica en que este proyecto del Cono Sur de América presenta aspectos tan singulares que lo excluyen un tanto de los sistemas integracionistas de su entorno - SICA y CAN. Aspectos devenidos de aquellos perfiles que ya hemos recalcado, como su origen intergubernamental y la naturaleza arbitral de sus tribunales, y que tal como vimos, constantemente esta cuestión es puesta de relieve por la doctrina ${ }^{142}$, pero además, en un plano realmente singular, los propios tribunales mercosureños en algunas ocasiones se han autoexiliado del modelo europeo, y con esta postura, de los otros dos latinoamericanos. Este autoexilio jurídico, que obstaculizaba que los Tribunales del Mercosur incorporaran criterios centrales del modelo europeo, lo desarrollaron tres TAAM usando una particular conexión con soluciones foráneas para desconectarse de éstas ${ }^{143}$. Conexión que no podríamos tildar de diálogo judicial si es que atendemos a que dicha técnica de comunicación extra-orgánica tiene como finalidad la importación de soluciones exógenas al sistema de la Corte que lo usa y teóricamente la noción de diálogo judicial toleraría sólo hasta el nivel del denominado diálogo monólogo o extractivo, como el extremo más débil del concepto.

${ }^{141}$ En la línea estadística que estamos destacando - luego lo veremos con más detalle- observamos que de todos los pronunciamientos dictados por ambos tipos de Cortes mercosureñas (26 sentencias, vid. nota anterior), las únicas 5 en que verificamos presencia de algún tipo de diálogo judicial, tanto con el modelo europeo como con alguno inter-americano, son: $1^{\circ}$. Laudo del TAAM (número 9) de 4 de abril de 2003 , República de Argentina c. República Oriental del Uruguay, $2^{\circ}$. Laudo del TPRM de 20 de diciembre de 2005 , República Oriental del Uruguay c. República de Argentina, as. 1/2005, 3. Laudo del TPRM de 13 de enero de 2006, Recurso de aclaratoria, as. 1/2006, $4^{\circ}$. Laudo del TPRM de 3 de abril de 2007, Opinión consultiva, Norte S.A. Imp. Exp. c/ Laboratorio Northia Soc. Anónima (...) s/indemnización de daños y perjuicios y lucro cesante, as. OC. 1-2007, y 5. Laudo del TPRM de 8 de junio de 2007, República Oriental del Uruguay c. República de Argentina, as. 1/2007.

${ }^{142}$ El carácter intergubernamental del Mercosur lo hemos abordado en los capítulos I y II en diferentes aspectos, y también hemos acotado que el Protocolo de Olivos vino en confirmar tal naturaleza. Vid. et al. ARBUET-VIGNALI, 1999. AMIN FERRAZ \& PICART GARCÍA, 2005. PÉREZ GONZÁLEZ, 2010. CIENFUEGOS MATEO, 2012b.

${ }^{143}$ Las singulares conexiones que efectuaron tres TAAM con jurisdicciones foráneas al merco-sistema para 'rechazar' importaciones desde el modelo europeo, o bien para resolver temáticas no particulares del Derecho de la Integración, fueron: (a) Laudo del TAAM Aclaratorio recaído en el recurso de aclaración deducido contra el Laudo del TAAM (número 5) de 29 de septiembre de 2001, República Oriental del Uruguay c. República de Argentina, (b) Laudo del TAAM (número 10) de 5 de agosto de 2005, República Oriental del Uruguay c. República Federativa del Brasil, y (c) Laudo del TAAM de 6 de septiembre de 2006, República Oriental del Uruguay c. República de Argentina. (Constituido para conocer sobre «Omisión del Estado Argentino en adoptar medidas apropiadas para prevenir y/o hacer cesar los impedimentos a la libre circulación derivados de los cortes en territorio argentino de vías de acceso a los puentes internacionales General San Martín y General Artigas que unen la República Argentina con la República del Uruguay»). 
Para estudiar el conjunto de los ocho laudos en que tanto los TAAM como los TPMR se conectan en alguna medida con jurisprudencias exógenas, hemos aplicado un criterio de análisis ascendente en cuanto a la trascendencia de dicha conexión. Arrojándonos como resultado tres etapas de desarrollo, la primera, es la que da cuenta de la época en que la conexión de los TAAM tuvo el propósito de autoexiliarse del derecho de la integración, la segunda etapa, fue la oportunidad en que se produjo la primera aproximación al diálogo judicial efectuada por un TAAM, en una baja intensidad, y la tercera etapa, corresponde al estadio en que algunos TPMR efectúan la mayor utilización del diálogo judicial para vincularse con los desarrollos europeos compatibles con el MERCOSUR.

\subsection{La Primera Etapa:}

LA SINGULAR CONEXIÓN DE ALGUNOS TAAM CON JURISDICCIONES AJENAS AL MERCOSUR PARA DISOCIARSE DEL MODELO EUROPEO

Esta primera etapa se desarrolla entre los años 2001 a 2006 y muestra por una parte, dos conexiones con la Corte de Luxemburgo para rechazar posibles importaciones de sus precedentes, y por otra parte, se produce una conexión con jurisprudencia de la Corte Internacional de Justicia de Naciones Unidas (CIJ) en una materia procesal no referida al derecho de la integración. Estas tres particulares situaciones poseen una importancia específica en el futuro surgimiento del diálogo judicial en el MERCOSUR tal como lo veremos a continuación.

\subsubsection{LA PRIMERA CONEXIÓN DE LA PRIMERA ETAPA:} UN TAAM SE CONECTA CON EL TJUE PARA DISTANCIARSE DE LA UE

La jurisprudencia que da inicio a esta primera etapa fue laudo aclaratorio del TAAM publicado sin fecha ${ }^{144}$, recaído en el recurso de aclaración contra el Laudo 5 (de 29-9-2001) el cual generó a nuestro juicio un hecho de relevancia histórica, pues por primera vez se materializaba una conexión desde una Corte mercosureña con una solución jurisdiccional

\footnotetext{
${ }^{144}$ Este laudo aclaratorio no fue publicado con fecha. No se indica ni en el sitio oficial del TPRM, ni en el texto publicado del mismo laudo. Por tal razón, para una correcta cronología, hemos seguido las normas procesales aplicables. En tal sentido el art. 28 del Protocolo de Olivos establece un plazo para interponer el recurso de aclaración de 15 días, agregando un plazo para la resolución de la Corte de otros 15 días, por lo que necesariamente — considerando además las notificaciones - se debió dictar este laudo aclaratorio en el mismo año 2001 (de hecho en los Considerandos 4 y 5 del mismo, se hace referencia art. 19 de las Normas de Procedimiento de constitución de ese TAAM y al art. 22 del Protocolo de Brasilia). Por todo lo anterior, nos hemos referido a este laudo como «Laudo del TAAM Aclaratorio recaído en el recurso de aclaración deducido contra el Laudo del TAAM (número 5) de 29 de septiembre de 2001, República Oriental del Uruguay c. República de Argentina».
}

324 
de la Corte de Luxemburgo. Pero la comunicación era leve, forzada y ecléctica, siendo utilizada por los árbitros para disociarse del TJUE, sin embargo, a nuestro juicio lo trascendente se ampara en que representó el puntapié inicial para comenzar a utilizar este recurso de la comunicación jurisdiccional extra-orgánica en el merco-sistema.

El caso de base, que luego dio paso al recurso, era Uruguay/Argentina ${ }^{145}$, en dicho juicio el actor planteaba que Argentina impedía el ingreso de bicicletas de la empresa Motociclo S.A. procedentes del Uruguay violando el Derecho del MERCOSUR, pidió que las medidas acusadas fuesen declaradas ilícitas y se le ordenara a Argentina a declararlas nulas, permitiendo el libre acceso. Pero Argentina pedía rechazar la acción, considerando que su proceder se ajustaba al Derecho Mercosur justificándose sus criterios de selectividad del control aduanero del valor de los productos. Así las cosas y sin ninguna referencia al modelo europeo la causa finalizó acogiendo el TAAM la acción uruguaya ${ }^{146}$.

Pues bien, tras aquel laudo ambas partes dedujeron sendos recursos de aclaración, que en lo pertinente a nuestra búsqueda de un posible diálogo judicial, resultó ser muy relevante la impugnación Argentina, pues reprochaba al TAAM un intento de derogar norma interna argentina, lo que no se ajustaría a las estructuras jurídicas del MERCOSUR. De hecho y como ya lo hemos analizado, esta intromisión no es permitida en ningún sistema de integración, donde la primacía del derecho de la integración —en el aspecto anotadocorre por el efecto de desplazamiento temporal de la ley nacional, jamás por su derogación, tal como lo vimos en el caso del TJCA al absolver la consulta de la Corte Suprema de Justicia de la República de Colombia; Germán y Ernesto Cavelier ${ }^{147}$.

\footnotetext{
${ }^{145}$ Laudo del TAAM (número 5) de 29 de septiembre de 2001, República Oriental del Uruguay c. República de Argentina.

${ }^{146}$ Hemos resumido de este modo sucinto la causa sub lite, pues en ésta no se produce el fenómeno en análisis, sino en el laudo aclaratorio dictado posteriormente por el mismo TAAM. Puntualmente Uruguay planteaba que Argentina violó las «DECISIONES CMC N 6/94, $\mathrm{N}^{\circ} 16 / 94, \mathrm{~N}^{\circ} 17 / 94$ y N 22/00, el art. 1 del Tratado de Asunción y, los arts. 1 y 10.2 del Anexo I del Tratado de Asunción» pues la normativa argentina para el control de valor en aduanas de las mercaderías violentaban el régimen de despacho y valoración aduaneras de mercaderías del MERCOSUR, que constituían dificultades irregulares generando un dilatado e ilegítimo impedimento de acceso a Argentina de aquellos productos. En cambio Argentina consideraba sus normas ajustadas al Derecho del MERCOSUR justificándose en aras al derecho de verificación, sosteniendo que no utilizaba procedimientos de valor referenciales, sino un primer control de valor que tiene por objeto verificar si el declarado concuerda o no con los usuales para mercancías idénticas y/o similares.

147 Sentencia del TJCA de 25 de mayo de 1988, Interpretación prejudicial, Germán y Ernesto Cavelier, consulta de la Corte Suprema de Justicia de la República de Colombia, as. 2-IP-88. GOAC N 33 de 1988.
} 
Pero el recurso de aclaración argentino se apoyó en buena parte en el modelo europeo, precisamente se amparó en el caso Humblet/Estado Belga ${ }^{148}$, lo que el recurrente expuso de la siguiente manera:

«En más de una ocasión, del Laudo se desprende que el Tribunal ha resuelto "revocar" la medida cuestionada [...] el Tribunal Arbitral ha incurrido en un error que debe rectificar [...], dado que una medida de derecho interno de un país en el estadio actual del MERCOSUR sólo podrá ser revocada por una nueva norma del derecho positivo interno de ese mismo país. [...]. De constatarse tal incumplimiento, el Tribunal deberá recomendar al Estado Parte que aplicó la medida, que la deje sin efecto [...]. Cabe señalar que esto es así aún en el ámbito de la Comunidad Europea donde se ha creado un nuevo ordenamiento jurídico [...], en ámbitos cada vez más amplios, [...] al punto de haberse establecido el principio de primacía del derecho comunitario [...] el efecto directo de las disposiciones aplicables a sus nacionales y a ellos mismos, [...]. Sin embargo, esta característica soberana del Tribunal de Justicia no llega al punto de facultarlo a derogar una norma de derecho interno. [...], sólo puede constatar el incumplimiento y esa constatación tiene un carácter puramente declaratorio, pues sólo los Estados pueden y deben acatar sus consecuencias. El Tribunal de Justicia tal como sostuvo en la sentencia Humblet no puede, como en un sistema federal, [...] anular o derogar él mismo las leyes nacionales» ${ }^{149}$.

Dado lo anterior, nos queda claro que el origen del recurso al diálogo judicial en el MERCOSUR no deviene del ejercicio espontáneo del TAAM, sino porque la defensa —y ahora recurrente de aclaración - propuso soluciones exógenas al merco-sistema, con el objeto de reprochar la tesis de un eventual efecto derogativo de leyes locales por parte del Derecho del Mercosur. Pero el resultado fue contrario al deseado por el recurrente que indujo la conexión, pues si bien el TAAM efectuó el análisis de las estructuras foráneas ${ }^{150}$, los árbitros articularon disociándose del modelo europeo. Para el TAAM el caso Humblet - traído a colación por Argentina- sólo poseía un valor histórico «no trasladable»al MERCOSUR, aseverando además que no era extrapolable el sistema de revisión jurisdiccional de la UE al MERCOSUR. Tal cotejo de ambos sistemas jurídicos lo desarrollan los árbitros expresando al respecto lo siguiente:

«En supuestos como el presente 'no' resulta fácilmente extrapolable la sistemática de revisión jurisdiccional generada en el ámbito de la Unión Europea. En primer

\footnotetext{
148 Sentencia del TJ de 16 de diciembre de 1960, Humblet/Etat belge, as. C-6/60-IMM, ECLI:EU:C:1960:48 (En el laudo aclaratorio la referencia a la sentencia del TJCE (TJUE) se expresó del siguiente modo «Asunto 6/60, Humblet/Estado belga, Recueil 1960, pág. 1.125»).

${ }^{149}$ Apartado 3 Revocación de una norma de derecho interno, del escrito impugnatorio de Argentina.

${ }^{150}$ Laudo del TAAM Aclaratorio recaído en el recurso de aclaración deducido contra el Laudo del TAAM (número 5) de 29 de septiembre de 2001, República Oriental del Uruguay c. República de Argentina.
} 
lugar, en la Unión Europea se desarrolló desde su inicio un sistema jurisdiccional articulado sobre distintas estirpes de recursos, en un extenso abanico de mecanismos contenciosos que va desde los recursos por incumplimiento, a los de reenvío prejudicial, los de anulación, los de responsabilidad y los de consulta. En el ámbito Mercosur la función jurisdiccional para los conflictos se atribuye a Tribunal Arbitrales "ad hoc" de manera muy genérica y sin especificar la naturaleza de los conflictos entre Estados, separando sólo en capítulo aparte los reclamos de particulares; $\mathrm{y}$, desde luego, sin delimitar si los Laudos han de tener valor meramente declarativo o de plena jurisdicción [...]

El precedente del caso Humblet que cita la representación Argentina tiene un valor histórico 'no' trasladable al caso aquí contemplado. De un lado, porque su propia antigüedad (1960) y la materia de referencia (Tratado CECA) difícilmente le darían virtualidad al supuesto estudiado».

Esta reacia actitud de los árbitros es la que nosotros confrontamos con la teoría de la comunicación extra-orgánica en estudio, resultando que no podemos calificarla de diálogo judicial, toda vez que la razón de ser del diálogo judicial es la importación de soluciones exógenas al sistema de la Corte que lo usa. Incluso si atendiéramos a su máximo margen de tolerancia, considerando el tipo monólogo o extractivo como el extremo más débil del concepto, tampoco nos permite reconocerla como diálogo judicial, pues en el caso concreto «nada se está incorporando» desde la jurisprudencia del TJUE al laudo de este TAAM.

Sin embargo — y he aquí lo relevante para esta sección - la conexión efectuada por el TAAM para rechazar la aplicación de las soluciones europeas, es del todo ecléctica y asienta un hito, pues incluso, para este rechazo razonado, el TAAM de facto se conectó con la solución del TJUE, la analizó, efectuó un test de compatibilidad con el Derecho del Mercosur y subsumió al caso concreto en dicho análisis. Si nos detenemos en el centro del carácter forzoso de esta conexión, en cuanto la Corte únicamente despliega el test de compatibilidad debido al impulso del recurrente —en ningún caso de modo oficioso, a diferencia de las sentencias ya analizadas para los casos de la CCJ y del TJCAdescubrimos una arista trascendente al razonar en el sentido de que, toda esta actividad comparativa que efectuó el TAAM, es imposible que hubiese ocurrido en un tribunal tradicional, ya que una Corte nacional ordinaria simplemente no se habría pronunciado sobre el derecho foráneo, por incompetente ${ }^{151}$. Imposibilidad teórica, del todo extrapolable a la CCJ, al TJCA y al TPRM.

${ }^{151}$ Aclaremos que la incompetencia de una Corte nacional ordinaria, obviamente es sin perjuicio de los casos particulares del DI y, sobre todo del DI Privado, donde justamente la colisión de sistemas y normas caen dentro del marco de la litis. Para lo cual habitualmente se presentan peritajes jurídicos especiales. Sin embargo, ese no es ni el contexto, ni el marco del caso en estudio, por las siguientes razones: ambos litigantes —Argentina y Uruguay — pertenecen al mismo sistema, están ante el juez natural — TAAM — y el derecho 
Dicha incompetencia habría detonado un cierre de compuertas abrupto en un modelo clásico, pues las potestades del tribunal no abarcan análisis de otros sistemas jurídicos, sencillamente no poseen tal función. En cambio el TAAM, precisamente por no ser un tribunal clásico u ordinario, lleva adelante toda una operación de análisis comparativo. Por ende, para nosotros, en el laudo bajo análisis, subyace un modelo ecléctico de conexión que, de un extremo no alcanza siquiera al diálogo judicial monólogo, pero del otro, sobrepasó de facto el encriptamiento intra-sistema del MERCOSUR que imperaba en esa época, por tal motivo es que seleccionamos esta jurisprudencia, toda vez que conlleva un trascendente carácter histórico.

Pero para ser justos y contextualizar, la timidez procesal y sustantiva internacional del TAAM se asienta en un punto concreto del recorrido del MERCOSUR, es decir, que para ese umbral de la trayectoria, no era aún oportuno tomar el ritmo europeo. Y en cierto modo el TAAM se escuda en tales criterios, señalando:

«Esa trayectoria concerniente al ámbito europeo [nota 4] ha de recorrerse en Mercosur de la manera peculiar que sus características exigen; pues no existiendo sino una sola clase de litigios entre Estados, los laudos deben adoptar la forma, bien declarativa, bien de plena jurisdicción, según requiera cada supuesto controvertido. En el caso presente, el Tribunal Arbitral entendió y entiende que lo más coherente con el ordenamiento jurídico Mercosur es la revocación del acto concreto y el mantenimiento de los bloques normativos concernidos. Esa doble decisión mantiene a la vez la primacía y el efecto directo del ordenamiento Mercosur, y la soberanía -a efectos normativos- de los Estados parte» ${ }^{152}$.

En tal razonamiento se inserta la mayor conexión del TAAM con el modelo europeo, expresamente pasando a referirse a tres sentencias concretas del TJUE, pero sólo mediante una pequeña nota a pie de página, en la cual indicó:

del foro y la norma decisoria litis, son los mismos, el Derecho del Mercosur. Justamente por ello el TAAM podría no haberse hecho cargo del derecho externo que ingresaba Argentina, y declararse incompetente para tal análisis. Pero, ingresó en él, lo analizó y lo comparó, incluso emitió opiniones específicas sobre el modelo europeo, efectuando en la práctica un test de compatibilidad con el mercosureño, aunque esto no alcanzó el nivel de diálogo judicial pues los árbitros rechazaron la importación. En cambio, los casos de conflictos de foros y de ley aplicable en el DI Privado son completamente diferentes. De hecho la jurisdicción y la competencia en materias de DI Privado presentan problemáticas diferentes al DI Público, et al. LUPOI, M. A. (2002). Conflitti transnazionali di giurisdizioni. Milano: Dott. A. Giuffrè., pp. 3-24. Otro, LUCAS SOSA, G. Y OYARZÁBAL, M. J. A. (2012). Derecho procesal transnacional: Homenaje al profesor doctor gualberto lucas sosa. Buenos Aires: Editorial Abaco de Rodolfo Depalma, pp. 140 y ss, y pp. 176 y ss.

${ }^{152}$ Párrafo 12 (con nota 4) del Considerando 6.3 del Laudo del TAAM Aclaratorio recaído en el recurso de aclaración deducido contra el Laudo del TAAM (número 5) de 29 de septiembre de 2001, República Oriental del Uruguay c. República de Argentina.

328 
«La doctrina del entonces T.J.C.E. respecto de la inaplicación de pleno derecho de la disposición nacional incompatible con el derecho comunitario resulta, entre otras de las Sentencias dictadas en las causas Comisión c/ Italia 48/71 (13.07.72); Comisión cl Francia 167/73 (04.04.74); Comisión c/Francia 24 y 97/80 $(28.03 .80){ }^{153}$.

\subsubsection{LA SEGUNDA CONEXIÓN DE LA PRIMERA ETAPA:} UN LAUDO DICOTÓMICO QUE SE APROXIMA A LOS DDHH Y SE DISTANCIA DE LA UE

Más tarde, en septiembre del 2006 otro TAAM dictaría un laudo bastante dicotómico, pues por una cara, resulta trascendente para la expansión de competencias de las Cortes mercosureñas en materias de derechos humanos, pero por otra cara $-\mathrm{y}$ en nuestra temática aquí - nuevamente se produce una conexión con la jurisprudencia europea sin llegar a ser calificable de diálogo judicial. El distanciamiento con las construcciones del TJUE se aprecian incluso con más énfasis que en el caso recién analizado, presentándose la diferenciación MERCOSUR $v / s$ UE casi como irreconciliable, diferenciando sus orígenes $\mathrm{y}$, con esto, las posibles aplicaciones de las soluciones europeas. Los árbitros primero se apartan de ambos litigantes respecto de las sentencias del TJUE que estaban trayendo a colación -en el caso anterior sólo Argentina propuso aplicar soluciones europeas, ahora ambos litigantes lo hacían - y en segundo lugar ha de considerarse que este laudo dictado en septiembre del 2006 es posterior a las otras manifestaciones de claro diálogo judicial ocurridas en 2003, 2005 y en enero 2006 - las cuales analizaremos, sumadas a otras, al referirnos a la segunda y tercera etapa - por lo tanto aquí hay un evidente retroceso de criterio.

Pues bien, tan obtusa insistencia en visualizar los dos sistemas en compartimentos estancos se repite en este laudo de septiembre de 2006 en la causa, nuevamente denominada República Oriental del Uruguay c. República de Argentina ${ }^{154}$. Uruguay pedía que

${ }^{153}$ Nota a pie de página número 4, en la cual el TAAM se está refiriendo a la Sentencia del TJ de 13 de julio de 1972, Comisión/Italia, as. C-48/71, ECLI:EU:C:1972:65, Sentencia del TJ de 4 de abril de 1974, Comisión/Francia, as. C-167/73, ECLI:EU:C:1974:35 y a los asuntos acumulados Sentencia del TJ de 28 de marzo de 1980, Comisión/Francia, as. C-24/80, ECLI:EU:C:1980:107, respectivamente. A lo anterior añade diversa doctrina que analiza la realidad europea, expresando «Y sobre todo porque como señaló PESCATORE ya en 1981, la doctrina del efecto directo de las Normas Comunitarias es posterior al año 1960 y el Tribunal de Justicia ha ido progresivamente confiriendo un alcance cada vez más amplio a ese principio, transformando, como escribió PLOUVIER en 1975, "vías inicialmente platónicas" en un medio cada vez más eficaz que permite obtener una aplicación máxima del derecho comunitario».

${ }^{154}$ Laudo del TAAM de 6 de septiembre de 2006, República Oriental del Uruguay c. República de Argentina. (Constituido para conocer sobre «Omisión del Estado Argentino en adoptar medidas apropiadas para prevenir y/o hacer cesar los impedimentos a la libre circulación derivados de los cortes en territorio argentino de vías 
Argentina tomase medidas para prevenir y hacer cesar los impedimentos a la libre circulación derivados de interrupciones en el territorio argentino de las carreteras de acceso internacionales que unen a esos países. La defensa argentina era sólida, pues sostenía que no podía aplicar medidas más drásticas contra manifestaciones públicas, ya que «aumentar la represión» implicaba colisionar con los derechos fundamentales de libertad, de expresión, de reunión y de manifestación. En tal contexto, Argentina planteó la incompetencia del TAAM en materias de derechos humanos. Lo sorprendente fue que la Corte decidió que sí tenía competencia e ingresó a las temáticas de esta clase de derechos, sin atender a la incompetencia deducida, signo evidente de un avance del tribunal respecto de sus potestades ${ }^{155}$.

Pero por la arista que aquí debemos analizar, centrémonos en que el TAAM se apartó de las posturas de ambos litigantes, materializando una irreconciliable posibilidad de diálogo judicial. Por considerar que cada sistema de derecho - UE $v / s$ MERCOSUR - se posicionaban en una dimensión jurídica distinta, una supranacional y la otra interestatal. Eliminando así todos los antecedentes europeos que intentaron introducir los dos litigantes. Observamos que el criterio de severidad empleado por el TAAM en esta oportunidad fue contundente y de carácter sustantivo, de allí que el retroceso conceptual respecto del 2003, como lo anunciamos y veremos más adelante, sea de envergadura. Aquí lo expresó del siguiente modo:

«El Tribunal considera que no son asimilables a este caso ninguno de los precedentes de la Corte de Justicia Europea invocados [...]. No sólo por la diferencia cualitativa que tiene el derecho comunitario europeo, de claro 'carácter supranacional' respecto del derecho del MERCOSUR que es de 'índole

de acceso a los puentes internacionales General San Martín y General Artigas que unen la República Argentina con la República del Uruguay»).

${ }^{155}$ Este laudo ha sido fundamental en la historia de acercamiento de los Tribunales Mercosur a las materias de derechos humanos, impensadas en el origen del proyecto político. Por esto, precisamente es signo del desarrollo del Mercosur. BAZÁN destaca «es remarcable que éste haya incursionado en el tema de los derechos humanos pese al cuestionamiento argentino (que consideramos inconsistente e infundado) en cuanto a la falta de competencia jurisdiccional de aquél para conocer de una cuestión que involucra aspectos de derechos humanos que, en tanto tales, devienen ajenos a la normativa del Mercosur». BAZÁN, V. (2012). Derechos humanos y mercosur: actualidad y prospectiva, Revista europea de derechos fundamentales, 20, pp. 83-152 (p. 142). Para CANEPA, quien también destaca el aporte de este laudo, hay un claro avance en el Mercosur en materias de derechos humanos, destacando que «A pesar de no contar con un tratado general específico sobre la materia, el derecho mercosureño ha hecho una tarea muy fructífera en relación a la protección de los derechos humanos y libertades fundamentales al crear institutos encargados del estudio e investigación de temas relativos a los derechos humanos. A su vez, también se han firmado varios acuerdos que pretenden dar cuenta de la preocupación de los Estados por esta temática». CANEPA, M. (2015). Los derechos humanos en el mercosur. Revista da secretaria do tribunal permanente de revisão, 3(6), pp. 161-177 (p. 175).

330 
interestatal' y por el hecho de que la normativa aplicable es diferente de la que rige en nuestro caso, sino también por razón de la peculiaridad de los casos» ${ }^{156}$.

Por lo tanto, el rechazo se basó en dos cuestiones, una de tipo cualitativa, cual es, ser derechos muy distintos, el del MERCOSUR es interestatal, mientras que el de la UE es supranacional, y la otra, basada en la peculiaridad de los casos, es decir, porque los presupuestos fácticos no se encuadran perfectamente entre las sentencias analizadas ya que, en unas hubo violencia y en otras no, más otros extremos ${ }^{157}$ — volveremos enseguida sobre las consecuencias de una eventual compatibilidad de los hechos. En lo central este laudo nuevamente llevó adelante un análisis jurídico de las sentencias europeas cotejándolas con el caso mercosureño.

Así las cosas, estos dos laudos (TAAM 2001, y septiembre 2006) si bien, implicaron un distanciamiento del modelo de la UE, les es aplicable el razonamiento ya expuesto sobre lo igualmente valioso de la conexión, toda vez que, de un lado no alcanzan siquiera al umbral de diálogo judicial monólogo y extractivo pues nada incorporan, además sólo el primero (2001) sobrepasó de facto el encriptamiento intra-sistema del MERCOSUR existente a esa época, lo que le imprimió el carácter histórico subrayado, y a su vez ambos, superaron el

${ }^{156}$ Párrafo 150, bajo el apartado II-G La conducta debida ante las circunstancias existentes, en el Laudo del TAAM de 6 de septiembre de 2006, República Oriental del Uruguay c. República de Argentina. (Constituido para conocer sobre «Omisión del Estado Argentino en adoptar medidas apropiadas para prevenir y/o hacer cesar los impedimentos a la libre circulación derivados de los cortes en territorio argentino de vías de acceso a los puentes internacionales General San Martín y General Artigas que unen la República Argentina con la República del Uruguay»).

${ }^{157}$ En los párrafos 151 y 152 del apartado y laudo ibídem, los árbitros analizan las sentencias del TJUE sugeridas como precedentes jurisprudenciales por los litigantes (Sentencia del TJ de 9 de diciembre de 1997, Comisión/Francia, as. C-265/95, ECLI:EU:C:1997:595 y Sentencia del TJ de 12 de junio de 2003, Schmidberger, as. C-112/00, ECLI:EU:C:2003:333). Pero el TAAM consideró la improcedencia de ambos fallos del TJUE, así «151. En el caso de la sentencia del 9-12-1997 en "Comisión de las CE contra la Rep. Francesa s/ libre circulación de las mercaderías" (Asunto C-265/95) se trataba de la obstrucción de particulares a la circulación de vehículos por territorio francés provenientes de otro país comunitario, pero el móvil que guiaba a los particulares que protagonizaron el hecho, era netamente discriminatorio contra el ingreso de la mercadería de otro de los países. A esto se suma que se produjeron hechos de violencia sobre los conductores y la carga, que no han existido en el caso que nos ocupa.- 152. El caso de la sentencia del 126-2003 en "Eugen Schmidberger, Internationale Transporte und Planzugue c/ la Rep. de Austria" (Asunto C112/00), se trataba de un corte, en Austria, de la ruta que une el tráfico entre Alemania e Italia. Pero, $a$ diferencia del caso en análisis, se trataba de una demanda de daños y perjuicios entablada directamente por el particular, y no un reclamo declarativo de incumplimiento de un Estado contra otro Estado. Además el período de interrupción del tráfico fue de tan sólo 28 horas y no de 3 meses, como el que nos ocupa, se produjo en una sola oportunidad y se trató de cortes anunciados y autorizados por la autoridad con hora de inicio y de culminación». 
posible silencio procesal ante una inminente incompetencia, como lo explicamos en el caso anterior $^{158}$.

Retomando el aspecto de los elementos de hecho que anunciamos pocas líneas atrás, desembocamos en un cuestionamiento jurídico relevante a partir de los «contenidos fácticos» de ambas causas. En el análisis de la jurisprudencia europea que efectuó el TAAM, los árbitros fueron muy precisos al analizar los hechos. Así, refiriéndose al caso Comisión de las CE c/ República Francesa s/ libre circulación de las mercaderías se distancian totalmente de los hechos concretos, agregando que en aquella causa se produjo violencia contra los conductores y la carga, lo que no ocurrió en América, y para el caso Eugen Schmidberger, Internationale Transporte und Planzugue c/ República de Austria también subrayaron que en un caso hubo violencia y en otro no, más otras diferencias empíricas que ya vimos y anotamos. Entonces, la legítima duda que a nosotros nos surge, es ¿qué habría sucedido si los hechos hubiesen sido similares? entonces ¿sí habría el TAAM importado las soluciones europeas? o igualmente negaría la conexión amparándose en el primer argumento, relativo a las naturalezas de los derechos —intergubernamental $v / s$ supranacional.

El cuestionamiento lo consideramos pertinente, dado la cronología en cuestión, toda vez que este laudo es de septiembre del 2006, muy posterior a la primera conexión que puede ser considerada diálogo judicial del año 2003 y a las del 2005 y de enero del $2006^{159}$. Entonces es claro que hubo un rotundo retroceso de criterio. Pues para no haberlo - a nuestro juicio - bastaba sólo con el segundo argumento, esto es, referirse exclusivamente a que no coincidían los hechos europeos con los del litigio mercosureño. Pero no fue así, sino que se profundizó en el primer argumento, respecto de la diferenciación sustantiva de los sistemas -intergubernamental $v / s$ supranacional- llevando adelante el test de compatibilidad, pulsando de paso los tensores competenciales en cuanto a tener o no, potestades para referirse a normas foráneas al merco-sistema.

En conclusión esta compleja situación, conformada por todas las aristas analizadas, termina por girar en contra de los deseos de aquellos dos TAAM. La historia así lo demostraría, tal como lo veremos al adentrarnos en la segunda y tercera etapa de desarrollo del diálogo

\footnotetext{
${ }^{158}$ Vid. nota 151 de este capítulo.

${ }^{159}$ En total son 5 los laudos que recurren al diálogo judicial — vid. nota 141 de este capítulo — ahora bien, los 3 laudos previos al que estamos analizando aquí, y que pudiesen haber desincentivado a este TAAM para levantar tan contundente diferencia y haberse quedado sólo con el argumento secundario, máxime teniendo en cuenta que dos de éstos provenían de su superior jerárquico —el TPRM - eran: $1^{\circ}$. Laudo del TAAM (número 9) de 4 de abril de 2003, República de Argentina c. República Oriental del Uruguay, $2^{\circ}$. Laudo del TPRM de 20 de diciembre de 2005, República Oriental del Uruguay c. República de Argentina, as. 1/2005, y $3^{\circ}$. Laudo del TPRM de 13 de enero de 2006, Recurso de aclaratoria, as. 1/2006.
}

332 
judicial por las Cortes mercosureñas. Por ahora, y sólo por orden metodológico, observemos la última conexión que cerró esta primera etapa.

\subsubsection{LA ÚLTIMA CONEXIÓN DE LA PRIMERA ETAPA:} UNA ESCUETA REFERENCIA A LA CORTE INTERNACIONAL DE JUSTICIA

El último caso con que se cierra esta primera etapa, en que un TAAM recurrió a la conexión con una Corte externa, lo encontramos en el año 2005 en el Laudo $10^{160}$ donde se produjo una pequeña referencia a la CIJ, órgano jurisdiccional de NU muy distante al derecho de la integración. Sin embargo consideramos oportuno incluir este antecedente a efectos de no dejar inacabada la idea de la factibilidad de las conexiones extra-orgánicas que puedan efectuar las Cortes del Mercosur, por esto sólo precisaremos dos aspectos de interés.

El primero es destacar que la conexión del TAAM va en un ritmo algo similar - aunque más distante - de aquel diálogo judicial que ya analizamos en el SICA para la Corte centroamericana cuando se conectó con un precedente de la Corte Constitucional italiana en la sentencia Coto Ugarte/Consejo Superior Universitario de la Univ. de El Salvador ${ }^{161}$, pero ahora aquí, no hay tal cercanía con materias sustantivas del derecho de la integración, como sí lo hubo en aquella ocasión entre la CCJ y la CCi.

En segundo lugar, solo visualizamos temas referidos a conceptualizar una noción de controversia. Lo relevante del punto, es que en la búsqueda de su fuente normativa el TAAM estimó idóneo emigrar a ordenamientos exógenos cada vez que sea pertinente, sosteniendo que:

«independientemente de la aplicación de la normativa específica del Mercosur, el Tribunal está obligado a observar, en la medida que sean de aplicación a la materia en conflicto, las normas y principios del Derecho Internacional» ${ }^{162}$.

Desde esa idea es que el TAAM se aproxima a la CIJ del siguiente modo:

«el Tribunal confirma la aplicación de criterios emanados del DI consuetudinario y avalados por la jurisprudencia internacional por los que es posible la identificación

\footnotetext{
${ }^{160}$ Laudo del TAAM (número 10) de 5 de agosto de 2005, República Oriental del Uruguay c. República Federativa del Brasil.

161 Sentencia de la CCJ de 5 de marzo de 1998, Coto Ugarte c. Consejo Superior Universitario de la Universidad de El Salvador, expediente 05-11-1996, as. 05/96. En aquel fallo se produjo un diálogo judicial monologo y extractivo con la sentencia italiana Corte Costituzionale, Sentenza de 18-12-1973, Frontini. Deposito in cancelleria 27-12-1973. Pubblicazione in Gazz. Uff. № 2, del 2 gennaio 1974.

162 Párrafo 3 bajo el apartado Derecho aplicable, del Laudo del TAAM (número 10) de 5 de agosto de 2005 , República Oriental del Uruguay c. República Federativa del Brasil.
} 
de una controversia entre Estados, sobre la base de desacuerdos o puntos de vista opuestos respecto a la existencia de un derecho o de una obligación [nota 7]» ${ }^{163}$.

Pero en realidad el TAAM está conectándose con la CIJ a efectos de ejemplificar con algunos casos que la CIJ conoció, y además, tal conexión la efectúa mediante una nota a pie de página, indicando:

«Idem ant., conf. Caso de las "Concesiones Mavrommatis en Palestina”, PCIJ, Serie A, n. 2, p. 11; Ver también, CIJ en el caso del "Camerún Septentrional”, ICJ Reports 1963, p. 27, y el caso sobre la "Aplicabilidad de la obligación de arbitraje en virtud de la Sección 21 del Acuerdo del 26 de junio de 1947 relativo a la Sede de la ONU”, ICJ Reports 1988, parág. 35. y en el caso del “Timor Oriental”, ICJ Reports 1995, p. 99. En el caso del "Africa Sudoccidental” la CIJ sostuvo que para determinar la existencia de una controversia hay que demostrar que el reclamo de una de las partes se opone positivamente al de la otra, ICJ Reports 1962, p. 328» ${ }^{164}$.

A nuestro juicio es claro entonces que en dicha conexión, no hay relación con el derecho de la integración, pero sí, de forma trascendente se muestra nuevamente la factibilidad concreta de que tribunales de integración (o de aspiraciones integracionistas) se conecten y analicen sentencias dictadas por órganos jurisdiccionales extra-sistemas.

En conclusión, la primera etapa, compuesta por los tres laudos analizados, representó una labor pionera, que en términos amplios, si bien da cuenta de simples referencias a sentencias foráneas que no alcanzan a ser calificadas siquiera como un diálogo judicial monologo y extractivo, pero su trascendencia radicó en que dichos análisis, aunque hayan sido, ora para distanciarse del derecho de la integración (con el TJUE), ora para resolver conceptos generales (con la CIJ), en la práctica, contribuyó a romper la inercia autocentrista de las Cortes mercosureñas, demostrando que es factible desarrollar cotejos del Derecho Mercosur con otros sistemas transnacionales — como el europeo precisamente. Así esta primera etapa, impulsó el fenómeno de comunicación, que luego vendría a presentarse con más intensidad en la segunda y tercera etapa, tal como lo pondremos de manifiesto a continuación.

\footnotetext{
${ }^{163}$ Párrafo 6 en apartado y laudo ibídem.

${ }^{164}$ Nota 7 del párrafo 6 en apartado y laudo ibídem. 
7.2. La Segunda Etapa:

LA GÉNESIS DEL RECURSO AL DIÁLOGO JUDICIAL de las Cortes Mercosureñas CON LA CORTE de LUXeMburgo

Fue en el año 2003 la época en que comenzó a superarse el criterio anterior, pues ahora vendrían a importarse efectivamente construcciones del TJUE. Esto sucedió por primera vez mediante una moderada conexión que el laudo República de Argentina c. República Oriental del Uruguay ${ }^{165}$ realizó con la sentencia Comisión v/ Luxemburgo y Bélgica ${ }^{166}$. Lo que entendemos, vino a ser el inicio de una nueva etapa del MERCOSUR, mucho más cercana al derecho de la integración. Argentina demandaba a Uruguay por bonificar exportaciones de productos industrializados de lana, lo que implicaba un incentivo prohibido en la intrazona mercosureña, además, sostenía la actora, la conformación de un mercado común impedía a los Estados Partes, interpretando funcional o teleológicamente el Tratado de Asunción (TA) en cuanto «mecanismo de integración», adoptar medidas contrarias a dicho objetivo. También acusó la violación del Entendimiento de 13-12-2000 suscrito entre ambas partes en la fase pre-arbitral, lo que reportaría una violación de un compromiso internacional ${ }^{167}$.

Uruguay sostuvo que no violó el TA, pues éste no sólo debía interpretarse funcional o teleológicamente, sino también lógico-sistemáticamente, según los principios de gradualidad, flexibilidad y equilibrio consagrados en el Preámbulo del TA. Expresó que el Entendimiento 13-12-2000 no podía constituirse en objeto de la controversia, pues Argentina había alterado sustancialmente las condiciones existentes a la época de la firma, al disponer medidas de análoga naturaleza a las que Uruguay se obligaba a desmantelar. Interponiendo entonces exceptio non adimpleti contractus. Se añade el hecho de que,

${ }^{165}$ Laudo del TAAM (número 9) de 4 de abril de 2003, República de Argentina c. República Oriental del Uruguay.

166 Sentencia del TJ de 13 de noviembre de 1964, Comisión de la CEE/Luxemburgo, as. C-90/63, ECLI:EU:C:1964:80.

${ }^{167}$ Argentina consideraba incompatible con el Derecho MERCOSUR los arts. 79 y 80 de la Ley uruguaya $\mathrm{N}^{\circ}$ 13.695 de 24 de octubre de 1968 y los Decretos complementarios para las exportaciones de productos industrializados de lana destinadas a los Estados Partes del MERCOSUR. Consideraba que colisionaban con el TA y la Decisión del CMC 10/94 sobre «Armonización para la aplicación y utilización de incentivos a las exportaciones por parte de los países integrantes del MERCOSUR» y que el mantenimiento de dicha bonificación implicaba, además, la violación del «Entendimiento de 13 de diciembre de 2000» suscrito entre ambas partes en la fase pre-arbitral, cuyo incumplimiento reporta una violación de un compromiso internacional. 
durante el juicio, Uruguay dejó sin efecto la bonificación, alegando que eso, implicaba la pérdida sobrevenida del objeto del proceso $^{168}$.

Sería la exceptio non adimpleti contractus la causa por la cual el TAAM se vinculó con las soluciones del TJUE, con la particularidad de que en esta ocasión ninguna de las partes lo propuso - lo que contrasta con los dos primeros casos de la etapa anterior - sino que los árbitros delimitan la excepción teniendo presente que esta se extrae del derecho romano, pero su aplicación en el DI se somete a más restricciones que en los contratos privados, dado la naturaleza especial de los Tratados, los cuales contemplan tanto aspectos contractuales como normativos. En segundo lugar $-\mathrm{y}$ de la mayor importancia para nosotros - explican que esta excepción es muy próxima a la represalia, por lo cual concluyen que no tiene sentido, en un proceso de integración, basándose en que en los sistemas de integración existen mecanismos de solución de disputas que permiten aplicar sanciones por medio del derecho. Por esto la exceptio non adimpleti contractus se limita al máximo dentro de una organización regional que desea un mercado común, pues se busca la concreción de una situación de derecho para que sea aún más pronunciada de lo que es en el DI público.

Centrado en dichas aristas se producen dos cuestiones de relevancia, 1) por una parte este TAAM reconoce que el MERCOSUR es un sistema de integración «no pleno» — según precisaremos enseguida. Sin embargo destaquemos primero que tal noción expuesta en este laudo (2003) es incompatible con la desarrollada más tarde en el laudo de septiembre de 2006 — según ya vimos en el apartado anterior - motivo por el cual anotábamos el retroceso que aquello había significado ${ }^{169}$, y 2) por otra parte, este laudo (2003) se conecta con la sentencia Comisión v. Luxemburgo y Bélgica del TJUE, produciéndose la primera manifestación de un diálogo monólogo y extractivo entre una Corte mercosureña y la Corte de Luxemburgo. Aunque el reconocimiento de la naturaleza integracionista del MERCOSUR y la conexión extra-orgánica, no son expuestas como elementos centrales, ni

168 Agregaba Uruguay, que dichos principios de gradualidad, flexibilidad y equilibrio consagrados en el Preámbulo del TA, deberían presidir la progresiva concreción, a través de la normativa vinculante emanada de los órganos del MERCOSUR, de los enunciados programáticos y principios generales que esencialmente encierra el cuerpo de dicho Tratado, el cual, reuniría inequívocamente las características de un tratado marco. Tampoco estimaba haber violado la Decisión CMC 10/94 en lo referente a la no aplicación de incentivos a la exportación en el comercio intrazona, al haber quedado ésta sujeta a condición suspensiva en virtud de la Decisión CMC 31/00, que — según explicaba Uruguay_plasmaba el propósito de armonización, equilibrio y gradualismo que inspiraba la configuración del MERCOSUR.

${ }^{169}$ El retroceso anotado fue en el Laudo del TAAM de 6 de septiembre de 2006, República Oriental del Uruguay c. República de Argentina. (Constituido para conocer sobre «Omisión del Estado Argentino en adoptar medidas apropiadas para prevenir y/o hacer cesar los impedimentos a la libre circulación derivados de los cortes en territorio argentino de vías de acceso a los puentes internacionales General San Martín y General Artigas que unen la República Argentina con la República del Uruguay»).

336 
menos con la contundencia deseada. Subrayemos al respecto que el primer extremo - su naturaleza - lo plantea el TAAM entre paréntesis, y el segundo — el diálogo- lo materializa mediante una sutil nota a pie de página. En cuanto a la naturaleza del MERCOSUR y su inalcanzada plenitud, se expresó:

«no se entiende que pueda resultar extensiva a normativa derivada de la intervención de órganos de un sistema de integración regional con poderes para la elaboración de reglas comunes, lo cierto es que el ordenamiento jurídico del MERCOSUR (que no hay duda que puede y debe calificarse de tal, por mucho que pueda discutirse su 'plenitud', habida cuenta de que estamos, como se ha descrito, ante un ordenamiento "organizado y estructurado, que posee sus propias fuentes, dotado de órganos y procedimientos aptos para emitirlas, interpretarlas, así como para constatar y sancionar los casos de incumplimiento y las violaciones") ha previsto una vía específica para reaccionar frente a infracciones al mismo [...], vía que no es otra que el sistema de solución de controversias» ${ }^{170}$.

Desde el anterior eslabón el TAAM empuja al MERCOSUR hacia los patrones del Derecho de la UE, pues abandona los contornos del merco-sistema buscando fuentes en la UE, y salvando un supuesto requisito de plenitud, lo cual estructura de la siguiente forma:

«Así pues, el Protocolo de Brasilia se adoptó no sólo para dar, sin más, cumplimiento formal a lo dispuesto [...en el] Tratado de Asunción, sino en el convencimiento de que el mismo serviría para fortalecer las relaciones entre las Partes basadas en la justicia y la equidad, así como en la reciprocidad entendida desde la lealtad hacia el sistema de integración [nota 17]. No es preciso, en consecuencia, que estemos ante un "derecho comunitario pleno" [nota 18] para excluir el mecanismo de autotutela del ordenamiento jurídico del MERCOSUR (y no otra cosa es, en última instancia, la exceptio non adimpleti contractus)» ${ }^{171}$.

Precisamente en su nota 18 desarrolla los efectos amplios del Tratado, en el sentido de que éste ha creado un nuevo ordenamiento jurídico, incompatible con la autotutela de los Estados, como lo es en el marco del DI. Conectándose con la sentencia del TJUE así:

«Caso del sistema europeo de integración, que ya en 1964, por boca de su Tribunal de Justicia (as. acm. 90/63 y 91/63 de 13-11-1964, Comisión v. Luxemburgo y Bélgica, Recop. española 137), sentó clara y tajantemente la doctrina [...] de que "el Tratado no se limita a crear obligaciones recíprocas [...] sino que establece un ordenamiento jurídico nuevo que regula las facultades, derechos y obligaciones de

\footnotetext{
${ }^{170}$ Considerando 63, en Laudo del TAAM (número 9) de 4 de abril de 2003, República de Argentina c. República Oriental del Uruguay.

${ }^{171}$ Considerando 65, bajo el apartado VIII. Sobre la exceptio non adimpleti contractus o excepción de inejecución alegada por Uruguay, del laudo ibídem.
} 
dichos sujetos, así como los procedimientos necesarios para obtener la declaración y la sanción de toda eventual violación", consecuencia de lo cual, [...], el sistema del Tratado supone la prohibición de que los Estados miembros practiquen la autotutela jurídica" (rechazando así la tesis de los Gobiernos demandados según la cual "dado que el DI reconoce a la parte perjudicada por el incumplimiento [...] la facultad de dejar de cumplir sus propias obligaciones...)» ${ }^{172}$.

En conclusión, se extrae de este laudo que si bien hay una relación evidente entre el DI y el Derecho de la Integración, esta gira por reconocer que el primero opera desde lo general imperando sin tan grandes obstáculos en las regiones no integradas, es decir, entre los países que no pertenecen a ningún esquema de integración. En cambio, según los árbitros, en las regiones en que impera el Derecho de la Integración, comprendido éste en el sentido amplio que ya hemos explicado, por ejemplo en la UE, no opera el DI directamente entre sus Estados miembros, sino que se anteponen las normativas específicas de todo el Bloque de Legalidad de la UE, o bien, tal como los árbitros lo razonan para el Derecho del Mercosur, el freno se comprende como una manifestación de la regla hermenéutica que reza, la ley especial prima sobre la ley general. Evidentemente este es un razonamiento para situaciones en que se ve una posible mezcla de aplicaciones del DI y del Derecho de la Integración, no para la mayoría de las situaciones en que se aprecian claramente diferenciadas las materias cubiertas por el Derecho de la Integración.

La trascendencia de este primer caso de empleo del diálogo judicial monólogo y extractivo, si bien es muy moderado, se destaca porque produjo una fisura expansiva desde del estrecho modelo intergubernamental mercosureño, hacia una dimensión un poco más cercana a la de un modelo integracionista, acercamiento que vendría a ser robustecido por los TPRM durante la tercera etapa que analizaremos a continuación.

\footnotetext{
${ }^{172}$ La nota 18 del laudo ibídem, está haciendo referencia a la Sentencia del TJ de 13 de noviembre de 1964 , Comisión de la CEE/Luxemburgo, as. C-90/63, ECLI:EU:C:1964:80.
} 


\subsection{LA TERCERA ETAPA:}

\section{EL TPRM Y EL MAYOR EMPLEO DEL DIÁLOGO JUDICIAL CON EL TJUE}

Pudimos constatar que las conexiones con jurisprudencias del TJUE se produjeron con mucha más contundencia desde la creación del TPRM como Corte superior de revisión de los TAAM. Nosotros tras haber analizado todos los laudos de los TPRM extrajimos la siguiente secuencia: primero, en diciembre de 2005 el inaugurado TPRM recurrió al diálogo judicial monólogo y extractivo; segundo, luego en el laudo aclaratorio del mismo juicio, en enero de 2006, haría una referencia indirecta al modelo europeo; tercero, le siguió la respuesta de abril del 2007 al responder una opinión consultiva; y cuarto, finalmente en junio de ese mismo año 2007 el TPRM efectuaría la más contundente recurrencia al diálogo judicial extractivo de un tribunal mercosureño para conectarse tanto con el modelo europeo, como con el andino. Estos cuatro laudos, que conforman la última etapa, los analizaremos en la secuencia descrita, quedando como sigue.

\subsubsection{EL PRIMER IMPULSO CONTUNDENTE DENTRO DE LA TERCERA ETAPA: NACE EL TPRM E IRRUMPE CONECTÁNDOSE A TRAVÉS DEL DIÁLOGO JUDICIAL DE MODO CONCRETO CON LA CORTE DE LUXEMBURGO Y CON LA CORTE ANDINA}

La primera situación se enmarca dentro del extenso conflicto por las restricciones que Argentina impuso al ingreso de neumáticos reconstruidos —remoldeados 0 recauchutados - del Uruguay. Esto originó una secuencia de cinco pronunciamientos de los tribunales mercosureños, de los cuales, sólo en dos laudos se usó un tipo de diálogo judicial ${ }^{173}$. En este litigio se daban cita el principio a la libre circulación de mercaderías, su posibilidad de limitación, el impacto al derecho fundamental a vivir en un medio ambiente libre de contaminación, entre otros. La primera oportunidad dentro de esta secuencia, en que se recurrió a un tipo de diálogo fue para revocar el laudo original del TAAM, y la

\footnotetext{
${ }^{173}$ Para evitar confusiones, reténgase que el desarrollo total del conflicto entre Uruguay y Argentina - por prohibición de ingreso de neumáticos reacondicionados- se compone de una secuencia de 5 laudos, de los cuales «sólo en 2» hay algún tipo de diálogo judicial: $1^{\circ}$. Comenzó con el Laudo del TAAM de 25 de octubre de 2005, República Oriental del Uruguay c. República de Argentina, as. TAH-2/2005, sin recurrir al diálogo judicial; $2^{\circ}$. Laudo del TPRM de 20 de diciembre de 2005, República Oriental del Uruguay c. República de Argentina, as. 1/2005, que revocó el anterior y por primera vez un TPRM usó un tipo de diálogo judicial; $3^{\circ}$. Laudo del TPRM de 13 de enero de 2006, Recurso de aclaratoria, as. 1/2006, sobre el recurso de aclaración del fallo anterior, sin usar el diálogo; $4^{\circ}$. Laudo del TPRM de 8 de junio de 2007, República Oriental del Uruguay c. República de Argentina, as. 1/2007, respecto del reclamo argentino por desproporcionalidad en las medidas compensatorias impuestas por Uruguay ante su desacato, ocasión en que se produce la mayor manifestación del diálogo judicial de un tribunal mercosureño; y $5^{\circ}$. Finalmente el Laudo del TPRM de 25 de abril de 2008, "Divergencia sobre el cumplimiento del Laudo $N^{\circ} 1 / 05$ iniciada por la República Oriental del Uruguay (artículo 30 - Protocolo de Olivos)”, Laudo 01/2008, as. 1/2005, en el que no hubo diálogo.
} 
segunda para determinar que no había desproporcionalidad en las medidas adoptadas por Uruguay ante el desacato de Argentina.

Todo se inició el 2005 con el laudo TAAM en Uruguay/Argentina ${ }^{174}$. Uruguay reclamaba que la ley argentina ${ }^{175}$ que prohibió la importación de neumáticos y cámaras neumáticas recauchutadas era incompatible con el Derecho del Mercosur, pues atentaba contra el principio de libre circulación de mercaderías injustificadamente, toda vez que dichos neumáticos son seguros y recomendados. Argentina argumentó, entre otros, en el cuidado al medio ambiente y subrayó el pasivo ambiental, trayendo a colación normativa exógena al merco-sistema, específicamente la Directiva del Parlamento Europeo (2000/53/CE) sobre vehículos, sus componentes y materiales al final de su vida útil ${ }^{176}$. Pero en definitiva, el TAAM rechazó la acción del Uruguay y declaró que la norma argentina era legítima. Todo, sin recurrir al diálogo judicial.

Dado el resultado anterior Uruguay interpuso un recurso de revisión ante el recién nacido superior jerárquico. Recurso procesal que le valió efectivamente al recurrente, pues el TPMR revocó el laudo, declarando que la norma argentina era incompatible con el Derecho del Mercosur, ya que obstaculizaba el libre tránsito de mercaderías ${ }^{177}$. El cambio de criterio obedeció a que para el TPMR la carga dinámica de la prueba habría sido alterada indebidamente por el TAAM, además el TPMR precisó que no existirían dos principios en colisión, como lo razonó el TAAM, sino sólo uno, el principio del libre comercio, al cual se le pueden oponer excepciones, como la medioambiental, aunque en el caso, Argentina no podía gozar de tal excepción, pues esta se materializa sólo cuando queda suficientemente acreditada por exigencias imperativas, que obliguen al empleo de determinadas restricciones, lo cual no fue probado.

Centrándonos en la búsqueda de algún tipo de diálogo judicial, destaquemos que el TPRM desde el momento mismo en que establece el objeto del juicio usó a esta técnica de

\footnotetext{
${ }^{174}$ Laudo del TAAM de 25 de octubre de 2005, República Oriental del Uruguay c. República de Argentina, as. TAH-2/2005.

${ }^{175}$ Ley argentina $\mathrm{N}^{\circ} 25.626$ de 09 de agosto del 2002.

${ }^{176}$ La referencia que hace la defensa hacia normativa ajena al MERCOSUR (la Directiva 2000/53/CE) va más bien en línea con la noción de diálogo de fuentes (SCOTTI, 2016 y JAYME, 1995 — vid. nota 21 de este capítulo), y en definitiva el laudo no se vincularía por ningún extremo con el modelo de la UE, tan solo expuso la argumentación de la defensa del siguiente modo «Se refiere la defensa al pasivo ambiental y los daños infringidos a la salud de las personas y animales por los neumáticos al final de su vida útil; los riesgos resultantes de la quema de tales productos; sobre los peligros resultantes de almacenaje a cielo abierto, recordando la Directiva del Parlamento Europeo (2000/53/CE) relativa a disposición de vehículos, sus componentes y materiales, al final de su vida útil».

${ }^{177}$ Laudo del TPRM de 20 de diciembre de 2005, República Oriental del Uruguay c. República de Argentina, as. $1 / 2005$.
} 
comunicación extra-orgánica ${ }^{178}$ y no sólo con el modelo europeo en aquella dinámica casi de verticalidad que hemos anotado ${ }^{179}$, sino que también, materializó un diálogo horizontal inter-americano con otra Corte de su entorno, el TJCA. El TPRM buscó auxilio en dichos modelos ajenos para incorporar al MERCOSUR la tesis del incumplimiento continuado, la cual acaece en los casos en que siendo demandado un Estado miembro, y debido a que una de sus normas nacionales es violatoria del ordenamiento integracionista, mientras transcurre el juicio, tal Estado, deroga la norma y dicta otra en similares términos pretendiendo burlar los efectos de la sentencia. Para evitar dicha mala práctica, el TPMR explica que ambos tribunales foráneos, el TJUE y el TJCA, declaran el incumplimiento de la demandada aunque la conducta infractora aparezca para la fecha de la sentencia recogida en otra normativa distinta a la señalada en la demanda. Pues bien, las consecuencias del diálogo judicial se hacen sentir ipso facto, ya que el TPMR concluye con la frase:

«Este TPR[M] 'incorpora' como precepto jurisprudencial tal concepción con el alcance mencionado y con 'todas' sus consecuencias» ${ }^{180}$.

Ahora bien, el TPRM reconoce que el MERCOSUR se encontraba en silencio de criterios normativos para listar las posibles excepciones lógicas al principio de libre circulación, y procede a suplir, mediante el mecanismo del diálogo judicial con la siguiente fórmula: primero advierte estar ante un caso de restricción al principio en cuestión, y en segundo lugar avanza, del siguiente modo hacia la solución:

«En concreto ante el error jurídico [...] de no detallar los criterios [...] para la invocación de excepciones [...], este Tribunal ante la ausencia normativa en el Mercosur [...] establece: a) [...]. Siendo este un caso piloto corresponde citar brevemente una referencia jurisprudencial del TJCE que 'calza perfectamente'. En efecto, en la causa individualizada como Comisión de las CE c/ Rep. de Austria [...] el TJCE ha determinado: se sostiene que es evidente que al prohibir los vehículos pesados [...] el Reglamento controvertido obstaculiza la libre circulación de mercancias [...] constituye una medida de efecto equivalente a restricciones cuantitativas, en principio incompatible con las obligaciones del Derecho comunitario [...], a menos que dicha medida pueda justificarse objetivamente» ${ }^{181}$.

\footnotetext{
${ }^{178}$ Considerando 5, bajo el apartado B. Objeto de la controversia, en laudo ibídem.

${ }^{179}$ No nos estamos refiriendo a la clásica clasificación de SLAUGHTER, sobre diálogo judicial vertical $v / s$ horizontal, sino al hecho de considerar a las Cortes de los tres modelos latinoamericanos en un nivel horizontal de índole inter-americano, y a la casi verticalidad para referirnos a la visión actual de éstas, respecto del TJUE - tal como ya lo anotamos, vid. nota 36 de este capítulo.

${ }^{180}$ Última parte del Considerando 5, bajo el apartado B. Objeto de la controversia, en Laudo del TPRM de 20 de diciembre de 2005, República Oriental del Uruguay c. República de Argentina, as. 1/2005.

${ }^{181}$ Considerando 14, bajo el apartado C.3 Criterios de rigor para el análisis de la viabilidad de las excepciones al libre comercio, en laudo ibídem. Los árbitros señalan conectarse a la Sentencia del TJ de 15 de noviembre de 2005, Comisión de las Comunidades Europeas c. Austria, as. C-320/03, ECLI:EU:C:2005:684.
} 
El TPRM avanzando en línea con tales disquisiciones europeas declaró «En nuestro caso, este TPR[M] entiende que la medida es directamente discriminatoria» ${ }^{182}$. Y manteniéndose en constante apoyo en la sentencia del TJUE, concluyó «En nuestro caso, este TPR[M] siguiendo la jurisprudencia citada considera de que la medida en cuestión no podría tener una debida justificación» ${ }^{183}$. Todo lo cual, lo hace lograr convicción de lo incorrecto de la postura argentina, revocando el laudo impugnado y terminando por declarar que «la medida es sencillamente del todo desproporcionada» ${ }^{184}$.

En conclusión, la importancia de este laudo radica en que diálogo judicial monólogo y extractivo lo concretó el recién creado TPRM, es decir, tal institucionalidad jurisdiccional, irrumpe conectando de forma más concreta al MERCOSUR con la UE, lo que da cuenta de que el progreso orgánico en el merco-sistema -incorporando este nuevo nivel de Corte mercosureña- implicó de inmediato un impulso sustantivo a todo el proyecto mercosureño, dando una concreta señal hacia el futuro.

\subsubsection{LA SEGUNDA CONEXIÓN DENTRO DE LA TERCERA ETAPA: \\ EL TPRM ACLARA SU LAUDO ANTERIOR MEDIANTE UN TÍMIDO DIALOGO JUDICIAL CON EL TJUE}

Dentro de esta tercera etapa, la segunda oportunidad de un claro uso del mecanismo de comunicación extra-orgánico bajo análisis, se produjo por el mismo TPRM, al hacerse cargo de los recursos de aclaración presentados por ambas partes. Así en su laudo aclaratorio $^{185}$ este TPRM intentó repeler el reproche que le hacía Argentina respecto de que el laudo desmerecía el avance del MERCOSUR en materias de derechos humanos, pues no los había considerado en carácter de principales o bien de principios. Ante esto el TPRM aclaró que no desmereció el avance en esas otras dimensiones de la integración. Cuestión que para nosotros es una aclaración muy bienvenida, toda vez que efectivamente el laudo impugnado dejaba una sensación de desinterés de los árbitros por dichas materias, pero certeramente fue corregido gracias a este cauce aclaratorio.

En cuanto al uso de un tipo de diálogo judicial para construir este laudo aclaratorio, tal mecanismo se presenta muy moderado, pues los árbitros solo se refieren indirectamente al modelo europeo, de la siguiente manera:

\footnotetext{
${ }^{182}$ Considerando 15 , bajo mismo apartado y laudo ibídem.

${ }^{183}$ Considerando 16, bajo mismo apartado y laudo ibídem.

${ }^{184}$ Considerando 17, bajo mismo apartado y laudo ibídem.

${ }^{185}$ Laudo del TPRM de 13 de enero de 2006, Recurso de aclaratoria, as. 1/2006. 
«El TPR[M] se limitó a señalar de todas maneras en ejercicio de su potestad jurisdiccional revisora el incorrecto alcance jurídico vinculado al objeto de la controversia establecido puntualmente en la segunda parte del ítem 90 del laudo del TAH [TAAM] aseverando que la pertinente cuestión se resolvía adoptando jurisprudencialmente la tesis del incumplimiento continuado de amplia divulgación en el derecho comparado. La adopción del TPR[M] de esta reconocida doctrina de manera alguna está en contradicción con la tesis argentina» ${ }^{186}$.

En conclusión, sumado a la moderación recién anotada, nosotros advertimos un pequeño freno por el cual la TPRM intenta desactivar la trascendencia del uso del diálogo judicial, pues los árbitros subrayan que se citó a la jurisprudencia europea sólo para mejor ilustrar, dado que a su juicio, esto era incluso innecesario ${ }^{187}$.

En definitiva, advertimos de modo nítido que estos tres últimos laudos analizados ${ }^{188}$ plantean de facto una mayor cercanía del MERCOSUR con el modelo de la UE, lo suficientemente similar, como para justificar las conexiones pretorianas mediante el diálogo judicial monologo y extractivo, pues para nosotros es evidente que si se extrae, se hace de una fuente compatible. Circunstancia de proximidad que paradójicamente colisionó con el fundamento central del posterior Laudo TAAM de 6-9-2006 según ya analizamos y subrayamos aquel lamentable retroceso conceptual que implicó ${ }^{189}$.

\subsubsection{LA ÚLTIMA CONEXIÓN DENTRO DE LA TERCERA ETAPA:}

EL TPRM MEDIANTE EL DIALOGO JUDICIAL MÁS CONTUNDENTE QUE HAYA EFECTUADO DESPOJA AL MERCOSUR DE LOS OBSTÁCULOS HISTÓRICOS

Finalmente en junio del año 2007 el TPMR desarrollaría la más contundente conexión a través de un tipo de diálogo judicial que una Corte mercosureña haya efectuado hasta hoy en día. Sucedió en el Laudo de la causa República Oriental del Uruguay c. República de

\footnotetext{
${ }^{186}$ Párrafo X del laudo ibídem.

${ }^{187}$ Idea que se sigue del contenido del Considerando XIX del laudo ibídem.

${ }^{188}$ Los tres laudos son: 1) Laudo del TAAM (número 9) de 4 de abril de 2003, República de Argentina c. República Oriental del Uruguay, 2) Laudo del TPRM de 20 de diciembre de 2005, República Oriental del Uruguay c. República de Argentina, as. 1/2005, y 3) Laudo del TPRM de 13 de enero de 2006, Recurso de aclaratoria, as. 1/2006.

${ }^{189}$ Laudo del TAAM de 6 de septiembre de 2006, República Oriental del Uruguay c. República de Argentina. (Constituido para conocer sobre «Omisión del Estado Argentino en adoptar medidas apropiadas para prevenir y/o hacer cesar los impedimentos a la libre circulación derivados de los cortes en territorio argentino de vías de acceso a los puentes internacionales General San Martín y General Artigas que unen la República Argentina con la República del Uruguay»).
} 
Argentina $^{190}$. El nuevo conflicto se originaba ahora porque Argentina - tras su propio desacato- alegó que las medidas compensatorias adoptadas por Uruguay eran desproporcionadas. Uruguay había tomado medidas especiales en atención a que expiró el plazo de 120 días para el cumplimiento del laudo y Argentina no se ajustaba a lo resuelto.

Lo interesante de este caso es la nueva visión que el TPMR le imprime en ese momento (año 2007) a todo el proyecto mercosureño, el cual ya no sólo decía relación con identificar patrones de conexión con el modelo de la UE, como lo habían hecho todos los anteriores laudos que ya hemos analizado, y que emplearon el diálogo judicial monólogo y extractivo, sino que ahora el camino buscado por el TPRM, no sólo era continuar aproximándose a la $\mathrm{UE}$, sino que además distanciarse del modelo $\mathrm{OMC}$, lo que marcaba un ritmo de coherencia con el previo acercamiento efectuado hacia la UE.

Argentina deseaba que se aplicaran los criterios compensatorios de la OMC y no los de la UE, por considerar que la estructura de la OMC era más próxima a la naturaleza y normativa del MERCOSUR orientándose a resolver materias comerciales y además porque el Derecho mercosureño se refiere expresamente a la OMC, y no a la UE. Así amparándose en la Convención de Viena sobre el Derecho de los Tratados, sostenía que nada autorizaría a aplicar en el MERCOSUR medidas punitivas del Derecho Comunitario europeo ni del Derecho Comunitario andino $^{191}$.

A nosotros nos parece que el criterio argentino es grave e incoherente, y no debe ser considerado como una simple defensa en un juicio, pues si la parte es un Estado que litiga dentro de un sistema de nivel internacional, del cual es miembro, entonces debe hacerse cargo de su trayectoria en tal OI, pues, si previamente está aportándole al mismo tribunal, precedentes del TJUE y argumentando que eran pertinentes sus aplicaciones en el MERCOSUR (en 2001 y en 2006) ${ }^{192}$, es sencillamente incoherente que ahora (en 2007)

\footnotetext{
${ }^{190}$ Laudo del TPRM de 8 de junio de 2007, República Oriental del Uruguay c. República de Argentina, as. $1 / 2007$.

${ }^{191}$ Argentina planteaba que siguiendo los criterios de la De la Convención De Viena sobre Derecho de los Tratados, en cuanto al indispensable consentimiento para que un Tratado Internacional pudiese crear obligaciones para los Estados, se requiere de norma expresa para aplicar el tipo de sanciones que se intentaban en su contra. Entonces, dado el marco que fijaban los Tratados, nada autorizaba a aplicar en el MERCOSUR, ni Derecho de la UE, ni Derecho de la CAN. El laudo en estudio (TPRM 8-6-2007) concentra estas posturas básicamente en el apartado 3 Alegaciones de las partes, vid. sub-apartados 3.1.12 y 3.1.14.

${ }^{192}$ En las dos causas que Argentina intentó que se considerasen antecedentes jurisprudenciales del TJUE, pueden verse primero en el Laudo del TAAM Aclaratorio recaído en el recurso de aclaración deducido contra el Laudo del TAAM (número 5) de 29 de septiembre de 2001, República Oriental del Uruguay c. República de Argentina, y el otro se observa en el Laudo del TAAM de 6 de septiembre de 2006, República Oriental del Uruguay c. República de Argentina. (Constituido para conocer sobre «Omisión del Estado Argentino en adoptar medidas apropiadas para prevenir y/o hacer cesar los impedimentos a la libre circulación derivados de 344
} 
sostenga una supuesta lejanía con la UE y una mayor proximidad con la OMC. Pues más allá de que los elementos fácticos de los juicios varíen, un Estado mercosureño debe mantener una unidad de criterio al momento de valorar al MERCOSUR, sobre todo, si consideramos que este proyecto ha ido madurando.

Certeramente los árbitros consideraron que ya a esa época (2007) se consolidaba una mayor cercanía con el esquema de integración de la UE, expresando que el MERCOSUR es mucho más próximo a la UE y a la CAN, que a la OMC, lo que justificaron reconociendo que en el MERCOSUR hay una comunidad de intereses no sólo económicos, representando un bloque regional consistente en un proceso de integración, y no un mero ente promotor de la liberalización comercial. Para el TPMR existe empíricamente «un proceso complejo de integración». Subrayemos que todos estos conceptos los agrupan los árbitros bajo el apartado que titularon «Marco conceptual». Y efectivamente en dicha sección del laudo, logran ser muy contundentes al explicar el progreso del proyecto mercosureño, así:

«a partir de la firma del Tratado de Asunción, los Estados Partes han creado una 'comunidad de intereses no sólo económicos y comerciales', sino también sociales, culturales, jurídicos y políticos. Ello se comprueba, principalmente [...] del Preámbulo del TA, y de su capítulo I "Propósitos, principios e instrumentos", pero así mismo a partir de considerar el desarrollo normativo del bloque, en el cual es posible encontrar normas sobre salud, justicia, educación, integración social, derechos laborales, medio ambiente, aspectos políticos, relaciones internacionales [...] como así también [...] de las Comunicaciones Presidenciales semestrales, la creación de determinados órganos de carácter no comercial, como el Parlamento del Mercosur» ${ }^{193}$.

El considerando transcrito marca un antes y un después en la historia de madurez del MERCOSUR, porque a esa altura era un hecho concreto el avance del proyecto en diversas áreas, pero no se lograban sumar todos los extremos de desarrollo en un único reconocimiento público que rindiera cuenta de un cambio ascendente del estadio del proceso MERCOSUR en su globalidad, cuestión que como vemos tuvo que venir por el cauce pretoriano, asentándose así, con claridad absoluta, que la comunidad mercosureña había sobrepasado con creces los contornos originarios meramente económicos, llegando a constituir una comunidad de mayor espectro.

los cortes en territorio argentino de vías de acceso a los puentes internacionales General San Martín y General Artigas que unen la República Argentina con la República del Uruguay»).

193 Apartado 7.2. del Laudo del TPRM de 8 de junio de 2007, República Oriental del Uruguay c. República de Argentina, as. 1/2007. Además vid. en particular los apartados 7.1, 7.2 y 7.5, y en general el apartado 7, titulado Marco conceptual. 
A partir de tan robusto argumento el diálogo judicial monologo y extractivo fluyó natural para el TPRM, pasando a conectarse con soluciones jurisprudenciales tanto del modelo europeo como del andino, lo cual desarrolló en extenso. Desde el TJUE extrajo algunos criterios aplicados en los casos Comisión c/República Helénica ${ }^{194}$, Comisión c/República Francesa (a) ${ }^{195}$, Comisión c/Reino de España ${ }^{196}$, Comisión c/República Francesa (b) ${ }^{197}$. Y en cuanto a su entorno, desde el TJCA importó determinadas soluciones de los casos Junta/Venezuela (a) ${ }^{198}$, Junta/Venezuela (b) ${ }^{199}$, Secretaría General/Perí ${ }^{200}$, y Secretaría General/Ecuador ${ }^{201}$.

En lo referido al desacato, el TPRM fue muy drástico. Para él, constituye uno de los actos unilaterales más delicados que un Estado Parte puede adoptar frente a las instituciones y al derecho mercosureño ${ }^{202}$. En tal posición y empleando el diálogo judicial monólogo y extractivo, primero pasó a alinearse - en línea horizontal - con el TJCA, expresando:

«Tal como lo ha sostenido el [TJCA], el desacato de una sentencia «constituye la más grave ofensa de cuantas puedan ser inferidos al Ordenamiento Jurídico Comunitario, pues lo resquebraja en su esencia al desconocer valores como el respeto del fallo que dirime una controversia en última instancia», tal situación «siempre y en todos los casos... es de gravedad extrema» ${ }^{203}$.

${ }^{194}$ Sentencia del TJ de 4 de julio de 2000, Comisión/Grecia, as. C-387/97, ECLI:EU:C:2000:356.

${ }^{195}$ Sentencia del TJ de 14 de marzo de 2006, Comisión/Francia, as. C-177/04, ECLI:EU:C:2006:173.

${ }^{196}$ Sentencia del TJ de 25 de noviembre de 2003, Comisión/España, as. C-278/01, ECLI:EU:C:2003:635.

${ }^{197}$ Sentencia del TJ de 12 de julio de 2005, Comisión/Francia, as. C-304/02, ECLI:EU:C:2005:444.

${ }^{198}$ Sentencia del TJCA de 20 de octubre de 1999, Sumario por incumplimiento de la sentencia del Proceso 1AI-97 Junta/Venezuela. GOAC 500, 25-10-99.

${ }^{199}$ Sentencia del TJCA de 27 de octubre de 1999, Sumario por incumplimiento de la sentencia del Proceso 3AI-96, Junta/Venezuela. GOAC 512, 26-11-99.

${ }^{200}$ Sentencia del TJCA de 1 de agosto de 2001, Sumario por incumplimiento de la sentencia del Proceso 34AI-99, Secretaría General/Perú.

${ }^{201}$ Sentencia del TJCA de 6 de marzo de 2002, Sumario por incumplimiento de la sentencia del Proceso 53AI-99 Secretaría General/Ecuador, GOAC 778 2-4-02.

${ }^{202}$ Apartado 8.3 en el Laudo del TPRM de 8 de junio de 2007, República Oriental del Uruguay c. República de Argentina, as. 1/2007.

${ }^{203}$ Apartado 8.4 en laudo ibídem, pasa a concretar un diálogo judicial extractivo con el TJCA, para lo cual el TPRM refiere textualmente así: «TJCA, 20 octubre 1999, sumario por el incumplimiento de la sentencia dictada en el Proceso 1-AI-97 Junta/Venezuela. GOAC 500, 25-10-99; de 27 octubre 1999, sumario por el incumplimiento de la sentencia dictada en el Proceso 3-AI-96, Junta/Venezuela. GOAC 512, 26-11-99, de 1 agosto 2001, sumario por el incumplimiento de la sentencia dictada en el Proceso 34-AI-99, Secretaría General/Perú, y de 6 marzo 2002, sumario por el incumplimiento de la sentencia dictada en el Proceso 53-AI99 Secretaría General/Ecuador, GOAC 778 2-4-02». 
Para el TPRM — apartándose de la postura argentina - la aplicación de los criterios andinos al desarrollo del MERCOSUR, son del todo correctos y perfectamente procedentes, de hecho se encargó de explicarlo utilizando dos casos del TJCA. Sobre el primero expresó: «En palabras del mismo Tribunal de Justicia, 'aplicables' al MERCOSUR, "Cuando se desacata una sentencia no sólo se causa un daño particular o concreto, que puede ser reparado con una medida compensatoria en favor de quien sufre el daño, sino que se agravia de una manera superlativa a todo el orden jurídico comunitario, convirtiéndose en un hecho que afecta a todos los Países Miembros, así como a los Órganos del Sistema al lesionar el proceso de integración"» ${ }^{204}$.

Y respecto del segundo indicó:

«Por otro lado, 'aplicando' la jurisprudencia andina, cabe constatar que en el caso de un incumplimiento de una decisión del Tribunal, la "gravedad de la infracción,... proviene del desacato de la sentencia que de por sí constituye un acto de gravedad extrema", pero así mismo "de la conducta” del Estado Parte que, en este caso afecta "uno de los pilares fundamentales en los que se asienta el proceso de integración" [...] al impedir la libre circulación de mercaderías reconocida por este Tribunal» ${ }^{205}$.

A diferencia de los casos analizados previamente, ahora el diálogo judicial monólogo y extractivo se usó de forma directa para dirimir el centro del conflicto respecto de los daños y de la proporcionalidad de las medidas uruguayas aplicadas contra Argentina. Para lo cual - y he aquí lo notable - el TPRM culminó por distanciar al MERCOSUR del modelo de la OMC, y lo aproximó directamente al de la UE. Ejercicio que fluye a partir del «marco conceptual» que el tribunal definió previamente según vimos pocas líneas atrás ${ }^{206}$.

Si bien este laudo no fue dictado por unanimidad, sino por mayoría, su valor es de trascendencia. Recordemos que el TPRM es una Corte de convocatoria permanente por lo que no se compone de los mismos árbitros en cada ocasión. Esta particularidad orgánica afecta lo sustantivo, pues dificulta el arrastre de criterios históricos del tribunal para que se culmine conformando un acervo del que emanen criterios más predecibles. De allí las drásticas diferencias que en ocasiones hemos observado en los laudos del merco-sistema ${ }^{207}$.

\footnotetext{
${ }^{204}$ Apartado 8.5 del Laudo del TPRM de 8 de junio de 2007, República Oriental del Uruguay c. República de Argentina, as. 1/2007. Aquí el TPRM realiza un diálogo judicial extractivo con el TJCA, indicando las referencias de la siguiente forma «TJCA, 6-3-2002, Proceso 53-AI-99, cit., y TJCA, 1-8-2001, sumario por el incumplimiento de la sentencia dictada en el Proceso 35-AI-99, Secretaría General/Perú».

205 Apartado 8.6 del laudo ibídem. El TPRM indica «TJCA, 4-8-2004, sumario por incumplimiento de la sentencia del Proceso 52-AI-02, Secretaría General/Venezuela, GOAC No 1108, 25-8-04».

${ }^{206}$ Apartado 7, titulado, Marco conceptual, en el Laudo del TPRM de 8 de junio de 2007, República Oriental del Uruguay c. República de Argentina, as. 1/2007.

207 Este laudo se dictó por mayoría. De acuerdo al art. 19 del Protocolo de Olivos para la Solución de Controversias Mercosur (POSCM), titulado Disponibilidad permanente, el TPRM es una Corte de convocatoria permanente — según ya lo analizamos en el capítulo II- por lo que no se compone de los
} 
Lo más significativo es que por medio de este laudo el TPRM abandonó las simples referencias o las tenues líneas de conexión con el modelo de la UE, para impactar de lleno y de forma contundente en el centro del litigio con los criterios importados, lo que efectúa del siguiente modo:

«Consecuencia de lo anterior, y de la antes citada diferencia con la OMC y semejanza con la Unión Europea y la Comunidad Andina, es que en el Mercosur se ha de prescindir del criterio del mero equilibrio entre las concesiones comerciales recíprocas aplicado en la primera de las Organizaciones citadas [OMC], y optarse por el criterio del daño globalmente considerado, afín con la práctica de estas últimas dada su diferente naturaleza, objetivo y alcance [nota 4]. [...].

[Nota 4] En la CE la Comisión en su comunicación sobre la aplicación del art.171 del Tratado CE (hoy art. 228 CE) No 96/C242/07 (DOCE No 242, 21 8-1996, p.6) estableció que: «La determinación del importe de la sanción debe estar guiada por el objetivo mismo de dicho instrumento: asegurar la aplicación efectiva del Derecho Comunitario. [...] debe calcularse en función de tres criterios fundamentales: la gravedad de la infracción, la duración de la misma, y la necesidad de asegurar el efecto disuasorio de la sanción para evitar la reincidencia», $[\ldots]{ }^{208}$.

De lo analizado en este apartado, se observa una especie de estrategia jurisdiccional mediante la cual el TPRM elimina los obstáculos históricos que se anclaban a los razonamientos interestatales originarios, con lo cual liberó al modelo mercosureño completo, pues lo impulsa a tomar conciencia del avance. Creemos que no podía ser de otra manera, pues un nuevo órgano debe traer nuevas luces al proyecto. Despejado entonces el camino, el laudo hace foco directo en sentencias específicas tanto del TJUE como del TJCA, incorporándolas sin problema alguno al merco-sistema, de la forma que sigue.

En relación al quantum aplicable, el TPRM estimó correcto el criterio europeo, por el cual la finalidad es inducir al cumplimiento, pero considerando la capacidad de pago del Estado incumplidor, conectándose con la solución europea así:

«En el caso europeo, el Tribunal de Justicia, al referirse a la suma a tanto alzada, y a la multa coercitiva como remedio para los supuestos de incumplimiento de sus sentencias, ha destacado que su finalidad es inducir al Estado miembro a que ponga

mismos árbitros en cada ocasión. En aquella oportunidad el tribunal fue integrado por el presidente del TPRM el Dr. Nicolás Becerra, el Dr. Wilfrido Fernández Frix como presidente de esa controversia, y el Dr. Ricardo Olivera, pero como la resolución fue por mayoría, no podemos conocer la opinión disidente, ya que en el MERCOSUR según el art. 25 del POSCM en este tipo de laudos no se publican las disidencias (excepto en las respuestas a las opiniones consultivas — art. 9, $\mathrm{n}^{\mathrm{o}}$ 1, literal c) del Reglamento del POSCM).

${ }^{208}$ Sub-apartado 10.1 y nota 4, bajo el apartado 10 Daños, en el Laudo del TPRM de 8 de junio de 2007, República Oriental del Uruguay c. República de Argentina, as. 1/2007. 
fin al desacato en el menor tiempo posible, fijando como criterio moderador que la misma sea proporcional a la capacidad de pago del Estado del que se trata y al incumplimiento propiamente dicho [nota 5]. [...].

[Nota 5] TJCE de 4-6-2000, Comisión c/Rep. Helénica, as. 387/97. Rec I5047. Considerandos 89 y ss.; y TJCE de 14-3-2006, Comisión c/Rep.

Francesa, as. 177/04. Rec I-2461. Considerando 61 y concordantes.

En cualquier caso, la medida aplicada debe garantizar que el Estado cumpla con la sentencia cuya falta de observancia se le imputa [nota 6]. [...].

[Nota 6] TJCE de 25-11-2003, Comisión c/Reino de España, as. 278/01. Rec I-14141. Considerandos 40 y ss.

y con ello garantizar la aplicación efectiva del Derecho Comunitario o, lo que es lo mismo, el restablecimiento de la legalidad jurídica [nota 7]. [...].

[Nota 7] TJCE de 12-7-2005, Comisión c/Rep. Francesa, as. 304/02. Rec I6263. Considerandos 80 y ss. y $103{ }^{209}$.

El TPRM se aleja de una naturaleza resarcitoria que pudiesen revestir las medidas tomadas ante un desacato, apoyándose los árbitros en cada sistema -UE y CAN. Primero afianzándose en el modelo europeo indicaron:

«El mismo Tribunal de Justicia ha destacado que las medidas mencionadas 'no tienen un sentido reparador' o de indemnización, sino presionar al Estado a que ejecute la sentencia dictada en su contra [nota 8].

[Nota 8] TJCE de 14-3-2006, Comisión c/Rep. Francesa, as. 177/04. Rec I2461. Considerandos 54 y ss.» ${ }^{210}$.

Y cuando vuelven la mirada a su entorno, destacan:

«Por su parte, el TJCA ha considerado que las sanciones que se apliquen en estos supuestos "no tienen por que estar referidas ni guardar relación sólo con la gravedad del daño ocasionado por la conducta que dio origen a que se adelantara la acción de incumplimiento y se dictara la sentencia objeto del desacato, sino que, 'necesariamente, debe descansar en el hecho objetivo del incumplimiento' de la sentencia del Tribunal" [nota 9].

[Nota 9] TJCA, 20-10-1999, Proceso 1-AI-97, cit.; de 27-10-99 Proceso 3AI-96, cit., y de 1-8-01 proceso 34-AI-99, cit.» ${ }^{211}$.

\footnotetext{
${ }^{209}$ Las sentencias indicadas en el Considerando 10.2 del laudo ibídem, en el mismo orden mencionado son las siguientes: Sentencia del TJ de 4 de julio de 2000, Comisión/Grecia, as. C-387/97, ECLI:EU:C:2000:356; Sentencia del TJ de 14 de marzo de 2006, Comisión/Francia, as. C-177/04, ECLI:EU:C:2006:173; Sentencia del TJ de 25 de noviembre de 2003, Comisión/España, as. C-278/01, ECLI:EU:C:2003:635; y Sentencia del TJ de 12 de julio de 2005, Comisión/Francia, as. C-304/02, ECLI:EU:C:2005:444.

${ }^{210}$ Considerando 10.3 del Laudo del TPRM de 8 de junio de 2007, República Oriental del Uruguay c. República de Argentina, as. 1/2007. Su nota 8, hace referencia a la Sentencia del TJ de 14 de marzo de 2006, Comisión/Francia, as. C-177/04, ECLI:EU:C:2006:173.
} 
Estimamos oportuno complementar aquí con un grado de precisión al fundamento que impulsa a abandonar el campo resarcitorio, pues en definitiva, ninguna de estas Cortes —ni las ubicadas en posición de fuentes, ni la receptora del diálogo judicial- explican el por qué estas medidas no colacionan en el campo resarcitorio. Únicamente asumen un cauce finalista para aseverar que los objetos de aquellas medidas serían el cumplimiento de los fallos, lo cual no está mal, pero es sólo el primer paso, porque al mostrar el objeto o fin de un instituto del derecho, sólo se nos anuncia el puerto de destino, tal como si se dibujase una ruta a seguir, en la cual se remarca el inicio y el final de la misma.

Ahora bien, la explicación del por qué ocurrirá tal efecto, se debe siempre enseñar en conexión a la naturaleza jurídica del instituto, en tal dirección, entendemos que si el objeto es extinguir el desacato, lo primero es retener que tal institución sólo deviene de rebeldías de sujetos procesales legitimados ante sentencias firmes, por tal motivo no tiene lógica alguna valorar el daño del incumplimiento, por cuanto no estamos en presencia de una acción indemnizatoria, sino que, en pleno campo procesal ante los efectos subjetivos de las sentencias, aunque con la particularidad de desplegarse éstos en el umbral internacional. Por dichas razones quedan comprendidas tales medidas, en el conjunto de «las herramientas de apremio, para la ejecución de las sentencias, aquí, en el nivel transnacional», lo que a su vez contribuye con el respeto a la res iudicata ${ }^{212}$ y con el efecto obligatorio de las sentencias de las Cortes de integración.

Por otro extremo, es notable apreciar el ejercicio liberatorio del TPRM al aseverar que «no requiere de delegación alguna de soberanía» para dar plena aplicación a un sistema foráneo de cálculo para multas coercitivas, entendiendo que con la desarrollada hasta ese momento más lo razonado, le era suficiente para insertar la mentada construcción exógena, la cual

${ }^{211}$ Considerando 10.4 del Laudo del TPRM de 8 de junio de 2007, República Oriental del Uruguay c. República de Argentina, as. 1/2007.

${ }^{212} \mathrm{Si}$ bien uno de los patrones centrales de las Cortes de Integración que ya estudiamos en el capítulo II es «la obligatoriedad de sus sentencias», la res iudicata en el nivel internacional basa gran parte de las expectativas de su cumplimiento en el auctóritas de la Corte. Lo cual se torna muy claro siguiendo el pensamiento de COUTURE, en cuanto, la sentencia es una obra humana, una creación de la inteligencia y de la voluntad, es decir: «una criatura del espíritu del hombre» [...], el contenido humano, profundo y entrañable del derecho, no puede ser desatendido ni desobedecido y «las sentencias valdrán lo que valgan los hombres que las dicten». COUTURE, 1949, vid. nota 28 de este capítulo. Pero cuando esto no opera, es menester hacer respetar la cosa juzgada por cauces coercitivos de ejecución, que precisamente es lo que está ocurriendo en los casos que se han comunicado mediante el tipo diálogo judicial en estudio. De allí la señalada naturaleza jurídica de las mentadas medidas, en simple y pleno ritmo de ejecución, tal como lo remarca GUASP al referirse a los efectos de las sentencias «la sentencia influye, además, constituyendo el título que permite una ejecución ulterior, supuesto típico y característico de las sentencias». GUASP, 1968, p. 526.

350 
desde ese instante pasó a ser parte del merco-sistema, pues resolvió que el Decreto uruguayo no era excesivo y rechazó la acción argentina.

La aseveración del tribunal se ubica en el centro de nuestra hipótesis, es decir, manifiesta el rol central de las Cortes de integración en sus procesos regionales, tendiendo a movilizarlos, fortalecerlos y a evitar el desinterés de los socios. Y no sólo este caso está en el centro de nuestra hipótesis, sino todos los que ya hemos destacados. Apréciese en este aspecto la conclusión del TPRM:

«el daño institucional comporta otro factor de vital importancia en la evaluación de la proporcionalidad [...]. A su vez, con las distancias del caso ya que en la Unión Europea están prohibidas las medidas compensatorias, sin embargo los criterios mencionados en este laudo dados a conocer por la Comisión Europea en relación al sistema de cálculo de multas coercitivas, son igualmente de plena aplicación al caso [...], para lo cual este Tribunal 'no' necesita en la realidad normativa actual de ninguna delegación de Soberanía» ${ }^{213}$.

\subsubsection{LA ANTESALA DE UN DIÁLOGO MÁS INTENSO DENTRO DE LA TERCERA ETAPA:} LA PREEMINENCIA DEL DERECHO MERCOSUR, EL DESPLAZAMIENTO DE LA LEY NACIONAL Y EL ORDEN PÚBLICO INTERNO NO ES UNA EXCEPCIÓN

Pocos meses antes de dictarse el laudo recién terminado de analizar, República Oriental del Uruguay c. República de Argentina cuestión que ocurrió en junio del 2007 y que hasta la fecha es el más contundente y rico en materia de diálogo judicial, el mismo TPRM dictó uno previo, en abril del mismo año, dando respuesta a una opinión consultiva en la causa Norte S.A. Imp. Exp. c/ Laboratorio Northia ${ }^{214}$. La razón que justifica que lo ubiquemos en una posición final, se debe a que no quisimos interrumpir la secuencia del conflicto de Uruguay con Argentina para una mejor comprensión global de aquella cuestión.

Pues bien, en este laudo, Norte S.A. Imp. Exp. c/ Laboratorio Northia, habían múltiples extremos, pero nosotros únicamente abocándonos a verificar algún tipo de diálogo, detectamos cuatro cauces en los que se usó dicha técnica de comunicación, en primer lugar, fue empleado para abordar la preeminencia del Derecho del Mercosur no sólo basado en el respeto a los Tratados, pues aquello sería una noción incompleta, en segundo lugar, se utilizó para establecer que, si el derecho de la integración «no fuese pleno» igualmente

\footnotetext{
${ }^{213}$ Párrafo $3^{\circ}$ del apartado IV Conclusiones, en TPRM, Laudo de 8-6-2007, República Oriental del Uruguay c. República de Argentina, as. 1/2007.

214 TPRM, Laudo de 3-4-2007, Opinión consultiva, Norte S.A. Imp. Exp. c/ Laboratorio Northia Soc. Anónima (...) s/ indemnización de daños y perjuicios y lucro cesante, as. OC. 1-2007.
} 
prevalece ante el DI, en tercer lugar, lo usó para explicar el desplazamiento del derecho interno ante el comunitario, y por último, el tribunal lo utilizó para importar el criterio de que el Orden Público no puede oponerse como excepción al cumplimiento comunitario.

En los cuatro cauces señalados en el párrafo anterior, el TPRM recurrió a dos modelos jurisdiccionales foráneos al merco-sistema, el primero, en una línea de casi verticalidad ${ }^{215}$ se conectó con las construcciones que el TJ hizo en sus sentencias Costa/Enel, y Dieter/Kombrach ${ }^{216}$; y el segundo, ahora en una línea más horizontal de diálogo judicial e inter-americano, recurrió a las sentencias del TJCA en Secretaría General/Ecuador, y en Consulta Corte Suprema de Colombia, Germán Cavelier y Alexandre Vernot ${ }^{217}$.

1. En cuanto a la prevalencia del derecho de la integración el TPRM la abordó desde varios ángulos. Comenzó por una aproximación amplia, en cuanto éste, simplemente es superior al nacional. Pero presionando en el argumento de tal superposición, aclaró que la supremacía del Derecho mercosureño no puede explicarse, únicamente, en base a que, un tal o cual Tratado Internacional lo disponga, pues eso supondría desnaturalizar esta clase de derecho. La Corte indicó que el argumento típico es cierto pero incompleto, y de paso enrostró a la doctrina y a la jurisprudencia un error constante, indicándolo del siguiente modo:

«Ha sido [...] un error constante tanto de la jurisprudencia como de la doctrina existente, el solo recurrir al argumento de la prevalencia del tratado sobre la ley para sostener la prevalencia [...]. Si bien este es un argumento [...] correcto, nunca debe constituirse en el argumento principal para el arribo a tal conclusión» ${ }^{218}$.

Para consolidar ese razonamiento recurrió a un diálogo judicial monólogo y extractivo, lo cual parecería una demostración de las tesis de los detractores del diálogo judicial, toda vez que los árbitros requirieron un respaldo foráneo, en un claro código de búsqueda de

\footnotetext{
${ }^{215}$ Recordemos que estamos empleando un concepto de 'cuasi' verticalidad para el diálogo monólogo y extractivo que emplean las Cortes latinoamericanas bajo análisis, cada vez que importan soluciones desde el TJUE, en razón del alto auctoritas que le reconocen al modelo europeo en su calidad de fuente, esquema pionero y vanguardista del Derecho de la UE, derecho que los esquemas latinoamericanos hacen coincidir con su visión amplia del Derecho de la Integración, y por lo cual buscan homologar criterios con las soluciones de la UE en la medida de las posibilidades latinoamericanas, tal como ya lo hemos analizado, vid. notas 35 y 43 de este capítulo.

${ }^{216}$ Sentencia del TJ de 28 de marzo de 2000, Krombach, as. C-7/98, ECLI:EU:C:2000:164.

${ }^{217}$ Sentencia del TJCA de 20 de septiembre de 1990, Interpretación prejudicial, Germán Cavelier y Alexandre Vernot, consulta de la Corte Suprema de Justicia de la República de Colombia, as. 2-IP-90. GOAC $\mathrm{N}^{\circ}$ 69, de 11-10-1990.

${ }^{218}$ Numeral 2 bajo el apartado C. Prevalencia de la norma de derecho de integración sobre la ley nacional, en el Laudo del TPRM de 3 de abril de 2007, Opinión consultiva, Norte S.A. Imp. Exp. c/ Laboratorio Northia Soc. Anónima (...) s/ indemnización de daños y perjuicios y lucro cesante, as. OC. 1-2007.
}

352 
legitimación ${ }^{219}$. Aunque a nosotros más bien nos parece la búsqueda de homogenización de criterios bajo el concepto amplio del derecho de la integración, exponiendo su criterio como sigue:

«El argumento principal debe ser siempre este: el derecho de integración por su concepto, naturaleza y finalidad debe ser siempre prevalente sobre los derechos nacionales respectivos por su misma esencia. Caso contrario, se desnaturaliza el concepto, la naturaleza y sobre todo la finalidad no solo del Derecho de Integración, sino del proceso de integración en sí mismo, o en palabras del Tribunal de Justicia de las Comunidades Europeas se pondría "en tela de juicio la base jurídica misma del Mercosur", La anterioridad o posterioridad de la norma nacional deviene absolutamente irrelevante [nota 10].

[Nota 10] TJCE, sentencia 15-7-1964 Costa/Enel, as. 6/64, EEE 1964-1966, pág. 99, (considerando décimo). A su vez dada la similitud con el presente asunto, resulta interesante recordar el [...] (considerando octavo)» ${ }^{220}$.

2. Luego avanzando en la prevalencia del Derecho de la Integración por sobre el DI Público y Privado, explica el TPRM que el derecho de la integración una vez que nace se alza absolutamente independiente del DI, у aunque "no fuere derecho comunitario pleno», debe igualmente prevalecer sobre el DI público y privado de todos los Estados Parte, independientemente de que tales normas fueren anteriores o posteriores al derecho de integración. Por tal razón no se puede justificar un incumplimiento comunitario, alegando un compromiso bilateral con otro Estado. Para explicarlo, se conecta con los razonamientos del TJUE del siguiente modo:

«El Derecho de Integración y Derecho Comunitario originario, si bien tienen su origen en una fuente propia del DI como lo son los tratados [...], a partir de su entrada en vigor adquieren evidentemente absoluta autonomía e independencia del ordenamiento internacional [nota 14].

[nota 14]. En tal sentido el TJCE ha destacado [...] -en conceptos aplicables al MERCOSUR - que "Considerando que, a diferencia de los Tratados internacionales ordinarios, el Tratado de la CEE creó un ordenamiento

\footnotetext{
${ }^{219}$ Retengamos que tal tipo de ejercicio no puede calificarse de diálogo judicial para los que niegan la teoría, pues justamente es este caso, el ejemplo que expone DE VERGOTTINI al decir «En otros casos respondería a la satisfacción de una exigencia de legitimación del juzgador cuando un tribunal está en el inicio de su actividad o cuando deba aplicarse un nuevo ordenamiento». DE VERGOTTINI, et al., 2010b. Vid. nota 30 de este capítulo.

${ }^{220}$ Numeral 3 bajo el apartado C. Prevalencia de la norma de derecho de integración sobre la ley nacional, en el Laudo del TPRM de 3 de abril de 2007, Opinión consultiva, Norte S.A. Imp. Exp. c/ Laboratorio Northia Soc. Anónima (...) s/ indemnización de daños y perjuicios y lucro cesante, as. OC. 1-2007. La jurisprudencia a que se está refiriendo el TPRM en su nota 10, es la Sentencia del TJ de 15 de julio de 1964, Costa/Enel, as. C-6/64, ECLI:EU:C:1964:66.
} 
jurídico propio, integrado en el sistema jurídico de los Estados miembros [...] que vincula a sus órganos jurisdiccionales" [TJCE sentencia 15-6-1964 Costa/Enel as. 6/64, EEE 1964-1966, p. 99 (considerando séptimo)] ${ }^{221} \gg$.

Entonces las justificaciones para la preeminencia del Derecho del Mercosur en los dos casos recién indicados (números 1 y 2 al margen, supra) sobrepasan el mero respeto a las obligaciones emanadas de un Tratado Internacional. Desde tal perspectiva, el derecho de la integración pasaría a ser más denso en su sustrato, es decir, comprendemos que su naturaleza privilegiada, lo libera de la obligatoria positivización exagerada de todas y cada una de las obligaciones que los Estados miembros deben asumir. Pues en realidad, los Estados al disponer voluntariamente el ser parte de la construcción de un proyecto integracionista, están obligándose para con las características de ese nuevo ordenamiento.

3. Al abordar la temática del desplazamiento del derecho nacional, ante el derecho de la integración, más no la derogación de la ley interna, el TPRM recurre nuevamente al diálogo, pero ahora se conecta con el TJCA. Recordemos que el tema del desplazamiento de la norma interna y del uso del diálogo para importar la solución, ya lo analizamos y para el mismo tribunal al cual el TPRM se está refiriendo aquí —el TJCA. Pero con la diferencia de que nosotros destacamos la sentencia de origen (1988) donde el TJCA importó la construcción europea $^{222}$, la cual es anterior a las que usa el TPMR, (1990 y 2002). El TPRM se conecta entonces con la secuela del criterio ya asentado en la CAN (que tampoco es el fallo que indica entre paréntesis así «recordando la sentencia dictada en el proceso 2IP-90»). Lo que en nada desmerece la figura del diálogo judicial, pero debimos acotarlo en esta investigación, a efectos de evitar confusiones en el lector. Los árbitros expresaron su criterio de la siguiente forma:

«Es asimismo tajante la siguiente jurisprudencia: 'El derecho de la integración, como tal, no puede existir si no se acepta el principio de su primacía o prevalencia sobre los derechos nacionales [...] En los asuntos cuya regulación corresponde al derecho comunitario [...] se produce automáticamente un desplazamiento de la competencia, la que pasa del legislador nacional al comunitario. La Comunidad organizada invade [...] el terreno legislativo nacional, [...] desplazando de este modo el derecho interno. El legislador nacional queda así inhabilitado para

\footnotetext{
${ }^{221}$ Numeral 2 bajo el apartado D Prevalencia de la norma de derecho de integración sobre el derecho internacional público y privado, en el Laudo del TPRM de 3 de abril de 2007, Opinión consultiva, Norte S.A. Imp. Exp. c/ Laboratorio Northia Soc. Anónima (...) s/ indemnización de daños y perjuicios y lucro cesante, as. OC. 1-2007. En la nota 14 del laudo, los árbitros se refieren nuevamente a la Sentencia del TJ de 15 de julio de 1964, Costa/Enel, as. C-6/64, ECLI:EU:C:1964:66.

${ }^{222}$ El caso que previamente estudiamos para el sistema de la CAN fue la Sentencia del TJCA de 25 de mayo de 1988, Interpretación prejudicial, Germán y Ernesto Cavelier, consulta de la Corte Suprema de Justicia de la República de Colombia, as. 2-IP-88. GOAC N 33 de 1988.
}

354 
modificar, sustituir o derogar el derecho común vigente en su territorio, [...] y el juez nacional [...] tiene la obligación de garantizar la plena eficacia de la norma común. El derecho de la integración 'no deroga leyes nacionales', las que están sometidas al ordenamiento interno: tan solo hace que sean 'inaplicables las que le resulten contrarias'. Ello no obsta, por supuesto, para que dentro del ordenamiento interno se considere inconstitucional o inexequible toda norma que sea incompatible con el derecho común ...'”. [TJCA sentencia 21-8-2002, as 34-AI-2001, Secretaría Gral/Ecuador, GOAC No 839, 25-9-02 (recordando la sentencia as. 2-IP-90)]» ${ }^{223}$.

4. Por último el TPRM usando este tipo de diálogo judicial monologo y extractivo, explicó lo impropio de oponer el Orden Público como una excepción al cumplimiento del Derecho de la Integración, adscribiendo a la tesis de la UE, por la que, si bien, no le compete definir el contenido del concepto de Orden Público, si le corresponde verificar sus límites, para neutralizar una excepción de tal estilo. Señalando al respecto:

«resulta aplicable al caso la siguiente jurisprudencia del TJCE: "por consiguiente, si bien no corresponde al TJ definir el contenido del concepto de orden público [...], sí le corresponde controlar los límites [...]. De ello se deduce que el orden público del Estado requerido no puede oponerse al reconocimiento o a la ejecución de una resolución dictada en otro Estado contratante por el solo hecho de que el tribunal de origen no haya respetado las normas del Convenio relativas a la competencia" (TJCE, 28-3-2000, Dieter/Kombrach, as. C-7/98, Rec. I-1935)» ${ }^{224}$.

El diálogo judicial empleado en este caso, es particularmente interesante dado la importancia de los criterios europeos importados, sumado al hecho — siempre valorableque las Cortes latinoamericanas usen conexiones con su entorno, más próximas a sus realidades, como en este caso lo fue con el modelo de la CAN. Aunque el TPRM no aclaró que el TJCA había previamente importado esta solución desde el TJUE, pues, con las sentencias andinas utilizadas, no se observa la importación que dicho tribunal hizo desde el modelo europeo. Podría entonces haber sido más preciso el TPRM y emplear la sentencia

\footnotetext{
${ }^{223}$ Numeral 5 bajo el apartado C Prevalencia de la norma de derecho de integración sobre la ley nacional, en el Laudo del TPRM de 3 de abril de 2007, Opinión consultiva, Norte S.A. Imp. Exp. c/ Laboratorio Northia Soc. Anónima (...) s/ indemnización de daños y perjuicios y lucro cesante, as. OC. 1-2007. El TPRM se conecta con la Sentencia del TJCA de 20 de septiembre de 1990, Interpretación prejudicial, Germán Cavelier y Alexandre Vernot, consulta de la Corte Suprema de Justicia de la República de Colombia, as. 2-IP-90. GOAC N ${ }^{\circ}$ 69, de 11-10-1990, y también con la Sentencia del TJCA de 21 de agosto de 2002, Secretaría General/Ecuador, as. 34-AI-2001. GOAC No 839, 25-9-02.

${ }^{224}$ Número 4 bajo el apartado E Prevalencia de la norma de derecho de integración sobre el orden público nacional e internacional, en el Laudo del TPRM de 3 de abril de 2007, Opinión consultiva, Norte S.A. Imp. Exp. c/ Laboratorio Northia Soc. Anónima (...) s/ indemnización de daños y perjuicios y lucro cesante, as. OC. 1-2007. En el paréntesis final de este número 4, los árbitros se refieren a la Sentencia del TJ de 28 de marzo de 2000, Krombach, as. C-7/98, ECLI:EU:C:2000:164.
} 
originaria del TJCA, a menos que, haya intentado mostrar dos orígenes diferentes. En realidad los criterios de las sentencias andinas usadas representan un rebote más de la fuente, la UE. Incluso, pudo ser más interesante transparentar el origen y, justificar la incorporación del criterio mediante el diálogo judicial ahora por el TPRM, bajo la lógica, nosotros también lo importaremos. O tan sólo fue un error. No lo sabremos.

En conclusión, de todo lo visto en el presente capítulo, se evidencia que las Cortes analizadas empleando un diálogo judicial monólogo, extractivo y de cuasi corte vertical incorporan elementos foráneos desde el TJUE; también desde otras fuentes, alcanzando al sistema internacional tradicional al usar criterios de la CIJ; asimismo se han conectado con Tribunales Constitucionales nacionales como con la CCi; y se auto-potencian al aplicar el diálogo de modo más horizontal conectándose a su entorno inter-americano entre el TPRM, el TJCA y la CCJ. Todo lo cual fortalece a los modelos latinoamericanos, pues la velocidad que apareja la importación de soluciones a través del diálogo judicial, es mayor a la que tiene el legislador de los esquemas de integración de América Latina.

Además, si todo lo anterior, se suma a la homogenización jurídica del derecho de la integración que pretenden las Cortes latinoamericanas, se concreta uno de los beneficios centrales del diálogo judicial, pues dicho fenómeno no se detiene a esperar la lenta movilización del legislador, sino que, aplica en el instante un remedio concreto al caso sub judice, con lo cual se introduce el criterio exógeno al sistema latinoamericano.

Ahora bien, del cúmulo de todas las cuestiones analizadas hasta este punto en la presente investigación, podemos hablar con propiedad de una influencia empírica del modelo europeo sobre los esquemas latinoamericanos, ya que en suma pudimos corroborar tres grandes afluentes que alimentan los proyectos latinoamericanos, primero, un afluente legislativo, a través de un evidente diálogo de fuentes ${ }^{225}$ según vimos en el capítulo II, al efectuar el cotejo estatutario de los modelos a ambos lados del Atlántico, segundo, un afluente jurisprudencial, tras constatar en el presente capítulo la existencia de un tipo de diálogo judicial monologo y extractivo desde el TJUE al cotejar las sentencias de las Cortes en análisis, y tercero, un afluente referido a la influencia de la doctrina estudiosa del modelo europeo.

${ }^{225}$ El diálogo de fuentes dice relación con la homogenización normativa que precisa una operación, no necesariamente interestatal, pues por ejemplo podría ser factible entre un Estado y una OI, o bien entre diversas OI. Nosotros lo hemos venido destacando en una aplicación hacia las construcciones jurídicas integracionistas — tal como ya lo vimos-SCOTTI, 2016, y JAYME, 1995.

356 
CAPÍtULO V

EL FUTURO DE LOS TRIBUNALES DE INTEGRACIÓN EN LOS PROCESOS REGIONALES DE AMÉRICA LATINA 


\section{CAPítulo V}

\section{EL FUTURO DE LOS \\ TRIBUNALES DE INTEGRACIÓN \\ EN LOS PROCESOS REGIONALES DE AMÉRICA LATINA}

\section{INTRODUCCIÓN}

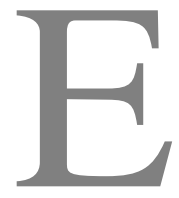

1 futuro de las Cortes latinoamericanas que fueron analizadas, la Corte Centroamericana de Justicia (CCJ) perteneciente al Sistema de Integración de Centroamérica (SICA), el Tribunal de Justicia de la Comunidad Andina (TJCA) perteneciente a la Comunidad Andina de Naciones (CAN) y el Tribunal Permanente de Revisión Mercosur (TPRM) comprendiendo en este último caso a los Tribunales Arbitrales ad hoc Mercosur (TAAM), es complejo de proyectar desde todos los ángulos que utilicemos, dado las constantes mutaciones, cambios de velocidad e intereses entre los Estados miembros de las tres organizaciones sui generis a que pertenecen nuestros objetos de análisis. Sin embargo, aquí intentaremos efectuar una proyección que recoja como antecedentes relevantes los avances de cada organización y Corte analizada.

Como lo planteamos al inicio de esta tesis, nos hemos encuadrado en una realidad concreta que de modo lo suficientemente amplio puede denominarse sistema integracionista, el cual es una realidad social, política y jurídica que existe y que responde a una teorización humana, precisamente a la teoría de la integración, la cual conlleva de modo indisoluble al derecho de la integración, comprendido éste en el sentido amplio ${ }^{1}$ tantas veces explicado y

\footnotetext{
${ }^{1}$ Como lo explicamos en el número 2 de la introducción de esta tesis, hemos considerado el concepto de Derecho de la Integración en un sentido amplio, refiriéndonos a la globalidad del fenómeno de la integración, tal como se emplea en los esquemas SICA, CAN y MERCOSUR para identificarlo como referente, o rama del derecho con la cual desean alinearse, considerándose en Latino América a la UE como la estructura pionera en la creación de este nuevo tipo de derecho y vanguardista en su interpretación y aplicación. En dicho
} 
que es precisamente el utilizado en Latinoamérica, foco de todos nuestros análisis en atención a que en tal contexto, existen y se desarrollan las Cortes latinoamericanas de los tres procesos de integración a que pertenecen.

Tanto la mega construcción de la UE donde se aposenta el TJUE, como las tres experiencias latinoamericanas el SICA con la CCJ, la CAN con el TJCA y el MERCOSUR con el TPRM y los TAAM, en su globalidad representan un desarrollo histórico vivo, en constante movimiento y expuesto desde sus inicios a las más críticas tensiones, por tal motivo su proyección global hacia el futuro, como dijimos, no es simple. Así las cosas, para comenzar ha de comprenderse la idea de éxitos exclusivos de la integración. En el sentido de que dicha proyección de lo que podría denominarse de modo amplio como sistema integracionista, y de los consecuentes modelos de integración sub-regionales que cobijan a las Cortes latinoamericanas analizadas, dependen por una parte, de la velocidad y grado de desarrollo que cada uno haya alcanzado, y por otra parte, de la valoración de sus éxitos constatables, los cuales necesariamente deben ser producto exclusivo de la asociación ${ }^{2}$. Es decir, aquellos que no hubiesen podido lograrse mediante esquemas colaborativos tradicionales, o peor aún, en el aislamiento estatal.

entendido los esquemas latinoamericanos bajo análisis, hacen coincidir casi de modo perfecto al Derecho de la UE con el Derecho de la Integración. En términos amplios en América Latina se hace referencia al Derecho de la Integración como un genérico para intentar destacar las similitudes entre todos los modelos. Recordemos además que algunos autores — que en cada caso ya los indicamos- emplean los conceptos amplios de Derecho del grupo, o simplemente Derecho de la Unión, para referirse de modo general a todos estos esquemas, en este último caso, incluso en la UE existe múltiple normativa redactada de esta simple forma, $v . g r$. en el TUE el art. 6.3 «... formarán parte del Derecho de la Unión como principios generales», el art. 17.1 «... del Derecho de la Unión bajo el...», siguen los arts. 19.1, 19.3.b, 64,1, etc., luego en el TFUE el art. 16.2 «...del Derecho de la Unión, y...», el art. 58, «...de la violación del Derecho de la Unión por parte...», el art. 62 «...o de la coherencia del Derecho de la Unión», le siguen los arts. 62 ter, 197.1, etc.

${ }^{2}$ Sin éxitos exclusivos de la asociación los modelos integracionistas carecen de todo sentido. Precisamente en un mundo globalizado, es donde mejor se observan los logros integracionistas. V.gr los beneficios para los ciudadanos de la UE que se siguen del Programa Espacial Galileo serían sencillamente impensables de otro modo, cuestión muy valorada por las nuevas generaciones, que son justamente a quienes debemos motivar en los valores positivos de la integración, para que trabajen en equipos de ambiciosos objetivos. Al respecto JUNCKER certeramente subraya: «Nuestro programa Galileo es el que mantiene actualmente a Europa en la carrera espacial. 'Ningún Estado miembro hubiera podido poner en órbita 26 satélites de los que se benefician 400 millones de usuarios en todo el mundo. Ningún Estado miembro podría haberlo conseguido de forma aislada'. Galileo es, en efecto, un éxito principal, si no exclusivamente, europeo. Sin Europa, no habría Galileo. Estemos orgullosos de ese logro». JUNCKER J-C. (2018). Estado de la unión 2018: la hora de la soberanía europea. Discurso sobre el estado de la Unión 2018, p. 5. Disponible en <https://ec.europa.eu/commission/priorities/state-union-speeches/state-union-2018_es> [última consulta, junio 14, 2019]. Otros objetivos exclusivos de la asociación son por ejemplo las mejores negociaciones comerciales con países foráneos y con otros bloques, el mantenimiento de la paz entre los asociados, etcétera. 362 
Toda valoración de proyectos u obras respecto de su proyección hacia el futuro, se enfrenta a la disyuntiva de sepultar el proyecto, o bien de insistir en estos, y en América Latina muchas veces se han deseado sepultar por completo los proyectos analizados (SICA, CAN y MERCOSUR), pero si nos quedamos en la segunda opción — la insistencia — aparecen otros diversos matices que emergen de las correcciones a los esquemas implementados. Esta última decisión es la más habitual en el mundo político y —en particular - en el nivel internacional, donde de tanto en tanto, se relanzan revitalizadas las OI y sus instituciones. Tales relanzamientos teñidos la mayoría de las veces por aquella tan poco creativa idea de cambiar el nombre a las instituciones, es un fenómeno real que no podemos ignorar y que veremos líneas más adelante.

Centrándonos en los esquemas de integración advertimos que éstos siempre han estado en constante acomodo y perfeccionamiento, en general, todos los que hemos analizado SICA, CAN y MERCOSUR - han progresado bastante desde sus orígenes, haciéndose cada vez un poco más robustos. Solidez que en lo medular no es cuantitativa, sino cualitativa. Razón por la cual esto nunca ha cruzado por la cantidad de socios, como si únicamente dependiesen de sus ingresos y salidas, sino que lo robusto de un modelo se encuentra en la lealtad, en el compromiso y en la cooperación reforzada de los que permanecen. Tales componentes son la causa de que en América Latina unos modelos se fortalezcan más que otros o tomen velocidades diferentes.

Ahora bien, la visión de progreso optimista orientada hacia el futuro para dichos modelos, es la que claramente no comparten los que reniegan de los esquemas de integración, como por ejemplo los euroescépticos ${ }^{3}$ o las corrientes disociadoras en América Latina. Para

${ }^{3}$ Los euroescépticos o desencantados son minoritarios en la UE. Nacen de críticas internas propias de los
inconformismos. No necesariamente porque hayan sufrido algún tipo de daño específico, sino más bien,
porque no constatan 'todos' los aspectos positivos deseados o prometidos. Vemos que los ciudadanos de la
UE son mucho más críticos con este proyecto, que el resto del mundo. Extra muros, se la observa como un
proceso exitoso, pues a la mayoría de las naciones les es suficiente con constatar las mega-estructuras
jurídico políticas creadas para valorar el proyecto. Nosotros estamos convencidos de que no podemos
pretender que los ciudadanos, no sean críticos de las estructuras que los regulan y les afectan. Por el contrario,
son los primeros llamados a ser severos con sus mandatarios que administran sus impuestos. Siempre
debemos estar atentos a las autocríticas de los destinatarios finales. Mucho - sino demasiado- se ha escrito
de los euroescépticos, et al. MORENO, alineándose con la metáfora «el cuento de navidad» -acuñado por
DULFFER- advierte que ya no puede sostenerse la narrativa unitaria construida por científicos sociales,
pues ha venido produciéndose una crisis fundamentalmente en dos direcciones: bien a través de la
problematización política del proyecto comunitario, bien como parte del conflicto simbólico en torno a la
identidad y cultura europeas. MORENO JUSTE, A. (2013). El fin del relato europeo. La crisis del proceso de
integración y su impacto sobre las narrativas europeas. Revista de derecho comunitario europeo, 17(45), 607-
630. Bastante más pesimistas SHMITE y NIN para quienes estaríamos frente a una crisis estructural en
Europa, el cual desde un análisis geográfico se detona en las ciudades altamente urbanizadas, donde los
habitantes exteriorizan sus desencantos. Sin embargo, dentro de sus críticas advierten que «a la UE se le 
nosotros, todas al alero de los mal denominados nacionalistas, pues, si verdaderamente fuesen nacionalistas, buscarían lo mejor para sus naciones, lo que jamás cruza por ingresarlas a un monasterio medieval de clausura.

Por lo tanto, toda visión de futuro enfocada a una estructura político-jurídico-social debe ser global, de lo contrario nunca podríamos apreciar - realmente - su comportamiento de grupo. Es decir, la visión macroscópica -y no la microscópica 4 - es la que debe prevalecer para efectuar los análisis de futuro como en el que nos estamos adentrando en el presente capítulo. Ya que las incidencias y conflictos los hay por cantidades abrumadoras. Pero éstos obstáculos, o poseen la fuerza para destruir el proceso completo, o pasan a recordarse como simples anécdotas históricas, como la silla vacía ${ }^{5}$ en el modelo europeo. Y de éstas últimas anécdotas, las construcciones humanas siempre salen fortalecidas. Bajo dicho planteamiento nos avocaremos en este último capítulo a mostrar una visión de futuro centrada en la CCJ, el TJCA y el TPRM.

deben reconocer logros importantes, como: la reconciliación y acercamiento con países que estuvieron enfrentados; la construcción de democracias estables en todos los países miembros; y el nivel de vida elevado, [...] es una de las regiones más dinámicas desde la perspectiva económica, y resulta atractiva para los ciudadanos de otros países de Europa del Este [...] incluso Turquía. Asimismo, para ciudadanos de otros países del mundo». SHMITE, S. M. \& NIN M. C. (2014). Europa en crisis: el desencanto de la unión europea. Papeles de geografía, 59(60), pp. 173-186 (p. 175).

${ }^{4}$ En nuestro caso, las proyecciones hacia una nueva era de la integración no admiten visiones mínimas, sólo amplias. Las visiones de campo amplio son las empleadas en el derecho por los grandes juristas cuando deben desempantanar conceptos, o bien para transitar de una era a otra. Tal como cuando COUTURE enfrenta las conceptualizaciones de ROUSSEAU con las de POTHIER, explicando «Entre el pensamiento de Pothier cuando fundamenta la cosa juzgada en el contrato privado y el pensamiento de Rousseau cuando busca la explicación de la convivencia humana en el contrato social, existe una diferencia de escala, pero no de esencia. El pensamiento de Pothier es microscópico; el de Rousseau macroscópico». COUTURE, E. J. (1949). Introducción al estudio del proceso civil. Depalma, Buenos Aires, Argentina, 1949, pp. 48-49.

${ }^{5}$ La crisis de la silla vacía ocurrió en el año 1965 y se caracterizó porque Francia — presidida por Charles de Gaulle - abandonó el Consejo y no asistió a las principales votaciones durante 6 meses, como un boicot por su disconformidad con el cambio del sistema de votación en el Consejo, el cual pasaba mutar de unanimidad a mayoría cualificada. Situación que fue superada en 1966. Puede revisarse con todo detalle en TRUYOL \& SERRA, A. (1999). La integración europea: Análisis histórico-institucional con textos y documentos - Tomo I génesis y desarrollo de la unión europea (1951-1979). Madrid: Tecnos, vid. en particular: Tomo I, Capítulo III, apartado: De la crisis de 1965 (...), p. 49. 


\section{LOS DESAFÍOS DE LOS MODELOS DE INTEGRACIÓN REGIONALES DE LATINOAMÉRICA QUE AFECTAN A SUS TRIBUNALES DE INTEGRACIÓN}

Los modelos integracionistas regionales o sub-regionales ${ }^{6}$ han llegado para quedarse dentro de las estructuras de la dimensión internacional. Máxime si a estas alturas el mundo se encuentra sorteando los efectos de la globalización y de las cada vez más sofisticadas necesidades de nuestras sociedades, las cuales unidas, logran objetivos que aisladamente no alcanzarían jamás. Todos los modelos sub-regionales y en particular sus órganos jurisdiccionales analizados, presentan grandes secuencias evolutivas cuyos principales hitos fuimos poniendo de relieve oportunamente, como por ejemplo el desarrollo del Sistema de Solución de Controversias del Mercosur (SSCM) que se construyó por medio de las etapas que vimos, o el hecho de que la CAN haya incorporado a su estructura institucional al TJCA, más todos los otros ejemplos de desarrollos de estos tribunales durante su ejercicio produciendo diversa jurisprudencia integracionista, tal como ya analizamos en extenso.

Nuestro referente es un caso exitoso por dónde se le aborde. La UE es un proyecto de futuro sembrado en las cenizas de la post Segunda Guerra Mundial, que luego sorteó la Guerra Fría, el complejo ingreso de socios, ha debido reinventarse en más de una oportunidad hasta llegar a la actual UE. En su línea de futuro constante, ha debido enfrentar múltiples problemas como el histórico evento de la silla vacía que mencionamos en el último párrafo del apartado anterior, también se ha debido reconducir buscando nuevos contenedores conceptuales como el Tratado de Lisboa ante la fallida Constitución para Europa $^{7}$, ha recibido reproches por las formas de enfrentar las crisis económicas (España y

\footnotetext{
6 Hablamos de esquemas de integración sub-regionales por lo establecido en nuestro marco de la investigación, lo que explicamos en el punto 2 de la introducción de esta tesis, en atención a la idea de que los esquemas que hemos considerado, no abarcan al continente americano por completo, sino a una zona menor, además así se recoge en diversa jurisprudencia y textos legales, por ejemplo en cuanto a jurisprudencia que use esta terminología encontramos: Sentencia de la CCJ de 27 de noviembre de 2001, Nicaragua c. Honduras, expediente 25-05-29-11-1999, as. 69/01. Sentencia del TJCA de 20 de octubre de 1999, Sumario por incumplimiento de la sentencia del Proceso 1-AI-97 Junta/Venezuela. GOAC 500, 25-10-99. Laudo del TAAM (número 9) de 4 de abril de 2003, República de Argentina c. República Oriental del Uruguay. Y ejemplos de cuerpos legales que se refieran de este modo, podemos destacar entre otros al Acuerdo de Integración 'Subregional' Andino. A su vez, la idea de modelo sub-regional o regional de integración, es menor a la noción que empleamos para sistema de integración, pues con en éste último intentamos englobar el fenómeno completo en el mundo, el cual nace en Europa manteniéndose la UE en su calidad de modelo pionero y vanguardista, al que le intentan seguir otros tantos modelos en América Latina, África y también en Asia en carácter de receptores incompletos o no plenos.

${ }^{7}$ Recordemos que el Tratado de Lisboa fue el contenedor de emergencia utilizado para salvar parte del contenido del fallido Tratado para la Constitución Europea. Nos remitimos en esto al capítulo I sobre análisis
} 
Grecia), o por la forma de abordar los tristes episodios migratorios, y hoy, se encuentra sorteando el Brexit, es decir, si el sistema más robusto y desarrollado enfrenta diversas dificultades, es evidente que también los esquemas Latinoamericanos enfrentaran los suyos.

En tal ritmo podríamos listar una infinidad de heridas que han obligado a la UE a adecuarse para continuar hacia el futuro. Injustamente, en ocasiones incluso, pareciera olvidársenos su monumental éxito, que es el de ser la primera estructura en toda la historia de Europa que ha consolidado la paz, y por las vías de la paz, «(...) mi generación es la primera generación de europeos que no ha ido a una guerra, 'todas' las anteriores habian estado en una» ${ }^{8}$. Nuestro modelo de referencia, ha desplegado notables ejercicios de madurez, que han conducido a esta sui generis organización - de profundas concepciones valóricas - a consolidarse como el espacio de libertad, seguridad y justicia que mejores condiciones de vida ofrece en todo el planeta. Pero el punto aquí, es mirar hacia Latino América.

En América Latina los socios de los tres modelos de integración son países en vías de desarrollo y de tanto en tanto enfrentan inestabilidades locales de varios tipos, creando un contexto de avances lentos, también de retrocesos y en ocasiones de repentinos éxitos. El SICA ha sabido - en su realidad y con sus recursos- organizarse y estructurarse con un proyecto de profunda integración sub-regional, el cual colisiona constantemente en incidencias locales, pero no se destruye. La CAN nace y se desarrolla convulsa, pero va incorporado una mayor institucionalidad como al TJCA, aunque siempre bajo críticas condiciones. El MERCOSUR por su parte es un caso de impensados progresos, pues una austera idea de cooperación comercial intergubernamental, ha mutado del modo más singular, desarrollando efectivamente su orgánica, incorporando sus actuales tribunales y cubriendo prácticamente todas las áreas de interés del ciudadano, incluso ingresando en la dimensión protectora de los derechos humanos. A todo lo anterior se suman dos aspectos de carácter expansivos, de un lado, la posibilidad de acercamientos más sustanciales entre los esquemas latinoamericanos, y de otro lado, la aparición de nuevos actores, o el desarrollo de participantes actualmente más débiles que los tres analizados y que pudiesen desarrollar nuevos esquemas más globales de integración.

histórico. Vid. además et. al. ALDEOCA LUZURRAGA, 2008. MATIA PORTILLA, et al. 2009. MÉNDEZ DE VIGO \& OREJA AGUIRRE, 2007. MILLÁN MORO, 2010.

${ }^{8}$ GIL ROBLES, «Quiero decir que los europeos tenemos ya una sensibilidad muy especial a todo lo que suponga conseguir la ausencia de enfrentamiento.- Mi generación es la primera generación de europeos que probablemente no ha ido a una guerra, y las siguientes más todavía. Todas las anteriores habían estado en una guerra, mundial, europea, o entre sus correspondientes países». GIL ROBLES, J. M. (2002). Los retos de la globalización y el liderazgo de la unión europea. Revista de derecho de la unión europea, (2), 225-232. (p. 228). 
Por la primera hipótesis expansiva, se ha planteado hacia el futuro un acercamiento más formal o bien institucional en el Cono Sur de América, esto es, entre la CAN y el MERCOSUR, cuestión que nos parece bastante difícil, toda vez que al menos actualmente estos esquemas obedecen a diversas ideas de integración, claramente el MERCOSUR arrastra su origen intergubernamental, mientras que la CAN intenta desarrollar patrones más cercanos al derecho de la integración, y a todo se suma la clara crisis ${ }^{9}$ de la CAN, mientras que el MERCOSUR se observa más sólido ${ }^{10}$.

Sin embargo, hacia el futuro pudiese ser factible el acercamiento pero teniendo en consideración algunas cuantas premisas, una, que no es posible pertenecer a dos esquemas de integración, aquello obedece a una contradicción en sí misma, dos, sería indispensable formalizar un vínculo entre las dos OI, tres, sería necesario crear, o fusionar algunos aspectos, dando paso a un ordenamiento jurídico común para las dos OI, cuatro, debe asegurarse una igualdad de rango entre las dos organizaciones, y cinco, resultaría fundamental crear una institucionalidad nueva en general ${ }^{11}$. Como vemos, la labor sería titánica, sin considerar el riesgo para el MERCOSUR, que ha sabido meridianamente sortear sus conflictos y avanzar objetivamente, a diferencia de los países integrantes de la CAN que en general, son más inestables.

\footnotetext{
${ }^{9}$ La crisis de la CAN la viene destacando mayoritariamente la doctrina. QUINDIMIL LÓPEZ, 2006. ACOSTA PUERTAS, 2006. GODOY \& GONZÁLEZ ARANA, 2009. GÓMEZ JUTINICO, 2010. BLANCO ALVARADO, 2014. CAETANO, 2015. BRICEÑO RUIZ, 2018.

${ }^{10}$ En esta línea para el MERCOSUR et al. BIZZOZERO REVELEZ, 2001. LUCÁNGELI, SANGUINETTI \& ZAMORANO, 2010.

${ }^{11}$ En este cauce de acercamiento, KÜHN destaca que Ecuador y Bolivia no desean abandonar a la CAN, sino pertenecer a ambos bloques - CAN y MERCOSUR. Pero el autor descarta la doble pertenencia, por una incompatibilidad de objetivos, por diferentes niveles de desarrollo, por incompatibilidad de sistemas jurídicos, etc. Propone entonces desarrollar un nuevo vínculo jurídico que compatibilice dichos proyectos, sin necesidad de crear más órganos, sino apostando a la cooperación. Para esta misión KÜHN ejemplifica con la relación entre la UE y la EFTA a través del Espacio Económico Europeo (EEE) por el cual se respeta el principio de homogeneidad que exige que existan condiciones de comercio idénticas dentro del mercado único; el principio de reciprocidad del DI que no tiene equivalente en el Derecho de la UE y es reflejo del hecho de que el Acuerdo EEE prevé la integración entre dos sistemas de integración distintos. Pero han de adoptarse principios del derecho comunitario, o de la integración. Como propuestas concretas para la CAN y el MERCOSUR, propone crear un ordenamiento jurídico común en base a un «acuerdo mixto» al que bautiza como «Tratado CANMER» el cual le ampliaría las competencias a todos los órganos. La matriz rectora de la nueva realidad debería ser el principio de la homogeneidad. Y en un aspecto bastante sensible, KÜHN propone que sea el TJCA el competente en acciones de incumplimiento y otras, mientras el MERCOSUR no tenga su pertinente órgano de naturaleza jurisdiccional y permanente. KÜHN BACA, W. M. (2015). Reflexiones sobre una posible convergencia regional con la participación de la Comunidad Andina y del Mercosur. Lecciones de la experiencia integracionista europea. Revista general de derecho europeo, 36, (RI $\S 416102)$.
} 
Por la segunda hipótesis expansiva, encontramos el posible hecho de que en el futuro, tal vez otros procesos de perfiles integracionistas mucho más débiles o incipientes que los tres latinoamericanos estudiados (SICA, CAN y MERCOSUR) pudiesen llevar adelante itinerarios de mayor madurez, como en su momento se pensó que pudiesen haber sido la Unión de Naciones Suramericanas (UNASUR) ${ }^{12}$ y la Caribbean Community $(\mathrm{CARICOM})^{13}$. Aunque hasta ahora eso no ha sido posible, de hecho UNASUR está ya completamente colapsada $^{14}$, sin embargo, algunos pocos aún le depositan esperanzas, incluso en su oportunidad se pensaba que esto debería comenzar a través del desarrollo de sus ambiciosos objetivos específicos, entre los cuales, se llegó a plantear una ciudadanía suramericana, hablándose hasta de la Corte de Justicia Unasur (CJU) ${ }^{15}$.

${ }^{12}$ UNASUR surge en 2008 mediante el Tratado Constitutivo de la Unión de Naciones Suramericanas. Posee su sede en Quito, Ecuador. Representando una organización de cooperación internacional de muy ambiciosos objetivos específicos en diversas áreas. Portal oficial UNASUR <https://www.unasursg.org> [última consulta, diciembre 20, 2018]. Los proyectos como UNASUR y ALBA aparecen dos décadas después de los analizados en esta tesis, intentando jugar un papel más amplio o a lo menos diferente al SICA, la CAN y Mercosur. CIENFUEGOS MATEO, M. \& SANAHUJA, J. A. (2010). Una región en construcción: UNASUR y la integración en américa del sur. Barcelona: Fundación CIDOB.

${ }^{13}$ La CARICOM nace en 1973 mediante el Tratado de Chaguaramas. Es una OI intergubernamental, orientada básicamente a aspectos comerciales, encontrándose lejana de los patrones de un modelo integracionista como los que hemos estudiado. Su idioma central es el inglés, posee una estructura institucional con tres tipos de instituciones: las comunitarias, las asociadas y las de cooperación funcional, entre las primeras encontramos a la Caribbean Court of Justice de 2005, cuyo acrónimo en inglés (CCJ) pasa a confundirse mucha veces con el acrónimo en español de la Corte Centroamericana de Justicia (CCJ) del SICA. La CARICOM ha significado un impulso para las economías centroamericanas, se ha mantenido en constante ejercicio, pero ha sufrido crisis importantes, lo que en 2012 llevó a levantar con el apoyo de la UE el reporte: Turning Around CARICOM: Proposals to Restructure the Secretariat, disponible en: <https://caricom.org/documents/9400-restructuring_the_secretariat_-_landell_mills_final_report.pdf> (última consulta: diciembre 24, 2018). Más detalles pueden consultarse en su Portal oficial disponible en: <https://caricom.org> [última consulta, diciembre 24, 2018].

${ }^{14}$ Diversos países han abandonado a la UNASUR y actualmente se ve ad portas de su desaparición. MIJARES, V. M. \& NOLTE, D. (2018). Regionalismo posthegemónico en crisis: ¿por qué la UNASUR se desintegra?. Foreign affairs: latinoamérica, 18(3), 105-112. También se observa una alta cantidad de noticias sobre la desaparición de UNASUR, et. al. SÁNCHEZ, F. (2018). ¿El fin de Unasur? y la crisis del regionalismo suramericano. Razón pública. Disponible en <https://www.razonpublica.com/index.php/politica-y-gobierno-temas-27/11364-el-fin-de-unasur-y-la-crisis-del-regionalismo-suramericano.html> [última consulta, mayo 26, 2019]. Otra, MIZARI, D. (2018). 5 claves para entender la crisis (¿final?) de la Unasur. Infobae. Disponible en <https://www.infobae.com/america/america-latina/2018/04/28/5-claves-paraentender-la-crisis-final-de-la-unasur/> [última consulta, mayo 30, 2019].

${ }^{15}$ UNASUR no posee otros órganos y, como anotamos, la mayoría de los países la han abandonado. Pero todo esto no ha impedido a una pequeña parte de la doctrina imaginar un tribunal para UNASUR. MAZZUOLI plantea una Corte inspirada en la CCJ (SICA) y en el modelo del TJUE, justificándose al expresar «Uno de los propósitos inmediatos de Unasur es fortalecerse como organización comunitaria capaz de atender las necesidades y objetivos comunes de sus miembros. La organización, sin embargo, solamente alcanzaría los propósitos para los cuales fue instituida cuando exista uniformidad jurídica en la aplicación, entre sus Estados-miembros, de ese derecho común (comunitario) pretendido para el bloque. En ese sentido, importa 368 
A efectos aclaratorios, y necesarios en un análisis de futuro como este, retengamos que es diferente la posición de la CARICOM pues, esta OI caribeña fundada en 1973, posee una institucionalidad más desarrollada que UNASUR. La CARICOM se sustenta en cuatro pilares, la integración económica, la coordinación de la política exterior, el desarrollo humano y social, y la seguridad. Su estructura orgánica presenta una división tripartita distinguiendo entre instituciones comunitarias, asociadas y de cooperación funcional, entre las primeras - las instituciones comunitarias - encontramos a su tribunal la Caribbean Court of Justice nacida en 2005. Como algunos de sus Estados pertenecen tanto al SICA como a la CARICOM, sumado al factor geográfico, las CCJs (la Caribbean Court of Justice y la CCJ) han entrado en un especial tipo de dinámica jurisdiccional para resolver conflictos propios de los mercados comunes y con esto contribuir al éxito de la región según destaca la doctrina ${ }^{16}$ especializada en esa zona de Latinoamérica. Pues bien, lo visto en este apartado es el contexto que debemos tener presente para proyectar el futuro de nuestros objetos de estudio, la CCJ, el TJCA y el TPRM.

que tenga existencia (y que funcione coherentemente, con jueces imparciales e independientes) un tribunal de solución de controversias, capaz de controlar la convencionalidad de las normas internas (de los Estados) y de sus propios órganos (de la propia Unasur) relativamente al Derecho Comunitario vigente». MAZZUOLI, V. d. O. (2014). Por un tribunal de justicia para UNASUR: La necesidad de una corte de justicia para américa del sur sobre los paradigmas del tribunal de justicia de la unión europea y de la corte centroamericana de justicia. Revista da secretaria do tribunal permanente de revisão, 2(4), 189-217 (p. 203).

${ }^{16}$ Para CASERTA la posibilidad real de que ambas Cortes incrementen un proceso de integración más robusto, en lo que él denomina motores de integración, cruzaría porque se les atribuyan nuevas competencias. CASERTA, S. (2017). Regional integration through law and international courts - the interplay between de jure and de facto supranationality in central america and the caribbean. Leiden journal of international law, 30(3), 579-601. Otra visión de esta interesante relación SICA/CARICOM, puede revisarse en: ANDÓN, A. (2017). Relaciones SICA-CARICOM: Un acercamiento histórico. Derecho y economía de la integración, (4), 121-129. Ahora bien, la relación del SICA/CARICOM se produce en una dinámica natural, toda vez que comparten geográficamente similares aspectos para el desarrollo del comercio de la sub-región. El aporte de ambas Cortes se produce más bien en aspectos del derecho comercial. Pero no perdamos de vista las reales dimensiones, ya que la Corte del SICA tiene un mayor desarrollo que la Corte de la CARICOM, posee muchísima más historia, obedece a lógicas integracionistas más robustas, y su experiencia es muy superior. 


\section{LOS DESAFÍOS DE FUTURO DE LAS CORTES LATINOAMERICANAS} DE LOS PROCESOS DE INTEGRACIÓN REGIONALES

En los tres modelos latinoamericanos analizados se presentan líneas de futuro bastante diferentes, así en lo sustantivo algunos modelos — como veremos en este apartadocuentan con proyectos ya en marcha y otros en reflexión, unos orientados a estabilizar su desarrollo y otros para dar pasos incluso orgánico-institucionales. Justamente en estos planes de futuro se disponen también de nuevos tribunales para algunos de sus mecanismos de administración de justicia, todos aspectos que veremos líneas adelante para cada una de las Cortes latinoamericanas bajo análisis.

Pero desde lo cuantitativo es importante considerar los flujos que traen las Cortes latinoamericanas enfocadas, pues aquello es un antecedente concreto de los tres sistemas jurisdiccionales - CCJ, TJCA y TPRM —, motivo por el cual hemos analizado cada una de las Memorias, Informes y publicaciones de toda la historia de los tres modelos latinoamericanos y pudimos comprobar los siguientes datos totales:

a. Procesado cada uno de los Informes de Gestión del TJCA ${ }^{17}$ y re-agrupándolos, obtuvimos como resultado general que aproximadamente ha dictado 2.514 sentencias en su historia.

b. Por su parte analizadas todas las Memorias de la $\mathrm{CCJ}^{18}$ nos muestran una producción jurisdiccional objetiva de un total aproximado en su historia de 166 sentencias, $\mathrm{y}$

c. Abordando los datos publicados por el Mercosur ${ }^{19}$ referidos a los laudos dictados, se desprende que en toda la historia los TAAM y TPMR juntos, no superan las 26 causas.

Con los resultados anteriores, más otros datos extraídos de las fuentes consultadas que en cada caso vamos mencionando, hemos preparado diversos gráficos y tablas con nuestros resultados cualitativos para una mejor visión del escenario latinoamericano, a continuación presentamos el primero de estos, en los cuales comparamos los datos de los tres esquemas latinoamericanos.

\footnotetext{
${ }^{17}$ INFORMES DE GESTIÓN DEL TRIBUNAL DE JUSTICIA DE LA COMUNIDAD ANDINA. Fuente: Portal oficial del TJCA. <http://www.tribunalandino.org.ec/itstudio/index.php/en/transparencia/2018-03-2809-30-19> [última consulta, enero 2, 2019].

${ }^{18}$ MEMORIAS DE LA CORTE CENTROAMERICANA DE JUSTICIA. Fuente: Portal oficial de la CCJ. <http://portal.ccj.org.ni/ccj/memorias/> [última consulta, diciembre 25, 2018].

19 TRIBUNAL PERMANENTE DE REVISIÓN DEL MERCOSUR. Fuente: Portal Oficial del TPRM. $<$ http://www.tprmercosur.org/es/sol_contr_laudos.htm> [última consulta 23-11-2018].
}

370 
Imagen 1. Compuesta de una tabla y dos gráficos, muestra la comparación entre la producción de sentencias de las tres cortes latinoamericanas. En orden descendente se ubican el TJCA, la CCJ y los TAAM+TPRM. De la tabla superior izquierda se aprecian las cantidades de sentencias dictadas por cada Corte latinoamericana. Datos que el gráfico de la derecha muestra en líneas de proyección, y el gráfico circular ofrece la conversión a porcentajes. De ambos claramente la Corte andina supera con creces a la Corte centroamericana y a las Cortes mercosureñas.
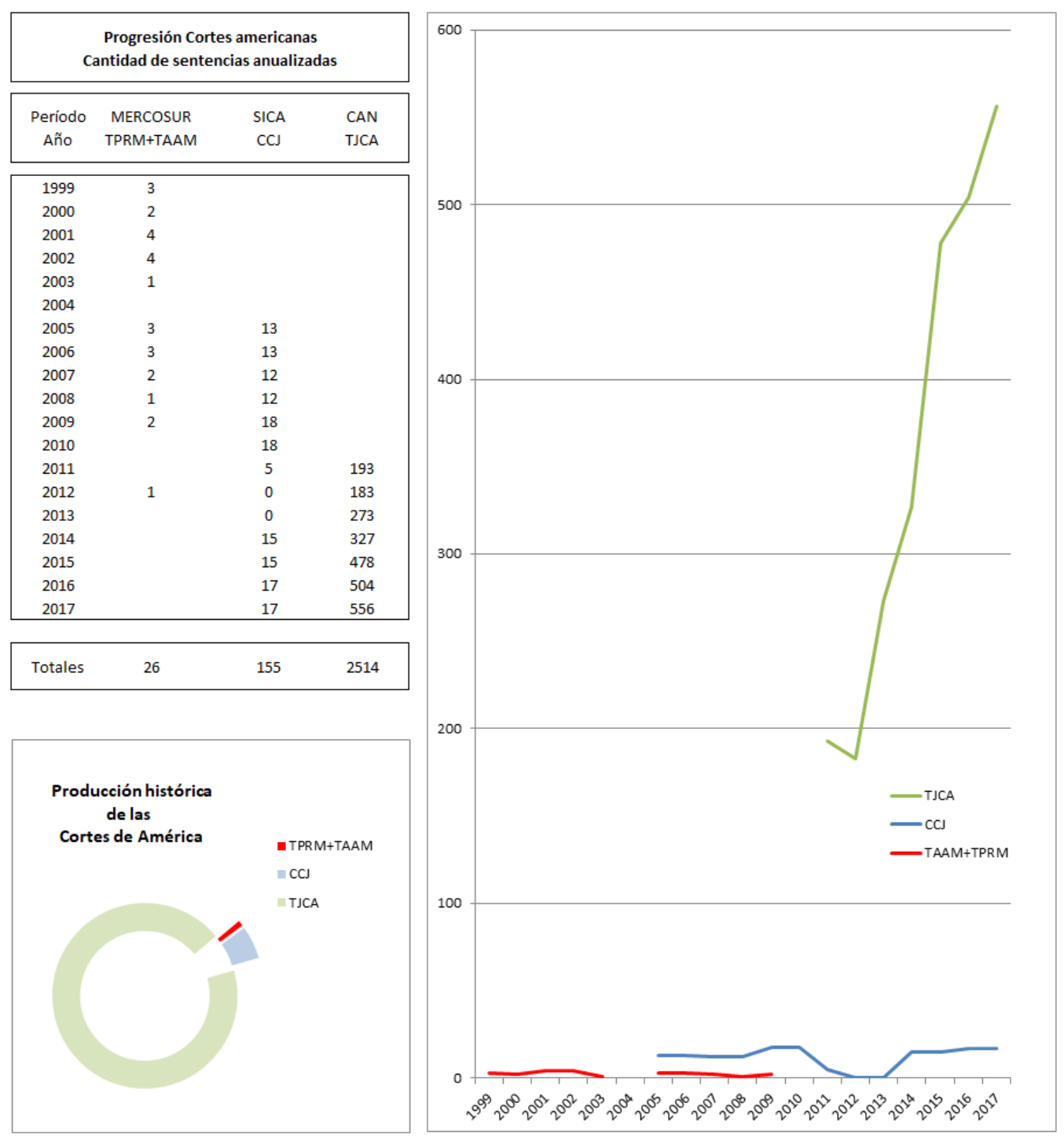

Tabla y gráficos, creación propia. 
Ahora bien, en un segundo ejercicio, hemos procedido a cotejar dicha realidad latinoamericana con el esquema europeo, dándonos como resultado que todas las cifras anteriores de las Cortes latinoamericanas, se observan insignificantes ante el ritmo que trae el TJUE.

Imagen 2. Esta visual, compuesta de una tabla y un gráfico de barras, muestra la comparación entre la producción de sentencias del TJUE respecto de la producción de las tres Cortes latinoamericanas en orden descendente, esto es, $1^{\circ}$ ) el TJUE, $2^{\circ}$ ) el TJCA, $3^{\circ}$ ) la CCJ y $4^{\circ}$ ) los TAAM+TPRM. La Corte de Luxemburgo sólo en un año procesó 1.600 causas aproximadamente. Aislando el año 2017 y comparado con las Cortes bajo análisis, obtenemos en concreto que el TJUE dictó 1594 sentencias, el TJCA 596, la CCJ solo 17, y el TPMR y TAAM juntos, cero laudos.

\begin{tabular}{|cc|}
\hline \multicolumn{2}{|c|}{ Comparación año $\mathbf{2 0 1 7}$} \\
\hline Tribunal & sentencias \\
\hline TJUE & 1594 \\
TJCA & 556 \\
CCJ & 17 \\
TAAM+TPRM & 0 \\
\hline
\end{tabular}

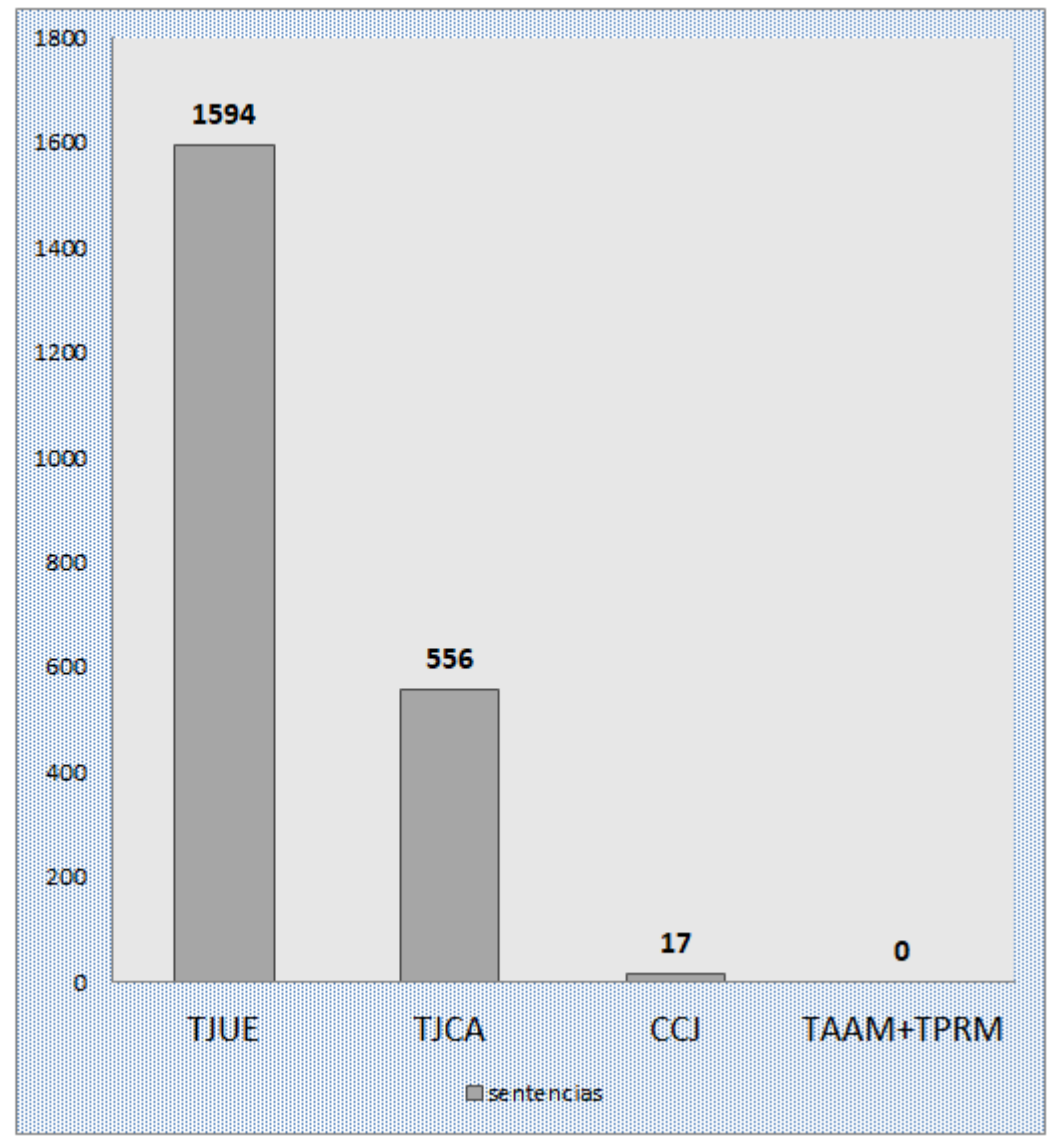

Tabla y gráfico, creación propia.

Pues bien, con los macro datos anteriores, más lo anunciado respecto de los elementos cualitativos, efectuaremos las proyecciones de futuro para cada una de las tres Cortes latinoamericanas bajo análisis. 


\subsection{LOS DESAFÍOS DE FUTURO DE LA Corte Centroamericana de Justicia}

Para proyectar hacia el futuro a la CCJ debemos considerar tanto su dimensión cuantitativa como la cualitativa y añadir determinados aspectos del SICA. En primer lugar, para despejar la dimensión cuantitativa hemos analizado cada una de las Memorias publicadas por la CCJ desde el año 1994 hasta el año 2017, tras ordenar y tabular sus datos, encontramos un total aproximado —en toda su historia - de 166 sentencias $^{20}$, lo cual es un pequeño número en atención al período de tiempo cubierto. Circunstancia que la deja dentro de su entorno, en un segundo lugar ${ }^{21}$. Destacando además que aproximadamente un $70 \%$ de su producción se refiere a causas contenciosas, mientras que sólo el $30 \%$ a consultas, los detalles se aprecian en la siguiente imagen compuesta de una tabla y un gráfico.

${ }^{20}$ Las MEMORIAS DE LA CORTE CENTROAMERICANA DE JUSTICIA publicadas, no siguen un mismo modelo de administración de datos, además falta el período 2012-2013. Sin embargo procesando sus datos obtenemos que en todo su desarrollo moderno (1994-2017) en resumen y aproximadamente hay 117 causas contenciosas más 49 consultas, esto nos da un el total de 166 causas que señalamos en el texto. Los cuales se desagregan en cada Memoria de la siguiente forma: $1^{\circ}$ ) CORTE CENTROAMERICANA DE JUSTICIA. Memoria 10 años: 1994-2004, (47 contenciosos más 21 consultas) vid. en cuadro resumen del período 1994-2004, p. 177. $2^{\circ}$ ) CORTE CENTROAMERICANA DE JUSTICIA. Memoria 2005-2006, (10 contenciosos más 3 consultas) vid. en línea resumen, p. 79. $3^{\circ}$ ) CORTE CENTROAMERICANA DE JUSTICIA. Memoria 2007-2008, (11 contenciosos más 1 consulta) vid. cuadros de causas contenciosas en pp. 24 a 26, más en el texto la única consulta, en p. 27. $4^{\circ}$ ) CORTE CENTROAMERICANA DE JUSTICIA. Memoria 2008-2009, (12 contenciosos más 6 consultas) vid. cuadros para causas contenciosas en pp. 30-33, más los procedimientos de consultas, en pp. 34-35. $5^{\circ}$ ) CORTE CENTROAMERICANA DE JUSTICIA. Memoria 2009-2010, (9 contenciosos -7 resueltos y 2 pendientes- más 9 consultas) vid. detalle de contenciosos y consultas prejudiciales en su texto bajo el acápite: c) Sobre los asuntos resueltos durante el periodo, en p. 19. $6^{\circ}$ ) CORTE CENTROAMERICANA DE JUSTICIA. Memoria 2010-2011, (2 contenciosos, 1 recurso de aclaración, más 3 consultas) vid. detalle de contenciosos y consultas en su texto bajo el acápite: c) Resoluciones aprobadas en el periodo, pp. 12-72. $7^{\circ}$ ) Datos de los años 2012-2013 no están publicados en el sitio web oficial. $8^{\circ}$ ) CORTE CENTROAMERICANA DE JUSTICIA. Memoria 2014-2015, (14 contenciosos más 1 consulta) vid. cuadros para contenciosos en pp. 25-29, más consultas, en p. 30. $9^{\circ}$ ) CORTE CENTROAMERICANA DE JUSTICIA. Memoria 2016-2017, (resueltos: 9 contenciosos y 3 consultas; en trámite: 3 contenciosos y 2 consultas; total: 12 contenciosos y 5 consultas), vid. visual 3. Fuente: Portal oficial de la CCJ <http://portal.ccj.org.ni/ccj/memorias/> [última consulta, diciembre 25, 2018].

${ }^{21}$ Vid. imagen 1 .. 
Imagen 3. Se muestra el ingreso de causas a la CCJ desagregados por principales tipos de acciones. La tabla superior detalla los períodos que cubren las Memorias analizadas, y como se puede observar, estas publicaciones no siguen un ritmo homogéneo, así la primera cubre 10 años, y además no hay información publicada para el período 2012/2013. Abajo el gráfico circular muestra la carga de trabajo de forma porcentual.

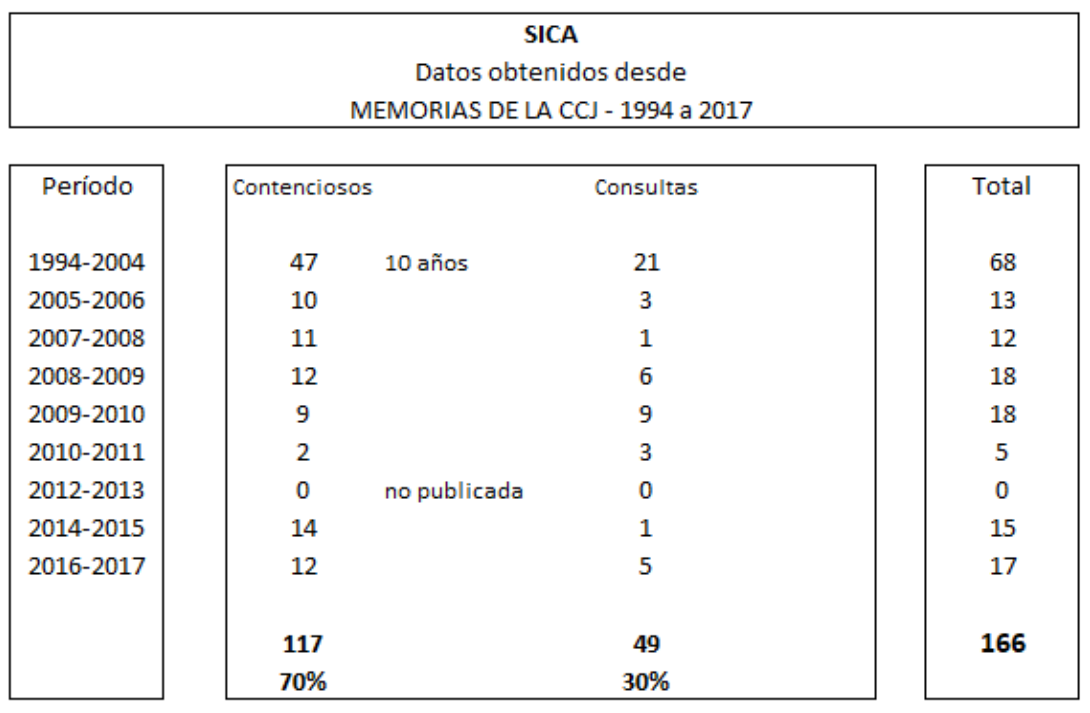

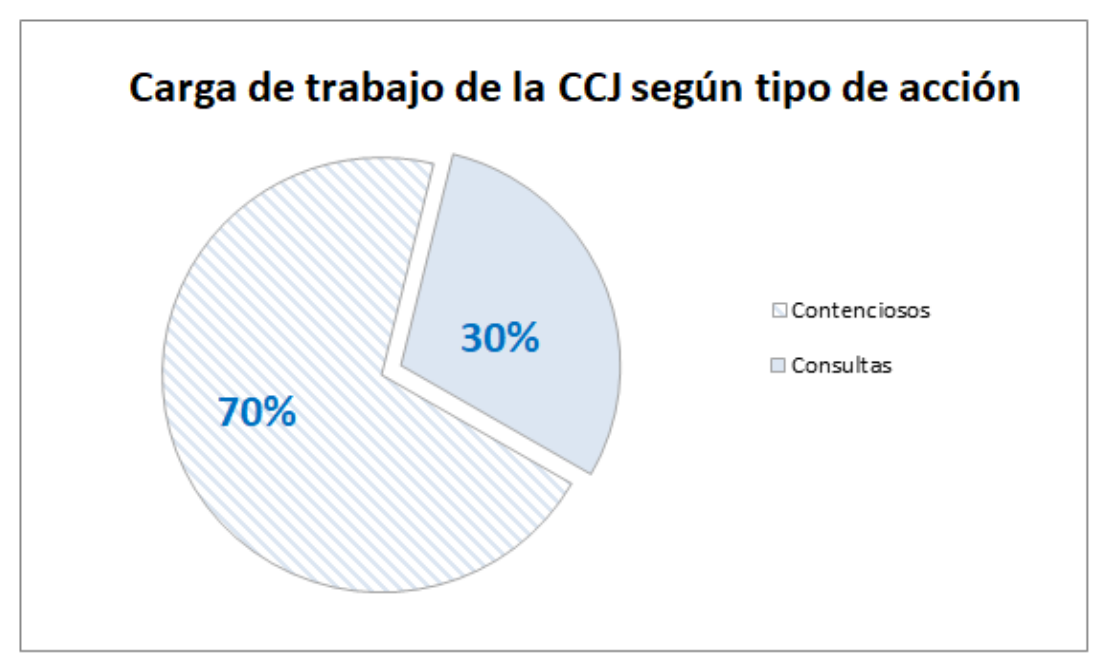

Tabla y gráfico, creación propia. 
En segundo lugar, al aproximarnos a la dimensión cualitativa, concluimos que ésta es la definitoria, pues resulta indispensable comprender correctamente todo el potencial de la expresión normativa originaria que reconoce a la CCJ el carácter de la representante de la conciencia nacional de Centroamérica y depositaria y custodia de los valores que constituyen la nacionalidad centroamericana ${ }^{22}$. Si bien, dicha norma la estudiamos en el capítulo II, sólo fue desde lo estatutario. Aquí en cambio, es indispensable poner de relieve cuatro puntos, uno, a diferencia de todos los modelos vistos - incluido el europeo- la Corte centroamericana, como autoridad y como esquema de administración de justicia es históricamente previa al SICA. En cambio en la CAN y en el MERCOSUR sus tribunales fueron posteriores a la OI y en la UE el TJ fue simultáneo, dos, sus ciudadanos se sienten orgullosos de haber visto nacer allí a la Corte de Cartago de 1907, tres, además, el sentido unitario de la región está enraizado históricamente ${ }^{23}$, y cuatro, todo lo anterior redunda en que fácticamente la CCJ continúa engarzada a diversos criterios y a cualidades de la primigenia Corte de Cartago, a quien le reconoce como su símil jurisdiccional antecesor, citándole directamente en sus sentencias hasta el día de hoy ${ }^{24}$.

Debido a las cuatro aristas subrayadas, pasa a ser más dócil para nosotros, extra-muros, el comprender, y para los centroamericanos, intra-muros, someterse y aceptar dicha posición de privilegio que asume la CCJ, pues en realidad los Estatutos sólo «reconocen» la posición que la Corte ya tenía en la cultura del istmo centroamericano.

Alineándose en esta compleja dimensión cualitativa de la que participa la CCJ, su juez presidente, Carlos Guerra Gallardo, con motivo de la celebración de El Día de la

\footnotetext{
${ }^{22}$ Art. 6 del Estatuto de la CCJ «La Corte representa la conciencia nacional de Centroamérica y se considera, además, depositaria y custodia de los valores que constituyen la nacionalidad centroamericana». Noción central que también se contiene en el párrafo final bajo el apartado Conclusiones, en la Exposición de Motivos del Estatuto de la CCJ.

${ }^{23}$ En los aspectos históricos nos remitimos en todo a las precisiones hechas en el capítulo I referido al análisis histórico. Et al. PÉREZ GONZÁLEZ, 2010.

${ }^{24}$ Como ejemplo de referencias en la era moderna de la Corte centroamericana, estructurada como la CCJ citando directamente a la Corte de Cartago, puede verse CCJ, Sentencia de 29-3-2005, República de Nicaragua c/ Asamblea Nacional de la República de Nicaragua, expediente 69-01-03-01-2005. La cual en su Considerando (II) expresa «Que en atención al derecho a aplicarse en este caso, se destaca en lo fundamental lo consignado en el literal $f$ ) del artículo 22 del Convenio de Estatuto de este Tribunal que dice "La Competencia de La Corte será f) Conocer y resolver a solicitud del agraviado de conflictos que puedan surgir entre los Poderes u Órganos Fundamentales de los Estados, y cuando de hecho no se respeten los fallos judiciales". 'Esta atribución que forma parte del acervo jurídico centroamericano originada en similar que tuvo la Corte de Justicia Centroamericana (Corte de Cartago), que funcionó de 1908 a 1918, cuyo objeto fue el mantenimiento de la paz en Centroamérica evitando el rompimiento del orden jurídico y logrando el funcionamiento democrático de los Gobiernos', atribución que también está contenida en la Exposición de Motivos del Convenio de Estatuto de este Tribunal».
} 
Integración Centroamericana de 2018, sostuvo que justamente la CCJ se enorgullece de ser el órgano judicial principal y permanente del SICA y de representar la conciencia nacional de Centroamérica y de ser la depositaria y custodia de los valores que constituyen la nacionalidad centroamericana. Esa es la razón por la cual la Corte incorpora el aporte axiológico que deberá informar a las futuras generaciones. Explicando que es un anhelo de la CCJ el cooperar para profundizar en la formación de una conciencia regional. En tal sentido — recalcó enfático el juez- que, representar la Conciencia Nacional significa:

«actuar como catalizador de una conciencia que debe estar anidada en el alma de todos los pueblos centroamericanos con un mismo sentimiento histórico, cultural, social y económico» ${ }^{25}$.

Para él, la sub-región centroamericana se puede definir como una agrupación de países ligados, por razones geográficas, históricas, culturales, económicas, sociales y políticas, cuya finalidad es regirse por los propósitos y principios recogidos en los artículos 3 y 4 del Protocolo de Tegucigalpa ${ }^{26}$.

Como vemos entonces desde esta segunda perspectiva la Corte centroamericana deberá asumir un rol de ente difusor del proyecto global del SICA. Observamos entonces que no estamos ante la satisfacción de un objetivo propio del órgano de la OI, y que desde su posición propia colabore mediante la realización correcta de su función, o bien que difunda la importancia de su existencia como órgano, sino que la CCJ tendrá que afrontar el desafío de difundir al SICA. En estas coordenadas nosotros somos cautos, pues en tal acometido se comienzan a mezclar a los jueces y/o al órgano jurisdiccional en funciones o promociones comunicacionales de aspectos políticos — pues no se refiere a una promoción del tribunal, sino del SICA mismo-, lo cual a nuestro juicio, no contribuye al principio general de separación de poderes.

${ }^{25}$ GUERRA GALlardo, C. (2018). Discurso del Presidente de la Corte Centroamericana de Justicia (14.12.2018). El día de la integración centroamericana. Disponible en: 〈http://portal.ccj.org.ni/ccj/el-dia-dela-integracion-centroamericana-carlos-guerra-gallardo-presidente-corte-centroamericana-de-justicia/> [última consulta, diciembre 24, 2018].

${ }^{26}$ El art. 3 del Protocolo de Tegucigalpa fija como objetivo fundamental del SICA la realización de la integración de Centroamérica para constituirla como una región de paz, libertad, democracia y desarrollo. Para esto dicha norma presenta una extensa lista de propósitos, entre los cuales destacan: la democracia, la unión económica, la autodeterminación, el desarrollo pleno y armonioso del individuo, la inserción como bloque económico exitoso en el mundo, el cuidado al medio ambiente, y sustentar el ordenamiento institucional y jurídico del SICA. En tanto el art. 4 pasa a detallar los principios fundamentales del SICA, en general indicando a) Los derechos humanos; b) Paz, Democracia, Desarrollo y Libertad, como un todo armónico e indivisible; c) La identidad centroamericana; d) La solidaridad; e) La gradualidad, especificidad y progresividad del proceso de integración; el tratamiento especial a países miembros de menor desarrollo relativo; la equidad y reciprocidad; y la Cláusula Centroamericana de Excepción; f) La globalidad del proceso de integración y la participación; g) La seguridad jurídica de las relaciones entre los Estados y la solución pacífica de sus controversias; h) La buena fe de los Estados; i) Respeto a los principios y normas de las Cartas de la ONU, de la OEA y las Declaraciones Presidenciales centroamericanas.

376 
Ingresando ahora por un cuarto aspecto a considerar para proyectar a la CCJ hacia el futuro, es relevante verificar los desafíos del SICA como organización a la que pertenece la Corte centroamericana. En este contexto observamos que el SICA se ha ido robusteciendo durante estos años, de hecho en diciembre del 2018 se incorporaron siete nuevos miembros observadores, Canadá, Bolivia, Rusia, Suecia, Egipto, Georgia y el Organismo Internacional de la Juventud $^{27}$, lo que concretamente constituye un nuevo progreso para el SICA, favoreciendo sin duda su proyección de futuro. Esta aseveración la justificamos porque dichas incorporaciones, parten del entendido de que la Comunidad Internacional continúa interesada en el porvenir del proyecto de integración centroamericano, concurriendo por lo tanto al proceso del SICA, desde la perspectiva que les corresponde.

En diciembre de 2018 se llevó a efecto la $52^{\circ}$ Reunión Ordinaria de Jefes de Estado y de Gobierno del SICA $^{28}$ firmándose la Declaración de Belice, la cual dentro de su contenido destacan una serie desafíos hacia el futuro que el SICA deberá enfrentar, abarcando acuerdos regionales en materia de cambio climático, de migración, también respecto del café, las energías renovables y temas de afrodescendientes, siendo todas estas cuestiones nuevas y grandes metas para el SICA.

Además y ya en un desafío de mayor envergadura, acordaron actualizar prontamente la Agenda Estratégica priorizada del SICA. Su Secretario General, Vinicio Cerezo, alineándose con los desafíos para el futuro, planteó ideas que siguen por el cauce de repensar a Centroamérica, con un plan de desarrollo renovado que inspire concesos y políticas públicas, alianzas público-privadas y también con la academia. Para él, la tarea hacia el futuro es inacabable, donde no se puede replantear el pasado, debe asimilarse el presente y desde ahí forjar un mejor futuro ${ }^{29}$.

También es relevante para el futuro de estos esquemas latinoamericano que se motiven acercamientos recíprocos, como el promovido con el MERCOSUR sobre «Intercambio de Buenas Prácticas en la Construcción de Políticas Públicas SICA-MERCOSUR», aunque

\footnotetext{
${ }^{27}$ Quedando así conformado el SICA por 8 Estados miembros, más 11 observadores americanos y 22 observadores extra-regionales. Para obtener estas nuevas cantidades, deben «sumarse» los ingresos señalados arriba, a las que se encuentran actualmente publicadas en el sitio oficial del SICA. Disponible en: $<$ https://www.sica.int/miembros/miembros.aspx> [última consulta, diciembre 25, 2018].

${ }^{28} 52^{\circ}$ REUNIÓN DE JEFES DE ESTADO Y DE GOBIERNO DEL SICA. Belize. Disponible en: $<$ https://www.sica.int/noticias/presidentes-del-sica-piden-avanzar-en-la-construccion-de-un-modelo-dedesarrollo-sostenible-para-la-region_1_116361.html> [última consulta, mayo 26, 2019].

${ }^{29}$ CEREZO, V. (2018). Discurso del Secretario General del SICA (14.12.2018). 52 ${ }^{\circ}$ REUNIÓN DE JEFES DE ESTADO Y DE GOBIERNO DEL SICA. Belize. Disponible en $<$ https://www.sica.int/noticias/presidentes-del-sica-piden-avanzar-en-la-construccion-de-un-modelo-dedesarrollo-sostenible-para-la-region_1_116361.html> [última consulta, diciembre 24, 2018].
} 
éste sólo fue un seminario, efectivamente constituye una buena señal de futuro. Consideramos que estos acercamientos en códigos horizontales inter-americanos deberían intensificarse cada vez más, lo cual no significa dejar de lado el contacto con la experiencia de la UE. Únicamente, desde nuestra perspectiva, subrayamos lo importante que resulta ser para generar implicancia local en los ciudadanos, que en América Latina se continúen desarrollando respuestas y fórmulas locales. En aquella ocasión participó la Presidencia Pro Tempore del MERCOSUR, más la Presidencia Pro Témpore del SICA, expresándose que, tal acontecimiento ha marcado un hito en la historia de los dos bloques ${ }^{30}$.

En conclusión, si consideramos entonces lo extraído del análisis sobre las Memorias de la CCJ, las cuales organizamos y graficamos, más la arista cualitativa de la Corte que da cuenta de una correcta respuesta jurisprudencial, tal como se sigue de los análisis de los dos capítulos anteriores, más las nuevas concreciones del SICA en sí mismo, incorporando nuevos miembros, desarrollando algunas actividades de acercamiento con el MERCOSUR, y fijándose desafíos al futuro mediante los instrumentos que señalamos, estimamos que respecto del resto de los modelos latinoamericanos, el SICA en su conjunto se observa más desarrollado que la CAN o el MERCOSUR, además logra motivar e involucrar de mejor manera a las personas ${ }^{31}$, por lo que estimamos que asumirá los desafíos descritos y los llevará adelante, a su velocidad y con sus recursos. Todo lo cual impacta positivamente en el futuro de la CCJ, la cual no existe sin el SICA. La Corte centroamericana debe continuar dando signos de madurez e independencia, por lo que al asumir un rol de difusor del modelo SICA tendrá que tener la precaución de no ingresar en materias políticas a efectos de no deslegitimizar a sus jueces.

\footnotetext{
30 SEMINARIO REGIONAL MERCOSUR - SICA "EXPERIENCIAS Y BUENAS PRÁCTICAS EN DERECHOS HUMANOS Y POLÍTICAS PÚBLICAS”. (11 y 12 de diciembre 2018). Montevideo. Disponible en <http://www.ippdh.mercosur.int/mercosur-y-sica-inauguran-historica-cooperacion-interregional-en-derechos-humanos-y-politicas-publicas/> [última consulta, enero 3, 2019].

${ }^{31}$ Sin motivación en los ciudadanos se devienen los complejos desencantos que buscan modos de expresión destructivos de los sistemas, como los euroescépticos o desencantados, nacidos de críticas internas propias de los inconformismos. MORENO JUSTE, 2013. SHMITE \& NIN, 2014.
} 


\subsection{LOS DESAFÍOS DE FUTURO DEL}

\section{TRIBUNAL DE JUSTICIA DE LA COMUNIDAD ANDINA}

El punto de partida para visualizar la proyección del TJCA es que éste pertenece a una OI que se encuentra muy desgastado según la opinión generalizada de la doctrina ${ }^{32}$, cuestión que incluso pudiese augurar el quiebre del esquema de la CAN. Además debemos añadir la sensación de que la CAN — de modo global— pudiese estar siendo eclipsada por los singulares desarrollos del MERCOSUR. Aunque técnicamente tal solapamiento ${ }^{33}$ es bastante sui generis, ya que la CAN ostenta instituciones de una naturaleza jurídica de mayor desarrollo que las del MERCOSUR, basta con cotejar entre sus órganos resolutores de conflictos, que en la CAN son de carácter jurisdiccional, mientras que en el MERCOSUR son sólo de naturaleza arbitral.

En esta misma línea de eclipse, se ha planteado la posibilidad de un fenómeno aún más extenso, llegando a sugerirse que, de modo amplio, habría una fuerza soterrada que hacia el futuro, estaría girando las fórmulas de integración latinoamericanas, transitándose desde la actual noción de Sur América, hacia la de Latino América. Incluso se ha sostenido que en tal movimiento la UNASUR, podría haber entrado a modificar la forma de la actual relación inter-americana, en una suerte de integración más amplia que hubiera incluido al MERCOSUR, a la CAN y, a las experiencias de Chile, Guyana y Surinam ${ }^{34}$, sin embargo es un hecho que UNASUR actualmente está colapsada ${ }^{35}$.

\footnotetext{
${ }^{32}$ El desgaste de la fórmula CAN ha venido siendo monitoreada de modo mayoritario por la doctrina, siempre en análisis comparativos. QUINDIMIL constata la crisis constante, incluso como causa del nacimiento del TJAC. QUINDIMIL LÓPEZ, 2006. Para CAETANO la crítica pudiese ir dirigida a todos los modelos, pero presiona con más fuerza sobre la CAN, manifestando que muchos de los procesos de integración que han surgido en América Latina, «han ingresado en situaciones críticas de diversa índole», lo que ha llevado inevitablemente a quiebres, los cuales en algunos casos han puesto en riesgo la continuidad efectiva de algunas de esas experiencias de integración. Esto último - precisa CAETANO - es lo que está ocurriendo actualmente con la CA, poniendo sobre la meza que las razones que explican el desgaste son multicausales [...], pero en parte, pueden explicarse por los efectos de un cambio en el paradigma global de integración, en el marco de nuevos escenarios a los que no todos los procesos han sabido adaptarse. CAETANO, G. (2015). ¿Hacia un nuevo paradigma integracionista en el MERCOSUR? contextos y desafíos de la encrucijada actual. Relaciones internacionales: Revista académica cuatrimestral de publicación electrónica, 30. Más análisis referidos al desgaste de la CAN en BRICEÑO RUIZ, 2018. También en BLANCO ALVARADO, 2014. Otro, GÓMEZ JUTINICO, 2010. Otro, GODOY \& GONZÁlEZ ARANA, 2009. Otro, ACOSTA PUERTAS, 2006.

${ }^{33}$ KÜHN BACA, 2015.

${ }^{34}$ En un enfoque de futuro demasiado optimista dado la casi desaparición de UNASUR, COMINI y FRENKEL detectan que muchos de los miembros de UNASUR interpretarían al nuevo bloque en el sentido de ser «un punto de inflexión, como una oportunidad para modificar el perfil de la matriz de relacionamiento
} 
Con todo, nosotros no compartimos tal concepción de futuro, es más, la descartamos del todo, ya que una estructura tan amplia como la pretendida — más allá de quien la encabece - desconocería las verdaderas zonas del continente americano. Adviértase que hablamos de una masa territorial de enormes dimensiones. Por lo tanto tal pretensión es sencillamente desconocer a América. Razón por la cual nosotros apostamos por motores de integración en cada sub-región, que dinamicen el «carácter unitario que en cada una de esas zonas encuentren», y no enfrentarnos a las colisiones evidentes de una megaampliación que desconozca factores de efectiva conectividad cultural y territorial, esenciales para mantener la cohesión, simplemente consideramos que sería no sólo inabordable e inmanejable, sino del todo irresponsable intentar avanzar hacia el futuro en tal dirección.

Estimamos que el decaimiento de la CAN, que proviene del desinterés de sus socios, precisamente es el fenómeno que se contrarresta en el SICA con el enraizado sentimiento unitario histórico que vimos para su caso. Lo que deja en evidencia que las combinaciones de factores positivos son los que realmente impulsan hacia el futuro a los modelos latinoamericanos. Siendo imposible detectar una fórmula certera, o pretender aislar un resorte único que asuma la causalidad absoluta del desarrollo de los esquemas latinoamericanos. Siempre serán combinaciones que van amoldándose a los complejos procesos socio-políticos que se van suscitando. Todo lo cual en definitiva afecta a nuestro foco de interés aquí, el TJCA.

La estructura orgánica e institucional de la CAN, que es el soporte de su nivel de desarrollo y de su posible mantención hacia el futuro, se anida en una enmarañada secuela de intentos políticos por lograr estabilizar un proyecto unitario en la zona. De tal suerte que, una parte de la debilidad actual de la CAN — y que complejiza bastante la visión de futuro - se explica de modo implosivo, en su propia historia. Incluso esa parte geográfica de América hasta mediados del siglo XX ha sido considerada por muchos, como una de las zonas más

vigente. Esto quedó plasmado en la idea de que 'la integración suramericana debe ser alcanzada a través de un proceso innovador' que incluya las experiencias del Mercosur y la Comunidad Andina de Naciones y las aportes propias de Chile, Guyana y Surinam», pero esta conceptualización apareja una seria problemática de futuro, primero en cuanto a una expansión en el sentido de poseer la capacidad de determinar quiénes serían sus miembros; segundo aparecerían decisiones de enfoque, los autores los denominan "conflictos de multiaxialidad e intergubernamentalidad» queriendo expresar, que habría que decidir sobre ciertos binomios, los cuales definirían la forma de encarar a la integración del futuro. Tales como: uniaxiales v/s multiaxiales, y supranacionales $v / s$ intergubernamentales. COMINI, N. \& FRENKEL, A. (2016). Unasur. De proyecto refundacional al fantasma del Sudamexit. En América Latina y el Caribe frente a la encrucijada actual de la globalización. Anuario de la integración regional de américa latina y el caribe, 13, pp. 181-208 (184-187).

${ }^{35}$ Vid. nota 14 de este capítulo. 
inestable o desestructuradas del mundo ${ }^{36}$. A mayor complejidad, la CAN está inmersa dentro del Sistema Andino de Integración (SAI), el cual comprende las estructuras orgánicas de la CAN más otros órganos e instituciones, creados en el marco de integración sub-regional andina ${ }^{37}$. Dado todo lo anterior resulta evidente que una visión de futuro específicamente para la CAN que no considere lo que venimos diciendo e ignore la singular historia de la CAN — capítulo I - sería una proyección destinada a estrellarse en campo errado. Sencillamente la realidad de la CAN es que está en serias dificultades para sostener su fórmula de integración hacia el futuro y por ende arrastraría en su fracaso al TJCA.

Ahora bien, las dificultades de la CAN en ningún caso son imputables al TJCA, sino todo lo contrario, pues la Corte andina ha efectuado correctamente su labor jurisdiccional. Es más, sin el TJCA, la CAN ya no existiría, pues la Corte nace en medio de una crisis para salvar a la CAN de la desintegración ${ }^{38}$. Tal desfase institucional es realzado muchas veces por metáforas como el pecado original de la CAN, o bien, la cojera inicial $^{39}$. Pero lo

${ }^{36}$ Para QUINDIMIL la región de Sur-América fue una de las regiones más desestructuradas del mundo, donde felizmente ya hace varias décadas se ha dado inicio a singulares procesos de integración, donde puntualmente, la CAN debe estudiarse con una metodología cartesiana y de modo global, únicamente en tal sentido se advertirá lo amplia y sofisticada que es la estructura orgánica de la CAN. QUINDIMIL LÓPEZ, J. A. (2006). Instituciones y derecho de la comunidad andina. Valencia: Tirant lo Blanch, p. 27.

${ }^{37}$ El SAI es el encargado de articular los órganos de la CAN, más otros creados en el marco de la integración sub regional andina, con lo que permite una coordinación efectiva entre todos éstos, profundiza la integración y promueve la proyección externa. Presentación del SAI en el Portal oficial de la CAN. Disponible en <http://www.comunidadandina.org/Seccion.aspx?id=4\&tipo=SA\&title=sistema-andino-deintegracion-sai> [última consulta, diciembre 26, 2018]. La CAN está actualmente integrada por Colombia, Ecuador, Perú y Bolivia. Un análisis exhaustivo del proceso de creación y de la institucionalidad lo presenta en QUINDIMIL, 2006, pp. 49-322.

${ }^{38}$ El nacimiento del TJAC si bien había sido pensado desde el inicio del proyecto de la CAN, pero como en su génesis no se presentaba una gran cantidad de conflictos, no se le dio mayor impulso, sin embargo los problemas comienzan paulatinamente a aumentar llegando a conformar una masa crítica de conflictividad que amenazaba con la desaparición de la organización. QUINDIMIL recuerda que la Junta del Acuerdo de Cartagena en su Informe del año 1972 sobre el Establecimiento de un Órgano Jurisdiccional del Acuerdo de Cartagena, sostenía que aún no había una masa considerable de conflictos. Pero más tarde -recuerda el autorse aumentaría peligrosamente, materializándose una crisis de conflictos de tal magnitud, que aceleró el nacimiento de la Corte. Nos remitimos en todo al capítulo I referido al análisis histórico. Vid. QUINDIMIL, 2006, pp. 328-330, 334 y 338.

${ }^{39}$ La sensible carencia orgánica es muy destacada, ZELADA expresa, el proceso de integración económica entre los países del Grupo Andino, por consiguiente, nació con una visible deficiencia en su ordenamiento jurídico y en su sistema institucional. ZELADA CASTEDO, A. (1985). Las posibles enmiendas al acuerdo de Cartagena. Integración latinoamericana. 10(106), INTAL, Buenos Aires, p. 126. (Instituto para la Integración de América Latina y el Caribe. (1976; 1995). Integración latinoamericana = Latin american integration : Revista mensual del INTAL. Bs. Aires: S.N.) Por su parte VIGIL refiere que el acuerdo nació cojo, al no haberse establecido desde el mismo momento en que renacía ese embrión de la integración subregional, un garante de legalidad conteniendo sólo un mecanismo poco ambicioso de solución de controversias basado en negociaciones, buenos oficios, mediación y conciliación. VIGIL TOLEDO, R. (2011). La estructura jurídica 
sustantivo era que no existía un factor disuasivo ${ }^{40}$ de la típica conflictividad de los países asociados. Pero hoy en día los problemas llegan a ser consustanciales a la CAN, más allá de la conflictualidad interna, ahora se presenta el desinterés de los socios.

Desde su origen esta Corte ha contribuido a dar una línea de flotación a la CAN, pues sus competencias — capítulo II — aplicadas al control judicial que efectúa — capítulo III - y su intensa labor jurisdiccional incluso importando soluciones europeas a través del diálogo judicial — capítulo IV - dan cuenta de que el TJCA ha sido fundamental para el buen funcionamiento del proyecto completo, asumiendo empíricamente un rol central ${ }^{41}$.

Sin embargo, se genera una dualidad en el análisis si procedemos a incorporar el factor estadístico de producción jurisprudencial de la Corte andina, ya que esta arista da cuenta de que resulta ser la Corte latinoamericana con mayor cantidad de sentencias dictadas, con más tráfico de procesos, y donde el $90 \%$ de sus causas registradas se refieren a cuestiones prejudiciales.

Para justificar la aseveración que nos precede, hemos analizado y tabulado los datos de todos los Informes de Gestión del TJCA correspondientes a los años 2011 al $2017^{42}$. De lo

y el futuro de la comunidad andina ( $1^{\mathrm{a}}$ ed.). Madrid: Civitas Thomson Reuters, p. 39. Es destacable como hace fuerza tal noción de auto-potenciamiento a la que nos hemos referido en diversas ocasiones en esta tesis, siendo una constante en la doctrina, el vincular la existencia de un tribunal ya sea internacional o de integración, con una sólida permanencia de una OI y o de Integración.

${ }^{40}$ Dentro de la multiplicidad teórica de los fines del proceso, está la preservación de la paz en todas sus dimensiones, principalmente evitándola. Por tal motivo la jurisdicción, acción y proceso — que son los tres pilares del derecho procesal - se potencian para disuadir la conflictividad, entre otros objetos. En uno de estos sentidos entendemos que QUINDIMIL manifieste que, como las decisiones políticas se tomaban por simple mayoría se aumentaba la potencial conflictividad entre los países socios, por lo que en tal contexto era lógico asirse a un tribunal de justicia, porque «una de las funciones del órgano jurisdiccional debe ser la de actuar como factor disuasivo de los conflictos, para evitar que la tensión política [que] de ellos deriva rompa el vínculo asociativo». Lo que entrecomilla el autor, es una cita textual que él hace de la página 17 del Informe de la Junta sobre el Establecimiento de un Órgano Jurisdiccional del Acuerdo de Cartagena, COM/XE/di 5 de 12-12-1972. QUINDIMIL, 2006, pp. 326-327.

${ }^{41}$ Más allá de que la existencia de un tribunal para el éxito de una OI, en general, sea transversalmente indispensable - tal como lo hemos venido destacando con múltiples ejemplos, y visualizando la doctrina que así lo refuerza - en el caso puntual de la CAN, lo más probable es que ella se hubiese desarticulado completamente y desaparecido, si no hubiese llegado esta Corte a disolver los conflictos y a disuadir las latencias antagónicas de intereses intersubjetivos (aquí principalmente entre Estados). En este cauce QUINDIMIL es certero en detectar el beneficio que el TJCA ha irrogado al proyecto, en su propia realidad sub-regional, expresando «el control judicial del Tribunal de Justicia constituye un fundamento 'axial' para el buen funcionamiento de la integración andina». QUINDIMIL, 2006, p. 47.

${ }^{42}$ Los siete INFORMES DE GESTIÓN DEL TRIBUNAL DE JUSTICIA DE LA COMUNIDAD ANDINA publicados, no siguen el mismo patrón de administración de datos, por tal motivo hemos procedido a desagregar la información y reagruparla en cinco secciones quedando como sigue: A) Para el período 2011 a 382 
anterior concluimos que la Corte andina ha ido aumentando drásticamente su cantidad de causas procesadas. Analizado esto, tanto desde el factor ingreso, como desde el factor sentencia dictada.

Para su mejor estudio hemos procedido a reagrupar los datos, obteniendo como resultado general que, la Corte andina ha dictado aproximadamente 2.514 sentencias en toda su historia, cuyos detalles quedan mucho mejor precisados en la siguiente imagen (4) la cual está compuesta de una tabla y de un gráfico.

$2017=2.514$ sentencias en total. B) Desagregados por factor sentencias/anualidad en el año $2017=556$ sentencias. En el año $2016=504$ sentencias. En el año $2015=478$ sentencias. En el año $2014=327$ sentencias. En el año $2013=273$ sentencias. En el año $2012=183$ sentencias. Y en el año $2011=193$ sentencias. C) Desagregados luego por factor de ingreso/anualidad/principal tipo, obtenemos lo siguiente, en el año 2017 = 545 Interpretación Prejudicial (In.Pr.) + 3 Acción de Nulidad (Ac.Nul.) + 7 Acción de Incumplimiento (Ac.Inc.) + 1 Laborales (Lab). En el año $2016=623$ In.Pr. + 5 Ac.Nul. + 2 Ac.Inc. + 0 Lab. En el año 2015 = 691 In.Pr. + 5 Ac.Nul. +10 Ac.Inc. +0 Lab. En el año $2014=325$ In.Pr. + 1 Ac.Nul. +0 Ac.Inc. +1 Lab.; año $2013=265$ In.Pr. +0 Ac.Nul. +1 Ac.Inc. +7 Lab. En el año $2012=176$ In.Pr. +2 Ac.Nul. + 1 Ac.Inc. +1 Lab. Y en el año $2011=190$ In.Pr. + 2 Ac.Nul. + 1 Ac.Inc. + 0 Lab. E) Sobre el 90\% de la labor de la Corte se refiere a consultas prejudiciales. Fuente: Portal oficial del TJCA. Datos extraídos de las siguientes páginas e informes: INFORME DE GESTIÓN TJCA 2017, Parte 1, apartado III Gestión Judicial; cuadro: Causas resueltas en 2017, pp. 7-8. INFORME DE GESTIÓN TJCA 2016, apartado III Gestión Judicial, pp. 3-6. INFORME DE GESTIÓN TJCA 2015, apartado II Gestión Judicial, pp. 7-10. INFORME DE GESTIÓN TJCA 2014, apartado II Gestión Judicial, pp. 4-5. INFORME DE GESTIÓN TJCA 2013, apartado II Gestión Judicial, pp. 4-5. INFORME DE GESTIÓN TJCA 2012, apartado II Gestión Judicial, pp. 4-5. INFORME DE GESTIÓN TJCA 2011, apartado II Gestión Judicial, pp. 6-7. Informes disponibles en <http://www.tribunalandino.org.ec/itstudio/index.php/en/transparencia/2018-03-28-09-30-19> [última consulta, enero 2, 2019]. 
Imagen 4. Primero, en la tabla de arriba se muestran los ingresos de causas al TJCA desagregados por cuatro tipos principales de acciones: interpretación prejudicial, acciones de nulidad, de incumplimiento y laborales. De lo que se desprende que casi toda la actividad del TJCA se basa en responder consultas. Segundo, el gráfico inferior muestra los datos llevados a porcentajes de carga de labor jurisdiccional.
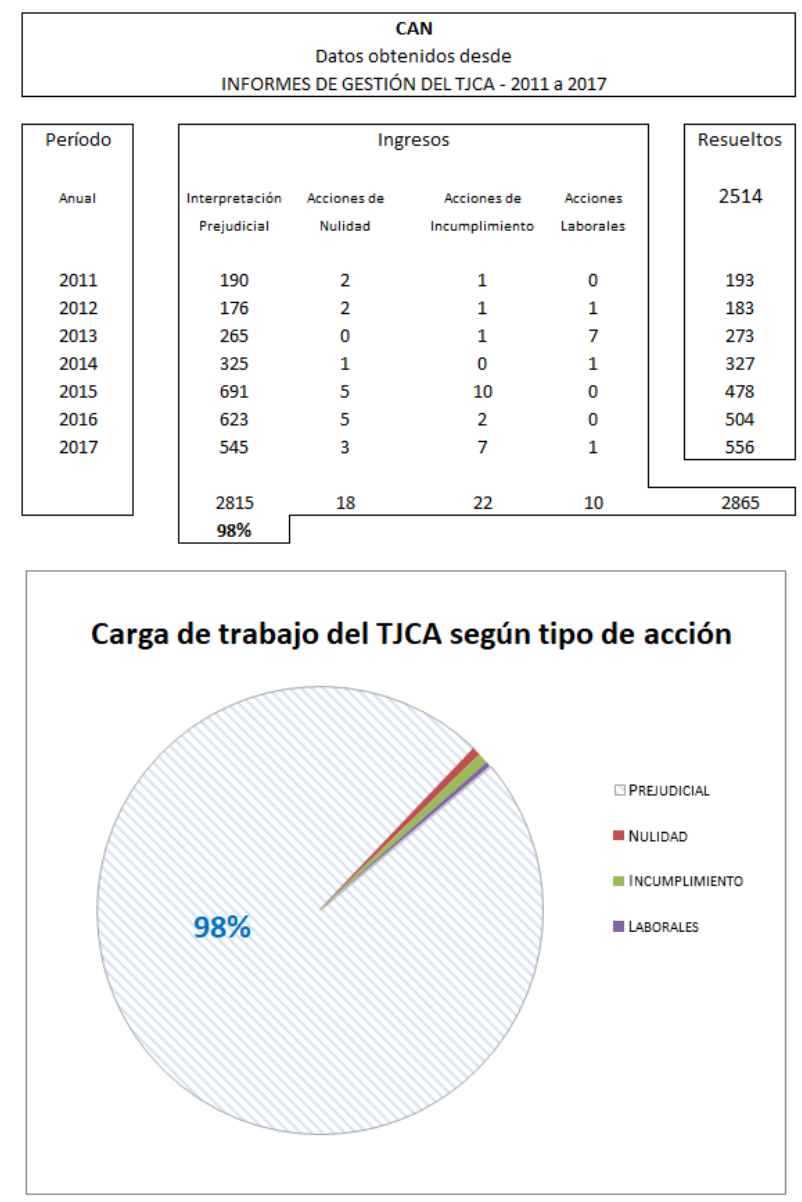

Tabla y gráfico, creación propia.

Como se aprecia de la tabla de la imagen 4, hay una bajísima tasa de contenciosos ventilados en la Corte andina, lo cual podría deberse, atendiendo al alto porcentaje de las respuestas prejudiciales que se observan, a que los conflictos se estarían disolviendo ante los tribunales nacionales, en carácter de juez natural. Por lo tanto no habría una excesiva litigación en contra los Estados miembros, o entre éstos, o bien en materias que involucren a las instituciones de la CAN.

Otra conclusión que se extrae de la imagen 4, es que el 98\% que representan las respuestas en consultas prejudiciales, internamente vienen en ascenso, siguiendo un ritmo muy intenso. Este punto concreto se responde también al interior de los Informes de Gestión del 
TJCA, señalando la Corte que se debería a dos razones, i) a su propia labor orientada a actividades de difusión del Derecho Andino con los tribunales nacionales ${ }^{43}$, y ii) al hecho de que también esta Corte haya interpretado de modo expansivo la legitimación activa para que los árbitros nacionales y algunos entes administrativos puedan solicitar consultas prejudiciales al TJCA antes de emitir sus laudos y dictámenes, respectivamente ${ }^{44}$.

En conclusión, la CAN deja a la vista un zigzagueante derrotero de altos y bajos de su esquema. Inestabilidad que es impredecible desde la sola lectura de sus Estatutos pues si únicamente nos quedamos en ese ángulo de análisis, el proyecto es más desarrollado que el MERCOSUR y el SICA, de allí que por ejemplo al crearse la Corte andina y ser comparada estatutariamente con el TJUE se veían extremadamente cercanos ${ }^{45}$. Y en esas condiciones

43 El juez presidente Hernán Romero Zambrano señala que el aumento del uso de esta Corte se debe fundamentalmente a la labor de difusión y conocimiento del Derecho Andino que la propia Corte efectúa con los jueces locales. Expresó «Asimismo, merece destaque la mayor utilización del Sistema Andino de Solución de Controversias [...], en la presente gestión casi triplicó el número de solicitudes realizadas por las autoridades nacionales [...], como resultado de la importante labor de difusión del ordenamiento jurídico andino que realizó este Tribunal en los principales órganos jurisdiccionales nacionales» (está haciendo alusión puntual a la mayor demanda de Ecuador, pero es extrapolable al universo en estudio) INFORME DE GESTIÓN TJCA 2016. pp. 4-5. (vid. en particular el párrafo 2, p. 5). Disponible en <http://www.tribunalandino.org.ec/itstudio/images/tjca/informesg/INFORME\%20DE\%20GESTI\%C3\%93N \%202016.pdf> [última consulta, enero 2, 2019].

44 El desarrollo jurisprudencial en cuanto a aumentar la legitimidad activa hacia los árbitros y entes administrativos, es muy destacado en el Informe de Gestión del TJCA del año 2016, así «Un aspecto de fundamental importancia es la ampliación del número de consultas facultativas presentadas por Jueces de Primera Instancia y Autoridades Administrativas de los Países Miembros. Sobre este particular, es importante recordar que 'el Tribunal reconoció la legitimidad activa para iniciar este procedimiento a los tribunales arbitrales', así como al Servicio Nacional de Propiedad Intelectual de Bolivia, al Instituto Nacional de Defensa de la Competencia y de la Protección de la Propiedad Intelectual del Perú, y a la Superintendencia de Industria y Comercio de la República de Colombia. De esta manera, se abrió la posibilidad de que las entidades administrativas que acrediten el cumplimiento de seis requisitos establecidos por el Tribunal accedan al citado mecanismo, a fin de contar con la interpretación del Tribunal [...] asegurando así la uniforme interpretación y aplicación de la norma comunitaria». El presidente del TJCA está refiriendo a (1) Respecto a la legitimidad de los árbitros, a los Procesos 03-AI-2010 y 181-IP-2013, (2) sobre Bolivia, al Proceso 105-IP-2014, (3) respecto de Perú, el Proceso 121-IP-2014, y (4) sobre Colombia, al Proceso 242-IP2015. INFORME DE GESTIÓN TJCA 2016. pp. 4-5. Disponible en <http://www.tribunalandino.org.ec/itstudio/images/tjca/informesg/INFORME\%20DE\%20GESTI\%C3\%93N \%202016.pdf> [última consulta, enero 2, 2019].

${ }^{45}$ Ambos tribunales pertenecen a un mismo esquema jurídico que fluye del Derecho de la Integración. DIEZ DE VELASCO sitúa en idéntico campo a ambos tribunales, expresando "[...] es el caso de una nueva forma de justicia universal nacida o corolario del fenómeno de la integración». Además este autor, subsumido en un intenso análisis comparativo entre el TJCE con el TJAC concluye que son extremadamente similares, puntualizando «Las diferencias en cuanto a organización interna y procedimiento entre ambos tribunales 'son mínimas' y de puro detalle. Ellas han nacido 'de peculiaridades' como el número de Estados y a su vez de jueces que las componen; pero 'en líneas generales los Estatutos y Reglamentos coinciden en las 
todos le deparaban un gran futuro a la CAN, se hablaba incluso de que, salvando las distancias, el TJUE y TJAC, ambos, pasaban a constituir sin duda, los modelos más avanzados de justicia comunitaria ${ }^{46}$. Pero, lamentablemente, la implementación, el respeto y la actitud de los países socios, dieron cuenta de que simplemente, no eran capaces de conducir tan sofisticados mecanismos y estructuras hacia buen puerto. Nuevamente el traje no había sido hecho a la medida de la sub-región andina. Y por lo tanto, ahora nos volvemos a encontrar rodeados de signos de desarticulación.

El futuro del TJCA depende entonces del destino de la CAN, ya que la Corte ha hecho todo lo que le correspondía. Aunque y para contextualizar correctamente, lo normal en esa zona son los constantes movimientos y ajustes. Por lo que - con una prudencial dosis de optimismo - tal vez no sea tan grave, como lo apreciamos desde afuera, al compararlo con los otros modelos vecinos. Sin embargo, y como se ha dicho por una parte de la doctrina, habría una crisis en el alma o en la identidad de los Estados miembros ${ }^{47}$, pues aflora una cierta tendencia de los Países andinos — no necesariamente a atomizarse — sino a adherir a otros esquemas internacionales. Para nosotros, la peligrosa e indeseada desarticulación de la CAN encuentra su pendiente más empinada en la falta de interés real de sus Estados miembros, cuestión que acusa una falta de decisión política que le pueda dar una proyección robusta de futuro.

Este daño en el sentir profundo de la CAN y que golpea de lleno en sus expectativas de futuro no puede explicarse en el cauce económico - lo que sería bastante más fácil de solucionar - sino que toca aspectos profundos, de orden jurídico y político, desde donde se evidencia una ausencia de cultura política de integración, lo que se demuestra porque los Estados miembros no se comportan en el marco de una auténtica integración, así el

cuestiones más importantes'». DIEZ DE VELASCO VALLEJO, M. (1989). Nuevas perspectivas de la justicia internacional: el tribunal de las comunidades europeas y el tribunal de justicia del acuerdo de Cartagena. En J. A. Barberis, F. F. García, E. Jimenez de Arechaga, H. Gros, C. García, M. A. Vieira, ... Diez De Velasco, M. Temas de derecho internacional : En homenaje a Frida M. Pfirter de Armas Barea. Buenos Aires: Fundación del Centro de Estudios Internacionales de Buenos Aires, pp. 257 y 264.

${ }^{46}$ Las grandes expectativas del TJAC y los análisis únicamente en papel de las Cortes Comunitarias de la época, mostraban modernos y casi idénticos al TJUE con el TJAC (hoy TJCA). Es muy llamativa la aseveración de QUNDIMIL «el Tribunal de Justicia de las Comunidades Europeas en Europa y el Tribunal de Justicia de la CAN en el Continente americano. Salvando las distancias existentes entre ambos tribunales, 'puede afirmarse que constituyen, sin duda, los modelos más avanzados de justicia comunitaria'.». QUINDIMIL, 2006, p. 38.

${ }^{47}$ Para BRICEÑO por ejemplo, refiriéndose a la CAN, sostiene en términos generales que estaría pasando por una «crisis de identidad» de quienes la integran, ya que, Bolivia y Ecuador se han mostrado más interesados en pertenecer a la Alianza Bolivariana para los Pueblos de América (ALBA) que profundizar en la fórmula de la CAN. Por su parte, tanto Colombia como Perú estarían bastante seducidos por la Alianza del Pacífico. BRICEÑO RUIZ, J. (2018). Razón de ser de la integración y conceptualización de un nuevo marco teórico de la integración de américa latina y el caribe. Derecho y economía de la integración, (6), 21-33.

386 
ciudadano andino en general desconoce la razón de ser de la CAN, lo cual acusa un déficit democrático, seguido de la inexistencia de espacios deliberativos, sin participación de las personas, hay una notoria ausencia de conocimiento del Derecho de la CAN por parte de los jueces nacionales y de los particulares, se suma la concentración de poder en los órganos intergubernamentales del SAI $v / s$ la reducción de funciones y autonomía de los órganos comunitarios como el Parlamento Andino y — justamente- el TJCA ${ }^{48}$.

Lo peor es que la crisis no es actual, sino consustancial. Lo que sucede es que en algunas etapas se ignora la problemática y en otras alcanza determinados picos muy dañinos, justamente porque se ignoraron los avisos previos. Dentro de los factores causales — varios ya mencionados - se suma el hecho de que cada país de la CAN enfrenta habitualmente sobresaltos internos de múltiples dimensiones. Por lo que, si ni siquiera logran estabilidad interna, menos podrán controlar estructuras superiores ${ }^{49}$. Los más pesimistas no le ven solución al futuro de la CAN — y por ende al TJCA — básicamente amparados en que se trataría de cuatro países subdesarrollados incapaces de solventar tamañas empresas ${ }^{50}$.

${ }^{48} \mathrm{El}$ centro de la crisis de la CAN es político, fenómeno que lamentablemente va a arrastrar consigo al tribunal, el que hasta hoy, ha aportado para mantener a flote al proyecto. Para BLANCO, actualmente, la integración andina es una utopía, aunque es el ideal hacia el cual hay que dirigirse. Según esta autora, la crisis obedecería fundamentalmente a aspectos de orden político y jurídico, no económicos, pues los Estados andinos no se comportan en el marco de un proceso de integración, por lo tanto no están preparados para asumirlo. La autora se explaya en una extensa lista de causales, todas no económicas, para justificarlo. BLANCO ALVARADO, C. (2014). La crisis de la comunidad andina. Revista de derecho universidad del norte. Barranquilla, Colombia, 42, pp. 1-32. Disponible en <http://www.scielo.org.co/$\mathrm{pdf} / \mathrm{dere} / \mathrm{n} 42 / \mathrm{n} 42 \mathrm{a} 02 . \mathrm{pdf}>$ [última consulta, noviembre 23, 2019].

${ }^{49} \mathrm{La}$ ausencia de voluntad política en el proyecto CAN, fermenta en problemáticas internas de los Estados miembros, las cuales provienen de los más diversos intereses locales. En este aspecto GODOY y GONZÁLEZ, refieren que la ausencia de voluntad política como variable real, al «descomponerse», se aprecia la incidencia de grupos de interés internos en la construcción de la política de cada Estado miembro, todas las cuales impactan negativamente al ideario de la CAN, expresando — ambos autores — que «Junto con los niveles sistémicos podemos identificar factores a nivel nacional y sub-nacionales que plantean dificultades para el avance en el proceso. En este sentido, los países de la región andina enfrentan problemas de niveles múltiples que hacen cuestionable la supervivencia de la institucionalidad alcanzada en la CAN. Entre éstos, la voluntad de los Estados y la influencia de los actores internos». GODOY, H. \& GONZÁLEZ ARANA, R. (2009). La crisis de la CAN: El caso de los actores internos. Investigación y desarrollo: revista del centro de investigaciones en desarrollo humano, 17(2), 350-367 (361).

${ }^{50}$ Al reflexionar ACOSTA sobre el futuro de la CAN, expresa «la integración, en suma, no se ha percibido como un instrumento determinante para una inserción internacional digna. En un mundo globalizado, en el cual todo sucede a una escala mayor, la CAN constituía una opción para construir economías de escala de distinto tipo: políticas, productivas, sociales y de conocimiento. Pero el subdesarrollo a veces acaba con los sueños». ACOSTA PUERTAS, J. (2006). La desintegración andina. Nueva sociedad, (204), 4-13, vid. apartado ¿La CAN tiene futuro? 
Agregándose, a todo lo anterior, que incluso son frecuentes los conflictos entre los dirigentes de cada país, tensionando cada cierto tiempo la zona ${ }^{51}$. De hecho la última reunión formal del Consejo Presidencial Andino - que es el órgano más importante de la CAN compuesto por los cuatro Jefes de Estado- se registra en el año $2011^{52}$. Como se aprecia, de no tomarse medidas sustanciales, y de acompañarse este proceso por organizaciones de mayor calado, el proyecto CAN aunque exista en el papel, desaparecerá definitivamente del sentir del ciudadano andino.

En cuanto al acompañamiento de la CAN, la UE ha estado presente desde diversos ángulos $^{53}$, también se han desarrollado actividades conjuntas con el MERCOSUR ${ }^{54}$ y el $\mathrm{SICA}^{55}$, lo cual si bien es positivo, no hay registros permanentes, ni menos actuales de

${ }^{51} \mathrm{Si}$ a todo lo anterior — cuestión que ya es más que suficiente- añadimos una falta de madurez en el modo de dirigir las políticas de vecindad, el problema central no tiene forma de ser abordado seriamente. GÓMEZ JUTINICO destaca esta adición expresando «la CAN no solo enfrenta la problemática derivada de su institucionalidad, también presenta dificultades de diferente orden que impiden la realización de sus objetivos, como los enfrentamientos políticos entre los dirigentes de los países miembros que ocasionan conflicto y tensión en la zona». Aunque para esta investigadora las dificultades de la CAN se manifiestan principalmente en «el constante e histórico incumplimiento o aplazamiento por parte de los Estados [de sus compromisos...], como ha sucedido principalmente en la conformación definitiva de la CAN en carácter de bloque comercial, lo que ha determinado en mayor medida el estancamiento de la Comunidad». GÓMEZ JUTINICO, A. (2010). Institucionalidad y problemáticas de la comunidad andina de naciones. Poliantea, 6(10), vid. apartado Introducción, p. 32 y apartado 2. Problemáticas de la CAN, p. 41.

${ }^{52}$ El Consejo Presidencial Andino que está integrado por los cuatro jefes de Estado de los Países miembros, registra su última reunión el 8 de noviembre del año 2011. Fuente: Portal oficial de la CAN. Disponible en: <http://www.comunidadandina.org/Seccion.aspx?id=10\&tipo=SA> [última consulta, diciembre 29, 2018].

${ }^{53}$ La UE ha colaborado constantemente con la CAN el MERCOSUR y el SICA. Ha desarrollado proyectos de apoyo, contribuido en estudios y experiencia desde hace muchos años. FRERES, C. (2003). La unión europea y la comunidad andina. Opciones para la política ante la crisis subregional. En E. V. Iglesias, V. Giscard d'Estaing, J. Solana Madariaga, C. Patten, J. Roy, A. Chanona Burguete, ... F. Granell. Retos e interrelaciones de la integración regional: europa y américa (1ª ed.). México. Plaza y Valdés., pp. $399-417$. Otro, GORDON VERGARA, A. \& FERNÁNDEZ FERNÁNDEZ, J. J. (2006). Alegato en favor del inicio de negociaciones para un acuerdo UE - CAN en la IV Cumbre de Viena. Agenda Internacional, XII(23), pp. 295326 (298-305). En general los estudios de la relación UE-CAN, no sobrepasan el año 2006, tampoco el Portal oficial de la UE mantiene registros posteriores de relevancia con la CAN.

${ }^{54} \mathrm{Si}$ bien entre la CAN y el MERCOSUR se han intentado acercamientos, como el crear una zona amplia de libre comercio, esto no ha sido posible, aunque algunas pocas actividades se registran entre 1998 y 2010. Disponibles en <http://www.comunidadandina.org/Seccion.aspx?id=111\&tipo=TE> [última consulta, diciembre 29, 2018]. Últimamente sólo se han producido acercamientos muy puntuales, como el referido a la Gestión de Riesgos de Desastres marcándose la ruta 2018-2021. Disponible en <http://www.comunidadandina.org/Prensa.aspx id=10027\&accion=detalle\&cat=NP\&title=comunidadandina-y-mercosur-trabajaran-conjuntamente-en-gestion-del-riesgo-de-desastres $>$ [última consulta, diciembre 29, 2018].

${ }^{55}$ La relación CAN y SICA también ha estado distante en lo sustantivo. En los últimos años sólo se registra actividad relevante entre ellos hasta el año 2011. Fuente: Portal oficial CAN. Disponible en 388 
relevancia que destacar. Pero, lo que se requiere centralmente, es de una mayor proactividad de los gobiernos de los Estados miembros.

Una posible solución para evitar la desintegración de la CAN es darle apoyo y acompañamiento, ya que no puede quedar sola, y a la suerte de sus fuerzas. Este imperativo de ayuda es el que ha motivado los apoyos de los otros modelos de integración, partiendo por la UE y también por sus vecinos el MERCOSUR y el SICA. Nosotros subrayamos que ese es el verdadero espíritu del sistema de integración, lograr que a todos nos interese el éxito de todos, de lo contrario, para qué nos integramos.

<http://www.comunidadandina.org/Prensa.aspx?id=2813\&accion=detalle\&cat=AF\&title=la-comunidadandina-buscara-propiciar-una-mayor-vinculacion-con-centroamerica> [última consulta, diciembre 29, 2018]. 


\subsection{LOS DESAFÍOS DE FUTURO DEL}

SISTEMA DE SOLUCIÓN DE CONTROVERSIAS DEL MERCOSUR

\section{El futuro del Tribunal Permanente de Revisión y de los Arbitrales ad hoC}

Los orígenes de todos los procesos en que se encuentran ancladas las Cortes latinoamericanas analizadas presentan aspectos propios y absolutamente distintos unos de otros, sin perjuicio de que los objetivos finales tiendan con los años a homogenizarse. Por ejemplo, el espíritu inicial del MERCOSUR sólo era enfrentar la liberalización mundial del comercio que aparejaba la globalización. Diferente al espíritu del SICA modelo muy anterior y que había sido empujado desde la independencia de España hacia su reunificación. Diferente también de la CAN donde se buscaba estabilizar una zona y superar la pobreza. Es más, ni siquiera orgánicamente todos contemplaban una Corte de justicia en sus inicios - la CAN y MERCOSUR no poseían tribunales. Y ninguno cruzó por cauces de reconstrucción post guerras, a diferencia de Europa ${ }^{56}$.

El MERCOSUR, dentro de sus posibilidades y realidad, ha ido sorteando diversas épocas, y no ha estado ajeno a los tan típicos re-lanzamientos propios de la dimensión internacional, los que llegan siempre en carácter de nuevos impulsos hacia el futuro. El cambio de milenio fue una de esas ocasiones, asumiendo el MERCOSUR nuevos objetivos, los denominados de tercera generación, además en ese momento el principal punto de futuro era consolidar el esquema de integración para la libre circulación de bienes, en miras a la siguiente centuria se planteaba alcanzar definitivamente un mercado común y se destacaba la celebración del denominado Pequeño Maastrich ${ }^{57}$. En general, las conclusiones iniciando el

56 En cuanto a las disimilitudes de orígenes, ACCIOLY PINTO DE ALMEIDA razonando sobre el MERCOSUR certeramente concluye «felizmente nuestra unión no se hizo por la guerra como en Europa. Nuestra unión se dio por los designios del comercio internacional, para que juntos los países puedan sumar fuerzas para enfrentar la globalización de la economía. La Europa Comunitaria es nuestra inspiradora, pero nuestra ruta no es la misma y tendremos que hacer nosotros nuestro propio camino. Al final, nuestras realidades son distintas». ACCIOLY PINTO DE ALMEIDA, E. (1998). Integración europea e integración latinoamericana: dos realidades distintas. En Accioly, E., Ciuro, M. A., Da Silva, C., Faria, W., Losfeld, G., Mariño, F., ... Zanin, G., El MERCOSUR en el siglo XXI. Bs. Aires: Ediciones Ciudad Argentina, p. 309.

57 El cambio de milenio fue un punto de valoración y de proyección para el MERCOSUR, pues los presidentes de los Estados miembros implementaron las actividades de relanzamiento del proyecto de cara a la siguiente centuria. Se incorporaron los denominados objetivos de tercera generación. Así lo destacó DELGADO, Embajador del Uruguay en aquella época, quien expresaba que dicho relanzamiento constituía un nuevo impulso político para acelerar y profundizar la realización de los objetivos trazados en el Mercosur. Además — destacaba - quizás, lo más importante fue el anuncio de la formalización del denominado «Pequeño Maastricht» que implicaba el primer esfuerzo serio que se realiza para la coordinación de políticas macroeconómicas. DELGADO, E. (2000). Relanzamiento del mercosur. Mercosur agenda para el futuro. 390 
milenio eran muy optimistas, destacándose que el MERCOSUR ya era parte de las historias de las Naciones integrantes, que estaba incorporado al léxico cotidiano y en definitiva se reconocían sus mejoras orgánicas en código de un efectivo spill over institucional ${ }^{58}$.

Pero en este camino de ajustes aparecían cuestionamientos referidos a si el mentado relanzamiento debía o no seguir un derrotero neoliberal, u orientarse hacia el futuro con políticas sociales más claras, y la compleja posibilidad de implementar efectivamente la Agenda de relanzamiento ${ }^{59}$. En definitiva, el MERCOSUR continuó su camino de desarrollo que ya analizamos ${ }^{60}$, incluso abarcando materias en derechos humanos, se crea el Instituto de Políticas Públicas en Derechos Humanos del Mercosur ${ }^{61}$, extremos axiológicos

Entorno 16, pp. 5-11 (p. 9, vid. apartado El relanzamiento del mercosur). Disponible en $<$ http://biblioteca.utec.edu.sv/entorno/index.php/entorno/article/view/269/268> [última consulta, diciembre 31, 2018].

${ }^{58}$ En un muy extenso análisis, que recorre diversos aspectos, BIZZOZERO reconoce varios avances efectivos hasta el vencimiento de la agenda 2000 del MERCOSUR señalando que hay avances objetivos (p. 98) en diversas áreas, además de un efectivo spill over institucional (p. 109), pero evidentemente — explica- se acumularon insuficiencias las que sumadas a la problemática internacional generaban una sensación de estancamiento de cara al año 2000 (pp. 129-130), y que incluso el mismo relanzamiento del año 2000 quedó cojo. Pero si se toman los parámetros, instrumentos, y definiciones en la construcción del proceso «la evaluación resulta positiva». Desde la perspectiva de los instrumentos y definiciones en la construcción, puede señalarse que «los desempeños del Mercosur han posibilitado gestar un patrimonio del proceso que ya es parte integrante de la historia de los países y se ha incorporado en el léxico cotidiano» (p. 136). BIZZOZERO REVELEZ, L. (2001). El proceso de construcción del mercosur: De la transición al relanzamiento. Colección, (12), pp. 89-136 (98, 109 y 129-130).

${ }^{59}$ Respecto de la preocupación por una implementación de una Agenda Social, que incluya el principio de solidaridad, vid. ESCRIBANO ÚBEDA-PORTUGUÉS, J. (2003). El relanzamiento del mercosur: La apuesta por la unión europea y el distanciamiento frente a estados unidos. Temas para el debate, (104), 52-54. Ya para el año 2005 LERMAN observaba como muy grave la situación del MERCOSUR dudando inclusive de su proyección y de la posibilidad real de implementar la agenda de relanzamiento. LERMAN ALPERSTEIN, A. (2005). La agonía del mercosur. Comercio exterior, 55(4), 362.

${ }^{60}$ En 2003 se adopta el Reglamento del Protocolo de Olivos. En 2005 se crea el PARLASUR. En 2006 se produce la primera ampliación adhiriéndose Venezuela. En 2015 la segunda, ingresando Bolivia. Se incorporan como países asociados Chile, Colombia, Perú, Ecuador, Guayana y Surinam. Se celebran diversos Tratados y convenios en múltiples áreas de interés.

${ }^{61}$ En junio del 2005 los Países mercosureños firmaron el Protocolo de Asunción sobre Compromiso con la Promoción y Protección de los Derechos Humanos quedando abierto al resto de los países asociados del Mercosur. Disponible en el Portal oficial del Mercosur en <https://www.mercosur.int/documento/protocolode-asuncion-sobre-compromiso-con-la-promocion-y-proteccion-de-los-derechos-humanos-en-el-mercosur/> [última consulta, septiembre 1, 2019]. En la actualidad el MERCOSUR cuenta con un conjunto amplio de medidas e instrumentos en materias de derechos humanos, diversas publicaciones especializadas, declaraciones y variados canales de difusión. Puede revisarse el enlace oficial Derechos Humanos en Mercosur, en <https://www.mercosur.int/temas/derechos-humanos/> [última consulta, septiembre 1, 2019]. 
altamente destacado por la doctrina ${ }^{62}$. Así para el 2010 la visión volvía a ser auspiciosa destacándose buenas condiciones en el merco-sistema. Con un avance lento pero real sobre las negociaciones UE-MERCOSUR el optimismo apareció nuevamente ${ }^{63}$, y actualmente se ha terminado el proceso de negociación del Acuerdo de Asociación Estratégica UEMERCOSUR. Todo lo anterior ha terminado por desbordar los primigenios objetivos del MERCOSUR.

La referida madurez del MERCOSUR, si es analizada como cauce proyectable hacia el futuro, pasa a ser una realidad muy significativa, ya que gracias a esto los Estados van homogenizando sus legislaciones lo que es un criterio básico en los modelos integracionistas, aunque tal conclusión es simple de comprender hoy en día, el punto es que el MERCOSUR ha venido transitando desde un origen alejado de los patrones integracionistas y va desafiando constantemente sus fines. De allí lo trascendente de que en este proyecto del Cono Sur de América también se haya constatado el fenómeno del diálogo de fuentes ${ }^{64}$. Por lo tanto, a partir de tales constataciones y de la historia, es desde donde hay que efectuar su proyección hacia el futuro, pero de modo responsable, es decir, despojado de discursos políticamente correctos o, de visiones obtusamente destructivas. En consecuencia, es en dicho contexto en el que debe posicionarse una proyección de futuro para el Sistema de Solución de Controversias Mercosur (SSCM).

Pero podemos constatar que hay tres posiciones respecto del futuro del merco-sistema, en primer lugar están los mayores críticos quienes ponen de relieve múltiples problemáticas que afectarían el curso total del proceso de integración en el Cono Sur de América. A juicio de estos escépticos, lamentablemente los conflictos se habrían convertido en una constante que afectan indefectiblemente al merco-sistema, se critica la actual postura del gobierno de

${ }^{62}$ ABRAMOVICH, V. (2013). Derechos humanos en el marco del proceso de integración regional en el MERCOSUR. Revista da secretaria do tribunal permanente de revisão, 1(2), 351-361.

${ }^{63}$ A partir del año 2010, son frecuentes las apariciones de opiniones más positivas sobre el futuro del MERCOSUR, ya que todas éstas verifican el logro de varios objetivos propuestos. En un minucioso examen comparativo por épocas, esquematizado y con diversas tabulaciones, LUCÁNGELI, SANGUINETTI y ZAMORANO en general coinciden con la idea de un buen escenario de futuro para el proyecto. LUCÁNGELI, J., SANGUINETTI, M. \& ZAMORANO, A. L. (2010). Mercosur: La consolidación de la expansión de la economía del bloque. Revista del CEI. Comercio exterior e integración, (18), 19-45.

${ }^{64}$ Mediante el diálogo de fuentes se tienden a homogenizar las leyes de los Estados partes, lo que en principio es evidente, pero lo que pasa a ser destacable es que se extienda hacia más materias que las primitivas. Por ejemplo en Argentina, respecto de las relaciones jurídicas en las que se presentan elementos extranjeros, SCOTTI destaca que, cuando éstas se desarrollan al interior de un espacio integrado nos encontraríamos ante uno de los ámbitos espaciales del Derecho Internacional Privado, relaciones que se crean desarrollan y extinguen en el contexto de un proceso de integración regional, como es el caso de Mercosur, por lo que en Argentina se ha llevado adelante un proceso de armonización jurídica con el bloque Mercosur. SCOTTI, L. B. (2016). Diálogo de fuentes: Las normas regionales del MERCOSUR y las nuevas disposiciones del derecho internacional privado argentino. Revista da secretaria do tribunal permanente de revisão, 4(7), 152-184. 
Brasil que es distante del MERCOSUR, la estabilidad política de Argentina y la manera de hacer frente a la crisis de Venezuela. Por lo tanto, sólo los pequeños Uruguay y Paraguay se plantean como los más estables. Ante tal catastrófico panorama — estas posturas — auguran un pésimo futuro ${ }^{65}$.

Nosotros no compartimos tales apreciaciones, de hecho, ni Argentina ni Brasil presentan riesgos para el merco-sistema, es más, la administración Macri y Bolsonaro se alinearon ${ }^{66}$ ante los desafíos de futuro del MERCOSUR y avanzan hacia el Acuerdo de Asociación UE el cual ha sido un éxito, toda vez que después de veinte años de intentos, fue el actual MERCOSUR — con Bolsonaro, Macri y la crisis de Venezuela - el que logró firmarlo, propio de los escenarios latinoamericanos.

En cambio, otras posturas no son tan pesimistas, y se limitan a precisar que en el MERCOSUR habría solo una carencia para alcanzar sus objetivos ${ }^{67}$, y bajo líneas ya más exculpatorias, se sostiene que todos los sistemas latinoamericanos presentan carencias de cumplimiento con sus propios Tratados, y el MERCOSUR no escaparía a dicha tendencia. La fórmula para quebrar tal ineficaz patrón, cruza por desplegar efectivamente una estrategia idónea de administración de conflictos y ser decididos en esto, aunque advirtiendo que en ninguna hipótesis el MERCOSUR desaparecería como proyecto ${ }^{68}$. Es

\footnotetext{
${ }^{65}$ En una mirada muy desalentadora TRADITI es de la opinión de que la falta de liderazgo y fuerza efectiva del MERCOSUR se ha vuelto una constante. Para esta autora, se requeriría de una mayor capacidad de adaptación del modelo mercosureño ante las problemáticas de la sub-región, para, de esa manera, poder salir, de la que refiere como una situación de parálisis en la que se encuentra este bloque regional. Además agrega - su desempeño ha sido precario como trampolín de inserción internacional, no ha sabido adaptarse a los cambios del sistema internacional. Desgaste que pasa a ser la causa de que los países miembros se aproximen a otros acuerdos comerciales más flexibles, como la Alianza del Pacífico. En tal contexto es imperativo un ejercicio de redefinición de objetivos. TARDITI, E. (2016). Mercosur en crisis o cuando lo excepcional se vuelve ordinario. Anuario de la integración regional de américa latina y el caribe, (13), pp. 208-222.

${ }^{66}$ NIEBIESKIKWIAT, 2019.

${ }^{67}$ Si bien - fácilmente — pudiésemos listar una gran cantidad de detractores del MERCOSUR, no es la idea en esta tesis, y por lo demás, tras todo lo analizado, no nos termina de convencer tal rotundo pesimismo, sino todo lo contrario - como lo veremos enseguida - por esto es suficiente con hacer el punto crítico. Por ejemplo, y de modo no tan incisivo, BRICEÑO puntualiza que el MERCOSUR, en efecto, no logra terminar de superar sus problemas comerciales, de cumplir con su agenda social, y de resolver temas productivos. BRICEÑO RUIZ, J. (2018). Razón de ser de la integración y conceptualización de un nuevo marco teórico de la integración de américa latina y el caribe. Derecho y economía de la integración, (6), pp. 21-33.

${ }^{68}$ En una posición más templada CAETANO sostiene que las diversas imputaciones al MERCOSUR resaltan el grado de incumplimiento de las normas aprobadas por los órganos con capacidad decisoria en cada caso. Pero - para este autor - es conocido que todos los procesos de integración de la región presentan gruesos incumplimientos a lo dispuesto en sus tratados fundacionales, hecho particularmente visible en el caso del Mercosur. Lo que nosotros destacamos es que CAETANO, a pesar de su crítica, él concluye con dos ideas de futuro más esperanzadoras, (i) por una parte aclara que, todo proceso de integración implica una sabia
} 
decir, se hace la crítica y se plantea la solución, pero siempre bajo el supuesto de la mantención del proyecto.

Como hemos señalado todas estas circunstancias afectan directamente las posibilidades de desarrollo del SSCM que incluye a los TAAM y al TPRM, sistema que requiere de visiones de futuro más optimistas para el MERCOSUR, por las cuales nos inscribimos nosotros. En esta línea se concluye que el MERCOSUR comporta un proceso dinámico y abierto, que en todo caso robustece la zona. Siendo objetivamente un proceso especial de integración regional y, que si atendemos a las circunstancias históricas, hoy sus Estados miembros lo reconocen efectivamente como un instrumento de integración. Porque sobrepasó con creces su tímido objeto inicial, el cual estaba constreñido, casi exclusivamente, a aspectos económicos. Coordenadas desde donde el MERCOSUR únicamente ha materializado progresos, más lentos o más rápidos, pero siempre desarrollos ${ }^{69}$. Además, los progresos descritos generan un desplazamiento sustantivo del MERCOSUR, movilizándolo desde un esquema de integración estructural hacia un sistema de integración sustancial, los cuales son evidentemente mucho más profundos tal como los vimos oportunamente y que subraya la doctrina ${ }^{70}$.

administración de conflictos pero también una mirada estratégica inteligente y convencida, y (ii) por otra parte que «en ninguna hipótesis el Mercosur desaparecerá como proyecto». CAETANO, G. (2015). ¿Hacia un nuevo paradigma integracionista en el MERCOSUR? contextos y desafíos de la encrucijada actual. Relaciones internacionales: Revista académica cuatrimestral de publicación electrónica, (30).

${ }^{69} \mathrm{El}$ progreso del MERCOSUR es signo de elogio por una buena parte de la doctrina, de hecho precisamente lo que diferencia a este esquema del SICA y de la CAN, es que el MERCOSUR es capaz de escapar de un molde económico, y avanzar hacia uno integracionista — tal como lo pudimos apreciar a partir del análisis jurisprudencial de sus tribunales en los capítulos III y IV. Para RUIZ-DÍAZ el MERCOSUR evoluciona hasta abarcar todas las áreas y sectores, movilizando a una sociedad entera, constituyendo de esta forma un bloque de integración Latinoamericano para enfrentar la globalización. RUIZ-DÍAZ LABRANO, R. (1999). Supranacionalidad y mercosur. En Irigoin Barrenne, J. (coord.), Rey Caro, E. (present.), Insulza Salinas, J. M. (disc.), Barros Charlín, R., Molina del Pozo, C. F., Narbone, L., ... Holzmann G., Chile y el mercosur en américa latina: VI encuentro internacional de derecho de américa del sur (1999). Tomo I. Santiago, Chile: Universidad de Chile. Facultad de Derecho, Editorial Jurídica de Chile, pp. 161-172.

${ }^{70}$ La mutación en ritmo de progreso mediante el cual el MERCOSUR alcanza esquemas de integración más sofisticados, lo destaca ARCARO CONCI quien apreciando que en el MERCOSUR se constata una proximidad a las temáticas protectoras de los DDHH, determina que ha abandonado un esquema de integración estructural pasando a contactarse con sistemas de integración sustancial los cuales son más profundos. Destaca que, si bien el MERCOSUR no posee una Carta de Derechos Fundamentales, fácticamente hay extremos que abren camino, v.gr. el hecho de haber impuesto restricciones al comercio destinadas a la protección de la vida y la salud, que no pueden ser consideradas como barreras no arancelarias; o el hecho de que los Estados miembros deben presentar relatos periódicos sobre su progreso en derechos sociales, económicos y culturales; o en materia medioambiental, se asume que la integración debe ser alcanzada mediante la preservación ambiental; o la importancia del Protocolo de Asunción sobre Compromiso con la Promoción y la Protección de los DDHH del Mercosur, que dispone sobre la cooperación para la promoción y protección de los DDHH y Libertades Fundamentales, establece el procedimiento de consultas y 394 


\subsection{EL PROYECTO DE LA NUEVA} Corte De Justicia Para Mercosur - CJM

La creación de la Corte de Justicia del Mercosur (CJM) sin lugar a dudas, por donde quiera que se le observe, comportaría un gran paso de futuro para el MERCOSUR. Pues no sólo supondría consolidar una forma superior de resolución de conflictos, sino que aproximaría realmente al MERCOSUR hacia los contenidos y exigencias del derecho de la integración. Bajo estas premisas, constituye para nosotros el más alto interés. La historia legislativa de este «Proyecto de Protocolo para la creación de una Corte de Justicia Mercosur» da cuenta de que éste emanó de la actividad del PARLASUR (MERCOSUR/PM/PN 02/2010), elevándose en el año 2010 a la consideración del Consejo del Mercado Común (CMC). Y en el mes de junio del año 2017, el PARLASUR insistió al CMC (MERCOSUR/PM/SO/REC.07/2017) que retomase el Proyecto de la nueva Corte ${ }^{71}$.

Como ya vimos - capítulo I - el SSCM es producto de todo un desarrollo estructurado en diversas etapas, el cual comenzó sin órganos específicos, sino tan solo, en manos de los instrumentos de la diplomacia. Más tarde progresaría, pero únicamente hasta un sistema de nivel arbitral. La máxima expresión del SSCM fue haber construido una jerarquía conformada por los TAAM como inferiores, y el TPRM en la cúspide. Sin duda, muy lejano de los desarrollos de carácter integracionistas. A pesar de que los propios laudos de estos tribunales mercosureños hayan declarado en diversas oportunidades que el MERCOSUR ha avanzado en diversas dimensiones y que se encuentra regido por múltiples principios del derecho de la integración, considerado éste último en sentido amplio, tal como lo vimos al analizar la jurisprudencia mercosureña y el diálogo judicial.

otras medidas, incluso la suspensión, cuando sean infructíferas las primeras, en casos de graves y sistemáticas violaciones de DDHH en situaciones de crisis institucional o durante la vigencia de un estado de excepción; o la Segunda Declaración Presidencial sobre Prevención y Erradicación del Trabajo Infantil en el Mercosur; y muchos más. ARCARO CONCI, L. G. (2015). Mercosur, integración regional y derechos humanos en un proceso multinivel. Estudios constitucionales: Revista del centro de estudios constitucionales, 13(2), 125-152. ${ }^{71}$ El Proyecto de Norma 02/10 del PARLASUR (MERCOSUR/PM/PN 02/2010) que aprueba el PROYECTO DE PROTOCOLO CONSTITUTIVO DE LA CORTE DE JUSTICIA DEL MERCOSUR, fue elevado al CMC para su consideración en diciembre del año 2010. Disponible en el Portal oficial del PARLASUR <https://www.parlamentomercosur.org/parlasur/2016/templates/buscador_documentos.jsp?titulo=corte+de+ju sticia\&anio $=2010 \&$ tipo $=0 \&$ site $=1 \& \mathrm{cmdaction}=$ search \&channel=parlasur\&site $=1 \&$ contentid=13006> [última consulta, mayo 30, 2019]. Vid. también en <https://www.parlamentomercosur.org/innovaportal/file/5353/1/proy-de-norma-02-1010-corte-de-justicia.pdf> [última consulta, mayo 30, 2019]. El 26 de junio 2017 el PARLASUR recomendó al CMC retomar el proyecto de la Corte (MERCOSUR/PM/SO/REC.07/2017). Disponible en <https://www.parlamentomercosur.org/innovaportal/file/13694/1/rec-07-2017.pdf> [última consulta, junio 15, 2019]. 
Por tal motivo consideramos que ante el Acuerdo de Asociación Estratégica con la UE, resulta evidente que el MERCOSUR queda al debe consigo mismo y con sus proyecciones de futuro coherente con un esquema de integración del siglo XXI, pues ya debería contar desde hace bastantes años con una verdadera Corte de Justicia integracionista, con estructuras, procedimientos y orgánica desarrolladas al menos como la de sus vecinos el TJCA o la CCJ. Es significativo observar empíricamente que su nivel de desarrollo sustantivo no se condice con el tipo de naturaleza jurídica de la que goza su actual mecanismo arbitral.

Dicha empozada y anacrónica posición, obtusa en plantear estructuras arbitrales para diseños que no son meramente interestatales, sino que aspiran a umbrales muy superiores, es una circunstancia que consideramos del todo absurda, y sobre la cual, se reclama constantemente por la doctrina estudiosa del Cono Sur de América, la que ha venido subrayando por largo tiempo la necesidad de que el MERCOSUR profundice su dimensión integracionista con la incorporación de un verdadero tribunal de integración ${ }^{72}$.

A nuestro juicio, si bien es cierto que algunos TAAM y TPRM (decimos algunos, porque como ya señalamos, estos tribunales sólo son de convocatoria permanente) han venido a ser un aporte sustantivo al acercamiento del MERCOSUR con el derecho de la integración, mediante los innovadores laudos que analizamos, no podemos dejar en manos de la buena voluntad del diálogo judicial, toda la construcción de los esquemas de integración en el MERCOSUR, menos las de soluciones orgánicas, aquello es imposible. Por tal razón es que debe concretarse institucionalmente esta mayor exigencia en lo jurisdiccional, para que en un futuro cercano se supere esta carencia ${ }^{73}$.

\footnotetext{
${ }^{72}$ Las solicitudes desde el mundo de la academia han sido numerosas e insistentes, en el sentido de que ya es tiempo de construir una Corte de naturaleza integracionista, o a lo menos que el MERCOSUR dé una señal clara y decidida respecto de su voluntad por contar prontamente con una corte con capacidad de desarrollarse hasta ese umbral. Por ejemplo FERNÁNDEZ LIESA expresa «queda por crear, sin embargo, un verdadero Tribunal de Justicia de integración del Mercosur». FERNÁNDEZ LIESA, C. R. (2008). La proliferación de tribunales internacionales en el espacio iberoamericano. REIB: Revista electrónica iberoamericana, 2(2), 1122. (p. 15). Otros, CIENFUEGOS MATEO, 2012b. JOVTIS, 2012. CENTURIÓN GONZÁLEZ, 2017. KÜHN BACA, 2017.

${ }^{73}$ En ese sentido, de mayor exigencia, teniendo en el horizonte la nueva Corte, CENTURIÓN manifiesta «el TPR[M] debe no solo seguir con su actual estructura sino ir pensando en exigirse más aún, mirando a un futuro Tribunal de Justicia del Mercosur, etapa donde las responsabilidades de este órgano serán mucho mayores. Dado que el Mercosur, 'una vez que arribe al estadio integracionista'... deberá... contar con un Tribunal de Justicia, necesitará de un órgano jurisdiccional dotado de mayores recursos y responsabilidades. Esto si bien parece un objetivo a largo plazo, comporta la responsabilidad de preparar paulatinamente a este importante órgano para tal fin». CENTURIÓN GONZÁLEZ, C. H. (2017). Aporte del tribunal permanente de revisión al proceso de integración del Mercosur: Reflexiones orientadas hacia la sociedad civil del mercosur. Revista da secretaria do tribunal permanente de revisão, 5(9), pp. 78-100 (p. 97).
} 
La buena noticia es que en línea con una visión de futuro, actualmente el MERCOSUR cuenta con el ya referido Proyecto de Protocolo para la creación de una Corte de Justicia Mercosur. Este proyecto técnico gira en ideas mucho más familiares al derecho de la integración. Y es el resultado de un sofisticado trabajo de derecho comparado, que incorpora valiosos aportes basados en la experiencia adquirida en los procesos de integración de la UE y seguidos por los latinoamericanos objeto de estudio en esta tesis. Este proyecto de Protocolo debería ser aprobado por los cuatro Estados miembros, quienes lógicamente tendrían que ajustar sus Constituciones y derecho derivativo. Posicionando de dicho modo a la futura CJM, como un órgano permanente al servicio de un proyecto integracionista $^{74}$.

Hacia el futuro las características que incorporaría el proyecto solucionarían las actuales carencias en materias de opiniones consultivas — de extremos que ya vimos en el análisis estatutario que efectuamos en el capítulo II - se amplía la legitimación activa en estas, pasarían a ser de interpretación y de validez, se tornarían obligatorias las respuestas de la CJM, entre otros muchos beneficios más ${ }^{75}$.

\footnotetext{
${ }^{74}$ Las referidas versatilidades son las que KÜHN destaca al analizar el proyecto de la Corte, expresando en tal sentido "The CJM [CIJ] is meant to be a contribution to the legal and institutional consolidation of the integration process. The draft protocol draws expressly from the experience gained in the application of both the protocols laying down the legal basis for Mercosur's current dispute settlement mechanism and the mechanisms in place in other integration systems characterised by a supranational format such as the EU, CAN, and SICA. The recitals confirm that the draft a protocol is essentially the product of a profound comparative study of integration law». KÜHN BACA, W. M. (2017). The draft protocol on the creation of the court of justice of mercosur. A new milestone in the judicialisation of regional integration law. Anuario mexicano de derecho internacional, (17), 405-442 (pp. 417-419, vid. en particular el apartado 4. Major aspects of the dispute settlement mechanism introduced by the draft protocol). Artículo también disponible en Revista general de derecho europeo, (39) 2016, (RI §417315).

${ }^{75}$ Las principales características que ostentaría la CJM, según destaca CIENFUEGOS, correrían por superar las carencias de la regulación de las opiniones consultivas. El autor puntualiza que, para comenzar, pasan a denominarse cuestiones prejudiciales y se amplía la legitimación activa a cualquier jurisdicción nacional, distinguiendo entre las que deciden en última instancia en el proceso nacional y aquellas cuyas decisiones son impugnables, así como a los órganos del Mercosur, incluida su Secretaría. El objeto de las cuestiones prejudiciales podrá ser la interpretación y la validez del derecho del Mercosur y, finalmente, las sentencias prejudiciales serán obligatorias. Agrega que, en caso de que este Protocolo sea aprobado en los términos del proyecto, se asegurará mucho mejor la aplicación uniforme de las normas mercosureñas en el Cono Sur, a la vez que mejorará sensiblemente la protección judicial en el Mercosur, puesto que contiene igualmente normas sobre las competencias de la nueva corte de justicia en el marco de acciones directas de nulidad, omisión e incumplimiento, etcétera. CIENFUEGOS MATEO, M. (2012a). La colaboración entre los jueces de los países del mercosur y del tribunal permanente de revisión mediante el procedimiento de opiniones consultivas. En M. Hernández Ramos (dir.), A. Sáiz Arnáis (dir.), A. Torres Pérez (dir.), M. Zelaia Garagarza (dir.), S. Deluca, O. Saldías, ... R. Bustos, Tribunales en organizaciones de integración: Mercosur, comunidad andina y unión europea ( $1^{\mathrm{a}}$ ed.). Cizur Menor: Thomson Reuters Aranzadi, pp. 209-213.
} 
Desde nuestra perspectiva consideramos que el proyecto de la CJM por donde se le analice es un salto gigantesco en la dimensión de la función jurisdiccional del MERCOSUR —a pesar de que nuevamente para muchos pueda no ser suficiente - pues pasaría ahora a delegarse en una Corte de naturaleza jurisdiccional y de carácter permanente. Además este último atributo, netamente orgánico, daría por superada la carencia de arrastre homogéneo de la jurisprudencia mercosureña, logrando que ésta se alinee con la seguridad jurídica, ya que al estabilizarse jueces y Corte, pasaría a ser más predecible el criterio jurisdiccional en el merco-sistema, evitándose aquellos giros y retrocesos que ya destacamos en el capítulo IV referido al diálogo judicial, en el sentido de que algunos TAAM no asumían los precedentes de otros TAAM o - peor aún- del TPRM. Recordemos que tras dicho análisis, nosotros acusábamos una disgregación de ideas que complotaba contra la conformación de un acervo jurisdiccional más constante y estable. Anomalía que comprendemos pasaría a ser resuelta por la CJM.

Se añade en línea con la estabilidad y la seguridad jurídica, lo correcto del sostener la idea de que este proyecto de futuro, en lo jurisdiccional, daría por superado la condición de permanente transitoriedad del MERCOSUR, ya que de modo constante se ha permanecido a la espera de una transformación profunda en dicha área, lo cual en esta ocasión, sí lo sería. Además abriría las puertas a los tan restringidos particulares, y aparejaría una rotunda expansión competencial ${ }^{76}$.

\footnotetext{
${ }^{76}$ Este movimiento superador de una etapa que venció sus fuerzas, y que definitivamente es reemplazado por otro, lo manifiesta JOVTIS, quien subraya las debilidades del actual mecanismo de solución de controversias del Mercosur, coordenadas desde donde pivota hacia elogiar el proyecto de protocolo de la CJM. Sostiene que el sistema de solución de controversias del Mercosur se ha caracterizado por su condición de transitorio [esto es] siempre a la espera de una revisión profunda. Agrega que, el actual esquema, no es adecuado para facilitar una interpretación uniforme del Derecho del Mercosur, ni para asegurar una efectiva tutela judicial a todos los que se ven afectados por el ordenamiento jurídico regional. Esto es así, no solo por las restricciones competenciales de los órganos arbitrales, sino también, por el [actual] papel reservado a los particulares, que es, como mínimo secundario. Ahora bien advierte que: si bien es cierto que no se deben imitar otros modelos de una manera automática — precaución a la que nosotros suscribimos en su totalidad - reconoce que tampoco debe ignorarse el papel clave que han tenido tribunales con competencias comparables a las que tendría la CJM (TJUE, TJCA, y la CCJ) en la interpretación uniforme de la normativa comunitaria y en la profundización de la integración. Las novedades más significativas se dan con relación a la expansión de las competencias de la CJM, con nuevas acciones, la ampliación de la legitimación activa, dejando a los particulares como los principales beneficiados, un nuevo y mejor tratamiento a las cuestiones prejudiciales, la que torna obligatoria, y sugiere ampliar la capacidad para peticionarla, entre otras tantas aristas más. JOVTIS, I. (2012). La legitimación activa en el actual sistema de solución de controversias del mercosur y perspectivas ante la futura creación de una Corte de Justicia regional. En M. Cienfuegos Mateo, W. Nerys Fernández, N. B. Mellado, M. L. Ali, J. C. Fernández Saca, R.M. Gajate, ... L. M. Ramírez, Desafíos del desarrollo de la infraestructura regional para el medio ambiente, la cohesión social y la gobernabilidad del mercosur. Uruguay: Taller de Comunicación, pp. 249-262 (p. 261). Disponible en <http://sedici.unlp.edu.ar/bitstream/handle/10915/59803/Documento_completo.pdf-PDFA.pdf?sequence=1> [última consulta, mayo 30, 2019].
}

398 
Sin embargo, nosotros observamos un problema que no ocultaremos aquí, sino que lo pondremos de relieve y dice relación con el efectivo tráfico de procesos ventilados en los tribunales del merco-sistema, el cual es ínfimo, ya que no superan las 26 causas $^{77}$ considerando los ejercicios de los TAAM y TPMR juntos, puede revisarse la imagen 5 compuesta de una tabla y de un gráfico que hemos preparado tras procesar los datos publicados para el MERCOSUR los que dan cuenta de la escasa producción jurisprudencial.

\footnotetext{
${ }^{77}$ La escasa producción de los Tribunales del Mercosur llega sólo a 26 laudos en toda su historia, sumados los TAAM y los TPRM. Puede observarse el detalle así, A) al TPMR sólo con 6 laudos y 3 respuestas sobre opiniones consultivas, y B) a los TAAM con 12 laudos y 5 aclaraciones. Los que en detalle siguen el siguiente orden cronológico: Los 6 laudos TPRM son identificados como 1/2005 (de 20-12-2005), 1/2006 (de 13-12006, Aclaración del 1/2005), 2/2006 (de 6-7-2006), 1/2007 (de 8-6-2007), 1/2008 (de 25-4-2008) y 1/2012 (de 21-6-2012). Las 3 opiniones consultivas son: 1/2007 (de 3-4-2007), 1/2008 (de 24-4-2009) y 1/2009 (de 15-6-2009). En tanto los 12 laudos y las 5 aclaraciones de los TAAM son Laudo 1 (de 28-4-1999), Laudo 2 (de 27-9-1999) más Aclaración (de 27-10-1999), Laudo 3 (de 10-3-2000) más Aclaración (de 7-4-2000), Laudo 4 (de 21-5-2001) más Aclaración (de 18-6-2001), Laudo 5 (de 29-9-2001) más Aclaración (del laudo 5, publicación sin fecha), Laudo 6 (de 9-1-2002), Laudo 7 (de 19-4-2002), Laudo 8 (de 21-5-2002) más Aclaración (de 19-6-2002), Laudo 9 (de 4-4-2003), Laudo 10 (de 5-8-2005). Los 10 primeros laudos fueron dictados conforme al Protocolo de Brasilia del año 1991, a los que se les suman otros 2 laudos más, que quedan comprendidos dentro de la nueva etapa, posterior al Protocolo de Olivos (2002, vigor 2004) identificados estos dos como Laudo de 25-10-2005 y Laudo de 6-9-2006. Fuente: Portal Oficial del Tribunal Permanente de Revisión del Mercosur <http://www.tprmercosur.org/es/sol_contr_laudos.htm> [última consulta, mayo 31, 2019].
} 
Imagen 5. A la izquierda, en la tabla se comparan numéricamente las producciones de laudos. A la derecha, en el gráfico se presentan porcentualmente la distribución de dichos laudos dictados por el TAAM y el TPRM.
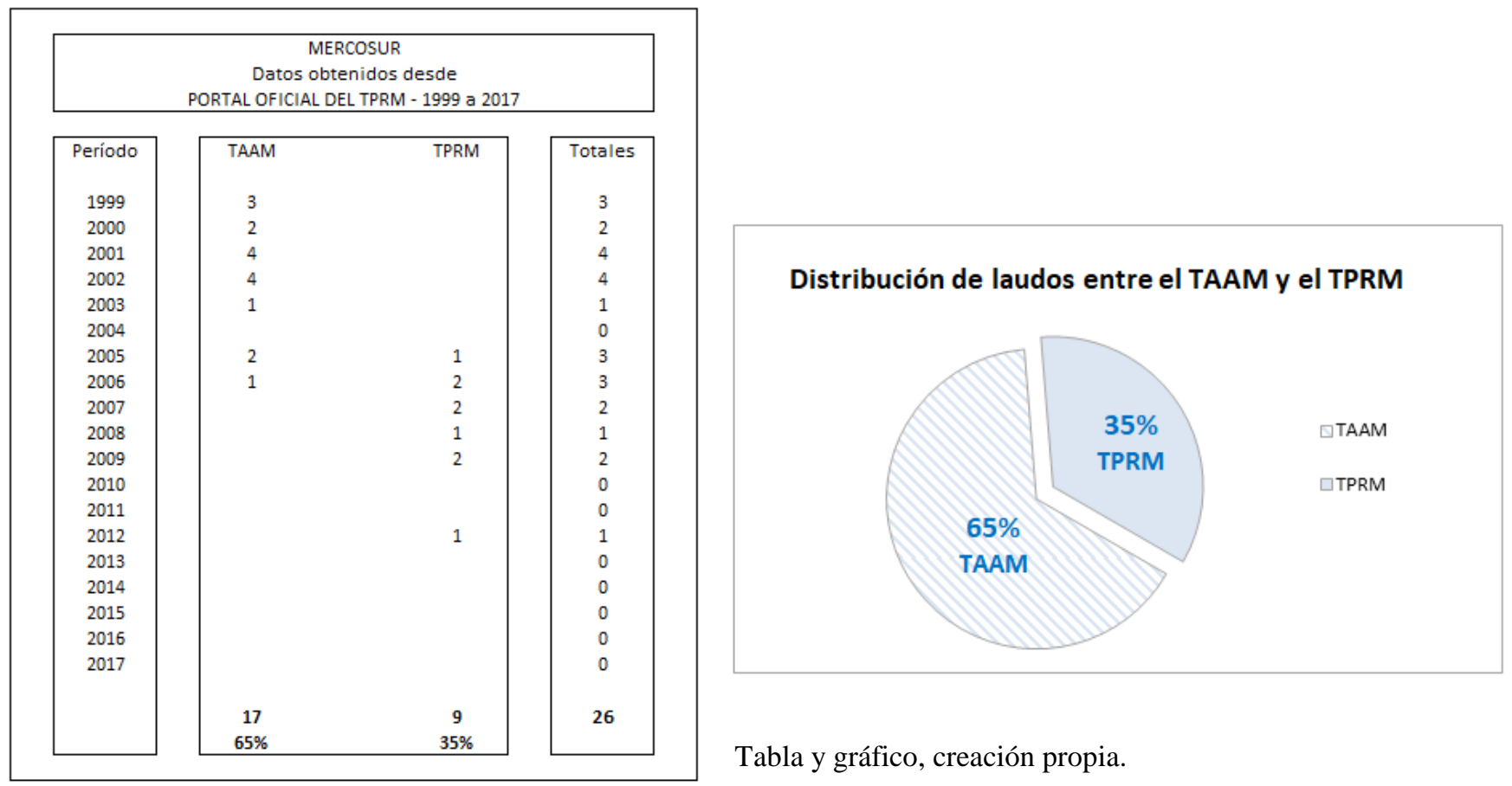

La baja producción de laudos que se muestra en la tabla de la izquierda de la imagen 5, es un dato relevante que pudiera frenar el despegue de la CJM. En realidad nosotros somos de la idea de que esta es la razón por la cual aún no toma rumbo final la nueva Corte. En términos absolutos la producción en el MERCOSUR es comparativamente la menor de su entorno. De hecho si lo cotejamos, encontramos que el modelo más productivo es el del TJCA que entre los años 2011 al 2017 dictó 2.514 sentencias $^{78}$, por su parte en el SICA, la CCJ en su época actual (de 1964 al 2017) contabiliza 166 sentencias $^{79}$. Esta realidad puede observarse a continuación, ahora en la imagen 6 , la cual se compone de tres tablas y de tres gráficos, los que en su conjunto presentan con todo detalle la triple comparación.

\footnotetext{
${ }^{78}$ El TJCA registra para el período 2011 a $2017=2.514$ sentencias. Anualizadas por factor sentencias dictadas, tenemos: En el año $2017=556$ sentencias. En el año $2016=504$ sentencias. En el año $2015=478$ sentencias. En el año $2014=327$ sentencias. En el año $2013=273$ sentencias. En el año $2012=183$ sentencias. En el año $2011=193$ sentencias. Vid. detalles en nota 42 de este capítulo y en la imagen 4 (p. 410).

${ }^{79}$ Estudiadas todas las MEMORIAS DE LA CORTE CENTROAMERICANA DE JUSTICIA, publicadas desde el año 1964 al 2017, totaliza 166 sentencias. Vid. detalles en nota 20 de este capítulo y en la imagen 3 (p. 400).

400
} 
Imagen 6. A la izquierda se muestran tres tablas anuales. A la derecha de cada una se procesan los datos mediante gráficos de proyección con las sentencias de la CCJ, el TJCA y los TAAM+TPRM en función de cada períodos publicado.
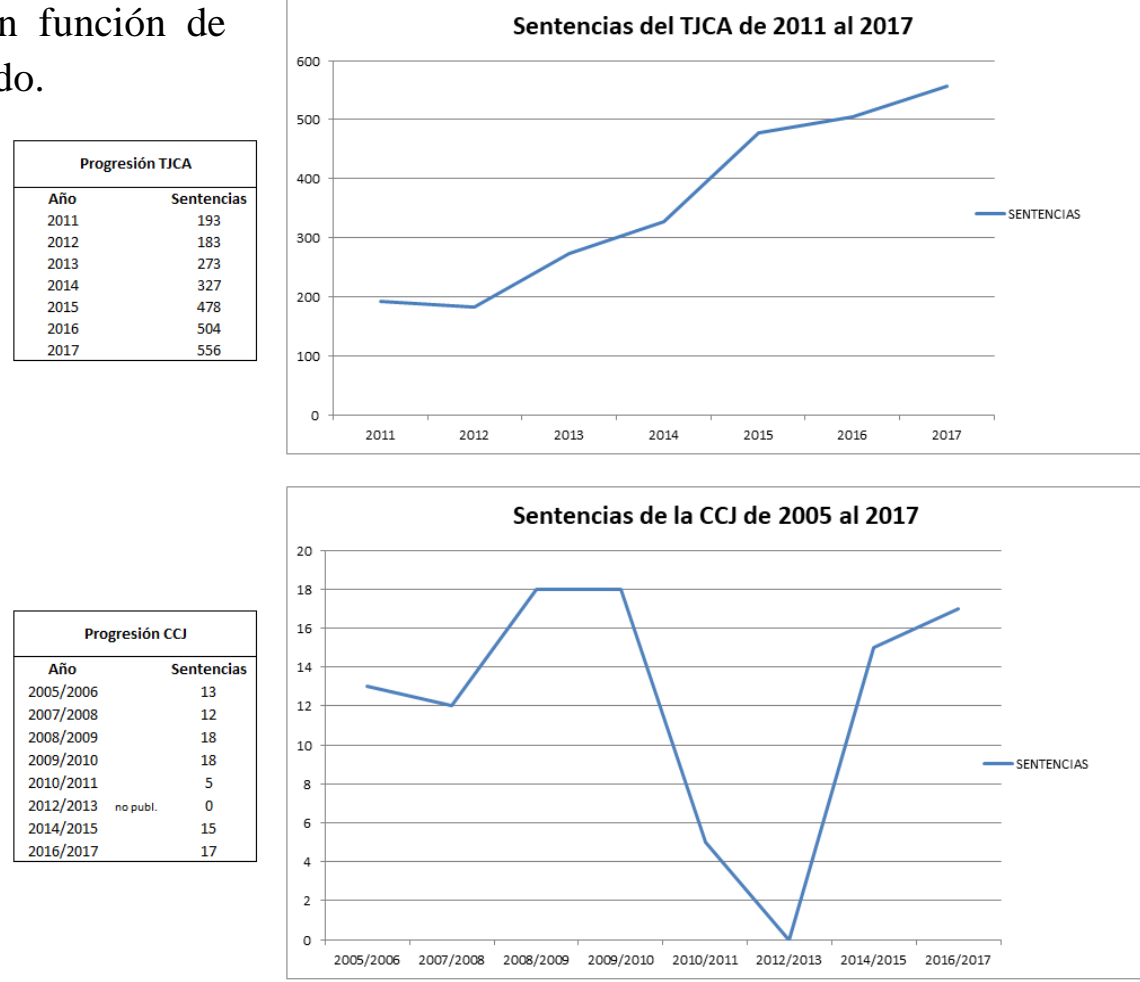

\begin{tabular}{|lc|}
\hline \multicolumn{2}{|c|}{ Progresión TAAM+TPRM } \\
\hline Año & Laudos \\
1999 & 3 \\
2000 & 2 \\
2001 & 4 \\
2002 & 4 \\
2003 & 1 \\
2004 & 0 \\
2005 & 3 \\
2006 & 3 \\
2007 & 2 \\
2008 & 1 \\
2009 & 2 \\
2010 & 0 \\
2011 & 0 \\
2012 & 1 \\
2013 & 0 \\
2014 & 0 \\
2015 & 0 \\
2016 & 0 \\
2017 & 0 \\
\hline
\end{tabular}

Tablas y gráficos, creación propia.

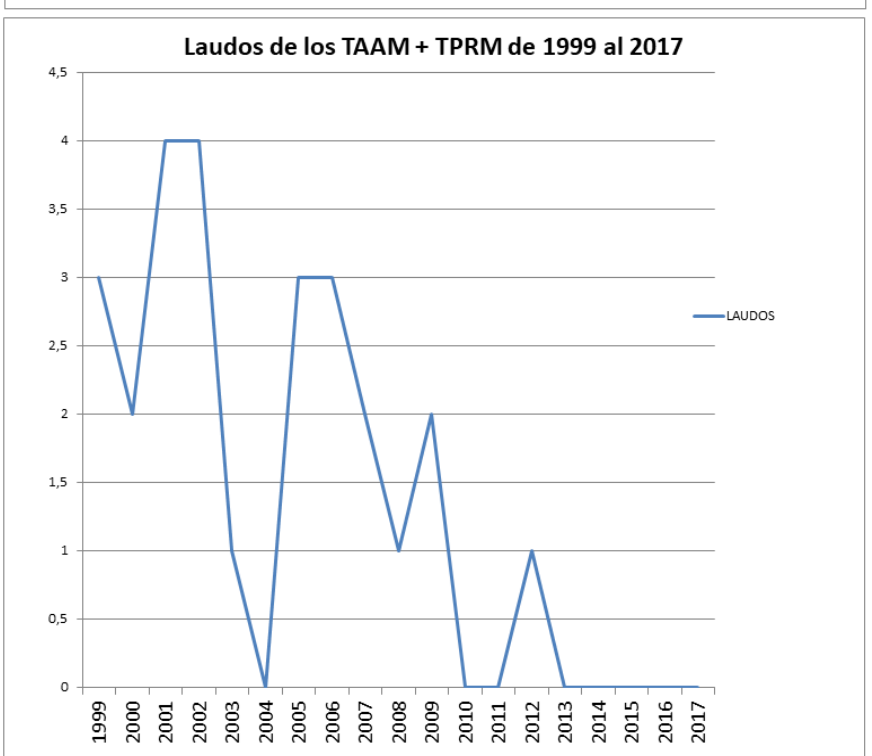

Es decir, el análisis horizontal inter-americano, resulta muy complejo para el MERCOSUR, ya que, si por ejemplo, tomásemos el último año 2017 aisladamente la visión es devastadora, serían cero $\operatorname{laudos}^{80}$. Frente a esto, sólo esperamos que el criterio no sea

${ }^{80}$ Si sólo tomamos horizontalmente al año 2017 obtenemos: En la UE el TJUE dictó = 1.594 sentencias. En la CAN el TJCA dictó $=556$ sentencias. En el SICA la CCJ dictó = 17 sentencias. Y en el MERCOSUR los 
cuantitativo, sino sustantivo en pos de la indispensable coherencia con el Derecho de la Integración. En tal sentido nosotros nos alineamos con la motivación del Proyecto de Protocolo Constitutivo de la CJM que en lo pertinente expresa:

«Convencidos de que la seguridad y certeza jurídicas que amparará este órgano judicial fortalecerán el esquema regional, coadyuvando a la consolidación del Estado de derecho hacia el interior del Mercosur y garantizando la igualdad de derecho entre partes» ${ }^{81}$.

En conclusión, consideramos excelente que el MERCOSUR cuente con la CJM, pues esto significará un nuevo avance concreto en la historia de dicho proceso de integración, y valoramos positivamente el progreso completo del MERCOSUR, toda vez que el análisis retrospectivo no engaña, así entre el inicio y hoy, existe objetivamente una enorme diferencia en la zona cubierta por el proyecto MERCOSUR.

El futuro del sistema de integración de América Latina dependerá de los éxitos de cada modelo sub-regional. Los Latinoamericanos deben asumir responsablemente el fortalecimiento de todas las variantes que les impactan, sobre todo la CAN, quien se muestra como el modelo más débil en cuanto a su estabilidad y permanencia. Para algunos la solución sea la absorción por el MERCOSUR logrando efectivamente la unión del Cono Sur de América, en una dinámica de retroalimentación, dado que las instituciones de la CAN — si es que previamente se libera del SIA — se presentarán de nivel Comunitario. Lo que colisionaría con las estructuras del MERCOSUR, pues éstas aún se encuentran en desplazamiento hacia ese nivel. Operación sensible, compleja y a muy largo plazo, que debe correr centralmente por el compromiso real de los Estados miembros de la CAN, de lo contrario sería extremadamente peligrosa la amalgama, ya que podría desestabilizar al MERCOSUR, tal como ya lo anotamos y explicamos. Nosotros en cambio, apostamos por «motores de integración sub-regionales» en las zonas en que actualmente están. Pensamos que la CAN debería sobrevivir en la sub-región en que se encuentra, con el acompañamiento del SICA y del MERCOSUR, más la siempre valiosa guía de la UE.

En cuanto al MERCOSUR, tras analizar todos los hitos de desarrollo que pusimos de relieve en este capítulo estimamos que éste esquema saldrá fortalecido hacia el futuro. Aunque nos preocupa de sobremanera la baja actividad jurisdiccional de sus actuales tribunales arbitrales. Seguramente el esperado nacimiento de la CJM traiga nuevos impulsos vitales a esta neurálgica función pretoriana, máxime la reciente firma del Acuerdo

TAAM y TPRM juntos, dictaron = 0 laudos (en 2012 se registró 1 laudo, el cual corresponde al último publicado, vid. imagen 2 (p. 398).

${ }^{81}$ Párrafo Convencidos, de las motivaciones del Protocolo Constitutivo de la Corte de Justicia del Mercosur (MERCOSUR/PM/PN 02/20190).

402 
de Asociación Estratégica UE-MERCOSUR. Respecto del SICA, como esquema de integración centroamericano, seguramente seguirá su camino integracionista y, terminará consolidando aquella valiosa historia unitaria que ya destacamos. Sin duda en la actualidad el SICA es el modelo mejor ubicado en Latino América.

Estamos conscientes de que hacia el futuro no hay nada seguro, pero entendemos que América Latina no puede perder más tiempo para fortalecer sus tres esquemas de integración, lo cual incide directamente en el futuro de los tribunales de integración que fueron el objeto de estudio en esta tesis. Los tres esquemas de integración latinoamericanos, a los que pertenecen la CCJ, el TJCA y el TPRM, se encuentran estratégicamente ubicados, uno en pleno istmo centroamericano, el otro con un enorme y preferente acceso al Pacífico, y el tercero con una excepcional orientación al Atlántico. Tampoco pueden desaprovechar las grandes facilidades que hoy existen y que antaño eran impensadas. La posibilidad técnica de llegar a cada ciudadano, de hacerlo partícipe mediante tele-conexiones y ambientes web en un mundo globalizado, será lo que realmente motive a las nuevas generaciones, cuando vean que sus aportes son considerados por los centros de poder. En general y basándonos en todo lo analizado somos del criterio de que el futuro en Europa, en América y en todo el mundo, será mejor con más integración sub-regional, en respeto a la siempre enriquecedora multi-culturalidad. 



\section{CONCLUSIONES}

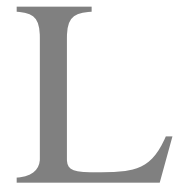

os orígenes de los esquemas modernos de integración latinoamericanos obedecieron a lógicas muy diferentes a las del modelo de la UE. En Latino América los intentos integracionistas modernos surgen en las dinámicas post Guerra Fría, y por lo tanto no fueron impulsados de modo definitivo - a diferencia de Europa - a partir de las catastróficas consecuencias de la Segunda Guerra Mundial, sino tras valorar la segunda etapa del proyecto europeo, aquella en que se le aprecian sus éxitos como un buen esquema para hacer frente a los efectos de la globalización.

Una de las conclusiones más relevantes que podemos seguir desde el ángulo histórico, es que diversas construcciones jurídicas que en Europa fueron creadas jurisprudencialmente por la Corte de Luxemburgo, en América Latina en cambio, se incorporan legislativamente, es decir, ya resueltas. Así por ejemplo en la CAN la declaración de la supremacía del derecho de la integración se efectuó estatutariamente, a diferencia del modelo europeo donde el TJ debió efectuar su construcción explicando lo que parecía evidente, que el Derecho Comunitario, hoy Derecho de la UE, gozaba de primacía sobre el derecho nacional.

Este es un claro beneficio del que gozaron los modelos integracionistas latinoamericanos por el hecho de ir a la zaga del europeo, salvando así, estatutariamente problemáticas que debió enfrentar el sistema pionero mediante la articulación jurisprudencial en sus primeras décadas, cuestión propia de los ajustes de la empresa europea que carecía de precedentes en los cuales apoyarse. Circunstancia completamente diferente a Latinoamérica, donde — casi 
únicamente - se han basado en la experiencia foránea, positivizándola en su mayoría, tal como incluso lo reconocen algunas importantes sentencias que han sido objeto de análisis en la presente investigación.

Como hecho irrefutable, el SICA, la CAN y el MERCOSUR, intentan replicar sólo en parte y en la medida de lo posible el modelo de la UE, por lo que en la práctica estos tres esquemas más bien adquieren una naturaleza de aspiraciones integracionistas. Pues ante la mega construcción de la actual UE, los proyectos latinoamericanos enfocados se aprecian del todo incompletos, sin alcanzar en plenitud los patrones centrales del derecho de la integración, ni mucho menos el umbral supranacional. Sin embargo, y he aquí un hecho significativo, el SICA, la CAN y el MERCOSUR, tampoco pueden calificarse de meras organizaciones internacionales intergubernamentales, ya que los tres esquemas, se aproximan a una noción amplia del derecho de la integración, lo cual fluye por dos conductos, uno, se proponen estatutariamente fines propios del derecho de la integración, y dos, los ejercicios jurisprudenciales de la CCJ, del TJCA y del TPRM vienen impregnados de abrumadores criterios de cercanía a la noción amplia del derecho de la integración. Concluimos entonces que es, justamente, esta posición intermedia la que les imprime a estas organizaciones un carácter especial que atrae la atención investigativa, ya que poseen la potencialidad de desplazarse hacia contenidos más maduros de la integración.

En la referida posibilidad de desplazamiento es donde los que fueron nuestros objetos de estudio - la CCJ, el TJCA y el TPRM junto a los TAAM - presentan sus mayores aportes. De hecho nuestra hipótesis nos exigía demostrar el rol de tales tribunales en los proyectos regionales a los cuales pertenecen. Por tal motivo, y tras haberlos sometido a un riguroso análisis estatutario, jurisprudencial y doctrinal, concluimos que en menor medida sí poseen diversas características que los aproximan al modelo europeo — más no lo igualan—, tanto desde el marco estatutario y legislativo, donde comprobamos que los patrones centrales que aislamos para el cotejo sí se presentan — con menor intensidad- en los modelos analizados, como desde el ángulo del ejercicio jurisdiccional, pues por este segundo cauce efectivamente todos los tribunales analizados producen jurisprudencia integracionista, y además, dicha actividad la llevan a cabo en gran medida utilizando un diálogo judicial monólogo y extractivo, casi de tipo vertical desde el TJUE, a lo que se suma un incipiente diálogo judicial interamericano de tipo más horizontal.

A partir de todas las condiciones expuestas y en una visión general, concluimos que más bien impera una influencia global del modelo europeo sobre los tres esquemas latinoamericanos analizados. Esto porque la noción de influencia sobrepasa por mucho la técnica del diálogo judicial, pues mediante este último únicamente fluyen las conclusiones de los jueces. En cambio, lo que hemos corroborado durante toda esta investigación es que primero hay un efectivo diálogo de fuentes, al que luego se le añade un concreto diálogo 408 
judicial y finalmente se suma una inspiración fáctica en la doctrina europea, pues las sentencias de las Cortes latinoamericanas que fueron objeto de análisis, van citando en abundancia a los autores europeos estudiosos de la misma UE.

El proyecto SICA presenta a favor de la CCJ un desarrollo jurídico mucho más sólido que el de sus vecinos, e incluso en algunas específicas materias, apuesta por soluciones más modernas que la propia UE, sobresaliendo el hecho de que ya desde sus Estatutos se posiciona de modo directo a la CCJ como un órgano central en la arquitectura institucional del SICA, además las competencias de la CCJ son más amplias en la fiscalización de los Tratados pues también puede controlar Tratados vigentes, concretando así una vigilancia $a$ posteriori. Se adiciona el hecho de que el SICA incorpora los denominados dictámenes ilustrativos, reservados para algunos casos en que los Estados o las Cortes Supremas le dirijan consultas a la CCJ, respuestas que, sin ser vinculantes, representan una herramienta adicional que no existe en ningún otro modelo. Ante la CCJ es más amplio el ius standi para los particulares, y es el único modelo integracionista en que se aplica el principio de publicidad de los actos de proceso a las opiniones particulares de los jueces, haciendo valer de mejor manera el principio de transparencia.

En el otro extremo, concluimos que el TPRM es el más débil de los tribunales analizados, esto se debe básicamente a que no se le atribuyó de forma directa la función hermenéutica de las Cartas Constitutivas, lo que lleva a considerar esta actividad como tangencial, por lo tanto, ante las Cortes mercosureñas la función interpretativa más bien se vincula con la función consultiva, y no con una directa y amplia función interpretativa, pero incluso, respecto de esta función consultiva, concluimos que es muy débil, ya que cada país tiene un proceso distinto, los legitimados están muy limitados y, sobre todo, el eslabón más débil es que la respuesta del TPRM no es obligatoria. Tampoco hay una acción específica para el control de legalidad de los actos — como sí la hay en la UE, en el SICA y en la CAN — por lo tanto, aquí debe ejercerse mediante una demanda general del afectado, lo que se convierte en un campo del todo inespecífico.

Por su parte el TJCA efectivamente posee competencias y características que lo asemejan, un poco más al modelo europeo. De hecho su estructuración fue fruto de un profundo trabajo de derecho comparado, llegando en su momento a hablarse de que, salvando las distancias el TJUE y el TJCA pasaban a constituir los modelos más avanzados de justicia comunitaria. Y en efecto, en lo estatutario sí hay patrones centrales para aproximarlo un tanto al TJUE, tales como sus competencias para llevar adelante la función hermenéutica de las Cartas Constitutivas, la función consultiva para varios objetos con una respuesta obligatoria, entre otras más que analizamos con detención. 
Respecto del carácter constitucional de los tres tribunales analizados - perfil claramente reconocido al TJUE según vimos - concluimos que para la CCJ, el TJCA y el TPRM, la situación no resulta ser homogénea, sino que tan sólo la CCJ y el TJCA tienen ese perfil, excluyéndose al TPRM.

Por cierto hemos considerado que, el hecho de que hayamos verificado en una Corte latinoamericana, determinados patrones centrales, no significa en ningún caso que se despliegue con la misma intensidad que en el TJUE, claramente en América Latina cada uno de los patrones centrales con los que efectuamos el análisis estatutario se presentan con mucho menos intensidad respecto de la UE. Sin embargo, y con la misma claridad anterior, concluimos que no es indispensable poseer una gran estructura normativa sobre un tipo de competencia o patrón central que se intente verificar, para concluir que una tal o cual Corte latinoamericana lo posea efectivamente, pues existen diferentes intensidades en cada uno de los proyectos integracionista extra-UE. Así por ejemplo, podrá constatarse una determinada competencia o característica, tanto en Cortes que participan de proyectos más avanzados, como en las que pertenecen a proyectos con construcciones legislativas menos intensas. En este último caso, simplemente, se presentará en menor medida. Cuestión que se conecta con la idea de que los procesos más robustos poseen Cortes con competencias muy amplias, a diferencia de los procesos menos desarrollados donde sus tribunales tendrán potestades en menor medida.

Desde el campo del análisis de la jurisprudencia, y tras aplicar nuestros criterios de selección de sentencias —explicados oportunamente—, pudimos demostrar que las Cortes latinoamericanas analizadas, producen efectivamente jurisprudencia integracionista en diversas áreas. Considerando por cierto que la jurisprudencia integracionista en sí misma es bastante más compleja que la jurisprudencia de un típico tribunal nacional o internacional, porque en su totalidad conlleva dos grandes funciones, por una parte resuelve los contenciosos, y por otra interpreta el derecho del grupo - de la UE, o del SICA, o de la CAN, o del MERCOSUR, según corresponda - responde consultas, construye soluciones jurídicas muchas veces mediante nuevos principios o bien reacomodando los anteriores, e incluso, llega a posicionarse en una dimensión constitucional. Ambas funciones dan cuenta de un equilibrio dual de una Corte de integración, que evidencia un fenómeno de una alta densidad de competencias. Justo en ese punto, concluimos que la CCJ, el TJCA y el TPRM hacen su aporte concreto a cada una de las organizaciones a que pertenecen, colaborando en el desplazamiento hacia los criterios del derecho de la integración. En este sentido, concluimos que el rol de tales Cortes no puede ser otro que actuar como un constante motor de avance para la madurez del proyecto de integración, a través de la única forma que les compete, esto es, generando jurisprudencia integracionista. Aunque puntualmente para el caso del TPRM la observamos menos intensa. 
Se suma el hecho de que las Cortes analizadas, construyen buena parte de sus sentencias mediante una importación jurisprudencial desde tres tipos de fuentes exógenas, en primer lugar, de forma principal a través de un diálogo judicial monólogo y extractivo con el TJUE casi en sentido vertical, esto último porque los tribunales latinoamericanos analizados valoran en tan alto grado el auctoritas del TJUE, que se someten casi sin obstáculo alguno a sus construcciones, posicionando a la Corte de Luxemburgo como un pseudo superior jerárquico, en sentido de pauta autorizada a seguir; en segundo lugar, comprobamos algunas incipientes conexiones más horizontales entre la CCJ, el TJCA y el TPRM en carácter de diálogo judicial integracionista entre Cortes del mismo entorno; y en tercer lugar, verificamos que en menor medida recurren a otras fuentes jurisdiccionales, alcanzando al sistema internacional tradicional usando algunos criterios de la Corte Internacional de Justicia, e incluso se han conectado con Tribunales Constitucionales nacionales, tal como lo analizamos para la Corte Constitucional italiana.

Ahora bien, este constante esfuerzo de la CCJ, del TJCA y del TPRM, tiene por objeto concreto darle un matiz unitario al derecho de la integración, en el sentido de que para ellos se correspondería con una rama del derecho, el cual coincide casi perfectamente con el Derecho de la UE, así en Latino América le dan un carácter amplio y como todo un modelo a seguir. Es en tal ejercicio que el recurso al diálogo judicial se presenta ante los tribunales latinoamericanos analizados, como la mejor herramienta para homogenizar criterios jurisprudenciales, pero sólo en el sentido de la adecuación de los modelos latinoamericanos respecto del referente europeo. De allí que el diálogo judicial sea del tipo extractivo y monólogo, sin ninguna respuesta desde el TJUE.

De todo lo visto fluye que la unidad del derecho de la integración en su sentido amplio, deviene centralmente de la confirmación de sus principios rectores $\longrightarrow$ patrones centrales - más no de una igualdad geométrica entre los ordenamientos jurídicos pertenecientes a un tal o cual proyecto de integración de alguna región o sub-región del mundo. Pero el deseo latinoamericano de que el derecho de la integración se observe como una teoría jurídica unitaria, idéntica, aplicable sin adecuaciones y de modo global, colisiona con las realidades regionales, todas distintas en historias, en desarrollos democráticos y en otras tantas cuestiones más. Por tales circunstancias concluimos que las metas y los logros de un conjunto de países desarrollados europeos, no pueden extrapolarse — sin más — a grupos de naciones latinoamericanas en vías de desarrollo, las que de tanto en tanto presentan serios problemas de madurez democrática.

Lo más beneficioso que genera el uso del tipo de diálogo judicial constatado, es que se aprovecha la velocidad propia del ejercicio jurisdiccional para enfrentar problemáticas concretas, sin tener que esperar la lentitud del legislador, lo que sumado a la homogenización jurídica que se obtiene tras el uso de dicho diálogo, terminan siendo las 
dos utilidades centrales de la clase de diálogo usado. Pero esa dosis de utilitarismo, del todo bienvenido, se suma a una conclusión sustantiva de mayor envergadura, en el sentido de que nosotros entendemos que si las Cortes latinoamericanas analizadas, están importando soluciones desde el TJUE, y las incrustan en sus modelos integracionistas latinoamericanos, es porque jurídicamente son compatibles. Por consiguiente subyace una similitud en determinados patrones centrales a ambos lados del Atlántico — por cierto en las medidas, intensidades y posibilidades de desarrollo ya analizadas en extenso-, de hecho son compatibles porque de modo previo, estatutariamente, los esquemas de integración latinoamericanos se basaron en importantes mecanismos jurídicos de la UE.

Por todo lo visto, lo cual ha sido analizado desde una multiplicidad de ángulos, aplicando las metodologías de investigación y dentro del marco investigativo dado para esta tesis doctoral, queda entonces empíricamente demostrada nuestra hipótesis, en el sentido de que «las Cortes de integración latinoamericanas analizadas, a pesar de estar insertas en sus singulares procesos regionales y siendo éstas bien distintas, se identifican efectivamente entre éstas, determinadas características comunes o patrones centrales. Cuestión que se explica porque las construcciones latinoamericanas copian -aunque de modo incompleto- el modelo europeo. Por tal motivo al ejecutarlos en América Latina se despliegan con menor intensidad, dejando a la vista sendas carencias. Todas las Cortes analizadas se relacionan de modo dicotómico con el derecho de la integración, comprendido éste de modo amplio, pues por una parte se nutren de él, y por otra, lo robustecen incorporándole nuevos conceptos que empíricamente fuimos destacando en cada caso. Y en su ejercicio jurisdiccional todo el cúmulo de las densas competencias que poseen, les fuerzan a desplazarse en un equilibrio dual, por una parte, disolviendo el contencioso, y por otra, ingresando a los principales aspectos del derecho de la integración comprendido éste del modo amplio que explicamos. Posicionándose entonces estos órganos jurisdiccionales integracionistas latinoamericanos en un rol central en cada uno de los proyectos sub-regionales a los que pertenecen».

\footnotetext{
* A efectos de evitar posibles confusiones aclaramos que esta tesis posee un total de 902 notas a pie de página. Pero cada capítulo inicia nuevamente su propia secuencia del siguiente modo: la introducción posee de la nota número 1 a la 21; el capítulo I presenta de la número 1 a la 135; el capítulo II de la número 1 a la 252; el capítulo III de la número 1 a la 188; el capítulo IV de la número 1 a la 225; y el capítulo V posee de la nota 1 a la 81, de esta forma en total se presentan las referidas 902 notas a pie de página.
} 


\section{BIBLIOGRAFÍA}

Todas las fuentes consultadas y citadas

\section{MONOGRAFÍAS, PARTICIPACIÓN EN OBRAS COLECTIVAS Y ARTÍCULOS CIENTÍFICOS}

Abellán Honrubia, V. (2005, 5 impr. 2008). La unión europea: aspectos generales. En V. Abellán Honrubia, B. Vilá Costa, A. Olesti Rayo, J. Añoveros Trias De Bes, M. Campins Eritja, M. Cienfuegos Mateo, ... M. Álvarez Verdugo, Lecciones de derecho comunitario europeo ( $4^{\mathrm{a}} \mathrm{ed}$.). Barcelona: Ariel.

Abramovich, V. (2013). Derechos humanos en el marco del proceso de integración regional en el MERCOSUR. Revista da secretaria do tribunal permanente de revisão, 1(2), 351-361.

Accioly Pinto de Almeida, E. (1998). Integración europea e integración latinoamericana: dos realidades distintas. En E. Accioly, M. A. Ciuro, C. da Silva, W. Faria, G. Losfeld, F. Mariño, ... G. Zanin, El MERCOSUR en el siglo XXI. Buenos Aires: Ediciones Ciudad Argentina.

Acosta Puertas, J. (2006). La desintegración andina. Nueva sociedad, (204), 4-13.

Aguilera Peralta, G. (2016). El regionalismo centroamericano: entre la unión y la integración. Oasis, 24, 89-105. DOI: http://dx.doi.org/10.18601/16577558.n24.06.

Ahijado Quintillán, M. (2000). Historia de la unidad europea: Desde los precedentes remotos a la ampliación al este ( $1^{\mathrm{a}}$ ed.) Ediciones Pirámide.

Aizenstatd Leistenschneider, A. (2011). Reflejos del derecho comunitario europeo en las decisiones de la corte centroamericana de justicia. Revista general de derecho europeo, (25).

Aldecoa Luzárraga, F. (2002). La integración europea: Análisis históricoinstitucional con textos y documentos - Tomo II génesis y desarrollo de la unión europea (1979-2002). Madrid: Tecnos. [Truyol y Serra, A. (1999). La integración europea: Análisis histórico-institucional con textos y documentos. - Tomo I génesis y desarrollo de la unión europea (1951-1979). Madrid: Tecnos].

Aldeoca Luzurraga, F. (2008). El tratado de Lisboa como salida al laberinto constitucional. En J. Martín y Pérez de Nanclares (coord.), F. Aldeoca Luzurraga, 
N. Mariscal Berástegui, M. A. Alcoceba Gallego, M. Guinea Llorente, A. Fernández Tomás, ... M. Urrea Corres, El tratado de lisboa: La salida de la crisis constitucional : Jornadas de la Asociación Española de Profesores de Derecho Internacional y Relaciones Internacionales celebradas en madrid el 17 y 18 de diciembre 2007 ( $1^{\mathrm{a}}$ ed.). Madrid: Iustel.

Alonso García, R. (2015). Sobre la adhesión de la UE al CEDH (o sobre cómo del dicho al hecho, hay un gran trecho). Civitas. Revista española de derecho europeo, 53, 11-16.

Álvarez, J. E. (2006). International organizations as law-makers (1es. ed.). Oxford; Madrid etc.: Oxford University Press.

Amigo Román, C. (1995). La solución de controversias internacionales y sus mecanismos. BFD: Boletín de la facultad de derecho de la UNED, (8), 511-534.

Amin Ferraz, D. y Picart García, S. M. (2005). El arbitraje como forma alternativa de solución de controversias en el mercosur. En V. Bou Franch (coord.), M. Badenes Casino, M. Torres Pérez, C. Quesada Alcalá, L. E. Nores Torres, E. López Terrada, ... S. M. Picart García, Nuevas controversias internacionales y nuevos mecanismos de solución ( $1^{\mathrm{a}} \mathrm{ed}$.) Tirant lo Blanch.

Andón, A. (2017). Relaciones SICA-CARICOM: Un acercamiento histórico. Derecho y economía de la integración, (4), 121-129.

Andrés Sáenz de Santa María, Paz. (2013). Derecho internacional público: Textos y materiales ( $2^{\mathrm{a}}$ ed.). Madrid: Civitas Thomson Reuters.

Araya I., M. E. (1992). La experiencia histórica en la resolución de conflictos internacionales en centroamérica: Esquipulas II y la corte centroamericana de justicia. Reflexiones, 3(1).

Arbuet-Vignali, H. (1999). El protocolo de ouro preto sus problemas y evolución. En Irigoin Barrenne, J. (coord.), Rey Caro, E. (present.), Insulza Salinas, J. M. (disc.), Barros Charlín, R., Molina del Pozo, C. F., Narbone, L., ... Holzmann G., Chile y el mercosur en américa latina: VI encuentro internacional de derecho de américa del sur (1999). Tomo I. Santiago, Chile: Universidad de Chile. Facultad de Derecho (Eds.), Editorial Jurídica de Chile.

Arcaro Conci, L. G. (2015). Mercosur, integración regional y derechos humanos en un proceso multinivel. Estudios constitucionales: Revista del centro de estudios constitucionales, 13(2), 125-152. 
Badenes Casino, M. (2005). La corte permanente de arbitraje: una institución decimonónica en el siglo XXI. En V. Bou Franch (coord.), M. Badenes Casino, M. Torres Pérez, C. Quesada Alcalá, L. E. Nores Torres, E. López Terrada, ... S. M. Picart García, Nuevas controversias internacionales y nuevos mecanismos de solución $\left(1^{\mathrm{a}} \mathrm{ed}\right.$.) Tirant lo Blanch.

Bazán, V. (2012). Derechos humanos y MERCOSUR: Actualidad y prospectiva. Revista europea de derechos fundamentales, 20, 83-152.

Bengoetxea, J. (2014). Judicial and interdisciplinary dialogues in european law. En B. Hess \& S. Ménetrey. Les dialogues des juges en europe. Bruxelles: Larcier., pp. 19-49. [Trans. Serna Hernández, A. J. (2015). Diálogos judiciales e interdisciplinarios en el derecho europeo. Sortuz: oñati journal of emergent sociolegal studies, 7(1), 160-183].

Bengtson, H., Schrader, C. y Calonge Ruiz, J. (2008). Historia de grecia. (Trad. J. Calonge). Madrid: Gredos (Original en alemán, título original: Griechische Geschichte von den Anfängen bis in die römische Kaiserzeit).

Berdah, J. F. (2007). Los orígenes de la construcción europea. De la idea europea a la europa unida. Cuadernos europeos de deusto, (37), 49-71.

Biacchi Gomes, E. (2014). La democratización del acceso al tribunal permanente de revisión del mercosur a través de las opiniones consultivas. Revista da secretaria do tribunal permanente de revisão, 2(4), 49-63.

Biacchi Gomes, E., Cartawinter, L. A. \& Buttendorff R. Beckers, A. C. (2018). Supranationalem and fundamental rights: the effectivity of the secondary legislation in the andenean community system and community and in the central american integration. Estudios constitucionales, 16(1), 99-128. Disponible en <http://dx.doi.org/10.4067/S0718-52002018000100099>.

Bizzozero Revelez, L. (2001). El proceso de construcción del mercosur: De la transición al relanzamiento. Colección, (12), pp. 89-136.

Blanc Altemir, A. (2004). La herencia soviética : La comunidad de estados independientes y los problemas sucesorios. Madrid: Tecnos.

Blanco Alvarado, C. (2014). La crisis de la comunidad andina. Revista de derecho universidad del norte. Barranquilla, Colombia, 42, pp. 1-32. Disponible en <http://www.scielo.org.co/pdf/dere/n42/n42a02.pdf > [última consulta, noviembre 23, 2019]. 
Bouhdiba, S. (2009). Unión del magreb, un caso de regionalismo sur-sur. Ciencia política, 7, 113-124.

Burgorgue-Larsen, L. (2013). La formación de un derecho constitucional europeo a través del diálogo judicial. En E. Ferrer Mac-Gregor, A. Herrera García, D. García Sayan, D. Valdés, L. Pegoraro, A. Bogdandy, ... A. A. Cancado Trindade. Dialogos jurisprudenciales en derechos humanos : entre tribunales constitucionales y cortes internacionales. México. Tirant lo Blanche.

Bustos Gisbert, R. (2012). XV proposiciones generales para una teoría de los diálogos judiciales. Revista española de derecho constitucional, 32(95), 13-63.

Briceño Ruiz, J. (2018). Razón de ser de la integración y conceptualización de un nuevo marco teórico de la integración de américa latina y el caribe. Derecho y economía de la integración, (6), 21-33.

Brito Melgarejo, R. (2011). Derecho comparado y actividad jurisdiccional: Los factores que favorecen el diálogo judicial transnacional. Quid iuris, (13), 39-60.

Caetano, G. (2015). ¿Hacia un nuevo paradigma integracionista en el MERCOSUR? contextos y desafíos de la encrucijada actual. Relaciones internacionales: Revista académica cuatrimestral de publicación electrónica, 30.

Caldentey del Pozo, P. (2010). Panorama de la integración centroamericana: dinámica, intereses y actores. En: P. Caldentey del Pozo (coord.), J. J. Romero Rodríguez (coord.), N. Mariscal Berastegui, A. Rodero Franganillo, M. López Martín, F. Santos Carrillo, ... L. G. Solís Rivera, El SICA y la UE: La integración regional en una perspectiva comparada. Colección de estudios centroamericanos (1). ( $1^{\text {a }}$ Ed.). Córdoba, España. Fundación ETEA para el desarrollo y la cooperación.

Canepa, M. (2015). Los derechos humanos en el MERCOSUR. Revista da secretaria do tribunal permanente de revisão, 3(6), 161-177.

Cano Linares, M. A. (2009). La corte centroamericana de justicia: un órgano único con diversidad de competencias. En M. Diez de Velasco Vallejo (prol.), C. R. Fernández Liesa, S. Astete Muñoz, F. González Morales, M. A. Cano Linares, B. Olmos Giupponi, ... P. Zapatero Miquel, Tribunales internacionales y espacio iberoamericano ( $1^{\mathrm{a}}$ ed.). Cizur Menor: Thomson Reuters. 
Carvalho de Vasconcelos, R. y Maia Tavares, S. (2014). La competencia consultiva del tribunal permanente de revisión del MERCOSUR: Legitimación y objeto. Revista da secretaria do tribunal permanente de revisão, 2(4), 117-134.

Carvalho de Vasconcelos, R. (2015). Organizaciones internacionales y tratados asociativos: Por una nueva clasificación de los sujetos de derecho internacional. Revista da secretaria do tribunal permanente de revisão, 3(6), 178206.

Caserta, S. (2017). Regional integration through law and international courts - the interplay between de jure and de facto supranationality in central america and the caribbean. Leiden journal of international law, 30(3), 579-601.

Cassese, S. (2009). Lezione sulla cosiddetta opinione dissenziente. Quaderni di diritto costituzionale, 4, versión ampliada disponible en <http://www.irpa.eu/areabibliografica/scritti/lezione-sulla-cosiddetta-opinione-dissenziente/> [Consulta: 5.4.2018]; versión impresa: Cassese, S. (2009). Una lezione sulla cosiddetta opinione dissenziente. Quaderni Costituzionali, 4, 973-983.

Cede, F. \& Sucharipa-Behrmann, L. (2001). The united nations : Law and practice. The Hague: Kluwer Law International.

Centurión González, C. H. (2017). Aporte del tribunal permanente de revisión al proceso de integración del Mercosur: Reflexiones orientadas hacia la sociedad civil del mercosur. Revista da secretaria do tribunal permanente de revisão, 5(9), 78100.

Cerezo, V. (2018). Discurso del Secretario General del SICA (14.12.2018). 52 ${ }^{\circ}$ REUNIÓN DE JEFES DE ESTADO Y DE GOBIERNO DEL SICA. Belize. Disponible en: <https://www.sica.int/noticias/presidentes-del-sica-piden-avanzaren-la-construccion-de-un-modelo-de-desarrollo-sostenible-para-laregion_1_116361.html> [última consulta: diciembre 24, 2018].

Cervera Vallterra, M. (2005). El tribunal de justicia de las comunidades europeas. En V. Bou Franch (coord.), M. Badenes Casino, M. Torres Pérez, C. Quesada Alcalá, L. E. Nores Torres, E. López Terrada, ... S. M. Picart García, Nuevas controversias internacionales y nuevos mecanismos de solución ( $1^{\mathrm{a}} \mathrm{ed}$.) Tirant lo Blanch.

Chediak González, J. y Benítez Rodríguez, P. (2014). Acerca de la competencia consultiva del tribunal permanente de revisión mercosur y de la experiencia del 
poder judicial del uruguay en la tramitación de opiniones consultivas, Revista de la secretaría del tribunal permanente de revisión. 2(4), 83-91.

Chiovenda, G. [Casais y Santaló \& Alfredo Salvador]. (1977). Principios de derecho procesal civil. Madrid: Reus.

Chiovenda, G. [Gómez \& Greco, trans.] (2005). Instituciones de derecho procesal civil - Vol. II. ( $1^{\mathrm{a}}$ ed.). Florida Buenos Aires: Valleta Ediciones.

Cienfuegos Mateo, M. (2012a). La colaboración entre los jueces de los países del mercosur y del tribunal permanente de revisión mediante el procedimiento de opiniones consultivas. En M. Hernández Ramos (dir.), A. Sáiz Arnáis (dir.), A. Torres Pérez (dir.), M. Zelaia Garagarza (dir.), S. Deluca, O. Saldías, ... R. Bustos, Tribunales en organizaciones de integración: Mercosur, comunidad andina y unión europea ( $1^{\mathrm{a}}$ ed.). Cizur Menor: Thomson Reuters Aranzadi.

Cienfuegos Mateo, M. (2012b). Opiniones consultivas en el MERCOSUR y cuestiones prejudiciales en la unión europea: Estudio comparativo. Revista de derecho comunitario europeo, 16(42), 433-476.

Cienfuegos Mateo, M. (2013). Cuestiones prejudiciales en la unión europea y consultas prejudiciales en la comunidad andina: similitudes, diferencias e influencias. Revista electrónica de estudios internacionales (REEI), 25.

Cienfuegos Mateo, M. y Sanahuja, J. A. (2010). Una región en construcción: UNASUR y la integración en américa del sur. Barcelona: Fundación CIDOB.

Comini, N. y Frenkel, A. (2016). Unasur. De proyecto refundacional al fantasma del Sudamexit. En América Latina y el Caribe frente a la encrucijada actual de la globalización. Anuario de la integración regional de américa latina y el caribe, 13, pp. 181-208.

Couture, E. J. (1949). Introducción al estudio del proceso civil. (2 $2^{\mathrm{a}}$ Ed. Reimpr. 1988) Buenos Aires, Argentina. Depalma.

Couture, E. J. (1958). Fundamentos del derecho procesal civil. (3 ${ }^{\mathrm{a}}$ ed.). Roque de Palma. Buenos Aires.

Da Silva, C. A. (1998). Globalización y regionalismo versus trabajo y desempleo. Notas de fin de milenio. En E. Accioly, M. A. Ciuro, C. da Silva, W. Faria, G. Losfeld, F. Mariño, ... G. Zanin, El MERCOSUR en el siglo XXI. Buenos Aires: Ediciones Ciudad Argentina. 
De Quadros, F. (1984). Direito das comunidades europeias e direito internacional público - contributo para o estudo da natureza jurídica do direito comunitário europeu. Lisboa: Almedina.

De Vergottini G. (2010a). Oltre il dialogo tra le Corti. Giudici, diritto straniero, comparazione. Bolonia. Ed. Il Mulino.

De Vergottini, G., García Roca, F. J. (prol.) y Tenorio Sánchez, P. J. (trad.). (2010b). Más allá del diálogo entre tribunales: Comparación y relación entre jurisdicciones ( $1^{\mathrm{a}}$ ed.). Madrid: Civitas Thomson Reuters.

De Vitoria, F., Pereña, L., Perez-Prendes y Muñoz de Arraco, J. M. \& Beltrán de Heredia, V. (1967). Relectio de indis o libertad de los indios [Español-Latín]. Madrid: Consejo Superior de Investigaciones Científicas.

De Yturriaga Barberán, J. A. (1964). Las organizaciones internacionales y la soberanía de los estados. Revista de estudios políticos, (135), 83-106.

Del Valle Gálvez, A. (2008). El espacio de libertad, seguridad y justicia. En J. Martín y Pérez de Nanclares (coord.), F. Aldeoca Luzurraga, N. Mariscal Berástegui, M. A. Alcoceba Gallego, M. Guinea Llorente, A. Fernández Tomás, ... M. Urrea Corres, El tratado de lisboa: La salida de la crisis constitucional : Jornadas de la Asociación Española de Profesores de Derecho Internacional y Relaciones Internacionales celebradas en madrid el 17 y 18 de diciembre 2007 (1 ${ }^{\mathrm{a}}$ ed.). Madrid: Iustel.

Delgado, E. (2000). Relanzamiento del mercosur. Mercosur agenda para el futuro. Entorno (16), 5-11. Disponible en: <http://biblioteca.utec.edu.sv/entorno/index.php/entorno/article/view/269/268> [última consulta: diciembre 31, 2018].

Deluca, S. (2012). Metodología para la selección de árbitros del sistema de controversias del mercosur (ad hoc y TPR). En M. Hernández Ramos (dir.), A. Sáiz Arnáis (dir.), A. Torres Pérez (dir.), M. Zelaia Garagarza (dir.), S. Deluca, O. Saldías, ... R. Bustos, Tribunales en organizaciones de integración: Mercosur, comunidad andina y unión europea $\left(1^{\mathrm{a}}\right.$ ed.). Cizur Menor: Thomson Reuters Aranzadi.

Desantes Real, M. y Pardo Iranzo, V. (2013). El sistema jurisdiccional de la ue: aspectos orgánico y procedimental. En V. Pardo Iranzo, J. L. Iglesias Buhigues, M. Desantes Real, M. Jimeno Bulnes, C. Arangüena Fanego, F.J. Jimenez Fortea ... M. 
Cervera Vallterra, El sistema jurisdiccional de la unión europea ( $1^{\mathrm{a}}$ ed.). Navarra: Aranzadi.

Díaz Abad, N. (2012). La defensa jurídica ante el tribunal de justicia de la unión europea. En J. M. Beneyto (dir.), J. Maillo González-Orús (coord.), B. Becerril Atienza (coord.), K. Lenaerts, J. A. Gutiérrez-Fons, A. Tizzano, ... F. Castillo de la Torre, Tratado de derecho y políticas de la unión europea, Tomo V Sistema jurisdiccional de la ue ( $1^{\mathrm{a}}$ ed.). Navarra, Pamplona: Cizur Menor, Thomson Reuters Aranzadi.

Díaz Crego, M. (2015). Diálogo judicial. Eunomía: Revista en cultura de la legalidad, 9, 289-299.

Diez de Velasco Vallejo, M. (1989). "Nuevas perspectivas de la justicia internacional: el tribunal de las comunidades europeas y el tribunal de justicia del acuerdo de Cartagena", en: J. A. Barberis, F. F. García, E. Jimenez de Arechaga, H. Gros, C. García, M. A. Vieira, ... Diez De Velasco, M. Temas de derecho internacional : En homenaje a Frida M. Pfirter de Armas Barea. Buenos Aires: Fundación del Centro de Estudios Internacionales de Buenos Aires, pp. 257 y 264.

Diez de Velasco Vallejo, M. y Escobar Hernández, C. (act.) (2013, reimpr. 2015). El concepto de derecho internacional público (i). En M. Diez de Velasco Vallejo, Instituciones de derecho internacional público (18 ${ }^{\mathrm{a}}$ ed.). Madrid: Tecnos.

Diez de Velasco Vallejo, M. y Sobrino Heredia, J. M. (2010 -reimpr. 2014). Las organizaciones internacionales $\left(16^{\mathrm{a}} \mathrm{ed}\right.$.). Madrid: Tecnos.

Díez-Hochleitner Rodríguez, J. (2013). El derecho a la última palabra: ¿Tribunales Constitucionales o Tribunal de Justicia de la Unión?. En Tribunal constitucional y diálogo entre tribunales: XVIII Jornadas de la asociación de letrados del tribunal constitucional. Instituto de derecho europeo e integración regional, universidad complutense, 17.

Dobovsek, J. y Sabat, J. M. (1999). Aspectos institucionales del mercosur. (...). En J. Irigoin Barrenne (coord.), E. Rey Caro (present.), J. M. Insulza Salinas (disc.), R. Barros Charlín, C. F. Molina del Pozo, L. Narbone, ... G. Holzmann, Chile y el mercosur en américa latina: VI encuentro internacional de derecho de américa del sur (1999). Tomo I. Santiago, Chile: Universidad de Chile. Facultad de Derecho (Eds.), Editorial Jurídica de Chile.

Dreyzin de Klor, A. (1999). La dinámica institucional del mercosur. En J. Irigoin Barrenne (coord.), E. Rey Caro (present.), J. M. Insulza Salinas (disc.), R. Barros 
Charlín, C. F. Molina del Pozo, L. Narbone, ... G. Holzmann, Chile y el mercosur en américa latina: VI encuentro internacional de derecho de américa del sur (1999). Tomo I. Santiago, Chile: Universidad de Chile. Facultad de Derecho (Eds.), Editorial Jurídica de Chile.

Escribano Úbeda-Portugués, J. (2003). El relanzamiento del mercosur: La apuesta por la unión europea y el distanciamiento frente a estados unidos. Temas para el debate, (104).

Escobar Hernández, C. (2013, reimpr. 2015). Procedimientos de aplicación de las normas internacionales (III): medios de arreglo de carácter jurisdiccional (I): cuestiones generales y tribunales especializados. En M. Diez de Velasco Vallejo, Instituciones de derecho internacional público (18 ${ }^{\mathrm{a}} \mathrm{ed}$.). Madrid: Tecnos.

Fabbricatore, A. (2011). Los tribunales arbitrales ad-hoc en el mercosur. En C. F. Molina del Pozo y C. Pizzolo, La administración de justicia en la unión europea y el mercosur : un análisis para su fortalecimiento ( $1^{\mathrm{a}}$ ed.). Buenos Aires: Eudeba.

Feria Tinta, M. (2006). La víctima ante la corte interamericana de derechos humanos a veinticinco años de su funcionamiento. Revista IIDH, 43, 159-203.

Fernández Liesa, C. R. (2008). La proliferación de tribunales internacionales en el espacio iberoamericano. REIB: Revista electrónica iberoamericana, 2(2), 11-22.

Fernández Reyes, J. (2006). El orden jurídico del mercosur. Revista de derecho, 5(9), 27-51.

Fernández-Shaw, F. (1959). La organización de los estados americanos : (O. E. A.) : Una nueva visión de américa. Madrid: Ediciones Cultura Hispánica.

Ferrer Mac-Gregor, E. \& Herrera García, A. (2013). La formación de un derecho constitucional europeo a través del diálogo judicial. En E. Ferrer Mac-Gregor, A. Herrera García, D. García Sayan, D. Valdés, L. Pegoraro, A. Bogdandy, ... A. A. Cancado Trindade. Dialogos jurisprudenciales en ddhh : entre tribunales constitucionales y cortes internacionales. México. Tirant lo Blanche.

Ferreres Comella, V. (2005). El juez nacional ante los derechos fundamentales europeos. Algunas reflexiones en torno a la idea de diálogo. En A. Saiz Arnaiz Y M. Zelaia (coords.). Integración europea y poder judicial. Oñati. IVAP.

Freres, C. (2003). La unión europea y la comunidad andina. Opciones para la política ante la crisis subregional. En E. V. Iglesias, V. Giscard d'Estaing, J. Solana 
Madariaga, C. Patten, J. Roy, A. Chanona Burguete, ... F. Granell, Retos e interrelaciones de la integración regional: europa y américa $\left(1^{\mathrm{a}} \mathrm{ed}\right.$.). México. Plaza y Valdés.

Frutos Miranda, J. y Espósito, C. (2012). La función consultiva: los dictámenes previos a la conclusión de acuerdos internacionales. En J. M. Beneyto (dir.), J. Maillo González-Orús (coord.), B. Becerril Atienza (coord.), K. Lenaerts, J. A. Gutiérrez-Fons, A. Tizzano, ... F. Castillo de la Torre, Tratado de derecho y políticas de la unión europea, Tomo V Sistema jurisdiccional de la ue ( $1^{\mathrm{a}} \mathrm{ed}$.). Navarra, Pamplona: Cizur Menor, Thomson Reuters Aranzadi.

Gamarra Chopo, Y. \& Fernandez Liesa, C. R. Nota preliminar. El comienzo de una nueva era para el derecho internacional. En Grasa, R., Forcadell, C., Peiró, I., Huguet, M., Magallón, C. y Blasco, S., Fernández, C., ... Ripol, S. (2015). Los orígenes del derecho internacional contemporáneo ( $1^{\mathrm{a}}$ ed.). Zaragoza: Institución Fernando el Católico.

Gambino, S. (2010). Jurisdicción y justicia entre tratado de lisboa, convenio europeo de derechos humanos y ordenamientos nacionales. Revista De Derecho Constitucional Europeo, 13, 83-120.

Gamboa Serazzi, F. (2002). Tratado de derecho internacional público. Santiago, Chile: Lexis Nexis.

Gascón Marcen, A. (2019). Réplica de mecanismos institucionales del TJUE en el TEDH ¿inspiración positiva o fuerza de la realidad? En J. Martín y Pérez de Nanclares, R. Bustos Gisbert, C. González Beilfuss, C. Martínez Capdevila, M. E. Salamanca Aguado, ... C. E. Oriozola Mariscal, El diálogo judicial internacional en la protección de los derechos fundamentales. Valencia. Tirant lo Blanch.

Gil Robles, J. M. (2002). Los retos de la globalización y el liderazgo de la unión europea. Revista de derecho de la unión europea, (2), 225-232.

Giammattei Avilés, J. A. (2002). La corte centroamericana de justicia como tribunal constitucional de la comunidad centroamericana. Anuario de Derecho Constitucional Latinoamericano, 2003, 507-522. Disponible en: https://revistascolaboracion.juridicas.unam.mx/index.php/anuario-derechoconstitucional/article/view/3602/3361 [última consulta: diciembre 10, 2018].

Godoy, H. \& González Arana, R. (2009). La crisis de la CAN: El caso de los actores internos. Investigación y desarrollo: revista del centro de investigaciones en desarrollo humano, 17(2), 350-367. 
Gómez Jutinico, A. (2010). Institucionalidad y problemáticas de la comunidad andina de naciones. Poliantea, 6(10).

González Campos, J. D., Sánchez Rodríguez, L. I. y Andrés Sáenz de Santa María, P. (2008). Curso de derecho internacional público (4a ed. rev.). Madrid: Cizur Menor, Thomson Civitas.

Gordon Vergara, A. y Fernández Fernández. J. J. (2006). Alegato en favor del inicio de negociaciones para un acuerdo UE - CAN en la IV Cumbre de Viena. Agenda Internacional, XII(23), pp. 295-326.

Gosalbo Bono, R. (2016). ¿Brexit o bremain?. Revista general de derecho europeo 39, pp. 1-23.

Groppi, T. \& Lecis Cocco-Ortu, A. M. (2014). Las referencias recíprocas entre el tribunal europeo y la corte interamericana de derechos humanos: ¿de la influencia al diálogo? Revista de derecho político, (91), 185-230.

Gros Espiell, H., Delpiazzo, C., Rotondo F., Vázquez, C. y Brito, M. (1999). El derecho de la integración del mercosur ( $1^{\mathrm{a}}$ ed.). Montevideo: Universidad de Montevideo, Facultad de Derecho.

Guariglia, O. (2010). En camino de una justicia global. Madrid: Marcial Pons.

Guasp, J. (1968). Derecho procesal civil : Tomo primero : Parte general ( $3^{\mathrm{a}}$ ed., $2^{\mathrm{a}}$ reimp.). Madrid: Instituto de Estudios Políticos.

Guerra, S. (2013). MERCOSUL: Do ideal bolivariano para a realidade atual (e quem sabe futura?). Revista da secretaria do tribunal permanente de revisão, 1(1), 275-293.

Guerra Gallardo, C. (2018). Discurso del Presidente de la Corte Centroamericana de Justicia (14.12.2018). El día de la integración centroamericana. Disponible en: $<$ http://portal.ccj.org.ni/ccj/el-dia-de-la-integracion-centroamericana-carlos-guerragallardo-presidente-corte-centroamericana-de-justicia/> [última consulta: diciembre 24, 2018].

Guerrero Mayorga, O. (2002). Esfuerzos históricos y perspectivas del locus standi ante la corte centroamericana de justicia. Revista de derecho, (2), 175-188. 
Huici Sancho, L. (2007). El hecho internacionalmente ilícito de las organizaciones internacionales : El proyecto de la Comisión de derecho internacional sobre responsabilidad de las organizaciones internacionales. Barcelona: Bosch.

Ibáñez García, I. (1998). "Los votos particulares en el proceso judicial comunitario; el contenido mínimo del derecho de petición ante el parlamento europeo y la protección de este derecho por el defensor del pueblo", Noticias de la unión europea, 156, 25-36.

Iglesias Buhigues, J. L. (2013). El papel del tribunal de justicia de la unión europea en el proceso de integración. En V. Pardo Iranzo, J. L. Iglesias Buhigues, M. Desantes Real, M. Jimeno Bulnes, C. Arangüena Fanego, F. J. Jimenez Fortea ... M. Cervera Vallterra, El sistema jurisdiccional de la unión europea (1 ${ }^{\mathrm{a}}$ ed.). Navarra: Aranzadi.

Jara Roncati, E. (2012). La unión europea, los países de américa latina y el caribe: Una relación con pasado, presente y futuro. Zaragoza: Fundación Manuel Giménez Abad de Estudios Parlamentarios y del Estado Autonómico.

Jayme, E. (1995). Identité culturelle et intégration : Le droit international privé postmoderne. In Collected courses of the hague academy of international law. Vol. 251. Brill. Nijhoff, Leiden. Boston.

Jovtis, I. (2012). La legitimación activa en el actual sistema de solución de controversias del mercosur y perspectivas ante la futura creación de una Corte de Justicia regional. En M. Cienfuegos Mateo, W. Nerys Fernández, N. B. Mellado, M. L. Ali, J. C. Fernández Saca, R.M. Gajate, ... L. M. Ramírez, Desafíos del desarrollo de la infraestructura regional para el medio ambiente, la cohesión social y la gobernabilidad del mercosur. Uruguay: Taller de Comunicación, pp. 249-262. Disponible en: http://sedici.unlp.edu.ar/bitstream/handle/10915/59803/Documento_completo.pdfPDFA.pdf?sequence=1 [última consulta: diciembre 10, 2018].

Juncker J-C. (2018). Estado de la unión 2018: la hora de la soberanía europea. Discurso sobre el estado de la Unión 2018, p. 5. Disponible en: $<$ https://ec.europa.eu/commission/priorities/state-union-speeches/state-union2018_es> [última consulta: junio 14, 2019].

Kant, I. (2002, $3^{\mathrm{a}}$ reimpr. 2008). Fundamentación para una metafísica de las costumbres ( $1^{\mathrm{a}}$ ed.). (Trad. A. Rodríguez). Madrid: Alianza (Original: Grundlegung zur Metaphysik der Sitten, 1785). 
Kühn Baca, W. M. (2015). Reflexiones sobre una posible convergencia regional con la participación de la Comunidad Andina y del Mercosur. Lecciones de la experiencia integracionista europea. Revista general de derecho europeo, 36, (RI $\S 416102)$.

Kühn Baca, W. M. (2017). The draft protocol on the creation of the court of justice of mercosur. A new milestone in the judicialisation of regional integration law. Anuario mexicano de derecho internacional, 17, 405-442.

Lauterpacht, H. \& Lauterpacht, E. (1970). International law: Being the collected papers of hersch lauterpacht. Cambridge: University Press.

Lauterpacht, H. (1933). The function of law in the international community. Oxforf: Clarendon Press.

Law, D. S. \& Chang, W. (2011). The limits of global judicial dialogue. Washington law review, 86(3), 523-577.

Lecourt, R. (1976). L'Europe des juges. Bruxelles: Bruylant.

Lenaerts, K. (2018). INFORME ANUAL 2017: ACTIVIDAD JUDICIAL. Tribunal de Justicia de la Unión 2018. Disponible en: $<$ https://curia.europa.eu/jcms/upload/docs/application/pdf/201806/ra_2017_es_web.pdf> [última consulta: mayo 30, 2019].

Lenaerts, K. y Gutiérrez-Fons, J. (2012). El papel del tribunal de justicia de la unión europea en el proceso de integración europea. En J. M. Beneyto (dir.), J. Maillo González-Orús (coord.), B. Becerril Atienza (coord.), K. Lenaerts, J. A. GutiérrezFons, A. Tizzano, ... F. Castillo de la Torre, Tratado de derecho y políticas de la unión europea, Tomo V Sistema jurisdiccional de la ue (1 ${ }^{\mathrm{a}}$ ed.). Navarra, Pamplona: Cizur Menor, Thomson Reuters Aranzadi.

Lerman Alperstein, A. (2005). La agonía del mercosur. Comercio exterior, 55(4), 362.

Liñán Nogueras, D. J. (2014a). Derechos humanos y libertades fundamentales en la unión europea. En A. Mangas Martín y D. J. Liñán Nogueras, Instituciones y derecho de la unión europea ( $8^{\mathrm{a}}$ ed.). Madrid: Tecnos.

Liñán Nogueras, D. J. (2014b). El tribunal de justicia de la unión europea: organización y funcionamiento. En A. Mangas Martín y D. J. Liñán Nogueras, Instituciones y derecho de la unión europea ( $8^{\mathrm{a}} \mathrm{ed}$.). Madrid: Tecnos. 
Liñán Nogueras, D. J. (2014c). El espacio de libertad, seguridad y justicia. En A. Mangas Martín y D. J. Liñán Nogueras, Instituciones y derecho de la unión europea ( $8^{\mathrm{a}}$ ed.). Madrid: Tecnos.

Liñán Nogueras, D. J. (2014d). El sistema jurisdiccional de la unión europea. En A. Mangas Martín y D. J. Liñán Nogueras, Instituciones y derecho de la unión europea ( $8^{\mathrm{a}}$ ed.). Madrid: Tecnos.

Liñán Nogueras, D. J. (2014e). El sistema de normas y actos en la unión europea (i). En A. Mangas Martín y D. J. Liñán Nogueras, Instituciones y derecho de la unión europea ( $8^{\mathrm{a}}$ ed.). Madrid: Tecnos.

Lorca Navarrete, A. M. (1991). Introducción al derecho procesal (2 $2^{\mathrm{a}}$ ed.). Madrid: Tecnos.

Lucas Sosa, G. y Oyarzábal, M. J. A. (2012). Derecho procesal transnacional: Homenaje al profesor doctor gualberto lucas sosa. Buenos Aires: Editorial Abaco de Rodolfo Depalma.

Lucángeli, J., Sanguinetti, M. y Zamorano, A. L. (2010). Mercosur: La consolidación de la expansión de la economía del bloque. Revista del CEI. Comercio exterior e integración, (18), 19-45.

Lupoi, M. A. (2002). Conflitti transnazionali di giurisdizioni. Milano: Dott. A. Giuffrè.

Lynch, A. (2004). Is judicial dissent constitutionally protected?. Macquarie law journal, 5. Disponible en: http://www5.austlii.edu.au/au/journals/MqLJ/2004/5.html [última consulta: diciembre 10, 2018].

Maeso Seco, L. F. (2007). Cuestiones prejudiciales. En L. Ortega Álvarez (dir.), J. A. Moreno Molina (coord.), I. Gallego Córcoles, L. F. Maeso Seco, J. M. A. Magán Perales, J. Morcillo Moreno, ... F. Sánchez Rodríguez, Derecho comunitario europeo ( $1^{\mathrm{a}} \mathrm{ed}$.). Valladolid: Lex Nova.

Mangas Manjarrás, J. (1986). Textos para la historia antigua de grecia (4 ${ }^{\mathrm{a}}$ ed.). Madrid: Cátedra.

Mangas Martín, A. (2014a). El proceso histórico de la integración europea. En A. Mangas Martín y D. J. Liñán Nogueras, Instituciones y derecho de la unión europea ( $8^{\mathrm{a}}$ ed.). Madrid: Tecnos. 
Mangas Martín, A. (2014b). El sistema institucional. En A. Mangas Martín y D. J. Liñán Nogueras, Instituciones y derecho de la unión europea ( $8^{\mathrm{a}}$ ed.). Madrid: Tecnos.

Mangas Martín, A. (2014c). La unión europea. En A. Mangas Martín y D. J. Liñán Nogueras, Instituciones y derecho de la unión europea ( $8^{\mathrm{a}}$ ed.). Madrid: Tecnos.

Marín Aís, J. R. (2013). La adhesión de la unión europea al convenio de roma. El cumplimiento de las obligaciones derivadas del convenio europeo de derechos humanos en el ordenamiento jurídico de la UE. Revista de Derecho Comunitario Europeo, 17(44), 233-276.

Marinho, M. E. \& Oliveira, L. P. S. (2014). O uso de precedentes judiciais de jurisdições estrangeiras em matéria de propriedade intelectual. En Marihnho, Silva, Oliveira, et al. Diálogos entre juízes. Brasilia: UniCEUB.

Martín Bañas, C. (2013). La excepción de ilegalidad. En V. Pardo Iranzo, J. L. Iglesias Buhigues, M. Desantes Real, M. Jimeno Bulnes, C. Arangüena Fanego, F.J. Jimenez Fortea ... M. Cervera Vallterra, El sistema jurisdiccional de la unión europea ( $1^{\mathrm{a}}$ ed.). Navarra: Aranzadi.

Martín Jiménez, A. J. (2013). El impacto de la jurisprudencia tributaria del TJUE en los tribunales latinoamericanos (o acerca del nacimiento de un nuevo "diálogo judicial global" en materia tributaria. Civitas. Revista española de derecho financiero (160)35-54.

Martín y Pérez de Nanclares, J. (2015). El TJUE pierde el rumbo en el dictamen 2/13: ¿merece todavía la pena la adhesión de la UE al CEDH?. Revista de Derecho Comunitario Europeo, 19(52), 825-869.

Martín y Pérez de Nanclares, J. (2017). El TJUE como actor de la constitucionalidad en el espacio jurídico europeo: La importancia del diálogo judicial leal con los tribunales constitucionales y con el TEDH. Teoría y realidad constitucional, (39), 235-269.

Martín y Pérez de Nanclares, J. (2019). El diálogo judicial internacional en la protección de los derechos fundamentales. Valencia. Tirant lo Blanch.

Martínez Alcañiz, A. (2014). El principio de justicia universal y los crímenes de guerra. Madrid: Instituto Universitario General Gutiérrez Mellado-UNED. 
Martínez Capdevila, C. (2014). El ius standi de los particulares frente a los "actos reglamentarios que no incluyen medidas de ejecución" (art. 263 TFUE) en la jurisprudencia del TJUE: Un análisis crítico. Civitas. Revista española de derecho europeo, 52, 159-187.

Martínez Lafuente, A. (2016). La cuestión prejudicial en el derecho de la unión europea. Carta tributaria. Revista de opinión, 19, 11-34.

Masson, A. \& Micheau, C. (2007). The "werner mangold" case: An example of legal militancy. European public law, 13(4), 587-593.

Matia Portilla, F. J. (dir.), Biglino Campos, P., Ceccherini, E., Carmona Contreras, A. M., Rodríguez-Izquierdo Serrano, M., Balaguer Callejón, F. ... Esteve, F. (2009). Estudios sobre el tratado de lisboa. Granada: Comares.

Matia Portilla, F. J., (2015). La adhesión de la UE al CEDH hoy: Una valoración de los trabajos realizados hasta el momento. En L. I. Gordillo Pérez (coord.), A. Oehling De Los Reyes, L. Álvarez Álvarez, L. I. Gordillo Pérez, C. Milione Fugali, M. Hernández Ramos, ... A. Tapia Trueba, Constitutionalism of european supranational courts: Recent developments and challenges, Aranzadi.

Mazzuoli, V. d. O. (2014). Por un tribunal de justicia para UNASUR: La necesidad de una corte de justicia para américa del sur sobre los paradigmas del tribunal de justicia de la unión europea y de la corte centroamericana de justicia. Revista da secretaria do tribunal permanente de revisão, 2(4), 189-217.

Mejía Herrera, O. (2011). El diálogo entre tribunales: la jurisprudencia del tribunal de justicia de la unión europea como fuente de inspiración para los tribunales de los sistemas de integración latinoamericanos. Boletín electrónico sobre integración regional del CIPEI, 1, 14-34. Disponible en Portal oficial CIPEI: http://www.boletincipei.unanleon.edu.ni/articulos.html [última consulta: diciembre 13, 2018].

Méndez de Vigo, I. y Oreja Aguirre, M. (2007). ¿Qué fue de la constitución europea? : El tratado de lisboa: Un camino hacia el futuro ( $1^{\mathrm{a}}$ ed.). Madrid: Fundación Rafael del Pino.

Mensa González, A. (2011). La competencia consultiva del tribunal permanente de revisión. En C. F. Molina del Pozo y C. Pizzolo, La administración de justicia en la unión europea y el mercosur : un análisis para su fortalecimiento ( $1^{\mathrm{a}} \mathrm{ed}$.). Buenos Aires: Eudeba. 
Mijares, V. M. \& Nolte, D. (2018). Regionalismo posthegemónico en crisis: ¿por qué la UNASUR se desintegra?. Foreign affairs: latinoamérica, 18(3), 105-112.

Millán Moro, L. (2010). El ordenamiento jurídico comunitario: Del tratado constitucional al tratado de lisboa. Revista de derecho comunitario europeo, 14(36), 401-438.

Miranda Bonilla, H. (2017). Dialogo judicial interamericano: una visión teórico práctica. En A. Milano Sánchez, A. Garro Vargas, C. Hines Céspedes, E. Briones Briones, E. Jinesta Lobo, F. Castillo Viquez, ... V. Orozco Solano. Constitucionalismo Costarricense. Libro en homenaje al prof. rubén hernández. valle. Ed. Juricentro., pp. 535-570.

Mizari, D. (2018). 5 claves para entender la crisis (¿final?) de la Unasur. Infobae. Disponible en: <https://www.infobae.com/america/america-latina/2018/04/28/5claves-para-entender-la-crisis-final-de-la-unasur/> [última consulta: mayo 30, 2019].

Montero Aroca, J. (2013). Prólogo. En V. Pardo Iranzo, J. L. Iglesias Buhigues, M. Desantes Real, M. Jimeno Bulnes, C. Arangüena Fanego, F. J. Jimenez Fortea ... M. Cervera Vallterra, El sistema jurisdiccional de la unión europea ( $1^{\mathrm{a}}$ ed.). Navarra: Aranzadi.

Montesinos Padilla, C. (2015). A las puertas del TJUE. La frustrada flexibilización de las condiciones de acceso del particular. Civitas. Revista española de derecho europeo, 55, 37-65.

Moreira, A. C. (2014). Mercosur ambiental. El aporte del laudo 1/2012 del tribunal permanente de revisión. Revista da secretaria do tribunal permanente de revisão, 2(3), 59-75.

Moreno Juste, A. (2013). El fin del relato europeo. La crisis del proceso de integración y su impacto sobre las narrativas europeas. Revista de derecho comunitario europeo, 17(45), 607-630.

Moreno Molina, J. A. (2007). Los principios generales del derecho. En L. Ortega Álvarez (dir.), J. A. Moreno Molina (coord.), I. Gallego Córcoles, L. F. Maeso Seco, J. M. A. Magán Perales, J. Morcillo Moreno, ... F. Sánchez Rodríguez, Derecho comunitario europeo $\left(1^{\mathrm{a}}\right.$ ed.). Valladolid: Lex Nova.

Niebieskikwiat, N. (2019). La relación Argentina-Brasil. Acuerdo UE-Mercosur: Bolsonaro le dio luz verde a Macri para avanzar. Clarín [en línea]. Disponible en: 
<https://www.clarin.com/politica/acuerdo-ue-mercosur-bolsonaro-dio-luz-verdemacri-avanzar_0_VrcuycACC.html> [última consulta: mayo 30, 2019].

Olmos Giupponi, B. (2009). El sistema de solución de controversias de mercosur. Análisis de la situación actual y propuestas para el futuro. En M. Diez de Velasco Vallejo (prol.), C. R. Fernández Liesa, S. Astete Muñoz, F. González Morales, M. A. Cano Linares, B. Olmos Giupponi ... P. Zapatero Miquel, Tribunales internacionales y espacio iberoamericano ( $1^{\mathrm{a}} \mathrm{ed}$.). Cizur Menor: Thomson Reuters.

Olmos Giupponi, M. B. y Ulate Chacón, E. (2011). Diálogo judicial y gobernanza global: La influencia del derecho comunitario europeo en la jurisprudencia de la corte centroamericana de justicia ( $1^{\mathrm{a}}$ ed.). España: Universidad Rey Juan Carlos. Editorial Dykinson, S.L.

Packwood, A. (2016). Churchill and the united states of europe, 1904-1948. Comillas journal of international relations (7), 1-9.

Panayotis Soldatos (1989). Le Système Institutionelle et Politique des Communautées Européennes Dans un Monde en Mutation, Bruylant, Bruxelles.

Pascual González, J. (1997). Grecia en el siglo IV a.C.: Del imperialismo espartano a la muerte de filipo de macedonia. Madrid: Síntesis.

Pascual Serrats, R. (2013). El recurso por responsabilidad extracontractual. En V. Pardo Iranzo, J. L. Iglesias Buhigues, M. Desantes Real, M. Jimeno Bulnes, C. Arangüena Fanego, F. J. Jimenez Fortea ... M. Cervera Vallterra, El sistema jurisdiccional de la unión europea ( $1^{\mathrm{a}} \mathrm{ed}$.). Navarra: Aranzadi.

Pastor Ridruejo, J. A. (2010). Curso de derecho internacional público y organizaciones internacionales $\left(14^{\mathrm{a}} \mathrm{ed}\right.$.). Madrid: Tecnos.

Pérez González, M. (2010, reimpr. 2014). Las organizaciones internacionales en américa (ii). En M. Díez De Velasco Vallejo y J. M. Sobrino Heredia, Las organizaciones internacionales (16 ${ }^{\mathrm{a}} \mathrm{ed}$.). Madrid: Tecnos.

Perotti, A. D. (2008). Tribunal permanente de revisión y estado de derecho en el mercosur. Madrid: Marcial Pons.

Perotti, J. (2010). La Acción Internacional de las Provincias y Municipios Argentinos. Memorias: V Congreso de Relaciones Internacionales, 24, 25, 26 de noviembre de 2010, Universidad Nacional de La Plata, La Plata, Argentina. 
Pescatore, P. \& INSTITUT UNIVERSITAIRE DE HAUTES ÉTUDES INTERNATIONALES (1972). Le droit de l'intégration : Emergence d'un phénomène nouveau dans les relations internationales selon l'expérience des Communautés Européenes. Leiden: Sijthoff.

Pi Llorens, M., Zapater Duque, E. y Vilá Costa, B. (2010). ¿Hacia una europa de las personas en el espacio de libertad, seguridad y justicia?. Madrid: Marcial Pons.

Pomeroy, B., Burstein, S., Donlan, W. \& Tolbert, J. (2001). La antigua grecia: Historia política, social y cultural. (Trad. T. de Lozoya). Barcelona: Crítica (Original: Ancient Greece: a political, social, and cultural history).

Pozo Silva, N. (1993). La sentencia. El juez y la sentencia. Santiago, Chile. Ediciones jurídicas.

Provin, A. F. \& Dos Santos Queiroz, Y. A. (2017). O diálogo entre as cortes. Anuario iberoamericano de justicia constitucional, 21, 111-127.

Quesada Alcalá, C. (2005). La corte penal internacional y la soberanía estatal. Valencia: Tirant lo Blanch.

Quindimil López, J. A. (2006). Instituciones y derecho de la comunidad andina. Valencia: Tirant lo Blanch.

Quindimil López, J. A. (2012). El acceso a tribunales de justicia supranacionales: aportes desde la comunidad andina y su incipiente ciudadanía comunitaria. En M. Hernández Ramos, A. Sáiz Arnáiz, A. Torres Pérez Y M. Zelaia Garagarza (Dirs.), Tribunales en organizaciones supranacionales de integración: mercosur, comunidad andina y unión europea ( $1^{\mathrm{a}}$ ed.), Cizur Menor: Thomson Reuters Aranzadi.

Quintero Berganza, J. G. (2010). Una aplicación a centroamérica de las claves de la unión europea. En P. Caldentey del Pozo (coord.), J. J. Romero Rodríguez (coord.), N. Mariscal Berastegui, A. Rodero Franganillo, M. López Martín, F. Santos Carrillo, ... L. G. Solís Rivera, El SICA y la UE: La integración regional en una perspectiva comparada. Colección de estudios centroamericanos (1). ( $1^{\text {a }}$ Ed.). Córdoba, España. Fundación ETEA para el desarrollo y la cooperación.

Rechsteiner, B. W. (2008). Direito internacional privado: teoria e prática. São Paulo: Saraiva. 
Requena Casanova, M. (2011). La tutela judicial del principio general de igualdad de trato en la Unión Europea: una jurisprudencia expansiva basada en una jerarquía de motivos discriminatorios. Revista de derecho comunitario europeo, 15(40), 767793.

Reuter, P. y Puente Egido, J. (1978). Derecho internacional público. Barcelona: Bosch.

Ripley, C. (2018). The central american court of justice (1907-1918): rethinking the word's first court. Diálogos: Revista electronica de historia, 19(1), 47-68.

Ripol Carulla, S. y Tribunal Europeo de Derechos Humanos. (2007). El sistema europeo de protección de los derechos humanos y el derecho español: La incidencia de las sentencias del tribunal europeo de derechos humanos en el ordenamiento jurídico español. Barcelona: Atelier.

Rodríguez Iglesias, G. C. (2010, reimpr. 2014). Estructura internacional de la unión europea. En M. Díez de Velasco Vallejo y J. M. Sobrino Heredia, Las organizaciones internacionales $\left(16^{\mathrm{a}} \mathrm{ed}\right.$.). Madrid: Tecnos.

Rodríguez Iglesias, G. C. y López Escudero, M. (2010a, reimpr. 2014). La unión europea. En M. Díez de Velasco Vallejo y J. M. Sobrino Heredia, Las organizaciones internacionales (16 ${ }^{\mathrm{a}} \mathrm{ed}$.). Madrid: Tecnos.

Rodríguez Iglesias, G. C. y López Escudero, M. (2010b, reimpr. 2014). Estructura institucional de la unión europea. En M. Díez de Velasco Vallejo y J. M. Sobrino Heredia, Las organizaciones internacionales (16 ${ }^{\mathrm{a}}$ ed.). Madrid: Tecnos.

Rodríguez Iglesias, G. C. y Baquero Cruz, J. (2006). Funciones constitucionales del tribunal de justicia de las comunidades europeas. Fundamentos (Cuadernos monográficos de teoría del estado, derecho público e historia constitucional), 4, 291-346.

Rodríguez Iglesias, G. C., Liñán Nogueras, D. J. y Abellán Honrubia, V. (1993). El derecho comunitario europeo y su aplicación judicial ( $1^{\mathrm{a}} \mathrm{ed}$.). Madrid: Civitas.

Rodríguez Mackay, M. Á. (2013). El principio de solución pacífica de controversias como norma de ius cogens en el derecho internacional. Lex: Revista de la facultad de derecho y ciencia política de la universidad alas peruanas, 11(12), 105-140.

Rosas (2007). The european court of justice in context: forms and patterns of judicial dialogue. European journal of legal studies, 1(2). 
Ruiz-Díaz Labrano, R. (1999). Supranacionalidad y mercosur. En J. Irigoin Barrenne (coord.), E. Rey Caro (present.), J. M. Insulza Salinas (disc.), R. Barros Charlín, C. F. Molina del Pozo, L. Narbone, ... G. Holzmann, Chile y el mercosur en américa latina: VI encuentro internacional de derecho de américa del sur (1999). Tomo I. Santiago, Chile: Universidad de Chile. Facultad de Derecho (Eds.), Editorial Jurídica de Chile.

Sáiz Arnáiz, A. (1999). El tribunal de justicia de las comunidades europeas como tribunal constitucional. Revista vasca de administración pública. 2, 223-256.

Saksena, K. P. (1993). Reforming the united nations : The challenge of relevance. New Delhi; London: Sage.

Sanchez-Covisa Hernando, J. (1976). La vigencia temporal de la ley en el ordenamiento jurídico venezolano. Ediciones de la Contraloría General de la República. Caracas.

Sánchez, F. (2018). ¿El fin de Unasur? y la crisis del regionalismo suramericano. Razón pública. Disponible en: <https://www.razonpublica.com/index.php/politicay-gobierno-temas-27/11364-el-fin-de-unasur-y-la-crisis-del-regionalismosuramericano.html> [última consulta: mayo 26, 2019].

Santos Vara, J. (2002). La participación de la unión europea en las organizaciones internacionales. Madrid: Colex.

Sarmiento Ramírez-Escudero, D. (2016). El derecho de la unión europea. Madrid, Barcelona, Buenos Aires, Sao Paulo: Marcial Pons.

Sarmiento, D. y Ruiz-Jarabo Colomer, D. (2004). Poder judicial e integración europea: La construcción de un modelo jurisdiccional para la unión ( $1^{\mathrm{a}}$ ed.). Madrid: Civitas.

Schillaci, A. y Calahorro A. A. (trans.) (2010). El sistema constitucional de italia. Revista de derecho constitucional europeo, (14), 75-115.

Schmidt, M. (2006). The principle of non-discrimination in respect of age: Dimensions of the ECJ's mangold judgment. German law journal, 7(5), 505-524.

Scotti, L. B. (2016). Diálogo de fuentes: Las normas regionales del MERCOSUR y las nuevas disposiciones del derecho internacional privado argentino. Revista da secretaria do tribunal permanente de revisão, 4(7), 152-184. 
Service, E. R. \& Ruiz de Elvira Hidalgo, M. (trans.) (1984). Los orígenes del estado y de la civilización : El proceso de la evolución cultural ( $1^{\mathrm{a}} \mathrm{ed}$.) Alianza.

Seyersted, F. (2008). Common law of international organizations. Leiden, Boston: Martinus Nijhoff.

Shmite, S. M. \& Nin M. C. (2014). Europa en crisis: el desencanto de la unión europea. Papeles de geografía, 59(60), pp. 173-186.

Silguero, R. F. (2013). Los objetivos del mercosur y la opción de foro. Revista da secretaria do tribunal permanente de revisão, 1(1), 229-257.

Slaughter, A. M. (1994). A typology of transjudicial communication. 29 University of richmond law review, 29, 99-137.

Sobrino Heredia, J. M. (2010a, reimpr. 2014). Las organizaciones internacionales en el mundo árabe e islámico y las organizaciones internacionales en áfrica. En M. Díez de Velasco Vallejo y J. M. Sobrino Heredia, Las organizaciones internacionales (16 ${ }^{\mathrm{a}}$ ed.). Madrid: Tecnos.

Sobrino Heredia, J. M. (2010b, reimpr. 2014). Las organizaciones internacionales: generalidades. En M. Díez de Velasco Vallejo y J. M. Sobrino Heredia, Las organizaciones internacionales $\left(16^{\mathrm{a}} \mathrm{ed}\right.$.). Madrid: Tecnos.

Soto-Díaz, D. (2014). Tribunales constitucionales y tribunal de justicia de la unión europea: El convulso vértice de la pirámide del sistema jurisdiccional europeo. Anuario da facultade de dereito da universidade da coruña, 18, 363-390.

Tarditi, E. (2016). Mercosur en crisis o cuando lo excepcional se vuelve ordinario. Anuario de la integración regional de américa latina y el caribe, (13), pp. 208-222.

Torrecuadrada García-Lozano, S. (2005). La sucesión entre organizaciones internacionales y la unión. Anuario español de derecho internacional, (21), 227272.

TRIBUNAL DE JUSTICIA DE LA UNIÓN EUROPEA (2010, diciembre). Tribunal de Justicia, Composición, competencias y procedimientos, [en línea]. Luxemburgo: Oficina de Publicaciones. doi: 10.2862/39016. ISBN 978-92-8291015-3. Disponible en https://studylib.es/doc/5394670/el-tribunal-de-justicia---curia [2019, 7 de diciembre]. (Este documento estuvo disponible en el enlace oficial: https://curia.europa.eu/jcms/upload/docs/application/pdf/2012-05/cjue_es.pdf al menos hasta julio 2018, luego fue retirado, pero es ubicable por su registro ISBN 
978-92-829-1015-3 en el enlace señalado anterior a este paréntesis, y por su número doi: 10.2862/39016).

Trindade, A. A. C. (2001). El acceso directo del individuo a los tribunales internacionales de derechos humanos. Bilbao: Universidad de Deusto.

Trindade, A. A. C. y Ventura Robles, M. E. (2003). El futuro de la corte interamericana de derechos humanos. San José, C. R.: Corte Interamericana de Derechos Humanos; Alto Comisionado de Naciones Unidas para los Refugiados.

Trujillo Sánchez, A. (2014). La corte penal internacional: La cuestión humana "versus" razón soberana (2a ed. rev. y act.). México, D.F.: Editorial Ubijus.

Truyol y Serra, A. (1999). La integración europea: Análisis histórico-institucional con textos y documentos.- Tomo I génesis y desarrollo de la unión europea (19511979). Madrid: Tecnos. [Aldecoa Luzárraga, F. (2002). La integración europea: Análisis histórico-institucional con textos y documentos - Tomo II génesis y desarrollo de la unión europea (1979-2002). Madrid: Tecnos].

Ulate Chacón, E. (2008). El protocolo de tegucigalpa y la jurisdicción de la corte centroamericana de justicia. REIB: Revista Electrónica Iberoamericana, 2(2), 2342.

Urrea Corres, M. (2002). La cooperación reforzada en la unión europea: Concepto, naturaleza y régimen jurídico. Madrid: Colex.

Van Den Hout, T. T. (2008). Resolution of international disputes: The role of the permanent court of arbitration - reflections on the centenary of the 1907 convention for the pacific settlement of international disputes. Leiden Journal of International Law, 21(3), 643-661.

Vigil Toledo, R. (2011). La estructura jurídica y el futuro de la comunidad andina $\left(1^{\mathrm{a}}\right.$ ed.). Madrid: Civitas Thomson Reuters.

Villamor Morgan-Evans, L. (2001). El tribunal de justicia de las comunidades europeas como garante del derecho comunitario por las propias instituciones y órganos comunitarios. Anuario de la facultad de derecho, 19, 457-472.

Virally, M. (1998). El devenir del derecho internacional: Ensayos escritos al correr de los años (1 ${ }^{\mathrm{a}}$ ed.). México, D.F.: Fondo de Cultura Económica. 
Vivas Barrera, T. G., y Cubides Cárdenas, J. A. (2012). Diálogo judicial transnacional en la implementación de las sentencias de la corte interamericana. Entramado, 8(2), 184-204.

Wach, A. [Banzhaf, T. A. (trans.) \& Alcalá-Zamora y Castillo, N.] (1977). Manual de derecho procesal civil. Buenos Aires: Ediciones jurídicas Europa-América.

Williams, S. (2012). Hybrid and internationalised criminal tribunals: Selected jurisdictional issues. Oxford: Hart Publishing.

White, N. D. (2005). The law of international organisations. Manchester: Manchester University press.

Zapater Duque, E. (2005a, 5 a impr. 2008). El tribunal de justicia de las comunidades europeas. En V. Abellán Honrubia, B. Vilá Costa, A. Olesti Rayo, J. Añoveros Trias De Bes, M. Campins Eritja, M. Cienfuegos Mateo, ... M. Álvarez Verdugo, Lecciones de derecho comunitario europeo (4 $4^{\mathrm{a}} \mathrm{ed}$.). Barcelona: Ariel.

Zapater Duque, E. (2005b, $5^{\text {a }}$ impr. 2008). III El tribunal de primera instancia de las comunidades europeas. En V. Abellán Honrubia, B. Vilá Costa, A. Olesti Rayo, J. Añoveros Trias De Bes, M. Campins Eritja, M. Cienfuegos Mateo, ... M. Álvarez Verdugo, Lecciones de derecho comunitario europeo (4 $4^{\mathrm{a}} \mathrm{ed}$.). Barcelona: Ariel.

Zelada Castedo, A. (1985). Las posibles enmiendas al acuerdo de Cartagena. En Integración latinoamericana. 10(106), INTAL, Buenos Aires.

\section{Tratados Internacionales, Cartas Constitutivas y documentos PÚblicos}

Acta de Buenos Aires de 6 de julio de 1990.

Acta Única Europea de 1986 - AUE (DO L 169 de 29.6.1987, pp. 1-28).

Acuerdo A/58/874 de 20 Agosto 2004, Relationship agreement between the United Nations and the International Criminal Court.

Acuerdo de Integración Subregional Andino - Acuerdo de Cartagena - CAN.

Acuerdo de Relación entre la Corte Penal Internacional y las Naciones Unidas. Documento ICC-ASP/3/25, Parte III, resolución ICC-ASP/3/Res.1, anexo. 
Carta de las Naciones Unidas y Estatuto de la Corte Internacional de Justicia. Nueva York: Naciones Unidas.

Convención de 1907 para la Resolución Pacífica de Controversias Internacionales.

Convenio de Viena sobre el Derecho de los Tratados - 23 de mayo de 1969.

Convenio Para la Protección de los Derechos Humanos y de las Libertades Fundamentales - Roma 4 noviembre 1950 - Council of Europe.

Decisión 30/05 del Grupo Mercado Común de MERCOSUR - Reglas de Procedimiento del Tribunal Permanente de Revisión - 8 diciembre 2005.

Decisión 37/03 del Grupo Mercado Común de MERCOSUR - Reglamento del Protocolo de Olivos Para la Solución de Controversias en el Mercosur - 15 diciembre 2003.

Decisión 500 - Estatuto del Tribunal de Justicia de la Comunidad Andina adoptada en Venezuela el 22 de junio 2001.

Declaración de Bruselas. EU-CELAC Summit 2015 Brussels - Unión Europea y Comunidad de Estados Latinoamericanos y Caribeños.

Declaración Política que Establece el Marco Para La Relación Futura entre La Unión Europea y El Reino Unido (XT 21095/18 - BXT 111) - noviembre de 2018.

Declaración Sobre Los Principios de Derecho Internacional Referentes a las Relaciones de Amistad y a la Cooperación entre los Estados de Conformidad con la Carta de las Naciones Unidas, (1970) A/RES/2625(XXV).

Estatuto de la Corte Centroamericana de Justicia - Suscrito en la República de Panamá el 10 de diciembre de 1992.

General Agreement on Tariffs and Trade - GATT.

INFORMES DE GESTIÓN DEL TRIBUNAL DE JUSTICIA DE LA COMUNIDAD ANDINA.

Los Anales de La Corte de Cartago, Mayo a Diciembre de 1913, Tomo III.

CORTE CENTROAMERICANA DE JUSTICIA. MEMORIA 10 AÑOS: 19942004. 
CORTE CENTROAMERICANA DE JUSTICIA. MEMORIA 2005-2006. CORTE CENTROAMERICANA DE JUSTICIA. MEMORIA 2007-2008. CORTE CENTROAMERICANA DE JUSTICIA. MEMORIA 2008-2009. CORTE CENTROAMERICANA DE JUSTICIA. MEMORIA 2009-2010. CORTE CENTROAMERICANA DE JUSTICIA. MEMORIA 2010-2011. CORTE CENTROAMERICANA DE JUSTICIA. MEMORIA 2014-2015. CORTE CENTROAMERICANA DE JUSTICIA. MEMORIA 2016-2017. Ordenanza de Procedimientos ante la Corte Centroamericana de Justicia (2014). INFORME DE GESTIÓN DEL TRIBUNAL DE JUSTICIA DE LA COMUNIDAD ANDINA, AÑO 2011.

INFORME DE GESTIÓN DEL TRIBUNAL DE JUSTICIA DE LA COMUNIDAD ANDINA, AÑO 2012.

INFORME DE GESTIÓN DEL TRIBUNAL DE JUSTICIA DE LA COMUNIDAD ANDINA, AÑO 2013.

INFORME DE GESTIÓN DEL TRIBUNAL DE JUSTICIA DE LA COMUNIDAD ANDINA, AÑO 2014.

INFORME DE GESTIÓN DEL TRIBUNAL DE JUSTICIA DE LA COMUNIDAD ANDINA, AÑO 2015.

INFORME DE GESTIÓN DEL TRIBUNAL DE JUSTICIA DE LA COMUNIDAD ANDINA, AÑO 2016.

INFORME DE GESTIÓN DEL TRIBUNAL DE JUSTICIA DE LA COMUNIDAD ANDINA, AÑO 2017.

Protocolo ( $\mathrm{N}^{\mathrm{o}}$ 3) Sobre el Estatuto del Tribunal de Justicia de la Unión Europea ETJUE. Versión consolidada.

Protocolo de la ECOWAS Court - 1991.

Protocolo de Olivos para la Solución de Controversias en el MERCOSUR - 2002. 
Protocolo de Ouro Prieto - 1994 - MERCOSUR.

Protocolo de Tegucigalpa a La Carta de La Organización de Estados Centroamericanos - del 13 de diciembre de 1991.

Protocolo de Ushuaia - MERCOSUR.

Proyecto de Norma 02/10 del Parlamento del MERCOSUR (MERCOSUR/PM/PN 02/2010), aprueba el Proyecto de Protocolo Constitutivo de la Corte de Justicia del MERCOSUR.

Recomendación (MERCOSUR/PM/SO/REC.07/2017) del PARLASUR al CMC para retomar el proyecto de la Corte de Justicia del MERCOSUR.

Resolución 54/03 del Grupo Mercado Común de MERCOSUR - Crea el Tribunal Administrativo Laboral - diciembre 2003.

Tratado de Creación del Tribunal de Justicia de la Comunidad Andina refundido con su Protocolo Modificatorio de Cochabamba - 28 de mayo de 1996 - TJCA.

Tratado de Funcionamiento de la Unión Europea - TFUE - Lisboa, 13 de diciembre de 2007.

Tratado de Integración, Cooperación y Desarrollo de 1988 - Argentina/Brasil.

Tratado de la Unión Europea - TUE - Lisboa, 13 de diciembre de 2007.

Tratado para la Constitución del Mercado Común del Sur - MERCOSUR.

\section{JURISPRUDENCIA}

\subsection{JuRisprudencia del TRIbunal de JuSTICIA de la Unión Europea}

Conclusiones del Abogado General Sr. Dámaso Ruiz-Jarvo Colomer de 27 de febrero de 1997, ECLI:EU:C:1997:100.

Dictamen del TJ de 14 de diciembre de 1991. Comisión. Dictamen emitido con arreglo al párrafo segundo del apartado 1 del art. 228 del Tratado CEE. Proyecto de Acuerdo entre la Comunidad, por una parte, y los países de la Asociación Europea de Libre Comercio, por otra parte, sobre la creación del Espacio Económico Europeo. Dictamen 1/91, ECLI:EU:C:1991:490. 
Dictamen del TJ de 18 de diciembre de 2014. Avis rendu en vertu de l'article 218, paragraphe 11, TFUE. Dictamen 2/13, ECLI:EU:C:2014:2454.

Sentencia del TJ de 16 de diciembre de 1960, Humblet/Etat belge, as. C-6/60-IMM, ECLI:EU:C:1960:48.

Sentencia del TJ de 5 de febrero de 1963, Van Gend \& Loos, as. C-26/62, ECLI:EU:C:1963:1.

Sentencia del TJ de 17 de julio de 1963, Italia c. Comisión, as. C-13/63, ECLI:EU:C:1963:20.

Sentencia del TJ de 15 de julio de 1964, Costa/Enel, as. C-6/64, ECLI:EU:C:1964:66.

Sentencia del TJ de 13 de noviembre de 1964, Comisión de la CEE/Luxemburgo, as. C-90/63, ECLI:EU:C:1964:80.

Sentencia del TJ de 13 de febrero de 1969, Walt Wilhelm, as. C-14/68 ECLI:EU:C:1969:4.

Sentencia del TJ de 12 de noviembre de 1969, Stauder c/ Stadt Ulm - Sozialamt, as. C-29/69, ECLI:EU:C:1969:57.

Sentencia del TJ de 17 de diciembre de 1970, Internationale Handelsgesellschaft mbH cl Einfuhr - und Vorratsstelle für Getreide und Futtermittel, as. C-11/70, ECLI:EU:C:1970:114.

Sentencia del TJ de 11 de febrero de 1971, Norddeutsches Vieh- und Fleischkontor - Finanzgericht Hamburg, as. C-39/70, ECLI:EU:C:1971:16.

Sentencia del TJ de 22 de junio de 1972, Frilli, as. C-1/72, ECLI:EU:C:1972:56.

Sentencia del TJ de 13 de julio de 1972, Comisión/Italia, as. C-48/71, ECLI:EU:C:1972:65.

Sentencia del TJ de 24 de octubre de 1973, Balkan-Import-Export, as. C-5/73, ECLI:EU:C:1973:109.

Sentencia del TJ de 4 de abril de 1974, Comisión/Francia, as. C-167/73, ECLI:EU:C:1974:35.

Sentencia del TJ de 30 de abril de 1974, Sacchi, as. C-155/73, ECLI:EU:C:1974:40. 
Sentencia del TJ de 14 de mayo de 1974, Nold, Kohlen - und Baustoffgroßhandlung c/ Comisión de las CE, as. C-4/73, ECLI:EU:C:1974:51.

Sentencia del TJ de 3 de diciembre de 1974, Van Binsbergen, as. C-33/74, ECLI:EU:C:1974:131.

Sentencia del TJ de 4 de diciembre de 1974, Van Duyn, as. C-41/74, ECLI:EU:C:1974:133.

Sentencia del TJ de 21 de junio de 1974, Reyners, as. C-2/74, ECLI:EU:C:1974:68.

Sentencia del TJ de 22 de enero de 1976, C. A. Ruso, as. C-60/75, ECLI:EU:C:1976:9.

Sentencia del TJ de 16 de diciembre de 1976, Rewe-Zentralfinanz, as. C-33/76, ECLI:EU:C:1976:188.

Sentencia del TJ de 16 de diciembre de 1976, Comet, as. C-45/76, ECLI:EU:C:1976:191.

Sentencia del TJ de 28 de junio de 1977, Balkan-Import-Export, as. C-118/76, ECLI:EU:C:1977:111.

Sentencia del TJ de 9 de marzo de 1978, Simmenthal, as. C-106/77, ECLI:EU:C:1978:49.

Sentencia del TJ de 24 de marzo de 1979, Comisión c. Reino Unido, as. C-231/78, ECLI:EU:C:1979:101.

Sentencia del TJ de 18 de marzo de 1980, Forges de Thy-Marcinelli y Monceau c. Comisión, as. C-26 y C-86/79, ECLI:EU:C:1980:82.

Sentencia del TJ de 18 de marzo de 1980, Debauve, as. C-52/79, ECLI:EU:C:1980:83.

Sentencia del TJ de 28 de marzo de 1980, Comisión/Francia, as. C-24/80, ECLI:EU:C:1980:107.

Sentencia del TJ de 3 de junio de 1980, Pieck, as. C-157/79, ECLI:EU:C:1980:179.

Sentencia del TJ de 5 de mayo de 1982, Schul, as. C-15/81, ECLI:EU:C:1982:135. 
Sentencia del TJ de 31 de enero de 1984, Luisi y Carbone, as. Acumulación C286/82 y C-26/83, ECLI:EU:C:1984:35.

Sentencia del TJ de 14 de noviembre de 1985, Neumann, as. C-299/84, ECLI:EU:C:1985:463.

Sentencia del TJ de 23 de abril de 1986. Parti écologiste "Les Verts" contra Parlamento Europeo, as. C-294/83, ECLI:EU:C:1986:166.

Sentencia del TJ de 30 de septiembre de 1987, Demirel, as. C-12/86, ECLI:EU:C:1987:400.

Sentencia del TJ de 14 de junio de 1988, Dansk Denkavit, as. C-29/87, ECLI:EU:C:1988:299.

Sentencia del TJ de 2 de febrero de 1989, Cowan, as. C-186/87, ECLI:EU:C:1989:47.

Sentencia del TJ de 19 de diciembre de 1991, A. Francovich y D. Bonifaci, as. Acumulación C-6/90 y C-9/90, ECLI:EU:C:1991:428.

Sentencia del TJ de 5 de marzo de 1996, Brasserie du Pêcheur, ex parte Factortame, as. C-48/93, ECLI:EU:C:1996:79.

Sentencia del TJ de 29 de mayo de 1997, Comisión/Francia, as. C-282/96, ECLI:EU:C:1997:271.

Sentencia del TJ de 5 de junio de 1997, Comisión/Francia, as. C-223/96, ECLI:EU:C:1997:287.

Sentencia del TJ de 9 de diciembre de 1997, Comisión/Francia, as. C-265/95, ECLI:EU:C:1997:595.

Sentencia del TJ de 11 de enero de 2000, Kreil, as. C-285/98, ECLI:EU:C:2000:2.

Sentencia del TJ de 28 de marzo de 2000, Krombach, as. C-7/98, ECLI:EU:C:2000:164.

Sentencia del TJ de 12 de junio de 2003, Schmidberger, as. C-112/00, ECLI:EU:C:2003:333.

Sentencia del TJ de 4 de julio de 2000, Comisión/Grecia, as. C-387/97, ECLI:EU:C:2000:356. 
Sentencia del TJ de 14 de diciembre de 2000, Masterfoods y HD, as. C-344/98, ECLI:EU:C:2000:689.

Sentencia del TJ de 25 de noviembre de 2003, Comisión/España, as. C-278/01, ECLI:EU:C:2003:635.

Sentencia del TJ de 12 de julio de 2005, Comisión/Francia, as. C-304/02, ECLI:EU:C:2005:444.

Sentencia del TJ de 15 de noviembre de 2005, Comisión de las Comunidades Europeas c. Austria, as. C-320/03, ECLI:EU:C:2005:684.

Sentencia del TJ de 22 de noviembre de 2005, Mangold/Helm, as. C-144/04, ECLI:EU:C:2005:709.

Sentencia del TJ de 14 de marzo de 2006, Comisión/Francia, as. C-177/04, ECLI:EU:C:2006:173.

Sentencia del TJ de 11 de julio de 2006, Chacón Navas/Eurest, as. C-13/05, ECLI:EU:C:2006:456.

Sentencia del TJ de 26 de enero de 2010, Transportes Urbanos y Servicios Generales, as. C-118/08, ECLI:EU:C:2010:39.

Sentencia del TJ de 6 de marzo de 2018, Slowakische Republik/Achmea BV, as. C284/16, ECLI:EU:C:2018:158.

\subsection{JURISPRUDENCIA DEL TRIBUNAL GENERAL DE LA UNIÓN EUROPEA}

Sentencia del TPCE de 2 de julio de 2002 (Sala Segunda), SAT.1 SatellitenFrensehen GmbH c. Oficina de Armonización del Mercado interior, as. T323/00, ECLI:EU:T:2002:172.

Sentencia del TPCE de 25 de septiembre de 2002 (Sala Cuarta), VikingUmwelttechnick GmbH c. Oficina de Armonización del Mercado interior, as. T316/00, ECLI:EU:T:2002:225. 


\subsection{Jurisprudencia de la Corte Centroamericana de Justicia}

Sentencia de la CCJ de 5 de agosto de 1997. Opinión consultiva. Haroldo Rodas Melgar, Secretario General de la Secretaria Permanente del Tratado General de Integración Económica Centroamericana (SIECA), expediente 13-02-01-05-1997.

Sentencia de la CCJ de 5 de marzo de 1998, Coto Ugarte c. Consejo Superior Universitario de la Universidad de El Salvador, expediente 05-11-1996, as. 05/96.

Sentencia de la CCJ de 27 de noviembre de 2001, Nicaragua c. Honduras, expediente 25-05-29-11-1999, as. 69/01.

Sentencia de la CCJ de 28 de noviembre de 2001, Honduras c. Nicaragua, expediente 26-06-03-12-1999.

Sentencia de la CCJ de 13 de enero de 2005, Reyes Wyld c. República de Guatemala, expediente 01-30-04-2004, as. 01/04.

Sentencia de la CCJ de 29 de marzo de 2005, Poder Ejecutivo de Nicaragua c. Asamblea Nacional de Nicaragua, expediente 69-01-03-01-2005.

Sentencia de la CCJ de 10 de noviembre de 2006, Consulta Parlacem/República Dominicana, expediente 76-03-12-09-2006, as. 76/06.

Sentencia de la CCJ de 8 de enero de 2008, Consulta Parlacen, expediente 81-0305-12-2007, as. 07/07.

Sentencia de la CCJ de 7 de octubre de 2009, Brenes Pérez y Dougherty Liekens c. Parlacem, expediente 88-07-07-10-2008.

Sentencia de la CCJ de 25 de enero de 2018, en Consulta del Administrador del Mercado Mayorista, expediente 03-08-06-2017.

\subsection{JuRisprudencia del Tribunal de Justicia de la COMUnidad Andina}

Sentencia del TJCA de 3 de diciembre de 1987, Interpretación prejudicial, Aktiebolaget Volvo c. Volmo, consulta de Consejo de Estado de la República de Colombia, Sala de lo Contencioso Administrativo, Sección Primera, as. 1-IP-87. 
Sentencia del TJCA de 25 de mayo de 1988, Interpretación prejudicial, Germán y Ernesto Cavelier, consulta de la Corte Suprema de Justicia de la República de Colombia, as. 2-IP-88. GOAC N 33 de 1988.

Sentencia del TJCA de 20 de septiembre de 1990, Interpretación prejudicial, Germán Cavelier y Alexandre Vernot, consulta de la Corte Suprema de Justicia de la República de Colombia, as. 2-IP-90. GOAC № 69, de 11-10-1990.

Sentencia del TJCA de 17 de febrero de 1994, Interpretación prejudicial, Louis Vuitton, as. 6-IP-93. GOAC No 150.

Sentencia del TJCA de 4 de julio de 1994, Interpretación prejudicial, Noel, as. 2-IP94.

Sentencia del TJCA de 11 de octubre de 1994, Interpretación prejudicial, Marca: Mac Pollo, as. 1-IP-94.

Sentencia del TJCA de 20 de abril de 1995, Interpretación prejudicial, consulta de la Corte Constitucional de la República de Colombia, as. 10-IP-94. GOAC 177 de 1995.

Sentencia del TJCA de 24 de marzo de 1997, Acción de incumplimiento, Junta del Acuerdo de Cartagena c/ República de Venezuela, as. 03-AI-96. GOAC 261 de 294-97.

Sentencia del TJCA de 24 de septiembre de 1998, Acción de incumplimiento, Secretaría General de la CA c/ la República del Ecuador, as. 02-AI-97.

Sentencia del TJCA de 20 de octubre de 1999, Sumario por incumplimiento de la sentencia del Proceso 1-AI-97 Junta/Venezuela. GOAC 500, 25-10-99.

Sentencia del TJCA de 27 de octubre de 1999, Sumario por incumplimiento de la sentencia del Proceso 3-AI-96, Junta/Venezuela. GOAC 512, 26-11-99.

Sentencia del TJCA de 3 de noviembre de 1999, Interpretación Prejudicial, Segunda Sala del Tribunal Distrital $N^{o} 1$ de lo Contencioso Administrativo de Ecuador. Marca: Denim, 30-IP-99.

Sentencia del TJCA de 12 de noviembre de 1999, Acción de incumplimiento, Secretaría General de la CA c/ la República del Perú, as. 07-AI-99.

Sentencia del TJCA de 1 de agosto de 2001, Sumario por incumplimiento de la sentencia del Proceso 34-AI-99, Secretaría General/Perú. 
Sentencia del TJCA de 28 de septiembre de 2001, Acción de incumplimiento, Secretaría General de la CA / República del Perú, as. 89-AI-2000. GOAC 722.

Sentencia del TJCA de 6 de marzo de 2002, Sumario por incumplimiento de la sentencia del Proceso 53-AI-99 Secretaría General/Ecuador, GOAC 778 2-4-02.

Sentencia del TJCA de 21 de agosto de 2002, Secretaría General/Ecuador, as. 34AI-2001. GOAC No 839, 25-9-02.

Sentencia del TJCA de 30 de noviembre de 2004, Interpretación prejudicial, Pfizer/Invima, as. 105-IP-2004.

Sentencia del TJCA de 20 de julio de 2005, Interpretación prejudicial, Marca: Envíos de dinero BBVA Bancomer más Gráfica a color, as. 89-IP-05.

Sentencia del TJCA de 19 de octubre de 2018, Acción de incumplimiento, Caracol Televisión S.A. y RCN Televisión S.A. / República de Colombia, as. acumulados 01 y $02-A I-16$.

\subsection{Jurisprudencia del Tribunal Permanente de Revisión Mercosur}

Laudo del TPRM de 20 de diciembre de 2005, República Oriental del Uruguay c. República de Argentina, as. 1/2005.

Laudo del TPRM de 13 de enero de 2006, Recurso de aclaratoria, as. 1/2006.

Laudo del TPRM de 3 de abril de 2007, Opinión consultiva, Norte S.A. Imp. Exp. c/ Laboratorio Northia Soc. Anónima (...) s/ indemnización de daños y perjuicios y lucro cesante, as. OC. 1-2007.

Laudo del TPRM de 8 de junio de 2007, República Oriental del Uruguay c. República de Argentina, as. 1/2007.

Laudo del TPRM de 25 de abril de 2008, "Divergencia sobre el cumplimiento del Laudo $N^{\circ} 1 / 05$ iniciada por la República Oriental del Uruguay (artículo 30 Protocolo de Olivos)", Laudo 01/2008, as. 1/2005.

Laudo del TPRM de 24 de abril de 2009, Opinión consultiva, República Oriental del Uruguay, as. OC. 01/2008. 
Laudo del TPRM de 21 de julio de 2012, República Oriental del Uruguay, as. $1 / 2012$.

\subsection{JURISPRUDENCIA DE LOS TRIBUNALES ARBITRALES AD HOC MERCOSUR}

Laudo del TAAM de 28 de abril de 1999, República Argentina c. República Federativa de Brasil, as. 1/1999.

Laudo del TAAM (número 5) de 29 de septiembre de 2001, República Oriental del Uruguay c. República de Argentina.

Laudo del TAAM Aclaratorio recaído en el recurso de aclaración deducido contra el Laudo del TAAM (número 5) de 29 de septiembre de 2001, República Oriental del Uruguay c. República de Argentina.

Laudo del TAAM (número 9) de 4 de abril de 2003, República de Argentina $c$. República Oriental del Uruguay.

Laudo del TAAM (número 10) de 5 de agosto de 2005, República Oriental del Uruguay c. República Federativa del Brasil.

Laudo del TAAM de 25 de octubre de 2005, República Oriental del Uruguay c. República de Argentina, as. TAH-2/2005.

Laudo del TAAM de 6 de septiembre de 2006, República Oriental del Uruguay c. República de Argentina. (Constituido para conocer sobre «Omisión del Estado Argentino en adoptar medidas apropiadas para prevenir y/o hacer cesar los impedimentos a la libre circulación derivados de los cortes en territorio argentino de vías de acceso a los puentes internacionales General San Martín y General Artigas que unen la República Argentina con la República del Uruguay»).

\subsection{JURISPRUdencia de OTRAS CORTES}

Sentencia de la CIJ de 11-4-1949. Opinión consultiva. Reparación de daños sufridos. Vid. en Compendio de Sentencias, Opiniones y Ordenes de Asesoramiento. Reparación de Daños al Servicio de las NU, p. 178.

Sentencia de la Corte Costituzionale (Italia) de 18-12-1973, Frontini. Deposito in cancelleria 27-12-1973. Pubblicazione in Gazz. Uff. N² 2, del 2 gennaio 1974. 


\section{BIBLIO-WEB}

Para un mejor orden se presentan los recursos web de la forma siguiente: $1^{\circ}$. Los libros y documentos electrónicos en línea están arriba insertos en el listado de Monografías, participación en obras colectivas y artículos científicos. $2^{\circ}$. Los enlaces web oficiales e institucionales, los presentamos en cada referencia a pie de página; y $3^{\circ}$. Los portales web oficiales e institucionales, los detallamos a continuación:

\section{PORTALES WEB OFICIALES E INSTITUCIONALES}

Portal oficial de COMESA Court of Justice <http://comesacourt.org/>

Portal oficial de Euro-Lex <https://eur-lex.europa.eu>

Portal oficial de European Justice (e-justice) <https://e-justice.europa.eu>

Portal oficial de la Comisión Africana de Derechos Humanos y de los Pueblos <http://www.achpr.org>

Portal oficial de la Comisión del Pacífico Sur - CPS <http://www.spc.int>

Portal oficial de la Comisión Internacional Contra la Impunidad en Guatemala $<$ http://cicig.org>

Portal oficial de la Comunidad Andina - CAN <http://www.comunidadandina.org>

Portal oficial de la Comunidad de Estados Independientes - CEI, en ruso Содружество Независимых Государств <http://www.e-cis.info>

Portal oficial de la Comunidad Económica de Los Estados Centro-Africanos CEECA <http://www.ceeac-eccas.org>

Portal oficial de la Comunidad Económica y Monetaria del África Central CEMAC <http://www.cemac.int>

Portal oficial de la Corte Africana de Derechos Humanos y de los Pueblos CADHDP <http://www.african-court.org>

Portal oficial de la Corte Centroamericana de Justicia - CCJ <http://portal.ccj.org.ni>

Portal oficial de la Corte Económica del CEI <http://sudsng.org>

Portal oficial de la Corte Interamericana de Derechos Humanos - CIDH <http://www.corteidh.or.cr>

Portal oficial de la Corte Internacional de Justicia - CIJ <http://www.icj-cij.org> 
Portal oficial de la Corte Penal Internacional - CPI <https://www.icc-cpi.int> Portal oficial de la Corte Permanente de arbitraje - CPA <http://www.pca-cpa.org> Portal oficial de la Cruz Roja española <http://www.cruzroja.es>

Portal oficial de la Economic Commission for Africa de United Nations <https://www.uneca.org>

Portal oficial de la Economic Community of West African States - ECOWAS $<$ http://www.ecowas.int>

Portal oficial de la EFTA Court - EFTAC <http://www.eftacourt.int>

Portal oficial de la European Court of Human Rights - TEDH <http://www.echr.coe.int>

Portal oficial de la European Free Trade Association - EFTA - AELC $<$ http://www.efta.int>

Portal oficial de la Embajada de Argentina en Brasil <http://www.argentinabrasil.com>

Portal oficial de la Liga de Estados Árabes <http://www.lasportal.org>

Portal oficial de la Organización de Estados Americanos - OEA <http://www.oas.org>

Portal oficial de la Organización de la Cooperación Islámica - OCI (ex Organización de la Conferencia Islámica) <http://www.oic-oci.org>

Portal oficial de la Organización Mundial del Comercio - OMC <https://www.wto.org>

Portal oficial de la UCL Faculty of laws <http://www.laws.ucl.ac.uk>

Portal oficial de La Unión Africana - UA <http://www.au.int>

Portal oficial de La Unión del Magreb Árabe - UMA <http://www.maghrebarabe.org>

Portal oficial de la Unión Europea - UE <europa.eu>

Portal oficial de la Universidad De Salamanca - Castilla y León $<$ http://www.usal.es>

Portal oficial de la Universitat de les Illes Balears <http://www.uib.cat>

Portal oficial de la Universitat Pompeu Fabra - Barcelona <https://www.upf.edu>

Portal oficial de las Extraordinary Chambers in the Courts of Cambodia. <https://www.eccc.gov.kh/en>

Portal oficial de Library of Congress <http://www.loc.gov>

Portal oficial de Unión Económica y Monetaria del Oeste Africano - UEMOA <http://www.uemoa.int> 
Portal oficial de United Nations - UN - ONU <http://www.un.org>

Portal oficial del Banco Mundial - BM - World Bank - WB <http://www.bancomundial.org>

Portal oficial del Cambodia Tribunal Monitor <http://www.cambodiatribunal.org>

Portal oficial del CIADI <https://icsid.worldbank.org>

Portal oficial del Comité Internacional de La Cruz Roja <https://www.icrc.org>

Portal oficial del Common Market for Eastern and Southern Africa - COMESA

<http://www.comesa.int>

Portal oficial del Consejo de Europa <http://www.coe.int $>$

Portal oficial del Counsil of Europa - COE <http://www.coe.int $>$

Portal oficial del International Center for Transitional Justice <https://www.ictj.org>

Portal oficial del Mecanismo de cierre de los TPIR y TPIY: $<$ http://www.irmct.org/en>

Portal oficial del Mercado Común del Sur - MERCOSUR <http://www.mercosur.int>

Portal oficial del Museo de La Paz de Sierra Leona <http://www.slpeacemuseum.org>

Portal oficial del Pacific Islands Forum - PIF - FPS <http://www.forumsec.org>

Portal oficial del Parlamento Europeo <http://www.europarl.europa.eu>

Portal oficial del Poder Judicial de la República de Chile <www.poderjudicial.cl>

Portal oficial del Project on International Courts and Tribunals <http://www.pictpcti.org>

Portal oficial del Sistema de la Integración Centroamericana - SICA $<$ http://www.sica.int>

Portal oficial del The New York Times <http://www.nytimes.com>

Portal oficial del Tribunal de Justicia de ECOWAS - TJECOWAS <http://www.courtecowas.org>

Portal oficial del Tribunal de Justicia de la Comunidad Andina - TJCA <http://www.tribunalandino.org.ec>

Portal oficial del Tribunal de Justicia de la Unión Europea - TJUE $<$ http://curia.europa.eu>

Portal oficial del Tribunal Especial para Sierra Leona <http://rscsl.org/>

Portal oficial del Tribunal Internacional de Derecho del Mar - TIDM $<$ https://www.itlos.org> 
Portal oficial del Tribunal Penal Internacional para el Líbano <https://www.stltsl.org/en/>

Portal oficial del Tribunal Penal Internacional para la Antigua Yugoslavia. <http://www.icty.org/>

Portal oficial del Tribunal Penal Internacional para Rúanda $<$ http://unictr.irmct.org/>

Portal oficial del Tribunal Permanente de Revisión - TPRM <http://www.tprmercosur.org>

Portal oficial del U.S. Department of State USA <http://www.state.gov> 